ICME-13 Monographs

Markku S. Hannula · Gilah C. Leder ·

Francesca Morselli · Maike Vollstedt .

Qiaoping Zhang Editors

Affect and

Mathematics

Education

Fresh Perspectives on Motivation,

Engagement, and Identity 


\section{ICME-13 Monographs}

\section{Series Editor}

Gabriele Kaiser, Faculty of Education, Didactics of Mathematics, Universität Hamburg, Hamburg, Germany 
Each volume in the series presents state-of-the art research on a particular topic in mathematics education and reflects the international debate as broadly as possible, while also incorporating insights into lesser-known areas of the discussion. Each volume is based on the discussions and presentations during the ICME-13 congress and includes the best papers from one of the ICME-13 Topical Study Groups, Discussion Groups or presentations from the thematic afternoon.

More information about this series at http://www.springer.com/series/15585 
Markku S. Hannula . Gilah C. Leder . Francesca Morselli - Maike Vollstedt . Qiaoping Zhang Editors

\section{Affect and Mathematics Education}

Fresh Perspectives on Motivation, Engagement, and Identity

黑 Springer Open 


\section{Editors}

Markku S. Hannula

Faculty of Educational Sciences

University of Helsinki

Helsinki, Finland

Francesca Morselli

Faculty of Mathematics

University of Genoa

Genoa, Italy

Qiaoping Zhang

Department of Mathematics

and Information Technology

The Education University of Hong Kong

Tai Po, Hong Kong
Gilah C. Leder

La Trobe University

Melbourne, VIC, Australia

\author{
Maike Vollstedt \\ Faculty of Mathematics \\ and Computer Science \\ University of Bremen \\ Bremen, Germany
}

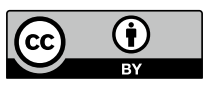

ISSN 2520-8322

ISSN 2520-8330 (electronic)

ICME-13 Monographs

ISBN 978-3-030-13760-1

ISBN 978-3-030-13761-8 (eBook)

https://doi.org/10.1007/978-3-030-13761-8

Library of Congress Control Number: 2019931829

(C) The Editor(s) (if applicable) and The Author(s) 2019. This book is an open access publication.

Open Access This book is licensed under the terms of the Creative Commons Attribution 4.0 International License (http://creativecommons.org/licenses/by/4.0/), which permits use, sharing, adaptation, distribution and reproduction in any medium or format, as long as you give appropriate credit to the original author(s) and the source, provide a link to the Creative Commons license and indicate if changes were made.

The images or other third party material in this book are included in the book's Creative Commons license, unless indicated otherwise in a credit line to the material. If material is not included in the book's Creative Commons license and your intended use is not permitted by statutory regulation or exceeds the permitted use, you will need to obtain permission directly from the copyright holder.

The use of general descriptive names, registered names, trademarks, service marks, etc. in this publication does not imply, even in the absence of a specific statement, that such names are exempt from the relevant protective laws and regulations and therefore free for general use.

The publisher, the authors and the editors are safe to assume that the advice and information in this book are believed to be true and accurate at the date of publication. Neither the publisher nor the authors or the editors give a warranty, expressed or implied, with respect to the material contained herein or for any errors or omissions that may have been made. The publisher remains neutral with regard to jurisdictional claims in published maps and institutional affiliations.

This Springer imprint is published by the registered company Springer Nature Switzerland AG

The registered company address is: Gewerbestrasse 11, 6330 Cham, Switzerland 


\section{Preface}

The ICME-13 topic study group on affect, beliefs and identity in mathematics education served as the catalyst for this book. The work presented offers a timely addition to the body of work on the interaction between affect and mathematics education. New trends in research in the area are presented and critiqued. The introduction and a survey chapter provide a succinct overview of the state-of-the-art in the field of mathematics-related affect. This is followed by work divided into three main parts: motivation and values, engagement and identity in mathematics education. Each part comprises several independent chapters based on original research, as well as a reflective commentary by an expert in the area. Collectively, the chapters present a rich methodological spectrum from narrative analysis to structural equation modelling. Finally, the editors provide a chapter in which they review the scope of the work presented and look ahead at future directions in the area of mathematics education-related affect.

Helsinki, Finland

Melbourne, Australia

Genoa, Italy

Bremen, Germany

Tai Po, Hong Kong SAR, China
Markku S. Hannula

Gilah C. Leder

Francesca Morselli

Maike Vollstedt

Qiaoping Zhang 


\section{Contents}

\section{Part I Introduction and Overview}

1 Fresh Perspectives on Motivation, Engagement, and Identity:

An Introduction . . . . . . . . . . . . . . . . . . . 3

Markku S. Hannula, Gilah C. Leder, Francesca Morselli,

Maike Vollstedt and Qiaoping Zhang

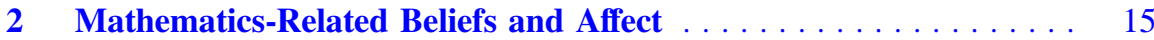

Gilah C. Leder

Part II Interest, Motivation, and Values

3 Multiple Solutions, The Experience of Competence, and Interest. . . . . . . . . . . . . . . . . . . 39

Kay Achmetli and Stanislaw Schukajlow

4 A Sociocultural Examination of Utility Value in Mathematics: The Role of Interdependence in Middle School Students'

Perceptions of Usefulness . . . . . . . . . . . . . . . . . . . . . . 67

Tracy E. Dobie

5 A Longitudinal Study of Mathematics and Science Motivation Patterns for STEM-Intending High Schoolers in the US . . . . . . . 89 James A. Middleton, Daniel Mangu and Andrew Lee

6 Perceived Social Support Network and Achievement: Mediation by Motivational Beliefs and Moderation by Gender . . . . . . . . . . 107 Emmanuel Adu-tutu Bofah and Markku S. Hannula

7 Assessment and Structure of Secondary Students' Personal Meaning Related to Mathematics

Maike Vollstedt and Christoph Duchhardt 
8 Middle School Boys' and Girls' Own Expressions of Aspirations for Their Mathematics Learning . . . . . . . . . . . . . . . . . . 165 Karina Joyce Wilkie

9 Implications of Training in Incremental Theories of Intelligence for Undergraduate Statistics Students .

Valorie Zonnefeld

10 A Commentary: Extending the Research Discourse from Interests and Beliefs to Values . . . . . . . . . . . . . . . . 219 Wee Tiong Seah

\section{Part III Engagement and Flow}

11 Intertwinement of Rationality and Emotions in Mathematics Teaching: A Case Study . . . . . . . . . . . . . . . . . . . . 233 Marina De Simone

12 Teachers' Classroom Engagement Structures: A Comparative Study of a Novice US and an Experienced UK Mathematics Teacher 255

Deena Khalil, Elizabeth Lake and Ayanna Johnson

13 Exploring Flow in Pre-service Primary Teachers Doing Measurement Tasks

Ana Belén Montoro and Francisco Gil

14 A Commentary: Accounting-of and Accounting-for the Engagement of Teachers and Teaching . . . . . . . . . . . . . . . 309 Peter Liljedahl

\section{Part IV Identity}

15 The Interplay of Rationality and Identity in a Mathematical Group Work

Laura Branchetti and Francesca Morselli

16 Belief Changes in the Transition from University Studies to School Practice

Ralf Erens and Andreas Eichler

17 The Struggle for Recognition and the Professional Identities of Mathematics Teachers

Clyde B. A. Felix

18 Teachers' Professional Identity

Andreas Karaolis and George N. Philippou 
19 Identity at the Crossroads, Collision or Conciliation?

A Commentary

Einat Heyd-Metzuyanim

\section{Part V Conclusion}

20 Fresh Perspectives on Motivation, Engagement, and Identity:

A Conclusion.

Markku S. Hannula, Gilah C. Leder, Francesca Morselli,

Maike Vollstedt and Qiaoping Zhang 


\section{Contributors}

Kay Achmetli University of Münster, Münster, Germany

Emmanuel Adu-tutu Bofah University of Helsinki, Helsinki, Finland

Laura Branchetti University of Parma, Parma, Italy

Marina De Simone Université de Genève, Geneva, Switzerland

Tracy E. Dobie University of Utah, Salt Lake City, UT, USA

Christoph Duchhardt University of Bremen, Bremen, Germany

Andreas Eichler University of Kassel, Kassel, Germany

Ralf Erens University of Education Freiburg, Freiburg, Germany

Clyde B. A. Felix Nelson Mandela University, Port Elizabeth, South Africa

Francisco Gil University of Almeria, Almeria, Spain

Markku S. Hannula University of Helsinki, Helsinki, Finland;

Volda University College, Volda, Norway

Einat Heyd-Metzuyanim Tehnion-Israel Institute of Technology, Haifa, Israel

Ayanna Johnson Howard University, Washington, DC, USA

Andreas Karaolis University of Nicosia, Engomi, Nicosia, Cyprus

Deena Khalil Howard University, Washington, DC, USA

Elizabeth Lake University College London, Bloomsbury, London, UK;

University of East Anglia, Norwich, UK

Gilah C. Leder La Trobe University, Melbourne, VIC, Australia; Monash University, Melbourne, VIC, Australia

Andrew Lee Arizona State University, Mesa, AZ, USA

Peter Liljedahl Simon Fraser University, Vancouver, Canada 
Daniel Mangu Arizona State University, Phoenix, AZ, USA

James A. Middleton Arizona State University, Tempe, AZ, USA

Ana Belén Montoro University of Granada, Granada, Spain

Francesca Morselli University of Genoa, Genoa, Italy

George N. Philippou University of Nicosia, Engomi, Nicosia, Cyprus

Stanislaw Schukajlow University of Münster, Münster, Germany

Wee Tiong Seah The University of Melbourne, Melbourne, Australia

Maike Vollstedt University of Bremen, Bremen, Germany

Karina Joyce Wilkie Monash University, Frankston, VIC, Australia

Qiaoping Zhang The Education University of Hong Kong, Tai Po, Hong Kong SAR, China

Valorie Zonnefeld Dordt University, Sioux Center, IA, USA 


\section{Part I \\ Introduction and Overview}




\title{
Chapter 1 \\ Fresh Perspectives on Motivation, Engagement, and Identity: An Introduction
}

\author{
Markku S. Hannula, Gilah C. Leder, Francesca Morselli, Maike Vollstedt \\ and Qiaoping Zhang
}

\subsection{Setting the Scene}

Well over a century has passed since the founding, in Rome in 1908, of the International Commission on Mathematical Instruction [ICMI]. Over time, the interest among mathematicians in school mathematics intensified: "as the mission of general education expanded (more advanced knowledge, for more people), the needs and complexity of mathematics education grew as well, leading to the development in due course of corresponding communities of both practicing professionals and scholars" (ICMI, no date, para 5).

\section{S. Hannula ( $\otimes)$}

Faculty of Educational Sciences, University of Helsinki, P.O. Box 9, 00014 Helsinki, Finland e-mail: markku.hannula@helsinki.fi

Volda University College, Joplassvegen 11, 6103 Volda, Norway

G. C. Leder

La Trobe University, Melbourne, VIC, Australia

e-mail: g.leder@latrobe.edu.au

Monash University, Melbourne, VIC, Australia

F. Morselli

Faculty of Mathematics, University of Genoa, Via Dodecaneso 35, 16146 Genoa, Italy

e-mail: morselli@dima.unige.it

\section{Vollstedt}

Faculty of Mathematics and Computer Science, University of Bremen, Bibliothekstraße 5, 28359

Bremen, Germany

e-mail: vollstedt@math.uni-bremen.de

Q. Zhang

Department of Mathematics and Information Technology, The Education University of Hong Kong, Lo Ping Road 10, Tai Po, Hong Kong SAR, China

e-mail: zqiaoping@eduhk.hk 
A new phase began some six decades after that meeting in Rome. In 1969 mathematicians and mathematics educators convened officially, in Lyons, at the first International Congress on Mathematical Education [ICME] conference. Further ICME conferences followed: next in the leap year of 1972, then every four years, and most recently in 2016 in Hamburg where ICME-13 was held.

\subsection{Genesis of the Book}

Almost 3500 participants from 105 countries took part in the ICME-13 conference. "The heart of the congress", wrote Kaiser (2017, p. 3) "consisted of 54 Topic Study Groups, devoted to major themes of mathematics education, in which 745 presentations were given". Among these was the Topic Study Group 28 on "Affect, beliefs and identity in mathematics education" which, in turn, spawned the contents of this volume.

Topic Study Group 28 [TSG28] was aimed at addressing all areas of affect, including attitude, anxiety, beliefs, meaning, self-concept, emotion, interest, motivation, needs, goals, identity, norms, values. The different approaches to study affect included psychological, social, and philosophical research perspectives. Moreover, the call for papers explicitly questioned the issue of the mutual relationship between affective constructs and their connection to cognition and other constructs studied in mathematics education, as well as the description of programs for promoting aspects of affect.

The activity of the working group was aimed at:

- Presenting an overview of the state of the art in the research field of affect in mathematics education, both at the students' and the teachers' (pre-service or in-service) level.

- To identify new trends and developments in research and practice in these areas.

- To engage participants in a critical reflection of this research field and generate discussion of an agenda for future research on affect in mathematics education. (Hannula, Morselli, Erktin, Vollstedt, \& Zhang, 2017, p. 507)

Two key measures were adopted to cope with the large number of papers submitted to TSG28, and yet ensure that each participant was allocated an adequate time for the presentation and discussion of his or her report. These were to use a process of peer review for the material submitted and to accept the need to schedule parallel sessions in the times allocated for the topic group. An overview of the various TSG28 presentations - their content and mode of delivery - can be found in Hannula et al. (2017). Collectively, the body of material presented, the lively discussions that ensued, and the thirst for continued work in the field of affect and mathematics education underpinned the development of the present volume.

Post ICME-13 preparations for the book largely followed an expected course. In the first instance the team needed to shepherd the new volume from conception to completion was finalized. This was followed by a call for an expression of interest to those involved in TSG28 and who might wish to modify and enlarge their initial contribution for inclusion in a follow-up volume. By the closing date for this call, 33 
reworked papers had been submitted. A further peer-reviewing process was put in place, with each of the reworked papers reviewed by at least one external reviewer and one member of the editorial team. Just under half of the work submitted (15 chapters) was judged to be suitable for inclusion in the book. These contributions were ultimately clustered as follows: a stand-alone overview chapter, followed by three sections with the provisionally titled headings of interest, motivation, and values; engagement and flow; and identity. To enrich and broaden the contents of the book even further, the assistance of three established mathematics educators, well versed in the field of affective research, was sought. Each was asked to write a succinct commentary and critique on one of the three clusters. In this way the final product comprised 20 chapters: 15 written by participants in TSG28, three commentaries, as well as an introduction and concluding chapter written by the editorial team.

\subsection{The Affective Domain and Mathematics Education}

Mathematics-related affect — or affect in general — is a research area with a variety of theoretical approaches so broad that it borders on being harmful (see, e.g. Hannula, 2012 and the chapter by Gilah Leder in this volume). Hannula (2012) has suggested three dimensions to categorize theories related to affect. The first dimension identifies three different types of affect: cognitive (e.g. beliefs), motivational (e.g. values), and emotional (e.g., feelings). The second dimension distinguishes between theories that focus on the relatively stable aspects of affect (i.e. traits) from the theories that focus on the dynamically changing aspects of affect (i.e. states). The third dimension identifies three different traditions for theorizing affect: physiological theories, psychological theories, and social theories. These three dimensions informed the categorisation of chapters in this book. Interest, motivation, and values all relate to the motivation aspect of mathematics-related affect. Flow and engagement includes three papers that focus on the dynamically changing affective states. The third section of the book includes three chapters explicitly focusing on identity, a social theory. It also includes one chapter with a focus on teacher professional beliefs, which we, the editors, considered to be so closely related to the two papers on teacher identity that they should be grouped together.

\subsection{About the Book}

As mentioned above, the book comprises three main sections which cover different yet overlapping themes. The international mix of the contributing authors (and of the reviewers of the work) is noteworthy, and undoubtedly contributes to a diversity of perspectives captured, and ensures that relevant research beyond that published in English is more likely to be referenced. 


\subsubsection{Overview}

To provide a common context for those who attended TSG28, Gilah Leder had been asked to present an overview of the state of the art of research on affect and mathematics education, with a special emphasis on gender issues. The opening chapter, Mathematics-related beliefs and affect, still reflects this request. The use and abuse of terms linked to the affective domain and the evolution of theoretically driven attempts at more definitional precision and consistency are outlined. Historical and contemporary approaches enlisted to probe the interaction between affect and mathematics learning are delineated. Snapshots of recent research are used to sketch currently accepted findings and highlight potentially promising new avenues for further research. Where deemed relevant and appropriate the impact on research in the affective domain of work conducted by those concerned with gender issues is also foregrounded.

\subsubsection{Interest, Motivation, and Values}

Kay Achmetli and Stanislaw Schukajlow report on their project MultiMa. In their chapter Multiple solutions, the experience of competence, and interest they show how students' learning is affected when they are asked to construct multiple solutions of real-world problems using different mathematical procedures. Their theoretical background is threefold and gives a concise summary of the relevant research on interest, experience of competence, as well as multiple solutions, and real-world problems. In their experimental intervention study, they investigated 307 ninth graders from twelve middle track classes. The study consists of two sessions, each of $90 \mathrm{~min}$ and framed by pre- and posttest on interest. The students' experience of competence was assessed through a short survey in session two. Three treatment conditions were implemented: In the multiple solution group, students were asked to produce two solutions for the real-world problem using two different mathematical procedures. The other two groups were asked to apply one specific procedure to solve the problem. Achmetli and Schukajlow developed a complex path model to hypothesise the influence of the development of one versus multiple solutions on the experience of competence and interest at post test, as well as the interaction of experience of competence and interest. "The results indicate that constructing multiple solutions has a positive influence on students' experience of competence but no effect on their interest in mathematics."

Tracy E. Dobie focuses on the students in her chapter: A sociocultural examination of utility value in mathematics: The role of interdependence in middle school students' perceptions of usefulness. She considers the relationship between students' personal values, which she understands as one facet of identity, and the perception of usefulness of mathematics. The conceptual framework draws on Eccles and Wigfield's (2002) expectancy-value model with a special focus on utility value. In addition, a 
sociocultural perspective is taken, bearing in mind that the Self is in relation to others and that mathematical understanding is also developed in out-of-school activities and families/communities. The participants in Dobie's study are 84 students from four seventh-grade classes with diverse ethnical backgrounds, feeling most comfortable speaking English and Spanish. Nearly $70 \%$ of the students were from low-income families. A special strength of Dobie's chapter is the triangulation of different data: student surveys to collect data on students' values and views of usefulness of mathematics, ethnographic classroom observations, and student interviews. Results show that the usefulness of the mathematics to be learnt is greatly important for students. In addition, "strong interdependent values related to both helping their families and collaborating with others" are shown. Some students even relate their independent values and the usefulness of mathematics.

In their chapter entitled A longitudinal study of mathematics and science motivation patterns for STEM-intending high schoolers in the US, James Middleton, Daniel Mangu, and Andrew Lee address the effect of motivational factors on students' intentions towards careers in STEM. The study draws on previous research on STEM education and on the effect of affective factors such as interest and self efficacy on STEM orientation. One special aspect of the reported study is the longitudinal nature, namely the specific focus on the changes of intentions throughout high school years. The study draws on data from the High School Longitudinal Study of 2009, which surveyed over 24,000 US students in ninth grade and again in eleventh grade. Motivational factors include identity, interest, utility, self-efficacy, and effort. Data show that occupational intentions change significantly between ninth and eleventh grades. The quantitative analysis addresses links between motivation factors and STEM career intention. Those who leave STEM orientation report a general decrease in interest, identity, self-efficacy, and utility. Conversely, those who initially had not chosen a STEM orientation and after two years change their mind, report a general increase in the same motivational variables. Moreover, the relationship between STEM intention and motivation is proved to be highly time-sensitive. As the authors point out, "students' motivations are highly located in the moment. Their experiences in mathematics and science in one year may not be related strongly to their experiences in another year, and their motivations, being tied to the experiences at hand, seem to be highly unstable". In their conclusion the authors indicate further research that is needed and advocate for a special attention in curriculum development, so as to maintain STEM subjects attractive for students.

Emmanuel Bofah and Markku S. Hannula, in their chapter Perceived social support network and achievement: Mediation by motivational beliefs and moderation by gender, study the link between perceived social support (as received from teachers and parents) and achievement. In particular, they study the possible mediating role played by extrinsic and intrinsic motivation and the possible moderating effect of gender. The relationship between achievement, motivational beliefs, and gender is conceptualized through the expectancy-value theory (Eccles (Parsons) et al., 1983). The authors perform a quantitative analysis, drawing on TIMSS 2011 data related to five African countries (Ghana, Botswana, South Africa, Morocco, and Tunisia). The focus on African countries is one special aspect of the study that can shed light 
on the issue of achievement in African countries, as well as test the generalizability of results previously obtained in other contexts. The study shows that "the association between perceived social support and achievement is accounted for entirely or partly by how the students value and like mathematics". In other words, teacher (and parent) support is beneficial when a student likes and values mathematics. The study data also show that gender has a moderating role on the effect of motivation, and that such a role varies across countries.

Maike Vollstedt and Christoph Duchhardt explore the concept of personal meaning, defined as "personal relevance of an object or action, when dealing with mathematics" (Vollstedt, 2011) in their chapter Assessment and structure of secondary students' personal meaning related to mathematics. The authors provide a theoretical background concerning the concept of meaning in mathematics education and discuss, from a theoretical point of view, the link between personal meaning and other constructs such as interest, motivation, values, and goals. A model for personal meaning, made up of 17 types, developed by Vollstedt in a former qualitative study (Vollstedt, 2011), is presented. Afterwards, the chapter reports a quantitative study aimed at assessing the 17 types of personal meaning and, thus, validating the theoretical model, by means of a questionnaire administered to 193 German students (age: 15-16). Cluster and correlation analyses generally support the theoretical concept of personal meaning. Exploratory factor analyses also suggest two meta-factors structuring the different personal meanings into those showing an orientation to mathematics and to social inclusion.

In her chapter, Middle school boys' and girls' own expressions of aspirations for their mathematics learning, Karina Wilkie draws on a large and diverse sample of more than 3500 middle school students to explore their aims and reasons for learning mathematics. The students came from 31 government and independent schools which varied in size and socioeconomic status and were spread across three states in Australia. A synopsis of relevant research precedes a description of the study, the instrument administered, and the analysis of the data gathers. This sketch offers a useful context and justification for the study carried out and reported, particularly for those less familiar with the broad research literature on affect and mathematics learning. The large sample size adds to the strength of the analysis of the data by gender. The use of "an open-ended response format to investigate the different facets of students' aspirations as expressed by the students themselves, without any a priori motivation constructs enabled [an] interpretive content analysis of their spontaneous responses", places students' voices at centre-stage and is certainly a further distinctive feature of the work.

Valorie Zonnefeld, in her chapter Implications of training in incremental theories of intelligence for undergraduate statistics students, studies the effect of a training course on growth mind-set (Dweck, 2006) on students' mastery of statistics and attitude towards statistics. The study involves 121 US students enrolled in introductory statistics courses. All students completed both a pre-test and post-test which examined attitudes towards statistics and mastery of statistics. Students in the treatment group received training in incremental theories of intelligence throughout the semester. The quantitative study examines the effect of such a training, with a focus on 
gender differences. Females in the treatment group demonstrate statistically significant greater growth in comparison to males regarding their attitudes towards statistics and mastery of statistics. The final part of the chapter contains recommendations for practice (how to exploit the results of the study so as to increase the representation and achievement of females in STEM), as well as suggestions for further research on the topic.

Wee Tiong Seah compared and contrasted these seven chapters in his contribution Extending the research discourse: From interests and beliefs to values. Research in the 'values in mathematics' domain served as an important unifying theme in his analysis of these chapters. This affective lens not only added a perspective not covered explicitly elsewhere in this volume but also enabled him to conclude that: "this section has pushed the boundaries of academic knowledge in the field a great deal".

\subsubsection{Engagement and Flow}

Marina De Simone examined a teacher's moment-to-moment decisions in her chapter, Intertwinement of rationality and emotions in the mathematics teaching: A case study. In her framework, she extended the Habermasian rationality with an affective dimension. The case study focuses on one Italian mathematics teacher, whose classroom behaviour was video recorded over five lessons. The data were analysed in detail with attention to not only verbal utterances, but also to gestures, facial expressions, and tone of voice, which were considered as potential emotional indicators. Moreover, the aim of the research was "to go beyond the Cartesian dualism between the res extensa and the res cogitans towards a holistic view between body and mind." The analysis focuses on identifying the epistemic, the teleological, and the communicative emotionalities, and through these, Marina De Simone is able to explain why the teacher "spoke in a particular manner within the classroom when she was trying to help her students understand". Specifically, while the teacher actions could be understood within the rationality framework, the affect component was necessary to explain the underlying reasons for these actions.

Deena Kahlil, Elizabeth Lake, and Ayanna Johnson, in their chapter Teachers' classroom engagement structures: A comparative study of a novice US and an experienced UK mathematics teacher, study the affective states of a novice teacher and an experienced one. The theoretical framework they employed refers to the concept of engagement structure (Goldin, Epstein, Schorr, \& Warner, 2011), initially developed for studying students' affect; the authors use the concept, in an original way, to better understand teachers' affective states. For their study the authors draw on material from a wider data collection carried out in the US and UK. In the chapter, two case studies are presented and discussed. The analysis suggests that the theory of engagement structures may link teachers' prior affective states as learners to their current affective state as teachers. Moreover, teacher education may use the idea of 
engagement structure to help teachers to connect their affective states to those of their students.

Drawing on Mihaly Csíkszentmihályi's flow theory, Ana Belén Montoro Medina, and Francisco Gil Cuadra focus in their chapter, Exploring flow in pre-service primary teachers doing measurement tasks, on the characteristics of mathematical tasks that evidently stimulate the occurrence of flow. Using a multi-phase approach, data were gathered from 230 pre-service primary teachers enrolled in a course about teaching and learning measurement at a Spanish university. In their study, the authors searched for evidence of flow while bearing in mind its constituent features: "a positive and gratifying state of consciousness ... a situation of high concentration, involvement, enjoyment, absorption in the task, unselfconsciousness, control, and clear-cut feedback on the course of activity" (Hektner, Schmidt, \& Csíkszentmihályi, 2007, p. 26). As in other chapters, an overview of relevant literature appropriately precedes the description of the study, the approach adopted, and the analysis and interpretation of the quantitative and qualitative data gathered. Through intensive scrutiny of participants' responses and behaviours, including material captured on video and gathered while participants solved measurement tasks, factors that appeared to influence flow are identified. Among these is the composition for group work. "We believe", Montoro and Gil wrote, "that when task complexity levels increase rapidly, using heterogeneous groups hinders the flow experience in students with lower mathematical skills, as they lack time to reflect on the tasks or to draw their own conclusions".

Peter Liljedahl then provides a rich and reflective commentary Accounting-of and accounting-for the engagement of teachers and teaching. By drawing on a diverse yet overlapping body of literature under headings such as 'engagement structure', 'studenting', 'flow', and 'modes of engagement', he set the scene for a more focussed discussion on the 'engagement of teachers and teaching' and ultimately on the work included in the chapters in this section and their location in the broader field, both within and beyond mathematics education. "Although", he writes "each of these chapters is, ostensibly, about understanding engagement, each of the results also makes a contribution to our understanding of how to create engagement".

\subsubsection{Identity}

In their chapter, The interplay of rationality and identity in a mathematical group work, Laura Branchetti and Francesca Morselli adopt a social-cultural perspective. They combined the lenses of rationality and identity as their research framework to analyze a series of episodes issued from different teaching experiments, gathered in grade four and in grade six respectively. Through the use of networked analysis, the authors show that both social skills and disciplinary issues influence the students' ability to participate in group work in a quite complex way. In particular, only a good mathematical identity, which means that the student feels he/she is good in mathematics, may lead the students to participate in the group work moving to an epistemic level and thus to develop relevant social skills related to mathematics. That 
the teacher plays a significant role in the construction of students' identities in group works is also confirmed. The interaction between teacher and students involves not only the mathematizing but also the identifying process.

Ralf Erens and Andreas Eichler, in their chapter Belief changes in the transition from university studies to school practice, address prospective and trainee teachers' beliefs, with a special focus on belief change that occurs when school practice starts. The chapter contains an overview on mathematical beliefs as well as on teacher change. Moreover, since the study focuses on beliefs concerning the teaching of calculus, part of the theoretical background presented in the chapter is devoted to relevant studies on the teaching of calculus. The qualitative study involves 20 German prospective and trainee teachers. Results confirm that central beliefs remain quite stable during the training period, while peripheral beliefs change slightly. Possible causes for change are identified in the authority and reflection factors.

In his contribution The struggle for recognition and the professional identities of mathematics teachers, Clyde Felix explored South African mathematics teachers' professional identities through their struggles for recognitions in the context in which they are situated. Through a narrative approach, these teachers' stories of their struggles for recognition were collected to shape their professional identities. During the semi-structured interviews, three mathematics teachers were asked to reflect on different stages in their professional teaching careers. These include the high points, low (nadir) points, and turning points. The author combines Honneth's (1995) levels of recognition, Kelchtermans (1993) components of the retrospective dimension of a professional self, and Huttunen and Heikkinen's (2004) circles of recognition to analyse teachers' narrative stories. Results show that these teachers' stories have much in common. Their struggles for recognition are at the level of self-esteem, which is for recognition of their worth as mathematics teachers. The teachers have also developed an ability to cope by counterbalancing the negative effects of a lack of recognition with the positive effects of recognition sourced from experiences elsewhere.

Andreas Karaolis and George Philippou, in their chapter Teachers' professional identity, reported the development of a scale to measure teachers' professional identity. Factor analysis was used to examine the responses of 315 primary teachers on a trial scale. This led to the final scale which comprised 48 items, clustered in seven factors: self-efficacy, constructive perceptions, intrinsic motivation, extrinsic motivation, traditional perceptions, future perspective, and professional commitment respectively. Teachers' individual characteristics were found to relate to some scale factors. For instance, as the teacher's service time increased, their internal motives tended to decline. Teachers with advanced graduate studies held more constructivist perceptions and simultaneously less traditional perceptions. Hierarchical cluster analysis led to three groups of teachers with different identity profiles. Apart from the quantitative data analyses, 20 primary teachers from different groups were selected for semi-structured interviews in order to deeper examine how teachers conceptualize themselves at work and locate possible differences among teachers with different professional identities. Results show that the differences concerning the teachers' professional identity factors are more pronounced among teachers with 
different professional profiles than with teachers belonging to the same group. The authors suggest that more attention should be paid to teachers' motivation during teacher education.

This section ends with Einat Heyd-Metzuyanim's analysis and reflections on the four papers in her chapter Identity at the crossroads, collision or conciliation? A commentary. As she points out, the "wide variability of empirical domains, disciplines and methodologies, and especially the fact that these do not necessarily form into neat packages, signals that identity in mathematics education is a field at the crossroads of various disciplinary approaches". She then elaborates all four chapters using a framework that "conceptualizes identity construction as a discursive or communicational activity", making two observations. First, there seems to be a gap between identity and mathematics, and also these chapters "found it difficult to connect between the 'self' and the mathematics with which this 'self' engages". Second, she discusses how in these chapters as in identity research in general the informant's and the researcher's narratives often collapse, prioritizing the researcher's voice and hiding alternative interpretations. Finally, she ends with a conclusion that while there is great variety in the approaches of these four chapters, "each of the approaches is valuable and therefore, none of them should be dismissed. How they should talk to each other, however, remains an open question."

\subsubsection{Conclusions}

Finally, the chapter Fresh perspectives on motivation, engagement, and identity: A conclusion, reflects the contents of the book, especially in relation to the issue of the mutual relationship between affective constructs and their connection to other constructs, as well as the description of programs for promoting aspects of affect, which were specified in the call for papers. The chapters represent a wide variety of theoretical and methodological approaches from beliefs to flow and from narrative analysis to structural equation modelling. A word count analysis of affect terms indicates a clear emphasis on motivational concepts in the book. Moreover, there are only a few chapters looking at the dynamics of the affective states while most chapters look at the relatively stable states. Embodied and social approaches are present, but less prominently than theorizing that focuses on the individual psychological constructs.

Research in mathematics-related affect continues to be rich and diverse. In this book there are both chapters that build on extensive research in the field as well as interesting new openings to the directions less explored in mathematics education to this date. 


\section{References}

Dweck, C. S. (2006). Mindset: The new psychology of success. New York, NY: Ballantine Books. Eccles, J. S., \& Wigfield, A. (2002). Motivational beliefs, values, and goals. Annual Review of Psychology, 53(1), 109-132. https://doi.org/10.1146/annurev.psych.53.100901.135153.

Eccles (Parsons), J. S., Adler, T. F., Futterman, R., Goff, S. B., Kaczala, C. M., Meece, J. L., et al. (1983). Expectations, values, and academic behaviors. In J. T. Spence (Ed.), Achievement and achievement motives: Psychological and sociological approaches (pp. 76-146). San Francisco, CA: Freeman.

Goldin, G. A., Epstein, Y. M., Schorr, R. Y., \& Warner, L. B. (2011). Beliefs and engagement structures: Behind the affective dimension of mathematical learning. ZDM-The International Journal on Mathematics Education, 43, 547-560. https://doi.org/10.1007/s11858-011-0348-z.

Hannula, M. S. (2012). Exploring new dimensions of mathematics-related affect: Embodied and social theories. Research in Mathematics Education, 14(2), 137-161. https://doi.org/10.1080/ 14794802.2012.694281.

Hannula, M., Morselli, F., Erktin, E., Vollstedt, M., \& Zhang, Q. P. (2017). Topic study group no. 28: Affect, beliefs and identity in mathematics education. In G. Kaiser (Ed.), Proceedings of the 13th International Congress on Mathematical Education, ICME-13 Monographs (pp. 507-510). Cham, Switzerland: Springer. https://doi.org/10.1007/978-3-319-62597-3_55.

Hektner, J. M., Schmidt, J. A., \& Csíkszentmihályi, M. (2007). Experience sampling method. Measuring the quality of everyday life. Thousand Oaks, CA: Sage. https://doi.org/10.4135/ 9781412984201.

Honneth, A. (1995). The struggle for recognition: The moral grammar of social conflicts (J. Anderson, Trans.). Cambridge, UK: Polity Press.

Huttunen, R., \& Heikkinen, H. L. (2004). Teaching and the dialectic of recognition. Pedagogy, Culture \& Society, 12(2), 163-174. https://doi.org/10.1080/14681360400200194.

International Commission on Mathematical Instruction [ICMI]. (no date). Historical sketch of ICMI . Retrieved from https://www.mathunion.org/icmi/organisation/historical-sketch-icmi.

Kaiser, G. (2017). Thirteenth international congress on mathematical education: An introduction. In G. Kaiser (Ed.), Proceedings of the 13th International Congress on Mathematical Education, ICME-13 Monographs (pp. 3-9). Cham, Switzerland: Springer. https://doi.org/10.1007/978-3319-62597-3_1.

Kelchtermans, G. (1993). Getting the story, understanding the lives: From career stories to teachers' professional development. Teaching and Teacher Education, 9(5/6), 443-456. https://doi.org/10. 1016/0742-051X(93)90029-G.

Vollstedt, M. (2011). Sinnkonstruktion und Mathematiklernen in Deutschland und Hongkong: Eine rekonstruktiv-empirische Studie [Personal meaning and the learning of mathematics: A reconstructive-empirical study]. Wiesbaden, Germany: Vieweg + Teubner. https://doi.org/10. 1007/978-3-8348-9915-6. 
Open Access This chapter is licensed under the terms of the Creative Commons Attribution 4.0 International License (http://creativecommons.org/licenses/by/4.0/), which permits use, sharing, adaptation, distribution and reproduction in any medium or format, as long as you give appropriate credit to the original author(s) and the source, provide a link to the Creative Commons license and indicate if changes were made.

The images or other third party material in this chapter are included in the chapter's Creative Commons license, unless indicated otherwise in a credit line to the material. If material is not included in the chapter's Creative Commons license and your intended use is not permitted by statutory regulation or exceeds the permitted use, you will need to obtain permission directly from the copyright holder.

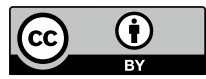




\title{
Chapter 2 \\ Mathematics-Related Beliefs and Affect
}

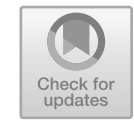

\author{
Gilah C. Leder
}

\begin{abstract}
Influential approaches to the definition and operationalization of beliefs and other affective dimensions are described in this chapter. Snapshots of research findings are presented, commonly used measures are listed, and some technologically enhanced approaches to the measurement of beliefs and affect are discussed. Contributions, both theoretical and practical, to research on the affective domain by those concerned with gender issues are also referenced.
\end{abstract}

Keywords Affect $\cdot$ Beliefs $\cdot$ Gender $\cdot$ Mathematics $\cdot$ Measuring affect

\subsection{About Beliefs, Affect, and Mathematics-Introduction}

\subsubsection{Setting the Context}

Why, it could be asked, are both beliefs and affect in the title of this contribution? The inclusion of both terms warrants a special comment.

In his influential and frequently cited article Pajares (1992) argued convincingly that, within the field of educational psychology,

\begin{abstract}
defining beliefs is at best a game of player's choice. They travel in disguise and often under alias - attitudes, values, judgments, axioms, opinions, ideology, perceptions, conceptions, conceptual systems, preconceptions, dispositions, implicit theories, explicit theories, personal theories, internal mental processes, action strategies, rules of practice, practical principles, perspectives, repertories of understanding, and social strategy, to name but a few that can be found in the literature. (p. 309)
\end{abstract}

Mason (2004) similarly argued that it is often difficult to work out what beliefs actually cover and illustrated this by producing "an entire alphabet of associated interlinked terms":

G. C. Leder $(\bowtie)$

La Trobe University, Melbourne, VIC, Australia

e-mail: g.leder@latrobe.edu.au

Monash University, Melbourne, VIC, Australia

(C) The Author(s) 2019

M. S. Hannula et al. (eds.), Affect and Mathematics Education,

ICME-13 Monographs, https://doi.org/10.1007/978-3-030-13761-8_2 
A is for attitudes, affect, aptitude, and aims; B is for beliefs; $\mathrm{C}$ is for constructs, conceptions, and concerns; $\mathrm{D}$ is for demeanor and dispositions; $\mathrm{E}$ is for emotions, empathies, and expectations; $\mathrm{F}$ is for feelings; $\mathrm{G}$ is for goals and gatherings; $\mathrm{H}$ is for habits and habitus; $\mathrm{I}$ is for intentions, interests, and intuitions; $\mathrm{J}$ is for justifications and judgements; $\mathrm{K}$ is for knowing; $\mathrm{L}$ is for leanings; $\mathrm{M}$ is for meaning-to; $\mathrm{N}$ is for norms; $\mathrm{O}$ is for orientations and objectives; $\mathrm{P}$ is for propensities, perspectives, and predispositions; $\mathrm{Q}$ is for quirks and quiddity; $\mathrm{R}$ is for recognitions and resonances; $\mathrm{S}$ is for sympathies and sensations; $\mathrm{T}$ is for tendencies and truths; $\mathrm{U}$ is for understandings and undertakings; $\mathrm{V}$ is for values and views; $\mathrm{W}$ is for wishes, warrants, worlds, and weltanschauung; $\mathrm{X}$ is for xenophilia (perhaps); $\mathrm{Y}$ is for yearnings and yens; and $\mathrm{Z}$ is for zeitgeist and zeal. (Mason, 2004, p. 347)

How specialists in mathematics education defined beliefs was explored some years ago by Furinghetti and Pehkonen (2002). In their small study they aimed to clarify which elements were widely accepted as core identifiers or descriptors of beliefs. Specifically, the participants in the study were asked to indicate whether they agreed fully, agreed partially but leaning towards agreement, agreed partially, agreed partially but leaning towards disagreement, or disagreed fully with a series of characterizations of beliefs found readily in the relevant research literature and to elaborate on their answer on a five-point scale. "The first surprising result", Furinghetti and Pehkonen wrote, "was that in the responses of the (18) specialists, there was no agreement" (p. 49). After a more nuanced analysis of the data gathered they concluded that

In characterizing beliefs and related concepts it is unlikely that complete agreement will be reached in the use of all the terms at issue. Nevertheless it can be asked that the authors of studies on beliefs reduce the terms and the concepts involved in their work to the minimum needed. Additionally, they have to make clear their assumptions, the meaning they give to basic words, and the relationship between the concepts involved. (p. 55)

Some years ago I trawled through the Conference Proceedings of two well established mathematics education research groups, the International Group for the Psychology of Mathematics Education [PME] and the Mathematics Education Research Group of Australasia [MERGA] for research on beliefs and mathematics education (see Leder, 2007). My concluding comments included:

- The mathematics education research community continues to explore how students' and teachers' beliefs affect mathematics learning and instruction.

- The use of the word belief/believe as a convenient synonym for other terms persists.

- Small sample, qualitative method studies, often of questionable generalizability, are common.

Thus Pajares' observation about educational researchers' all too frequent use of belief as a generic term seemingly applies as well to researchers in mathematics education. It is worth noting that the review of the contents of the two sets of proceedings also identified a number of painstakingly crafted and theoretically driven studies which pointed to new avenues for capturing students' and teachers' multifaceted beliefs and their impact on mathematical learning behaviours. From Liljedahl and Hannula's (2016) review of work presented at PME's annual conferences in the decade 2006-2015 it is apparent that the diversity of research on affective issues 
has continued. Captured in that chapter are examples of work embodying loosely defined concepts as well as research designed and executed within a carefully elaborated theoretical framework.

\subsubsection{Defining Beliefs-A Continuing Story}

In the mathematics education literature, beliefs have been conceptualized and operationalized in different, and evolving, ways. This is illustrated by a sample of excerpts published a decade apart.

According to McLeod (1992):

beliefs are largely cognitive in nature, and are developed over a relatively long period of time.... (W)e can think of beliefs, attitudes, and emotions as representing increasing levels of affective involvement, decreasing levels of cognitive involvement, increasing levels of intensity of response and decreasing levels of response stability. (p. 579)

Nuanced differences in affective subdomains have been described by Goldin (2002, p. 61):

(1) Emotions (rapidly changing states of feeling, mild to very intense, that are usually embedded in context), (2) attitudes (moderately stable predispositions toward ways of feeling in classes of situations, involving a balance of affect and cognition), (3) beliefs (internal representations to which the holder attributes truth, validity, or applicability, usually stable and highly cognitive, may be highly structured), and (4) values, ethics, and morals (deeply-held preferences, possibly characterized as "personal truths", stable, highly affective as well as cognitive, may also be highly structured).

A decade later Hannula (2012) argued that terminological ambiguity has continued to be a problem and that a new framework might be needed to move the field forward:

The review of research on mathematics-related affect indicates that the dominant framework of beliefs, emotions and attitudes is not sufficiently broad to incorporate all research in this area. More specifically, embodied perspectives and strong social theories go beyond that frame.... Many frameworks aim to theorise the interaction between different aspects. (p. 155)

Ways in which the call to re-examine prevailing assumptions has been taken up can be seen in, for example, the recently published book From beliefs to dynamic affect systems in mathematics education, edited by Pepin and Roesken-Winter (2015). "Systems thinking", they explain,

is based on the belief that the component parts of a system can best be understood in the context of relationships with each other and with other systems rather than in isolation - in other words, on the belief that 'the whole is greater than the sum of its parts'.... Linking this to 'affect systems', we can see why there have been so many debates over the last few decades about what constitutes 'emotions', 'attitudes', 'beliefs' and 'values', and there are no clear definitions available to date. Could it be that emotions, attitudes, beliefs and values each constitute a system (e.g. in an individual, or in a collective/group) and that these systems are 
indeed inter-related, or 'nested' within any one person/group, albeit nurtured by the context? (pp. xv-xvi)

It is perhaps no coincidence that, referring not to beliefs about mathematics but to mathematics anxiety, Dowker, Sarkar, and Looi (2016) have argued for a more intensive focus on the putative link between different factors and specific aspects of mathematics anxiety. They concluded:

Our biggest need for further learning may involve not so much any specific aspect, as the ways in which the aspects relate to one another. How do the social aspects relate to the neural aspects? How do either or both of these relate to changes with age? How might appropriate treatment be related to age and to the social and cognitive characteristics of the individuals.

(Dowker et al., 2016, p. 12)

Explanations for the continuing focus among researchers and practitioners on the affective domain abound. Some may be encouraged by Kramers' (n.d.) acknowledgement that the physical sciences, too, are plagued by a lack of precision. "In the world of human thought generally, and in physical science particularly", he argued, "the most important and fruitful concepts are those to which it is impossible to attach a well-defined meaning".

The continuing preoccupation with the affective domain is arguably also fuelled by the attention given to it in influential overviews and comparisons of international student achievement data such as those reported in the Trends in International Mathematical and Science Study [TIMSS] and the Programme for International Student Assessment [PISA]. The following is taken from a PISA publication:

\footnotetext{
Individuals' attitudes, beliefs and emotions play a significant role in their interest and response to mathematics in general, and their employment of mathematics in their individual lives. Students who feel more confident with mathematics, for example, are more likely than others to use mathematics in the various contexts that they encounter. Students who have positive emotions towards mathematics are in a position to learn mathematics better than students who feel anxiety towards that subject. Therefore, one goal of mathematics education is for students to develop attitudes, beliefs and emotions that make them more likely to successfully use the mathematics they know, and to learn more mathematics, for personal and social benefit. (OECD, 2013, p. 42)
}

Highlighted in extracts such as the above is an acceptance of the close interplay between the learning of mathematics and a host of affective factors. This widespread acceptance can be seen as a driving force for continuing work concerned with subtle distinctions between different affective components as well as investigations germinated by different theoretical orientations.

\subsection{About Beliefs, Affect, and Mathematics: What We Think We Know}

Research on mathematics-related beliefs and affect can be clustered in many different ways. For example, groupings could be in terms of measurement of affective 
factors; descriptive studies in which affective factors are of secondary interest and are overwhelmed by factors considered to be of greater importance; comparisons of affective and cognitive variables; and theoretical driven papers-which are often presented without any experimental data. Another option is to segment the field, and again not uniquely or unambiguously, under headings focusing on mathematics; on students (both internal and external factors); and on teachers (internal and external factors). Common to different approaches is the widespread acceptance that beliefs and other aspects of the affective domain cannot be measured directly, nor can they be readily observed. Instead they need to be inferred from behaviour, speech, or responses to specifically designed stimuli or instruments. How these measurements are devised, focused, administered, and interpreted inevitably affects the nature and scope of the belief or other affective construct "captured".

From the above it is apparent that compiling a comprehensive overview of relevant research is no small task, nor one readily summarized within one chapter. As argued by Schoenfeld (2015, p. 395): "Research in the 'affective domain' is densely populated with overlapping constructs, partially commensurate methods, and somewhat contradictory findings". Definitional imprecision is a further confounding factor.

In this chapter I am relying on descriptive snapshots of research on affect, drawn from three recently published and influential contributions to the field, to provide a succinct yet varied overview of relevant work. These are: The Encyclopedia of Mathematics Education (Lerman, 2014), The ICME-13 Topical Survey on Attitudes, Beliefs, Motivation and Identity in Mathematics Education (Goldin et al., 2016), and Research in Mathematics Education in Australasia 2012-2015 (Makar et al., 2016). Pertinent summaries are presented in turn below.

\subsubsection{The Encyclopedia of Mathematics Education}

Three of the entries in this encyclopedia are of particular interest. These are the entries by Zan and Di Martino (2014), Liljedahl and Oesterle (2014) and Hannula (2014).

Focussing on attitudes in mathematics education, Zan and Di Martino (2014) reported that:

- Initially, research on attitudes tended to focus on the development of measuring instruments rather than on the theoretical definition of the construct.

- The correlation between attitudes and achievement in mathematics is typically not high.

- The importance of incorporating qualitative measures has been increasingly recognized.

- Attitude is now often considered "a flexible and multidimensional tool, aimed at describing the interactions between affective and cognitive aspects of mathematical activity". 
The authors indicated that they themselves favour an "interpretative approach based on the collection of autobiographical narratives of (a large number of) students". Using this approach three dimensions were found to feature consistently: emotions, vision of mathematics, and perceived competence. More targeted intervention programs, Zan and Di Martino argued, can be devised using these distinctions.

Liljedahl and Oesterle's (2014) covered teacher beliefs, attitudes, and self-efficacy in mathematics education. Their findings included:

- Various definitions are provided for both beliefs and attitudes.

- Research on teacher self-efficacy is "challenged by difficulties in clearly defining and measuring self-efficacy and its impact".

- Both consistencies and inconsistencies have been reported between teachers' espoused beliefs, enacted beliefs, actual beliefs, and the attributed beliefs that the researchers assign to them.

- Negative attitudes towards mathematics, which can be very difficult to change in adults, can interfere with teacher learning.

- Included among desirable teacher attitudes are curiosity, high motivation, and appreciation of "good" problems and elegant solutions.

- But: much is still unknown about the relationship between teachers' attitudes and practice.

In the section on affect, Hannula's (2014) focus was primarily on emotional states and traits. Findings included:

- Mathematics anxiety is related to general anxiety, test anxiety, and low mathematics attainment.

- Students with a positive disposition towards mathematics tend to experience positive emotions more frequently and negative emotions less frequently than students with a negative disposition.

- Students' affective and social interactions in mathematics classes are interdependent.

- Emotions may affect memory retrieval and performance.

- Emotions can often be identified from facial or behavioural expressions (and these may be more accurate indicators than self-report measures).

- Classrooms are "often emotionally flat, and boredom is one of the most frequently experienced emotions".

- Features of the classroom climate and teachers behaviours which can enhance positive student emotions continue to attract research attention.

Collectively, the three entries cover a number of interacting, and at times overlapping, affective factors. 


\subsubsection{The ICME-13 Topical Survey on Attitudes, Beliefs, Motivation and Identity in Mathematics Education}

In the introduction of the monograph compiled by Goldin et al. (2016), the view was re-iterated that research on mathematics-related affect is broad and varied. Core topics reviewed and discussed included "attitude towards mathematics, self-efficacy beliefs, teacher beliefs, mathematical identities, and mathematical motivation" (p. 23). Here I focus primarily on a number of the "open" questions identified and highlighted by the various contributors to this volume and their suggestions for further work to move the field forward. These included:

- Aim for further refinement of instruments used to tap attitudes to mathematics.

- Use the design and implementation of carefully planned cross- and inter-cultural studies to achieve consensus on putatively robust results.

- Plan and conduct longitudinal studies to monitor more stringently the efficacy of intervention studies.

- Aim for further explorations of the relationship between beliefs and practice, while taking into account possible confounding factors linked to different mathematics topics.

- Design contextual studies with a focus on factors influencing changes in beliefs, and particularly those set within teacher development programs and those incorporating e-learning environments.

- Build on small qualitative studies to extend defensible generalizations beyond the specific setting and sample initially studied.

- Build on in-the-moment perspectives to capitalize on researchers' better control over personal and environmental variables.

\subsubsection{Research in Mathematics Education in Australasia 2012-2015}

In this publication it is the chapter on "Mathematics education and the affective domain" (Attard, Ingram, Forgasz, Leder, \& Grootenboer, 2016) that is of special interest. Highly relevant, too, is the identification of largely neglected areas of research. Aspects identified as glaringly in need of further consideration included:

- Paying greater attention to sample and setting characteristics in order to facilitate and promote an evidence based synthesis of diverse findings.

- Interrogating and documenting if, and how, the widespread incorporation of technology into mathematics curricula has an influence on affective components. As Attard et al. (2016) noted: "Consideration of the impact of technology on this digital generation of teachers and students and the ways it influences their perceptions of and interactions with mathematics education is imperative" (p. 91). 
- Exploring how the ready availability of new, user-friendly software can support the analysis of data gathered in affective studies.

- Capitalizing on advances in cognitive neuroscience to explore the impact of affective factor on mathematics learning.

Research on mathematics and the affective domain, it is apparent from the examination of the above publications, certainly warrants further carefully conceived and planned research.

Though not specifically highlighted in the excerpts taken from these publications, issues of gender often permeate - to a greater or lesser extent-research on mathematics and the affective domain. McLeod's (1992, p. 580) observation that research on beliefs "comes mainly out of the work on gender differences in mathematics education" has lost none of its currency. Dowker et al. (2016, p. 7) likewise noted: "One of the factors that has received most study with regard to mathematics anxiety is that of gender". In the overview provided in this chapter, the impact on the field of research on gender issues is incorporated where pertinent, and particularly in the discussion of approaches to the measurement of affect appropriated in mathematics education research.

\subsection{About Beliefs, Affect, and Mathematics: New Directions?}

It is not easy to gauge uniquely just how much progress has been made in recent decades in the field of mathematics education and affective research. It is, however, both revealing and informative to revisit some earlier work presented at the annual conference of PME, with its substantial number of international attendees and presenters.

\subsubsection{From the PME Archives}

The archival snapshots selected are taken from the records of three annual conferences held 10 years apart: in 1985, 1995, and 2005. Each presentation was designated in the PME Proceeding for that year as belonging under the umbrella of affective topics. The relevant headings comprised teacher behaviour and attitude; beliefs; and affect, emotion, beliefs and attitudes.

The study by Fresko and Ben-Chaim (1985) was titled "Confidence, competence and in-service education for math teachers". Using a pre-test and post-test quasi-experimental design, teachers attending in-service courses completed measures which tested their confidence with respect to subject matter skills and their confidence about their ability to teach topics included in the curriculum. More specifically, participants were required to solve a series of mathematics problems at a level 
commensurate with that expected of their own students, were asked to indicate how confident they were that they themselves could solve the problems, and how confident they were about teaching the topics covered in the in-service course. The authors of the research report concluded that:

Many mathematics teachers in their sample needed to learn mathematics better. Thus contentoriented in-service programs are needed.

Teachers who are not confident about the subject matter they need to teach also tend to lack self-confidence. So, first teachers' level of subject matter knowledge needs to be addressed, followed by efforts to reinforce their self-confidence with respect to their subject matter competency and also with respect to their teaching capability.

The focus of the study reported by Yusof and Tall (1995) was captured economically in the title of their presentation: "Professors' perceptions of students' mathematical thinking: Do they get what they prefer or what they expect?" In this study, members of a university mathematics department were asked to complete a survey about attitudes to mathematics and attitudes to problem solving.

In the first instance the professors were asked to indicate the responses they expected from a typical student in their lecture group. Next, they were asked to respond to each item on the survey by indicating how they preferred that students would respond. The thrust of the survey items can be gauged from the findings presented by the authors and quoted in some detail below.

As well, interviews were used to probe in more detail the group's attitudes to problem solving. Perhaps not unexpectedly, the qualitative responses yielded information not necessarily congruent with that gathered via the surveys. Lecturers, it was concluded, preferred students to have a range of positive attitudes to mathematics but they expected reality to be different. Yusof and Tall (1995) wrote:

Although lecturers prefer students to have a range of positive attitudes to mathematics, they expect the reality to be different. They prefer students to see mathematics as solving problems, making sense, with students working hard, able to relate ideas without needing to learn through memory, having confidence, deriving pleasure, with low anxiety and fear, ready to try a new approach and unwilling to give up easily on difficult problems. On the other hand, they expect them to see mathematics as abstract, failing to understand it quickly, not making sense, working hard to learn facts and procedures through memory, unable to relate ideas, with less confidence, obtaining less pleasure, working only to get through the course, with anxiety, fear, seeking only correct answers, and ready to give up when things get difficult. (Yusof and Tall, 1995, p. 177)

"Teachers' beliefs of the nature of mathematics: effects on promotion of mathematical literacy" presented by Webb and Webb (2005) is the third article retrieved from the PME archives. In this study a variety of measures was used to encourage teachers not only to reflect on their own beliefs but also to make them explicit. To do this, participants (in-service teachers) were asked to complete a Likert-scale questionnaire based on videotapes of lessons they viewed. A sub sample of the larger group was interviewed individually to explore in greater depth their perceptions of the nature of mathematics and their own teaching practices. These views were then tested against the practices observed when the teachers were videotaped in their own classrooms. Webb and Webb (2005) concluded: 
Data generated by videos support the findings of similar studies, i.e. that teachers' beliefs of the nature of mathematics are often not reflected in their practice. This has far-reaching implications for the implementation of compulsory mathematical literacy to (various) grades, as the mode of delivery is envisaged to be through contextual problem solving. (pp. 1-293)

Though conducted years ago, each of the studies reviewed, it can be seen, relied on an approach and an area of research that still resonate with current work and presentations at contemporary conferences and meetings. Well-tried avenues, at times supplemented with new approaches, continue to be pursued to progress our understanding of the interaction between affect and mathematics learning and instruction.

\subsection{About Beliefs, Affect, and Mathematics: Testing the Boundaries}

A diverse range of instruments has been used to measure affect and its role in the learning and teaching of mathematics. Self-report measures - with or without open-ended responses - are frequently used. Interviews, and particularly 'structured' interviews with their predetermined list of specific questions to be asked, are considered by some as little more than orally administered questionnaires. Unstructured interviews, on the other hand, can uncover views not anticipated in advance. A combination of these approaches - the semi-structured interview-is popular in mathematics education research. Interviews and surveys have been used as stand-alone measures and, at times, as a part of more diverse testing regime.

Other methods adopted rely on the interpretation of, or inferences drawn from, observed behaviours. Information gleaned from physiological or neural activity is used in some work. As described below, if deemed opportune, researchers have not hesitated to introduce variations to previously published instruments, adapt existing instruments to new settings or to benefit from advances in technology. They have, however, not necessarily grappled with the attendant methodological or newly introduced ethical issues. Examples of commonly used instruments and strategies are presented below.

\subsection{Measuring Affect}

\subsubsection{Self-report Measures-Likert Scales}

Likert-item surveys, possibly with the option of open ended responses, are widely used to measure single or multiple aspects of affect. As Ruthven (2015, p. 393) has noted: "this is an unusually convenient technique which serves researchers well in generating results". The extent to which the tools actually reveal what they purport to measure remains a matter for debate, however. 
Items commonly used in the internationally administered TIMSS and PISA testing programs have fuelled many Likert surveys, as have the Fennema-Sherman Mathematics Attitude scales.

The latter, which can be used individually or in their entirety, have been embraced particularly enthusiastically by the research community. Recent statistics (data accessed April 8, 2015) provided by the Journal for Research in Mathematics Education revealed that Fennema and Sherman (1976a) was identified as its second most accessed article, both in the short and long term (the previous three months and the previous three years respectively). Over the longer period monitored it was reportedly accessed 1870 times. In the more detailed Fennema and Sherman (1976b) the authors wrote:

Each scale assesses an attitude that has been hypothesized to be related to the study and/or learning of mathematics by males and females. The scales include (a) confidence in learning mathematics; (b) father, mother, and teacher scales measuring perceptions of attitudes toward one as a learner of mathematics; (c) effectance motivation in mathematics; (d) attitude toward success in mathematics; (e) mathematics as a male domain; (f) usefulness of mathematics, and (g) mathematics anxiety scale. (p. $i$ )

The scales, collectively, reinforce the belief that mathematics learning is influenced by a variety of attitudes, strategically captured in the different sets of items. The scales have been adopted, and adapted, widely and persistently.

\subsubsection{The Fennema-Sherman Scales and Gender Differences in Mathematics Learning}

The mathematics as a male domain [MD] scale has been particularly influential in investigations of gender differences in mathematics learning. However, a key assumption that underpinned the development of the MD scale, namely that "the less a person stereotyped mathematics, the higher the score ... as it was assumed that the less a female stereotyped mathematics as a male domain, the more apt she would be to study and learn mathematics" (Fennema \& Sherman, 1976a, p. 7) was challenged by Forgasz, Leder, and Gardner (1999). They argued that, with changing social circumstances, although many still considered mathematics to be a male domain some now thought of mathematics as a female domain. To overcome this uncertainty they produced two new instruments (Leder \& Forgasz, 2002). The Mathematics as a gendered domain survey consists of traditional Likert type items clustered into three subscales: mathematics as a male domain, mathematics as a female domain, and mathematics as a neutral domain. When administered, the 48 items are presented in a random order. The Who and mathematics instrument contains items similar to those on the Mathematics as a gendered domain instrument but respondents are asked to indicate for each item if it applies more to boys than to girls (definitely/probably); there is "no difference between boys and girls"; or it applies more to girls than to boys (probably/definitely). The instruments are reportedly effective in tapping gender 
differences in beliefs and attitudes about mathematics and its learning. Importantly, this example illustrates how theoretical assumptions can influence the content and response format of an instrument and, if flawed, distort or constrain the determination, formation and assessment of the affective domain.

Issues of definitional imprecision, as already discussed in some detail, plague the affective domain.

That this problem is not unique to the affective domain but is also raised with respect to describing gender identity also warrants a comment.

Those well versed in research on gender and mathematics education are well aware that both the terms sex differences and gender differences are readily found in the literature. Originally, the term sex differences was used uniquely and consistently. In more recent times, sex has more commonly been used to denote biologically-based differences. The usage of gender evolved following debates on whether all differences could or should be attributed to biology alone. Gender, as a term was consequently often used to describe differences between males and females that are not attributable to biology. For a detailed overview of the fluid terminology and shifting views in recent decades about gender diversity and sexual orientation see, for example, the definitions promoted by the American Psychological Association [APA] (2015).

Recently the sufficiency of the male-female binary distinction has been further challenged and more nuanced refinements have been recommended:

In the April issue of AERA Highlights, AERA announced that members would soon have the option to select from an expanded list of gender identity categories when renewing their membership or joining the association... (A) two-step approach to collecting data on gender: the first being the collecting of data on the biological sex assigned at birth, and the second asking members how they describe their gender.... The wording of the two questions would be as follows:

Biological sex designated at birth (check all that apply):

Female

Male

Intersex

Biological sex not listed above (please specify):

Prefer not to answer

Gender (check all that apply):

Agender

Cisgender Man

Cisgender Woman

Gender Expansive

Gender Fluid

Gender Non-Conforming

Genderqueer

Man

Non-Binary

Transgender 
Trans Man
Trans Woman
Trans/Trans*/Trans+
Two-spirit
Woman
Gender not listed above (please specify):
Prefer not to answer. (Levine, 2016)

How, or whether, these new categorizations will impinge on research on gender/sex differences in mathematics learning remains to be seen.

Also worth noting is the diverse range of personal and situational variables supposed to be linked to gender differences in mathematics learning. Factors invoked include stereotype threat, motivational differences, attribution theory, self-efficacy, autonomous learning, research on gender differences in a range of settings and endeavours is pursued seemingly unabated. Whether such a plethora of apparently different yet overlapping perspectives stimulates or obstructs a systematic study of the field is a question worth pursuing.

\subsubsection{Projective Techniques}

A variety of projective techniques has been used to tap affective factors. In this approach, respondents are shown an unstructured or ambiguous stimulus related to the attitude object of interest and are asked to react to this or explain what they see or think about it. Examples include a sentence completion task ("a good mathematics lesson is..."), a word association test, a picture preference test, a request to write a story (Anne/John came top of her/his mathematics class. Who will John/Anne tell about this?), or draw a picture in response to a particular cue. The technique is readily adapted for use with older or younger students and can yield powerful insights into their perceptions of mathematics and mathematics learning. The difficulty of achieving consistent scoring, and hence satisfactory reliability and validity, remains problematic but has not severely dented mathematics educators' reliance on projective measures. It continues to be favoured by, for example, those concerned that explicit Likert items may draw responses thought to be socially or culturally acceptable rather than answers actually indicative of the attitudes held by the respondent.

\subsubsection{Observations}

Observations of behaviours in both structured and natural settings have also been used to infer attitudes about various objects or activities. When carried out by expert and objective observers, supported by a carefully designed observation schedule and 
systematic recording, determination of affect is fairly consistent. However, as it is usually difficult to predict when pertinent behaviours will be observed this method is generally regarded as too inefficient and expensive to be used as a stand-alone measure. In educational research real time observations are often supported by audioor videotaped recordings of the sessions observed. These tapes can then be analyzed and interpreted at length at a convenient time.

Attitudes to mathematical activities and learning have certainly been inferred from observations in a natural setting. For example, classroom teachers invariably take note of, and respond to, students' behaviours in class. While such observations cannot be termed a formal measure of affect they are, nevertheless, consciously or unconsciously, used to make inferences about students' beliefs about themselves and attitudes to their work.

\subsection{Enhanced Measures}

As already noted above, surveys and self-report measures are widely used to measure single or multiple aspects of affect. Technology facilitated adaptations of these approaches are increasingly being adopted. Some examples of technology enhanced research and already trialled for use in, and beyond the classroom, are presented next. That in such work ethical issues may arise beyond those inherent in traditional methods employed for data gathering is worthy of careful consideration but outside the scope of this chapter.

\subsubsection{Enhanced Self-report Measures}

In many Western homes and classrooms, tablet computers are now readily available. Much has been written elsewhere about the educational advantages and disadvantages of using these devices as teaching tools or aids. Of interest here, however, is their potential for use in research about affect and mathematics learning.

In a small study, Larkin and Jorgensen (2015) asked students in elementary school to use their tablet computers to video record mathematical activities and their reactions to them.

Two tents were erected, one in each year 3 and 6 shared space, to create a 'mathematical thinking space'. Students were able to enter the tent to record their video as they chose, within the boundaries of the usual classroom teaching requirements. This was usually during the times when students would be seated doing individual work or when they had completed set tasks; however, there was no requirement that all students must record a video. Students were able to use the video camera that comes standard with any iPad, to record their musings, and if they needed, they could also use the camera to take photographs of mathematics work relevant to their conversations. (Larkin \& Jorgensen, 2015, p. 6) 
Extra prompts, given as needed to probe students' attitudes and reactions to the task at hand, included questions such as " What would I tell my mum and dad or my principal about what I did in maths today?' or 'If maths were a food what type of food would it be?'. The experiences of students, and their reactions to them, were collected over a sustained period. The authors argued that the scope of the data obtained was far richer than would be gathered using more traditional methods.

Using the internet to administer surveys has also become increasingly feasible and popular. Even with limited resources, larger and geographically diverse samples can be reached promptly and efficiently. For example, building on information gathered through a face-to-face survey, Forgasz, Leder, and Tan (2014) used Facebook to reach an international sample to explore prevailing societal beliefs and attitudes in different countries about the gendering of mathematics and related issues. Mathematics, they reported from the data gathered in nine countries, was invariably believed to be important and worthy of continued study even when it was no longer a compulsory subject. Although the level of gender stereotyping of mathematics by parents varied somewhat by country, the authors concluded that "the consistency in the direction of the findings in support of the traditional male stereotype provides strong evidence that gendered perceptions of mathematics and related careers persist in many parts of the world" (p. 386). This finding, they added, serves yet again, as an important reminder that external factors should not be discounted by those aiming to counter gender stereotyped beliefs about students' proficiency in, and attitudes about, mathematics learning.

As foreshadowed earlier in this section, reliance on Facebook for sample recruitment can raise ethical issues as well as questions about the reliability and validity of the findings obtained. Advantages and disadvantages of this mode of recruitment are considered constructively by Kosinski, Matz, Gosling, Popov, and Stillwell (2016). How the ethics committee at a major international university wrestled with potentially additional ethical considerations associated with sample recruitment via social networking sites such as Facebook is described in some detail in Forgasz, Tan, Leder, and McLeod (2017).

\subsection{2 "Virtual" Observations}

The Experience Sampling Method [ESM] developed by Csikszentmihalyi (1997) enables "a virtual film strip of daily activities and experiences" (p. 15) to be provided. It has been used to tap affective factors over an extended period and, if used creatively, can serve as a substitute for real time observations. Furthermore, the obtained data is in a format that can be analyzed and interpreted at length at a convenient time.

The ESM requires participants to respond to signals and, at the time of contact, record their activities and reactions on specifically designed Experience Sampling Forms (ESFs). In studies involving university students (Leder \& Forgasz, 2004) and secondary mathematics teachers (Forgasz \& Leder, 2006), mobile phone and computer technology were exploited to send simultaneous SMS (text) messages to 
participants in diverse geographic locations to indicate that it was time to complete ESFs. Signals, sent multiple times a day over one week, yielded a rich body of data about the individuals' activities, both mathematics related and more broadly. Data about the daily activities of males and females, and their behavioural and affective responses to them, were gathered in a natural setting, via self-report data, and in a less obtrusive and less resource intensive manner than possible through sustained observations or shadowing." The examples presented here are indicative of the ways in which traditional survey type self-report measures and instruments have been modified and extended in ways not conceivable without now readily available technology.

\subsection{Physiological and Neurological Measures}

Elsewhere I have written (Leder, 1985) that attempts to incorporate physiological indicators of affect with respect to mathematics learning and achievement are not a recent phenomenon - see, for example Dreger and Aiken (1957) who incorporated a measure of electrical skin resistance in their long-ago investigation of mathematics anxiety in college students or the study by Dew, Galassi, and Galassi (1984) who monitored college students' heart rate, skin conductance level, skin fluctuations, as they worked on mathematics problems. At that time I also noted that the use of such measures, particularly in a regular classroom setting, was likely to remain limited, as indeed it has.

It is also appropriate to consider here some early research purported to be on mathematics learning and brain activity. Once again it is useful to turn to work presented at annual PME conferences. Three presentations (Fidelman, 1983; Ransley, 1983; Yeshurun, 1983) with promising titles, placed under the overall heading of "Learning theories" and the further subheading "Neuropsychological theories", are found in the 1983 proceedings. Brief excerpts from each of these presentations are useful to capture the scope of the research actually conducted.

\subsubsection{From the PME Archives-Again}

In a paper titled " "Real life' numeracy, arithmetical competence and prediction from a neuropsychological theory", Ransley checked the effectiveness of some simple tests, administered by research assistants, to predict individual differences in performance among young school students experiencing learning difficulties and concluded:

Luria's theory of brain functioning has led to the development of a simple psychometric model with obvious relevance to the classroom. Measurement of competence in the model can be carried out using tasks which do not require any special formal knowledge and do not demand any particular higher order intellectual functioning. (pp. 112-113, emphasis added) 
Under the title "Learning of non-standard arithmetic and the hemispheres of the brain", Fidelman presented his investigation of the interaction between the two hemispheres of the brain, inferred from students' attempts at a variety of mathematical proving tasks. Hemispheric activity was measured using:

- Counting of tachistoscopically represented dots as a test for the right hemisphere, and

- Counting of signs appearing rapidly one after another as a test for the left hemisphere.

The students' responses to different problems were described, with answers to some tasks interpreted to be examples of "an inhibition of the right hemisphere by the left" (p. 119) and answers to others as "the inhibition of the left hemisphere by the right" (p. 119).

The paper "Practical applications of psychomathematics and neuropsychomathematics" by Yeshurun began with the definition of both psychomathematics and neuropsychomathematics, with the latter explained as "the study of the connection between brain functioning and behaviour" (p. 120). These new branches of research, Yeshurun stated, are "in the juncture of at least four sciences: psychology, mathematics, physiology, and education. For this reason progress is difficult and slow ... but there are some results. We want to deal here with their practical applications only" (p. 120). Reference was made to the importance of adapting teaching methods to promote the learning of new material, and to the role putatively played by the right or left hemisphere in processing material. Yet no direct evidence was presented to indicate how this might actually be achieved, or stimulated, in practice.

To summarize, while collectively these presentations represent, at a somewhat primitive level, tenuous efforts to capitalize indirectly on advances in cognitive neuroscience, the impact of affective factors on mathematics learning was not really considered implicitly or explicitly.

\subsubsection{Some Contemporary Examples}

While still attracting only limited research attention, the relevance of cognitive neuroscience to mathematics education, and within it the affective domain, is now increasingly recognized (see, for example, Goswami, 2004; Schlöglmann, 2008; Tzur \& Leikin, 2015). That neuroscience can be used to improve education is enthusiastically advocated by Pincham et al. (2014). An issue faced by a teacher wishing to optimize her students' learning of mathematics is used as an example of how this could be done. More generally, the authors recommended a four-stage process with the following elements: identify an educational need; develop a research proposal; test what is proposed in the classroom; communicate the results and, neuroscientist and teacher together, evaluate the outcome. Critically, they recommended, "(e)ducational neuroscientists must work with educators to draw on the educators' wealth of practical knowledge regarding existing classroom practices and the feasibility of the proposed 
project" (Pincham et al., 2014, p. 29) within the school setting. More widespread adoption of such a collaborative and interdisciplinary approach — not necessarily restricted to neuroscience-is a recommendation that can be fruitfully followed by those engaged in research on affect and mathematics education. A measure of how far research on affect per se has progressed in recent years is summed up evocatively by Cooper, Blackman and Kelly (2016):

Surely, when Thurstone pronounced that attitudes can be measured, he had no inkling that people's evaluations would be assessed with changes in oxygenated blood flow or with eventrelated potentials measured at the scalp. Social neuroscience has opened new windows to the study of social processes in general, and attitudes in particular, that were not conceivable a few decades ago (p. 282)

The challenge to benefit, draw, and build on these newly opened windows is one which should not go unheeded by the mathematics education community. Collaborative, interdisciplinary work is likely to be required if mathematics education researchers, students, and teachers are to reap the full benefits of the new approaches pioneered in other fields.

\section{References}

American Psychological Association. (2015). APA dictionary of psychology (2nd ed.). Washington, DC: Author. In particular the document retrieved from https://www.apa.org/pi/lgbt/resources/ sexuality-definitions.pdf.

Attard, C., Ingram, N., Forgasz, H., Leder, G., \& Grootenboer, P. (2016). Mathematics education and the affective domain. In K. Makar, S. Dole, J. Visnovska, M. Goos, A. Bennison, \& K. Fry (Eds.), Research in mathematics education in Australasia 2012-2015 (pp. 73-95). Singapore: Springer.

Cooper, J., Blackman, S., \& Keller, K. (2016). The science of attitudes. New York: Routledge.

Csikszentmihalyi, M. (1997). Finding flaws: The psychology of engagement with everyday life. New York: Basic Books.

Dew, K. M. H., Galassi, J., \& Galassi, M. D. (1984). Math anxiety: Relation with situational test anxiety, performance, physiological arousal, and math avoidance behavior. Journal of Counselling Psychology, 31, 580-583.

Dowker, A., Sarkar, A., \& Looi, C. Y. (2016). Mathematics anxiety: What have we learned in 60 years? Frontiers in Psychology, 7. Article 508.

Dreger, R. M., \& Aiken, C. R. (1957). The identification of number anxiety in a college population. Journal of Educational Psychology, 47, 344-351.

Fennema, E., \& Sherman, J. (1976a). Fennema-Sherman mathematics attitudes scales: Instruments designed to measure attitudes toward the learning of mathematics by Females and Males. Journal for Research in Mathematics Education, 7(5), 324-326.

Fennema, E., \& Sherman, J. (1976b). Fennema-Sherman mathematics attitude scales. JSAS Catalog of Selected Documents in Psychology, 6(1), 31 (Ms. No. 1225).

Fidelman, U. (1983). Learning of non-standard arithmetic and the hemispheres of the brain. In R. Hershkowitz (Ed.), Proceedings of the 7th International Conference for the Psychology of Mathematics Education (pp. 114-119). Rehovot, Israel: Weizmann Institute of Science.

Forgasz, H. J., \& Leder, G. C. (2006). Work patterns and stressors of experienced and novice mathematics teachers. Australian Mathematics Teacher, 62(3), 36-40. 
Forgasz, H. J., Leder, G. C., \& Gardner, P. L. (1999). The Fennema-Sherman mathematics as a male domain scale re-examined. Journal for Research in Mathematics Education, 30(3), 342-348.

Forgasz, H. J., Leder, G. C., \& Tan, H. (2014). Public views on the gendering of mathematics and related careers: International comparisons. Educational Studies in Mathematics, 87(3), 369-388.

Forgasz, H. J., Tan, H., Leder, G. C., \& McLeod, A. B. (2017). Enhancing survey participation: Facebook advertisements for recruitment in educational research. International Journal of Research \& Method in Education. https://doi.org/10.1080/1743727X.2017.1295939.

Fresco, B., \& Ben-Chaim, D. (1985). Confidence, competence and in-service education for mathematics teachers. In L. Streefland (Ed.), Proceedings of the 9th International Conference for the Psychology of Mathematics Education (pp. 437-442). Utrecht, The Netherlands: OW \& OC.

Furinghetti, F., \& Pehkonen, E. (2002). Rethinking characterizations of beliefs. In G. C. Leder \& G. Törner (Eds.), Beliefs: A hidden variable in mathematics education? (pp. 39-58). Dordrecht, The Netherlands: Kluwer.

Goldin, G. A. (2002). Affect, meta-affect, and mathematical belief structures. In G. C. Leder, E. Pehkonen, \& G. Törner (Eds.), Beliefs: A hidden variable in mathematics education? (pp. 59-72). Dordrecht, The Netherlands: Kluwer.

Goldin, G. A., Hannula, M. S., Heyd-Metzuyanim, E., Jansen, A., Kaasila, R., Lutovac, S., et al. (2016). Attitudes, beliefs, motivation and identity in mathematics education. An overview of the field and future directions. Cham, Switzerland: Springer.

Goswami, U. (2004). Neuroscience and education. British Journal of Educational Psychology, 74, $1-14$.

Hannula, M. S. (2012). Exploring new dimensions of mathematics-related affect: Embodied and social theories. Research in Mathematics Education, 14(2), 137-161.

Hannula, M. S. (2014). Affect in mathematics education. In S. Lerman (Ed.), Encyclopedia of mathematics education (pp. 23-27). Dordrecht, The Netherlands: Springer.

Kosinski, M., Matz, S. C., Gosling, S. D., Popov, V., \& Stillwell, D. (2016, March). Facebook as a research tool. In Monitor on psychology. https://www.apa.org/education/ce/facebook-research. pdf.

Kramers, H. A. (n.d.). Quotes. Retrieved from http://www.quotes.net/authors/H.A.Kramers.

Larkin, K., \& Jorgensen, R. (2015). 'I hate maths: Why do we need to do maths?' Using iPad video diaries to investigate attitudes and emotions towards mathematics in year 3 and year 6 students. International Journal of Science and Mathematics Education, 1-20. https://doi.org/10. 1007/s10763-015-9621-x.

Leder, G. C. (1985). Measurement of attitude to mathematics. For the Learning of Mathematics, 5(3), 18-21.

Leder, G. C. (2007). Beliefs: What lies behind the mirror? In The Montana mathematics enthusiast, monograph (Vol. 3, pp. 39-50). The Montana Council of Teachers of Mathematics.

Leder, G. C., \& Forgasz, H. J. (2002). Two new instruments to probe attitudes about gender and mathematics. ERIC document number ED463312/TM033744.

Leder, G. C., \& Forgasz, H. J. (2004). Australian and international mature age students: The daily challenges. Higher Education Research and Development, 23(2), 183-198.

Lerman, S. (Ed.). (2014). Encyclopedia of mathematics education. Dordrecht, The Netherlands: Springer.

Levine, F. J. (2016, May). From the desk of the executive director-AERA to further refine gender demographic categories. Retrieved from http://www.aera.net/Newsroom/AERA-Highlights-Enewsletter/AERA-Highlights-May-2016/From-the-Desk-of-the-Executive-DirectorAERA-toFurther-Refine-Gender-Demographic-Categories.

Liljedahl, P., \& Hannula, M. S. (2016). Research on mathematics-related affect: Examining the structures of affect and taking the social turn. In A. Gutiérrez, G. C. Leder, \& P. Boero (Eds.), The second handbook of research on the psychology of mathematics education. The journey continues (pp. 417-446). Rotterdam, The Netherlands: Sense. 
Liljedahl, P., \& Oesterlei, S. (2014). Teacher beliefs, attitudes, and self-efficacy in mathematics education. In S. Lerman (Ed.), Encyclopedia of mathematics education (pp. 583-586). Dordrecht, The Netherlands: Springer.

Makar, K., Dole, S., Visnovska, J., Goos, M., Bennison, A., \& Fry, K. (Eds.). (2016). Research in mathematics education in Australasia 2012-2015. Singapore: Springer.

Mason, J. (2004). Book review. Mathematical Thinking and Learning, 6(3), 343-352. https://doi. org/10.1207/s15327833mt10603_4.

McLeod, D. B. (1992). Research on affect in mathematics education: A reconceptualization. In D. A. Grouws (Ed.), Handbook of research in mathematics teaching and learning (pp. 597-622). New York: MacMillan.

OECD. (2013). PISA 2012 assessment and analytical framework: Mathematics, reading, science, problem solving and financial literacy. OECD. Retrieved from http://dx.doi.org/10.1787/ 9789264190511-en.

Pajares, M. F. (1992). Teachers' beliefs and educational research: Cleaning up a messy construct. Review of Educational Research, 62(3), 307-332.

Pepin, B., \& Roesken-Winter, B. (Eds.). (2015). From beliefs to dynamic systems in mathematics education. Cham, Switzerland: Springer.

Pincham, H. L., Matejko, A. A., Obersteiner, A., Killikelly, C., Abrahao, K. P., Benavides-Varela, S., et al. (2014). Forging a new path for educational neuroscience: An international young-researcher perspective on combining neuroscience and educational practices. Trends in Neuroscience and Education, 3, 28-31.

Ransley, W. K. (1983). "Real life" numeracy, arithmetical competence and prediction from a neuropsychological theory. In R. Hershkowitz (Ed.), Proceedings of the 7th International Conference for the Psychology of Mathematics Education (pp. 107-113). Rehovot, Israel: Weizmann Institute of Science.

Ruthven, K. (2015). Reaction to section 3: Some methodological reflections on studies of mathematical affect. In B. Pepin \& B. Roesken-Winter (Eds.), From beliefs to dynamic systems in mathematics education (pp. 383-393). Cham, Switzerland: Springer.

Schlöglmann, W. (2008). Is cognitive neuroscience relevant to mathematics education research? Retrieved from https://www.unige.ch/math/EnsMath/Rome2008/WG5/Papers/SCHLOEG.pdf.

Schoenfeld, A. H. (2015). What counts, when?-Reflections on beliefs, affect, attitude, orientation, habits of mind, grain size, time scale, context, theory and method. In B. Pepin \& B. RoeskenWinter (Eds.), From beliefs to dynamic systems in mathematics education (pp. 395-404). Cham, Switzerland: Springer.

Tzur, R., \& Leikin, R. (2015). Interweaving mathematics education and cognitive neuroscience. In K. Beswick, T. Muir, \& J. Wells (Eds.), Proceedings of 39th Psychology of Mathematics Education Conference (Vol. 1, pp. 91-121). Australia: Hobart.

Webb, L., \& Webb, P. (2005). Teachers' beliefs of the nature of mathematics: Effect on promotion of mathematical literacy. In H. L. Chick \& J. L. Vincent (Eds.), Proceedings of the 29th Conference of the International Group for the Psychology of Mathematics Education (Vol. 1, p. 293). Melbourne: PME.

Yeshurun, S. (1983). Practical applications of psychomathematics and neuropsychomathematics. In R. Hershkowitz (Ed.), Proceedings of the 7th International Conference for the Psychology of Mathematics Education (pp. 120-122). Rehovot, Israel: Weizmann Institute of Science.

Yusof, Y. B., \& Tall, D. (1995). Professors' perceptions of students' mathematical thinking: Do they get what they prefer or what they expect? In R. Hershkowitz (Ed.), Proceedings of the 7th International Conference for the Psychology of Mathematics Education (pp. 114-119). Rehovot, Israel: Weizmann Institute of Science.

Zan R., \& Di Martino, P. (2014). Students' attitudes in mathematics. In S. Lerman (Ed.). Encyclopedia of mathematics education (pp. 572-577). Dordrecht, The Netherlands: Springer. 
Open Access This chapter is licensed under the terms of the Creative Commons Attribution 4.0 International License (http://creativecommons.org/licenses/by/4.0/), which permits use, sharing, adaptation, distribution and reproduction in any medium or format, as long as you give appropriate credit to the original author(s) and the source, provide a link to the Creative Commons license and indicate if changes were made.

The images or other third party material in this chapter are included in the chapter's Creative Commons license, unless indicated otherwise in a credit line to the material. If material is not included in the chapter's Creative Commons license and your intended use is not permitted by statutory regulation or exceeds the permitted use, you will need to obtain permission directly from the copyright holder.

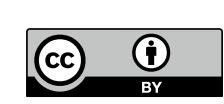


Part II

Interest, Motivation, and Values 


\title{
Chapter 3 \\ Multiple Solutions, The Experience of Competence, and Interest
}

\author{
Kay Achmetli and Stanislaw Schukajlow
}

\begin{abstract}
In the project MultiMa, we have been investigating how students' learning is affected when they construct multiple solutions while solving real-world problems by applying multiple mathematical procedures. Three hundred seven ninth graders from twelve middle-track classes took part in this study involving four lessons. We tested students' experience of competence during the teaching unit as well as students' interest before and after the teaching unit. The results indicate that constructing multiple solutions has a positive influence on students' experience of competence but no effect on their interest in mathematics.
\end{abstract}

Keywords Experience of competence $\cdot$ Interest $\cdot$ Multiple solutions $\cdot$ Real-world problems

\subsection{Introduction}

Affect appears to be essential for students' learning and achievement. There have been a number of calls for the development of teaching methods that can improve students' affect (Di Martino et al., 2015). To answer these calls, we conducted an experimental intervention study aimed at investigating methods for improving students' affect. As interest in mathematics is an important affective variable (Schukajlow \& Krug, 2014) and the experience of competence is one of the so called "basic psychological needs" (Deci \& Ryan, 2000) that can contribute to interest development (Krapp, 2005), we decided to focus on these two variables in the present study. As solving real-world problems is an important part of mathematics education (Niss, Blum, \& Galbraith, 2007), we chose this type of task to investigate the effects of constructing multiple solutions by applying different mathematical procedures on students' interest and experience of competence.

\footnotetext{
K. Achmetli $(\varangle) \cdot$ S. Schukajlow

Department of Mathematics, University of Münster, Fliednerstraße 21, 48149 Münster, Germany e-mail: k_achm01@uni-muenster.de

S. Schukajlow

e-mail: schukajlow@uni-muenster.de

(C) The Author(s) 2019

M. S. Hannula et al. (eds.), Affect and Mathematics Education,

ICME-13 Monographs, https://doi.org/10.1007/978-3-030-13761-8_3 
In this article, we report the results of the experimental intervention study we conducted in order to investigate how multiple solutions for real-world problems by applying different mathematical procedures could affect students' interest and their experience of competence. Furthermore, we examined the role students' experience of competence has in students' interest development. Thus, we analyse the indirect effects of constructing multiple solutions on students' interest via their experience of competence as well as the indirect effects of students' prior interest on their interest at post-test via their experience of competence.

\subsection{Theoretical Background}

\subsubsection{Interest}

Interest is acknowledged as an important affective variable in the learning process, because it can affect students' attention, goals, and levels of learning (see Hidi \& Renninger, 2006, for a summary). Furthermore, it is closely connected to strategy use (Schiefele \& Schreyer, 1994), self-regulation (Pintrich, 1999), performance goals (Harackiewicz, Durik, Barron, Linnenbrink-Garcia, \& Tauer, 2008) and achievement in mathematics (Fisher, Dobbs-Oates, Doctoroff, \& Arnold, 2012; Köller, Baumert, \& Schnabel, 2001; Schiefele, Krapp, \& Schreyer, 1993). According to the selfdetermination theory of human motivation and the person-object theory of interest, it emerges from an individual's interaction with the environment and therefore represents a specific person-object relationship (Hidi \& Renninger, 2006; Krapp, 2005). More specifically, "whereas the potential for interest resides in the person, the environment and the content define the direction of interest and contribute to its development" (Hidi, 2006). Theories of interest distinguish between cognitive and emotional aspects, which regulate the development of interest (Hidi, Renninger, \& Krapp, 2004; Krapp, 2005) and are connected to situational and personal or individual interest dimensions (Hidi \& Renninger, 2006). A situational interest is an interest in a particular object, which is environmentally triggered and may or may not last (Hidi et al., 2004). Individual interest develops over time and is a relatively enduring predisposition over time that also refers to a psychological state (Hidi, 2006; Krapp, 1999). Both kinds of interest are closely connected, as they both can be associated with the psychological state of interest (Hidi, 2006; Krapp, 1999) and because a situational interest can grow into an individual interest (Hidi \& Renninger, 2006).

In conclusion, there are at least three important characteristic of the construct of interest (Frenzel, Pekrun, Dicke, \& Goetz, 2012). First, its state- and traitlike nature which reflects the level of temporal stability of this affective construct (Schukajlow, Rakoczy, \& Pekrun, 2017): situational interest concerned to be temporal more stable than individual interest. In the present study we addressed the individual interest. Second, interest is considered to be content specific (Hidi \& Renninger, 2006), which is why we focus on the domain of mathematics. And third, interest can be 
conceptualised as a multicomponent construct (Frenzel et al., 2012) and includes both emotional and cognitive components.

The conceptualization of interest development as an outcome of the interaction of a person and an environment has particular relevance, because educators can actively influence environmental aspects, by selecting resources that triggers students' situational interest (Hidi, 2006). This is especially important because many students are not intrinsically motivated to learn mathematics and only a few develop an above-average interest in mathematics (Heinze, Reiss, \& Rudolph, 2005). Moreover, students' interest in MINT subjects decrease over the years, while they are in school (Köller, Baumert, \& Schnabel, 2000; Kunter, 2005). However, we do not know much about how different methods of teaching in the classroom influence students' individual interest (Heinze et al., 2005) and how individual and classroom factors work together to increase or decrease interest (Carmichael, Callingham, Watson, \& Hay, 2009). There are some indications, that students' interest improves stronger in student-centred learning environments, where students have the possibility to work in groups, rather than in teacher-centred instructional settings (Lerkkanen et al., 2012; Schukajlow et al., 2012). A situation of collective interest, which can be created through an interest-dense situation (Bikner-Ahsbahs, 2004) while working on a cognitive demanding problem, may also improve students' individual interest. Because students spend most of their math-lesson time working on mathematical problems (Hiebert et al., 2003), and previous research has shown, that teachers can trigger students' situational interest by using appropriate learning materials (Mitchell, 1993), selecting interesting problems is a mandatory first step in fostering students' individual interest. As interest is subject- and object-specific (Hidi \& Renninger, 2006), students' interest develops according to task-specific characteristics such as an existing connection to reality (Krug \& Schukajlow, 2013; Pekrun et al., 2007; Schukajlow \& Krug, 2012a, 2012b) or a match between contexts and their personal background or preferences (Ku \& Sullivan, 2002; López \& Sullivan, 1992). Real-world tasks are connected to reality and, in comparison with intra-mathematical tasks, real-world tasks offer more opportunities for increasing the value of a problem for an individual by matching the context of a task with an individual's personal background and preferences. Therefore, solving real-world tasks might lead to higher interest. However, we know from previous studies that students' interest on problems with connection to reality is similar as for problem without connection to real-world (Schukajlow et al., 2012). In a recent study, students' interest in problems with connection to reality was even lower than their interest in problems without connection to reality (Rellensmann \& Schukajlow, 2017), taking the task-difficulty into account. Thus, the teaching method of real-world problems seems to be at least as much important for triggering students' interest as the problem that teachers chose for particular classes. 


\subsubsection{Experience of Competence}

According to the theory of self-determination of human motivation (Deci \& Ryan, 2000; Ryan \& Deci, 2000) it is assumed that humans are naturally endowed with a system of basic psychological needs (Deci \& Ryan, 2008). Three essential needs: competence, autonomy, and relatedness are postulated to be important not only for well-being and psychological growth, but also for a variety of developmental processes, including interest development (Deci \& Ryan, 2000). According to Deci and Ryan (1991) the "need for competence encompasses people's strivings to control outcomes and to experience effectance; in other words, to understand the instrumentalities that lead to desired outcomes and to be able to reliably effect those instrumentalities." Conclusively, competence refers to the desire to feel efficacious, to have an effect on one's environment, and to be able to attain valued outcomes (Deci 1998). The experience of competence playes an important role in social cognitive models of achievement motivation (Wigfield, Battle, Keller, \& Eccles, 2002) or in learning theories regarding self-regulation (Boekaerts \& Corno, 2005; Zimmerman $\&$ Schunk, 2001). It is furthermore closely related to other motivational constructs such as intrinsic motivation (Deci \& Ryan, 2000), ability beliefs (Wigfield \& Eccles, 2000), and goals (Hannula, 2006). It increases intrinsic motivation and interest in the learning activity (Hänze \& Berger, 2007; Krapp, 2005; Schukajlow \& Krug, 2014). These results were found in different studies from vocational education (Krapp, 2005) and from research in regular classrooms in science (Hänze \& Berger, 2007) and mathematics (Schukajlow \& Krug, 2014).

Furthermore, we address students' experience of competence, because if a person has positive experiences while engaging in mathematics, their individual interest can be improved (Mitchell, 1993; Renninger \& Hidi, 2002). The experience of competence and as well as the experience of autonomy found to be crucial factors that provide feedback about students' states of functioning and thus influence interest (Krapp, 2005). However, empirical results from research on multiple solutions only partly support this expectation (Schukajlow \& Krug, 2014). While the experience of competence had a nearly significant influence on students' interest, the influence of the experience of autonomy on interest was small and not significant. Thus, the experience of competence is the centerpiece of the current study.

As shown above, the experience of competence is an important basic need of students that should be fullfilled in order to positively influence their motivation and increase their interest in mathematics. Learning environments that aim to fulfil basic needs and to improve students' motivation are assumed to be student-centred (Hannula, 2006). Empirical evidence for a better development of motivational variables derives from the comparison on student-centred teaching in which cooperative learning are typically used with teacher-centred methods of instruction (Schukajlow et al., 2012; Slavin, Hurley, \& Chamberlain, 2003; Webb \& Palincsar, 1996). Comparable results have been revealed by studies about the effects of self-regulated learning (Minnaert, Boekaerts, \& Opdenakker, 2008) on students' affect, achievements, and their perceptions of their abilities (Marcou \& Lerman, 2007; Panaoura, Gagatsis, \& 
Demetriou, 2009). One important factor of self-regulatory skills are self-monitoring activities, which are closely connected to the experience of competence. That is why we used a student-centred learning environment for our current study.

\subsubsection{Multiple Solutions and Real-World Problems}

Gaining experience in solving problems in more than one way is viewed as crucial for learning (Silver, Ghousseini, Gosen, Charalambous, \& Font Strawhun, 2005), fostering the connectedness of knowledge (Levav-Waynberg \& Leikin, 2012), and leading to a deeper understanding of the learning subject (Neubrand, 2006). Accordingly, developing, comparing, and reflecting on multiple solutions are important instructional elements that are part of high-quality teaching standards in different countries (National Council of Teachers of Mathematics, 2000).

Studying the effects of constructing multiple solutions on cognitive outcomes is an important goal for research in mathematics education and has thereby been intensively investigated in the last decade. Several experimental studies have shown positive effects of constructing multiple solutions on achievement, understanding, creativity, and procedural flexibility in the domain of mathematics (Leikin \& Lev, 2007; Schukajlow \& Krug, 2012a, 2012b; Schukajlow, Krug, \& Rakoczy, 2015; Star \& Rittle-Johnson, 2009). Because there is evidence about the positive connection between interest and achievement (Köller et al., 2001), both cognitive and affective outcomes should be taken into account for high-quality mathematics teaching. However, the impact of constructing multiple solutions on students' affect have very rarely been taken into account. One exception is our previous study (Schukajlow \& Krug, 2014).

We investigated the effects of constructing multiple solutions while solving realworld problems on the topic of linear functions because the ability to solve such problems is an important goal of mathematics education (Niss et al., 2007), because such problems are important for students' current and future lives. Although there are many different features of real-world problems (see Maßß, 2010, for a summary), the common core of real-world problems is the demanding process of transferring information between reality and mathematics (Blum, Galbraith, Henn, \& Niss, 2007). However, successfully solving real-world problems requires much more than mathematizing processes. The wide range of required activities is described in modelling circles (Blum \& Leiss, 2007; Galbraith \& Stillman, 2006; Verschaffel, Greer, \& De Corte, 2000) and implies, among other practices, the correct use of mathematical procedures (Niss et al., 2007; Schukajlow et al., 2012), which are a key point of our current study.

Analyses of problem-solving activities (Blum et al., 2007; Pollak, 1979; Verschaffel et al., 2000) have shown that there are different ways to construct multiple solutions while solving real-world problems (Fig. 3.1). One type of multiple solutions results from different assumptions while solving real-world problems with missing information and leads to different outcomes (Schukajlow \& Krug, 2014). Another 


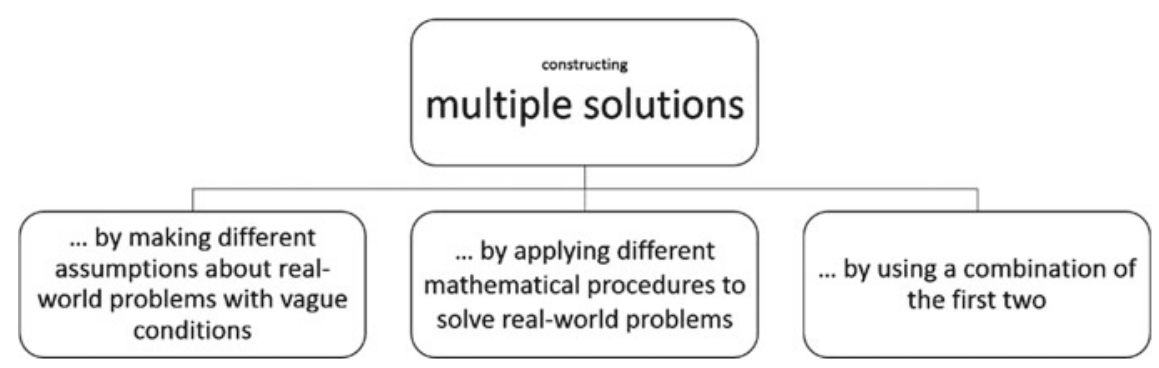

Fig. 3.1 Different categories of multiple solutions

BahnCard
Mr. Besser lives in Hamburg. His parents live in Bremen. For the outward and return
journeys with the "Deutsche Bahn" (German Rail), Mr. Besser has to pay $100 €$. There
are two special offers, the so-called "BahnCard 25 " and the "BahnCard 50 " The prices
for each year and the prices for the outward and return journeys from Hamburg to
Bremen for owners of the "BahnCards" are listed below.
\begin{tabular}{|l|l|}
\hline \multicolumn{1}{|c|}{ BahnCard 25} & \multicolumn{1}{c|}{ BahnCard 50} \\
\hline $\begin{array}{l}\text { Price per year: } 59 € \\
\text { Price for a round-trip journey: } 75 € \\
\text { Number of customers: } 3.1 \text { million }\end{array}$ & $\begin{array}{l}\text { Price per year: } 240 € \\
\text { Price for a round-trip journey: } 50 € \\
\text { Number of customers: } 1.6 \text { million }\end{array}$ \\
\hline
\end{tabular}
$\begin{aligned} & \text { Mr. Besser is going to buy a "BahnCard." When is it worth buying the "BahnCard } 25 \text { " and when the "BahnCard } 50 \text { "? } \\
& \text { Write down your solution. }\end{aligned}$

Fig. 3.2 Real-world task "BahnCard"

type of multiple solutions, addressed in the present study, results from applying different mathematical procedures or strategies while solving a problem and usually leads to the same mathematical outcome. The combination of these two types of multiple solutions is also possible and may be seen as a third type of multiple solutions.

To illustrate the two different mathematical procedures for real-world problems on the topic of linear functions that we focused on in the present study, we will present the process of solving the task "BahnCard," which was developed within the framework of our project (Fig. 3.2).

First, one has to understand the given problem and construct a model of the given situation. This model needs to be simplified and structured by identifying the important values. In the case of the task "BahnCard," these values are the prices per year for each card and the amounts that would be paid using each card for the round-trip journey. Next, the simplified model can be mathematized, and different mathematical procedures can be applied. One way to solve this problem is to apply the mathematical procedure "table." Students can make assumptions about a possible number of journeys per year and calculate the total costs for owners of the "BahnCard 25" and the "BahnCard 50." By comparing the costs for different numbers of journeys, they will be able to systematically identify the number of journeys that would make the "BahnCard 25" or the "BahnCard 50" a better deal. Another way to solve this 
problem is to apply the mathematical procedure "differences." Identifying the important values and calculating the differences for both of them, one recognizes that the "BahnCard 50" is $181 €(=240 €-59 €)$ more expensive than the "BahnCard 25," and each round-trip journey with the "BahnCard 25 " is $25 €(=75 €-50 €)$ more expensive than with the "BahnCard 50." Then the question arises as to how often one has to take a trip with the more expensive "BahnCard 50" until the cheaper price for the journey pays off, which is exactly after $7.24(=181 € \div 25 €)$ journeys per year. Finally, the outcomes of both mathematical procedures need to be interpreted and validated before one can present a recommendation about which offer is preferable for a certain number of journeys. In this case, the recommendation can be: "Starting with the eighth journey of the year, the BahnCard 50 is preferable. Otherwise, it is better to buy the BahnCard 25."

\subsection{Research Questions}

In this study, we addressed two research questions:

1. Does constructing multiple solutions while solving real-world problems affect students' experience of competence and their interest in mathematics?

2. How does constructing multiple solutions work together with the experience of competence and prior interest to improve students' interest at post-test?

\subsection{Hypothesised Path Model}

We applied a path model to the data, because we wanted to investigate whether and how intervention would work. Based on the theories about interest, the selfdetermination theory of motivation, and previous research, it allowed us to test predictions about possible factors (e.g., experience of competence) that transmit the effects of the experimentally manipulated treatment condition (e.g., MS vs. OS) on the outcome variables (e.g., interest at post-test).

The path analytic model (Fig. 3.3) is based on theoretical considerations about the effects of constructing multiple solutions by applying different mathematical procedures on students' experience of competence and their interest. We predicted that constructing multiple solutions would have a positive impact on students' experience of competence during the teaching unit and their interest at post-test. Furthermore, we predicted that experience of competence would lead to higher interest at post-test and that students' prior interest would have a positive influence on students' experience of competence and predict their interest at post-test. Finally, we expected indirect effects of constructing multiple solutions and prior interest on students' interest at post-test via their experiences of competence during the teaching, which results from the direct effects of the treatment on students' experiences of competence, the direct 


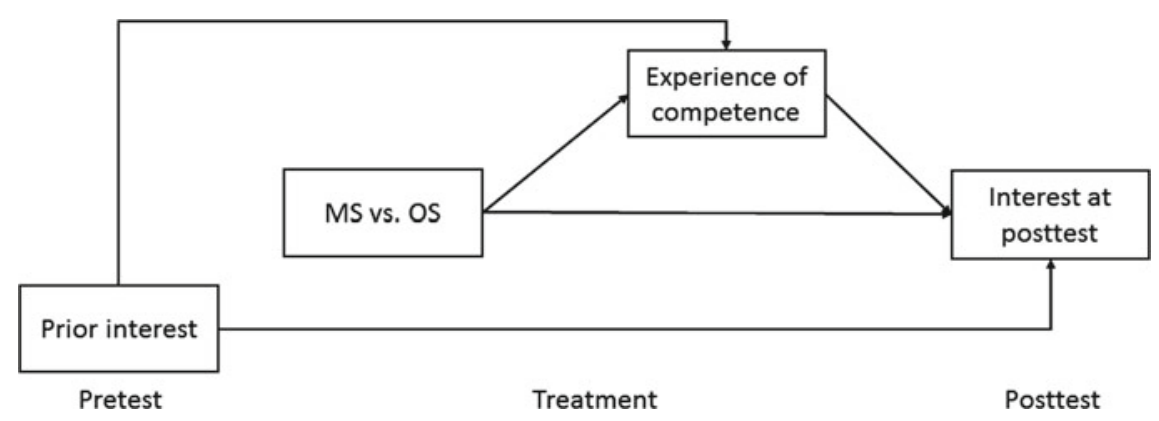

Fig. 3.3 Hypothesised path analytic model

effects of prior interest on students' experience of competence and from the direct effects from experiences of competence on interest at post-test and therefore do not needed a specific theoretical or empirical argumentation. For all of the described direct paths hypothesised in our path model above we found studies that had investigated single paths separately, only one study we found had a path model applied to the data to investigate indirect effects.

\subsubsection{Linking the Treatment Condition to the Experience of Competence}

Constructing more than one solution for one problem provides students with feedback about their competence in the learning situation (Schukajlow \& Krug, 2014) and positively affects their understanding of mathematics (Neubrand, 2006; Star \& Rittle-Johnson, 2009). Thus, we expected to find a positive effect of constructing multiple solutions by applying different mathematical procedures on students' experience of competence. The rationale behind this expectation is that students who are able to construct multiple solutions to solve a problem might feel more competent in mathematics than students who can find the solution using only one mathematical procedure. The positive influence of prompting students to find multiple solutions on the experience of competence was confirmed by Schukajlow and Krug (2014) who asked students to provide multiple solutions that result from different assumptions while solving real-world problems with missing information. The influence of constructing multiple solutions by applying multiple mathematical procedures on the experience of competence has yet to be investigated and is one question that we addressed in the present study. 


\subsubsection{Linking the Treatment Condition to Interest at Post-test}

Constructing multiple solutions to real-world problems provides students with the opportunities to discuss individual solutions during group work phases, to summarize possible links between different mathematical procedures, and to discuss differences and similarities between solutions, all of which in turn can improve students' interest (Schukajlow et al., 2012). As the development of interest is affected by cognitive aspects (Krapp, 2005) and the positive effect of using multiple solutions on cognitive aspects was found in prior studies (e.g., understanding and procedural flexibility; Rittle-Johnson \& Star, 2009), we expect positive effects of constructing multiple solutions on students' interest.

\subsubsection{Linking Experience of Competence to Interest at Post-test}

The link from experience of competence to interest at post-test has been supported by different empirical studies. Empirical evidence for the positive influence of students' experience of competence on their interest derives from vocational education (Krapp, 2005) and from research in regular classrooms in science (Hänze \& Berger, 2007) and mathematics (Schukajlow \& Krug, 2014). Furthermore, Students' self-concept at the beginning of a school year, which is conceptually related to their experience of competence (Wigfield \& Cambria, 2010), predicted their interest at the end of that year (Marsh, Trautwein, Lüdtke, Köller, \& Baumert, 2005). There is evidence on the topic of statistics that students' interest is influenced by their perceptions of their own competence (Carmichael et al., 2009). Students who report increases in their experience of competence also often report on a higher intrinsic motivation (Guay, Boggiano, \& Vallerand, 2001; Harter, Whitesell, \& Kowalski, 1992), which, according to Krapp (2005) is an interest-related motivational orientation. Additionally, Zimmerman and Kitsantas (1997) demonstrated that increased self-efficacy, which is frequently used interchangeably for experience of competence, was associated with increased interest.

\subsubsection{Linking Prior Interest to Experience of Competence and Interest at Post-test}

The relation between interest and self-efficacy might not be as unidirectional as stated above. Not only can increased experience of competence lead to an increase in interest, but through activities that are interest driven, individuals may change in a positive manner the ways in which they perceive their competence (Hidi, 2006). Thus, we hypothesised that prior interest would influence students' experience of 
competence positively, partly because it is an important factor for interest related motivational orientations and had been shown that it can positively influence the experience of competence (Marsh et al., 2005).

As interest is a stable construct, the link between prior interest and interest at posttest seems obvious and should not need further grounding. One exemplary empirical result is given by the study of Minnaert et al. (2008).

\subsection{Method}

\subsubsection{Sample}

The participants were 307 German ninth graders (48.26\% female; mean age 14.6 years) from four comprehensive schools (German Gesamtschule) with three middle-track classes each. Because in middle-track classes students from low- to high-achieving can be found, those classes were selected in order to increase the representativeness of the study. Students of the current sample did not have any formal experience in dealing with real-world problems nor did they have any prior knowledge in solving linear equation systems.

\subsubsection{Study Design}

Each of these classes were divided into two parts with the same number of students in each part in such a way that the average level of achievement in the two parts did not differ, and the ratio of males to females was approximately the same in each part. Using this method we generated six groups at each school.

In order to analyse the effects of constructing multiple solutions by applying two mathematical procedures on students' interest, we needed to control these effects in comparison to constructing only one solution. As previous studies on multiple solutions had underlined the importance of context factors (Große, 2014; Große \& Renkl, 2006), and the kind of mathematical procedures students apply represent such a contextual factor, it could be possible that different mathematical procedures lead to different outcomes. That is why we not only needed two (multiple solutions vs. one solution) but three treatment conditions (see next section).

Each group than was assigned to a treatment condition in such a way, that students of the same classes never were treated in the same treatment condition and that each treatment condition was evenly frequent at each school (Fig. 3.4).

To implement the treatment, which consisted of solving real-world problems using different mathematical procedures to solve each problem, the six teachers who participated in this study received instructional manuals containing all the tasks to be administered in each condition, the solutions to the problems, and a detailed plan for 


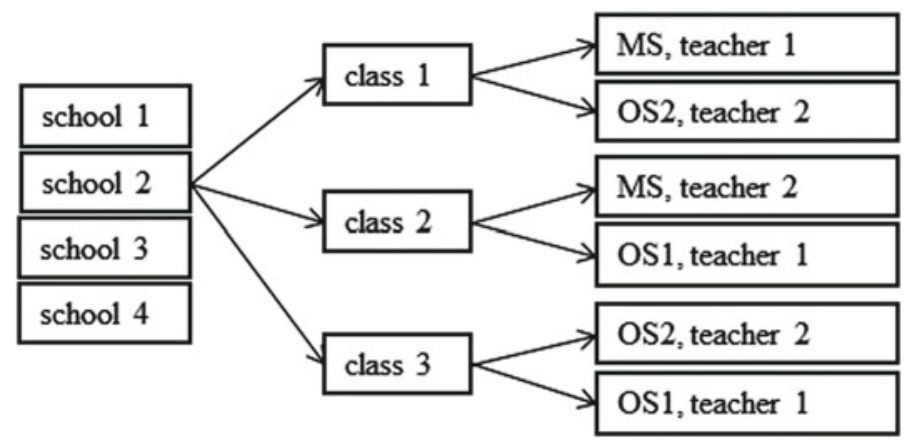

Fig. 3.4 Assignment of students to the treatment conditions

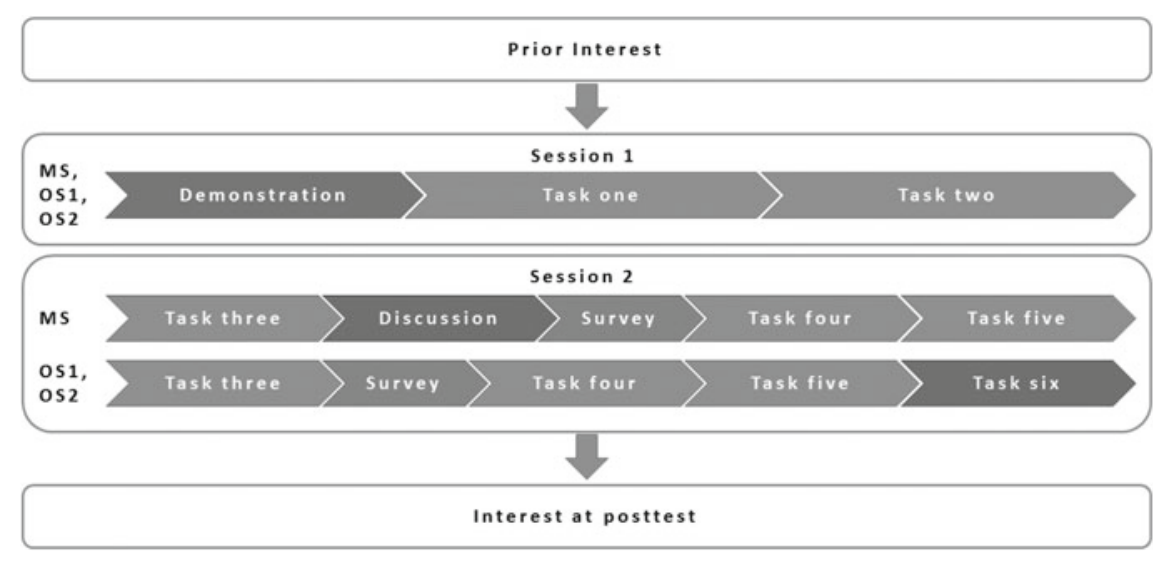

Fig. 3.5 Overview of the study design

the teaching unit. Each teacher taught the same number of student groups in each treatment condition, so the influence of a teacher on students' learning did not differ between conditions.

The research team provided the teachers with all real-world problems, the solution spaces, and manuals with lesson plans. Before the experiment began the key points of each treatment condition (see next section) were discussed in training for all participating teachers.

The teaching unit was carried out during regular classes and consisted of two sessions of each $90 \mathrm{~min}$. Students' were asked to report on their experience of competence during the teaching unit using a short survey (in the second session; Fig. 3.5). They were also asked about their interest in mathematics before and after the fourlesson teaching unit. Students did not have any regular mathematics classes during our current study, so the effects of constructing multiple solutions on students' interest and experience of competence was not falsified. 


\subsubsection{Treatment}

For the purposes of the study, three treatment conditions were implemented. In the multiple solution condition (MS), real-world problems were posed, and the students were prompted to apply two mathematical procedures. In both of the one-solution conditions (OS1 and OS2), similar problems were posed, but the task instructions indicated that only one solution was required (mathematical procedure "table" and mathematical procedure "differences" in OS1 and OS2, respectively). In the multiplesolution condition, one sample problem was the "BahnCard" problem (Fig. 3.2) with the following modification: "Use two different mathematical procedures to solve this problem." In the one-solution conditions, students solved the original version of the "BahnCard" problem.

All three treatment conditions were based on the positively evaluated studentcentred learning environment for teaching modelling problems from the DISUM Project (Schukajlow et al., 2009, 2012), which had demonstrated a positive influence on students' affect and learning. We complemented this learning environment by a direct instruction at the beginning. Students were instructed about the goals of the respective treatment condition, the key features of the problems that would be presented during the teaching unit and how such real-world problems could be solved using multiple mathematical procedures (in the MS condition) or one specific procedure (in the OS conditions). Then students solved tasks using the demonstrated procedures according to a special procedure for group work. At first, they worked individually and developed first ideas about how to solve the problem. Afterwards they worked cooperatively in groups of four and discussed their ideas for solving the problem. Subsequent they wrote down one's own individual solution by applying multiple mathematical procedures or one mathematical procedure. Following this group a voluntary student presented how to solve the problem applying one or two mathematical procedures respectively and the whole class discussed the solution. Finally, the teacher summarized the key points of each treatment condition. Furthermore, in the MS condition, the teacher emphasized the development of two different procedures and after the first task in the second session in the MS-condition, the teacher highlighted and summarized the links between the two mathematical procedures, compared and contrasted the mathematical procedures, and fostered discussions about students' preferences for one or the other procedure. In order to compensate the time needed for this phase, students in the OS conditions solved an additional task at the end of session two.

Four out of six tasks given in the MS condition required the development of two mathematical procedures: "Use two different mathematical procedures to solve this problem. Write both down." In the OS conditions, students solved a standard version of this task (see Fig. 3.2) using the demonstrated mathematical procedure. 
Table 3.1 Items used in the study to assess interest and experience of competence

\begin{tabular}{l|l}
\hline Scale & Item \\
\hline Interest (Frenzel et al., 2012) & $\begin{array}{l}\text { I am interested in mathematics } \\
\text { I like to read books and solve brain teasers related to } \\
\text { mathematics } \\
\text { Doing mathematics is one of my favorite activities }\end{array}$ \\
\hline Experience of competence & $\begin{array}{l}\text { I noticed that i really understood things (Hänze \& Berger, } \\
\text { 2007) } \\
\text { I felt able to master the work (Hänze \& Berger, 2007) } \\
\text { I felt confident about my knowledge about the topic today } \\
\text { (Schukajlow \& Krug, 2014) }\end{array}$ \\
\hline
\end{tabular}

\subsubsection{Measures}

Students' interest and experience of competence were assessed using two separate measures (Table 3.1). Each measure was assessed on a 5-point Likert scale ( $1=$ not at all true, $5=$ completely true).

Conceptually, interest can be differentiated in situational and individual interest. Thus, for the measurement of interest it is important to know, which kind of interest one is interested in measuring effects on. As individual interest is on a higher level of interest development (Hidi \& Renninger, 2006) and situational interest can contribute to individual interest, we decided to measure students' individual interest. It was measured using a scale that included three items from the Project for the Analysis of Learning and Achievement in Mathematics (PALMA-Project). These items refer to individual interest in the subject of mathematics, comprising of various components of the construct, including emotional and cognitive aspects: (a) "I am interested in mathematics," (b) "I like to read books and solve brain teasers related to mathematics," and (c) "Doing mathematics is one of my favourite activities" (Frenzel et al., 2012). These items measured students' individual interest in mathematics and have been validated using qualitative and quantitative methods.

For the measurement of students' experience of competence, three items from a well-evaluated scale by Schukajlow and Krug (2014) were used: (a) "I noticed that I really understood things," (b) "I felt able to master the work," and (c) "I felt confident about my knowledge about the topic today".

Both measures have been used in previous studies. The items measured students' interest in mathematics have been validated with qualitative and quantitative methods and revealed that each item assessed the emotional an personal dimensions of students' individual interest (Frenzel et al., 2012). In the current study, the reliability values (Cronbach's alpha) were 0.77 and 0.75 at pre-test and post-test, respectively, and were similar to the reliabilities found in another study (Schukajlow \& Krug, 2014). The scale experience of competence was based on three items that refer to understanding and mastering the assigned work. Two items were taken from the study by Hänze and Berger (2007) and one item was taken from the study by Schukajlow 
and Krug (2014). In the current study, the reliability of this scale is 0.74 and is therefore comparable to a previous study (Schukajlow \& Krug 2014).

\subsubsection{Data Analysis}

We started our analysis by examining the influence of the treatment conditions on "experience of competence" and "interest". In order to answer the second research question we applied a path model with 13 free parameters and 307 subjects to the data. The ratio of subjects to parameters was above the critical value of 5 for obtaining correct results (Kline, 2005) and therefore sufficient for addressing the research question. In all analyses, dummy codes for the treatment factor $(0=\mathrm{OS} ; 1=\mathrm{MS})$ were used.

Another important factor that needs to be accounted for is the possible clustering of the data. As we wanted to increase the external validity of our study, students were instructed in small groups of 9-16 students from the same mathematics class rather than individually. Students of the same class were assigned to a randomly chosen treatment condition, taking into account their achievement. To examine the degree of dependence within these groups $(n=24)$ for students' prior interest, we calculated the intraclass correlation coefficient (ICC) using the statistical program Mplus (Muthén \& Muthén, 1998-2012) and transformed them into design effects (Muthén \& Satorra, 1995) to indicate the loss of statistical power due to the dependence of observations. As the ICC was low (0.038) the resulting design effect of 1.41 is below the critical value of 2 (Muthén \& Satorra, 1995). Furthermore, the within-group variability was significant $(p<0.001)$, and the between-group variability was not significant $(p$ $>0.10)$. As there are no significant clustering effects of interest within treatment conditions, no statistical control was needed.

To answer the second research question we needed to test indirect effects. An indirect effect is the product of two direct paths. We estimated standard errors using a bootstrapping approach, which is one of the preferable methods for testing indirect effects (MacKinnon, Lockwood, Hoffman, West, \& Sheets, 2004). Ten-thousand bootstrap samples were drawn and bootstrap percentiles are used to form the $95 \%$ non-symmetric bootstrap confidence interval (CI) (Muthén, Muthén, \& Asparouhov, 2016). The null hypotheses (there is no direct/ indirect effect) was rejected if zero was not included in the $95 \%$ CI. Therefore all effects of the path model will be reported with their respective $\mathrm{CI}$ rather than with a $p$-value.

The chosen method of the current study allowed us to directly test the significance of the indirect effect (MacKinnon, 2008), which is the preferable method compared to a stepwise regression method (e.g., Baron \& Kenny, 1986), because it has a higher statistical power at a comparable Type I error (MacKinnon, Lockwood, Hoffman, West, \& Sheets, 2002). Furthermore, the existence of a total effect is not required if the indirect effect is directly tested (MacKinnon, 2008).

Missing values are an important issue typically found in longitudinal studies. In the current study the percentage of missing values differed across the measures from 
$7.5 \%$ for experience of competence to $8.5 \%$ for interest at post-test. The use of the full information likelihood estimator or multiple imputation are the preferred solution to address the problem of missing values (Peugh \& Enders, 2004). We decided to use the full information likelihood algorithm implemented in Mplus (Muthén \& Muthén, 1998-2012), which uses the full information of the covariance matrices to estimate the missing values. Taking into account the missing at random assumption, the usage of this algorithm, should not have a bias for the estimation of our model parameters (Schafer \& Graham, 2002).

\subsubsection{Treatment Fidelity}

All participating teachers were experienced in teaching real-world problems and were further instructed for one day with regard to the teaching method they should apply. In each lesson, at least one member of the research group was present in order to administer tests and assessment scales and to videotape and observe the implementation of the treatment. Furthermore, all of the students' written work was collected. The analysis of the videos and students' solutions revealed that the time spent on the tasks did not differ across the conditions and that the tasks were solved as intended for each condition. As intended teachers in the MS condition needed more time after the first task than in the OS conditions to highlight and summarize the links between the two mathematical procedures and to foster a discussion about students' preferences for one or the other procedure. This was consistent in all MS conditions and was compensated by an additional task for the OS condition which was solved in all groups and discussed as intended.

Another important aspect of our treatment fidelity involved the number of mathematical procedures students used during the treatment (see Achmetli, Schukajlow, $\&$ Krug, 2014). Theoretically, the number could range from 0 (no mathematical procedure) to 3 (more than two mathematical procedures). For our analysis, two independent raters rated $20 \%$ of the tasks with a high level of agreement (Cohen's Kappa between 0.89 and 0.94). As intended in our study, nearly all students in the MS condition used two or more mathematical procedures (mean $M=1.92$, standard deviation $S D=0.25$ ), whereas in the OS conditions, students did not or rarely constructed two or more mathematical procedures $(M=1.01, S D=0.08$ and $M=1.04$, $S D=0.24) . T$-tests indicated that there were highly significant differences between the conditions in the number of mathematical procedures that students used to solve the problems (MSM vs. OSM1: $t(116)=34.0 ; p<0.001$; effect size Cohen's $d=$ 4.97 and MSM vs. OSM2: $t(194)=25.2 ; p<0.001 ; d=3.61)$. 
Table 3.2 Students' interest on the pre-test and post-test and their experience of competence during the teaching unit in the one-solution conditions

\begin{tabular}{|c|c|c|c|c|c|}
\hline \multirow[t]{2}{*}{ Variable } & OS1 & OS2 & \multirow{2}{*}{$\begin{array}{l}t(d f= \\
186)\end{array}$} & \multirow[t]{2}{*}{$p^{*}$} & \multirow[t]{2}{*}{$d$} \\
\hline & $M(S D)$ & $M(S D)$ & & & \\
\hline Prior interest & $2.38(0.95)$ & $2.40(0.97)$ & -0.182 & 0.856 & 0.03 \\
\hline Experience of competence & $4.21(0.87)$ & $4.22(0.75)$ & -0.310 & 0.975 & 0.00 \\
\hline Interest at post-test & $2.51(0.98)$ & $2.49(0.82)$ & 0.135 & 0.892 & 0.02 \\
\hline
\end{tabular}

*Two-tailed

\subsection{Results}

\subsubsection{Preliminary Results and Analysis of Treatment Effects}

As our statistical analysis for all three variables did not show a difference at the $5 \%$ level of significance between the two OS conditions (Table 3.2), and in order to simplify the analysis of the effects, we combined the OS1 and OS2 conditions into one OS condition.

Furthermore, the analysis of interest on the pre-test revealed no differences between the MS and OS conditions (MS: $M=2.39$ ( $S D=0.90)$, OS: $M=2.39$ (SD $=0.96)$ ). Similar results were also found for self-regulation (Achmetli et al., 2014). These results indicate similar motivational prerequisites in the two conditions.

\subsubsection{Effects of Constructing Multiple Solutions on Experience of Competence and Interest in Mathematics}

In order to compare the interest between the MS and OS condition at post-test, we took students' prior interest into account and calculated an adjusted post-test value for each student. Students' interest tended to be higher in the MS condition, but a $t$ test showed that there were no significant differences ( $p=0.313$; effect size: Cohen's $d=0.13$ ) between the two conditions (Table 3.3). Thus, constructing multiple solutions for real-world problems by applying multiple mathematical procedures did not have a positive effect on interest. According to this result, students who applied multiple mathematical procedures during the teaching unit reported a level of interest in mathematics that was comparable to students who used only one mathematical procedure.

Students in both conditions experienced a high level of competence (MS: mean $=$ $4.44((S D)=0.60)$, OS: $M=4.21(S D=0.81))$. To examine the influence of multiple solutions for real-world problems by applying multiple mathematical procedures on students' experience of competence, we used a $t$-test. Levene's test showed that there 
Table 3.3 Students' adjusted interest on the pre-test and their experience of competence during the teaching unit in the multiple-solution condition and one-solution condition

\begin{tabular}{|c|c|c|c|c|c|}
\hline \multirow[t]{2}{*}{ Variable } & MS & OS & \multirow{2}{*}{$\begin{array}{l}t(d f= \\
279)\end{array}$} & \multirow[t]{2}{*}{$p^{*}$} & \multirow[t]{2}{*}{$d$} \\
\hline & $M(S D)$ & $M(S D)$ & & & \\
\hline Experience of competence & $4.44(0.60)$ & $4.21(0.81)$ & 2.361 & 0.019 & 0.30 \\
\hline Adj. interest at post-test & $2.58(0.71)$ & $2.49(0.70)$ & 1.011 & 0.313 & 0.13 \\
\hline
\end{tabular}

*Two-tailed

was heterogeneity of variance; therefore, we used the adjusted degrees of freedom and $t$-values. The results indicated that there were significant differences between the MS condition and the OS condition $(t(231)=2.616 ; p<0.05 ; d=0.30)$. Thus, students in the MS condition reported a higher experience of competence than students in the OS condition.

\subsubsection{Statistical Procedure and Analysis of Model Fit}

The maximum-likelihood algorithm implemented in Mplus was used for the statistical analyses of the path model (Muthén \& Muthén, 1998-2012). This algorithm allows the calculation of fit values for the path model in order to analyse whether the data provide a good fit to the hypothesised model or not. We applied a combination of cut-off values (Hu \& Bentler, 1999) of the comparative fit index (CFI) $>0.95$, the standardized root mean square residual $(\mathrm{SRMR})<0.08$ and the root mean square error of approximation (RMSEA) $<0.06$ and aimed for a ratio of $\chi^{2}$ and $d f$ below 2.5. The hypothesised model fit the data well according to all fit indexes $\left(\chi^{2} / d f=0.02\right.$; $\mathrm{RMSEA}=0.00,90 \% \mathrm{CI}[0.00,0.07], p=0.925 ; \mathrm{CFI}=1.000 ; \mathrm{SRMR}=0.003)$ and $40 \%$ of the variance in interest at post-test could be explained by this model.

The calculated correlation matrix of the variables measured in the current study is presented in Table 3.4. The analysis of the values showed that all the correlations were in the expected direction (e.g., both interest measures were significantly correlated with each other and all correlations between interest and experience of competence were positive).

\subsubsection{Direct and Indirect Effects on Students' Interest}

In this section, we present the results of the estimates calculated for the hypothesised path model. Because the treatment conditions represented a binary factor (MS vs. OS), StdY values were used to calculate the standardized estimates in Mplus. Thus, $\beta$ coefficients may be interpreted as the predicted change in (residualised) criterion measures (in standard deviation units) when the treatment changes from 0 (one solu- 
tion) to 1 (multiple solutions). Confidence intervals are used to identify significant regression coefficients and are presented in Table 3.5.

The analysis of the path model (Fig. 3.6) reveals that the treatment condition predicts students' experience of competence during the teaching unit $(\beta=0.14 ; 95 \%$ CI $[0.04,0.25])$ but not their interest at post-test $(\beta=0.05 ; 95 \%$ CI $[-0.04,0.14])$. Another result was a significant prediction of students' experience of competence from their prior interest $(\beta=0.21 ; 95 \%$ CI $[0.07,0.35])$. Furthermore, students' interest at post-test is predicted by their prior interest $(\beta=0.64 ; 95 \%$ CI $[0.53$, $0.74]$ ) but not by their experience of competence during the teaching unit $(\beta=-$ $0.04 ; 95 \%$ CI $[-0.16,0.07])$.

One of the main reasons for using a path model is the analysis of indirect effects. We analysed two indirect effects on students' interest at post-test: From the treatment condition through the experience of competence and from students' prior interest via the experience of competence. The main result of the path model is that there are no significant indirect effects of the treatment condition on students' interest via their experience of competence $(\beta=-0.01 ; 95 \%$ CI [ $-0.02,0.01])$. Conclusively and consistent to the result of the treatment effects, there are no total effects of the treatment condition on students interest at post-test $(\beta=0.04 ; 95 \% \mathrm{CI}[-0.05,0.14])$. Moreover, there are no significant indirect effects of students' prior interest on their interest at post-test via their experience of competence during the teaching unit ( $\beta$

Table 3.4 Correlations among the measures

\begin{tabular}{l|l|l|l}
\hline Variable & Prior interest & $\begin{array}{l}\text { Experience of } \\
\text { competence }\end{array}$ & $\begin{array}{l}\text { Interest at } \\
\text { post-test }\end{array}$ \\
\hline $\begin{array}{l}\text { 1. Prior interest } \\
\begin{array}{l}\text { Experience of } \\
\text { competence }\end{array}\end{array}$ & - & & \\
\hline 3. Interest at post-test & $0.62^{*}$ & - & \\
\hline
\end{tabular}

${ }^{*} p<0.01$, two-tailed

Table 3.5 Direct effects on experience of competence and interest

\begin{tabular}{l|l|l|l|l|l|l}
\hline \multirow{2}{*}{ Variable } & \multicolumn{5}{l|}{ Experience of competence } & \multicolumn{4}{l}{ Interest at post-test } \\
\cline { 2 - 8 } & $95 \%$ CI & \multicolumn{2}{l}{$95 \%$ CI } & \\
\cline { 2 - 8 } & $\beta$ & $L L$ & $U L$ & $\beta$ & $L L$ & $U L$ \\
\hline Predictor & & & & & & \\
\hline Prior interest & $0.21^{*}$ & 0.07 & 0.35 & $0.64^{*}$ & 0.53 & 0.74 \\
\hline Treatment condition & $0.14^{*}$ & 0.04 & 0.25 & 0.05 & -0.04 & 0.14 \\
\hline Intervening variable & & & & & & \\
\hline Experience of competence & & & & -0.04 & -0.16 & 0.07 \\
\hline
\end{tabular}

Note CI Confidence interval; $L L$ Lower limit; UL Upper limit

*Significant regression coefficient (zero not included in the $95 \% \mathrm{CI}$ ) 


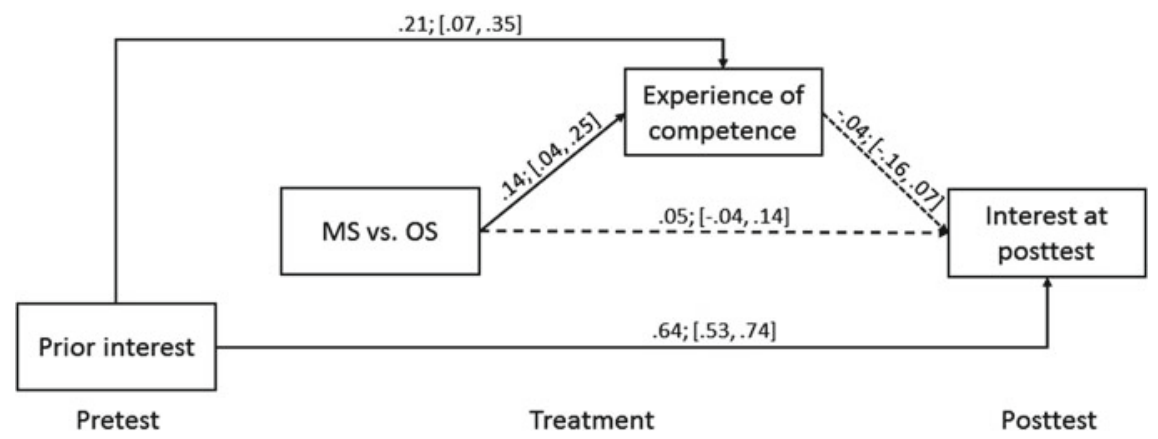

Fig. 3.6 Graphical illustration of direct effects in the path model. Note Significant paths are illustrated with solid lines, and nonsignificant paths are illustrated with a broken line

$=-0.01 ; 95 \% \mathrm{CI}[-0.04,0.02])$. Yet, there is still a total effect of prior interest on interest at post-test $(\beta=0.63 ; 95 \% \mathrm{CI}[0.53,0.73])$.

\subsection{Discussion}

The effects of constructing multiple solutions for real-world problems on students' interest and experience of competence address an important issue in mathematics education. Even though there are theoretical models about the development of interest and empirical results about the connection between students' basic needs and interestrelated measures, there has not been a brought range of information about how these needs influence students' interest. In this study, we analysed the influence of students' interest on their experience of competence and vice versa. Moreover, we investigated the effects of constructing multiple solutions, which only a few randomized experimental studies have investigated so far, on students' interest and experience of competence. In addition and to the best of our knowledge, there is only one study that analysed these effects on the basis of real-world problems, although these problems should be used in the classroom because of their importance for students' current and future lives. In our current study, we used the topic of linear functions to assess our research questions and used path analysis to determine the impact of constructing multiple solutions on students' interest.

On the basis of theoretical considerations and empirical results we predicted that constructing multiple solutions by applying different mathematical procedures would directly affect students' interest. However, the results of our study did not confirm this prediction. Students in the multiple solution condition and one solution condition reported on a similar level of interest at post-test after the four-lesson teaching unit. This result is in contrast to previous findings (Schukajlow \& Krug, 2014) that did identify effects of constructing multiple solutions by making different assumptions for vague conditions on students' interest. One possible explanation for this finding is 
that the approaches differed between this study and the previous one. In the current study, students in the MS condition had to use specific mathematical procedures, which were presented at the beginning of the teaching unit, and were not given the opportunity to choose their own individual routes to the solution during the teaching units as they had in the previous study (Schukajlow \& Krug, 2014).

As expected, we found a significant difference in the experience of competence between the MS condition and the OS condition. Thus, constructing multiple solutions can foster not only performance, conceptual knowledge, and cognitive flexibility (Levav-Waynberg \& Leikin, 2012; Rittle-Johnson et al., 2009; Star \& RittleJohnson, 2008) but also a basic need. This result is in line with the study by Schukajlow and Krug (2014) in which they revealed the importance of prompting students to construct multiple solutions for real-world problems with vague conditions for students' experience of competence. Therefore, we were able to extend the research on basic needs (e.g., Krapp, 2005; Renninger \& Hidi, 2002) by finding that students' experience of competence tended to be higher in the multiple solutions treatment conditions of the current and previous study. Furthermore, the findings confirm the view that instructional conditions can have an effect on students' individual interest (Hidi \& Renninger, 2006). Because students in both conditions all worked in groups on the same type of tasks and experienced the roughly the same methodological order, we argue that this is due to the prompts to use, to contrast and to compare two mathematical procedures in the MS-condition.

In order to explore how constructing multiple solutions by applying different mathematical procedures and students' prior interest would influence students' interest at post-test, we examined our hypothesised path model. As expected, the path model provided a good fit to the data according a combination of cutoff values ( $\mathrm{Hu} \&$ Bentler, 1999).

No indirect effects of constructing multiple solutions on students' interest at post-test were found. This result is in contrast to previous findings (Schukajlow \& Krug, 2014) and we argue that the lack of opportunity to choose their own solution routes might have negatively affected students' experience of autonomy and thus also impeded students' interest (Deci \& Ryan, 2000; Krapp, 2005). Another explanation for why our expectation for the positive influence of multiple solutions on interest was not confirmed emerges from the similarity of the tasks that were presented in the classroom in the present study. The real-world problems that were presented in the MS or OS condition were based on the same context, included the same numbers, and differed only in whether students were supposed to apply one or two mathematical procedures. It seems that this prompt positively influences students' perceived competence, but have not increased their interest. Trying to actively match the contexts to students' personal backgrounds and preferences in order to trigger their interest $(\mathrm{Ku}$ \& Sullivan, 2002; López \& Sullivan, 1992) or giving them the opportunity to choose their preferred contexts during the teaching unit are important aspects that can have a positive influence on interest. The roles of these aspects for interest-related measures needs to be investigated in future studies. Further, students report on a significant higher experience of competence in the presents study compared to previous study (Schukajlow \& Krug, 2014), the mean values for experience of competence in the 
present study were nearby the theoretical maximum of 5 and the standard deviation of experience of competence was lower than in the previous study. As interest in mathematical problems was found to be positively connected to task difficulty (Rellensmann \& Schukajlow, 2017), offering students more difficult problems during the teaching unit might increase the variance in students' experiences of competence and affect students' interest positively. Lastly, students' individual interest is a stable construct of a predisposition (Schukajlow et al., 2017) and an intervention of $180 \mathrm{~min}$ might just not be enough to have an impact.

The relevance of students' prior interest to their experiences of competence as well as their interest at post-test was another point we investigated. Previous studies have shown the relationship of competence-related measures and interest (Zimmerman \& Kitsantas, 1997). However, the direction of this connection was not completely clear (Hidi, 2006). The results of our study show that students' prior interest positively influences their experiences of competence, while a higher experience of competence during the teaching unit did not lead to a higher interest at post-test. Conclusively, there are no indirect effects of prior interest on students' interest at post-test via their experience of competence. As there are still total effects (which are the sum of all direct and indirect effects) of students' prior knowledge on their interest at post-test, we conclude that the experience of competence is not a transmitting variable for the effects of prior interest and the treatment condition on the interest at post-test. However, concerning the influence of prior interest for interest at post-test, we could confirm that interest is a stable construct, as prior interest had a high positive influence on interest at post-test.

\subsection{Strengths and Limitations}

The effects of the treatment condition and prior interest on experience of competence and on interest at post-test was explored using inferential and path analyses. Because the teaching method was actively manipulated, causal interpretations of the effects of multiple solutions on the outcome variables are allowed. However, such causal interpretations of paths in the path model should be made with caution. The validity of the analysis of path models depends on the times at which the data were collected and on evidence from previous research. We collected data before (prior interest), during (experience of competence) and after the teaching unit (interest at post-test), so that the data would be ordered along a timeline. Thus, it was possible to determine the direction of the effects and to examine the path model.

The assumed path model was derived from theories about interest (Krapp, 2000; Hidi \& Renninger, 2006) and the self-determination theory of human motivation (Deci \& Ryan, 2000). The results of previous empirical studies have inspired the hypothesised path between the treatment condition, students' experience of competence and their interest. One limitation derives from a possible incompleteness of the path model, as other intervening variables might need to be included. Interest, for example, has in contrast to other cognitively driven motivational variables both 
an affective and a cognitive component (Hidi, 2006). Experiencing interest involves affect from the outset of experience and can be assumed to be combined or integrated with cognition as it develops (Hidi \& Renninger, 2006; Krapp, 2000). Thus, positive and negative affect during the teaching unit as well as other cognitive variables could be important variables, which need to be considered in further analyses. One starting point is, that the experience of competence has been shown to be connected to students' autonomy, social relatedness, and intrinsic motivation. Thus, the other two basics needs should be included in future studies, in order to validate our findings. Positive effects of constructing multiple solutions for real-world problems by applying multiple mathematical procedures on these variables can be expected and transmitted on students' interest at post-test. This hypothesis should be tested in future studies using a corresponding mediation model that takes into account affective (e.g. enjoyment and boredom) and cognitive (e.g. experience of competence, experience of autonomy and experienced meaningfulness of the learning content) variables could be useful for further decomposing the effects on students' interest and should be applied in future studies.

\subsection{Conclusion}

Constructing multiple solutions is an important theme that has been investigated in research frameworks about the impact of comparison (Rittle-Johnson \& Star, 2007, 2009; Rittle-Johnson, Star, \& Durkin, 2009; Star \& Rittle-Johnson, 2008, 2009) and in experimental studies (Schukajlow \& Krug, 2014; Schukajlow et al., 2015). Our current is an extension to the previous experimental studies on constructing multiple solutions for real-world problems by making different assumptions about vague conditions. The aim of the study was to explore the effects of constructing a different kind of multiple solutions (using different mathematical procedures) on students' experience of competence and their interest. The inferential and path analyses, which were based on theories about interest and the self-determination theory, showed a positive influence of constructing multiple solutions on experience of competence but not on individual interest. However, the effects might be different for other affective variables. For example, we found positive indirect effects of constructing multiple solutions on self-efficacy via experience of competence for students' with low prior self-efficacy (Schukajlow, Achmetli, \& Rakoczy, in press).

\section{References}

Achmetli, K., Schukajlow, S., \& Krug, A. (2014). Effects of prompting students to use multiple solution methods while solving real-world problems on students' self-regulation. In C. Nicol, S. Oesterle, P. Liljedahl, D. Allan (Eds.), Proceedings of the Joint Meeting of PME 38 and PME-NA 36 (pp. 1-8). Vancouver, Canada: PME. 
Baron, R. M., \& Kenny, S. A. (1986). The moderator-mediator variable distinction in social psychological research: Conceptual, strategic, and statistical considerations. Journal of Personality and Social Psychology, 51(6), 1173-1182.

Bikner-Ahsbahs, A. (2004). Interest-dense situations and their mathematical valences. Contribution to the topic study group 24 on students' motivations and attitudes towards mathematics and its study. In 10th International Congress for Mathematics Education. Copenhagen, Denmark. Retrieved from http://www.math.uni-bremen.de/didaktik/ma/bikner/articles/article1.pdf.

Blum, W., Galbraith, P. L., Henn, H.-W., \& Niss, M. (2007). Modelling and applications in mathematics education. The 14th ICMI study. New York, NY: Springer.

Blum, W., \& Leiss, D. (2007). How do students and teachers deal with mathematical modelling problems? The example sugarloaf and the DISUM project. In C. Haines, P. L. Galbraith, W. Blum, \& S. Khan (Eds.), Mathematical modelling (ICTMA 12): Education, engineering and economics (pp. 222-231). Chichester, UK: Horwood.

Boekaerts, M., \& Corno, L. (2005). Self-regulation in the classroom: A perspective on assessment and intervention. Applied Psychology, 54(2), 199-231.

Carmichael, C. S., Callingham, R., Watson, J. M., \& Hay, I. (2009). Factors influencing the development of middle school students' interest in statistical literacy. Statistics Education Research Journal, 8(1), 62-81.

Deci, E. L. (1998). The relation of interest to motivation and human needs: The self-determination theory viewpoint. In L. Hoffmann, A. Krapp, K. A. Renninger, \& J. Baumert (Eds.), Interest and Learning. Proceedings of the Seeon-Conference on Interest and Gender (pp. 146-162). Kiel, Germany: IPN.

Deci, E. L., \& Ryan, A. M. (2000). The „What” and „Why” of goal pursuits: Human needs and the selfdetermination of behavior. Psychological Inquiry, 11(4), 227-268.

Deci, E. L., \& Ryan, R. M. (1991). A motivational approach to self: Integration in personality. In R. A. Dienstbier (Ed.), Perspectives on motivation (pp. 237-288). Lincoln, NE: University of Nebraska Press.

Deci, E. L., \& Ryan, R. M. (2008). Self-determination theory: A macrotheory of human motivation, development, and health. Canadian Psychology/Psychologie Canadienne, 49(3), 182-185.

Di Martino, P., Gómez-Chacón, I., Liljedahl, P., Morselli, F., Pantziara, M., \& Schukajlow, S. (2015). Introduction to the papers of TWG08: Affect and mathematical thinking. In Proceedings of the Ninths Congress of the European Society for Research in Mathematics Education. Prague: Czech Republic, Charles University of Prag.

Fisher, P. H., Dobbs-Oates, J., Doctoroff, G. L., \& Arnold, D. H. (2012). Early math interest and the development of math skills. Journal of Educational Psychology, 104(3), 673-681.

Frenzel, A. C., Pekrun, R., Dicke, A.-L., \& Goetz, T. (2012). Beyond quantitative decline: Conceptual shifts in adolescents' development of interest in mathematics. Developmental Psychology, 48(4), 1069-1082.

Galbraith, P. L., \& Stillman, G. (2006). A framework for identifying student blockages during transitions in the modelling process. ZDM Mathematics Education, 38(2), 143-162.

Große, C. S. (2014). Mathematics learning with multiple solution methods: effects of types of solutions and learners' activity. Instructional Science, 42(5), 715-745.

Große, C. S., \& Renkl, A. (2006). Effects of multiple solution methods mathematics learning. Learning and Instruction, 16(2), 122-138.

Guay, F., Boggiano, A. K., \& Vallerand, R. J. (2001). Autonomy support, intrinsic motivation, and perceived competence. Conceptual and empirical linkages. Personality and Social Psychology Bulletin, 27(6), 643-650.

Hannula, M. S. (2006). Motivation in mathematics: Goals reflected in emotions. Educational Studies in Mathematics, 63, 165-178.

Hänze, M., \& Berger, R. (2007). Cooperative learning, motivational effects, and student characteristics: An experimental study comparing cooperative learning and direct instruction in 12th grade physics classes. Learning and Instruction, 17(1), 29-41. 
Harackiewicz, J. M., Durik, A. M., Barron, K. E., Linnenbrink-Garcia, L., \& Tauer, J. M. (2008). The role of achievement goals in the development of interest: Reciprocal relations between achievement goals, interest, and performance. Journal of Educational Psychology, 100(1), 105-122.

Harter, S., Whitesell, N. R., \& Kowalski, P. (1992). Individual differences in the effects of educational transitions on young adolescents' perceptions of competence and motivational orientation. American Educational Research Journal, 29(4), 777-808.

Heinze, A., Reiss, K., \& Rudolph, F. (2005). Mathematics achievement and interest in mathematics from a differential perspective. ZDM Mathematics Education, 37(3), 212-220.

Hidi, S. (2006). Interest: A unique motivational variable. Educational Research Review, 1(2), 69-82.

Hidi, S., \& Renninger, K. A. (2006). The four phase model of interest development. Educational Psychologist, 41(2), 111-127.

Hidi, S., Renninger, K. A., \& Krapp, A. (2004). Interest, a motivational variable that combines affective and cognitive functioning. In D. Y. Dai \& R. J. Sternberg (Eds.), Motivation, emotion, and cognition: Integrative perspectives on intellectual functioning and development (pp. 89-115). Mahwah, NJ: Lawrence Erlbaum Associates.

Hiebert, J., Gallimore, R., Garnier, H., Givvin, K. B., Hollingsworth, H., Jacobs, J., et al. (2003). Teaching mathematics in seven countries. Results from the TIMSS 1999 video study. Washington, DC: NCES.

Hu, L., \& Bentler, P. M. (1999). Cutoff criteria for fit indexes in covariance structure analysis: Conventional criteria versus new alternatives. Structural Equation Modeling, 6(1), 1-55.

Kline, R. B. (2005). Principles and practice of structural equation modeling. New York, NY: Guilford Press.

Köller, O., Baumert, J., \& Schnabel, K. (2000). Zum Zusammenspiel von schulischem Interesse und Lernen im Fach Mathematik: Längsschnittanalysen In den Sekundarstufen I und II. In U. Schiefele \& E. Wild. (Eds.), Interesse und Lernmotivation (pp. 163-181). Münster: Waxmann.

Köller, O., Baumert, J., \& Schnabel, K. (2001). Does interest matter? The relationship between academic interest and achievement in mathematics. Journal for Research in Mathematics Education, 32(5), 448-470.

Krapp, A. (1999). Interest, motivation and learning: An educational-psychological perspective. European Journal of Psychology of Education, 14(1), 23-40.

Krapp, A. (2000). Interest and human development during adolescence: An educationalpsychological approach. In J. Heckhausen (Ed.), Motivational psychology of human development (pp. 109-128). Amsterdam, The Netherlands: Elsevier.

Krapp, A. (2005). Basic needs and the development of interest and intrinsic motivational orientations. Learning and Instruction, 15, 381-395.

Krug, A., \& Schukajlow, S. (2013). Problems with and without connection to reality and students' task-specific interest. In A. M. Lindmeier \& A. Heinze (Eds.), Proceedings of the 37th Conference of the International Group for the Psychology of Mathematics Education (pp. 209-216). Kiel, Germany: PME.

Ku, H.-Y., \& Sullivan, H. J. (2002). Student performance and attitudes using personalized mathematics instruction. Educational Technology Research and Development, 50(1), 21-34.

Kunter, M. (2005). Multiple Ziele im Mathematikunterricht [Multiple goals in mathematics lessons]. Münster, Germany: Waxmann.

Leikin, R., \& Lev, M. (2007). Multiple solution tasks as a magnifying glass for observation of mathematical creativity. In J.-H. Woo, H.-C. Lew, K.-S. P. Park, \& D.-Y. Seo (Eds.), Proceedings of the 31st International Conference for the Psychology of Mathematics Education (pp. 161-168). Seoul, Korea: PME.

Lerkkanen, M.-K., Kiuru, N., Pakarinen, E., Viljaranta, J., Poikkeus, A.-M., Rasku-Puttonen, H., et al. (2012). The role of teaching practices in the development of children's interest in reading and mathematics in kindergarten. Contemporary Educational Psychology, 37(4), 266-279.

Levav-Waynberg, A., \& Leikin, R. (2012). The role of multiple solution tasks in developing knowledge and creativity in geometry. Journal of Mathematical Behavior, 31, 73-90. 
López, C. L., \& Sullivan, H. J. (1992). Effect of personalization of instructional context on the achievement and attitudes of Hispanic students. Educational Technology Research and Development, 40(4), 5-14.

Maaß, K. (2010). Classification scheme for modelling tasks. Journal für Mathematikdidaktik, 31(2), 285-311.

MacKinnon, D. P. (2008). Introduction to statistical mediation analysis. Routledge, UK: Taylor \& Francis.

MacKinnon, D. P., Lockwood, C. M., Hoffman, J. M., West, S. G., \& Sheets, V. (2002). A comparison of methods to test mediation and other intervening variable effects. Psychological Methods, 7(1), 83.

MacKinnon, D. P., Lockwood, C. M., \& Williams, J. (2004). Confidence limits for the indirect effect: Distribution of the product and resampling methods. Multivariate Behavioral Research, 39(1), 99-128.

Marcou, A., \& Lerman, S. (2007). Changes in students' motivational beliefs and performance in a self-regulated mathematical problem-solving environment. In D. Pitta-Pantazi \& G. Philippou (Eds.), European Research in Mathematics Education V. Proceedings of the Fifth Congress of the European Society for Research in Mathematics Education. Larnaca, Cyprus 22-26 February 2007 (pp. 288-297). Larnaca, Cyprus: ERME. Retrieved from http://www.mathematik.uni-dortmund. de/ erme/CERME5b/WG2.pdf.

Marsh, H. W., Trautwein, U., Lüdtke, O., Köller, O., \& Baumert, J. (2005). Academic self-concept, interest, grades, and standardized test scores: Reciprocal effects models of causal ordering. Child Development, 76(2), 397-416.

Minnaert, A., Boekaerts, M., \& Opdenakker, M.-C. (2008). The relationship between students' interest development and their conceptions and perceptions of group work. Unterrichtswissenschaft, 36(3), 216-236.

Mitchell, M. (1993). Situational interest: Its multifaceted structure in the secondary school mathematics classroom. Journal of Educational Psychology, 85(3), 424-436.

Muthén, B. O., Muthén, L. K., \& Asparouhov, T. (2016). Regression and mediation analysis using Mplus. Los Angeles, CA: Muthén \& Muthén.

Muthén, B. O., \& Satorra, A. (1995). Complex sample data in structural equation modeling. Sociological Methodology, 25, 267-316.

Muthén, L. K., \& Muthén, B. O. (1998-2012). Mplus user's guide. Los Angeles, CA: Muthén \& Muthén.

National Council of Teachers of Mathematics. (2000). Principles and standards for school mathematics. Reston, VA: NCTM.

Neubrand, M. (2006). Multiple Lösungswege für Aufgaben: Bedeutung für Fach, Lernen, Unterricht und Leistungserfassung [Multiple procedures for problems: importance for content, learning, teaching and measurement of performance]. In W. Blum, C. Drüke-Noe, R. Hartung \& O. Köller. Bildungsstandards Mathematik: Konkret. Sekundarstufe I: Aufgabenbeispiele, Unterrichtsanregungen, Fortbildungsideen [Standards for school mathematics on the low-secondary level: tasks, ideas for teaching and teacher training] (pp. 162-177). Berlin, Germany: Cornelsen.

Niss, M., Blum, W., \& Galbraith, P. L. (2007). Introduction. In W. Blum, P. L. Galbraith, H.-W. Henn, \& M. Niss (Eds.), Modelling and applications in mathematics education: The 14th ICMI study (pp. 1-32). New York, NY: Springer.

Panaoura, A., Gagatsis, A., \& Demetriou, A. (2009). An intervention to the metacognitive performance: Self-regulation in mathematics and mathematical modeling. Acta Didactica Universitatis Comenianae Mathematics, 9, 63-79.

Pekrun, R., vom Hofe, R., Blum, W., Frenzel, A. C., Goetz, T., \& Wartha, S. (2007). Development of mathematical competencies in adolescence: The PALMA longitudinal study. In M. Prenzel. Studies on the educational quality of schools. The final report on the DFG priority programme (pp. 17-37). Münster, Germany: Waxmann.

Peugh, J. L., \& Enders, C. K. (2004). Missing data in educational research: A review of reporting practices and suggestions for improvement. Review of Educational Research, 74(4), 525-556. 
Pintrich, P. R. (1999). The role of motivation in promoting and sustaining self-regulated learning. International Journal of Educational Research, 31, 459-470.

Pollak, H. (1979). The interaction between mathematics and other school subjects. In UNESCO (Ed.), New trends in mathematics teaching IV (pp. 232-248). Paris, France: UNESCO.

Rellensmann, J., \& Schukajlow, S. (2017). Does students' interest in a mathematical problem depend on the problem's connection to reality? An analysis of students interest and pre-service teachers judgments of students' interest in problems with and without a connection to reality. ZDM Mathematics Education, 49(3), 367-378.

Renninger, K. A., \& Hidi, S. (2002). Student interest and achievement: Developmental issues raised by a case study. In A. Wigfield \& J. S. Eccles (Eds.), Development of achievement motivation (pp. 173-195). San Diego, CA: Academic Press.

Rittle-Johnson, B., \& Star, J. R. (2007). Does comparing solution methods facilitate conceptual and procedural knowledge? An experimental study on learning to solve equations. Journal of Educational Psychology, 99(3), 561-574.

Rittle-Johnson, B., \& Star, J. R. (2009). Compared with what? The effects of different comparisons on conceptual knowledge and procedural flexibility for equation solving. Journal of Educational Psychology, 101(3), 529-544.

Rittle-Johnson, B., Star, J. R., \& Durkin, K. (2009). The importance of prior knowledge when comparing examples: Influences on conceptual and procedural knowledge of equation solving. Journal of Educational Psychology, 101(4), 836-852.

Ryan, R. M., \& Deci, E. L. (2000). Self-determination theory and the facilitation of intrinsic motivation, social development, and well-being. American Psychologist, 55, 68-78.

Schafer, J. L., \& Graham, J. W. (2002). Missing data: Our view of the state of the art. Psychological Methods, 7(2), 147-177.

Schiefele, U., Krapp, A., \& Schreyer, I. (1993). Metaanalyse des Zusammenahngs von Interesse und schulischer Leistung. Zeitschrift für Entwicklungspsychologie und Pädagogische Psychologie, 25, $120-148$.

Schiefele, U., \& Schreyer, I. (1994). Intrinsische Lernmotivation und Lernen. Ein Überblick zu Ergebnissen der Forschung. Zeitschrift für Pädagogische Psycholgie, 8, 1-13.

Schukajlow, S., Achmetli, K., \& Rakoczy, K. (2019). Does constructing multiple solutions for real-world problems affect self-efficacy. Educational Studies in Mathematics, 100, 43-60.

Schukajlow, S., Blum, W., Messner, R., Pekrun, R., Leiss, D., \& Müller, M. (2009). Unterrichtsformen, erlebte Selbständigkeit, Emotionen und Anstrengung als Prädiktoren von SchülerLeistungen bei anspruchsvollen mathematischen Modellierungsaufgaben [Teaching methods, perceived self-regulation, emotions, and effort as predictors for students' performance while solving mathematical modelling tasks]. Unterrichtswissenschaft, 37(2), 164-186.

Schukajlow, S., \& Krug, A. (2012a). Effects of treating multiple solutions on students' selfregulation, self-efficacy and value. In T. Y. Tso (Ed.), Proceedings of the 36th Conference of the International Group for the Psychology of Mathematics Education (pp. 59-66). Taipei, Taiwan: PME.

Schukajlow, S. \& Krug, A. (2012b). Treating multiple solutions in the classroom and their influence on students' achievements and the affect-Theoretical background and design of the quasiempirical study. In ICME 12 Conference (pp. 3414-3422). Seoul, Korea: ICME.

Schukajlow, S., \& Krug, A. (2014). Do multiple solutions matter? Prompting multiple solutions, interest, competence, and autonomy. Journal for Research in Mathematics Education, 45(4), 497-533.

Schukajlow, S., Krug, A., \& Rakoczy, K. (2015). Effects of prompting multiple solutions for modelling problems on students' performance. Educational Studies in Mathematics, 89(3), 1-25.

Schukajlow, S., Leiss, D., Pekrun, R., Blum, W., Müller, M., \& Messner, R. (2012). Teaching methods for modelling problems and students' task-specific enjoyment, value, interest and selfefficacy expectations. Educational Studies in Mathematics, 79(2), 215-237. 
Schukajlow, S., Rakoczy, K., \& Pekrun, R. (2017). Emotions and motivation in mathematics education: Theoretical considerations and empirical contributions. ZDM Mathematics Education, 49(3), 307-322.

Silver, E. A., Ghousseini, H., Gosen, D., Charalambous, C. Y., \& Font Strawhun, B. T. (2005). Moving from rhetoric to praxis: Issues faced by teachers in having students consider multiple solutions for problems in the mathematics classroom. Mathematical Behavior, 24(3-4), 287-301.

Slavin, R. E., Hurley, E. A., \& Chamberlain, A. (2003). Cooperative learning and achievement: Theory and research. In W. M. Reynolds \& G. E. Miller (Eds.), Handbook of psychology: Educational psychology (pp. 177-198). New York, NY: Wiley.

Star, J. R., \& Rittle-Johnson, B. (2008). Flexibility in problem solving: The case of equation solving. Learning and Instruction, 18, 565-579.

Star, J. R., \& Rittle-Johnson, B. (2009). It pays to compare: An experimental study on computational estimation. Journal of Experimental Child Psychology, 102(4), 408-426.

Verschaffel, L., Greer, B., \& De Corte, E. (2000). Making sense of word problems. Lisse, The Netherlands: Swets and Zeitlinger.

Webb, N. M., \& Palincsar, A. S. (1996). Group processes in the classroom. In D. C. Berliner \& R. C. Calfee (Eds.), Handbook of educational psychology (pp. 841-873). New York, NY: Macmillan.

Wigfield, A., Battle, A., Keller, L. B., \& Eccles, J. S. (2002). Sex differences in motivation, selfconcept, career aspiration, and career choice: Implications for cognitive development. In R. De Lisi \& A. McGillicuddy-De Lisi (Eds.), The development of sex differences in cognition (pp. 93-124). Westport, CT: Ablex Publishing.

Wigfield, A., \& Cambria, J. (2010). Students' achievement values, goal orientations, and interest: Definitions, development, and relations to achievement outcomes. Developmental Review, 30, $1-35$.

Wigfield, A., \& Eccles, J. S. (2000). Expectancy-value theory of achievement motivation. Contemporary Educational Psychology, 25, 68-81.

Zimmerman, B. J., \& Kitsantas, A. (1997). Developmental phases in self-regulation: Shifting from process goals to outcome goals. Journal of Educational Psychology, 89(1), 29-36.

Zimmerman, B. J., \& Schunk, D. H. (Eds.). (2001). Selfregulated learning and academic achievement: Theoretical perspectives. Mahwah, NJ: Erlbaum.

Open Access This chapter is licensed under the terms of the Creative Commons Attribution 4.0 International License (http://creativecommons.org/licenses/by/4.0/), which permits use, sharing, adaptation, distribution and reproduction in any medium or format, as long as you give appropriate credit to the original author(s) and the source, provide a link to the Creative Commons license and indicate if changes were made.

The images or other third party material in this chapter are included in the chapter's Creative Commons license, unless indicated otherwise in a credit line to the material. If material is not included in the chapter's Creative Commons license and your intended use is not permitted by statutory regulation or exceeds the permitted use, you will need to obtain permission directly from the copyright holder.

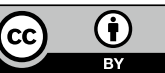




\title{
Chapter 4
}

\section{A Sociocultural Examination of Utility Value in Mathematics: The Role of Interdependence in Middle School Students' Perceptions of Usefulness}

\author{
Tracy E. Dobie
}

\begin{abstract}
This research takes a sociocultural approach to the study of perceived utility value in mathematics. In particular, this research examines students' values and considers the role that one's values might play in ideas about the usefulness of mathematics. To highlight students' values and perspectives on usefulness, this work uses a combination of semi-structured interviews, classroom observations, and surveys. Findings underscore that students placed great importance on learning mathematics that is useful and also exhibited strong interdependent values related to both helping their families and collaborating with others. Opportunities for drawing on these values to enhance perceptions of usefulness are considered, and implications for research and practice are discussed.
\end{abstract}

Keywords Utility value $\cdot$ Sociocultural context $\cdot$ Middle school $\cdot$ Student values Qualitative research

\subsection{Introduction}

Despite the increasing importance of mathematics in the world today, we continue to face issues of declining motivation in school mathematics and underrepresentation of racial and ethnic minority students in advanced mathematics courses. A range of countries including Germany, Australia, and the United States have attempted to address such issues by working to enhance students' perceptions of usefulness, which can improve academic performance, course enrollment, and interest (e.g. Harackiewicz, Rozek, Hulleman, \& Hyde, 2012; Hulleman, Godes, Hendricks, \& Harackiewicz, 2010). While potential benefits of perceived usefulness have been illustrated, little research has examined the relationship between students' perceptions of usefulness and their own goals and identity, which Eccles and Wigfield (2002) highlight as a direct influence on perceived utility. In this research, I take a sociocultural approach to consider the relationship between students' perceptions of usefulness

T. E. Dobie $(\varangle)$

University of Utah, 1721 Campus Center Drive, Salt Lake City, UT 84112, USA

e-mail: tracy.dobie@utah.edu 
and one aspect of identity, students' personal values, or "those beliefs held by individuals to which they attach special priority or worth, and by which they tend to order their lives" (Hill, 1991, p. 4). In particular, this work focuses on independent versus interdependent values, which are especially important to explore given current emphases in the literature. While existing research on utility value has typically emphasized independent conceptions of usefulness, or ways in which school content can be applied to accomplish individual tasks or to perform well personally, research on models of the self has illustrated that working-class contexts in the United States tend to promote interdependence, or connectedness and the needs of others, rather than independence (Grossmann \& Varnum, 2011; Stephens, Markus, \& Townsend, 2007). These different perspectives highlight a potential point of mismatch between existing conceptions of usefulness and the values of students in working-class communities.

This research explores the question, What is the relationship between students' personal values and their ideas about the usefulness of mathematics? In particular, this work explores potential connections between perspectives on usefulness and interdependent values among a group of predominantly Latinx ${ }^{1}$ middle school students in a working-class community. In discussing the implications of this work, I also consider how classroom instruction might draw on students' personal values to enhance their perceptions of the usefulness of mathematics.

\subsection{Conceptual Framework}

Literature in three primary areas informs this research - the expectancy-value model, sociocultural theories, and models of the self. I will describe key findings and constructs from each of these bodies of research below.

\subsubsection{Expectancy-Value Model}

In order to understand how students' values and beliefs influence their achievementrelated choices and performance, Eccles and colleagues amended and expanded Atkinson's (1964) expectancy-value model (Eccles \& Wigfield, 2002; Eccles (Parsons) et al., 1983; Wigfield \& Eccles, 1992). In the updated expectancy-value model, there are a multitude of direct and indirect influences on one's achievement-related choices and academic performance (Eccles \& Wigfield, 2002). Some indirect influences are personal beliefs, such as one's own self-concept or one's perceptions of others' expectations, while others are features of one's environment, such as family demographics and existing cultural stereotypes. All of these beliefs and features of

\footnotetext{
${ }^{1}$ In this chapter, I use the terms Latinx and Chicanx as gender-neutral alternatives to Latino/a and Chicano/a that move away from the gender binary.
} 
the environment influence the two factors that directly affect achievement-related choices and performance: expectations of success and beliefs about the value of a task. While both of these factors are certainly important, in this paper I focus on one particular component of one's beliefs about the value of a task-utility value.

\subsubsection{Utility Value}

Utility value, or the relevance of a task for one's current/future goals or other aspects of one's life, is one of four components of task value in the expectancy-value model (Eccles \& Wigfield, 2002; Eccles (Parsons) et al. 1983; Wigfield \& Eccles, 1992). As the model highlights, utility value can directly impact one's achievement-related choices and performance. In particular, research has highlighted the relationship between high perceptions of usefulness and improved academic performance (Bong, 2001; Durik, Vida, \& Eccles, 2005; Hulleman, Durik, Schweigert, \& Harackiewicz, 2008; Mac Iver, 1991; Simons, Dewitte, \& Lens, 2004), greater enrollment in mathematics courses (Durik et al., 2005; Updegraff, Eccles, Barber, \& O’brien, 1996), and enhanced interest (Harackiewicz, Durik, Barron, Linnenbrink-Garcia, \& Tauer, 2008; Hulleman et al., 2008). Several studies have also illustrated the ability to manipulate students' perceived utility value and for enhanced perceptions of utility to increase interest and course performance (Canning \& Harackiewicz, 2015; Harackiewicz et al., 2012; Hulleman \& Harackiewicz, 2009; Hulleman et al., 2010). Furthermore, some of these studies have found that enhanced perceptions of utility are particularly advantageous for low performers in mathematics (Hulleman \& Harackiewicz, 2009; Hulleman et al., 2010). However, very few studies have examined the role of utility value, or even task values more broadly, among early adolescents from racial or ethnic minority groups (e.g. Safavian \& Conley, 2016). Given the potential benefits of utility beliefs for academic performance, persistence, and interest, it is crucial that we explore strategies for improving perceptions of utility in the mathematics classroom for youth from diverse racial/ethnic backgrounds.

\subsubsection{Utility Value Interventions}

In existing research, two main types of interventions have been conducted to enhance perceptions of usefulness: directly communicated utility value interventions and selfgenerated utility value interventions. In interventions involving directly communicated utility value, participants are told about the ways in which the techniques they are learning or courses they are taking can be useful (Durik, Shechter, Noh, Rozek, \& Harackiewicz, 2014; Harackiewicz et al., 2012). For example, in Durik and Harackiewicz's (2007) research, college students were taught how to use a particular technique for solving two-digit multiplication problems. In one condition, participants also received information about the utility of the technique for "everyday situations that would be relevant to college students" (p. 603). They were provided examples such as "doing personal banking, tallying grocery bills, and taking notes during math 
lectures" (p. 603), as well as calculating restaurant tips and store discounts. In contrast, interventions that involve the use of self-generated utility value statements ask participants to make their own connections between the material they are learning and its usefulness in other contexts (Hulleman \& Harackiewicz, 2009). For example, Hulleman et al. (2010) introduced college participants to the aforementioned twodigit multiplication technique; however, rather than being told how the technique could be useful, participants were asked to write a short essay "describing the potential relevance of this technique to your own life, or to the lives of college students in general" (p. 22). Similarly, Harackiewicz, Canning, Tibbetts, Priniski, and Hyde (2016) implemented a written utility-value intervention with the goal of enhancing perceptions of utility among first-generation and underrepresented minority college students in introductory biology courses.

Recently, Canning and Harackiewicz (2015) compared the effectiveness of interventions involving the use of directly communicated utility value versus selfgenerated utility value. Their findings illustrate that direct communication of utility value undermines the interest and performance of students with low perceptions of competence, while self-generated utility value interventions are beneficial to that same subset of students. However, they found that effects were most powerful for college students with low perceptions of competence when both direct communication and self-generation techniques were used. In other words, students who were told about the value of a technique and also asked to write about how it might apply to their lives reaped the greatest benefit from the intervention. Similarly, Gaspard et al. (2015) successfully implemented an intervention involving both techniques with ninth-grade students, who read quotations from young adults about the usefulness of mathematics and then evaluated the personal relevance of those statements. Including both directly communicated and self-generated utility value statements was more effective at enhancing students' perceptions of usefulness than employing self-generated utility value statements alone.

Additionally, Canning and Harackiewicz (2015) included a manipulation to examine the impact of focusing on utility for everyday activities versus utility for school or career. Through this manipulation, the authors found that directly communicated utility value was effective for participants with low confidence only when examples of utility for everyday activities were provided. They hypothesized that everyday examples are more accessible and less threatening to individuals with low perceived competence in school and that future interventions involving direct communication should tailor information "to the characteristics and needs of the individual" (p. 65).

The current study aims to contribute to such efforts by digging more deeply into the characteristics and needs of middle school learners. While the expectancy-value model highlights that one's own goals and self-schemata are direct influences on an individual's perceived utility value (Eccles \& Wigfield, 2002), little research has explored the ways in which one's goals and values might influence perceptions of usefulness. Thus, in this study, I apply a sociocultural lens to consider one component of students' values and explore the ways in which those values might be related to students' ideas about the usefulness of mathematics. 


\subsubsection{Sociocultural Perspectives in Education}

Applying a sociocultural lens (e.g. Lave \& Wenger, 1991; Rogoff, 2003) to study perceived utility in mathematics necessitates building on the knowledge that social and cultural processes mediate thought and activity. Thus, in order to understand one's learning or thinking in a given moment we must consider the influence of prior experiences and interactions over time. As such, it is important to examine not solely the individual but the individual in interaction with the environment.

In mathematics education research, such approaches have highlighted that children and adolescents develop mathematical understandings through participation in out-of-school activities that often go unnoticed in the classroom (Brenner, 1998; Nasir, 2000; Taylor, 2009). For example, Saxe (1988) illustrated the power of drawing on everyday understandings in his study of Brazilian child candy sellers. He found that the children used complex mathematics to solve problems related to candy selling and explored the degree to which that knowledge might influence their performance on school problem-solving tasks. While sellers and non-sellers performed comparably on certain traditional tasks, Saxe found that sellers were able to apply their candy selling strategies to solve school mathematics problems that were closely linked to the selling practice. In particular, candy sellers outperformed non-sellers on tasks that required them to do arithmetic calculations with bills and to compare two pricing ratios. This finding, as well as the results of other studies such as Taylor and Dobie's $(2013,2016)$ examination of mathematical understandings learned through the practice of tithing (giving $10 \%$ of one's earnings to the church), highlights achievement-related benefits of creating tasks and assessments that draw on and are aligned with students' own experiences and cultural practices.

Additionally, research on funds of knowledge has illustrated that the knowledge developed within families and communities can serve as a rich resource in the classroom (e.g. Moll, Amanti, Neff, \& Gonzalez, 1992). Drawing on funds of knowledge in the school setting has the potential to improve students' participation and interest in mathematics (Civil, 2002, 2007). For example, Civil (2007) analyzed second grade students' experiences participating in a series of lessons in which they created garden enclosures and explored the sizes of their gardens. She found that as students participated in the lessons, they drew on everyday experiences, engaged with challenging mathematics, and exhibited personal interest while working on tasks.

Across this body of work-as well as research on culturally relevant pedagogy (Ladson-Billings, 1995) and teaching mathematics for social justice (Gutstein, 2006) — researchers have highlighted the importance of grounding instruction in students' own daily practices and lived experiences to enact pedagogy that is socially and culturally relevant to students. This practice of building bridges between school mathematics and everyday cultural practices can be especially powerful in working towards achieving equity in mathematics education (Tate, 1994, 1995). In the current study, applying a sociocultural lens means considering the culturally based knowledge and practices that students bring to discussions of utility, focusing especially on students' values, prior experiences, and relationships with others. In this work, 
I examine those themes and then use that knowledge to explore the possibility of drawing on students' values and everyday experiences to improve their perceptions of the usefulness of mathematics.

\subsubsection{Models of the Self}

Given the sociocultural focus of this work, it is important to consider the culturally based knowledge and values that influence the ways in which students view and interact with the world. In particular, I draw on research on cultural models of the self, or views about one's relation to other people and to the world. Research has illustrated that while U.S. middle-class contexts typically promote independent models of the self, or a focus on personal motives and distinctiveness from others, U.S. workingclass contexts typically promote interdependence, or connectedness and the needs of others (Grossmann \& Varnum, 2011; Stephens et al., 2007). One's model of the self can in turn influence a variety of outcomes, including one's academic experiences.

Stephens, Fryberg, and Markus (2012a) and Stephens, Fryberg, Markus, Johnson, and Covarrubias (2012b) examined the relationship between educational context and one's view of the self in a study of students who attend American colleges. The researchers discovered a mismatch between American colleges, which typically promote norms of independence, and students from working-class backgrounds, who most often identified with interdependent norms. The latter group experienced greater difficulty on academic tasks and lower grades in college when the culture of the university was described in terms of independent norms, such as exploring one's own personal interests, expressing one's opinions, participating in independent research, and developing one's own intellectual journey. However, when the university culture was presented as promoting interdependence-characterized by being part of a community, connecting with other students and faculty members, working together, and taking part in collaborative research—students from working-class backgrounds performed equivalently to students from middle-class backgrounds. In other words, students' academic success increased and experience of difficulty decreased when college was framed in a way that aligned with their interdependent values.

Similarly, researchers have highlighted an emphasis on interdependent motives in particular ethnic communities. For example, Gay (2002) notes that "many students of color grow up in cultural environments where the welfare of the group takes precedence over the individual" (p. 110). In particular, familism—or having a strong identification with and loyalty to one's family - is a central value among Latinxs (Esparza \& Sanchez, 2008; Sabogal, Marín, Otero-Sabogal, Marín, \& Perez-Stable, 1987), and Mexican and Mexican-American communities often exhibit strong family values (Valdés, 1996). Given that students in the current study identify primarily as Mexican, Mexican-American, and Chicanx, considering the possible role of students' models of the self in their views about the usefulness of mathematics seems especially important. 
Additionally, applying this lens of models of the self to research on utility value reveals that conceptions of utility in existing research tend to focus on independent goals and usefulness for the individual (e.g. for getting accepted into college or performing a job), rather than interdependent goals. For students who live in communities that promote interdependence over independence, seeing the usefulness of mathematics for achieving interdependent goals might be especially motivating. For example, in Gutstein's (2006) work on social justice mathematics, using mathematics for interdependent purposes - such as to liberate one's community-had the potential to improve students' attitudes towards mathematics and ability to use mathematics to better understand the world. Similarly, Moses' work on the Algebra Project (Moses \& Cobb, 2001; Moses, Kamii, Swap, \& Howard, 1989) connects mathematics literacy with economic access in Black urban and rural communities, highlighting implications of learning algebra for equality and citizenship. By emphasising the social and political implications of being mathematically literate, Moses encouraged students to pursue mathematics as a tool to liberate their communities. In existing research on utility value, while interdependence has not generally been explicitly promoted, Harackiewicz et al. (2016) found that underrepresented minority and first-generation college students emphasized social relationships-and family, in particular-in their essays about the relevance of mathematics for their own lives. This focus aligned with the students' expressed emphasis on helping their families and communities, which was a primary motive for attending college. The current research builds on such work by examining students' values and prior experiences and then considering how we can align discussions and interventions related to the utility of mathematics with those values.

\subsection{Methods}

In this section I describe the methods and forms of analysis that were used to explore the aforementioned questions, drawing on a subset of data collected for a study of perceptions of usefulness in mathematics (Dobie, 2016). I first describe the focal participants and then discuss the three forms of data collection-student surveys, student interviews, and ethnographic classroom observations - that were used in this research. Finally, I highlight the qualitative and quantitative methods that were used to analyze this data. Rather than seeking to make causal claims, this work aims to uncover information about students' values and experiences with mathematics that can inform research and design moving forward. 


\subsubsection{Participants}

Participants in this study were four classes of seventh-grade students ( $n=84$, mean age $=12.7$ years) at Legacy Middle School, ${ }^{2}$ which is located in the suburbs of a large city in the United States. When asked to describe their race or ethnicity using as many identifications as appropriate, students reported the following: $76 \%$ identified as Mexican, Mexican-American, or Chicanx; 18\% identified as Puerto Rican; $18 \%$ identified as White/European-American; and 10\% identified as African American. Of the 83 students who completed a question about gender identification, 47 identified as male, and 36 identified as female. Students were also asked to report the languages they felt most comfortable speaking. Eighty of 83 students selected English, and 32 selected Spanish; only two students listed both English and a language other than Spanish. According to data gathered by the state, approximately $68 \%$ of students in the school come from low-income families.

\subsubsection{Student Surveys}

Student surveys were one form of data collection used to explore students' values and views of usefulness in mathematics. All 84 students completed a survey, which examined conceptions and perceptions of usefulness, attitudes towards mathematics, feelings of competence in mathematics, and personal values. In this paper, findings focus on two survey questions. First, to gain insight into students' values, students were asked about the importance of various reasons for wanting to do well in school, based on the Motives for Attending College scale items used by Stephens et al. (2012a, 2012b). Ten of the twelve scale items from the original scale were used, and one new item was added ("Gain respect from my friends"). The two items selected for removal focused on motives that were not relevant to middle school students. Language was also changed to make items more understandable to and relevant for middle school students.

The second survey question discussed in this paper was created to examine students' values specific to their mathematics learning. In particular, students were asked to use a scale of $1-5$ ( $1=$ Strongly Disagree, $5=$ Strongly Agree $)$ to rate their agreement with the statement, "It is important to me that the math I'm learning..." Six different sentence completers were provided for rating — "is fun," "is useful," "is easy," "challenges me," "relates to my everyday life," and "reflects my culture."

\footnotetext{
${ }^{2}$ Psuedonyms are used to refer to the school and any student or teacher mentioned by name.
} 


\subsubsection{Ethnographic Classroom Observations}

Ethnographic observations of three of the four classes were conducted 1-3 times per week for five months. The classes were selected both to include variation in level/track and to comply with their teacher's observation preferences. One of the classes was labeled an "honors" mathematics class, and the other two were considered "regular" mathematics classes. In total, 60 classroom observations were conducted across the three classes between January and May of 2015 to explore discussions of usefulness, student values, student interactions, and references to everyday experiences with mathematics. Jottings were taken during all class sessions, and fieldnotes were written up after each observation.

\subsubsection{Student Interviews}

Student interviews were also conducted with 12 students across the three observed classes to delve into students' survey responses. Students were selected across the three classes to maximize diversity in achievement level, gender, and attitudes towards mathematics. Each interview lasted between 16 and 34 minutes, with the mean interview length being approximately 26 minutes. Interviews were structured around four main themes: definitions of and attitudes towards mathematics, ideas about the usefulness of mathematics, experiences in mathematics class during the current academic year, and mathematics in one's daily life.

Responses to several questions in particular are drawn upon for analyses. First, one item asked students to elaborate on their survey ratings specifying whether it is important that the mathematics they learn is useful. Additionally, students were asked to report where they currently use mathematics and how they expect mathematics to benefit them - if at all—in the future. Students were also asked to consider where-if anywhere - they might use six specific mathematics topics in the future. Finally, students were asked questions about their current mathematics class, including what topics they found to be useful and not useful and how they would describe their own participation in math class.

\subsubsection{Data Analysis}

In study analyses, triangulation of the three data sources was used to increase the robustness of findings and examine both the breadth and depth of various themes using a combination of quantitative and qualitative analyses. Means and standard deviations of individual items were calculated for survey responses, and paired t-tests were used to examine differences in students' responses. A coding scheme was also developed to analyze observation and interview data. The coding scheme focused 
on student interactions, orientations, and perceptions with particular attention to dimensions that align with themes of interdependence. Coding categories drawn on for the current analyses include conceptions of utility in mathematics (e.g. utility for a job, utility for daily activities), connections between mathematics and students' out-of-school lives (e.g. connections to activities involving money, connections to family), and orientation towards collaboration (e.g. valuing collaboration, opposing collaboration). Two coders applied the coding scheme to several sets of fieldnotes, comparing their coding and then refining the coding scheme as needed throughout. Two new sets of fieldnotes, which constituted approximately $10 \%$ of the data, were then selected for interrater reliability coding, which occurred in two rounds. After each round of coding, Cohen's Kappa was calculated, and a strong level of agreement was achieved in both instances (Cohen's Kappa $=0.76,0.85$ ). Any segments that were coded differently were discussed by the coders, and a single code was agreed upon for each excerpt. Both coders then shared the responsibility of coding the remainder of the data.

\subsection{Findings}

Three main themes will be examined in this section-students' emphasis on learning mathematics that is useful, students' focus on interdependence, and connections between students' interdependent values and ideas about the usefulness of mathematics.

\subsubsection{Emphasis on Usefulness in Mathematics}

Before exploring potential influences on students' ideas about the usefulness of mathematics, we should first examine the importance that students place on usefulness. On a survey question about values in mathematics, students reported finding it very important that they learn mathematics that is useful (see Table 4.1). The statement "It is important to me that the math I'm learning is useful" received the highest mean rating of agreement with the smallest standard deviation $(M=4.35, S D=0.692)$, illustrating that students have a strong desire to learn mathematics they perceive as useful. In fact, only two of the eighty-two students disagreed with the statement, and four were neutral; all other students either agreed or strongly agreed that it is important for the mathematics they learn to be useful.

While we might entertain the fact that students' calls for usefulness are actually expressions of boredom or frustration with the difficulty of mathematics, these results suggest otherwise. Paired samples t-tests were conducted to compare students' ratings of the importance of mathematics being useful to their ratings of the importance of mathematics being fun or easy. There were significant differences in students' ratings of the importance of mathematics being useful and the importance of mathe- 
Table 4.1 Mean student ratings of important features of mathematics ( $1=$ Strongly disagree, $5=$ Strongly agree)

\begin{tabular}{l|l|l}
\hline It is important to me that the math I'm learning... & Mean rating (SD) & $n$ \\
\hline$\ldots$. is useful & $4.35(0.692)$ & 82 \\
\hline$\ldots$ challenges me & $4.10(0.951)$ & 82 \\
\hline ...relates to my everyday life & $3.88(0.992)$ & 81 \\
\hline$\ldots$. is fun & $3.78(0.930)$ & 82 \\
\hline$\ldots$. is easy & $3.01(1.024)$ & 82 \\
\hline ...reflects my culture & $2.94(0.934)$ & 82 \\
\hline
\end{tabular}

matics being fun, $t(81)=5.58, p=0.000$, as well as between ratings of usefulness and easiness, $t(81)=11.019, p=0.000$. Furthermore, the item with the second highest mean was "It is important to me that the math I'm learning challenges me" ( $M$ $=4.10, S D=0.951$ ). Ratings of the importance of challenge were also statistically significantly higher than ratings of the importance of mathematics being easy, $t(81)$ $=6.816, p=0.000$, or fun, $t(81)=2.323, p=0.023$. Thus, it is unlikely that students primarily emphasize usefulness because they find mathematics too challenging or boring.

To explore students' emphasis on usefulness in greater depth, interview participants were asked to explain why they either agreed or strongly agreed that it is important for the mathematics they learn to be useful. Of the twelve interviewees, six expressed that they do not see a purpose in learning mathematics that is not useful when they could instead be learning mathematics that they will use in the future. For example, Rachelle explained that she will be happier in the future if she learns useful mathematics now, rather than being taught concepts that she has no reason to learn: "If I learn math that's not useful, then it will be kind of like pointless to learn it, but if I learn math that is useful, then I can use it and it can be like very helpful for whatever I do and I'll be really glad that I knew it." Omar similarly echoed that he doesn't see a purpose in learning mathematics that is not useful since there are many types of mathematics he believes he needs to use in his life: "Math is in effect our everyday lives... So I feel like... if we don't learn math that is useful... why learn it at all?"

Meanwhile, five students focused on the fact that it is important to them that mathematics is useful specifically because of its applicability to future jobs or careers. While two students mentioned the importance of learning mathematics that will be needed "to get a better job" or for a career broadly speaking, three students mentioned specific careers. For example, Victoria stated that she wants to be an engineer, so learning useful mathematics "will help me do better in my job and like help me get hired."

One student blended together these two types of explanations, stating that it is important to learn mathematics that will be needed in the future and that careers are one place where mathematics might be needed. This student, Carrie, also connected her perceptions of usefulness to her motivation in mathematics: 
If I'm learning things that I'm actually not going to use later on in my life, you know, I'm not going to know the things that I do need to know, for like careers and stuff, but if I learn things that are useful to me, I feel like-I mean, I pay attention in class but it would make me a little bit more you know, I'm going-you need this, so I better pay attention.

In this quote, Carrie not only emphasized the importance of learning things that she will need to know in the future but also explained that learning useful material will increase her focus. Thus, in addition to reporting an emphasis on learning mathematics that is useful, students also offered particular ideas about why learning useful mathematics is beneficial to them.

\subsubsection{Emphasis on Interdependence}

Since one influence on perceptions of usefulness is students' own goals and values, we can explore these goals and values as a means of understanding the factors that affect students' experiences of the usefulness of mathematics. In this section, I examine one value in particular-interdependence. Students' survey and interview responses, as well as classroom comments, highlight a strong focus on interdependence. On the survey, students were asked to rate the importance of different reasons for wanting to do well in school on a scale of $1-5$, where $1=$ Not at all important and $5=$ Extremely important. Students' mean ratings can be viewed in Table 4.2. Of eleven survey items, the three that related to family received the highest mean ratings of importance: "Make my family proud" received the highest rating (4.55/5.00, SD $=0.848)$; "Provide a better life for my own children" received the second highest rating $(4.43 / 5.00, S D=0.926)$; and "Help my family out after I graduate" received the third highest rating $(4.34 / 5.00, S D=0.887)$. These responses demonstrate not only a significant emphasis on interdependent reasons for success but also strong family values in particular.

During classroom observations and student interviews, this theme of interdependence arose, as well-albeit in different forms. While connections to family emerged as significant for some students during interviews, students' value of family infrequently surfaced in classroom observations. Rather, students were observed emphasising the importance of working collaboratively with their peers.

After analysing classroom observation fieldnotes coded for themes of collaboration and independence, a focus emerged on students valuing collaboration over independent work. Across all sets of fieldnotes, students were captured opposing collaboration or requesting independent work on only six occasions. Furthermore, in some of those instances students were not opposing collaboration at large but rather collaboration with particular classmates. In contrast, 16 requests for collaboration were captured, as well as seven comments that expressed opposition to independent work. Requests for collaboration included questions such as "Can we work with our tables?" and "Can we work with partners?" Meanwhile, opposition to independent work occurred when students either commented that they did not want to work independently or questioned why they had to work independently, as in the following 
Table 4.2 Importance of reasons for wanting to do well in school

\begin{tabular}{l|l|l}
\hline Reason for wanting to do well in school & Mean $(S D)$ & $n$ \\
\hline Make my family proud & $4.55(0.848)$ & 82 \\
\hline Provide a better life for my own children & $4.43(0.926)$ & 83 \\
\hline Help my family out after I graduate & $4.34(0.887)$ & 83 \\
\hline Show that people like me can do well & $4.12(0.961)$ & 82 \\
\hline Learn more about my interests & $4.01(1.000)$ & 82 \\
\hline Expand my knowledge of the world & $4.00(1.018)$ & 82 \\
\hline Explore new interests & $3.98(1.012)$ & 83 \\
\hline Expand my understanding of the world & $3.93(1.022)$ & 83 \\
\hline Gain respect from my friends & $3.81(1.076)$ & 83 \\
\hline Give back to my community & $3.66(1.172)$ & 83 \\
\hline Be a role model for people in my community & $3.60(1.249)$ & 83 \\
\hline
\end{tabular}

Note $1=$ Not at all important, $5=$ Extremely important

example: "Upon hearing the noise, Ms. Sanchez comes over and tells them to work independently. 'My god, why we always gotta work independently?' the boy asks." (February 26, 2015)

In addition to students' requests for collaboration and opposition to independent work, on three occasions students were captured stating the importance of collaboration. For example, on January 23, 2015, Carrie was working with her group when some members started to get sidetracked. After about a minute, Carrie loudly and sternly announced to her classmates that they all needed to "focus and pay attention and help each other out... because some of us don't get it." Similarly, on January 27, 2015, a different student was captured telling his tablemates, "We need to work together if we're going to get through this."

Finally, some students commented on the authenticity of different forms of engagement in the mathematics classroom. Related to interacting with others in particular, one student compared the way activity is arranged in the mathematics classroom to the way activity is arranged in everyday life. After Ms. Sanchez asked the class to work independently, the boy highlighted the disconnect between working independently in mathematics class and regularly engaging with others in everyday life: "'Why does everything have to be independent?' a boy sitting near me asks. 'Life is not independent. You have a partner!' A few seconds later he adds more quietly, 'And then you have kids.'” (April 17, 2015) This comment illustrates the boy's view of life not as an independent endeavour but as one that involves connections with other people. He saw a lack of authenticity in the way activity was organized in the mathematics classroom and felt that he was often asked to work independently even though "life is not independent." As this comment came from only one student, I do not attempt to claim that it illustrates a theme across the entire sample of students. Rather, I propose that the comment suggests a possible relationship between students' requests to work collaboratively in the classroom and students' value of 
family and working together in their everyday lives. One potential reason why students might oppose independent work and prefer collaboration is because working independently does not align with the forms of engagement they see and experience in their everyday lives, an idea that will be further considered in the discussion.

\subsubsection{Connections Between Usefulness and Interdependence}

One place where explicit connections emerged between students' emphasis on usefulness and their value of interdependence was during student interviews and observations. In this section, I provide brief case studies of two students, Liliana and Ethan, who discussed ways of using mathematics to achieve interdependent goals.

Liliana is a 13-year-old girl who attends seventh grade at Legacy Middle School and who identifies as Mexican/Mexican-American/Chicana. She considers herself to be "not the best student in math," though she sees herself as "improving." Liliana reported that she views mathematics as a very useful subject and believes that she will use mathematics in the future because of the many examples that her parents and teachers have provided to her.

On two occasions during her interview, Liliana mentioned interdependent uses of mathematics as she discussed ways in which mathematics will benefit her in the future. First, while responding to a question about what things she expects mathematics will help her with, Liliana mentioned her career, purchasing goods, and "even just teaching other people what it is." When asked to elaborate on the latter comment, Liliana clarified that she was thinking in particular about helping her brother with mathematics. Similarly, as Liliana recalled particular mathematics topics from the current year that she found to be useful, she explained that those concepts helped her in several family-related situations: "When we were doing things like when my mom would need, like, help with something-like anything like when we go out, I would immediately know what to do, you know? Um, and helping my cousins or my brother with homework." Again, Liliana focused on the usefulness of mathematics for helping others - and this time not only her brother, but also her mother and her cousins.

During her interview, Liliana also discussed how using mathematics with her family helped her in the mathematics classroom. While discussing her participation in mathematics class, Liliana recalled a period of time during which she felt very competent as a result of prior experiences working with her parents. She first commented, "There was like this one month that I got everything [my teacher] was telling me. So it was really, really exciting." When asked about what she was studying that month, she identified the topic as "commission and markup" and then again emphasized that it was "really, really good." She even added, "I was super, super happy I got it," highlighting the strong positive emotions she experienced as a result of feeling competent. When prompted to talk about why that topic in particular made so much sense to her, she associated her success with her parents: "Just because both of my parents have- they work uh, dealing with money and everything. Um, and 
I've-well, not for my mom, but for my dad who owns a shop, I will help out and I guess that kind of reminded me of that." In this exchange, Liliana identified her experience helping her parents as critical in her success with the commission and markup unit. Furthermore, she expressed repeated positive sentiments regarding her feelings of competence on those topics, which she attributes to the work she did in her father's shop.

Another student, Ethan, also made connections between the mathematics he was learning and interdependent goals/activities. Like Liliana, Ethan is a 13-year-old student in seventh-grade at Legacy Middle School. He identifies as African American and views himself as very competent in mathematics. Ethan believes that mathematics is the most useful subject and expects to encounter problems that involve mathematics in the future.

During his interview, Ethan mentioned several ways in which he expects to use mathematics related to family. First, when discussing where he might use particular mathematics topics, he suggested that adding and multiplying fractions is useful to know "because if, say in the future, I decide to get married and have a family, I know that possibly my children will be using this." As Ethan thought about potential uses of different mathematics topics, he reflected on the fact that some material might be useful to know so that he will have the knowledge to help out his own future children. During another part of the interview, Ethan reflected on how he uses mathematics now. He recalled, "I would use it when I'm getting a snack or something, how to like cut, split it between me and my brother, and my sister." Again, though he was never prompted to think about family, Ethan made his own connections between the usefulness of mathematics and his family.

Finally, like Liliana, Ethan also gained experience from working with his family that helped him in mathematics class. During one classroom observation, Ms. Sanchez introduced her students to the concept of sales tax. (This was part of the same unit Liliana mentioned on commission and markup.) When the teacher asked if anyone knew what sales tax was, Ethan loudly and immediately replied, "I know what this is. I use sales tax when I help sell candy." He then added, "My family owns a candy truck." Following that commentary, Ethan contributed several thoughts related to sales tax, which he learned from selling sweets in his family's candy truck. Thus, in addition to viewing mathematics as useful for helping his own family, Ethan also gained knowledge of important mathematics concepts through participation in outof-school activities with his family.

\subsection{Discussion}

Findings from this research highlight three main themes. First, students emphasized the importance of mathematics being useful. Second, students in this study exhibited strong interdependent values, related to both family and collaboration with others. Third, some students made connections between their interdependent values and the usefulness of mathematics, highlighting ways they could use mathematics to help 
others. Below I discuss each of these themes in turn and then highlight implications of this work, as well as directions for future research.

\subsubsection{Emphasis on Usefulness}

One finding emerging from this work is the importance to students of learning mathematics that is useful. Although we might question whether students' calls for usefulness symbolize some other frustration with or lack of interest in mathematics, two pieces of evidence suggest that is not the case. First, the students on average rated the importance on mathematics being useful as significantly higher than the importance of mathematics being fun or easy. This suggests that students' calls for usefulness are distinct from their desire for enjoyment or simple success. Additionally, the students more strongly agreed that they want mathematics to be challenging than to be easy, again suggesting that they are not simply expressing frustration with the difficulty of mathematics through their calls for usefulness. Furthermore, these students had real reasons for wanting to learn mathematics that they perceived as useful. In particular, they expressed the importance of learning information that they could apply in the future and reported that they expect to need mathematics for their future careers.

\subsubsection{Interdependent Values}

A second finding emerging from this work is that the students in the study exhibited strong interdependent values. The top three reasons students reported for wanting to do well in school all related to family, which is consistent with existing research on familism in Latinx communities (Esparza \& Sanchez, 2008; Sabogal et al., 1987) and helping motives among underrepresented minority college students (Harackiewicz et al., 2016; Stephens et al., 2012a, 2012b). Furthermore, Ms. Sanchez's students regularly requested to collaborate with others in mathematics and tended to oppose independent work, which echoes prior research on interdependent motives in working-class communities (Grossmann \& Varnum, 2011; Stephens et al., 2007) and concern for the group, rather than the individual, among students of color (Gay, 2002). The students' requests for collaboration might be a product of the disconnect that some of them observed between ways of interacting in everyday life and ways of interacting in the mathematics classroom. As one student highlighted, life involves working with others; however, students are often asked to work independently in math class. It might be the case that students will see mathematics as more useful if the ways in which they are asked to participate and interact with others in the classroom more closely align with the ways in which they expect to participate and interact with others in their everyday lives. 


\subsubsection{Connections Between Usefulness and Interdependence}

Third, some students made explicit connections between their interdependent values and ideas about the usefulness of mathematics. For example, Liliana and Ethan identified ways in which they both currently use mathematics to help their families and expect to use mathematics to help their families in the future. While little research has explicitly discussed the potential link between independent or interdependent values and ideas about usefulness (e.g. Harackiewicz et al., 2016), Eccles and Wigfield's (2002) expectancy-value model illustrates the direct relationship between one's own identity — which might include a focus on independent or interdependent values - and perceptions of usefulness. Thus, identifying students' models of the self might be helpful in understanding the judgments they make about the usefulness of mathematics. In contrast to Liliana and Ethan, many students who expressed strong interdependent values did not explicitly make such connections. This absence does not necessarily signal that those connections do not exist. Rather, it might be the case that many students do not see the relationship between mathematics and achieving interdependent goals since independent goals tend to be emphasized in U.S. classrooms. While these independent goals might be connected to larger, interdependent goals, those latter goals are generally not discussed. For example, teachers often tell students about how mathematics will be useful for their future jobs or for doing taxes and budgeting. While earning a living and handling finances are activities that allow one to provide for and contribute to one's family, that connection is typically not discussed. It might be the case that many students do not make such connections on their own, so drawing attention to how mathematics can be useful for providing for one's family, for example, would be especially helpful for students with strong interdependent values.

\subsubsection{Implications and Future Directions}

There are several important implications of this research. First, this work highlights the need to attend to the connection between one's personal values and perceptions of usefulness in both research and practice. For example, among students who express strong interdependent values, connections might be made to underscore the usefulness of content for helping or working with others, rather than solely for independent means. Building on prior research illustrating the effectiveness of interventions that combine directly communicated and self-generated utility value (Canning \& Harackiewicz, 2015; Gaspard et al., 2015), students might be asked to reflect on statements or quotations that highlight the usefulness of mathematics for helping others. This focus on interdependent goals might be especially motivating for students who emphasize the role of family and their desire to provide for their families in the future. Similarly, teachers can also work to increase alignment with students' values in the classroom. For students who emphasize collaboration with others-as the students in this study 
did - teachers might incorporate more collaboration into the classroom. While doing so, teachers might also highlight the usefulness of the practice of collaborating for students who do not see value in collaboration. For example, teachers might discuss with students the importance of collaborating in workplace interactions or when navigating personal relationships. Highlighting such connections might help students to see mathematics as more useful, as they will be able to identify how interactions in math class can have value in out-of-school contexts.

On a similar note, consistent with research on funds of knowledge (Civil, 2007; Moll et al., 1992), this study suggests that students have rich experiences with mathematics in their out-of-school lives that might be valuable to draw on in the classroom. Future research might explore such resources and also tap into students' interdependent values by gathering examples of students using mathematics to help their families. These stories can then be used as the basis for designing problem-solving tasks that are grounded in students' real world experiences and that students are likely to perceive as useful. To further incorporate students' emphasis on interdependence, these tasks might be completed using collaborative participation structures to both mirror forms of interaction that students experience in their everyday lives and allow students to draw on the rich funds of knowledge of their classmates. Additionally, in the classroom, teachers might have students share their views about the usefulness of different mathematics topics with their classmates. Students have valuable stories and thoughts about how they use mathematics now and expect to use mathematics in the future. Thus, having peers share their personal experiences with each other rather than only framing usefulness from the teacher's perspective might be especially effective at enhancing students' perceptions of usefulness.

More broadly, findings from this research highlight the importance of applying a sociocultural lens to study utility value. Examining students' own perspectives is crucial for developing equitable interventions that build on the views of diverse populations of students. Prior survey items and interventions have tended to focus on ways in which mathematics can be used for accomplishing independent goals (e.g. Anderman, Eccles, Yoon, Roeser, Wigfield, \& Blumenfeld, 2001; Durik et al., 2005; Fennema \& Sherman, 1976; George, 2006; Harackiewicz et al., 2012; Hulleman et al., 2010). However, in this study, students reported strong interdependent values and emphasized collaborative modes of learning, which aligns with research on models of the self (Stephens et al., 2007, 2012a, 2012b) and familism in Latinx communities (Esparza \& Sanchez, 2008; Sabogal et al., 1987). Additionally, these perspectives echo work in the area of social justice mathematics that explores ways of using mathematics to work towards liberation and achieve social change (Gutstein, 2006). Despite these connections to interdependent values in other bodies of research, such themes have rarely been explored in utility value research. This study brought together both perspectives by including analytical tools that tapped into students' own perspectives and focusing on the perceptions of usefulness of students whose voices are typically underrepresented in this research. Moving forward, I argue for the importance of carefully considering the theoretical and methodological approaches applied to this work to broaden existing utility value research and identify ways to 
create more equitable learning opportunities for students in mathematics moving forward.

\section{References}

Anderman, E. M., Eccles, J. S., Yoon, K. S., Roeser, R., Wigfield, A., \& Blumenfeld, P. (2001). Learning to value mathematics and reading: Relations to mastery and performance-oriented instructional practices. Contemporary Educational Psychology, 26(1), 76-95.

Atkinson, J. W. (1964). An introduction to motivation. Princeton, NJ: Van Nostrand.

Bong, M. (2001). Role of self-efficacy and task-value in predicting college students' course performance and future enrollment intentions. Contemporary Educational Psychology, 26(4), 553-570.

Brenner, M. E. (1998). Adding cognition to the formula for culturally relevant instruction in mathematics. Anthropology \& Education Quarterly, 29(2), 214-244. https://doi.org/10.1525/aeq.1998. 29.2.214.

Canning, E. A., \& Harackiewicz, J. M. (2015). Teach it, don't preach it: The differential effects of directly-communicated and self-generated utility-value information. Motivation Science, 1(1), $47-71$.

Civil, M. (2002). Everyday mathematics, mathematicians' mathematics, and school mathematics: Can we bring them together? Journal for Research in Mathematics Education. Monograph, 11, 40-62 (Chapter 4).

Civil, M. (2007). Building on community knowledge: An avenue to equity in mathematics education. In: Improving access to mathematics: Diversity and equity in the classroom (pp. 105-117).

Dobie, T. E. (2016). Middle school students' conceptions of the usefulness of mathematics: A sociocultural approach to the study of utility value (Doctoral dissertation). Retrieved from ProQuest Dissertations Publishing, No. 10193449.

Durik, A. M., \& Harackiewicz, J. M. (2007). Different strokes for different folks: How individual interest moderates the effects of situational factors on task interest. Journal of Educational Psychology, 99(3), 597.

Durik, A. M., Shechter, O. G., Noh, M., Rozek, C. S., \& Harackiewicz, J. M. (2014). What if I can't? Success expectancies moderate the effects of utility value information on situational interest and performance. Motivation and Emotion, 39(1), 104-118.

Durik, A. M., Vida, M., \& Eccles, J. S. (2005). Task values and ability beliefs as predictors of high school literacy choices: A developmental analysis. Journal of Educational Psychology, 98(2), 382-393.

Eccles, J. S., \& Wigfield, A. (2002). Motivational beliefs, values, and goals. Annual Review of Psychology, 53(1), 109-132.

Eccles (Parsons), J., Adler, T. F., Futterman, R., Goff, S. B., Kaczala, C. M., Meece, J. L., et al. (1983). Expectancies, values, and academic behaviors. In J. T. Spence (Ed.), Achievement and achievement motivation (pp. 75-146). San Francisco: Freeman.

Esparza, P., \& Sanchez, B. (2008). The role of attitudinal familism in academic outcomes: A study of urban, Latino high school seniors. Cultural Diversity and Ethnic Minority Psychology, 14(3), 193.

Fennema, E., \& Sherman, J. A. (1976). Fennema-Sherman mathematics attitudes scales: Instruments designed to measure attitudes toward the learning of mathematics by females and males. Journal for Research in Mathematics Education, 7(5), 324-326.

Gaspard, H., Dicke, A.-L., Flunger, B., Brisson, B. M., Häfner, I., Nagengast, B., et al. (2015). Fostering adolescents' value beliefs for mathematics with a relevance intervention in the classroom. Developmental Psychology, 51, 1226-1240.

Gay, G. (2002). Preparing for culturally responsive teaching. Journal of Teacher Education, 53(2), $106-116$. 
George, R. (2006). A cross-domain analysis of change in students' attitudes toward science and attitudes about the utility of science. International Journal of Science Education, 28(6), 571-589.

Grossmann, I., \& Varnum, M. E. (2011). Social class, culture, and cognition. Social Psychological and Personality Science, 2(1), 81-89.

Gutstein, E. (2006). Reading and writing the world with mathematics: Toward a pedagogy for social justice. New York, NY: Routledge.

Harackiewicz, J. M., Canning, E. A., Tibbetts, Y., Priniski, S. J., \& Hyde, J. S. (2016). Closing achievement gaps with a utility-value intervention: Disentangling race and social class. Journal of Personality and Social Psychology, 111(5), 745-765.

Harackiewicz, J. M., Durik, A. M., Barron, K. E., Linnenbrink-Garcia, L., \& Tauer, J. M. (2008). The role of achievement goals in the development of interest: Reciprocal relations between achievement goals, interest, and performance. Journal of Educational Psychology, 100(1), 105.

Harackiewicz, J. M., Rozek, C. S., Hulleman, C. S., \& Hyde, J. S. (2012). Helping parents to motivate adolescents in mathematics and science: An experimental test of a utility-value intervention. Psychological Science, 23(8), 899-906.

Hill, B. V. (1991). Values education in Australian schools. Melbourne: The Australian Council for Educational Research.

Hulleman, C. S., Durik, A. M., Schweigert, S. B., \& Harackiewicz, J. M. (2008). Task values, achievement goals, and interest: An integrative analysis. Journal of Educational Psychology, 100(2), 398.

Hulleman, C. S., Godes, O., Hendricks, B. L., \& Harackiewicz, J. M. (2010). Enhancing interest and performance with a utility value intervention. Journal of Educational Psychology, 102(4), 880 .

Hulleman, C. S., \& Harackiewicz, J. M. (2009). Promoting interest and performance in high school science classes. Science, 326(5958), 1410-1412.

Ladson-Billings, G. (1995). Toward a theory of culturally relevant pedagogy. American Educational Research Journal, 32(3), 465.

Lave, J., \& Wenger, E. (1991). Situated learning: Legitimate peripheral participation. Cambridge, UK: Cambridge University Press.

Mac Iver, D. J. (1991). Explaining within-semester changes in student effort in junior high school and senior high school courses. Journal of Educational Psychology, 83(2), 201-211.

Moll, L. C., Amanti, C., Neff, D., \& Gonzalez, N. (1992). Funds of knowledge for teaching: Using a qualitative approach to connect homes and classrooms. Theory into Practice, 31(2), 132-141.

Moses, R. P., \& Cobb, C. E. (2001). Radical equations: Math literacy and civil rights. Boston, MA: Beacon Press.

Moses, R. P., Kamii, M., Swap, S. M., \& Howard, J. (1989). The algebra project: Organizing in the spirit of Ella. Harvard Educational Review, 59(4), 423-444.

Nasir, N. S. (2000). "Points ain't everything": Emergent goals and average and percent understandings in the play of basketball among African American students. Anthropology \& Education Quarterly, 31(3), 283-305.

Rogoff, B. (2003). The cultural nature of human development. New York, NY: Oxford University Press.

Sabogal, F., Marín, G., Otero-Sabogal, R., Marín, B. V., \& Perez-Stable, E. J. (1987). Hispanic familism and acculturation: What changes and what doesn't? Hispanic Journal of Behavioral Sciences, 9(4), 397-412.

Safavian, N., \& Conley, A. (2016). Expectancy-value beliefs of early-adolescent hispanic and nonhispanic youth: Predictors of mathematics achievement and enrollment. AERA Open, 2(4), 1-17.

Saxe, G. B. (1988). Candy selling and math learning. Educational Researcher, 17(6), 14.

Simons, J., Dewitte, S., \& Lens, W. (2004). The role of different types of instrumentality in motivation, study strategies, and performance: Know why you learn, so you'll know what you learn! British Journal of Educational Psychology, 74(3), 343-360.

Stephens, N. M., Fryberg, S. A., \& Markus, H. R. (2012a). It's your choice: How the middle-class model of independence disadvantages working-class Americans. In S. T. Fiske \& H. R. Markus 
(Eds.), Facing social class: How societal rank influences interaction (pp. 87-106). New York, NY: Russell Sage Foundation.

Stephens, N. M., Fryberg, S. A., Markus, H. R., Johnson, C. S., \& Covarrubias, R. (2012b). Unseen disadvantage: How American universities' focus on independence undermines the academic performance of first-generation college students. Journal of Personality and Social Psychology, 102(6), 1178-1197.

Stephens, N. M., Markus, H. R., \& Townsend, S. S. M. (2007). Choice as an act of meaning: The case of social class. Journal of Personality and Social Psychology, 93(5), 814.

Tate, W. F. (1994). Race, retrenchment, and the reform of school mathematics. The Phi Delta Kappan, 75(6), 477-484.

Tate, W. F. (1995). Returning to the root: A culturally relevant approach to mathematics pedagogy. Theory into Practice, 34(3), 166-173.

Taylor, E. (2009). The purchasing practice of low-income students: The relationship to mathematical development. Journal of the Learning Sciences, 18(3), 370-415.

Taylor, E. V., \& Dobie, T. E. (2013, April). Religious engagement and context in mathematical problem-solving. Poster presented at the National Council of Teachers of Mathematics Research Pre-session, Denver, CO.

Taylor, E. \& Dobie, T. E. (2016). A study of context and representation in rational number understanding: Mathematical problem solving in religious practices. Manuscript submitted for publication.

Updegraff, K. A., Eccles, J. S., Barber, B. L., \& O’brien, K. M. (1996). Course enrollment as self-regulatory behavior: Who takes optional high school math courses? Learning and Individual Differences, 8, 239-260.

Valdés, G. (1996). Con respeto: Bridging the distances between culturally diverse families and schools. New York, NY: Teachers College Press.

Wigfield, A., \& Eccles, J. S. (1992). The development of achievement task values: A theoretical analysis. Developmental Review, 12(3), 265-310. 
Open Access This chapter is licensed under the terms of the Creative Commons Attribution 4.0 International License (http://creativecommons.org/licenses/by/4.0/), which permits use, sharing, adaptation, distribution and reproduction in any medium or format, as long as you give appropriate credit to the original author(s) and the source, provide a link to the Creative Commons license and indicate if changes were made.

The images or other third party material in this chapter are included in the chapter's Creative Commons license, unless indicated otherwise in a credit line to the material. If material is not included in the chapter's Creative Commons license and your intended use is not permitted by statutory regulation or exceeds the permitted use, you will need to obtain permission directly from the copyright holder.

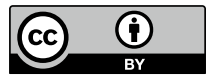




\title{
Chapter 5
}

\section{A Longitudinal Study of Mathematics and Science Motivation Patterns for STEM-Intending High Schoolers in the US}

\section{James A. Middleton, Daniel Mangu and Andrew Lee}

\begin{abstract}
This research explored various motivational factors that influence US high school students' intentions regarding careers in STEM. Data from the High School Longitudinal Study of 2009 surveyed 24,000 students in 9th and 11th grades. Respondents showed four categories of intentions: (1) Not STEM Intending, those who did not select a STEM field as an intended occupation in either the 2009 or 2011 administrations; (2) Leavers, students who selected a STEM occupation in 2009 but not in 2011, (3) Newcomers, those who did not originally specify a STEM career in 2009, but who did in 2011; and (4) Stayers, those who chose STEM careers in both 2009 and 2011. Results show that occupational intentions change dramatically between 9 th and 11th grades, and that the relationship between STEM intention and motivation is highly time-sensitive: Of the STEM intending students in 2009 (29\% of the total sample), only $48 \%$ remained STEM intending in 2011.
\end{abstract}

Keywords Motivation - Career intentions - Secondary data analysis • Longitudinal $\cdot$ STEM

\subsection{Introduction}

For many years, the relationship between students' attitudes and their college and career intentions has been an important area of inquiry in Science, Technology, Engineering and Mathematics (STEM) education. In general, research has found that, since students perceive their earlier STEM experiences as indicative of future

\footnotetext{
J. A. Middleton $(\bowtie)$

Arizona State University, Box 896101, Tempe 85287-6101, AZ, USA

e-mail: jimbo@asu.edu

D. Mangu

Arizona State University, PO Box 82431, Phoenix 85071, AZ, USA

e-mail: dmangu@asu.edu
}

\author{
A. Lee \\ Arizona State University, PO Box 6572, Mesa 85216, AZ, USA \\ e-mail: andrew.ryan.lee@gmail.com \\ (C) The Author(s) 2019


experiences, particularly potential successes and failures in a potential occupational field, these perceptions also color their career intentions and occupational choices (Suárez-Álvarez, Fernández-Alonso, \& Muñiz, 2014).

Students' perceptions of their mathematics experiences in high school and early college, have been shown to be a strong predictor of their occupational intentions; perceptions of bad experiences tend to filter out future mathematically-intensive courses and academic majors that could lead to participation in STEM occupations (VanLeuvan, 2004). In seminal work in this area, Betz and Hackett (1983), for example, examined the impact that mathematics self-efficacy beliefs had on high schoolers' intention to select science majors in college. They surveyed upwards of 250 students and found that, not only are students' expectations for future success in mathematics significantly related to their choice of college major, but that young women and young men differed significantly in their mathematical self-efficacy. Partial causative factors for this disparity include young women's beliefs in the utility of STEM for their future career goals, lack of role models, and young women having more developed communal goals, as opposed to individualistic goals, than young men (Cass, Hazari, Cribbs, Sadler, \& Sonnert, 2011). Following up on this line of reasoning Hackett and Betz (1989) found that college students' mathematics achievement was significantly predicted by mathematics self-efficacy, perceptions of the utility of mathematics, and lower mathematics anxiety. These perceptions significantly predicted their choice of a science-related major versus non-science, accounting for more variation than even mathematics performance measures.

Similarly, Priess-Groben and Hyde (2017) studied US adolescents as they transitioned through high school and then into college. Using surveys, high school records, and interviews during college, they found four variables that significantly impact mathematics course taking in college: Expectancies of success in high school, mathematics self-concept, utility value of mathematics, and high school mathematics achievement. Their Structural Equations Model supports the integration of these variables in predicting intent to study further mathematics. Specifically, they found that mathematics self-concept influenced their expectancies of success, and this in turn influenced the utility value that future mathematics courses had in their collegiate plans.

However, lack of participation, and intent to pursue, STEM careers is not solely a function of poor experiences in mathematics. The STEM fields in general, are perceived by both men and women, but particularly women as not fostering communal goals and interests, instead promoting agentic goals (individualistic, self-promoting) (Diekman, Brown, Johnston, \& Clark, 2010), potentially leading many to pursue careers they feel better match their desire to help and care for others.

More recently, Sadler, Sonnert, Hazari, and Tai (2012), administered a retrospective survey of a representative sample of 6000 students enrolled in 34 two- and four-year colleges in the US. They asked the students questions such as "Which of the following BEST describes what you want(ed) to be" at various stages in their lives (e.g., start of high school, end of high school, start of college). They provided the students a set of 19 career fields and asked them to choose one from the list with which to answer the question. They found that students who desired to go into 
STEM fields at the beginning of high school were 9 times more likely to continue in STEM in college, than students who were not interested at the beginning of high school. They also found large gender differences with only about half of the females surveyed interested at the end of high school, who were interested in STEM careers at the beginning of high school. This and other studies show the importance of the development of STEM interest early on, and the relationship of long-term interest and career aspiration. We interpret such results to mean that the "catch-and-hold" process that is used to describe the transition from situational interest to personal interest (Harackiewicz, Barron, Tauer, Carter, \& Elliot, 2000) also is a useful model for describing the transition from personal interest to career interest.

But interest is only one of several factors interacting in the long-term development of career intentions. As mentioned above, Self-Efficacy beliefs constrain young people's intentions when there is a perceived mismatch between the rigors of higher level mathematics and science, and the learner's own perception of their capabilities. Lent, Lopez, and Bieschke (1991) show us that mathematical Self Efficacy influences students' science career intentions. Additionally, mathematical Self-Efficacy and Interest were found to be highly related. Presumably, we become more interested in subject matter in which we perceive ourselves to be efficacious. Other research has shown that situational interest in subject-matter increases task persistence, and personal, long-term interests is associated with career choice. Thus, a cycle of situational interest increasing task-level persistence, thus improving performance is begun. (Un)Improved performance, then alters self-efficacy beliefs, and these beliefs impact long-term interest in the subject matter and associated career pathways.

Two other factors have been found in the literature to interact significantly with interest and self-efficacy: Utility and Identity. When subject matter is found to be instrumental for the student's personal goals, i.e., is considered useful, the subject matter, or task within which the subject matter has been situated, is perceived as more interesting than tasks that have no instrumental value. This instrumental value can be short term, wherein the knowledge learned in the task helps to solve an immediate problem, or it can be long term, wherein performance on the task may be necessary to obtain a grade or continue in a mathematically intensive course (Husman \& Hilpert, 2007). So, this utility factor can also be seen as interacting with a student's nascent, task-based interest and efficacy beliefs, but also contributing to longer-term goals and aspirations stemming from their growing academic and career identities (Boaler \& Greeno, 2000). This plays into the student's Identity, which interacts strongly with a student's educational and career intentions. Factors relating to identity within at least one domain (mathematics) are highly predictive of pursuit of STEM in general, and engineering in particular (Cass et al., 2011).

Identity is developed over time in a field, but there is evidence that consistency across the high school years is paramount for keeping students engineering intending. Adelman (1998) analyzed the transcripts of persons enrolled in the High School and Beyond longitudinal study (1982-1993) and their subsequent choices of major and occupation. He found that at age $28 / 29$, the people who persisted in engineering displayed a consistent occupational goal, beginning in high school. Forty-one percent of engineers displayed a consistent goal through high school and through 
college, as compared to only $10 \%$ of engineers who changed their career goals often. Because many students move from discipline to discipline in college, the likelihood of a student with engineering intent going into university actually graduating with a degree in engineering is below 50\%. This is especially true for women. Marra et al. (2009) studied nearly 200 undergraduate women to ascertain their efficacy-related beliefs and career intentions. They found that self-efficacy mediated students' career intentions, and that, at least for women, it should be a factor in deciding when to switch majors.

It has been consistently shown that these key variables: Interest, Identity, SelfEfficacy, and Utility each impact the effort adolescents are willing to expend in academic subject matter, and that they interact to significantly predict academic performance in STEM subject matter (Middleton, 2013). In general, a voluminous body of research suggests that interest and perceived utility of the subject matter is a key driver of effort students are willing to expend, and that self-efficacy and identity mediate students' goals for engaging and persisting in STEM (See Middleton, Jansen, $\&$ Goldin, 2017). The purpose of the present study builds on this body of research to ascertain the longitudinal impact of these variables on the career intentions of high schoolers, with particular attention to STEM aspirations. Mathematics and science beliefs are analyzed separately since, though they are related, they also show quite different patterns in students' identity and the role they play in students' career aspirations (Christensen, Knezek, \& Tyler-Wood, 2015).

\subsection{Method}

\subsubsection{HSLS: 09}

The High School Longitudinal Study of 2009 (HSLS:09, NCES, 2011) is a longterm study of 21,000 US 9th graders in 944 schools administered by the United States National Center for Education Statistics. The intent of the study was to paint a picture of students' experiences in high school, focusing specifically on mathematics and science courses. Students' projected career aspirations including whether they planned to take future mathematics and science courses, and their desired majors were a special focus of the study.

The initial administration of the HSLS: 09 began in Fall, 2009, surveying 9th graders on their past experiences in middle school, and on their current attitudes, motivation, and achievement. Students were surveyed again in the Spring of 2011, and a follow up survey was administered again in 2013 following expected graduation. Future data collections are planned to learn about students' experiences and success post-graduation. 


\subsubsection{Study Population}

HSLS: 09 generated a sample of 944 high schools, including public and private schools, that are representative of communities in the US. Following sampling schools, approximately 25 ninth-graders were randomly selected from each school. The resulting sample totaled approximately 24,000 students. The students are representative of all ethnic categories and socioeconomic strata in the US. We only analyzed data at the national level in this report.

\subsubsection{Motivation Scales}

Sixteen items common to the 2009 and 2011 administrations were utilized in the construction of motivation and achievement indices in the present study. Table 5.1 provides the list of items in each scale. HSLS has aggregated some items to create scales for of the variables hypothesized in this report (e.g., Identity). Some variables such as Effort, however, were not constructed by the HSLS authors. For that reason, we developed scales by examining the wording of each of the mathematics related attitude items, and constructing scales whose wording addressed the hypothesized variables best theoretically, eliminating items with low reliability. We used listwise elimination of cases with missing values. This reduced the response rate to 17,602 out of the original 24,000 (around 73\%). The items for each scale are presented in Table 5.1. All items were measured on a (4 point) Likert scale. Unfortunately, the authors of the study did not use parallel items to measure effort in 2009 and 2011. In 2009, effort was operationally defined as a general construct: academic effort, and was not focused on mathematics and/or science coursework. In contrast, the 2011 scale specifically asked students to rate their frequency of effortful behaviors specifically related to mathematics and science classwork (see Table 5.1).

\subsubsection{STEM Intention}

STEM career intentions were measured using standard categories from the US Bureau of Labor Statistics (2010): Computers/Mathematics, Architecture/Engineering, Life and Physical Sciences, and Healthcare Professionals. Participating students were asked to choose from 23 standard occupational categories. Students who chose one of these four categories of occupations as "where they see themselves at age 30" was classified as STEM intending. With measures administered longitudinally at two points in time (2009 and 2011), we classified students into four categories of intentions: (1) Not STEM Intending-those who did not select a STEM occupation in either administration; (2) Leavers, students who selected a STEM occupation in 2009 but not in 2011, (3) Newcomers, those who did not spec- 
Table 5.1 HSLS:09 items chosen to comprise motivational scales

Motivation scale

Prompt

Item

Identity

How much do you agree or disagree with the following statements?

1. You see yourself as a math person

2. Others see you as a math person

\section{Interest}

How much do you agree or disagree with the following statements about your Fall 2009 math course?

1. You are enjoying this class very much

2. You think this class is a waste of your time $(\mathrm{R})$

3. You think this class is boring $(\mathrm{R})$

\section{Utility}

How much do you agree or disagree with the following statements about the usefulness of your Fall 2009 math course? What students learn in this course...

1. is useful for everyday life

2. will be useful for college

3. will be useful for a future career

\section{Self-Efficacy}

How much do you agree or disagree with the following statements about your Fall 2009 math course?

You are confident that you can do an excellent job on tests in this course

You are certain that you can understand the most difficult material presented in the textbook used in this course

You are certain that you can master the skills being taught in this course

You are confident that you can do an excellent job on assignments in this course

\section{Effort (2009)}

How often do you..

1. go to class without your homework done? (R)

2. go to class without pencil or paper? (R)

3. go to class without books? (R)

4. go to class late? $(\mathrm{R})$

\section{Effort (2011)}

How often [do/did] you do these things in [math/science course title]?

1. You [pay/paid] attention to the teacher

2. You [turn/turned] in your assignments and projects on time

3. When an assignment [is/was] very difficult, you [stop/stopped] trying

4. You [do/did] as little work as possible; you just [want/wanted] to get by

(R) indicates reverse scored items 
ify a STEM career in 2009, but who did in 2011; and (4) Stayers, those who chose STEM careers in both 2009 and 2011.

\subsection{Results}

Results show that STEM intentions changed dramatically between 9th and 11th grades. Of the nearly 6800 STEM intending students in 2009 (29\% of the total sample), only roughly 3500 remained STEM intending in 2011 . This is an overall attrition rate of $48 \%$ for the 2009 cohort. The attrition away from STEM occupations was heavy across all occupational categories. Computer/Mathematics professions saw a drop from 350 original students to only 94 (a drop of 73\%). Architecture/Engineering dropped from 1035 to 363, an attrition of 65\%. Physical and Biological Sciences saw the largest attrition, dropping from 1055 to 208, an $80 \%$ rate. Health Professions, the category representing the largest group of STEM intending students in 2009, dropped from 4348 to 2193 (50\%).

While attrition away from STEM occupations was heavy across all occupational categories, there is hope! Overall, students selecting STEM careers as their intended occupation at age 30 increased only by $5 \%$ over the two-year study. Table 5.2 details the behavior of students regarding their career intentions for 2009 and 2011. A significant number of students intending towards a given STEM field in 2009 selected away from a STEM field in 2011. Of those intending to major in computers and mathematics in 2009, only 94 (26.9\%) students were consistent with that choice in 2011. However, some of those who had previously shown no interest in STEM (244 students) selected into computers/mathematics in 2011. There is an increase in students interested in computers/mathematics, architecture/engineering, and health, which bodes well for STEM major selection. Table 5.3 summarizes the transitory behavior of students between years.

\subsubsection{Relationship Between Motivation Variables and STEM Career Intention}

When investigating the relationship between the motivational factors and career intentions, it is important to consider the reverse-coding of some factors as is evident in the mean values of some, as they appear in Table 5.3 with negative signs. Not surprisingly, Stayers tended to maintain a positive view of mathematics (and science) over the two years studied. Leavers initially showed positive ratings in 2009, but then dropped significantly by 2011, while Newcomers initially had negative ratings in 2009, but then increased significantly by 2011) (see Table 5.4). Specifically, nonSTEM intending students dropped in their ratings of Identity and Interest over the two years, while increasing in ratings of Utility and Self-Efficacy. Leavers, as expected, dropped across all motivation variables between 2009 and 2011. Newcomers, as 


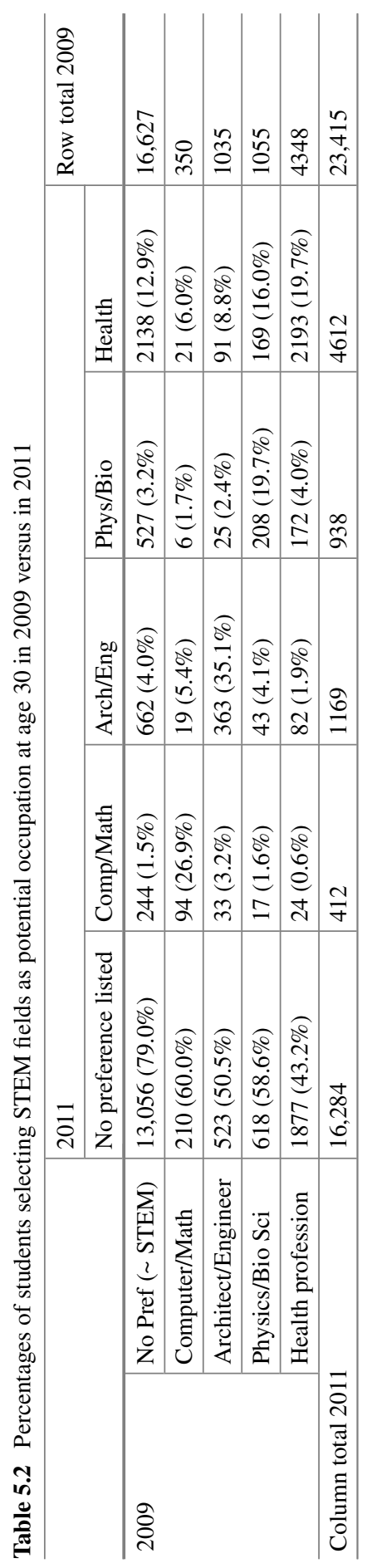


Table 5.3 Student transition behavior between 2009 and 2011

\begin{tabular}{|c|c|c|c|c|c|c|}
\hline & $\begin{array}{l}\text { No } \\
\text { Preference } \\
\text { Listed }\end{array}$ & Comp/Math & Arch/Eng & Phys/Bio & Health & Total \\
\hline $\begin{array}{l}\text { Total } \\
\text { STEM } \\
\text { intending } \\
2009\end{array}$ & & & & & & 6788 \\
\hline $\begin{array}{l}\text { Total } \\
\text { switching } \\
\text { within } \\
\text { STEM } \\
\text { fields }\end{array}$ & & $\begin{array}{l}168 \\
(2.4 \%)\end{array}$ & $\begin{array}{l}507 \\
(7.5 \%)\end{array}$ & $\begin{array}{l}411 \\
(6.1 \%)\end{array}$ & $\begin{array}{l}2474 \\
(36.4 \%)\end{array}$ & 3650 \\
\hline $\begin{array}{l}\text { Total } \\
\text { leaving } \\
\text { STEM } \\
\text { (leavers) }\end{array}$ & & & & & & 3228 \\
\hline $\begin{array}{l}\text { Total } \\
\text { switching } \\
\text { into } \\
\text { STEM } \\
\text { (newcom- } \\
\text { ers) }\end{array}$ & 3571 & & & & & \\
\hline $\begin{array}{l}\text { Total } \\
\text { STEM } \\
\text { intending } \\
2011\end{array}$ & & & & & & 7131 \\
\hline
\end{tabular}

expected increased across all motivation variables between 2009 and 2011. Stayers are a bit more random: They decreased slightly in mathematics identity, but increased slightly in science Identity over the two years, increased in utility in both subject areas, increased in Self-Efficacy and decreased in Interest for both mathematics and science.

Effort, interestingly decreased across all categories of students, and was especially low for non-STEM intending and Leavers. Some of this has to do with differences in mathematics and science attitudes and behaviors, compared with those for general academics, but it is also likely (though not testable with this data) that effort in mathematics and science decreased over the same period, in order to reach such a low negative value.

\subsubsection{Volatility of STEM Career Intentions}

One question that kept arising in examining the data across years was, "why is there so much volatility in students' career intentions over just two years in high 
Table 5.4 Means and standard deviations for motivation factors by STEM Intention

\begin{tabular}{|c|c|c|c|c|}
\hline \multirow{2}{*}{$\begin{array}{l}\text { Motivation factor STEM } \\
\text { intent }\end{array}$} & \multicolumn{2}{|l|}{ Mathematics } & \multicolumn{2}{|l|}{ Science } \\
\hline & $\begin{array}{l}2009 \\
\text { Mean }(\mathrm{S})\end{array}$ & $\begin{array}{l}2011 \\
\text { Mean (S) }\end{array}$ & $\begin{array}{l}2009 \\
\text { Mean (S) }\end{array}$ & $\begin{array}{l}2011 \\
\text { Mean (S) }\end{array}$ \\
\hline \multicolumn{5}{|l|}{ Identity } \\
\hline STEM & $-1.07(2.77)$ & $-1.60(3.26)$ & $-1.14(2.78)$ & $-1.73(3.24)$ \\
\hline Leavers & $0.05(1.35)$ & $-2.05(3.69)$ & $0.18(1.39)$ & $-2.07(3.69)$ \\
\hline Newcomers & $-1.34(3.25)$ & $0.03(1.63)$ & $-1.38(3.22)$ & $0.10(1.67)$ \\
\hline Stayers & $0.30(1.22)$ & $0.22(1.51)$ & $0.0 .38(1.35)$ & $0.43(1.58)$ \\
\hline \multicolumn{5}{|l|}{ Utility } \\
\hline$\sim$ STEM & $-1.86(3.33)$ & $-1.63(3.27)$ & $-2.38(3.49)$ & $-1.64(3.27)$ \\
\hline Leavers & $-0.65(2.43)$ & $-2.12(3.66)$ & $-0.96(2.88)$ & $-2.12(3.66)$ \\
\hline Newcomers & $-1.98(3.49)$ & $-0.05(1.67)$ & $-2.46(3.65)$ & $-0.05(1.67)$ \\
\hline Stayers & $-0.51(2.39)$ & $0.06(1.60)$ & $-0.76(2.88)$ & $0.07(1.67)$ \\
\hline \multicolumn{5}{|l|}{ Self-efficacy } \\
\hline$\sim$ STEM & $-1.89(3.37)$ & $-1.67(3.36)$ & $-2.34(3.54)$ & $-1.79(3.42)$ \\
\hline Leavers & $-0.67(2.46)$ & $-2.14(3.70)$ & $-1.06(2.46)$ & $-2.25(3.76)$ \\
\hline Newcomers & $-1.99(3.59)$ & $-0.14(1.93)$ & $-2.42(3.70)$ & $-0.15(1.97)$ \\
\hline Stayers & $-0.40(2.39)$ & $0.03(1.73)$ & $-0.81(2.84)$ & $-0.02(1.94)$ \\
\hline \multicolumn{5}{|l|}{ Interest } \\
\hline STEM & $-2.02(3.47)$ & $-2.63(3.72)$ & $-2.50(3.61)$ & $-3.24(3.79)$ \\
\hline Leavers & $-0.77(2.67)$ & $-2.83(3.88)$ & $-1.13(3.01)$ & $-3.27(3.91)$ \\
\hline Newcomers & $-2.11(3.65)$ & $-1.07(3.00)$ & $-2.54(3.74)$ & $-1.53(3.33)$ \\
\hline Stayers & $-0.53(2.60)$ & $-0.85(2.91)$ & $-0.93(2.99)$ & $-0.98(3.10)$ \\
\hline \multicolumn{5}{|l|}{ Effort $^{\mathrm{a}}$} \\
\hline$\sim$ STEM & $2.02(0.69)$ & $-2.53(3.67)$ & - & $-3.14(3.79)$ \\
\hline Leavers & $1.98(0.66)$ & $-2.72(3.86)$ & - & $-3.19(3.91)$ \\
\hline Newcomers & $1.95(0.66)$ & $-0.97(2.87)$ & - & $-1.48(3.24)$ \\
\hline Stayers & $1.79(0.62)$ & $-0.74(2.80)$ & - & $-0.96(2.99)$ \\
\hline
\end{tabular}

All $p<0.01$

${ }^{\text {a}}$ Effort (2009) reported here is general academic effort, not subject specific

school?" Patterns in the motivation data across categories of STEM intention show that there are significant differences in motivations corresponding to changes in students' career intentions, but the reasons behind those correspondences is unclear. As an ad hoc analysis, we decided to examine if there might be any underlying relationships between motivation variables that could point to particular changes (e.g., lowering of self-efficacy, or increase in interest) that could explain the movement of students from STEM intending to Non-Intending or vice versa. 
Table 5.5 Principal components scores for motivation variables by year

\begin{tabular}{l|l|l}
\hline \multirow{2}{*}{ Variable } & \multicolumn{2}{l}{ Component } \\
\cline { 2 - 3 } & \multicolumn{2}{l}{2} \\
\hline 2009 & \multicolumn{2}{l}{} \\
\hline Math identity & 0.190 & $\mathbf{0 . 7 5 3}$ \\
\hline Math utility & 0.221 & $\mathbf{0 . 8 0 9}$ \\
\hline Math self-efficacy & 0.252 & $\mathbf{0 . 8 0 6}$ \\
\hline Math interest & 0.247 & $\mathbf{0 . 7 9 4}$ \\
\hline Science identity & 0.177 & $\mathbf{0 . 7 5 2}$ \\
\hline Science utility & 0.238 & $\mathbf{0 . 7 9 8}$ \\
\hline Science self-efficacy & 0.252 & $\mathbf{0 . 7 9 5}$ \\
\hline Science interest & 0.253 & $\mathbf{0 . 7 8 7}$ \\
\hline 2011 & & \\
\hline Math effort & $\mathbf{0 . 7 7 3}$ & -0.120 \\
\hline Science effort & $\mathbf{0 . 7 3 9}$ & -0.080 \\
\hline Math identity & $\mathbf{0 . 8 7 7}$ & -0.220 \\
\hline Math utility & $\mathbf{0 . 8 5 6}$ & -0.230 \\
\hline Math self-efficacy & $\mathbf{0 . 8 4 8}$ & -0.207 \\
\hline Math interest & $\mathbf{0 . 7 7 6}$ & -0.118 \\
\hline Science identity & $\mathbf{0 . 8 6 4}$ & -0.218 \\
\hline Science utility & $\mathbf{0 . 8 5 2}$ & -0.249 \\
\hline Science self-efficacy & $\mathbf{0 . 8 3 4}$ & -0.206 \\
\hline Science interest & $\mathbf{0 . 7 4 3}$ & -0.084 \\
\hline & &
\end{tabular}

To examine these relationships, we performed Principle Components Analysis (PCA) on each of the mathematics and science-related scale scores for each respondent. This analysis extracted two significant components accounting for close to $65 \%$ of the total variation in the data. When the scale scores of all the motivational variables in the dataset are correlated with these two "true" principle components, we see that they fall out clearly by year. The Principle Component scores presented in Table 5.5 show that students' motivations in 2009 are closely related to each other, but these 2009 motivations are only weakly associated with the same variables in 2011. What does this mean? Essentially, it may suggest that students' motivations are highly located in the moment. Their experiences in mathematics and science in one year may not be related strongly to their experiences in another year, and their motivations, being tied to the experiences at hand, seem to be highly unstable. Indeed, when Pearson correlations are computed for these variables across years, none of the 2009 scale scores correlates strongly with any of the 2011 scores (no correlations showed a magnitude greater than 0.20). See Table 5.6. 


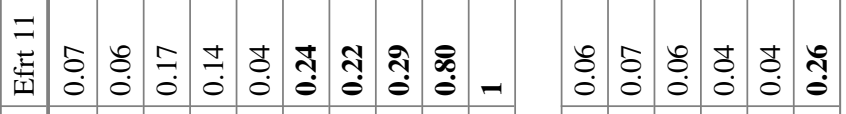

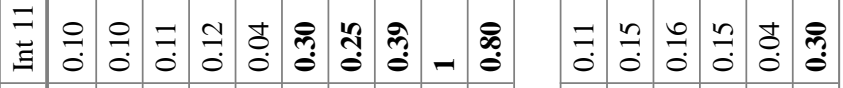

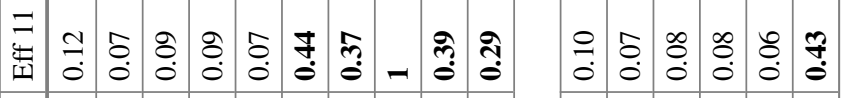

J

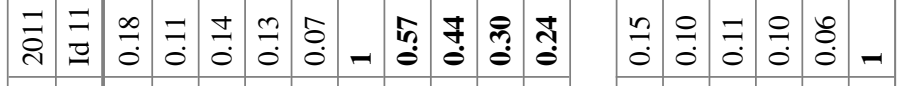

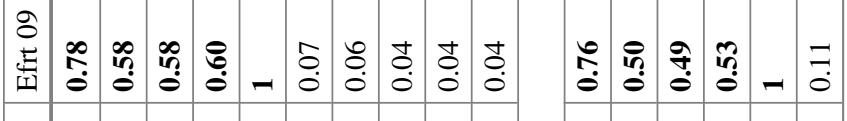

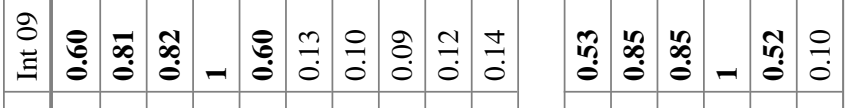

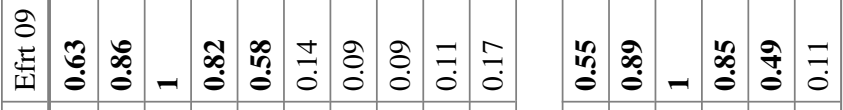

可

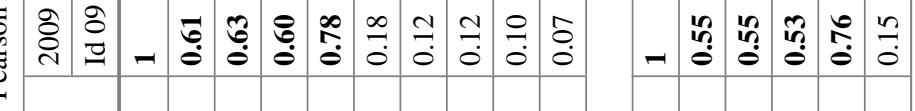

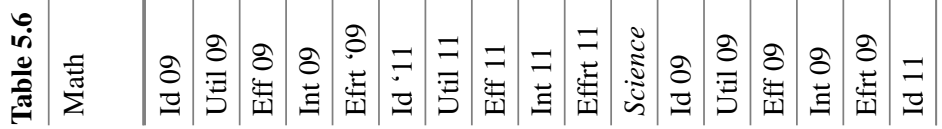




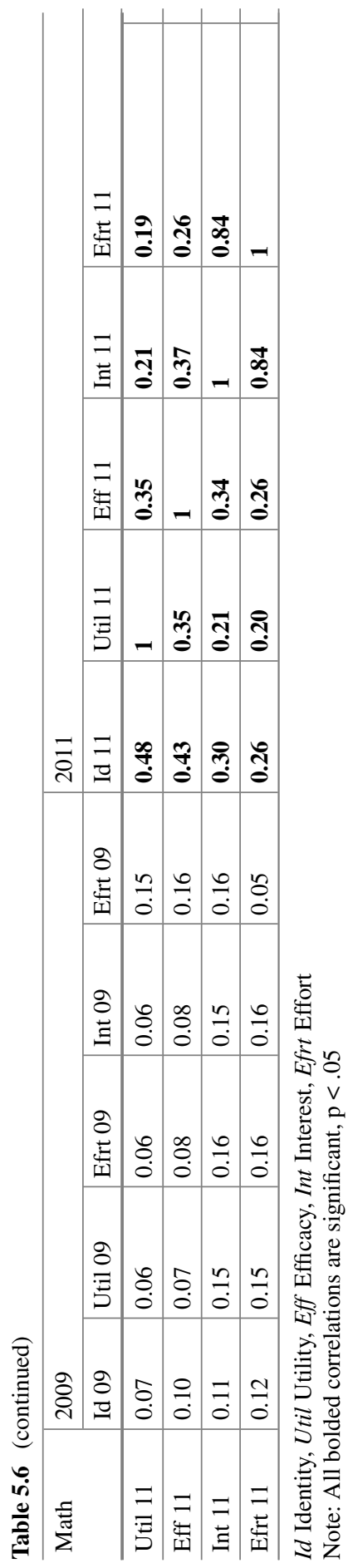




\subsection{Discussion}

Results show clearly that US high schoolers typically change their career intentions between grade 9 and 11. This two-year period is one of high volatility, with people originally STEM intending no longer remaining interested, while others not originally STEM intending beginning to see STEM as a potential future pathway. Motivationally, the interest, identity, and beliefs about utility and efficacy of these Leavers and Newcomers reflect their changing views towards mathematics and science subject matter. Leavers tended to grow more disillusioned with STEM, while Newcomers tended to grow more enamored. These two years are critical for STEM student cultivation, and special attention should be taken in the development of curriculum for them such that STEM fields remain an attractive career option to reduce attrition and potentially increase the number of students that gravitate towards them.

Our results are consistent with those of Sadler et al. (2012), who also found that STEM career intention is highly volatile over the high school years. Like us, they found that "By far the most dominant factor influencing engineering or science career interest at the end of high school is student interest at the start of high school" (p. 422), although we also found Utility to be a strong predictor, and the others to be significant predictors of STEM intention. Their data, however, is retrospective survey data of college-level students, and their recollections of their early high school attitudes and interests may be colored by their more recent experiences. Nevertheless, together these studies show that volatility is the norm, and that loss of students' interest in STEM during this period is a serious roadblock for students' continued STEM career pathways.

The role of mathematics motivations specifically is more muddled. Wang (2013) showed that intent to major in STEM is strongly related to exposure to (more advanced) mathematics and science courses, and math self-efficacy beliefs. In our own study, the relatively disconnected motivations between students' first year and their 3rd year of high school, and the disconnect between subjects would indicate that students' college major and career intentions are changing during this period, and that potential career pathways are becoming more solidified by the end of their 3rd year. This makes sense, as students in the United States often have options for more advanced, "College-Preparatory" courses such as Advanced Placement Calculus and Physics in their 3rd and 4th year of high schools, and if interest, effort, utility beliefs and self-efficacy plummet in this period, it is likely that academic performance and the ability to enroll in such courses is likewise curtailed, limiting students' options for future careers.

In practical terms, we speculate that students' experiences in mathematics and science coursework greatly determine their motivations towards that subject matter, and subsequently towards the amount of effort they are willing to expend, and ultimately the extent to which a career in a STEM field might be considered a possibility. It is likely that Leavers who had initially positive STEM experiences in the elementary and middle grades may have confronted difficulties in early high school that convinced them to be less enamored with STEM and potential STEM-related 
careers. Likewise, Newcomers may have encountered excellent teachers, or mentors in extracurricular activities, and changed their beliefs for the better. There may have been opportunities for some students to take courses that had a strong effect on their beliefs and intentions. Physics has a particularly strong effect on students' intentions to major in a STEM field, as Bottia et al. (2015) uncovered in their research, as students' experiences in physics class tend to influence a student's opinion of STEM as a whole. Or there may be an issue of how the curriculum is written, explained in textbooks, or the methods by which it is taught. There is even the possibility that the reasons behind them are entirely social in nature, given the stereotype of the high school years as an important and influential time for a student's life. More research must be done in this vein to determine if the factors behind the interest change are more easily controllable through education.

Moreover, the fact that there is a general decrease in Interest, Identity, Self-Efficacy and Utility for Leavers, and a general increase across these variables for Newcomers indicates that whatever experiences students may have had in between the time in which they enrolled in High School, and the beginning of their third year, these experiences are interpreted, motivationally, through these variables. Middleton (2013) shows that these variables are highly interconnected in predicting mathematics performance in high school, and that Utility in particular plays an important role in connecting Interests and Achievement, while Self-Efficacy is critically implicated in predicting Identity. As Wang (2013) found in her research, Self-Efficacy produces strong effects on STEM interests and STEM choice, Math Self-Efficacy especially. Examining the results of her study and this one, one can follow the connection between Math Self-Efficacy and STEM intention through Math Identity. In short, relatively short-term motivations appear to greatly impact career aspirations. An effort should be made to make STEM curricula continuously attractive in new ways throughout a student's high school education, given the volatility of STEM career intentions. It is as-of-yet unclear how robust students' career aspirations remain following the first couple of years of high school, but given the ease with which students shift from one category to another, one should consider it to be far less robust than is desirable. As the HSLS study continues through transcript studies and follow-up after students graduate high school, we will be able to augment these analyses with (hopefully) some predictive models of career transition.

The fact that Leavers, Newcomers, and Stayers made up equal proportions of students in the nationally representative sample means that there was only small increase in overall STEM intending numbers between 2009 and 2011. Instead of growing stability, these developmental years show tremendous volatility in career choices, and the extent to which mathematics and science experiences in those years influence this volatility is a hypothesized mediating variable. More research must be done to establish key factors in curriculum and instruction, as well as social norms and expectations of family and community, to paint a fuller picture of why many students choose to continue with rigorous STEM coursework and why most do not (see Froiland \& Davison, 2016). Given the importance of consistent STEM intent for predicting actual STEM occupations after college, it is highly likely that little net increase in the STEM workforce is upcoming in the near future in the US. 


\section{References}

Adelman, C. (1998). Women and men of the engineering path: A model for analyses of undergraduate careers. US Government Printing Office, Superintendent of Documents, Mail Stop: SSOP, Washington, D.C., 20402-9328.

Boaler, J., \& Greeno, J. G. (2000). Identity, agency, and knowing in mathematics worlds. In J. Boaler (Ed.), Multiple perspectives on mathematics teaching and learning (Vol. 1, pp. 171-200). Westport, CT: Greenwood.

Betz, N. E., \& Hackett, G. (1983). The relationship of mathematics self-efficacy expectations to the selection of science-based college majors. Journal of Vocational behavior, 23(3), 329-345.

Bottia, M. C., Stearns, E., Mickelson, R. A., Moller, S., \& Parker, A. D. (2015). The relationships among high school STEM learning experiences and students' intent to declare and declaration of a STEM major in college. Teachers College Record, 117(3), 1-46.

Cass, C. A., Hazari, Z., Cribbs, J., Sadler, P. M., \& Sonnert, G. (2011, October). Examining the impact of mathematics identity on the choice of engineering careers for male and female students. In Frontiers in Education Conference (FIE) (pp. F2H-1). IEEE.

Christensen, R., Knezek, G., \& Tyler-Wood, T. (2015). A retrospective analysis of stem career interest among mathematics and science academy students. International Journal of Learning, Teaching and Educational Research, 10(1). Available Online: http://www.ijlter.org/index.php/ ijlter/article/view/226.

Diekman, A. B., Brown, E. R., Johnston, A. M., \& Clark, E. K. (2010). Seeking congruity between goals and roles: A new look at why women opt out of science, technology, engineering, and mathematics careers. Psychological Science, 21(8), 1051-1057.

Froiland, J. M., \& Davison, M. L. (2016). The longitudinal influences of peers, parents, motivation, and mathematics course-taking on high school math achievement. Learning and Individual Differences, 50, 252-259.

Hackett, G., \& Betz, N. E. (1989). An exploration of the mathematics self-efficacy/mathematics performance correspondence. Journal for Research in Mathematics Education, 20(3), 261-273.

Harackiewicz, J. M., Barron, K. E., Tauer, J. M., Carter, S. M., \& Elliot, A. J. (2000). Short-term and long-term consequences of achievement goals: Predicting interest and performance over time. Journal of Educational Psychology, 92(2), 316.

Husman, J., \& Hilpert, J. (2007). The intersection of students' perceptions of instrumentality, selfefficacy, and goal orientations in an online mathematics course. Zeitschrift für Pädagogische Psychologie, 21(3/4), 229-239.

Lent, R. W., Lopez, F. G., \& Bieschke, K. J. (1991). Mathematics self-efficacy: Sources and relation to science-based career choice. Journal of Counseling Psychology, 38(4), 424.

Marra, R. M., Rodgers, K. A., Shen, D., \& Bogue, B. (2009). Women engineering students and self-efficacy: A multi-year, multi-institution study of women engineering student self-efficacy. Journal of Engineering Education, 98(1), 27-38.

Middleton, J. A. (2013). More than motivation: The combined effects of critical motivational variables on middle school mathematics achievement. Middle Grades Research Journal, 8(1), 77-95.

Middleton, J. A., Jansen, A., \& Goldin, G. A. (2017). The complexities of mathematical engagement: Motivation, affect, and social interactions. In J. Cai (Ed.), Compendium for research in mathematics education (pp. 87-119). Reston, VA: National Council of Teachers of Mathematics.

National Center for Education Statistics. (2011). High school longitudinal study of 2009 (HSLS:09). Base year data file documentation. Washington, D.C.: NCES. Available Online: http://nces.ed. gov/surveys/hsls09/pdf/2011328_1.pdf.

Priess-Groben, H. A., \& Hyde, J. S. (2017). Implicit theories, expectancies, and values predict mathematics motivation and behavior across high school and college. Journal of Youth and Adolescence, 1-15.

Sadler, P. M., Sonnert, G., Hazari, Z., \& Tai, R. (2012). Stability and volatility of STEM career interest in high school: A gender study. Science Education, 96(3), 411-427. 
Suárez-Álvarez, J., Fernández-Alonso, R., \& Muñiz, J. (2014). Self-concept, motivation, expectations, and socioeconomic level as predictors of academic performance in mathematics. Learning and Individual Differences, 30, 118-123.

US Bureau of Labor Statistics. (2010). 2010 SOC user guide. Washington, D.C.: US Bureau of Labor Statistics.

VanLeuvan, P. (2004). Young women's science/mathematics career goals from seventh grade to high school graduation. The Journal of Educational Research, 97(5), 248-268.

Wang, X. (2013). Why students choose STEM majors: Motivation, high school learning, and postsecondary context of support. American Educational Research Journal, 50(5), 1081-1121.

Open Access This chapter is licensed under the terms of the Creative Commons Attribution 4.0 International License (http://creativecommons.org/licenses/by/4.0/), which permits use, sharing, adaptation, distribution and reproduction in any medium or format, as long as you give appropriate credit to the original author(s) and the source, provide a link to the Creative Commons license and indicate if changes were made.

The images or other third party material in this chapter are included in the chapter's Creative Commons license, unless indicated otherwise in a credit line to the material. If material is not included in the chapter's Creative Commons license and your intended use is not permitted by statutory regulation or exceeds the permitted use, you will need to obtain permission directly from the copyright holder. 


\title{
Chapter 6 \\ Perceived Social Support Network \\ and Achievement: Mediation \\ by Motivational Beliefs and Moderation \\ by Gender
}

\section{Emmanuel Adu-tutu Bofah and Markku S. Hannula}

\begin{abstract}
Research has shown that perceived social support (PSS) (from parents and teachers) influences achievement. However, little is known about how this relationship operates. This study examines the multiple mediational effects of students' motivational beliefs in relationship to the association between PSS and mathematics achievement. The sample included the African countries that participated in the TIMSS 2011 (Ghana, Botswana, South Africa, Morocco, and Tunisia). A bootstrap analysis indicated a unique pattern of the role of motivational beliefs in mediating the relationships between PSS and achievement. Moreover, gender was found to moderate the indirect effect in some countries. The findings indicate that total mediation effect of students' motivational belief on the relationship between PSS and achievement is "culture-fair but not culture-free".
\end{abstract}

Keywords Social support $\cdot$ Motivational beliefs $\cdot$ Gender $\cdot$ Multiple mediation • Moderated mediation $\cdot$ Mathematics achievement

\subsection{Introduction and Background}

African countries face an endemic problem such as low achievement in mathematics, mathematics-related motivational beliefs and enrolment in mathematics related programs (Gerdes, 1998). An emerging consensus exists in mathematics education literature about what contributes to students' academic success. Research has indicated that achievement in mathematics is a function of many interrelated variables such as socioeconomic, social support (from peers, parent, and teachers), and motivational

E. A. Bofah $(\varangle) \cdot$ M. S. Hannula

University of Helsinki, Helsinki, Finland

e-mail: emmanuel.bofah@hotmail.com; ebofah72@gmail.com

M. S. Hannula

e-mail: markku.hannula@helsinki.fi

M. S. Hannula

Volda University College, Joplassvegen 11, 6103 Volda, Norway

(C) The Author(s) 2019

M. S. Hannula et al. (eds.), Affect and Mathematics Education,

ICME-13 Monographs, https://doi.org/10.1007/978-3-030-13761-8_6 
beliefs. Conditions such as perceived social support (from parent, teachers and peers) and motivational beliefs have been known and discussed extensively and proven empirically (Ahmed, Minnaert, van der Werf, \& Kuyper, 2010; Eccles[Parsons] et al., 1983; Mutodi \& Ngirande, 2014).

Understanding the role of motivation and social support on achievement in mathematics has attracted serious attention in recent years. However, extant literature suggest that the presence of social support (or lack thereof) may lead to positive or negative affective disposition, which in turn influences achievement (Ahmed et al., 2010; Bofah \& Hannula, 2015; Eccles[Parsons] et al., 1983; Eccles, 2007; Roeser, Eccles, \& Sameroff, 2000; Rosenfeld, Richman, \& Bowen, 2000).

The concept of motivation stands at the center of achievement. Theories of motivations such as the Expectancy-value theory (EVT) have treated motivation as a concept that varies in amount whereas others theories such as the self-determination theory place emphasis on the type of motivation rather than the amount (Ryan \& Deci, 2000). Ryan and Deci (2000) have theorized motivation to include extrinsic and intrinsic motivation and indicated that motivation is influenced by the "response to what the social environment affords" (Ryan \& Deci, 2009, p. 175).

In the EVT model (Eccles[Parsons] et al., 1983), motivational beliefs such as intrinsic value and utility value or value beliefs have been discussed as predictors of performance and choice.

Intrinsic value is the enjoyment someone achieve from doing a given task; the task is an end to itself - the task must be intrinsically rewarding, and this notion have been discussed to be similar to the concept of intrinsic motivation by Ryan and Deci (2009). Moreover, Intrinsic value has been linked to the construct of individual interest, enjoyment and liking (Gaspard et al., 2015, p. 664), hence the term like to be synonymous to intrinsic motivation in the present study.

Value beliefs captures more "extrinsic" or the usefulness of engaging in a certain task for short- and long-term goals (Gaspard et al., 2015, p. 664). As Gaspard et al. (2015) indicate: "the task is a means to an end rather than an end in itself" (p. 664). In other words, value beliefs or usefulness refers to how a task fits into an individual's future plans, for instance, taking a mathematics class to fulfill a requirement for a science degree (Wigfield \& Cambria, 2010). Value beliefs, is thus instrumental in nature and tied to extrinsic motivation (see Ryan \& Deci, 2000, 2009 for further discussion).

Several arguments have been discussed in the literature concerning motivational belief and achievement. One argument is that the complex relationship between motivational belief and achievement could be best understood under wider social and psychological settings in which it operates (Bronfenbrenner, 1979; Eccles[Parsons] et al., 1983). Perception of social support that adolescents receive from significant others have been known to facilitate adaptive behaviors in most academic domains (Cutrona, Cole, Colangelo, Assouline, \& Russell 1994). Parents, teachers, and peers are major sources of support during adolescence. Most often, studies assess perceived social support from these social network agents using a single construct (cf. Ahmed et al., 2010; Wentzel, 1998) without distinguishing each support unit. However, each support source may influence motivation and achievement differently depending on 
the measurement model. Moreover, the psychological mechanism through which social support (from teachers, parents and peers) influence academic achievement may be different for each different source. For instance, Wentzel (1998) showed that academic motivation such as interest and achievement goal mediates the relationship between social support and academic performance (composite final grades in English, science, social studies, and mathematics). Ahmed et al. (2010) found that motivational measures like competence, importance, enjoyment (including interest), and anxiety significantly mediate the associations between social support (from teachers, parents, and peer) and achievement.

However, most of these studies primarily was conducted with Western educational sample and settings. Moreover, the relationship between motivation and achievement might be moderated by culture values (Meece, Glienke, \& Burg, 2006; Rosenfeld et al., 2000). Evidence indicates that students with higher extrinsic motivation show lower academic achievement in some countries (Marsh et al., 2013), but not in others (Bofah \& Hannula, 2015; Chiu \& Chow, 2010). Our present sample, which is a national representation of five African countries, will help incorporate cross-cultural perspectives into the previous research, thus will help test the generalizability of the previous findings. This can help challenge the foundations of current theories and provide ways to improve upon it.

Gender differences in motivational beliefs and mathematics achievement have received a lot of attention in the literature on mathematics education. Many social and cultural barriers influence gendered motivational beliefs and achievement. These barriers vary across and within countries, but generally the influences on girls are significant (Chaman, Beswick, \& Callingham, 2014). Studies have argued that gender differences in motivational beliefs and mathematics achievement are culture-specific (Forgasz, Leder, Mittelberg, Tan, \& Murimo, 2015; Hyde \& Mertz, 2009). Other studies have indicated that, mathematics-achievement gap "is due, in a large part, to sociocultural and other environmental factors" (Hyde \& Mertz, 2009), and “... the fact that girls' progress in mathematics has been improving over time, even though boys still perform better, suggests that mathematics ability is not innate but susceptible to social influences and instruction" (Stromquist, 2007, p. 37). Studies have shown that in some countries (e.g., gender-equal cultures) girls have reached parity with boys in mathematics performance (Hyde, Fennema, \& Lamon, 1990; Hyde, Lindberg, Linn, Ellis, \& Williams, 2008; Hyde \& Mertz, 2009), a pattern that is not found in some other nations (Bofah \& Hannula, 2015).

Research on gender differences in motivational beliefs (like and values of mathematics) have yielded inconsistent outcomes. Some reported higher values for boys in Germany (Gaspard et al., 2015; Marsh, Trautwein, Lüdtke, Köller, \& Baumert, 2005), whereas other studies reported no differences in the United States (Eccles, Wigfield, Harold, \& Blumenfeld, 1993; Jacobs et al., 2002; Wigfield et al., 1997). In general, “... girls perceive mathematics as a subject of importance in the school context but also perceive it as personally unimportant and unrelated to their future plans" (Gaspard et al., 2015, p. 672). With like mathematics, males have been found to report higher liking for mathematics in Germany as well as Australia (Frenzel, Pekrun, \& Goetz, 2007; Gaspard et al., 2015; Watt, 2004; Watt et al., 2012). In Australia, 
Thomson, Hillman, and Wernert (2012) reported evidence from the 2011 Trends in International Mathematics and Science Study (TIMSS 2011) that boys were more likely than their female peers to like mathematics, and value it. They further noted a positive relationship between these measures and mathematics performance on the TIMSS assessment.

Modern expectancy-value theory (EVT; Eccles[Parsons] et al., 1983) is a useful framework for conceptualizing the relationship between achievement, motivational beliefs and gender. The theory proved to be highly effective in explaining gender differences in achievement. EVT indicates that motivational beliefs are important factors in explaining gender differences in academic choices (Eccles, 2009).

The present study expands the present literature and examines the unconditional or mediational role of students' motivational belief measures such as the "like mathematics", and the value of mathematics on the relationship between perceived social support network (PSS: from parents and teachers) and achievement in an African context. Specifically, we tested the cultural specificity associated with the mechanism through which perceived social support from parents and teachers influence achievement jointly by students' motivational belief measures (e.g., Like and value mathematics). The study also examines whether students' gender moderates the indirect effect of PSS on achievement through their motivational beliefs. To date, no study has examine the moderated mediation of gender in the relationship between PSS and achievement via motivational belief using TIMSS in the African context. The hypothesized multiple mediation or unconditional model (panel A; statistical form in panel B) and the moderated mediation or conditional model (panel C; statistical form in panel D) is presented in Fig. 6.1. The study used multiple mediators because a single motivational measure cannot explain the complex interplay between social support network and achievement (Preacher \& Hayes, 2008).

\subsection{Method}

\subsubsection{Study Design and Analysis}

The present study is based on the TIMSS 2011 across the five participating African countries (Ghana, Botswana, South Africa, Morocco and Tunisia) (see Table 6.1). The study used the Mplus version 7.4, involving latent variable models together with Mplus complex survey design option to control for the clustered design and adjusted standard errors. 

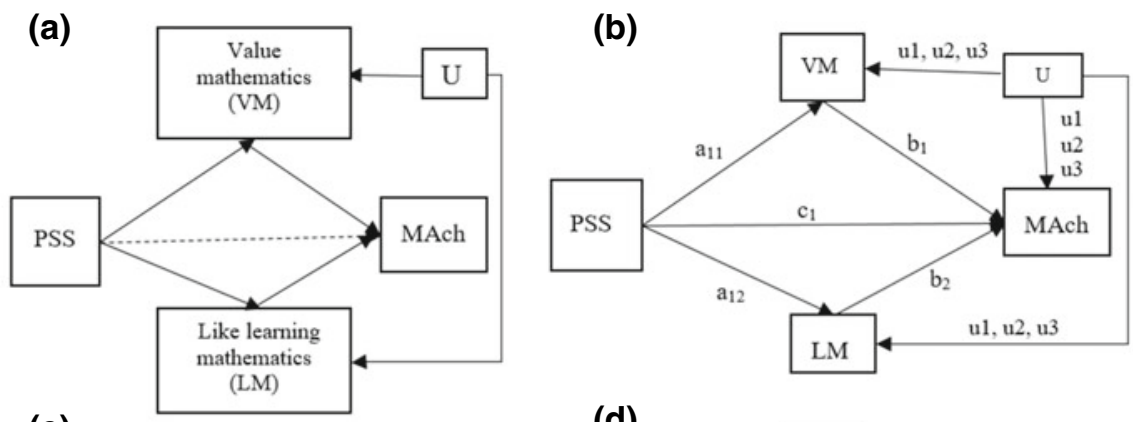

(c)
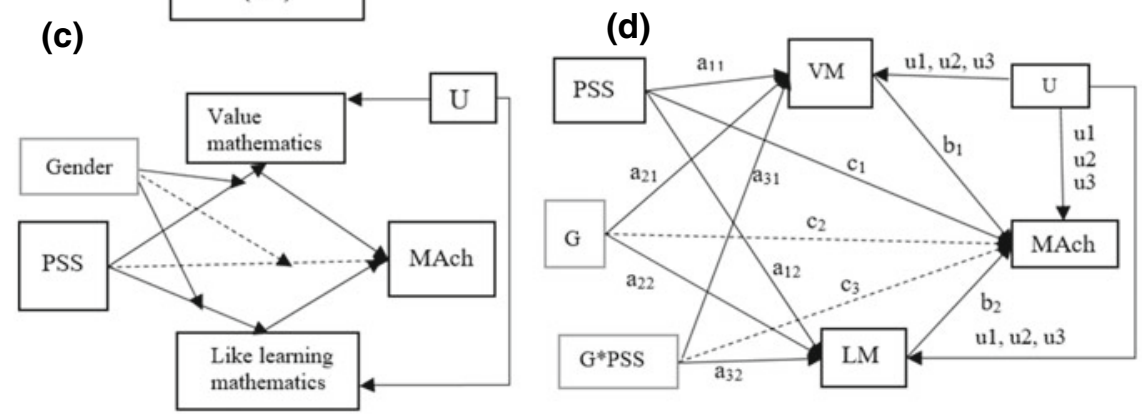

Fig. 6.1 The conceptual multiple mediation model (panel A) and a moderated multiple mediation (panel C) model in conceptual form. Panel B and panel D translate into a statistical model for panel A and C respectively. $G$ gender; PSS perceived social support (from teachers and parents); MAch mathematics achievement, $L M$ like learning mathematics, $V M$ value mathematics, u1-u3 indicates the covariates: parental education (u1), Long-term educational aspirations (u2), weekly time spent on mathematics homework (u3). Dotted lines represent optional moderator effects which can be included without affecting the estimates of the index of moderated mediation provided in the text

Table 6.1 Sample breakdown and characteristics

\begin{tabular}{l|l|l|l|l|l|l}
\hline Country & N & $\begin{array}{l}\text { Girls } \\
(\%)\end{array}$ & Schools & $\begin{array}{l}\text { Clusters } \\
\text { (intact } \\
\text { classes })\end{array}$ & $\begin{array}{l}\text { Average class } \\
\text { size }\end{array}$ & Grade \\
\hline Ghana & 7323 & 48 & 161 & 173 & 41 & 8 \\
\hline Morocco & 8986 & 48 & 279 & 279 & 32 & 8 \\
\hline Tunisia & 5128 & 51 & 207 & 207 & 25 & 8 \\
\hline Botswana & 5400 & 49 & 150 & 151 & 35 & 9 \\
\hline South Africa & 11,969 & 49 & 285 & 317 & 37 & 9 \\
\hline
\end{tabular}




\subsubsection{Participants}

The participants in this study are the students from the five African countries (Botswana, Ghana, South Africa, Morocco, and Tunisia) that participated in the TIMSS 2011 study (see Table 6.1). Sample involved 38,806 students (49.2\% girls) from 989 intact classrooms (clusters) with an average of 39 students per class.

\subsubsection{Measures of Social Support and Mathematics Achievement}

Each support measure includes four items on a four-point scale. This measure asks students to indicate their perception about how their parents and teachers show supportive behaviors such as caring, understanding, responsiveness and guiding them in the learning of mathematics. An example item of the perceived parental support is "my parents ask me what I am learning in school". An example item of the perceived teacher support construct is "My teacher is easy to understand". The construct reliability and validity have been established in several studies (see Bofah, 2015, 2016; Bofah \& Hannula, 2015).

TIMSS reported students' mathematics achievement in five plausible values (see Foy, Brossman, \& Galia, 2013 for scaling and proficiency estimation with plausible values). All five plausible values were used in the mediation analysis but, due to computational challenges associated with combining multiple imputation and bootstrapping, one plausible value was randomly selected for the moderated mediation analysis.

\subsubsection{Mediating and Moderating Variables}

Motivation has been discussed in the literature as a measure of intrinsic (i.e., the students like learning mathematics scale (LM)) and extrinsic (i.e., the students value mathematics scale (VM)) motivation (Ryan \& Deci, 2000). In the present study, measures of the motivational beliefs included two measures: the "students' value mathematics" scale and the "students like learning mathematics" scale. For easy reading, we use the terms value of mathematics and like mathematics, to mean the students value mathematics scale (VM), and the students like learning mathematics scale (LM) respectively. There were six items on the VM scale and five items on the LM scale both rated on a 4-point Likert type scale. An example item for like mathematics is "I like mathematics" and sample item for value mathematics is "I need to do well in mathematics to get the job I want". The reliability of the mediator(s) have been shown to be reliable and valid in previous studies (Bofah, 2015, 2016; 
Bofah \& Hannula, 2015). Gender was the moderating variable and was coded ' 0 ' for female and ' 1 ' for male.

\subsubsection{Control Variables}

We added some additional variables to assess the vulnerability of our findings. Consistent with previous research, parental education (Bronfenbrenner, 1986), weekly time spent on mathematics homework (Singh et al., 2002), and students long-term educational aspirations (Bofah, 2015; Bofah \& Hannula, 2015) were statistically controlled and entered into the model as covariates.

\subsubsection{Statistical Approaches to the Hypothesised Model}

Mplus software version 7.4 (Muthén \& Muthén, 1998-2015) was used to test all the hypothesised model. To account for the non-independence of the student data, model parameters were estimated by means of the Mplus robust maximum likelihood estimator (MLR) in combination with the "complex" option. Sampling weights were taken into account (weighting variable supplied with the data). We used the Mplus multiple imputation procedure with five imputed data set, combining the results of the five sets of plausible values using Rubin (1987) formulas.

We used a latent variable framework to provide estimates of country differences taking into account the multiple indicators, measurement errors, and the complex structural relationships associated with the variables as well as account for the low reliabilities so as not to inflate the estimates.

Because the structural model includes latent variables, there was the need to ascertain the validity of the measured constructs, by examining the psychometric properties. Once the measurement model adequately fit the data, then one can confidently examine the structural model. In the present study, confirmatory factor analyses (CFAs) were conducted for the perceived support and mediational constructs together. We control method effect associated with the use of negatively phrased item in surveys by allowing the correlated uniqueness of the two negatively phrased items on the "like mathematics" construct to covary (see Bofah \& Hannula, 2015).

Most research on cross-cultural comparison advocates the use of measurement invariance to ease cross-cultural generalizability (Bofah, 2016; Bofah \& Hannula, 2015; Little, 1997; Steenkamp \& Baumgartner, 1998; Vandenberg \& Lance, 2000). Since country differences can only be properly examined if the same constructs are measured for the five countries, multiple-group factor-analytic models were applied (Little, 1997; Lubke, Dolan, Kelderman, \& Mellenbergh, 2003; Sass, 2011). This involved using multiple-group factor-analytic models to examine whether the model showed the appropriate level of measurement invariance between countries. If measurement invariance does not hold, any inference drawn about group differences 
may be flawed or meaningless (Little, 1997; Lubke, Dolan, Kelderman, \& Mellenbergh, 2003; Sass, 2011). There are several levels of measurement invariance. Two levels are of significance in this study and cross-cultural comparison in general if factor mean comparison across groups or countries is not the focus. The two levels are: configural, and metric (also referred to as factor loading invariance) invariance. In testing measurement invariance across groups, a series of hierarchical stepwise operations based on multiple-group factor analytic models in a logically defined and increasingly restrictive models are tested (Byrne, 2010). Before examining the hypothesized model, test of invariance of the measurement construct for each country was constructed. Support for configural invariance indicates that factors are similar across groups. On the other hand, support for factorial invariance indicates that the constructs are on the same scale and any differences in variation of the measured variable are due to latent variables (Keith, 2015). It is thus possible to compare the structural paths in our structural model.

\subsubsection{Mediation and Moderation Analysis}

The analysis was done separately for each perceived support unit (teacher and parent). For computational accuracy, the unconditional model (i.e., mediation or indirect effect model) and the conditional model (i.e., moderation mediation) were estimated separately for each support source (Preacher, Rucker, \& Hayes, 2007).

Mediation, or an indirect effect, is said to occur when the causal effect of an independent variable $(\mathrm{X})$ (here, perceived social support (PSS: from parents and teachers) on a dependent variable (Y) (MAch: mathematics achievement in this case) is transmitted via a mediator or intervening variable $(\mathrm{M})$ (motivational belief: value or like mathematics in this study) (Preacher \& Hayes, 2008). Figure 6.1 illustrates a scenario involving multiple mediators (e.g., value mathematics (VM) and like mathematics (LM)). This figure serves as the theoretical model for the study. In Fig. 6.1, panel A is the conceptual model and panel B is the statistical model. In the statistical model, the effect of PSS on mediators VM and LM are designated as $\mathrm{a}_{11}$ and $\mathrm{a}_{12}$ respectively, the effect of VM on Y as $\mathrm{b}_{1}$, LM on Y as $\mathrm{b}_{2}$, and the effect of PSS on MAch as $c_{1}$. The effect of PSS on Y is called the direct effect $\left(c_{1}\right)$. The indirect effect of PSS on MAch via the mediator(s) is defined as the product of the two paths linking PSS to MAch via that mediator. In Fig. 6.1b (panel B), the specific indirect effect of PSS on MAch through VM and LM is quantified as $\mathrm{a}_{11} \times \mathrm{b}_{1}$ and $\mathrm{a}_{12} \times \mathrm{b}_{2}$ respectively. The total indirect effect of PSS on MAch is the sum of the specific indirect effects (i.e., $a_{11} b_{1}+a_{12} b_{2}$ ), and the total effect (often represented as c) of PSS on MAch is the sum of the direct effect $\left(c_{1}\right)$ and the total indirect effects $\left(a_{11} \times b_{1}+a_{12} \times b_{2}\right)$ (i.e., $\mathrm{c}=\mathrm{c}_{1}+\mathrm{a}_{11} \times \mathrm{b}_{1}+\mathrm{a}_{12} \times \mathrm{b}_{2}$ ). In Fig. 6.1 panel $\mathrm{B}$, coefficients $\mathrm{a}_{11}$ and $\mathrm{a}_{12}$ represent the effects of social support on value and like mathematics, respectively, whereas coefficients $b_{1}$ and $b_{2}$ represent the effects of mediator(s) value and like mathematics on achievement after controlling for the effect of social support respectively. As indicated in both the conceptualized and statistical model we controlled for parental education, students' long-term educational aspirations and weekly time spent on 
mathematics homework. The terms mediation and indirect effect will be used loosely and somewhat interchangeably in this paper.

Moderated mediation occurs when the strength of an indirect effect depends on the level of some variable, or in other words, when mediation relations are contingent on the level of a moderator (gender in this study) (Preacher et al., 2007, p. 193). As Edwards and Lambert (2007, p. 6) indicated “...moderated mediation means that either or both of the path $X$ to $M$ and from $M$ to $Y$, which constitute the indirect effect of $X$ to $Y$, vary across levels of the moderator variable $\mathrm{V}$ (say gender)". Different forms of moderated mediation exist in the literature depending on the number of mediators as well as path(s) being moderated (Edwards \& Lambert, 2007; Hayes, 2013; Preacher et al., 2007). In this paper, conditional indirect effect or moderated mediation is characterized as a model in which the indirect effect of PSS on MAch through M is moderated by V (gender), as is the direct effect of PSS on MAch. In simple terms the path from the intervention (here, perceived social support) to the mediator(s) (i.e., PSS $\rightarrow$ VM or LM; motivational beliefs in this case) as well as the direct effect depends on the level of a third variable $\mathrm{V}$ (gender in this case), whereas the effect of the mediator on the outcome (i.e., VM/LM $\rightarrow$ MAch: mathematics achievement in this study) is constant controlling for parental education, students' long-term educational aspirations and weekly time spent on mathematics homework. This has been described by Edwards and Lambert (2007, p. 10) as "First Stage and Direct effect Moderation Model". It is a conditional process model because it involves moderation and mediation processes (Hayes \& Preacher, 2013). Using the concept and approach discussed in (Edwards \& Lambert, 2007; Hayes, 2015; Preacher \& Hayes, 2008; Preacher et al., 2007) the conditional indirect effect of PSS on achievement through value mathematics (VM) or like mathematics (LM) (Fig. 6.1) are presented as simple slopes as:

$\omega=b_{1} *\left(a_{11}+a_{31} *\right.$ gender $)=a_{11} b_{1}+a_{31} b_{1} *$ gender for value mathematics, and $\omega=b_{2} *\left(a_{12}+a_{32} *\right.$ gender $)=a_{12} b_{2}+a_{32} b_{2} *$ gender for like mathematics.

The conditional indirect effect is quantified by Hayes (2015) as $\mathrm{a}_{31} \mathrm{~b}_{1}$ through SVM and $\mathrm{a}_{32} \mathrm{~b}_{2}$ through SLM and is called the index of moderated mediation (MM) - which is a direct quantification of the linear association between the indirect effect and the putative moderator of that effect (Hayes, 2015, p. 3). Hayes (2015) indicated that for dichotomous moderator, the index of $\mathrm{MM}$ is a test of equality or difference of the conditional indirect effects in the two groups (here between male and female).

Similarly the conditional direct effect PSS on MAch or moderated mediation is presented as a simple slope as: MAch $=c_{1}+c_{3} *$ gender. Similarly as above, the moderated mediation equates to test of equality or difference of the conditional direct effects in the two groups (between male and female). Specifically, the female conditional indirect effect was subtracted from the male conditional indirect effect as a contrast.

Bootstrapping procedures were used to test the multiple mediation and the moderated mediation (conditional indirect effect) hypotheses. Establishing mediation indicates that the total unconditional path $\left(a_{11} * b_{1}+a_{12} * b_{2}\right)$ in Fig. 6.1b which is the sum of the product of the coefficients $\left(a_{11} * b_{1}\right)$ and $\left(a_{12} * b_{2}\right)$ is statistically 
significant, and establishing moderation mediation indicates that the index of moderation mediation (e.g., $\mathrm{a}_{31} \mathrm{~b}_{1}$ through SVM and $\mathrm{a}_{32} \mathrm{~b}_{2}$ through SLM) or test of equality or difference of the conditional direct effects in the two groups (between male and female) are statistically significant.

When the $95 \%$ confidence interval (CI) of the total indirect effect does not include zero, then it is assumed that motivational beliefs mediate the relationship between PSS and achievement. Furthermore, when the $95 \%$ confidence interval of the index of moderated mediation does not include zero, then the conclusion is that the (in)direct effects at various levels of the moderator are statistically significantly different. Subsequently, the type of mediation will be based on the direct effect $\left(\mathrm{c}^{1}\right)$ being significant and positive (i.e., complementary or partial mediation), negative (competitive or inconsistent mediation), or not significant (i.e., indirect-only or full mediation) (Little, Card, Bovaird, Preacher, \& Crandall 2007; Zhao, Lynch, \& Chen, 2010). The analysis was done separately for each perceived support unit.

To ascertain the model fit, several model fit indices were consulted with emphasis placed on the comparative fit index (CFI), the Tucker-Lewis index (both normed along a 0 -to- 1 continuum with values greater than 0.90 reflecting acceptable fit to the data), the root-mean-square error of approximation (RMSEA; values less than 0.08 are indicative of an acceptable fit $)$ and the chi-square test statistic $\left(\chi^{2}\right.$ : for informative purposes only because of its sensitivity to large sample size) (West, Taylor, \& Wu, 2012). Also the differences in model fit between the less and the more constrained models in the model series test should be negligible (e.g., $\triangle \mathrm{CFI}<0.01 ; \triangle \mathrm{RMSEA}$ $<0.015$ ) (Chen, 2007; Cheung \& Rensvold, 2002). Moreover, the final or preferred model should be substantive and meaningful.

\subsection{Results}

We began our evaluation of model fit by considering our measurement or standard model. Goodness-of-fit related to the four-factor model $\left(\chi^{2}{ }_{(145)}=6523.192 ; \mathrm{CFI}=\right.$ $0.922 ; \mathrm{TLI}=0.909 ; \mathrm{RMSEA}=0.034$ ) exhibited an exceptionally good fit to the data. Multi-group CFA was used to examine whether the measurement model is invariant across groups (e.g., the five countries here), whereas multi-group SEM was used to examine whether the mediational model is invariant across the five educational system/cultures. For the measurement model, the configural and metric invariance models were compared across the groups. There was support for the configural $\left(\chi^{2}{ }_{(725)}=8078.600 ; \mathrm{CFI}=0.919 ; \mathrm{TLI}=0.905 ; \mathrm{RMSEA}=0.036\right)$ and factor loading $\left(\chi^{2}{ }_{(785)}=8451.272 ; \mathrm{CFI}=916\right.$; TLI $=0.909$; RMSEA $\left.=036\right)$ invariance. Moreover, the small change in fit index $(\triangle \mathrm{RMSEA}=0.000 ; \Delta \mathrm{CFI}=0.003)$ between the two models across countries also indicated that the factor loadings are equally held across the groups. In all subsequent analysis the factor loadings were held to be equal across the five educational systems or cultures.

We began our detailed analysis by examining the relationship amongst our variables. As can be seen in Table 6.2, there was a strong relationship between students' 
perceived social support from their teachers and higher motivational beliefs (VM: $r=0.640, p<0.001$; LM: $r=0.674, p<0.001$ ), and this in turn was related to mathematics achievement (VM: $r=0.217, p<0.001$; LM: $r=0.128, p<0.001$ ). There was also positive relationship between perceived parental support and students motivational beliefs, however these relationships were lower (VM: $r=0.214, p<$ 0.001; LM: $r=0.233, p<0.001$ ).

A further look at the individual country correlations showed a different pattern. Expressed in terms of simple association, there was no evidence of a relationship between perceived social support (from parents and teachers) and achievement in Tunisia. No relationships was also found between perceived teacher support and achievement in South Africa. However, ".... lack of correlation does not disprove causation (Bollen, 1989, p. 52)". Our model proposes an indirect effect—one that links PSS to achievement through motivational beliefs. Indirect effects can exist even when there is no evidence of simple association (Hayes, 2009; Pollack, Vanepps, \& Hayes 2012; Rucker, Preacher, Tormala, \& Petty 2011) as such a significant total effect is not a requisite for testing indirect effects (Zhao et al., 2010).

\subsubsection{Overall Population Test of the Hypothesized Model}

In order to examine the potential mechanisms underlying the relations between PPS, motivational beliefs and mathematics achievement, we investigated an unconditional mediation effect model, whereby we hypothesized that motivational belief mediated the relation between PSS and achievement controlling for students' parental education, long-term educational aspirations, and hours spent on homework using the approach discussed in Hayes (2013). The statistical diagram (Fig. 6.2; for the overall sample) shows the parameter estimates. As a prelude to the multiple mediation and moderation analysis, the direct effects of perceived social support on the mediators as well as the direct effects of the mediators on achievement were examined for each of the support sources separately controlling for parental education, long-term educational aspiration and weekly time spent on mathematics homework.

Using the overall sample, the results showed that for the perceived parental support model, parental support had a direct effect on "like" and "value mathematics" but a direct negative effect on mathematics achievement. The mediators significantly predicted mathematics achievement. For teacher support model, teacher support had direct positive effects on "like" and "value mathematics" but a direct negative effect on mathematics achievement. Both mediators had a direct effect on mathematic achievement. Results based on the total sample clearly support the notion that motivational beliefs mediate the relationship between students' perceived social support and achievement. Further discussion of this finding will be presented later. From the parameters estimates, one could see that perceived social support from the teachers plays a unique role in bolstering students' motivation beliefs more than parental support after controlling for parental education, long-term educational aspiration and weekly time spent on mathematics homework. 


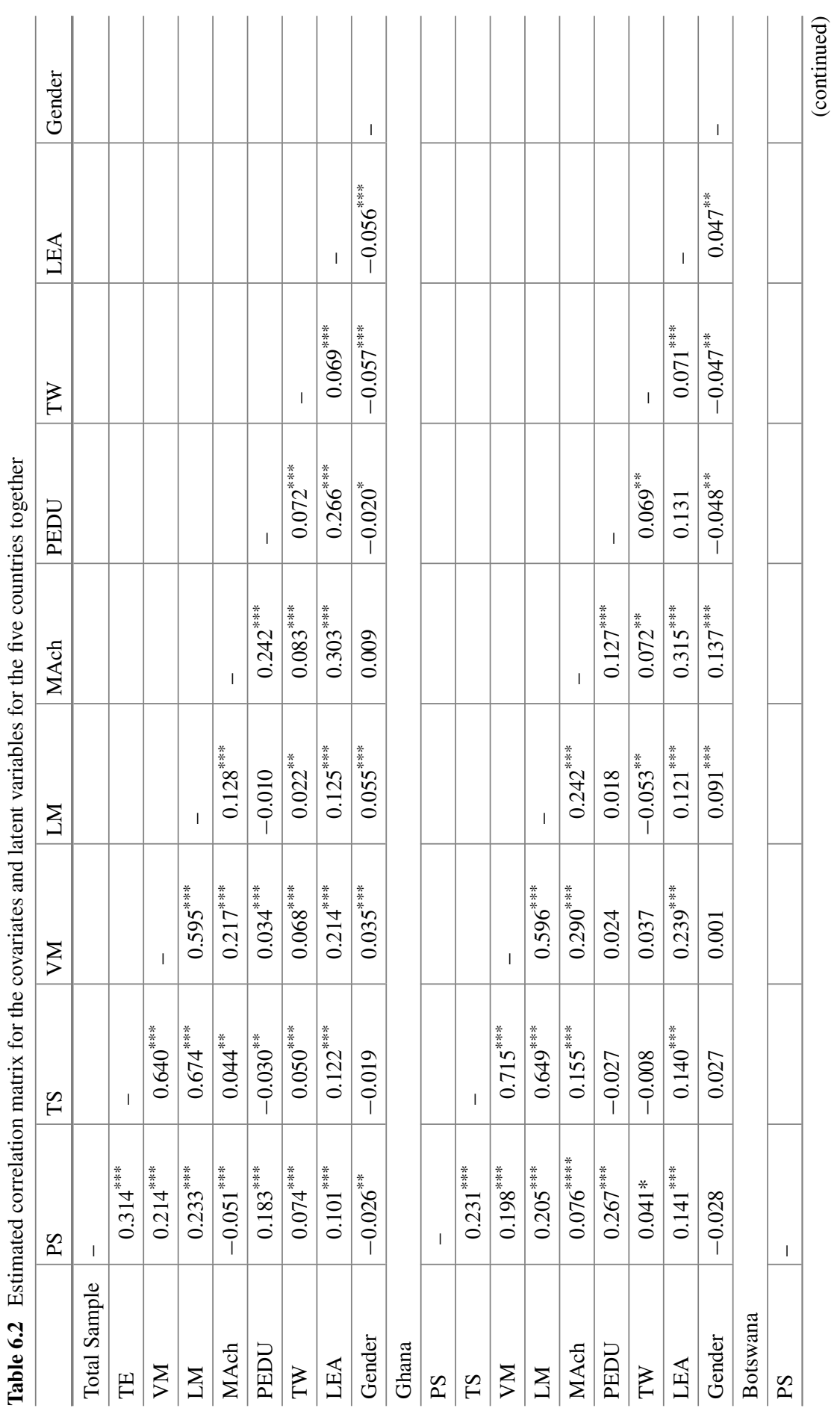




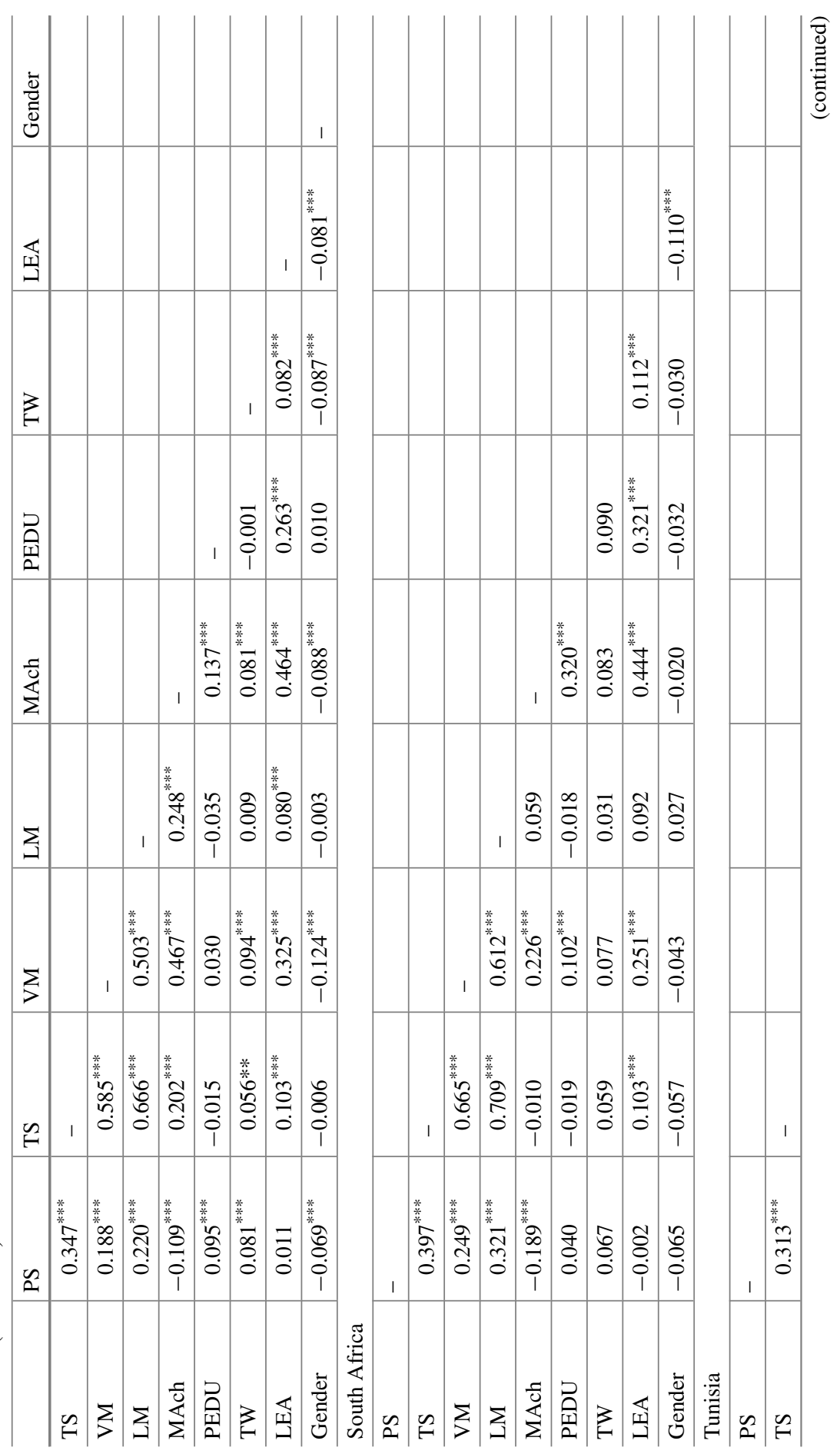




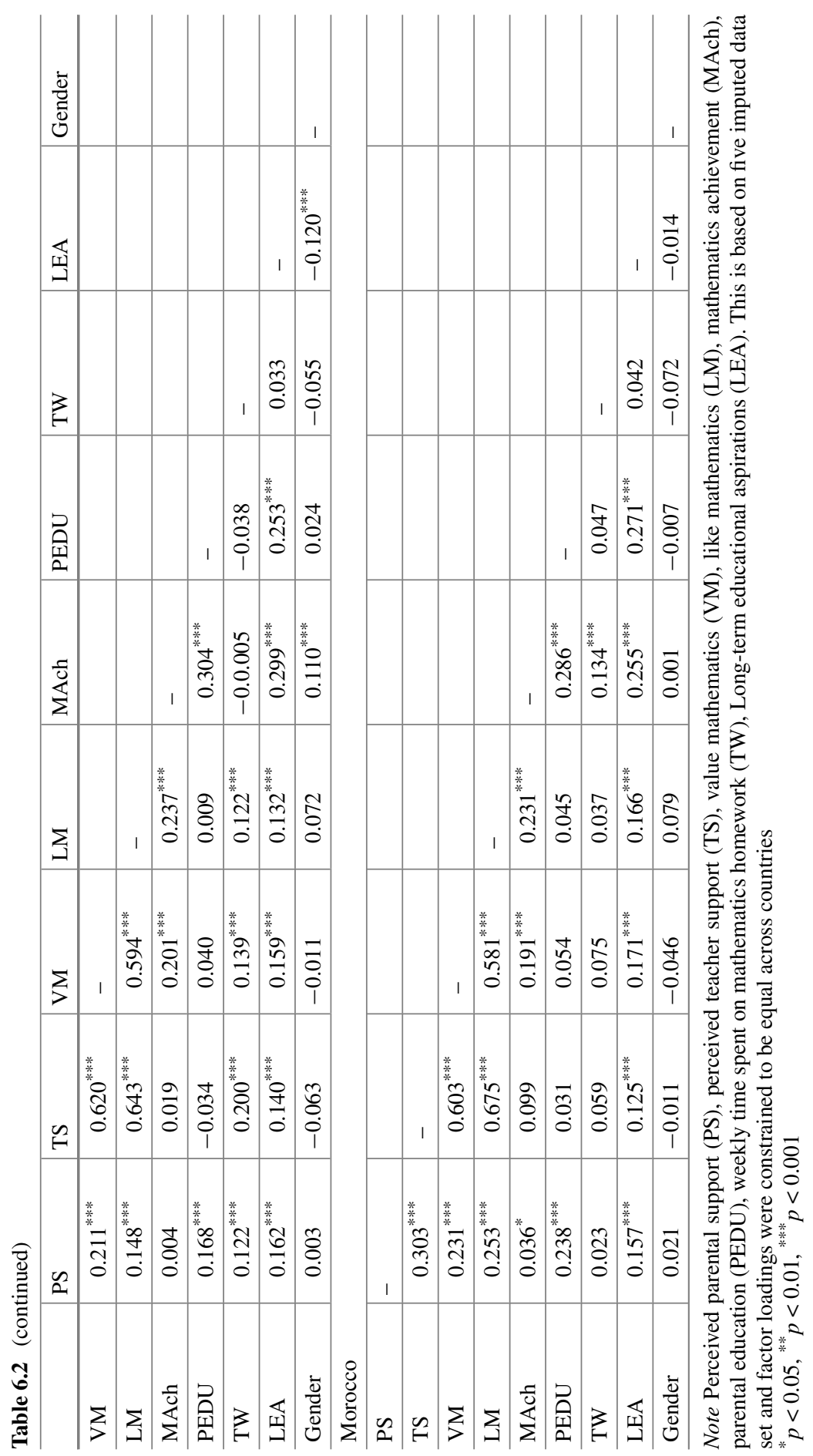



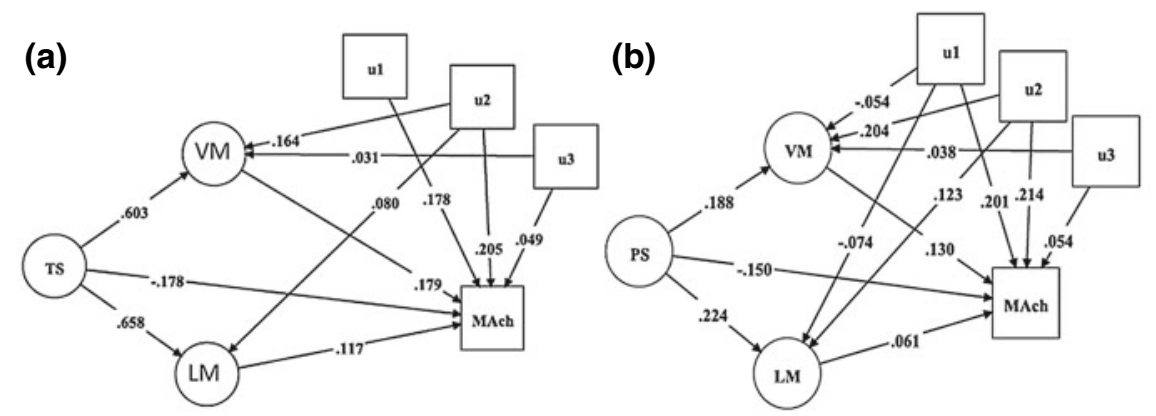

Fig. 6.2 The statistical outcome of the conceptual model using the whole sample. Panel A is the model for the perceived teacher support and panel B is the model for perceived parental support. We allowed the error terms of the two mediators to covary but not shown. PS perceived parental support, $T S$ perceived teacher support, $V M$ value mathematics, $L M$ like mathematics, MAch mathematics achievement. u1-u3 indicates the covariates: parental education (u1), Long-term educational aspirations (u2), weekly time spent on mathematics homework (u3). Estimates are based on five imputed data sets. To reduce visual clutter, only path arrows and statistically significant paths are presented

\subsubsection{Cultural Comparison of the Mediational Model}

We examine whether the mediational model is invariant across the five educational systems by comparing two models for each support source. Comparison was made between two nested models: model with factor loading invariance and path estimates freely estimated and a model with factor loadings and path estimates invariance. For the teacher support model the multi-group equivalence test indicated an acceptable support for the claim of an invariance of the mediational model across countries due to the small change in fit index for the two models ( $\triangle \mathrm{RMSEA}=0.000 ; \triangle \mathrm{CFI}$ $=0.002)$. Similar outcome was achieved for the perceived parental support model $(\triangle \mathrm{RMSEA}=0.000 ; \Delta \mathrm{CFI}=0.005)$. In brief, the multi-group cultural equivalence tests show acceptable support for our hypothesized mediational model. However, a closer look at the parameter values of the paths estimates indicated a wide variation in the parameter estimates across countries. It is therefore advisable to investigate our hypothesized model for each country separately. However this analysis was based on the fact that factor loadings were constrained to be equal across country. Figure 6.3 is the outcome for the parental support model whereas Fig. 6.4 is for the teacher support model.

\subsubsection{Mediation Model Across Country}

As shown in Table 6.3, in all countries, the total indirect effect (i.e., unconditional mediation effect) was statistically significant with a $95 \%$ bias corrected bootstrap 


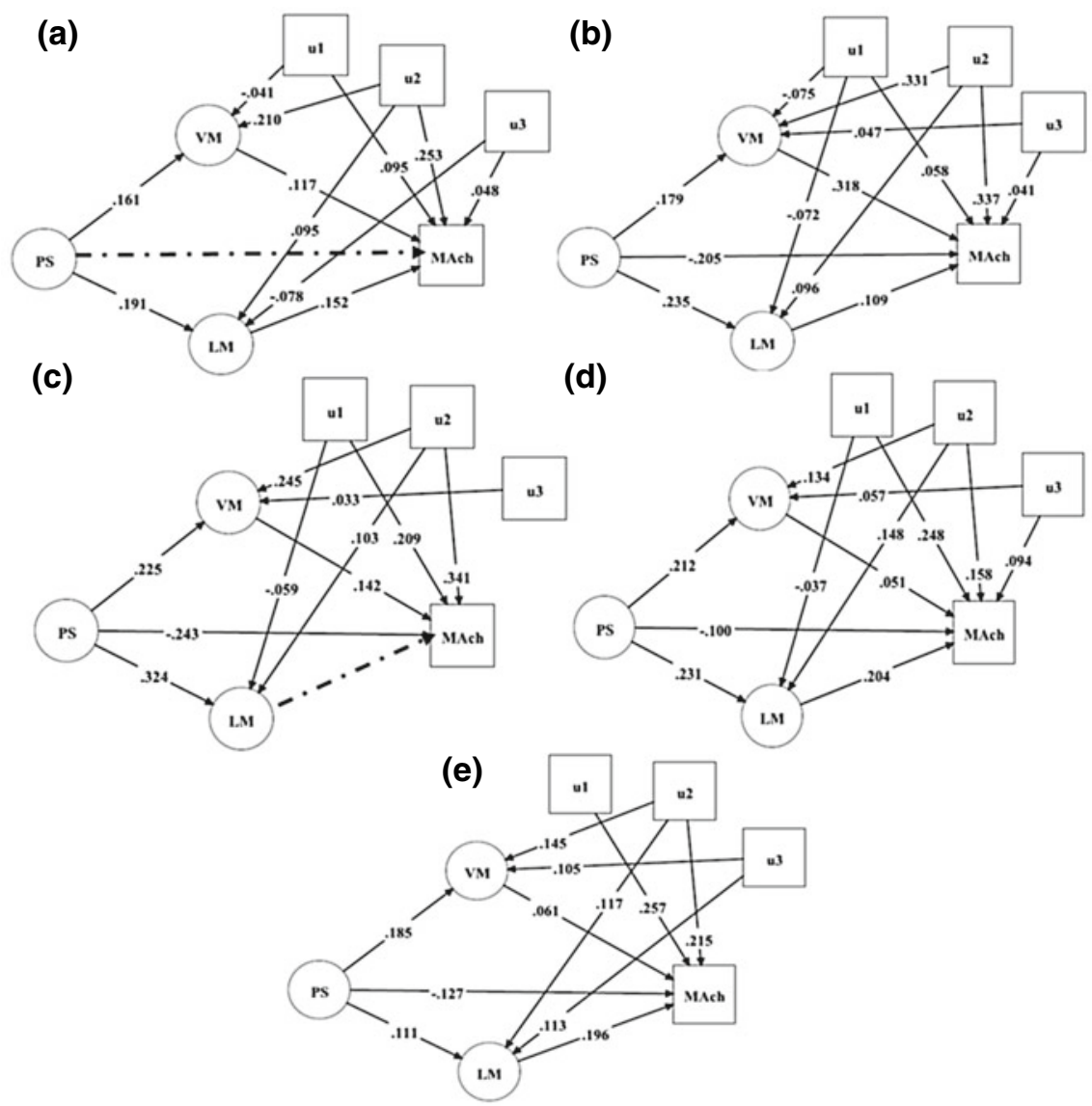

Fig. 6.3 is the statistical outcome of the conceptual model perceived parental support for each country (Model in Fig. 6.1a). Panel A, B, C, D and E are for Ghana, Botswana, South Africa, Morocco and Tunisia respectively. We allowed the error terms of the two mediators to covary but not shown. $P S$ perceived parental support, $V M$ value mathematics, $L M$ like mathematics, MAch mathematics achievement. u1-u3 indicates the covariates: parental education (u1), Long-term educational aspirations (u2), weekly time spent on mathematics homework (u3). Estimates are based on five imputed data sets. To reduce visual clutter, only path arrows and significant path for the covariates are shown. The dash line is a non-significant path

confidence interval. This indicates that, as a set students' motivational belief significantly mediates the relation between PSS and achievement holding constant parental education, weekly time spent on mathematics homework, and students' long-term educational aspirations. Specific indirect effect through "like mathematics" and value mathematics for the two support sources were statistically different from zero except in South Africa that the specific indirect effect of the parental support through "like mathematics" was not statistically different from zero. For the two-support source, PSS predicted students' motivational belief. On the relationship between the media- 


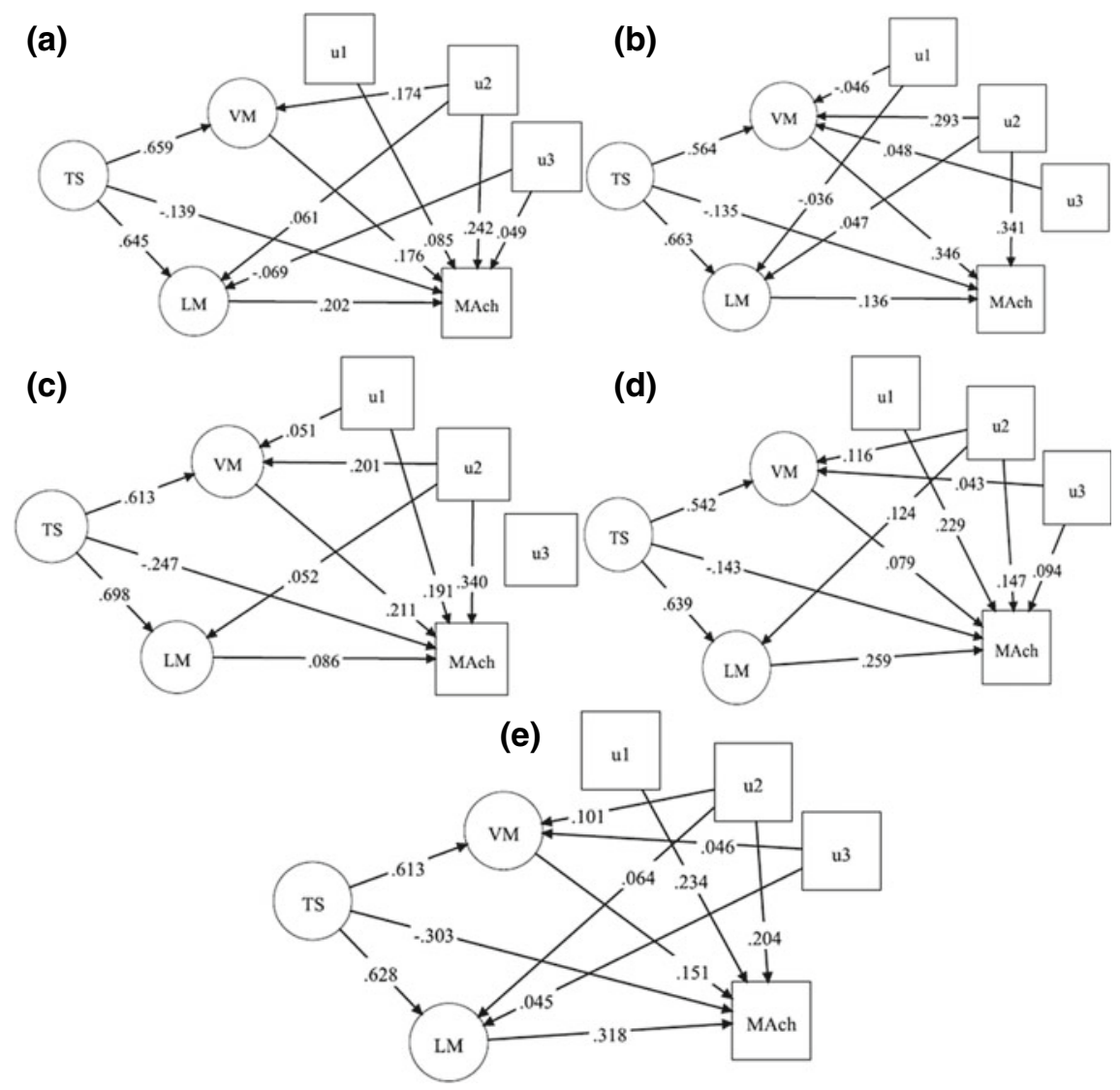

Fig. 6.4 The statistical outcome of the conceptual model perceived teacher support for each country (Model from Fig. 6.1b). Panel A, B, C, D and E are for Ghana, Botswana, South Africa, Morocco and Tunisia respectively. To reduce visual clutter, only path arrows appear and significant path for the covariates are shown. We allowed the error terms of the two mediators to covary but not shown. $T S$ perceived teacher support, $V M$ value mathematics, $L M$ like mathematics, MAch mathematics achievement. u1-u3 indicates the covariates: parental education (u1), Long-term educational aspirations (u2), weekly time spent on mathematics homework (u3). Estimates are based on five imputed data sets

tors and achievement, both mediators positively significantly predicted achievement in all the countries. The parameter estimates from all the countries indicates that perceived social support from the teachers is an important predictor of students' motivation beliefs more than parental support after controlling for parental education, long-term educational aspiration and weekly time spent on mathematics homework.

Further pairwise contrast (see Table 6.3) on the magnitude of the indirect effect indicated that, in the perceived parental support model the two indirect effects for Ghana and Tunisia cannot be distinguished in terms of magnitude, but in Botswana, Morocco and South Africa the indirect effect differ significantly in magnitude for the 


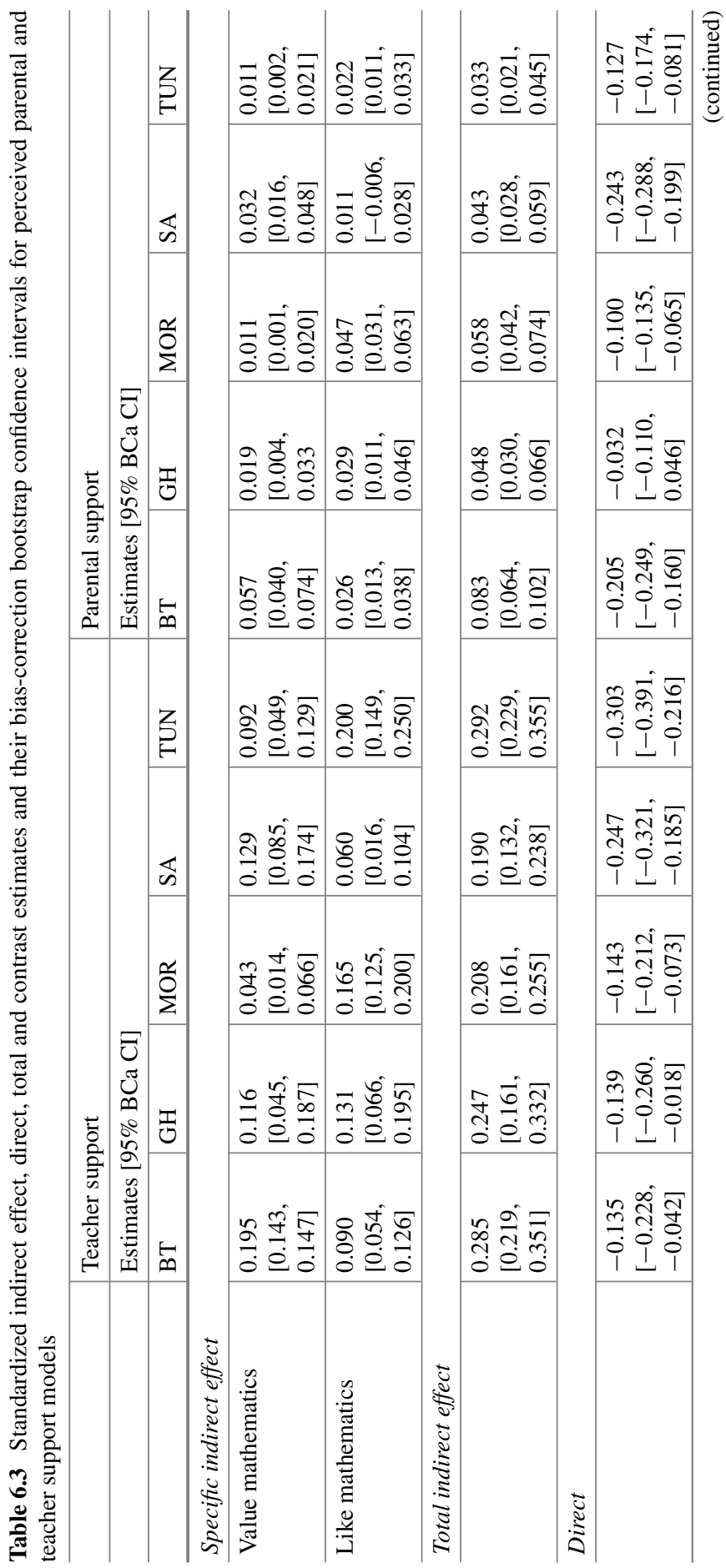


6 Perceived Social Support Network and Achievement: Mediation ...

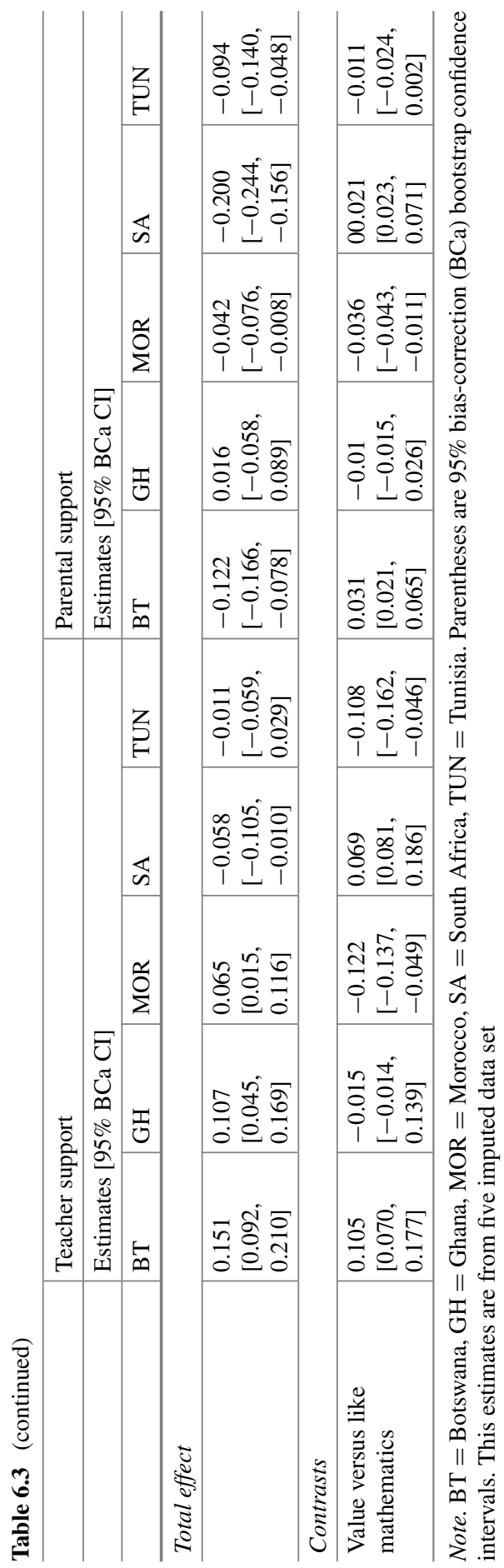


two motivational measures. For the perceived teacher support model, the magnitude of the indirect effect differ significantly across all countries except in the case of Ghana where the contrast comparison indicated that the magnitude of the indirect effect cannot be distinguished in terms of magnitude.

A further examination of the direct effect and total indirect effect for each country indicated an interesting scenario. With the perceived teacher support, holding the mediators constant and controlling for parental education, weekly time spent on mathematics homework, and students' long-term educational aspirations, the direct effect was significant but negative for all the countries.

However, the magnitude of the direct effect was found to be greater than the total effect (except Botswana). Also for Botswana, the mediated effect and direct effect were statistically significant but point in opposite directions. The indirect effect was statistically significant and positive whereas the direct effect was negative and statistically significant. These scenarios are known in the literature as competitive or inconsistent mediation or a mediation with a suppression effect (Little et al., 2007; Zhao et al., 2010)_ “a variable which increases/decreases the predictive validity of another variable (or set of variables) by its inclusion in a regression equation" (Conger, 1974, pp. 36-37) where predictive validity is assessed by the magnitude of the regression coefficient (MacKinnon, Krull, \& Lockwood, 2008, p. 175). The possible reason for this phenomenon is that students' motivational belief suppresses the irrelevant variance in perceived social support, thus allowing for an increased relationship between perceived social support and achievement.

However, in some situations of inconsistent mediation the total effect (sum of the direct and total indirect effects) may be attenuated despite the significance of the direct and indirect paths, because these effects mathematically cancel one another out. This was true in our perceived teacher support model for Tunisia, where the sign of the direct effect was negative and statistically significant (estimate $=-0.303$, $95 \% \mathrm{CI}[-0.391,-0.216])$ and a significant positive total indirect effect (estimate $=$ $0.292,95 \%$ CI $[0.229,0.355])$, but as a result of their opposite signs, the total effect was close to zero (estimate $=-0.0011,95 \%$ CI $[-0.059,0.036])$. Similar scenario was found in Ghana for the parental support model (see Table 6.2).

In the perceived parental support model, similar scenarios of mediation with suppressor effect were found for the Tunisia, Morocco, South Africa, and Botswana. However, the motivational belief measures fully mediated the relationships between parental support and achievement in Ghana for the perceived parental support model. In summary, including the motivational beliefs measures in the model nevertheless improved the overall prediction by effectively removing the measurement artifact variance associated with the perceived support source, thereby making them purer and thus more effective predictors of mathematics achievement. This indicates that although the motivational belief measures act as suppressor variables in essence, these variables suppress irrelevant variance in the PSS measure. Thus, on the contrary, students' motivational beliefs are actually important because they improve the prediction of the students' perceived social support. 


\subsubsection{Moderated Mediation Models Across Country}

The hypothesis that the relation between PSS and achievement via motivational belief is condition on students' gender was examined using moderated mediation analyses otherwise known as conditional process analysis (Hayes \& Preacher, 2013). The goal is to test the conditional direct and indirect effect(s) of PSS on achievement at values of the moderator; male or female. Latent moderated structural equations (LMS) approach was used to estimates the interaction effects.

Using the approach discussed in (Edwards \& Lambert, 2007; Preacher \& Hayes, 2008; Preacher et al., 2007), for the perceived teacher support model (see Table 6.4), the index of MM was statistically significant for the indirect effect through value mathematics for Botswana, South Africa, and Morocco. This indicates that the indirect effect through value of mathematics is moderated by students' gender in Botswana, South Africa, and Morocco with the effect higher for males in these countries. For the indirect effect via "like mathematics", the index of MM was not statistically significant in all the countries indicating that the indirect effect via "like mathematics" does not differ between males and females in those countries.

Differences in these effects are depicted as simple slopes in Fig. 6.5, panlels A through B for males and females. Figure 6.5a shows that, gender moderated each path of the mediated model relating perceived teacher support (factor mean set at default of 0 ), value mathematics, and achievement, such that the indirect effect relating perceived teacher support through value mathematics were stronger for girls when teacher support is lower and stronger for boys when teacher support is higher Morocco, South Africa, and Botswana. On the other hand, the indirect effect of teacher support through "like mathematics" was higher for boys when teacher support is lower and higher for girls when teacher support was higher in Tunisia and Morocco.

\subsection{Discussion}

In the present investigation, we examined the mediational roles of motivational beliefs ("like" and "value mathematics") in relation with the association between perceived social support (PSS: from parents and teachers) and mathematics achievement in an African context. Furthermore, the study examined if the indirect effect of PSS on achievement via motivational belief is contingent on students' gender.

Generally, the results indicated that motivational beliefs taken as a set and individually mediate the effect of PSS on achievement, thereby supporting the multiple mediation model that we proposed. The current results corroborated the results of other studies (Ahmed et al., 2010; Song, Bong, Lee, \& Kim, 2015; Wentzel, 1998) which found that students' motivational beliefs generally serve as an important link between their perceived social support and academic achievement. In general, the analyses support the mediational assumptions in the literature (e.g., Ahmed et al., 


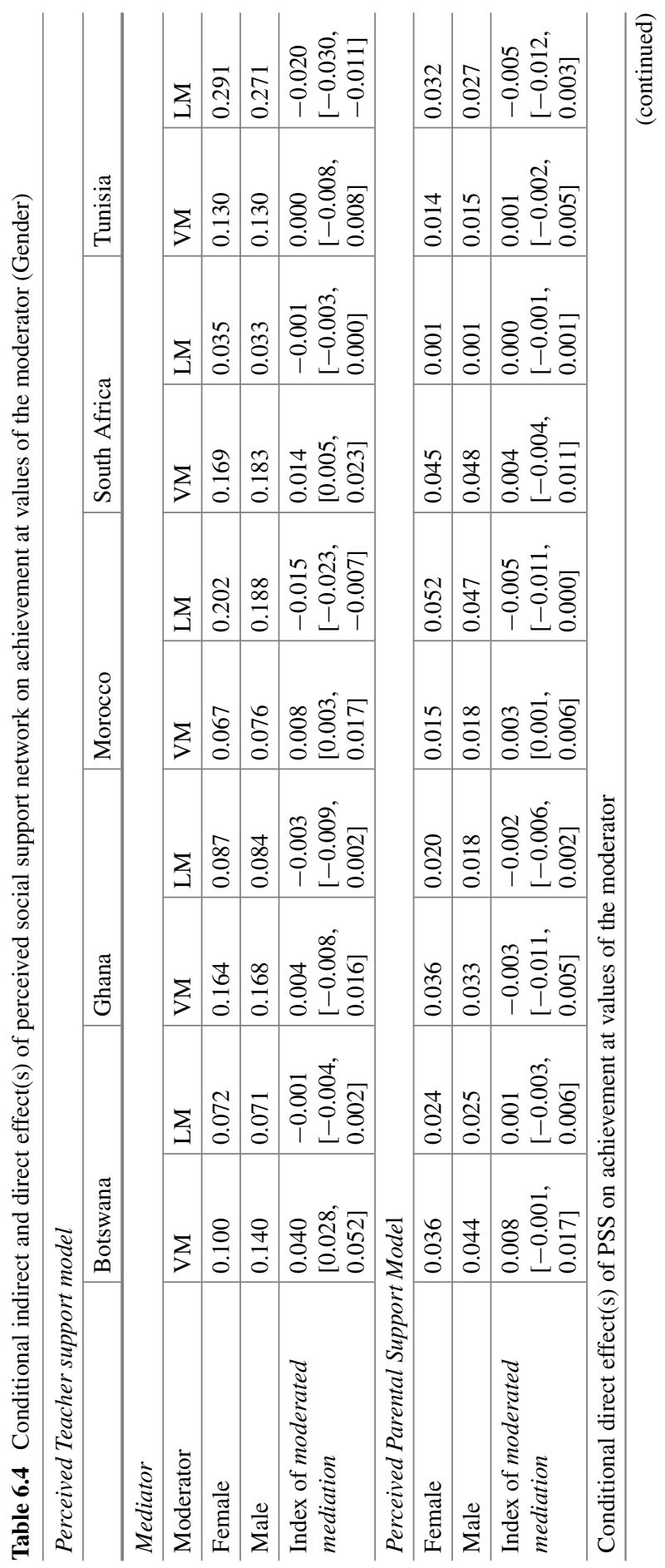




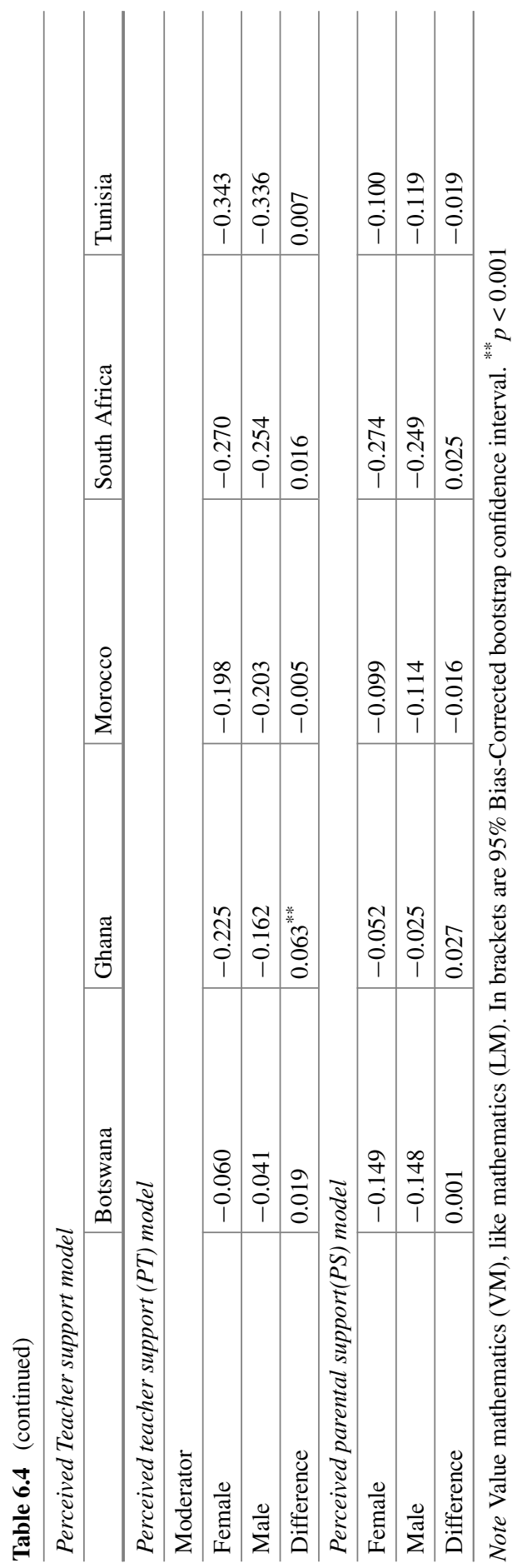


(a)

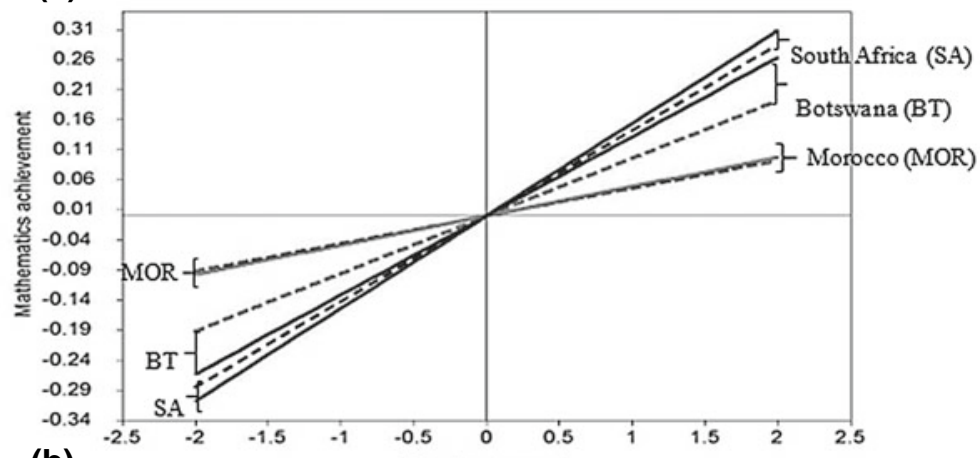

(b)

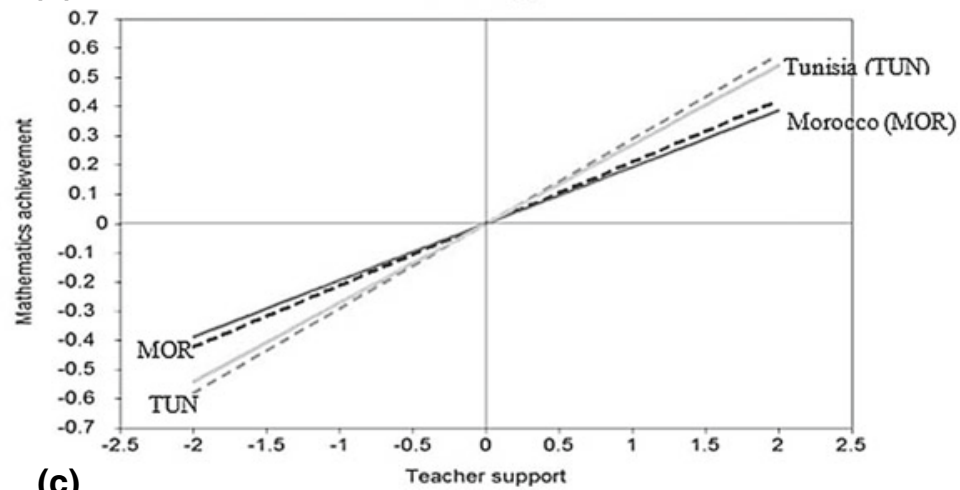

(c)

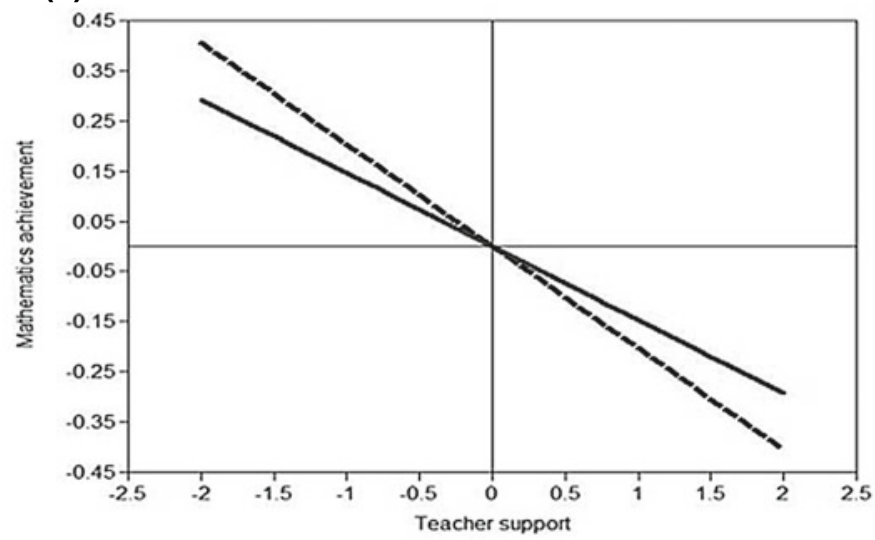

Fig. 6.5 Plots of simple paths conditional indirect model with gender as the moderator variable. In Panels A is the model for the conditional indirect with value mathematics as the mediator and panel B like mathematics as the mediator. Panel C is the direct effect model for Ghana. Dash line (一) is females and continuous lines males. The mean of the perceived teacher support construct was set to zero and plotted between \pm 2 standard deviations of the mean 
2010; Wentzel, 1998). These results, however, refute the long assertion that perceived social support (e.g., from parents) uniquely influences academic performance (e.g., Mackinnon, 2012); rather, the association between perceived social support and achievement is accounted for entirely or partly by how the students value and like mathematics. One important finding from our study was that the mediational hypothesis was supported in all the countries.

The mediation with suppression effect found in the present study indicates that perceived social support from teachers strengthened when students like and understand the importance of mathematics in their life. Inclusion of motivational beliefs improved the prediction power of perceived social support from teachers because the motivational beliefs measures removes any irrelevant artifact variance associated with the perceived teacher support making it "purer" and an absolute predictor of mathematics achievement. Teacher support is beneficial when student like and value mathematics. Similar outcome was witness with the parental support model, however, in Ghana support from parents weakens when students understand the importance of and enjoy mathematics because the relationship between parental support and achievement is completely mediated via students' motivational beliefs. This findings support the notion that parental support has a cultural dimension that transcends geographical boundaries of home and the school (Bofah \& Hannula, 2015). These findings indicate the significant role of perceived social support on students' selfbeliefs and achievement.

Moreover, contrast comparison shows that the magnitude of the indirect effect cannot be distinguished in terms of magnitude in three out of the 10 specific indirect models. Four contrast comparisons indicated that the indirect effect through value of mathematics was stronger whereas three other indirect effect, it was stronger for "like mathematics". This shows the cultural complicity associated with affective measures. The study indicates that perceived social support from the teachers plays a unique role in bolstering students' motivational beliefs (Rueger, Malecki, \& Demaray, 2009; Schneider, Tomada, Normand, Tonci, \& de Domini, 2008) more than parental support, which contradicts studies that support from parents is the most important source of support (Cutrona, Cole, Colangelo, Assouline, \& Russell, 1994).

In respect of gender moderating the indirect effect, the outcomes from this study indicates that the conditional indirect effect of perceived teacher support on achievement through like mathematics is moderated by gender in some countries, contradicting other studies in the literature (e.g., Thomson, Hillman, \& Wernert, 2012). For the conditional indirect effect through value of mathematics the outcome from this study support the literature (Gaspard et al., 2015; Marsh et al., 2005), but the outcome is also dependent on the level of perceived teacher support. However, this conclusion has a culture dimension. The varying gender differences across nations support the cultural specificity of gender as a moderator in these relations (Bofah \& Hannula, 2015; Hyde \& Mertz, 2009; Forgasz et al., 2015). The outcome of this study can influence educational policies on affect and achievement, because the relationship between affect and achievement is the backbone of many affective enhancement programs throughout the world. This is based on the fact that improving affect will lead to achievement and vice versa (Bofah, 2015). 
The results support the motivational and affective significance of social support (e.g., parental support) in students' academic performance (e.g., Rosenfeld et al., 2000). For instance, increasing close contact between teachers and their students would prove beneficial. Schools should also focus on cultivating supportive social relationships between parents and their children and inform parents about the benefits of motivational beliefs such as value and like math in their children's mathematics achievement.

In brief, this study attests to the findings in Rosenfeld et al. (2000), that support reduces uncertainty associated with affect, which then influences school outcomes. Similar models are supported by (Ahmed et al., 2010; Levitt, Levitt, Franco, \& Silver, 1995; Song et al., 2015). Results from this study indicate that educators should work to strengthen students' motivational beliefs so as to shape students' academic performance. For instance, students should receive more information and counselling about mathematics and their future use, which would stimulate their interest in mathematics. Educators should promote more positive affective measures by promoting specific and inclusive self-enhancement strategies to create a supportive and more effective teaching/learning environment for all students in an effort to improve school outcomes.

Some limitations should be considered when interpreting the results. First, data were based on self-report, and thus suffer the limitations associated with all selfreported data. Second, data were cross-sectional, so analyses cannot provide a causal interpretation which requires longitudinal data. Third limitation is that social support from peers was not measured.

Despite these limitations, this study makes significant contributions to the existing research in a number of ways. First, this study expands our understanding of the interplay between perceived social support and motivational beliefs in predicting achievement as well as the role of gender in that effect. This finding of a synergistic role of motivational belief in the relationship between perceived social support and achievement implies interventions that aim at strengthening motivational beliefs will be effective in promoting educational outcomes. Second, because of the strength of the TIMSS data, it is probably the strongest cross-cultural analysis of the relationship between social support and achievement in the African context.

In conclusion, this study provides a comprehensive view showing the differential roles of motivational beliefs in predicting achievement. It also provides a comprehensive picture showing the differential roles of gender beliefs and their interaction with perceived social support in predicting achievement.

\section{References}

Ahmed, W., Minnaert, A., van der Werf, G., \& Kuyper, H. (2010). Perceived social support and early adolescents' achievement: The mediational roles of motivational beliefs and emotions. Journal of Youth and Adolescence, 39(1), 36-46. https://doi.org/10.1007/s10964-008-9367-7.

Bofah, E. A. (2015). Reciprocal determinism between students' mathematics self-concept and achievement in an African context. In K. Krainer \& N. Vondrová (Eds.), CERME 9-Ninth Congress 
of the European Society for Research in Mathematics Education (pp. 1688-1694). Prague, Czech Republic. Retrieved from https://hal.archives-ouvertes.fr/hal-01287995/.

Bofah, E. A. (2016). A cross-cultural analysis of the dimensions of mathematics-related affect: Assessing the psychometric properties and the relationship with achievement (University of Helsinki, Department of Education, Research Report No. 390). University of Helsinki, Helsinki, Finland. Retrieved from https://helda.helsinki.fi/handle/10138/161278.

Bofah, E. A., \& Hannula, M. S. (2015). TIMSS data in an African comparative perspective: Investigating the factors influencing achievement in mathematics and their psychometric properties. Large-Scale Assessments in Education, 3(1), 4. https://doi.org/10.1186/s40536-015-0014-y.

Bollen, K. A. (1989). Structural equations with latent variables. Wiley series in probability and mathematical statistics. New York, NY: Wiley.

Bronfenbrenner, U. (1979). The ecology of human development: Experiments by nature and design. Cambridge, MA: Harvard University Press.

Bronfenbrenner, U. (1986). Ecology of the family as a context for human development: Research perspectives. Developmental Psychology, 22(6), 723-742. https://doi.org/10.1037/0012-1649.22. 6.723 .

Byrne, B. M. (2010). Structural equation modeling with AMOS: Basic concepts, applications, and programming (3rd ed.). New York: Routledge. http://doi.org/10.4324/9781410600219.

Chaman, M. J. M., Beswick, K., \& Callingham, R. (2014). Factors influencing mathematics achievement among secondary school students: A review. In N. Fitzallen, R. Reaburn, \& S. Fan (Eds.), The future of educational research: Perspectives of beginning researchers (Vol. 37, pp. 227-238). Rotterdam, The Netherlands: Sense Publishers. http://doi.org/10.1007/978-94-6209-512-0_19.

Chen, F. F. (2007). Sensitivity of goodness of fit indexes to lack of measurement invariance. Structural Equation Modeling: A Multidisciplinary Journal, 14(3), 464-504. https://doi.org/10.1080/ 10705510701301834.

Cheung, G. W., \& Rensvold, R. B. (2002). Evaluating goodness-of-fit indexes for testing measurement invariance. Structural Equation Modeling: A Multidisciplinary Journal, 9(2), 233-255. https://doi.org/10.1207/S15328007SEM0902_5.

Chiu, M. M., \& Chow, B. W. Y. (2010). Culture, motivation, and reading achievement: High school students in 41 countries. Learning and Individual Differences, 20(6), 579-592. https://doi.org/ 10.1016/j.lindif.2010.03.007.

Conger, A. J. (1974). A revised definition for suppressor variables: A guide to their identification and interpretation. Educational and Psychological Measurement, 34, 35-46. https://doi.org/10. 1177/001316447403400105.

Cutrona, C. E., Cole, V., Colangelo, N., Assouline, S. G., \& Russell, D. W. (1994). Perceived parental social support and academic achievement: An attachment theory perspective. Journal of Personality and Social Psychology, 66(2), 369-378. https://doi.org/10.1037//0022-3514.66.2. 369.

Eccles, J. S. (2007). Families, schools, and developing achievement-related motivations and engagement. In J. E. Grusec \& P. D. Hastings (Eds.), Handbook of socialization (pp. 665-691). New York, NY: The Guilford Press.

Eccles, J. S. (2009). Who am I and what am I going to do with my life? Personal and collective identities as motivators of action. Educational Psychologist, 44(2), 78-89. https://doi.org/10. 1080/00461520902832368.

Eccles, J. S., Adler, T. F., Futterman, R., Goff, S. B., Kaczala, C. M., Meece, J. L., et al. (1983). Expectations, values, and academic behaviors. In J. T. Spence (Ed.), Achievement and achievement motives: Psychological and sociological approaches (pp. 76-146). San Francisco, CA: W. H. Freeman and Company.

Eccles, J., Wigfield, A., Harold, R. D., \& Blumenfeld, P. (1993). Age and gender differences in children's self- and task perceptions during elementary school. Child Development, 64(3), 830-847. https://doi.org/10.2307/1131221.

Edwards, J. R., \& Lambert, L. S. (2007). Methods for integrating moderation and mediation: A general analytical framework using moderated path analysis. Psychological Methods, 12(1), 1-22. https://doi.org/10.1037/1082-989X.12.1.1. 
Forgasz, H., Leder, G., Mittelberg, D., Tan, H., \& Murimo, A. (2015). Affect and gender. In B. Pepin \& B. Roesken-Winter (Eds.), From beliefs to dynamic affect systems in mathematics education (pp. 245-268). Cham, Switzerland: Springer. http://doi.org/10.1007/978-3-319-06808-4_12.

Foy, P., Brossman, B., \& Galia, J. (2013). Scaling the TIMSS and PIRLS 2011 achievement data. Chestnut Hill, MA. Retrieved from http://timssandpirls.bc.edu/methods/index.html.

Frenzel, A. C., Pekrun, R., \& Goetz, T. (2007). Girls and mathematics-A "hopeless" issue? A control-value approach to gender differences in emotions towards mathematics. European Journal of Psychology of Education. http://doi.org/10.1007/BF03173468.

Gaspard, H., Dicke, A. L., Flunger, B., Schreier, B., Häfner, I., Trautwein, U., et al. (2015). More value through greater differentiation: Gender differences in value beliefs about math. Journal of educational psychology, 107(3), 663-677. https://doi.org/10.1037/edu0000003.

Gerdes, P. (1998). Culture and mathematics education in (Southern) Africa. In C. Alsina, J. M. Alvarez, B. Hodgson, C. Laborde, \& A. Perez (Eds.), 8th International Congress on Mathematical Education. Selected Lectures (pp. 221-231). Sevilla: S.A.E.M. Thales.

Hayes, A. F. (2009). Beyond Baron and Kenny: Statistical mediation analysis in the new millennium. Communication Monographs, 76(4), 408-420.

Hayes, A. F. (2013). Introduction to mediation, moderation, and conditional process analysis: A regression based approach. New York: The Guilford Press. http://doi.org/978-1-60918-230-4.

Hayes, A. F. (2015). An index and simple test of linear moderated mediation. Multivariate Behavioral Research, 50(1), 1-22. https://doi.org/10.1080/00273171.2014.962683.

Hayes, A. F., \& Preacher, K. J. (2013). Conditional process modeling: Using structural equation modeling to examine contingent causal processes. In G. R. Hancock \& R. O. Mueller (Eds.), Structural equation modeling: A second course (2nd ed., pp. 219-266). Charlotte, NC: Information Age Publishing.

Hyde, J. S., Fennema, E., \& Lamon, S. J. (1990). Gender differences in mathematics performance: A meta-analysis. Psychological Bulletin, 107(2), 139-155.

Hyde, J. S., Lindberg, S. M., Linn, M. C., Ellis, A. B., \& Williams, C. C. (2008). Gender similarities characterize math performance. Science, 321(July), 494-495. https://doi.org/10.1126/science. 1160364.

Hyde, J. S., \& Mertz, J. E. (2009). Gender, culture, and mathematics performance. Proceedings of the National Academy of Sciences of the United States of America, 106(22), 8801-8807. https:// doi.org/10.1073/pnas.0901265106.

Jacobs, J. E., Lanza, S., Osgood, D. W., Eccles, J. S., Wigfield, A., Osgood, W. D., et al. (2002). Changes in children's self-competence and values: Gender and domain differences across grades one through twelve. Child Development, 73(2), 509-527. https://doi.org/10.1111/1467-8624. 00421.

Keith, T. Z. (2015). Multiple regression and beyond: An introduction to multiple regression and structural equation modeling ( 2 nd ed.). New York: Routledge.

Levitt, M. J., Levitt, J. L., Franco, N., \& Silver, M. E. (1995). Social support networks and achievement: The role of network member attitudes. In Paper presented at the Annual Meeting of the American Educational Research Association. San Francisco, CA. Retrieved from http://eric.ed. gov/?id=ED385906.

Little, T. D. (1997). Mean and Covariance Structures (MACS) analyses of cross-cultural data: Practical and theoretical issues. Multivariate Behavioral Research, 32, 53-76.

Little, T. D., Card, N. A., Bovaird, J. A., Preacher, K. J., \& Crandall, C. S. (2007). Structural equation modeling of mediation and moderation with contextual factors. In T. D. Little, N. A. Card, \& J. A. Bovaird (Eds.), Modeling contextual effects in longitudinal studies (pp. 207-230). Mahwah, NJ: Lawrence Erlbaum Associates.

Lubke, G. H., Dolan, C. V., Kelderman, H., \& Mellenbergh, G. J. (2003). On the relationship between sources of within- and between-group differences and measurement invariance in the common factor model. Intelligence, 31(6), 543-566. https://doi.org/10.1016/S0160-2896(03)00051-5.

MacKinnon, D. P., Krull, J. L., \& Lockwood, C. M. (2008). Equivalence of the mediation, confounding and suppression effect. Prevention Science, 1(4), 173-181. https://doi.org/10.1016/j. drugalcdep.2008.02.002.A. 
Mackinnon, S. P. (2012). Perceived social support and academic achievement: Cross-lagged panel and bivariate growth curve analyses. Journal of Youth and Adolescence, 41(4), 474-485. https:// doi.org/10.1007/s10964-011-9691-1.

Marsh, H. W., Abduljabbar, A. S., Abu-Hilal, M. M., Morin, A. J. S., Abdelfattah, F., Leung, K. C., et al. (2013). Factorial, convergent, and discriminant validity of TIMSS math and science motivation measures: A comparison of Arab and Anglo-Saxon countries. Journal of Educational Psychology, 105(1), 108-128. https://doi.org/10.1037/a0029907.

Marsh, H. W., Trautwein, U., Lüdtke, O., Köller, O., \& Baumert, J. (2005). Academic self-concept, interest, grades, and standardized test scores: Reciprocal effects models of causal ordering. Child Development, 76(2), 397-416. https://doi.org/10.1111/j.1467-8624.2005.00853.x.

Meece, J. L., Glienke, B. B., \& Burg, S. (2006). Gender and motivation. Journal of School Psychology, 44(5), 351-373. https://doi.org/10.1016/j.jsp.2006.04.004.

Muthén, L. K., \& Muthén, B. O. (1998). Mplus user's guide (7th ed.). Los Angeles, CA: Muthén and Muthén.

Mutodi, P., \& Ngirande, H. (2014). The influence of students' perceptions on mathematics performance. A case of a selected high school in South Africa. Mediterranean Journal of Social Sciences, 5(3), 431-445. http://doi.org/10.5901/mjss.2014.v5n3p431.

Pollack, J. M., Vanepps, E. M., \& Hayes, A. F. (2012). The moderating role of social ties on entrepreneurs' depressed affect and withdrawal intentions in response to economic stress. Journal of Organizational Behavior, 33, 839-862. https://doi.org/10.1002/job.1794.

Preacher, K. J., \& Hayes, A. F. (2008). Asymptotic and resampling strategies for assessing and comparing indirect effects in multiple mediator models. Behavior Research Methods, 40(3), 879-891. https://doi.org/10.3758/BRM.40.3.879.

Preacher, K. J., Rucker, D. D., \& Hayes, A. F. (2007). Addressing moderated mediation hypotheses: Theory, methods, and prescriptions. Multivariate Behavioral Research, 42(1), 185-227.

Roeser, R. W., Eccles, J. S., \& Sameroff, A. J. (2000). School as a context of early adolescents' academic and social-emotional development: A summary of research findings. The Elementary School Journal, 100(5), 443. https://doi.org/10.1086/499650.

Rosenfeld, L., Richman, J., \& Bowen, G. (2000). Social support networks and school outcomes: The centrality of the teacher. Child and Adolescent Social Work Journal, 17(3), 205-226.

Rubin, D. B. (1987). Multiple imputation for nonresponse in surveys (Vol. 307). New York: Wiley.

Rucker, D. D., Preacher, K. J., Tormala, Z. L., \& Petty, R. E. (2011). Mediation analysis in social psychology: Current practices and new recommendations. Social and Personality Psychology Compass, 5(6), 359-371. https://doi.org/10.1111/j.1751-9004.2011.00355.x.

Rueger, S. Y., Malecki, C. K., \& Demaray, M. K. (2009). Relationship between multiple sources of perceived social support and psychological and academic adjustment in early adolescence: Comparisons across gender. Journal of Youth and Adolescence, 39(1), 47-61. https://doi.org/10. 1007/s10964-008-9368-6.

Ryan, R. M., \& Deci, E. L. (2000). Intrinsic and extrinsic motivations: Classic definitions and new directions. Contemporary Educational Psychology, 25, 54-67. https://doi.org/10.1006/ceps. 1999.1020.

Ryan, R. M., \& Deci, E. L. (2009). Promoting self-determined school engagement: Motivation, learning, and well-being. In K. R. Wentzel \& A. Wigfield (Eds.), Handbook of motivation at school (pp. 171-195). New York: Routledge.

Sass, D. A. (2011). Testing measurement invariance and comparing latent factor means within a confirmatory factor analysis framework. Journal of Psychoeducational Assessment, 29(4), 347-363. https://doi.org/10.1177/0734282911406661.

Schneider, B. H., Tomada, G., Normand, S., Tonci, E., \& de Domini, P. (2008). Social support as a predictor of school bonding and academic motivation following the transition to Italian middle school. Journal of Social and Personal Relationships, 25(2), 287-310. https://doi.org/10.1177/ 0265407507087960.

Singh, K., Granville, M., \& Dika, S. (2002). Mathematics and science achievement: Effects of motivation, interest, and academic engagement. The Journal of Educational Research, 95(6), 323-332. https://doi.org/10.1080/00220670209596607. 
Song, J., Bong, M., Lee, K., \& Kim, S. (2015). Longitudinal investigation into the role of perceived social support in adolescents' academic motivation and achievement. Journal of Educational Psychology, 107(3), 821-841. https://doi.org/10.1037/edu0000016.

Steenkamp, J.-B. E. M., \& Baumgartner, H. (1998). Assessing measurement invariance in crossnational consumer research. Journal of Consumer Research, 25(1), 78-90.

Stromquist, N. P. (2007). Gender equity education globally. In Handbook for achieving gender equity through education (2nd ed., pp. 33-42). Mahwah, NJ: Erlbaum.

Thomson, S., Hillman, K., \& Wernert, N. (2012). Monitoring Australian year 8 student achievement internationally: TIMSS 2011. Camberwell, Victoria, Australia: Australian Council for Educational Research. Retrieved from http://research.acer.edu.au/timss_pirls_2011/1/.

Vandenberg, R. J., \& Lance, C. E. (2000). A review and synthesis of the measurement invariance literature: Suggestions, practices, and recommendations for organizational research. Organizational Research Methods, 3, 4-70. https://doi.org/10.1177/109442810031002.

Watt, H. M. G. (2004). Development of adolescents' self-perceptions, values, and task perceptions according to gender and domain in 7th- through 11th-grade Australian students. Child Development, 75(5), 1556-1574. https://doi.org/10.1111/j.1467-8624.2004.00757.x.

Watt, H. M. G., Shapka, J. D., Morris, Z. A., Durik, A. M., Keating, D. P., \& Eccles, J. S. (2012). Gendered motivational processes affecting high school mathematics participation, educational aspirations, and career plans: A comparison of samples from Australia, Canada, and the United States. Developmental Psychology, 48(6), 1594-1611.

Wentzel, K. R. (1998). Social relationships and motivation in middle school: The role of parents, teachers, and peers. Journal of Educational Psychology, 90(2), 202-209. https://doi.org/10.1037/ 0022-0663.90.2.202.

West, S. G., Taylor, A. B., \& Wu, W. (2012). Model fit and model selection in structural equation modeling. In R. H. Hoyle (Ed.), Handbook of structural equation modeling (pp. 209-231). New York: The Guilford Press.

Wigfield, A., \& Cambria, J. (2010). Students' achievement values, goal orientations, and interest: Definitions, development, and relations to achievement outcomes. Developmental Review, 30(1), 1-35. https://doi.org/10.1016/j.dr.2009.12.001.

Wigfield, A., Eccles, J. S., Yoon, K. S., Harold, R. D., Arbreton, A. J. A., Freedman-Doan, C., et al. (1997). Change in children's competence beliefs and subjective task values across the elementary school years: A 3-year study. Journal of Educational Psychology, 89(3), 451-469. https://doi. org/10.1037/0022-0663.89.3.451.

Zhao, X., Lynch, J. G., Jr., \& Chen, Q. (2010). Reconsidering Baron and Kenny: Myths and truths about mediation analysis. Journal of Consumer Research, 37(2), 197-206. https://doi.org/10. $1086 / 651257$.

Open Access This chapter is licensed under the terms of the Creative Commons Attribution 4.0 International License (http://creativecommons.org/licenses/by/4.0/), which permits use, sharing, adaptation, distribution and reproduction in any medium or format, as long as you give appropriate credit to the original author(s) and the source, provide a link to the Creative Commons license and indicate if changes were made.

The images or other third party material in this chapter are included in the chapter's Creative Commons license, unless indicated otherwise in a credit line to the material. If material is not included in the chapter's Creative Commons license and your intended use is not permitted by statutory regulation or exceeds the permitted use, you will need to obtain permission directly from the copyright holder.

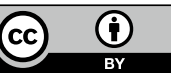




\title{
Chapter 7
}

\section{Assessment and Structure of Secondary Students' Personal Meaning Related to Mathematics}

\author{
Maike Vollstedt and Christoph Duchhardt
}

\begin{abstract}
Students are in need of meaning when dealing with mathematics in a school context. To describe meaning, objective and personal facets need to be distinguished. This paper focuses on students' perspectives in describing the concept of personal meaning as personal relevance of a mathematical concept or action. To conceptualise personal meaning for quantitative studies, a survey was developed that makes 16 different personal meanings assessable with reliable scales. Results from cluster and correlation analyses generally support the underlying theory of personal meaning. Exploratory factor analyses suggest two meta-factors structuring the different personal meanings into those showing an orientation to mathematics and to social inclusion, respectively. Future research intends to investigate the relationship between personal meaning and affective psychological constructs like motivation and interest.
\end{abstract}

Keywords Personal meaning in mathematics - Orientation to individual • Orientation to mathematics - Orientation to social inclusion - Survey construction • Item response theory (IRT)

\subsection{Introduction}

The aim for meaning in education has been pervasive for many years and meaningful learning is assumed to be a fundamental drive (Biller, 1991) as well as one of the major goals (Vinner, 2007) of education. Hence, one of the challenges of (mathematics) education is to find convincing responses to the quest for meaning as well as to develop learning environments that foster meaningful learning. In addition, it is important to study personal meaning to comprehend how students relate mathemat-

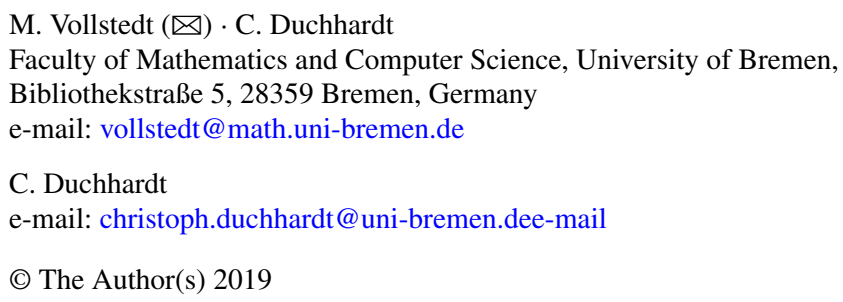


ical contents to their biography so as to better understand their learning processes (Meyer, 2008). Yet even when only the field of mathematics education is considered, the notion of meaning is complex and multifaceted. This article elaborates on a facet that considers the perspectives of the students and asks what is personally relevant for them when they are involved with mathematics in a school context. Vollstedt (2011c) names this facet personal meaning (c.f. also Vollstedt, 2010a, 2011a). In a former qualitative study (see Sect. 7.2.2, cf. Vollstedt, 2011c), 17 different personal meanings were reconstructed from interviews with secondary students. Subsequently, a survey was constructed with the aim to assess those different personal meanings. This paper reports on the study in which (1) the survey was tested whether it is a reliable instrument for the assessment of those 17 personal meanings; and (2) the theoretical model of personal meaning as presented in Vollstedt (2011c) was empirically tested on a larger data set.

\subsection{Theoretical Framework}

It is generally accepted that humans have a need for meaning (e.g. Biller, 1991; Bruner, 1991; Frankl, 1988; Heine, Proulx, \& Vohs, 2006; Vinner, 2007). Accordingly, the question for meaning is dealt with in very different scientific communities among which philosophy may be the most fundamental one (Kilpatrick, Hoyles, \& Skovsmose, 2005b). Skovsmose (2016) gives a brief overview of philosophers that developed theories of meaning with a paradigmatic interpretation from Plato in antiquity to Frege and Wittgenstein in the 19th and 20th centuries. In addition, the question for meaning in life is intensively discussed in different fields of psychology (e.g. Frankl, 1984; Heine et al. 2006; Reber, 2018; Schnell, 2011).

In general, Heine, Proulx, and Vohs characterise meaning from a psychological perspective as relation between people, places, objects, and ideas:

\footnotetext{
In simple terms, meaning is what connects things to other things in expected ways-anything and any way that things can be connected. Meaning is what connects the people, places, and things around oneself: hammers to nails, cold to snow, mothers to daughters, or dawn to the rising sun. Meaning connects elements of the self: thoughts, behaviours, desires, attributes, abilities, roles, and autobiographical memories. Meaning is what connects people to that which lies beyond the self: the people, places, and things that surround them. Meaning can come in as many forms as there are ways to relate these elements of perception and understanding (2006, p. 90).
}

In the basic assumptions of their Meaning Maintenance Model (MMM) they propose that humans seek meaning in three domains: the external world (combining the beliefs about the outside world), the self (combining beliefs about oneself to arrive at a coherent self across time as well as across roles and contexts), and the self in relation to the outside world (the desire be part of a coherent cultural worldview). Hence, the need for meaning is related to all aspects of human life and, thus, it is only reasonable to assume that children and adolescents also strive for meaning at school. Although the meaning of life and meaningful learning may constitute dif- 
ferent notions, they may well relate to the same source (Vinner, 2007). Accordingly, meaning also plays an important role in education (Reber, 2018). In the following, the focus will thus be on meaning in education with special attention to mathematics education.

\subsubsection{Aspects of Meaning}

The fundamental role of meaning in education is indisputable and the term meaning is used in a very big share of the papers that have recently been published in mathematics education journals. ${ }^{1}$ However, hardly any paper does consider meaning as a central focus of study so that one can still argue that the notion of meaning has not yet received the focus that it deserves in mathematics education (Skovsmose, 2016; Thompson, 2013). One of the reasons why meaning is not discussed more may be related to a difficulty inherent in the concept itself: it is hard to capture conceptually. This may also be the reason why there is yet no commonly accepted definition for the term meaning in the field of mathematics education (Kilpatrick, Hoyles, \& Skovsmose, 2005c; Thompson, 2013). On the contrary, there is a rich diversity of meanings for meaning. A resulting problem is that different interpretations of the term meaning are often used synonymously, which—strictly speaking — are not synonymous at all: a global understanding in contrast to different facets which each focus on a certain aspect of meaning.

Based on the discussions within the BACOMET-group, Kilpatrick et al. (2005c, pp. 12-15) present different facets of meaning of a mathematical concept content $X$, which are heavily linked: the meaning of $X$ from a content perspective (as a content to be taught and as a content of reference from mathematical theory), the meaning of $X$ within different spheres of practice (e.g. in scientific mathematics, in applications, or in the mathematics classroom), and the meaning of $X$ from the perspectives of the different individuals involved in its construction (the student's vs. the teacher's point of view). They conclude:

These views are actually different meanings of meaning insofar as different methodological tools are needed to explore them, different theoretical frameworks, etc. They insist on several different dimensions of meaning: psychological, social, anthropological, mathematical, epistemological or didactical. But all these dimensions must not be seen as isolated, one from the other. In fact they constitute a system of meanings whose interactions shape what may be seen as the meaning of a mathematical concept (2005c, pp. 14-15).

Another approach to defining meaning comes from an interdisciplinary group of educational scientists (Birkmeyer, Combe, Gebhard, Knauth, \& Vollstedt, 2015). In

\footnotetext{
${ }^{1}$ The authors have exemplarily checked all original articles (except editorials, call for papers, book reviews etc.) that were published in 2018 for the journals Educational Studies in Mathematics (ESM) and ZDM Mathematics Education. From 49 articles published in ESM, 42 refer at least once to one facet or the other of meaning; for ZDM, 81 out of 93 articles refer to meaning. This means that more than $85 \%$ of the articles deal with meaning in one way or the other. [We want to give credit to Rudolf Sträßer who gave us the idea of counting articles in the first place].
} 
a theoretical article, they present ten theses to build up a theoretical, conceptual, and pragmatic basis for describing the constitution of meaning. They relate meaning to cognition and affect: For the individual learner's acts of consciousness, meaning denotes a dimension that - apart from the realms of experience and action-focuses on a sphere of self-assuring clearance and clarification in the process of learning. The achievements of the consciousness with respect to giving meaning, as well as its affective embedment, generate effects of meaningfulness in learning processes, which are more or less distinct or can be experienced as such. Hence, it is also a matter of an inner psychic experience of meaning. This is neither sensation only nor thinking without emotion, and neither pure and isolated cognition nor knowledge that is independent from consciousness.

Following this description, the global concept of meaning has a dialectical relation to psychological as well as cognitive aspects. Both aspects contribute to the development of one's own identity: when something is meaningful to an individual, the content somehow makes sense for him or her (in terms of sense-making and understanding) and she or he gains orientation from it (in terms of understanding oneself and the development of one's own identity) (Birkmeyer et al., 2015). Hence, meaning is something other than pure sense-making of the content as it additionally relates the content to the individual's identity and biography. This relation is elaborated in the description of the relational framework of the study (see Sect. 7.2.2.1 below).

The differentiation between cognitive and affective aspects of meaning also becomes obvious when one considers that "even if students have constructed a certain meaning of a concept, that concept may still not yet be 'meaningful' for him or her in the sense of relevance to his/her life in general" (Kilpatrick et al., 2005c, p. 14). The first kind of meaning mentioned in the quotation involves a cognitive interpretation as the construction of a concept's meaning and usually involves sense-making processes. The second kind of meaning, however, is of affective nature as the relevance of the concept is related to the personal life of the individual. Generally speaking, two very different aspects of meaning can be distinguished here, namely "those relating to relevance and personal significance (e.g., 'What is the point of this for me?') and those referring to the objective sense intended (i.e., signification and referents). These two aspects are distinct and must be treated as such" (Howson, 2005, p. 18). In line with Howson's distinction, Vollstedt (2010a, 2011c) uses the term personal meaning to denote the first aspect of relevance and personal significance. Personal meaning denotes the personal relevance of a mathematical procedure, content, or the people involved in the learning process for an individual, in our case mostly a student of mathematics. Key questions in this area include: What is personally relevant for me when I am involved with mathematical contents? Why should I learn this? How do the contents relate to my own biography? In addition, we suggest to further differentiate Howson's second facet of the intended objective sense of a mathematical concept into collective meaning and innermathematical meaning. Collective meaning on the one hand denotes the relevance of a mathematical procedure or content for a certain group of people in contrast to an individual. This group of people can be characterised by a set of shared beliefs about the use of mathematics e.g. in terms 
of application in a certain profession, in life, in other scientific areas etc. The key question in this field is: What is the relevance of a mathematical procedure or content for certain professions and applications in other scientific areas? Innermathematical meaning on the other hand denotes the relevance of a mathematical procedure or content without a relation that refers to something else than mathematical theory. Key questions include: What is the meaning of a certain mathematical theorem for other areas of mathematics? Why are some theorems judged as being more important than others (e.g. fundamental theorems)? How could criteria of relevance look like? In addition to this distinction, other differentiations between different facets of meaning are possible. Reber (2018), for instance, discusses objective and subjective meaning in the context of meaning in life and making school meaningful. In his understanding of objective meaning, he enlarges Metz's (2013) understanding of meaning as the pursuit of " "the good, the true, and the beautiful' ... as a rough way of referring to certain kinds of moral achievement, intellectual reflection, and aesthetic creation" (p. 5). Reber understands objective meaning as "knowledge about meaning (roughly corresponding to the true), caring (good) and aesthetic experience (beautiful) [and further includes] meaning from creating identity, maintaining tradition or from agency" (2018, p. 3). With reference to Wolf (2010), he finally makes the following distinction: "Objective meaning is related to actions and parts of life that provide meaning without regard of whether a person herself considers these parts as meaningful. Subjective meaning is the personal experience of meaningfulness" (2018, p. 3). Personal meaning understood as personal relevance of a mathematical procedure, content, or the people involved in the learning process for the individual is, thus, per se subjective. In addition, objective meaning can also become personally relevant and, hence, subjective and personal.

\subsubsection{Personal Meaning}

It can be seen that the term meaning is multifaceted and hard to describe. As the focus of this study is on the students' points of view, the following elaborations are restricted to the field of personal meaning and are characterized in line with Howson's (2005) previously discussed distinction by personal relevance or significance. Accordingly, Vollstedt's (2011c) definition of a mathematical procedure, content, or the people involved in the learning process being personally meaningful for an individual when it is/they are personally relevant for him or her is adopted. The individual then shows a special relation to the object, action of person in question and relates it/him/her to his or her own biography (Meyer, 2008). Thus, the focus on the learner's perspective is emphasized. Accordingly, this paper does not focus on what might be meaningful from a normative or domain-specific perspective, but—on the contrary - the aspects students judge to be meaningful for them. As Kilpatrick et al. (2005c) pointed out (see above), these do not necessarily have to (but may) be the same. 
Kilpatrick et al. (2005c) also link meaning to aspects important to the student himor herself personally, being a student in the school environment, and being involved in a bigger system of education and relationships:

Some students find it pointless to do their mathematics homework; some like to do trigonometry, or enjoy discussions about mathematics in their classrooms; some students' families think that mathematics is useless outside school; other students are told that because of their weakness in mathematics they cannot join the academic stream (p. 9).

Among others, this quotation also relates meaning to aspects such as purpose or usefulness, interest and motivation, the need for relatedness and friendship, as well as the students' performance and perspectives on their lives. All these can become relevant for the construction of personal meaning in a school context. When taking the personal relevance of an object or action as a defining criterion for personal meaning, all of these instances can be taken as examples for this concept. Thus, the rich diversity of personal meaning is maintained when thinking of it as personal relevance.

But is there a difference between personal meaning and other affective concepts such as interest, motivation, values, goals etc.? To approach this question, Heine et al.'s (2006) basic propositions shall be considered. They propose that human beings are meaning-makers who are able to create relations where they do not naturally exist and who create mental representations of expected relations that link elements of their external world, elements of the self, as well as elements of the self to the external world and vice versa. Those elements are to be integrated into existing relational structures so that a feeling of congruity is caused. This feeling, in turn, motivates people to interpret or, if necessary, reinterpret the elements so that they are consistent with their mental representations. The overall goal is establish "a sense of normalcy and coherence in their lives" (Heine et al., 2006, p. 89). Heine et al. conclude that "the one account that is parsimonious across each and every instance is that people are striving to affirm coherent structures of expected relationships" (2006, p. 102), i.e. meaning. Thus, the need for meaning and a coherent system of meaning is forming the basis for the development of a coherent sense of self. Thus meaning forms the basis of the other affective constructs and can be assumed to be their generating force. In addition, the idea of meaning is very broad and covers lots of aspects. When taking over the students' perspective and asking what is personally relevant for them, also ideas become relevant which are also important in other psychological theories such as values, goals, or motivation. Thus, there is a very close relationship between meaning and the other constructs so that a considerable amount of overlap can be assumed between the concepts and no sharp line of division can be drawn. Empirical studies are needed to further elaborate on the finer structure and relation between those concepts. First empirical results that help to discuss these issues can be found on the one hand by e.g. Mitchell (1993) who considers meaningfulness as one out of five catch or hold facets respectively that generate situational interest (meaningfulness and involvement constitute the two hold facets whereas group work, computers, and puzzles constitute the three catch facets). Suriakumaran and colleagues, on the other hand, have a deeper look at the structural relationship between meaning and 
motivation. From a theoretical perspective, they propose meaning as a generating source for the development of values, which, in turn, are crucial for the development of motivation if one follows Expectancy-Value-Theory (Wigfield, Tonks, \& Klauda, 2016; cf. Suriakumaran, Duchhardt, \& Vollstedt, 2017). To enable future studies that shed some more light on these issues, the survey that was developed in this study may be used.

\subsubsection{Construction of Personal Meaning}

So how is personal meaning constructed? The model of personal meaning (Vollstedt, 2011c) adopted for this study consists of a relational framework involving different concepts from mathematics education (e.g. mathematical beliefs), educational science (with a special focus on educational experience and learner development, e.g. developmental tasks), and educational psychology (e.g. learning motivation, academic self-concept, basic needs; see Fig. 7.1). The framework describes a (learning) situation in which an individual is dealing with subject content. The context of this learning situation does not only consist of the plain subject context; rather both the situation in the classroom and the individual's prior knowledge and experience are relevant for the construction of personal as well as objective meaning (Kilpatrick et al., 2005c). Mercer (1993) states:

What counts as context for learners ... is whatever they consider relevant. Pupils accomplish educational activities by using what they know to make sense of what they are asked to do. As best they can, they create a meaningful context for an activity, and the context they create consists of whatever knowledge they invoke to make sense of the task situation. (pp. 31-32, italics in original)

Therefore the students decide what information and experiences are relevant for them, to deal with a given task. These are, however, subject to cultural influences as culture has a strong impact on the way learning takes place in any learning situation (see Vollstedt, 2010b, 2011a, 2011b, 2011c for the impact of culture and context on personal meaning). According to Mercer (1993, p. 43; see also Birkmeyer et al., 2015), learning in the classroom depends both on culture and context as it is "(a) culturally saturated in both its content and structure; and (b) accomplished through dialogue which is heavily dependent on an implicit context constructed by participants from current and past shared experience."

Also, according to Vollstedt's (2011c) relational framework, certain preliminaries are relevant that constitute parts of the individual's personality and identity, i.e. personal background and personal traits respectively. Aspects of the personal background include an individual's cultural and family background. Skovsmose (2005) agrees that making mathematics education meaningful is essential. I also agree that meaningfulness has to do with the cultural background of the students, but I would argue that meaningfulness has much to do with another dimension as well, namely the foreground of each student (p. 6).

He defines the complex notion of the foregrounds of a person as follows: 


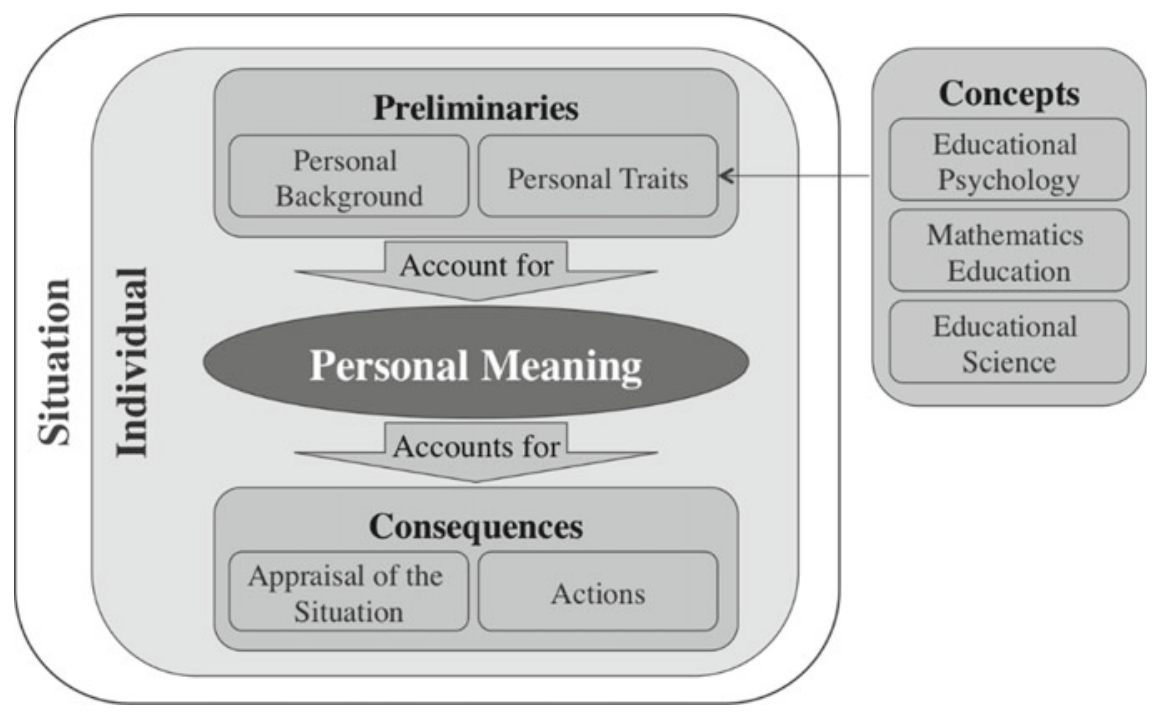

Fig. 7.1 Relational framework of personal meaning (Vollstedt, 2011c)

On the one hand, a foreground is formed through the possibilities, tendencies, propensities, obstructions, and barriers, which the social context provides for a person. One can therefore see the foreground as structured through economic, political, cultural, and discursive parameters.... On the other hand, one should not think of the foreground of a person as a simple objective affair. The foreground is formed as much through the person's experiences and interpretations of possibilities, tendencies, propensities, obstructions, and barriers (2014, p. 5 , italics in original).

Thus, the foreground of a person is not just objectively given to him or her, but rather is a personal interpretation of former experiences and future possibilities (Skovsmose, 1994, 2005, 2014). Intentionality is another important part of foreground (Skovsmose, 2016).

The foreground, then, is one important aspect of the individual's personal traits together with various concepts from for example, mathematics education, educational science, and educational psychology. Another central concept, which is strongly linked to the students' foreground, is developmental tasks (Havighurst, 1972). Meyer (2008) connects developmental tasks to personal meaning such that the developmental tasks posed by society are the engine of learning. He explains that the student who experiences meaning, or who has the feeling that the teacher demands things that are meaningless, argues from his or her biographical situation, anticipating his or her future in a particular way. Thus, the construction of personal meaning is the production of objective meaning of content with relation to the person itself. Meaningfulness is the expression of and simultaneous work on the development of competence and the construction of identity. Meaning builds a bridge towards the content, relates it to imagination, experiences, attitudes, and values, and relates it at the same time to the environment separate from teaching and school. 
Other influential concepts that appear to play a decisive role for the construction of personal meaning are mathematical beliefs (Op 't Eynde \& Verschaffel, 2002), different aspects of learning motivation (Krapp, 1999), academic self-concept (Marsh, 1986), and the three basic needs for autonomy, competence, and relatedness (Deci \& Ryan, 2002).

Based on these preliminaries, the individual then constructs personal meaning with relation to learning content in the school context. Therefore, the construction of personal meaning is inherently subjective and individual. This means that every person constructs her or his own meaning with respect to a certain object or action. There is no given objective meaning, which can simply be adopted. Meaning cannot be endowed. Also, as the construction of meaning is not collective but individual; different students attending the same lesson can also construct different meanings for it. However, if a certain meaning is offered by the teacher or it is likely due to the context of the task, this meaning can be assimilated. Yet the individual is involved in the process of constructing a meaning before a certain personal meaning is generated.

In addition, personal meanings can, but do not have to be reflected on. On the one hand, this suggests that the process of construction of personal meaning may in some aspects be dominant in the situation so that one is aware of what is going on; the meaning enters consciousness. An aha-experience (Liljedahl, 2005), for instance, is an example of a meaning, which is dominant and conscious in the actual situation. On the other hand, meaning does not have to be conscious but can be constructed implicitly so that it is there without being dominant in the situation. From a constructivist perspective, Kilpatrick et al. (2005a, p. 137) state that in a learning situation, "the problem of construction of meaning itself is not really tackled. This is an evasive problem: It is difficult to know what each partner thinks; we can only hypothesise this by interpreting what they do and say." So, although it is not possible to directly ask for personal meaning, it is still possible to ask for it indirectly and for aspects or concepts related to it. Therefore, it is possible to hypothesise about personal meaning from interpreting interview data. The premise is that the construct of personal meaning is researchable with qualitative methods.

According to the framework in Fig. 7.1, the situation in which the student is involved is assessed depending on which personal meanings have been constructed and with relation to his of her personal background and personal traits, especially the foreground (Skovsmose, 2014). Depending on the appraisal of the situation, the different outcomes may then, accordingly, be followed by different actions that may have intentional or functional character. Thus, different actions can result from different personal meanings when dealing with mathematics. To conclude, the key characteristics of personal meaning are that (1) it is subjective and individual, (2) its construction is context bound, and (3) it can be reflected on, but does not have to.

\subsubsection{Development of the Model of Personal Meaning}

The model of personal meaning discussed here was developed in a former qualitative study (Vollstedt, 2011c) that was embedded in the Graduate Research Group on 
Educational Experience and Learner Development at the University of Hamburg, Germany. The main focus of this research was on the learners' perspective on their educational process. Taking this perspective, Vollstedt (2011c) demonstrates that mathematical content and learning mathematics contain a productive range of aspects that may be personally relevant for the students.

The model resulting from the study was developed from 34 guided interviews conducted with students from the lower secondary level in Germany and Hong Kong ${ }^{2}$ (17 interviews per country with students from grade 9 or 10 aged 15-16). The guided interviews began with a sequence of stimulated recall (Gass \& Mackey, 2000) in which the students were shown a video abstract of five to ten minutes from the last lesson they attended. Their task was to utter and reflect on the thoughts they had when having attended the lesson. The interviews then tackled various topics inspired by the relational framework of personal meaning (see above) and lasted for about 35-45 min. Sample questions were for instance: How did you like this mathematics lesson? What was especially interesting? What feelings do you relate to mathematics lessons? Why do you learn mathematics? What can mathematics be used for? (cf. Vollstedt, 2011c for the detailed interview guide) The data were coded following Grounded Theory (Strauss \& Corbin, 1990; see Vollstedt, 2015 for a detailed description of the coding process) and theoretical saturation (Strauss $\&$ Corbin, 1990) was reached. In the course of the analysis process after the last two interviews, no new categories were developed and the relationships among the categories seemed well established and validated. Also, from a theoretical point of view, the theory could be judged as thick for this age group. This, however, does not mean that the theory may not require subsequent revision. Although the theory of personal meaning may be corroborated by future research, it may well be that it can also be elaborated further (Vollstedt, 2015).

In total, 17 different personal meanings were reconstructed from the data. Those personal meanings were then further developed into seven types according to theoretical perspectives. The typology was constructed in relation to the level of the orientation to mathematics and the self of each personal meaning (cf. Fig. 7.2; see Vollstedt, 2011a, 2015).

As this model was developed from the analysis of 34 student interviews, there was the need to examine if the theory of personal meaning is supported empirically with a larger sample.

\footnotetext{
${ }^{2}$ The aim of the study was on the one hand to develop an empirically grounded model of personal meaning. On the other hand, another research question tackled the role of the learning culture the students are accustomed to. Thus, the study was conducted in Germany and Hong Kong serving as examples for two very different learning cultures such as the Western and the Confucian Heritage Culture (CHC). Similarities and differences could be worked out for the students from the two cultures (cf. Vollstedt, 2010b, 2011a, 2011b, 2011c for more information).
} 


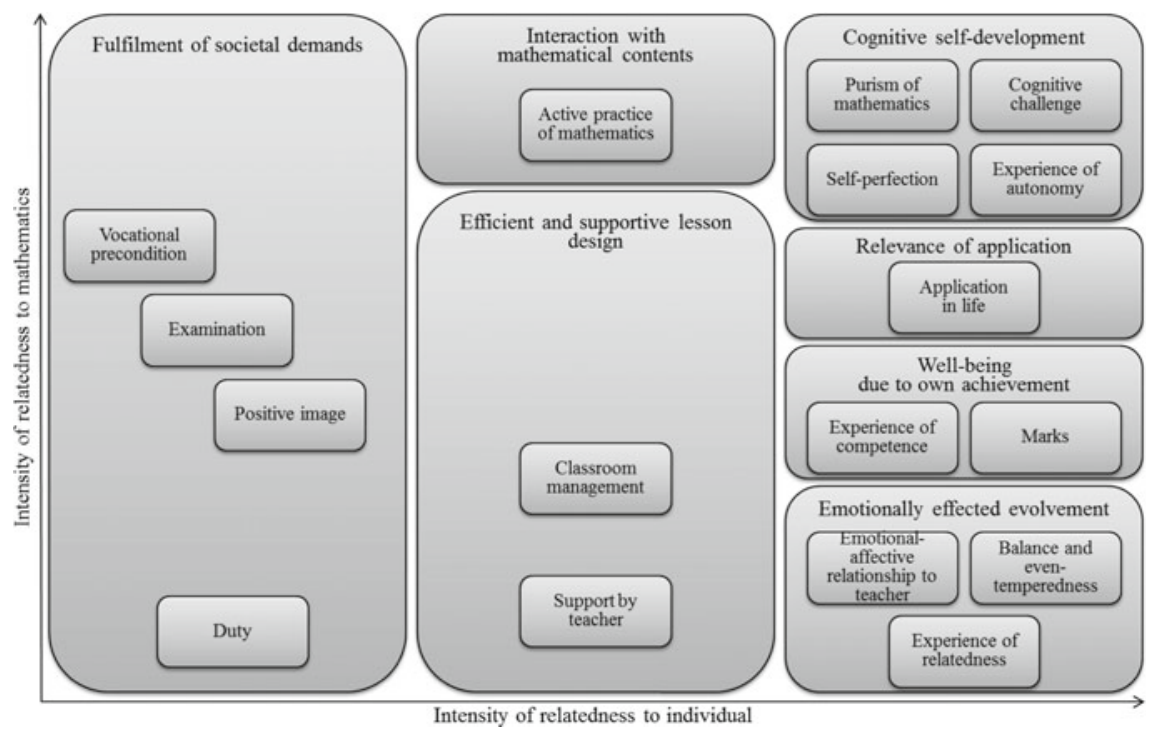

Fig. 7.2 The typology of personal meaning with relation to the intensity of relatedness to mathematics and the individual consisting of the 17 personal meanings. A slight change was made with respect to the personal meaning Efficiency from (Vollstedt, 2011a), which was changed to Classroom management in this study. See Sect. 7.3.1 for details

\subsubsection{Research Questions}

The preceding section highlighted that the concept of personal meaning is both multifaceted and highly relevant for learning mathematics in a school context. One interesting question in this field is what structural relations can be found between the concept of personal meaning and the different kinds of motivation (cf. Suriakumaran et al., 2017). To investigate this relationship, as well as other research questions, and in studies with larger sample sizes, a survey is needed. As quantitative empirical research in this field is still in its infancy, this paper addresses some initial research questions that focus on the assessability of personal meaning, descriptive results from a pilot study, and the validation of a model for personal meaning. All questions relate to the previously described model for personal meaning (Vollstedt, 2011c).

Assessability of personal meaning. Vollstedt's (2011c) typology for personal meaning was reconstructed in a qualitative interview study and thus it is currently based on a small number of cases. In order to further investigate personal meaning and its relation to adjacent constructs, personal meaning need to be evaluated for its ability to be quantitatively assessable. Hence the first research question addressed in this paper is:

1. Is it possible to construct a psychometrically sound survey the scales of which assess the different personal meanings? 
Descriptive results. Based on Vollstedt's (2011c) data, no reliable conclusions can be drawn about the frequency of the different personal meanings among students. A potential direction for future research could investigate whether students from the same class tend to have similar preferences for personal meanings compared to students from different classes. This leads to the next questions:

2. Which personal meanings are especially popular among students aged 15-16?

3. To what extent does the fact that students are nested in different classes explain any variance in the different personal meanings?

Validation of the theoretical model of personal meaning (Vollstedt, 2011c). The arrangement of the different personal meanings in relation to their levels of orientation to mathematics and to the self as well as the resulting typology (cf. Fig. 7.2; Vollstedt, 2011c) were solely based on theoretical considerations. This motivates the following questions:

4. What is the correlational structure of the different personal meanings? Do the personal meanings within a type of personal meaning correlate highly?

5. Is it possible to identify meta-factors that structure the empirical results with relation to the students' different personal meanings? Can these meta-factors be associated with the dimensions from Vollstedt's (2011c) typology that were developed from a theoretical perspective (relatedness to mathematics and the relatedness to the individual)?

\subsection{Methods}

One of the aims of this study was to develop and test a survey containing scales for the 17 different personal meanings introduced in Vollstedt (2011c). Item response theory was chosen for primary data analysis, as it allows model assumptions to be checked and scale qualities to be evaluated. To validate the theoretical model previously described, a high-dimensional model was specified, in which each personal meaning was included as a dimension of its own. As a second step, factor analytic techniques were then applied to the resulting correlation matrix in order to uncover higher order (meta-)factors underlying these personal meanings. In the following sub-sections, the survey design as well as the sample will be described. Then, the analysis steps summarised above will be explained in detail.

\subsubsection{Instrument}

Pillath (2011) and Dahms (2012) undertook the first attempts to develop a survey to assess the different kinds (Pillath) and types (Dahms) of personal meaning. Both attempts did not provide reliable scales, but, together with a re-analysis of Dahms' 
data, provided a sound basis for revision. A fully revised survey was then developed by the authors in collaboration with Neruja Suriakumaran and three masters students (cf. Büssing, 2016; Schröder, 2016; Wieferich, 2016). Its objective was to provide 17 scales for the 17 different personal meanings reconstructed in Vollstedt (2011c). At one stage, a theoretical revision was necessary, as the personal meaning Efficiency from Vollstedt (2011c) combined two aspects: efficient classroom management and students' efficient ways of working, which proved not assessable with one scale. Instead, items addressing the latter aspect were merged with Active practice of mathematics and Experience of autonomy. The remaining scale was consequently renamed Classroom management. The resulting instrument was used in the current study. Table 7.1 shows the operationalization of the personal meanings.

\subsubsection{Data Collection and Sample}

Prior to the main study, cognitive labs were carried out in order to ensure that the items were formulated clearly and thus understood in the intended way. In March 2016 , the survey was finally used in a study with students $(N=193)$ aged $15-16$ from four Northern German schools: two higher secondary schools (Gymnasium) and two lower secondary schools (Oberschule). Although this was a convenience sample, it also approximately mirrors the situation in Germany, where roughly 30-50\% of the students (depending on the federal state) attend higher secondary schools, whereas the others attend some lower secondary school. Here, systems and designations vary considerably between federal states. The two lower secondary schools of the study provide a good cross section of the wide range of different lower secondary schools in Germany. The participating students (51.8\% girls) were from seven classes in grade nine $(n=119)$, and four classes in grade ten $(n=74)$. They had one regular school lesson (45 min) to fill in the paper and pencil survey. Cognitive labs and data collection were part of three masters theses (Büssing, 2016; Schröder, 2016; Wieferich, 2016).

\subsubsection{Data Analysis}

Data management and analyses were conducted in R (R Core Team, 2015).

\subsubsection{Scaling of Personal Meanings}

In order to answer the question whether assessing personal meanings with a survey yields scales with good psychometrical properties, item response theory (IRT, de Ayala, 2013) scaling methods were used. For every personal meaning, a partial credit model (PCM; Masters, 1982; Masters \& Wright, 1997) was fitted to the data. 
Table 7.1 Operationalization of personal meanings: number of items and example items

\begin{tabular}{|c|c|c|}
\hline Personal meaning & $\begin{array}{l}\text { Number of } \\
\text { items }\end{array}$ & Example item(s) \\
\hline Active practice of mathematics (Act) & $13^{*}$ & $\begin{array}{l}\text { I like to deal actively with mathematics. } \\
\text { Working actively on tasks helps me } \\
\text { understand the content }\end{array}$ \\
\hline Application in life (App) & $16^{*}$ & $\begin{array}{l}\text { Learning mathematics is important to me } \\
\text { because in doing so you learn for life. } \\
\text { Tasks referring to everyday life make me } \\
\text { occupy myself more deeply with the } \\
\text { mathematical content }\end{array}$ \\
\hline Balance and even-temperedness (Bal) & 5 & $\begin{array}{l}\text { I like it when we can finally relax after a } \\
\text { strenuous working phase in mathematics }\end{array}$ \\
\hline Classroom management (Cla) & 9 & $\begin{array}{l}\text { It is important to me that at the beginning } \\
\text { of mathematics class, the teacher } \\
\text { summarizes the previous lesson }\end{array}$ \\
\hline Cognitive challenge $(\mathrm{Cog})$ & 7 & $\begin{array}{l}\text { I get bored when mathematical content is } \\
\text { too simple }\end{array}$ \\
\hline Obligation (Obl) & 7 & $\begin{array}{l}\text { I do mathematics mainly because it is a } \\
\text { compulsory subject }\end{array}$ \\
\hline $\begin{array}{l}\text { Emotional-affective relationship to } \\
\text { teacher (Emo) }\end{array}$ & 6 & $\begin{array}{l}\text { It is important to me that I feel valued by } \\
\text { my teacher }\end{array}$ \\
\hline Examination (Exa) & 8 & $\begin{array}{l}\text { I do mathematics in order to pass exams } \\
\text { and tests }\end{array}$ \\
\hline Experience of autonomy (Aut) & 8 & $\begin{array}{l}\text { Working autonomously is important to } \\
\text { me to when it comes to mathematics }\end{array}$ \\
\hline Experience of competence (Com) & 7 & $\begin{array}{l}\text { I do mathematics because my learning } \\
\text { success makes me feel good }\end{array}$ \\
\hline Experience of relatedness (Rel) & 8 & $\begin{array}{l}\text { It is important to me that there is a } \\
\text { positive classroom climate during } \\
\text { mathematics classes }\end{array}$ \\
\hline Marks (Mar) & 5 & $\begin{array}{l}\text { I do mathematics in order to be proud of } \\
\text { my marks }\end{array}$ \\
\hline Positive impression (Pos) & 8 & $\begin{array}{l}\text { It is important to me that my family can } \\
\text { be proud of my mathematics performance }\end{array}$ \\
\hline Purism of mathematics (Pur) & 7 & $\begin{array}{l}\text { In its purity, mathematics is uniquely } \\
\text { beautiful to me }\end{array}$ \\
\hline Self-perfection (Per) & 8 & $\begin{array}{l}\text { I work on many mathematics tasks } \\
\text { because becoming better and faster } \\
\text { matters to me }\end{array}$ \\
\hline
\end{tabular}


Table 7.1 (continued)

\begin{tabular}{l|l|l}
\hline Personal meaning & $\begin{array}{l}\text { Number of } \\
\text { items }\end{array}$ & Example item(s) \\
\hline Support by teacher (Sup) & 6 & $\begin{array}{l}\text { It is important to me that my teacher } \\
\text { communicates my progress in } \\
\text { mathematics to me }\end{array}$ \\
\hline Vocational precondition (Voc) & 5 & $\begin{array}{l}\text { I do mathematics because I need it for my } \\
\text { desired profession }\end{array}$ \\
\hline
\end{tabular}

Note Agreement to statements was given on a four-point Likert scale ranging from strongly disagree to strongly agree

*The large number of items is due to the fact that one of the research questions in Büssing (2016) and Schröder (2016) was to investigate the sub-facets of these personal meanings. Their results are, however, not relevant for this paper. Still, two exemplifying items are given to illustrate the different facets of the respective personal meanings

The PCM is a generalization of the Rasch model (Rasch, 1960) to items with more than two ordered response categories, like Likert scale items. Within the PCM, an item can be described by transition parameters pertaining to two adjacent response categories (de Ayala, 2013; Wu \& Adams, 2007). These parameters describe points on the underlying latent variable scale where the respective two category characteristic curves intersect. The item location parameter, defined as the arithmetical mean of an item's transition parameters, is one way to gauge that item's "difficulty". Model parameters were determined with marginal maximum likelihood (MML) estimation using the R package TAM (Kiefer et al., 2015). Thereby, the mean of the trait distribution was constrained to zero. Missing values were not recoded in any way.

Fit of the PCM models was evaluated on both item and scale level. Given the relatively small sample size, item fit was evaluated based on the $t$-values of the weighted fit mean-square (Infit; Wu \& Adams, 2007). Infit is an IRT statistic that describes how well the observed data match the IRT model predictions for a single item. The expected value of a perfectly fitting item is 1 , with Infit values $>1$ indicating less discrimination than predicted (underfit). If an item showed significant underfit, i.e. $t$ (Infit) $\geq 1.96$, it was removed from the scale. Overfitting items $(t$ (Infit $) \leq-$ 1.96), i.e. items that discriminated too well, were only removed if additionally Infit $<0.8$ (Wu \& Adams, 2007). After removing an item, the model was refitted, possibly leading to an iterative procedure. On scale level, EAP/PV reliability and the variance of the trait distribution were considered. EAP/PV reliability is an IRT measure of person parameter accuracy; its size is comparable to Cronbach's $\alpha$.

In the sample of this study, the students were nested in classes. One crucial question with clustered data like these is whether observations from the same cluster are more similar to each other than random observations. This is expressed by the intraclass correlation coefficient (ICC). An ICC substantially greater than 0 implies that observations cannot be considered independent, possibly necessitating more advanced methods-multilevel modelling-in further analyses. In addition, it provides insight into the personal meanings themselves: To what extent is the class level responsi- 
ble for the construction of personal meaning? Hence, computation of ICCs for the personal meanings was considered both informative from a theoretical perspective and essential for further work with the scales. To do so, for each personal meaning person parameters-Warm's (1989) weighted likelihood estimates (WLE)-were extracted. Then, using the R package lme4 (Bates et al., 2015), they were used as dependent variable in a simple random intercept model with class as the only predictor. Comparison of estimated intercept variance and residual variance yielded the ICC.

\subsubsection{Structure of Personal Meanings}

The correlational structure between those personal meanings that could be assessed reliably was investigated in two steps. First, a high-dimensional PCM that included the different personal meanings as separate dimensions was specified. Thereby, items showing misfit in the prior unidimensional analyses were not included. Again, MML estimation implemented in the R package TAM (Kiefer et al., 2015) was used. However, for computational reasons, quasi Monte Carlo integration (González et al., 2006; Pan \& Thompson, 2007) with $2000 \times$ (number of dimensions) nodes was employed instead of Gaussian integration. This model yielded latent correlations between the personal meanings.

For better readability and interpretability, a hierarchical cluster analysis (Kaufman \& Rousseeuw, 1990) using Ward's method (Ward, 1963) was applied to the resulting correlation matrix. Thereby, the distance between two personal meanings was defined as 1 - the latent correlation between those two dimensions).

In a second, exploratory step, the correlation matrix was analysed using exploratory factor analysis (EFA; Thompson, 2004). As multivariate normality of the personal meanings could be assumed, maximum likelihood extraction of factors as implemented in the R package psych (Revelle, 2016) was applied. EFA was preferred over principal components analysis as the objective of this step was to uncover larger meta-factors underlying the various personal meanings rather than data reduction. It was not the primary goal to make these supposed meta-factors measurable in a psychometric sense. Instead, it was intended to compare resulting meta-factors from EFA with the dimensions on which Vollstedt's (2011a) typology is based.

The number of extracted factors was determined by parallel analysis (Horn, 1965), scree plot inspection (Cattell, 1966), and the Kaiser criterion (Guttman, 1954; Kaiser, 1960). As explained above, no attention was paid to criteria that try to optimize the resulting measurement model, like $\chi^{2}$, Root Mean Square Error of Approximation (RMSEA), or Bayesian Information Criterion (BIC; Schwarz, 1978). There was no reason to expect uncorrelated meta-factors, so an oblique rotation using the promax algorithm was applied. Significance of coefficients and correlations between the meta-factors was determined using a bootstrap analysis with 5,000 samples. 


\subsection{Results}

In Vollstedt (2011a), 17 personal meanings could be reconstructed from interview data. For subsequent quantitative research involving personal meaning, it was considered necessary to assess these constructs by means of a survey. As this had not been accomplished prior to this study, the structural relationships between the different personal meanings as postulated in Vollstedt (2011a) had not yet been investigated quantitatively.

Results related to research question 1, i.e. whether assessing personal meaning by means of survey scales is possible, as well as descriptive results concerning the different personal meanings (cf. research questions 2 and 3), are presented in the first section. The second section addresses structural relationships between the different personal meanings: First, the correlational structure of the personal meanings is investigated (cf. research question 4). Building on that, meta-factors resulting from an EFA (cf. research question 5) are described.

\subsubsection{Scaling of Personal Meanings}

Table 7.2 shows the results from the (iterative) scaling process for each personal meaning. For most scales, only up to two items were excluded, which was considered uncritical for scale validity. The exceptions were Obligation and Classroom management, where three of the initial seven items and six of the initial nine items, respectively, had to be removed. In the first case, a close inspection of that personal meaning showed that the remaining items still cover its content validly. In the case of Classroom management, however, the remaining three items only focused on a very narrow facet of that personal meaning. Consequently, the whole scale was excluded from further analyses.

Overall, the psychometric properties of the remaining scales were good: As can be seen, estimated variances ranged from 0.64 to 4.56 , with most values around or above 1. Only those for the personal meanings Application in life, Experience of relatedness, Positive impression, and Emotional-affective relationship to teacher were somewhat low. Scale reliabilities ranged from an acceptable 0.68 to a very good 0.86 .

Intraclass correlations of the scales were very low, ranging from 0 to 0.055 . Only for Application in life and Experience of relatedness did class membership account for more than $5 \%$ of the variance.

Table 7.3 shows descriptive results characterizing the popularity of the scales after badly fitting items (and the scale for Classroom management) had been removed. Values pertaining to item means are in the original Likert scale metric ranging from 0 (expressing strong disagreement with the scale) to 3 (expressing strong agreement), 
Table 7.2 Scaling results per Personal Meaning: number of remaining items, variance of underlying construct, reliability, and intraclass correlation (ICC)

\begin{tabular}{|c|c|c|c|c|}
\hline Personal meaning & $\begin{array}{l}\text { Number of remaining } \\
\text { items (initial number) }\end{array}$ & Variance & EAP/PV reliability & ICC \\
\hline $\begin{array}{l}\text { Active practice of } \\
\text { mathematics (Act) }\end{array}$ & $12(13)$ & 0.86 & 0.83 & 0 \\
\hline $\begin{array}{l}\text { Application in life } \\
\text { (App) }\end{array}$ & $16(16)$ & 0.64 & 0.84 & 0.055 \\
\hline $\begin{array}{l}\text { Balance and } \\
\text { even-temperedness } \\
\text { (Bal) }\end{array}$ & $4(5)$ & 1.07 & 0.68 & 0.017 \\
\hline $\begin{array}{l}\text { Classroom } \\
\text { management (Cla) }\end{array}$ & $3(9)$ & \multicolumn{3}{|c|}{ - (Scale removed)- } \\
\hline $\begin{array}{l}\text { Cognitive challenge } \\
\text { (Cog) }\end{array}$ & $6(7)$ & 0.94 & 0.75 & 0.008 \\
\hline Obligation $(\mathrm{Obl})$ & $4(7)$ & 4.40 & 0.85 & 0 \\
\hline $\begin{array}{l}\text { Emotional-affective } \\
\text { relationship to teacher } \\
\text { (Emo) }\end{array}$ & $6(6)$ & 0.74 & 0.69 & 0.027 \\
\hline Examination (Exa) & $6(8)$ & 1.25 & 0.78 & 0 \\
\hline $\begin{array}{l}\text { Experience of } \\
\text { autonomy (Aut) }\end{array}$ & $7(8)$ & 0.79 & 0.73 & 0 \\
\hline $\begin{array}{l}\text { Experience of } \\
\text { competence (Com) }\end{array}$ & $7(7)$ & 0.94 & 0.75 & 0 \\
\hline $\begin{array}{l}\text { Experience of } \\
\text { relatedness (Rel) }\end{array}$ & $8(8)$ & 0.67 & 0.73 & 0.052 \\
\hline Marks (Mar) & $5(5)$ & 1.10 & 0.73 & 0.024 \\
\hline $\begin{array}{l}\text { Positive impression } \\
\text { (Pos) }\end{array}$ & $7(8)$ & 0.71 & 0.72 & 0 \\
\hline $\begin{array}{l}\text { Purism of mathematics } \\
\text { (Pur) }\end{array}$ & $5(7)$ & 4.56 & 0.86 & 0.011 \\
\hline Self-perfection (Per) & $8(8)$ & 0.87 & 0.77 & 0 \\
\hline $\begin{array}{l}\text { Support by teacher } \\
\text { (Sup) }\end{array}$ & $6(6)$ & 1.39 & 0.77 & 0 \\
\hline $\begin{array}{l}\text { Vocational } \\
\text { precondition (Voc) }\end{array}$ & $4(5)$ & 3.34 & 0.82 & 0.023 \\
\hline
\end{tabular}

whereas location parameters are in the IRT logit metric, where low values indicate that it is easy to agree with an item.

Item means varied considerably over all scales. There was quite strong disagreement (0.62) for the item "As it is fun, I occupy myself with mathematical tasks or contents in my leisure time." (Active practice of mathematics) and quite strong agreement (2.62) for the item "It is important to me that my teacher explains the contents 
Table 7.3 Descriptive results per personal meaning: minimum, maximum, and mean of item means as well as mean of location parameters

\begin{tabular}{|c|c|c|c|c|}
\hline Personal meaning & $\begin{array}{l}\text { Minimum of } \\
\text { item means }\end{array}$ & $\begin{array}{l}\text { Maximum of } \\
\text { item means }\end{array}$ & $\begin{array}{l}\text { Mean of item } \\
\text { means }\end{array}$ & $\begin{array}{l}\text { Mean of } \\
\text { location } \\
\text { parameters }\end{array}$ \\
\hline $\begin{array}{l}\text { Active practice of } \\
\text { mathematics (Act) }\end{array}$ & 0.62 & 2.26 & 1.58 & -0.27 \\
\hline $\begin{array}{l}\text { Application in life } \\
\text { (App) }\end{array}$ & 1.30 & 2.00 & 1.64 & -0.23 \\
\hline $\begin{array}{l}\text { Balance and } \\
\text { even-temperedness } \\
\text { (Bal) }\end{array}$ & 1.51 & 2.35 & 1.96 & -0.76 \\
\hline $\begin{array}{l}\text { Cognitive challenge } \\
\text { (Cog) }\end{array}$ & 0.73 & 1.88 & 1.21 & 0.41 \\
\hline Obligation (Obl) & 1.55 & 1.85 & 1.70 & -0.41 \\
\hline $\begin{array}{l}\text { Emotional-affective } \\
\text { relationship to } \\
\text { teacher (Emo) }\end{array}$ & 1.81 & 2.24 & 2.00 & -0.83 \\
\hline Examination (Exa) & 1.41 & 2.38 & 1.87 & -0.68 \\
\hline $\begin{array}{l}\text { Experience of } \\
\text { autonomy (Aut) }\end{array}$ & 1.28 & 2.06 & 1.70 & -0.44 \\
\hline $\begin{array}{l}\text { Experience of } \\
\text { competence (Com) }\end{array}$ & 1.23 & 2.44 & 1.84 & -0.59 \\
\hline $\begin{array}{l}\text { Experience of } \\
\text { relatedness (Rel) }\end{array}$ & 1.44 & 2.28 & 1.98 & -0.73 \\
\hline Marks (Mar) & 1.68 & 2.10 & 1.83 & -0.60 \\
\hline $\begin{array}{l}\text { Positive impression } \\
\text { (Pos) }\end{array}$ & 0.70 & 1.94 & 1.29 & 0.43 \\
\hline $\begin{array}{l}\text { Purism of } \\
\text { mathematics (Pur) }\end{array}$ & 0.90 & 1.20 & 1.00 & 1.44 \\
\hline Self-perfection (Per) & 0.72 & 2.13 & 1.48 & 0.04 \\
\hline $\begin{array}{l}\text { Support by teacher } \\
\text { (Sup) }\end{array}$ & 1.55 & 2.62 & 2.03 & -1.05 \\
\hline $\begin{array}{l}\text { Vocational } \\
\text { precondition (Voc) }\end{array}$ & 1.12 & 1.84 & 1.58 & -0.33 \\
\hline
\end{tabular}

Notes All Likert scales were coded from 0 (strongly disagree) to 3 (strongly agree). Negatively worded questions were recoded. Items removed during the scaling procedure were not included 
well to me." (Support by teacher). For some scales (like Obligation) the item means did not vary considerably, whereas for other scales (like Self-perfection) they did, indicating scales of different homogeneity.

\subsubsection{Structure of Personal Meanings}

The 16-dimensional PCM fitted to the data of the remaining personal meaning scales yielded the latent correlations. Overall, correlations ranged from -0.79 to 0.85 . (In general, sizes of correlation coefficients should be interpreted against the background of the theories involved. Having said that, following the frequently cited book by Cohen (1988), correlation coefficients could be classified according to their absolute value as small $(>0.1)$, medium $(>0.3)$, or large $(>0.5)$, respectively.) For clarity of presentation, a hierarchical cluster analysis was used to detect groups of personal meanings in which personal meanings are similar to each other (with regard to correlations). Then, the correlation matrix was ordered accordingly. Figure 7.3 presents the correlational structure of the personal meanings in different ways: The upper part shows results from the cluster analysis, whereas the lower part presents the correlation matrix arranged accordingly.

Both results of the cluster analysis and correlational patterns indicate two clusters of personal meaning. The smaller cluster comprises the personal meanings Balance and even-temperedness, Obligation, Emotional-affective relationship to teacher, Support by teacher, and Experience of relatedness. Those are precisely the personal meanings that Vollstedt (2011b) characterized as having a low level of orientation towards mathematics (cf. Fig. 7.2). Amongst themselves, these personal meanings show positive correlations ranging from 0.22 to 0.73 with an average of 0.50 . The larger cluster comprises the remaining personal meanings. Within this second cluster, all correlations are positive, too, with an average of 0.60 .

Two sub-clusters stand out as particularly homogeneous: correlations between Marks, Positive impression, and Experience of competence range from 0.67 to 0.82 , and correlations between Purism of mathematics, Cognitive challenge, Active practice of mathematics, and Experience of autonomy range from 0.74 to 0.85 . Additionally, between personal meanings from this latter sub-cluster and the personal meanings Balance and even-temperedness and Obligation, correlation are substantially negative, ranging from -0.49 to -0.79 with a mean of -0.65 .

Prior to the subsequent exploratory factor analysis, it was checked whether the data were suitable for this procedure. The Kaiser-Meyer-Olkin measure (KMO; Kaiser, $1970)$, KMO $=0.91$, confirmed very good sampling adequacy. So did measures of sampling adequacy for individual personal meanings, which ranged from 0.79 to 0.96 . Bartlett's test of sphericity, $\chi^{2}(120)=3534.4, p<001$, strongly indicated that correlations were sufficiently high to carry out an EFA.

All three criteria employed to determine the number of factors clearly indicated that two meta-factors should be retained. Table 7.4 shows the main results of factor analysis after oblique rotation. After inspection of substantial pattern and structure 


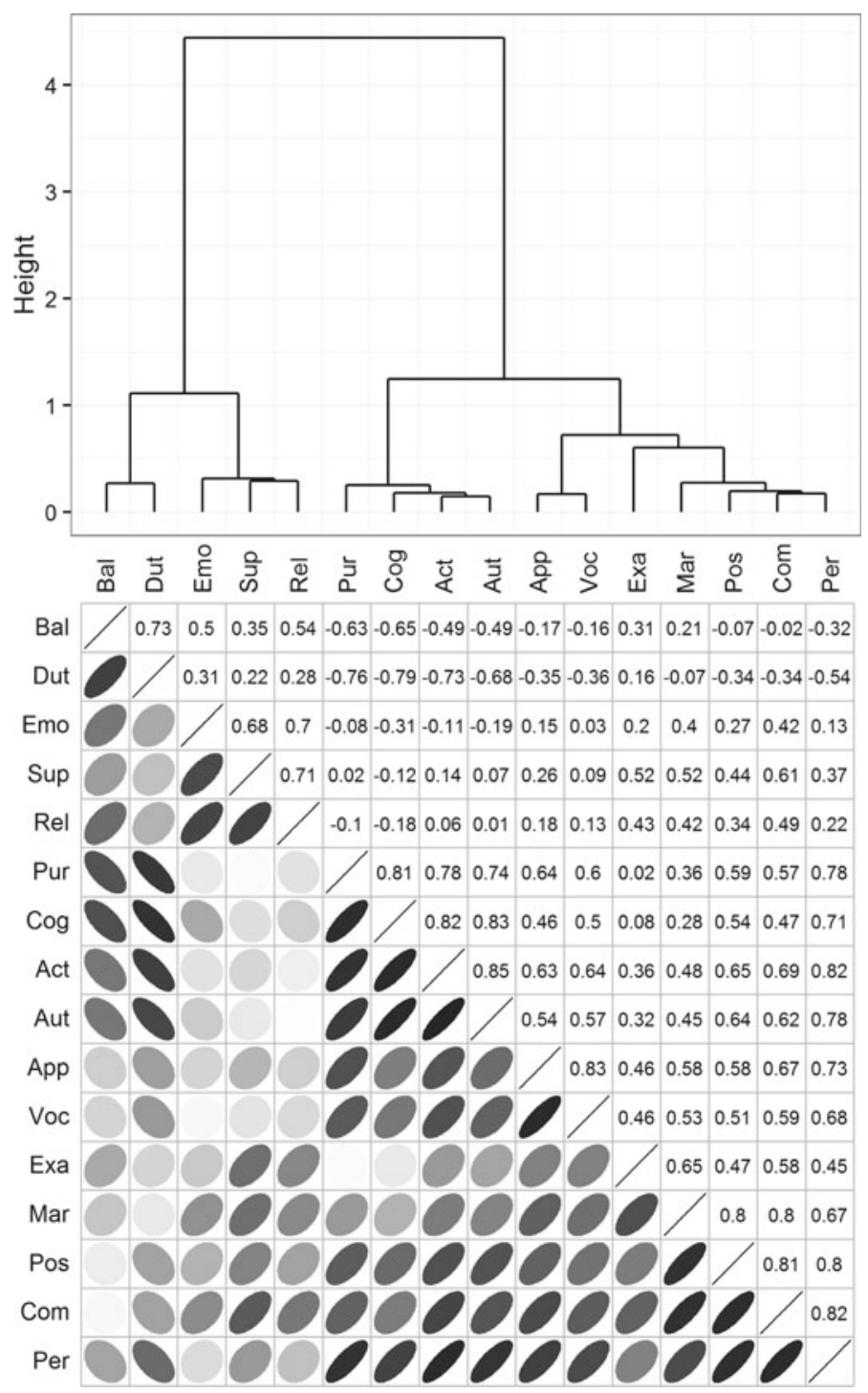

Fig. 7.3 Relations between personal meanings. Lower part: Latent correlations between personal meanings computed in a 16-dimensional model given as numeric values (above diagonal) and represented with an ellipse depicting the shape of a bivariate normal distribution with that correlation (below diagonal). Personal meanings are ordered according to a hierarchical cluster solution (see upper part). Upper part: Results of hierarchical clustering of the correlations between the personal meanings 
Table 7.4 Summary of promax-rotated factors for 16 personal meanings $(n=193)$ : pattern coefficients, structure coefficients, and communalities

\begin{tabular}{|c|c|c|c|c|c|}
\hline \multirow{2}{*}{$\begin{array}{l}\text { Personal } \\
\text { meaning }\end{array}$} & \multicolumn{2}{|l|}{ Pattern } & \multicolumn{2}{|l|}{ Structure } & \multirow[t]{2}{*}{$h^{2}$} \\
\hline & $\begin{array}{l}\text { Orientation } \\
\text { towards } \\
\text { mathematics }\end{array}$ & $\begin{array}{l}\text { Orientation } \\
\text { towards social } \\
\text { inclusion }\end{array}$ & $\begin{array}{l}\text { Orientation } \\
\text { towards } \\
\text { mathematics }\end{array}$ & $\begin{array}{l}\text { Orientation } \\
\text { towards social } \\
\text { inclusion }\end{array}$ & \\
\hline Bal & -0.71 & 0.64 & -0.59 & 0.50 & 0.74 \\
\hline Dut & -0.86 & 0.39 & -0.79 & 0.22 & 0.77 \\
\hline Emo & -0.27 & 0.74 & -0.13 & 0.69 & 0.55 \\
\hline Sup & & 0.81 & & 0.80 & 0.64 \\
\hline Rel & -0.18 & 0.79 & & 0.75 & 0.59 \\
\hline Pur & 0.91 & -0.09 & 0.89 & & 0.81 \\
\hline $\operatorname{Cog}$ & 0.94 & -0.24 & 0.90 & & 0.86 \\
\hline Act & 0.91 & 0.06 & 0.92 & 0.24 & 0.85 \\
\hline Aut & 0.89 & & 0.89 & 0.18 & 0.79 \\
\hline App & 0.60 & 0.35 & 0.67 & 0.46 & 0.56 \\
\hline Voc & 0.61 & 0.25 & 0.66 & 0.37 & 0.49 \\
\hline Exa & 0.13 & 0.66 & 0.26 & 0.69 & 0.49 \\
\hline Mar & 0.35 & 0.72 & 0.49 & 0.79 & 0.74 \\
\hline Pos & 0.60 & 0.52 & 0.70 & 0.64 & 0.75 \\
\hline Com & 0.57 & 0.65 & 0.70 & 0.77 & 0.90 \\
\hline Per & 0.81 & 0.34 & 0.88 & 0.50 & 0.89 \\
\hline
\end{tabular}

Notes Personal meanings are arranged according the cluster analysis introduced in Fig. 7.3. For ease of interpretation, non-significant coefficients are suppressed and coefficients with absolute value $>0.4$ appear in bold

coefficients the two meta-factors were identified. As can be seen most clearly from the pattern coefficients, in a positive way the personal meanings Cognitive challenge, Purism of mathematics, Active practice of mathematics, Experience of autonomy, and Self-perfection (i.e. becoming a better or smarter person by being involved with mathematics) contribute most to the first meta-factor, whereas Obligation as well as Balance and even-temperedness contribute negatively to it. Therefore, it was interpreted as Orientation towards mathematics. The second meta-factor is best described by the personal meanings Support by teacher, Experience of relatedness, Emotionalaffective relationship to teacher, and Marks. It was hence interpreted as Orientation towards social inclusion. The correlation of 0.2 between the two meta-factors was low, but significant with confidence interval [0.1, 0.28].

Fit indices show that the above meta-factor solution makes a poor measurement model: Neither the Comparative Fit Index (CFI) of 0.836, nor the Tucker-Lewis Index (TLI) of 0.776 or the RMSEA of 0.186 were even close to acceptable. Extracting measurable meta-factors was, however, not the goal of this study. On the contrary, this 
finding indicates that there is a lot more to personal meaning than two meta-factors can express.

\subsection{Discussion}

In this study, a survey was developed to assess the students' personal meaning, understood as personal relevance of an object or action, when dealing with mathematics (Vollstedt, 2011c). Results relating to research question 1 show that the scales for the different personal meanings show all good psychometric properties, except for the scale Classroom management. Here, six out of nine items had to be removed to meet acceptable psychometric results, but the remaining three items did only cover one core aspect of Classroom management (summary of lesson contents at different points of time). Hence, this scale is not acceptable and is being revised and tested in an ongoing study (cf. Suriakumaran et al., 2017).

When looking at the preferred personal meanings of the students (research question 2), results show that on the one hand Balance and even-temperedness, Emotionalaffective relationship to teacher, Experience of relatedness, and Support by teacher matter much to students, as do Examination, Marks, and Experience of competence on the other hand. Interestingly, the first group combines personal meanings of a social nature that are located in the bottom right corner of Vollstedt's (2011c) typology (low relatedness to mathematics, high relatedness to individual, see Fig. 7.2). The second group then groups personal meanings with medium relatedness to mathematics that all belong to the realm of performance and achievement. The personal meanings least preferred are Cognitive challenge, Purism of mathematics, Self-perfection, and Positive image. The first three all belong to the type Cognitive self-development (high relatedness to mathematics and individual) and combine aspects that value the beauty of mathematics, being challenged by difficult mathematical tasks and, thus, being able to become better and develop oneself. This facet may relate to Positive image (low relatedness to individual, medium relatedness to mathematics), which denotes that it is relevant for the students that other people value them and get a positive impression of them.

Results related to the third research question show that personal meaning seems to be indeed personal as belongingness to a certain class usually accounts for less than $5 \%$ of the variance in the respective scale. The ICC was just slightly bigger than that for Application in life (0.055) and Experience of social relatedness (0.052). These results are rather surprising. One would have expected bigger effects since personal meanings are supposed to be dependent on the context, which is highly influenced by the teacher and his or her way of teaching. However, this study only researched eleven classes from four schools, which is quite a small number for conducting multilevel analyses. This should be seen as a limitation, and results should be interpreted with the appropriate caution.

The correlational structure between the different personal meanings of a certain type (research question 4) shows that there are close relations within all types. The 
personal meanings from the type Cognitive self-development correlate highly (all $>0.7$ ) so that one could suggest to group them together and assess them in one scale instead of four. However, Schröder's (2016) model comparisons show that the fourdimensional model suits the data considerably better than the one-dimensional one. It follows that these personal meanings should be best assessed as dimensions of their own. In analogy, Wieferich's (2016) results show that the same holds true for the two personal meanings from Well-being due to own achievement, which show a correlation of 0.8 , and the three personal meanings from Emotionally effected evolvement, the correlations between which range from 0.5 to 0.7 . Within Fulfilment of societal demands, however, there are only substantive correlations between Vocational precondition, Examination, and Positive image ranging from 0.46 to 0.51 . Obligation is the only personal meaning that does not totally fit, showing correlations ranging from -0.36 to 0.16 . This could be explained using the Organismic Integration Theory from Self-Determination Theory of Motivation (Deci \& Ryan, 2002): Obligation seems to be the only personal meaning that is characterized by external regulation whereas all other personal meanings seem to be related to some level of self-regulation ranging between introjected and intrinsic motivation. To conclude, the correlational structure of the types broadly agrees with Vollstedt's (2011c) typology. Again, the relatively small sample size for the complex multidimensional IRT-model constitutes a certain limitation of this study.

Results pertaining to the fifth research question finally indicated two meta-factors that structure the personal meanings with respect to Orientation towards mathematics and Orientation towards social inclusion. At first glance there is an obvious relation between the mathematical meta-factor and one of the dimensions that formed the basis of Vollstedt's (2011c) typology: Relatedness to mathematics. The second meta-factor (Orientation towards social inclusion) does, however, not correspond with the second dimension from the typology (Relatedness to individual). It rather describes what becomes personally relevant to students when it is not the subject that matters, i.e. social inclusion. Thus, the two meta-factors both seem to describe the two directions of Relatedness to mathematics: a high relatedness to mathematics corresponds with an Orientation towards mathematics whereas a low relatedness goes along with an Orientation towards social inclusion. The correlation of 0.2 between the two meta-factors indicates that they are not excluding counterparts.

In addition, fit indices imply that the two meta-factor model is not an adequate measurement model for the data. For this study this is considered a positive result as this means that Vollstedt's (2011c) typology of personal meaning cannot be reduced to just these two meta-factors indicating orientation towards mathematics and social inclusion, respectively.

To conclude, this paper could show that it is possible to assess 16 personal meanings in a survey. Main results from correlation analyses generally support Vollstedt's (2011c) type structure. In addition, multilevel analyses suggest that personal meaning is personal whereas EFA indicates that math matters for the construction of personal meaning. 


\subsection{Further Perspectives}

As could be seen from the results presented above, the subject contents matter with being either very valued or quite unimportant, in which case social inclusion is put forward. However, Vollstedt's (2011c) second dimension (Relatedness to the individual) could not yet be related to the data. This gap might be closed drawing on affective psychological constructs related to subject contents or the learning of mathematics such as motivation, interest, mathematical beliefs, self-efficacy etc. As these constructs may have an influence on the continuum of the individual's affectedness towards (the learning of) mathematics, they may also indicate the relatedness of the individual to subject contents or the learning of mathematics. In line with Vollstedt's (2011c) theoretical framework, this may result in the construction of different personal meanings showing a stronger or weaker relatedness to the individual, i.e. different values on the second dimension of Vollstedt's (2011c) typology. The relationship between personal meaning and the affective psychological constructs will be investigated in future studies (cf. e.g. Suriakumaran et al., 2017).

\section{References}

Bates, D., Mächler, M., Bolker, B., \& Walker, S. (2015). Fitting linear mixed-effects models using Ime4. Journal of Statistical Software, 67(1), 1-51.

Biller, K. (1991). Habe Sinn und wisse Sinn zu wecken! Sinntheoretische Grundlagen der Pädagogik [Have meaning and know how to arouse meaning! Theoretical foundations of education related to meaning]. Hohengehren, Germany: Schneider.

Gass, S. M., \& Mackey, A. (2000). Stimulated recall methodology in second language research. Mahwah, NJ: Lawrence Erlbaum.

Birkmeyer, J., Combe, A., Gebhard, U., Knauth, T., \& Vollstedt, M. (2015). Lernen und Sinn: Zehn Grundsätze zur Bedeutung der Sinnkategorie in schulischen Bildungsprozessen [Learning and meaning: Ten basic principles on the significance of the category of meaning for education processes at school]. In U. Gebhard (Ed.), Sinn im Dialog: Zur Möglichkeit sinnkonstituierender Lernprozesse im Fachunterricht [Meaning in dialogue: On the possibility of the constitution of meaning in the process of learning in different subjects]. Wiesbaden, Germany: Springer.

Bruner, J. (1991). Acts of meaning. Cambridge, MA: Harvard University Press.

Büssing, J. (2016). Zur Dimensionalität der Sinnkonstruktionstypen „Erfüllung gesellschaftlich geprägter Anforderungen “ und „Aktive Auseinandersetzung mit Mathematik“ Eine quantitative Fragebogenstudie [On the dimensionality of the types of personal meaning "interaction with mathematical contents" and "emotionally effected evolvement": A quantitative study using a survey]. (Unpublished master's thesis). Bremen University, Bremen, Germany.

Cattell, R. B. (1966). The scree test for the number of factors. Multivariate Behavioral Research, 1(2), 245-276.

Cohen, J. (1988). Statistical power analysis for the behavioral sciences (2nd ed.). Hillsdale, NJ: Lawrence Erlbaum.

Dahms, A. (2012). Entwicklung eines Instruments zur Erfassung von Sinnkonstruktionstypen bei Schülerinnen und Schülern im Mathematikunterricht der SekundarstufeI [Development of an instrument to assess types of personal meaning related to mathematics with students from lower secondary level]. (Unpublished master's thesis). University of Kiel, Kiel, Germany.

de Ayala, R. J. (2013). The theory and practice of item response theory. New York, NY: Guilford. 
Deci, E. L., \& Ryan, R. M. (Eds.). (2002). Handbook of self-determination research. Rochester, NY: University of Rochester Press.

Frankl, V. E. (1984). Man's search for meaning (3rd ed.). New York, NY: Washington Square Press.

Frankl, V. E. (1988). The will to meaning: Foundations and applications of logotherapy (Expanded ed.). New York, NY: Meridian.

González, J., Tuerlinckx, F., de Boeck, P., \& Cools, R. (2006). Numerical integration in logisticnormal models. Computational Statistics \& Data Analysis, 51(3), 1535-1548.

Guttman, L. (1954). Some necessary conditions for common-factor analysis. Psychometrika, 19(2), $149-161$.

Havighurst, R. J. (1972). Developmental tasks and education (3rd ed.). New York, NY: Longman.

Heine, S. J., Proulx, T., \& Vohs, K. D. (2006). The meaning maintenance model: On the coherence of social motivations. Personality and Social Psychology Review, 10(2), 88-110.

Horn, J. L. (1965). A rationale and test for the number of factors in factor analysis. Psychometrika, 30(2), 179-185.

Howson, A. G. (2005). "Meaning" and school mathematics. In J. Kilpatrick, C. Hoyles, \& O. Skovsmose (Eds.), Meaning in mathematics education (pp. 17-38). New York, NY: Springer.

Kaiser, H. F. (1960). The application of electronic computers to factor analysis. Educational and Psychological Measurement, 20(1), 141-151.

Kaiser, H. F. (1970). A second generation little jiffy. Psychometrika, 35(4), 401-415.

Kaufman, L., \& Rousseeuw, P. J. (1990). Finding groups in data: An introduction to cluster analysis. Hoboken, NJ: Wiley.

Kiefer, T., Robitzsch, A., \& Wu, M. (2015). TAM: Test analysis modules (Version 1.995-0) [Computer Software]. Retrieved from http://CRAN.R-project.org/package=TAM.

Kilpatrick, J., Hoyles, C., \& Skovsmose, O. (2005a). Communication and construction of meaning. In J. Kilpatrick, C. Hoyles, \& O. Skovsmose (Eds.), Meaning in mathematics education (pp. 129-137). New York, NY: Springer.

Kilpatrick, J., Hoyles, C., \& Skovsmose, O. (2005b). Introduction. In J. Kilpatrick, C. Hoyles, \& O. Skovsmose (Eds.), Meaning in mathematics education (pp. 1-8). New York, NY: Springer.

Kilpatrick, J., Hoyles, C., \& Skovsmose, O. (2005c). Meanings of 'meaning of mathematics'. In J. Kilpatrick, C. Hoyles, \& O. Skovsmose (Eds.), Meaning in mathematics education (pp. 9-16). New York, NY: Springer.

Krapp, A. (1999). Interest, motivation and learning: An educational-psychological perspective. European Journal of Psychology of Education, 14(1), 23-40.

Liljedahl, P. G. (2005). Mathematical discovery and affect: The effect of AHA! experiences on undergraduate mathematics students. International Journal of Mathematical Education in Science and Technology, 36(2-3), 219-234.

Marsh, H. W. (1986). Verbal and math self-concepts: An internal/external frame of reference model. American Educational Research Journal, 23(1), 129-149.

Masters, G. N. (1982). A Rasch model for partial credit scoring. Psychometrika, 47(2), 149-174.

Masters, G. N., \& Wright, B. D. (1997). The partial credit model. In W. J. Van der Linden \& R. K. Hambleton (Eds.), Handbook of modern item response theory. New York, NY: Springer.

Mercer, N. (1993). Culture, context and the construction of knowledge in the classroom. In P. Light \& G. Butterworth (Eds.), Context and cognition. Ways of learning and knowing (pp. 28-46). Hillsdale, NJ: Lawrence Erlbaum.

Metz, T. (2013). Meaning in life. Oxford, UK: Oxford University Press.

Meyer, M. A. (2008). Unterrichtsplanung aus der Perspektive der Bildungsgangforschung [Lesson planning from the perspective of research on educational experience and learner development]. Zeitschrift für Erziehungswissenschaft, 10(Special issue 9), 117-137.

Mitchell, M. (1993). Situational interest: Its multifaceted structure in the secondary school mathematics classroom. Journal of Educational Psychology, 85(3), 424-436.

Op 't Eynde, P., de Corte, E., \& Verschaffel, L. (2002). Framing student's mathematics-related beliefs: A quest for conceptual clarity and a comprehensive categorization. In G. C. Leder, E. 
Pehkonen, \& G. Törner (Eds.), Beliefs. A hidden variable in mathematics education? (pp. 13-37). Dordrecht, The Netherlands: Kluwer.

Pan, J., \& Thompson, R. (2007). Quasi-Monte Carlo estimation in generalized linear mixed models. Computational Statistics \& Data Analysis, 51(12), 5765-5775.

Pillath, C. (2011). Zum Zusammenhang von Interesse und Sinnkonstruktion im Kontext schulischen Mathematiklernens [About the relation between interest and personal meaning in the context of learning mathematics at school]. (Unpublished bachelor's thesis). University of Hamburg, Hamburg, Germany.

R Core Team. (2015). R: A language and environment for statistical computing [Computer software]. Vienna, Austria: R Foundation for Statistical Computing. Retrieved from http://www.Rproject.org/.

Rasch, G. (1960). Probabilistic models for some intelligence and attainment tests. Copenhagen, Denmark: Nielsen and Lydiche.

Reber, R. (2018). Making school meaningful: Linking psychology of education to meaning in life. Educational Review, 1-21.

Revelle, W. (2016). Psych: Procedures for personality and psychological research (Version 1.6.4) [Computer software]. Retrieved from http://CRAN.R-project.org/package=psych.

Schnell, T. (2011). Individual differences in meaning-making: Considering the variety of sources of meaning, their density and diversity. Personality and Individual Differences, 51(5), 667-673.

Schröder, M. (2016). Zur Dimensionalität der Sinnkonstruktionstypen „,Kognitive Selbstentwicklung “ und „Anwendungsrelevanz": Eine quantitative Fragebogenstudie [On the dimensionality of the types of personal meaning "cognitive self-development" and "relevance of application": A quantitative study using a survey]. (Unpublished master's thesis). Bremen University, Bremen, Germany.

Schwarz, G. (1978). Estimating the dimension of a model. The Annals of Statistics, 6(2), 461-464.

Skovsmose, O. (1994). Towards a philosophy of critical mathematics education. Dordrecht, The Netherlands: Kluwer.

Skovsmose, O. (2005). Foregrounds and politics of learning obstacles. For the Learning of Mathematics, 25(1), 4-10.

Skovsmose, O. (2014). Foregrounds: Opaque stories about learning. Rotterdam, The Netherlands: Sense.

Skovsmose, O. (2016). An intentionality interpretation of meaning in mathematics education. Educational Studies in Mathematics, 90(3), 411-424.

Strauss, A. L., \& Corbin, J. M. (1990). Basics of qualitative research: Grounded theory procedures and techniques. Newbury Park, CA: Sage.

Suriakumaran, N., Duchhardt, C., \& Vollstedt, M. (2017). Personal meaning and motivation when learning mathematics: A theoretical approach. In European Society for Research in Mathematics Education (ERME) (Ed.), European Research in Mathematics Education X. Proceedings of the Tenth Congress of the European Society for Research in Mathematics Education. Dublin, Ireland: University of Dublin. Retrieved from http://www.mathematik.unidortmund.de/ieem/erme_temp/CERME10_Proceedings_final.pdf.

Thompson, B. (2004). Exploratory and confirmatory factor analysis: Understanding concepts and applications. Washington, DC: American Psychological Association.

Thompson, P. W. (2013). In the absence of meaning... In K. R. Leatham (Ed.), Vital directions for mathematics education research (pp. 57-93). New York, NY: Springer.

Vinner, S. (2007). Mathematics education: Procedures, rituals and man's search for meaning. Journal of Mathematical Behaviour, 26(1), 1-10.

Vollstedt, M. (2010a). „After I do more exercise I won’t feel scared anymore”: An example of personal meaning from Hong Kong. In V. Durand-Guerrier, S. Soury-Lavergne, \& F. Arzarello (Eds.), European Research in Mathematics Education VI. Proceedings of the Sixth Congress of the European Society for Research in Mathematics Education. January 28th - February 1st 2009, Lyon (France) (pp. 131-140). Lyon: Institut National de Recherche Pédagogique. Retrieved from http://www.mathematik.uni-dortmund.de/ erme/doc/cerme6/cerme6_proceedings.pdf. 
Vollstedt, M. (2010b). The impact of culture on the construction of personal meaning. In M. M. F. Pinto \& T. F. Kawasaki (Eds.), Proceedings of the 34th Conference of the International Group for the Psychology of Mathematics Education. Mathematics in different settings (Vol. 2, p. 120). Belo Horizonte, Brazil: PME.

Vollstedt, M. (2011a). The impact of context and culture on the construction of personal meaning. In M. Pytlak, T. Rowland, \& E. Swoboda (Eds.), European Research in Mathematics Education VII. Proceedings of the Seventh Congress of the European Society for Research in Mathematics Education. February 9th - February 13th 2011, Rzeszów (Poland) (pp. 1249-1258). Rzeszów: University of Rzeszów. Retreived from http://www.mathematik.uni-dortmund.de/ prediger/ERME/ CERME7-Proceedings-2011.pdf.

Vollstedt, M. (2011b). On the classification of personal meaning: Theory-governed typology vs. empiricism-based clusters. In B. Ubuz (Ed.), Proceedings of the 35th Conference of the International Group for the Psychology of Mathematics Education (Vol. 4, pp. 321-328). Ankara: PME.

Vollstedt, M. (2011c). Sinnkonstruktion und Mathematiklernen in Deutschland und Hongkong: Eine rekonstruktiv-empirische Studie [Personal meaning and the learning of mathematics: A reconstructive-empirical study]. Wiesbaden, Germany: Vieweg+Teubner.

Vollstedt, M. (2015). To see the wood for the trees: The development of theory from empirical data using grounded theory. In A. Bikner-Ahsbahs, C. Knipping, \& N. Presmeg (Eds.), Advances in Mathematics Education: Vol. 9. Approaches to Qualitative Research in Mathematics Education. Examples of Methodology and Methods (pp. 23-48). Dordrecht, The Netherlands: Springer.

Ward, J. H. (1963). Hierarchical grouping to optimize an objective function. Journal of the American Statistical Association, 58(301), 236-244.

Warm, T. A. (1989). Weighted likelihood estimation of ability in item response theory. Psychometrika, 54(3), 427-450. https://doi.org/10.1007/BF02294627.

Wieferich, A. (2016). Zur Dimensionalität der Sinnkonstruktionstypen „, Wohlbefinden durch eigene Leistung“ und „Emotional-affektiv geprägte Entfaltung “: Eine quantitative Fragebogenstudie [On the dimensionality of the types of personal meaning "well-being due to own achievement" and "emotional-affective development": A quantitative study using a survey]. (Unpublished master's thesis). Bremen University, Bremen, Germany.

Wigfield, A., Tonks, S., \& Klauda, S. L. (2016). Expectancy-value theory. In K. R. Wentzel \& A. Wigfield (Eds.), Handbook of motivation at school (pp. 55-75). New York, NY: Routledge.

Wolf, S. R. (2010). Meaning in life and why it matters. Princeton, NJ: Princeton University Press.

Wu, M., \& Adams, R. (2007). Applying the Rasch model to psycho-social measurement: A practical approach. Melbourne, Australia: Educational Measurement Solutions.

Open Access This chapter is licensed under the terms of the Creative Commons Attribution 4.0 International License (http://creativecommons.org/licenses/by/4.0/), which permits use, sharing, adaptation, distribution and reproduction in any medium or format, as long as you give appropriate credit to the original author(s) and the source, provide a link to the Creative Commons license and indicate if changes were made.

The images or other third party material in this chapter are included in the chapter's Creative Commons license, unless indicated otherwise in a credit line to the material. If material is not included in the chapter's Creative Commons license and your intended use is not permitted by statutory regulation or exceeds the permitted use, you will need to obtain permission directly from the copyright holder.

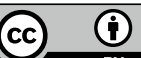




\title{
Chapter 8 \\ Middle School Boys' and Girls' Own Expressions of Aspirations for Their Mathematics Learning
}

\author{
Karina Joyce Wilkie
}

\begin{abstract}
As an alternative approach to studying the affective dimensions of students' learning with normative surveys, pre-defined constructs, and Likert-scale response items, this study used a free-response format that sought students' views in their own words. Data were collected on over 3500 middle school students' aspirations for mathematics learning and generated a wide range of responses related to goals, interest, self-efficacy, and effort. The students also shared their perspectives on interactions with teachers, the classroom environment, and learning tasks. This chapter presents a comparative analysis of boys' and girls' responses at different year levels, to investigate the nature and frequency of their aspirations and to seek evidence of spontaneously generated goal orientations.
\end{abstract}

Keywords Affect gender - Goal orientations • Middle school mathematics • Motivation

\subsection{Introduction}

Prevalent research efforts to improve middle school students' engagement in mathematics (e.g., Attard, 2013; Grootenboer \& Marshman, 2016; Middleton, 2013; Plenty \& Heubeck, 2013; Turner \& Meyer, 2009) highlight the importance of finding ways to plan, teach, and assess mathematics that align with students' own hopes for their learning. Students in the middle years (approximately 9-14 years old) have demonstrated less interest, less self-efficacy, and poorer achievement in mathematics over time (e.g., Gottfried, Marcoulides, Gottfried, Oliver, \& Guerin, 2007; Rolland, 2012). This study ${ }^{1}$ sought to explore the extent of this apparent negative attitude and reluctance to engage with learning, by seeking students' own perspectives in their own

\footnotetext{
K. J. Wilkie $(\bowtie)$

Faculty of Education, Monash University, Frankston, VIC, Australia

e-mail: karina.wilkie@monash.edu
${ }^{1}$ This chapter extends on findings presented by the author at the 13th International Congress on Mathematical Education 2016 and reported in Wilkie (2016).


words, thus finding out more about what matters to students themselves, and allow teachers to respond in productive ways.

Researchers have investigated differences between boys' and girls' attitudes, engagement, and motivation in learning mathematics, and have drawn diverse conclusions (e.g., Chouinard, Karsenti, \& Roy, 2007; Green, Martin, \& Marsh, 2005; Leder \& Forgasz, 2002). Yet there is consensus that both boys and girls experience decreased motivation in the middle years of schooling (e.g., Meece, Glienke, \& Burg, 2006; Watt, 2004). This study provided an opportunity to compare and explore the self-expressed wishes of a large cohort of Australian girls and boys at different year levels as another way to investigate this issue. It was assumed that awareness of students' own desires for their mathematics learning might help teachers to reflect on and respond to students' voice, through understanding more about how students learn effectively (Robinson \& Taylor, 2007). They could gain insights into how to broaden their repertoire for teaching mathematics in ways that positively influence boys' and girls' motivation and achievement.

The study addressed the following research questions: What wishes for mathematics learning do upper primary and early secondary boys and girls express? What evidence of mastery or performance goal orientations do boys and girls spontaneously generate? The term 'wish' was used to gain insights into the students' aspirations since it was assumed to be familiar and meaningful to this cohort of young adolescents. Its commonplace definition is "a desire or hope for something to happen." It is suggestive of wanting "something that cannot or probably will not happen" (Oxford Living Dictionaries, 2016). The psychology literature describes several studies exploring people's wishes as a projective method for researching motivation, desires, and related goal concepts (Ables, 1972; King, 1995; Tafarodi et al., 2012). In the following section theoretical perspectives from the research literature that framed the study are discussed.

\subsection{Theoretical Framework}

As with a learner's effort to reach particular achievement goals in any given domain, a student's motivation in mathematics can relate intrinsically to features inherit in his/her disposition, and also to extrinsic factors in the surrounding environment, such as the learning context and the activities provided for learning (Eccles \& Wigfield, 2002). These internal and external factors both influence motivation (Middleton \& Jansen, 2011).

In this study, it was anticipated that the students' expressions of aspirations might relate to intrinsic motivational features of their mathematics learning, such as their goals, interests, attitudes, and effort. It was also anticipated that they might refer to extrinsic aspects of their classroom environment, such as interactions with their teacher, preferred learning tasks, and working arrangements. The following two subsections review theoretical perspectives and research findings on these dimensions in the literature. 


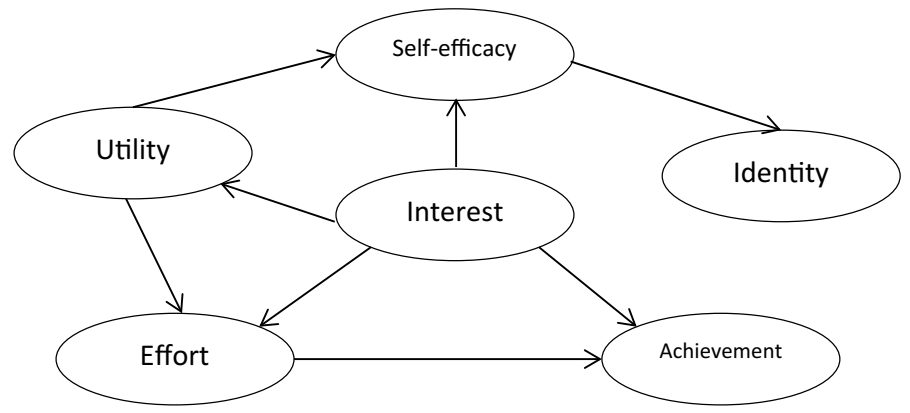

Fig. 8.1 Motivation variables in mathematics learning at the middle years of schooling. Adapted from Middleton (2013)

\subsubsection{Perspectives on Intrinsic Motivation}

Motivation is an important construct for theorising how learners manage themselves - their choice to engage or not in an activity, how much effort they decide to expend (Middleton \& Toluk, 1999), their goals, and their choices in longer-term academic pursuits (Middleton, 2013; Pintrich \& Schunk, 2002). An earlier large review of studies on student motivation in the mathematics education literature found that students evaluated their likely success in mathematics using their beliefs about mathematics itself and about how mathematics is learnt (the process of achieving success). This influenced the extent to which they then engaged (Middleton \& Spanias, 1999). This relates to Hannula's (2006) finding from a longitudinal qualitative study that three aspects appeared to influence students' regulation of their motivation: their derivation of goals from their needs, their appraisal of the accessibility of their goals, and their automatic emotional reactions from earlier experiences that can create inertia against change. He conceptualised motivation as "a potential to direct behaviour through the mechanisms that control emotion" and which is "structured through needs and goals" (Hannula, 2006, p. 175). This definition highlights the close relationship between students' needs, goals, emotions, and motivation.

The literature highlights many interrelated and sometimes overlapping and confusing operational definitions of a range of intrinsic variables that relate to student motivation (Grootenboer \& Marshman, 2016), such as beliefs, attitudes, emotions, values, self-efficacy, effort, and identity. Yet there is general consensus that alongside mathematical knowledge, such motivational factors directly influence students' academic achievement in mathematics (Eccles \& Wigfield, 2002). A theoretical model linking several motivational variables with mathematics achievement was developed using structural equations modelling with an extremely large data set (24,000 US middle school mathematics and science students). It is presented in Fig. 8.1. The model emphasises the central role of interest in directly influencing achievement and also other key motivational variables such as utility, effort, and self-efficacy (Middleton, 2013). 
Interest as a motivational variable has been conceptualised as relating to intrinsic goal-directedness, curiosity, and personal identity (Middleton, Lesh, \& Heger, 2002). It can also be viewed as situational —related to extrinsic environmental characteristics at a particular moment in time, such as the "novelty, challenge, social interaction, or other hypothesised characteristics" (Middleton, 2013, p. 79). Student interest can therefore ebb and flow in different situations (Schweinle, Meyer, \& Turner, 2006).

\subsubsection{Students' Goal Orientations}

An extensive body of research considers the relationships between a learner's particular goals and his/her likely motivational, behavioural, affective, and cognitive outcomes (Rolland, 2012; Urdan, 2001). One theoretical perspective conceptualises four different goal orientations based on a dichotomy of mastery and performance (e.g., Ames, 1992; Pintrich \& Schunk, 2002) intersecting with another dichotomy of approach and avoidance. These four types describe how a particular goal orientation might influence a learner's effort, self-efficacy, and identity (Elliot, 1999; Elliot \& Murayama, 2008). An individual with a mastery goal orientation seeks to improve his/her own learning and achieve task-based outcomes. An individual with a performance goal orientation focuses on comparison with others to define achievement, such as having better test results or winning in competitive situations. The approach and avoidance dichotomy describes how competence is valenced: how a situation or experience involves inherent attraction, leading to approach, or aversion, leading to avoidance.

There is ongoing debate about whether or not it is possible for an individual to hold both mastery and performance goal orientations in the same domain simultaneously (Brophy, 2005; Hulleman, Schrager, Bodmann, \& Harackiewicz, 2010; Martin, 2013). Hulleman et al. (2010) conducted a meta-analysis of 243 studies of achievement goals and concluded that there were discrepancies in how the studies defined and operationalised goal orientations. The studies also measured goals differently, leading to divergent, even conflicting results, and inconsistent implications for motivational processes. Hulleman and colleagues suggested distinguishing between achievement and performance goals so that there might be less confusion. They asserted that achievement goals are actually neutral in terms of how competence is defined. An achievement goal might be related to a mastery orientation (an "A" grade demonstrates mastering the content) or to a performance orientation (an "A" grade demonstrates outperforming others). Within the performance goal orientation, Hulleman et al. (2010) additionally distinguished three components: appearance (demonstrating competence), normative (performing better than others), and evaluative (being judged as demonstrating competence relative to others). These three performance components are all about being compared with others.

The resulting four goal-orientation types in a two-by-two framework, using Elliot's original conceptualisations and Hulleman's and colleagues' further distinctions, is presented in Table 8.1. Three of the four goal orientations have been empiri- 
Table 8.1 Conceptualising four types of student goals using mastery-performance and approachavoidance dichotomies

\begin{tabular}{|c|c|}
\hline Mastery-approach goal orientation & Performance-approach goal orientation \\
\hline $\begin{array}{l}\text { - Interest and curiosity: Learning something } \\
\text { interesting } \\
\text { - Task: Mastering a task } \\
\text { - Challenge: Mastering a challenge } \\
\text { - Improvement or attainment: Learning as much } \\
\text { as possible; improving my knowledge; } \\
\text { understanding the content as thoroughly as } \\
\text { possible; acquiring new skills }\end{array}$ & $\begin{array}{l}\text { - Appearance: Demonstrating } \\
\text { competence/ability } \\
\text { - Normative: Performing better than other } \\
\text { students } \\
\text { - Evaluative: Demonstrating my ability } \\
\text { relative to others in the class (as judged by } \\
\text { authority figure such as a teacher) }\end{array}$ \\
\hline Mastery-avoidance goal orientation & Performance-avoidance goal orientation \\
\hline $\begin{array}{l}\text { - Task: Avoiding forgetting what I have already } \\
\text { learnt } \\
\text { - Improvement or attainment: Avoiding losing } \\
\text { my skills/abilities/knowledge; avoiding } \\
\text { stagnation or lack of development }\end{array}$ & $\begin{array}{l}\text { - Appearance: Avoiding looking } \\
\text { incompetent/'dumb' } \\
\text { - Normative: Avoiding performing poorly in } \\
\text { the class } \\
\text { - Evaluative: Avoiding demonstration of } \\
\text { lack of ability relative to others (as judged } \\
\text { by authority figure) }\end{array}$ \\
\hline
\end{tabular}

Adapted from Elliot (1999, 2008), Hulleman et al. (2010)

cally supported by research over several years, and the mastery-avoidance orientation more recently (Elliot \& Murayama, 2008; Jang \& Liu, 2012).

Despite conflicting findings in the literature, there is evidence that students are more likely to demonstrate mastery than performance goal orientations, that "social comparisons exert less influence on engagement in academic tasks than the aspiration to understand and to learn academic content" (Chouinard et al., 2007, p. 514). Brophy (2005) raised the issue, however, that most studies using goal theory to date have relied on experimental induction procedures or Likert-scale response items, which use a priori constructs based on researchers' definitions. These research methods do not allow investigation into the degree to which students spontaneously generate evidence of the four goal orientations. He suggested that there is very limited evidence to indicate that students actually do hold performance goals: "looking good in comparison with their classmates" (p. 171). This study provided the opportunity to seek evidence for the four goal orientations in the students' spontaneously generated responses.

\subsubsection{Studies on Boys' and Girls' Motivation and Goal Orientations}

Historically and in a range of contexts, gender differences in mathematics achievement have been found (Grootenboer \& Marshman, 2016) and have been attributed in part to affective factors (Leder, 1992). In recent years, researchers have paid attention to differences between boys' and girls' beliefs, attitudes, emotions, and dispositions. A review of studies found that overall, boys tend to report a higher interest in learn- 
ing mathematics than girls (Meece et al., 2006). Chouinard et al. (2007) found that more girls reported mastery goals and higher effort than boys. A study of approximately 1200 German secondary students found that nearly half reported believing that boys achieve more, one fifth reported that girls achieve more, and the rest indicated no gender difference. Of those students who reported that they believe girls achieve more, the three most frequently cited reasons were effort, concentration, and ambition—not ability (Kaiser, Hoffstall, \& Orschulik, 2012).

In the Australian context, which is relevant to this study, Watt (2004) found that boys maintained a higher interest in and liking for mathematics and a higher perception of competence (ability rather than effort) than girls throughout adolescence. In contrast to these findings, Leder and Forgasz (2002) studied over 800 lower secondary students and found that although the majority viewed mathematics as a gender-neutral domain in terms of ability or achievement, they reported believing that girls are more interested in mathematics and enjoy it more, whereas the boys are more likely to find it difficult and boring-that they need more help to learn it than girls. Another Australian study of 1800 secondary students found that the middle school girls demonstrated more mastery goals and more effort than boys (Green et al., 2005). An international comparative longitudinal study of secondary students found that Australian girls had significantly lower intrinsic value (utility) for mathematics than the boys, unlike those in Canada and the United States. Yet they did not demonstrate a lower perception of competence than the boys, as did the girls in Canada and the US (Watt et al., 2012). Plenty and Heubeck (2013) studied over 500 rural Australian students (Years 7-9) longitudinally and found similar trajectories of decreasing motivation, similar patterns of self-efficacy and utility, but that the girls expressed greater mastery orientation and also more anxiety about assessment tasks than the boys. Overall, these studies suggest that Australian girls in recent years are likely to believe they have similar competence to boys, but are more anxious about their learning.

In a recent study of over 1800 New Zealand middle school students, Grootenboer and Marshman (2016) found overall that the boys were significantly more positive in their attitude towards mathematics, believed mathematics was more useful (utility), and were less anxious than the girls. In comparing year levels, they found that the Year 7/8 students were more negative about mathematics, had lower self-efficacy, and were more anxious than the Year 5/6 students, supporting previously mentioned findings from other studies of a decrease in motivation as students move from upper primary to lower secondary school (Meece et al., 2006; Watt, 2004).

\subsubsection{Extrinsic Motivational Factors in the Classroom Environment}

Teachers who understand more about how students' motivation is influenced by both intrinsic and extrinsic dimensions can make choices in their teaching practice, 
such as what types of tasks to use, how to design the learning environment, and teaching strategies to use, that help maximise students' opportunities to achieve in mathematics (Megowan-Romanowicz, Middleton, Ganesh, \& Joanou, 2013). If it is true that "motivation and achievement are developmental, interdependent, and influenced by the design of educational experiences" (Middleton, 2013, p. 91), then it is worthwhile to examine how students describe the extrinsic characteristics of their classroom environment and relate them to their motivation and goals for learning. Middleton's (2013) analysis of the previously mentioned data set of US middle school students indicated that extrinsic influential factors are likely to be present and appear to influence interest and effort. Factors that were suggested included: the classroom environment, learning strategies and resources, teacher attitude, and family environment. It was proposed that teacher actions, setup of the classroom environment, choice of mathematical tasks, and use of tools could influence students' interest and therefore effort and achievement (Middleton, 2013).

In recent years, researchers have begun to examine the potential influence of external factors in specific achievement environments on an individual's internal goal orientation. There seems to be consensus that extrinsic factors in a specific context may play a role in influencing an individual's goal orientation by promoting a particular view of achievement or competence (Allen, 2003; Rolland, 2012; Urdan, 2001). Urdan (2001) asserted that the achievement goals an individual pursues in a given situation depend both on his/her intrinsic goal orientation and on extrinsic messages received in that environment that make certain goals salient to him/her. A context in which progress in learning, persistence, and effort are promoted can influence learners to adopt more mastery-oriented goals whereas a context emphasising competitive performance can promote the adoption of more performance-oriented goals (Dweck, 2007; Elliot, 1999; Elliot \& Murayama, 2008; Jang \& Liu, 2012). In a large review of research on the relationships among student-perceived classroom goal structures, teacher support, and student motivational variables, Rolland (2012) found that teachers' (socio-emotional and instructional) support and emphasis of mastery goals in the classroom promoted positive affective outcomes for secondary middle school students, but not with younger cohorts (Year 6), suggesting more direct teacher effects for older students. In particular, teacher support was strongly related to student interest in learning tasks.

The study discussed in this chapter was conducted with Australian students in the context of a recently introduced national curriculum for mathematics (Australian Curriculum Assessment and Reporting Agency, 2015) emphasising learning tasks that promote reasoning, understanding, problem solving, and fluency (Kilpatrick, Swafford, \& Findell, 2001). Yet it has been reported that typical teaching approaches for middle school and secondary mathematics in Australia tend to focus on procedures and computational processes rather than concepts and problem solving (e.g., Hollingsworth, Lokan, \& McCrae, 2003). There is little in the literature on how students themselves view particular teaching approaches and how they might relate these to their engagement and motivation.

In a study of Australian middle school students' views after attempting a challenging task, Sullivan et al. (2014) found that a majority of both the primary and 
secondary students preferred to work on tasks at least as difficult as the challenging task. They also found a variety of preferences for working arrangements: one third indicated they preferred working individually, one third reported that they liked working with another student, and a third preferred to listen to explanations from the teacher first. Although small-group work for mathematics learning is widely advocated in mathematics education policy and curriculum, little is known about its use in Australian settings. A large-scale survey in the United States found that slightly less than $25 \%$ of middle school students experienced regular collaborative opportunities (Banilower et al., 2013).

These studies posit an influential role for the external environment in which students learn, and suggest that the choices teachers make in their teaching practice and interactions with students influence students' affect and motivation. This study was an opportunity to examine Australian students' spontaneously generated responses for evidence of preferences for different extrinsic environmental features, for example, particular teacher actions, different teaching approaches, and independent or collaborative learning. The following section provides details on how the research was designed to elicit students' spontaneous expressions about their aspirations.

\subsection{Research Design}

Much of the research literature describes attempts to define and to measure different aspects of the affective dimensions of students' motivation for learning-their attitude, self-efficacy, beliefs, values, and other variables - to theorise causal relationships among motivation, behaviour, and academic achievement. Structured surveys and Likert-scale response items are typically used in large-scale studies, which aim to measure pre-defined aspects of motivation (Hannula, 2006) and approach relationships from a normative view (di Martino \& Zan, 2010). As discussed earlier in the chapter, Brophy (2005) expressed concern that pre-defined surveys suggest to students goal orientations they may not have produced on their own, and also that they limit the range of possible responses to those conceptualised by the researcher. He highlighted the lack of research that explores what students might say about their goals in their own words. This study was designed to address the need for research in the affective domain that seeks students' own views and expressions (Grootenboer \& Marshman, 2016).

The issue of 'voice' in research is discussed extensively in the literature: how to give participants greater voice about issues that directly and indirectly affect them, especially those whose voices are not often heard (Flutter \& Rudduck, 2004). There seems to be an increased valuing of consulting learners about their views, thoughts, feelings and experiences, for making teaching and learning more effective (Flutter \& Rudduck, 2004; Robinson \& Taylor, 2007). This study was an opportunity to seek middle school students' voice specifically about their wishes for mathematics learning. 
As a complementary approach to pre-defined quantitative studies on motivational aspects, this study used an open-ended response item to investigate the different facets of students' aspirations as expressed by the students themselves, without any a priori motivation constructs. It enabled interpretive content analysis of their spontaneous responses (Lieblich, Tuval-Mashiach, \& Zilber, 1998; Mayring, 2015). The students were asked: "If you had one wish for your mathematics learning, what would it be?" As previously explained, the word 'wish' was chosen for the wording of the survey question because it was likely to be familiar to students from everyday usage (e.g., 'I wish I could...', 'three wishes', 'make a birthday wish'), and is also suggestive of desiring something that may not necessarily happen-something hoped for but perhaps ordinarily unattainable.

The purpose of the study was not to infer causal relationships between motivational variables but to understand more about what students themselves choose to focus on when articulating their aspirations and how these might relate to different aspects of their experiences, goals, and motivation in mathematics learning. An interpretive approach and avoiding "heavy-handed, intrusive analysis" was an aim of the study (Wolcott, 2009, p. 33). It was also considered important to provide anonymity so that the students were not obliged to say what they thought was expected of them (Robinson \& Taylor, 2007). They could describe critical or negative or nonsensical ideas or not respond at all.

\subsubsection{The Participants}

Although seeking qualitative data, the research generated a large amount of data from 3562 middle school students in 2015 (93\% response rate) from three Australian states: Victoria, New South Wales, and Tasmania. The students were from 31 government and independent schools of varying sizes and socioeconomic status. They were at the beginning of their participation in a larger project ${ }^{2}$ that is studying the types of tasks that can encourage students to persist in their learning, and strategies teachers can use for increasing student effort (see Sullivan et al., 2014). The students typed their own responses to the question via an online survey, and these ranged from a few words to a long paragraph. They did not appear to have any technical difficulty with the process of typing their responses or intellectual difficulty with understanding the question. The shorter responses tended to be a phrase expressing one aspiration whereas the longer responses often included an explanation for why the student wished for something or expressed more than one aspiration. Examples of different responses are presented in the Discussion of findings section.

\footnotetext{
${ }^{2}$ The Encouraging Persistence Maintaining Challenge (EPMC) project was funded through an Australian Research Council Discovery Project (DP110101027) and involved collaboration between Monash University and the Australian Catholic University. The views expressed are those of the author. The generous participation of project schools is acknowledged.
} 


\subsubsection{Coding the Students' Responses}

The research team (author, research assistant, and overall project chief investigator) employed a process model for forming codes and grouping them conceptually in categories. Researcher-driven line-by-line coding was used rather than automated software counting procedures, despite the large data collection, because there was the perceived need to make nuanced interpretations of the phrasing that the students used, not only individual words. The students' own words and phrases were incorporated in the node labels to provide a sense of how they were interpreted and grouped conceptually. The use of the NVivo 10 software program supported this process and enabled the team to make cyclical comparisons of coding frequencies and adjustments throughout the process to improve intra- and inter-coding reliability.

The author initially developed a coding scheme by analysing a set of 500 student responses. A research assistant then used the initial coding scheme for the same 500 responses; the coding was then compared node by node and the scheme refined and re-arranged after discussions with the team. Two members then coded another 400 responses and repeated the process of comparing and refining to maintain inter-coder reliability. A set of nearly 2000 responses was then coded by one team member and examined by another; only minor adjustments were needed by this stage. The coding of the rest of the responses then occurred and was double-checked. Table 8.1 presents the final coding scheme for the study with percentage frequencies for year levels, students overall, and genders by year level and overall.

A student's response was sometimes found to relate to more than one category and was therefore coded at more than one node and holistically, to avoid data fragmentation and the use of data out of context (Bazeley, 2007; Lieblich et al., 1998). Some of the codes in the fifth category 'About being taught' appeared similar in nature to those in other categories, but were deliberately coded separately, even though it made the framework bulkier. The intent was to distinguish explicit references to the role of the teacher in their wish, for example, teachers making maths fun or interesting (more suggestive of the extrinsic motivational dimension) and more enjoyment, fun in the category 'Type of task' (perhaps more suggestive of an intrinsic view about mathematics itself or the process of learning mathematics).

\subsection{Discussion of Findings}

The following discussion focuses on the nature of the students' self-expressed aspirations and also on evidence of different goal orientations in their use of language. Comparisons are made between upper primary (Year 5/6) and lower secondary (Yr 7/8) students' responses, as well as between those of girls and boys. The coding framework, presented in Table 8.2, demonstrates the diverse range of students' responses to being asked about their wishes for mathematics learning. Although there are many ways the data could have been analysed, in this study the codes were 
grouped into five main categories, presented in order of overall frequency: 'About learning or achievement', 'Type of task', 'About affect or motivation' (explicit reference), 'Working arrangement, and 'About being taught'. Overall, the responses were noticeably worded in positive terms. Each code contains responses from both upper primary and lower secondary students and from both boys and girls, suggesting that the types of wishes expressed by this cohort were salient across different ages and genders. Less than $2 \%$ of the responses were unclear or irrelevant.

\subsubsection{The Nature of Students' Aspirations}

Overall, the most frequent category for the students' responses was 'About learning or achievement' $(60 \%)$. A higher percentage of Year $7 / 8$ students $(67 \%)$ made a response in this category compared to Year 5/6 students (53\%). A noticeably larger percentage of Year 7/8 girls, compared to younger girls or the boys, expressed a desire for greater fluency: being able to learn or answer quicker or more easily or efficiently (10\%). The desire for fluency was also evident from many of the students expressing the wish to know their times Tables ( $8 \%$ overall; $12 \%$ of Year 5/6 students). A higher percentage of Year 7/8 girls also expressed a desire to learn multiple strategies, ways to solve, how others solve (8\%). A study of secondary teachers highlighted their mistaken perception that the students would resist learning multiple strategies (Leikin, Levav-Waynberg, \& Mednikov, 2006) so it is interesting that nearly $10 \%$ of the Year 7/8 girls spontaneously expressed their desire for this type of approach.

The percentage of Year 5/6 students who expressed the desire for more challenge in their learning (8\%) was nearly double that of the Year $7 / 8$ students, for example:

I wish that we could do harder things in class because everything in math is so easy. Maths isn't fun anymore because it's so easy. I want a challenge. (Yr 5/6 boy \#641)

To be given harder maths tasks to work on during class, because I find the work we are doing lately is a bit too easy. (Yr 5/6 girl \#280)

It has been argued that teachers expect students to dislike more challenging tasks (Sullivan et al., 2014) so it is also interesting to find that the younger students in this cohort, at upper primary levels, raised their desire for more not less challenge. Less than $1 \%$ of the overall responses contained a wish for less effort or doing easier work.

The percentage of girls' responses (5\%) that related to retaining (not forgetting, remembering, memorising, off by heart, revising) was more than double that of the boys' responses, and were also more frequent at the Year 7/8 level. This perhaps suggests some anxiety for this cohort about having to remember what they have learnt so far in mathematics, perhaps because of the considerable amount of content to be covered at secondary levels. This result resonates with quantitative studies that found maths anxiety to be higher among girls (Grootenboer \& Marshman, 2016; Plenty \& Heubeck, 2013). 


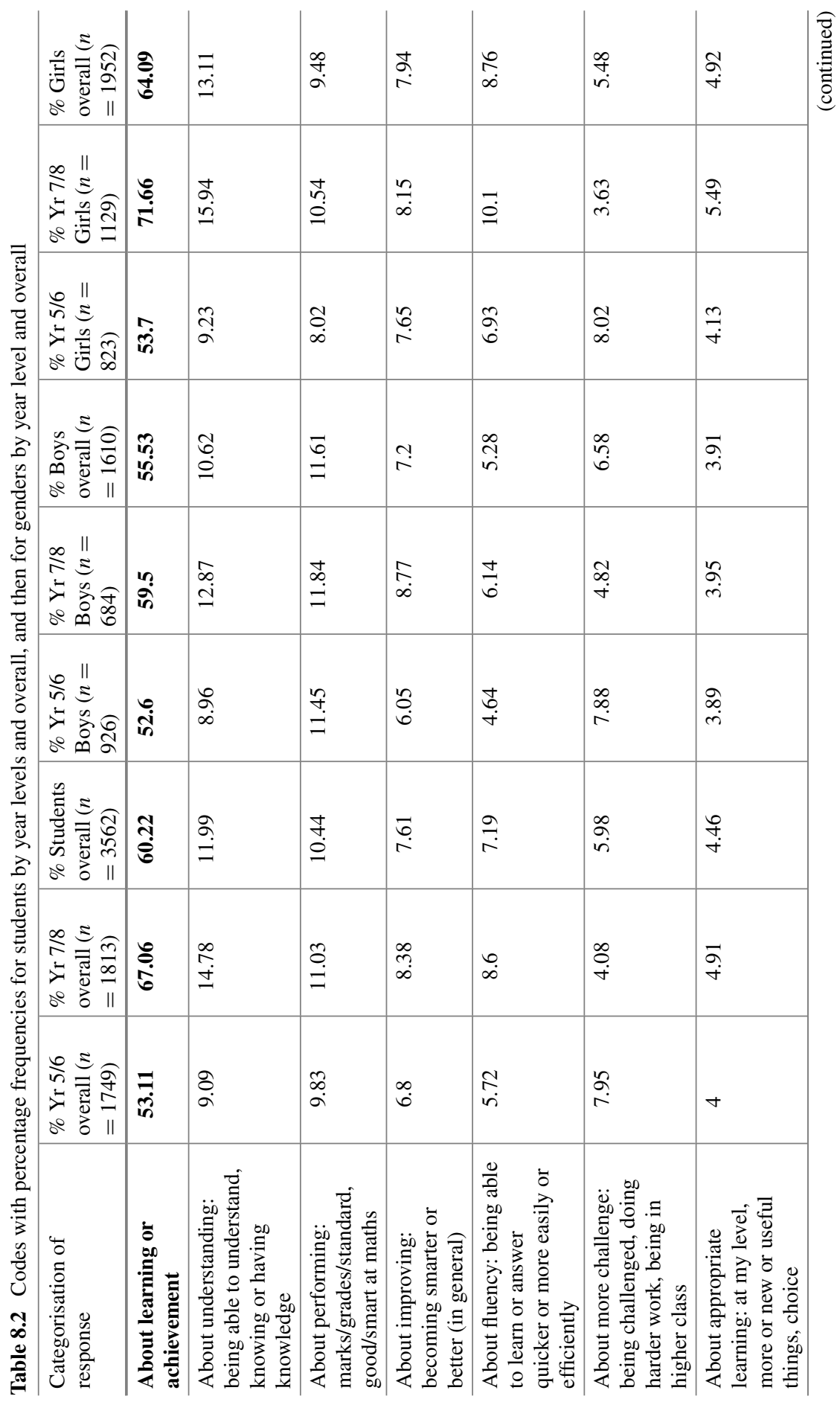


8 Middle School Boys' and Girls' Own Expressions of Aspirations ...

\begin{tabular}{|c|c|c|c|c|c|c|c|c|c|c|c|}
\hline 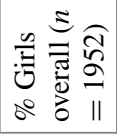 & $\begin{array}{l}\infty \\
n \\
n \\
n\end{array}$ & $\begin{array}{l}\stackrel{\infty}{+} \\
\text { i. }\end{array}$ & ત̃ & $\bar{n}$ & $\stackrel{5}{0}$ & $\begin{array}{l}2 \\
\stackrel{6}{6} \\
18\end{array}$ & $\begin{array}{l}\overline{0} \\
\stackrel{+}{+} \\
i\end{array}$ & $\begin{array}{l}= \\
\ddot{n}\end{array}$ & $\tilde{n}$ & $\begin{array}{l}n \\
n \\
n\end{array}$ & ळo \\
\hline 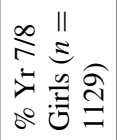 & $\underset{\infty}{\stackrel{d}{~}}$ & ָֻ & $\vec{\sim}$ & $\frac{\infty}{0}$ & $\stackrel{\infty}{0}$ & $\begin{array}{l}\text { ลें } \\
\text { ભે }\end{array}$ & $\begin{array}{l}\hat{\sigma} \\
\dot{\sim} \\
i \\
i\end{array}$ & $\begin{array}{l}n \\
\infty \\
\infty\end{array}$ & సֶ. & $\stackrel{+}{i}$ & $\stackrel{\circ}{\stackrel{一}{+}}$ \\
\hline 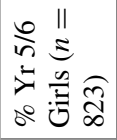 & $\stackrel{+}{-}$ & 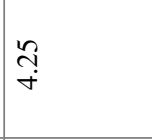 & $\vec{n}$ & $\stackrel{a}{\text { gे }}$ & $\stackrel{m}{\stackrel{0}{0}}$ & बें & $\begin{array}{l}+ \\
+ \\
\infty \\
i \\
i\end{array}$ & $\begin{array}{l}\hat{n} \\
\tilde{n}\end{array}$ & $\begin{array}{l}\stackrel{\partial}{.} \\
\dot{ \pm}\end{array}$ & $\begin{array}{l}+ \\
\infty \\
\sigma\end{array}$ & రై \\
\hline 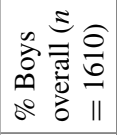 & $\begin{array}{l}\vec{\sigma} \\
i\end{array}$ & $\begin{array}{l}\bar{\sigma} \\
i\end{array}$ & $\stackrel{n}{i}$ & $\underset{\sim}{\mathbb{i}}$ & ஜ̊ & ले & $\stackrel{m}{m}$ & 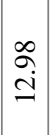 & $\vec{\sigma}$ & iे & nn \\
\hline 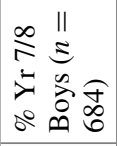 & $\tilde{n}$ & ๙ิ & 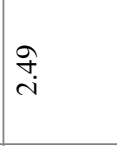 & $\stackrel{\Re}{\tilde{o}}$ & J & $\frac{n}{20}$ & 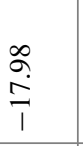 & $\stackrel{\partial}{\vec{n}}$ & $\begin{array}{l}\hat{\sigma} \\
i\end{array}$ & $\stackrel{9}{9}$ & $\stackrel{\text { ले }}{+}$ \\
\hline 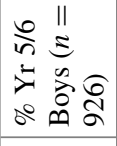 & $\stackrel{9}{\stackrel{-}{\rightleftarrows}}$ & 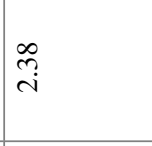 & 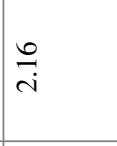 & $\stackrel{m}{m}$ & $\begin{array}{l}\mathscr{0} \\
\ddot{0}\end{array}$ & $\frac{m}{n}$ & $\begin{array}{l}\bar{\sigma} \\
\stackrel{+}{+}\end{array}$ & $\begin{array}{l} \pm \\
\underset{\infty}{\infty}\end{array}$ & $\stackrel{N}{\stackrel{N}{a}}$ & $\begin{array}{l}\infty \\
\infty \\
\infty\end{array}$ & $\stackrel{9}{=}$ \\
\hline 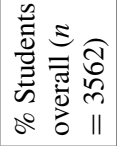 & 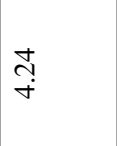 & $\stackrel{\infty}{\underset{+}{+}}$ & $\stackrel{\widehat{ָ}}{i}$ & $\stackrel{\infty}{=}$ & ర్ర. & $\begin{array}{l}\stackrel{0}{+} \\
\stackrel{\leftrightarrow}{f}\end{array}$ & $\hat{i}$ & $\begin{array}{l}n \\
\stackrel{n}{ \pm}\end{array}$ & 弪 & $\hat{n}$ & $\begin{array}{l}0 \\
\infty \\
i\end{array}$ \\
\hline 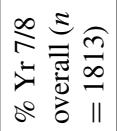 & 志 & $\hat{b}$ & ָิ & ले & $\stackrel{\bullet}{:}$ & ల్ & $\begin{array}{l}\infty \\
\text { } \\
\stackrel{\imath}{i}\end{array}$ & $\underset{\substack{\infty \\
\sim}}{ }$ & $\begin{array}{l}n \\
\infty \\
+ \\
+\end{array}$ & $\overrightarrow{\widetilde{i}}$ & $\stackrel{+}{\stackrel{+}{+}}$ \\
\hline 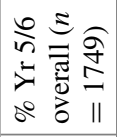 & $\stackrel{+}{n}$ & 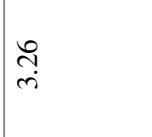 & $\stackrel{\overbrace{}}{\stackrel{\lambda}{i}}$ & $\sim$ & bे & ma & $\frac{z}{i}$ & 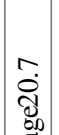 & $\stackrel{\infty}{\stackrel{\infty}{=}}$ & $\stackrel{?}{a}$ & $\bar{\sigma}$ \\
\hline 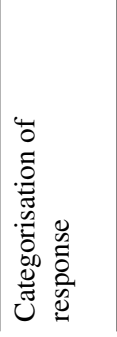 & 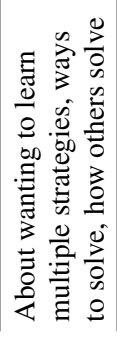 & 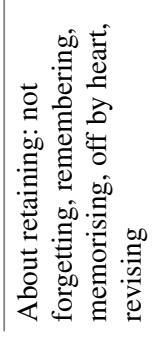 & 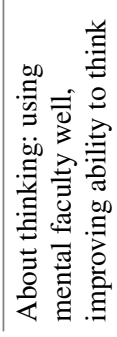 & 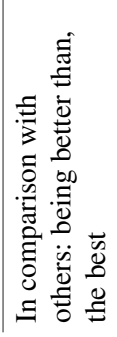 & 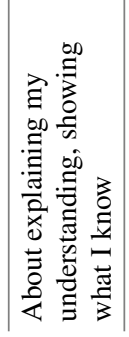 & | & 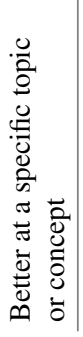 & 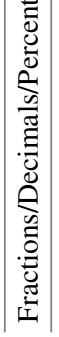 & $\mid$ & .0 & 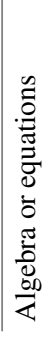 \\
\hline
\end{tabular}




\begin{tabular}{|c|c|c|c|c|c|c|c|c|c|c|c|}
\hline 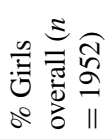 & $\stackrel{0}{\stackrel{0}{6}}$ & $\bar{ָ}$ & $\stackrel{m}{-}$ & $\stackrel{m}{\dddot{m}}$ & 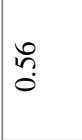 & $\underset{0}{+}$ & $\begin{array}{l}\stackrel{\partial}{\stackrel{ \pm}{ \pm}} \\
\text { }\end{array}$ & $\begin{array}{l}\Delta \\
\ddot{n}\end{array}$ & $\begin{array}{l}\underset{\infty}{\infty} \\
\stackrel{+}{*}\end{array}$ & $\overline{\widetilde{n}}$ & ? \\
\hline 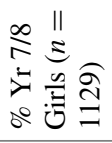 & 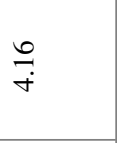 & $\stackrel{尺}{\beth}$ & $\stackrel{\mathcal{I}}{-}$ & $\stackrel{尺}{\stackrel{f}{-}}$ & $\stackrel{F}{0}$ & $\begin{array}{l}\tilde{b} \\
\stackrel{0}{0}\end{array}$ & 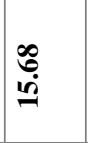 & ஸู & $\stackrel{m}{6}$ & $\overrightarrow{\widetilde{\lambda}}$ & ஸे \\
\hline 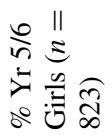 & $\stackrel{\cong}{\varrho}$ & $\begin{array}{l}\dot{J} \\
\dot{r}\end{array}$ & $\stackrel{\text { ปே }}{-}$ & $\stackrel{\overbrace{}}{\stackrel{0}{0}}$ & ़ֻ? & $\frac{1}{0}$ & & $\begin{array}{l}n \\
n \\
n\end{array}$ & $\stackrel{a}{\vec{i}}$ & $\underset{\stackrel{f}{i}}{\mathrm{r}}$ & 守 \\
\hline 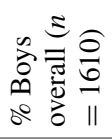 & $\begin{array}{l}\frac{0}{n} \\
\dot{n}\end{array}$ & $\underset{i}{\tilde{b}}$ & $\begin{array}{c}\infty \\
\stackrel{\infty}{+} \\
\text { i }\end{array}$ & $\stackrel{\vec{\sigma}}{-}$ & $\stackrel{\text { ñ }}{0}$ & $\begin{array}{l}8 \\
0 \\
0\end{array}$ & $\begin{array}{l}\infty \\
\stackrel{\Theta}{\Theta}\end{array}$ & $\stackrel{\text { I }}{i}$ & $\stackrel{\text { I }}{\text { r. }}$ & 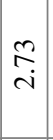 & $\underline{n}$ \\
\hline 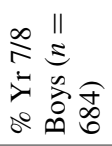 & $\underset{\text { ș }}{\text { s. }}$ & $\stackrel{\text { fo }}{\sim}$ & 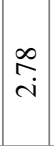 & $\stackrel{\vec{n}}{\sim}$ & $\underset{0}{\sharp}$ & $\frac{n}{0}$ & $\stackrel{\text { ঙ̆ }}{=}$ & $\underset{\mathrm{c}}{\mathrm{i}}$ & $\begin{array}{l}\stackrel{i}{1} \\
\text { in }\end{array}$ & $\begin{array}{l}2 \\
i \\
i\end{array}$ & $\stackrel{゚}{\stackrel{0}{+}}$ \\
\hline 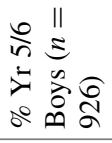 & $\hat{\sigma}$ & $\stackrel{\circ}{\stackrel{0}{n}}$ & $\stackrel{\grave{i}}{\grave{i}}$ & $\stackrel{\infty}{\circ}$ & $\overrightarrow{0}$ & 0 & $\stackrel{\mathfrak{N}}{a}$ & $\hat{i}$ & $\underset{c}{n}$ & 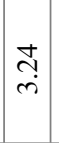 & $\stackrel{m}{-}$ \\
\hline 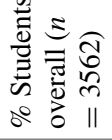 & $\begin{array}{l}+ \\
0\end{array}$ & $\underset{\text { 守 }}{\text { i }}$ & $\begin{array}{l}n \\
\stackrel{n}{-\infty} \\
-1\end{array}$ & $\stackrel{\text { ơ }}{\text { +. }}$ & $\stackrel{\text { I }}{0}$ & ָ̃ & $\begin{array}{l}\vec{b} \\
\stackrel{0}{c}\end{array}$ & $\stackrel{n}{\ddot{r}}$ & $\stackrel{\infty}{\stackrel{\infty}{+}}$ & $\stackrel{n}{i}$ & $\vec{\infty}$ \\
\hline 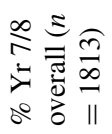 & $\frac{n}{\stackrel{n}{r}}$ & $\stackrel{n}{\sigma}$ & $\stackrel{\Re}{\Omega}$ & $\stackrel{\Omega}{\sigma}$ & $\vec{b}$ & $\underset{⿱}{ \pm}$ & $\begin{array}{l}\infty \\
\infty \\
\ddot{n}\end{array}$ & $\begin{array}{l}\hat{b} \\
\dot{+}\end{array}$ & $\stackrel{\infty}{\vec{b}}$ & $\stackrel{-}{\sigma}$ & $\stackrel{\mathbb{2}}{0}$ \\
\hline 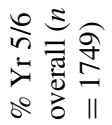 & $\stackrel{+}{\infty}$ & $\stackrel{\text { ஸे }}{\text { ñ }}$ & 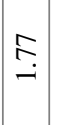 & $\bar{\sigma}$ & $\stackrel{\overbrace{}}{0}$ & $\begin{array}{l}0 \\
0 \\
0\end{array}$ & $\frac{\infty}{\stackrel{0}{0}}$ & $\begin{array}{l}\stackrel{\circ}{\circ} \\
\stackrel{+}{*}\end{array}$ & $\underset{\sim}{\stackrel{\sim}{c}}$ & 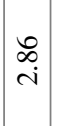 & $\bar{a}$ \\
\hline 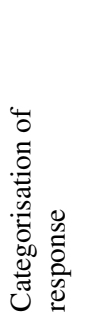 & 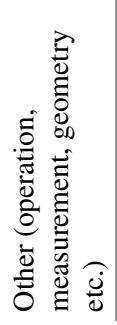 & 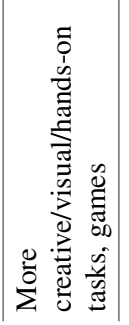 & \begin{tabular}{|c|} 
\\
0 \\
0 \\
00 \\
0 \\
0 \\
0 \\
0 \\
0 \\
0 \\
0 \\
0 \\
$\Sigma$ \\
$\Sigma$
\end{tabular} & 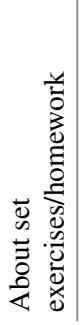 & 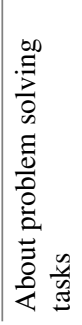 & 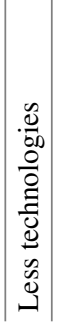 & 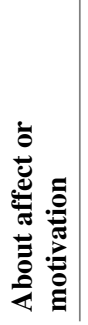 & 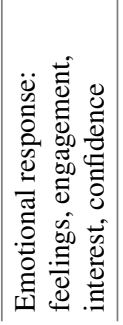 & 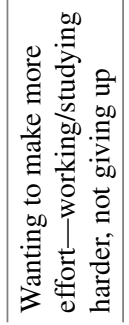 & 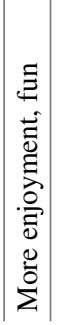 & 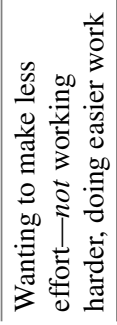 \\
\hline
\end{tabular}


8 Middle School Boys' and Girls' Own Expressions of Aspirations ...

\begin{tabular}{|c|c|c|c|c|c|c|c|c|c|c|c|c|}
\hline 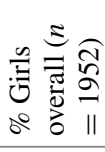 & $\stackrel{n}{0}$ & $\stackrel{\text { ઼ָ }}{\beth}$ & ָָ & $\begin{array}{l}\stackrel{2}{c} \\
i\end{array}$ & $\stackrel{i}{\hat{0}}$ & ח̊ & $\stackrel{\square}{0}$ & $\stackrel{n}{\varrho}$ & $\begin{array}{l}\mathbb{J} \\
\dot{c}\end{array}$ & ๙ิ & $\stackrel{\overbrace{}}{\stackrel{n}{\longrightarrow}}$ & $\begin{array}{l}0 \\
\infty \\
0 \\
0\end{array}$ \\
\hline 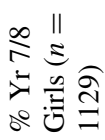 & సֶ. & 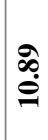 & $\frac{2}{i}$ & $\stackrel{\stackrel{\Im}{\unlhd}}{-}$ & $\tilde{n}$ & O̦ & $\tilde{n}$ & $\underset{\Xi}{\stackrel{\Xi}{\Xi}}$ & ô. & $\hat{m}$ & $\stackrel{\text { f }}{\rightarrow}$ & 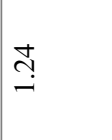 \\
\hline 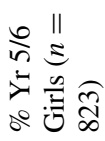 & 0 & $\stackrel{\vec{G}}{=}$ & f̊ & $\begin{array}{l}\hat{\lambda} \\
\text { in }\end{array}$ & $\stackrel{g}{-}$ & 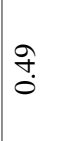 & $\stackrel{m}{0}$ & กุ่ & $\stackrel{n}{+}$ & 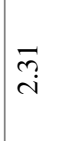 & $\hat{a}$ & 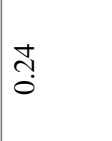 \\
\hline 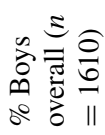 & $\stackrel{?}{\circ}$ & $\stackrel{2}{\stackrel{2}{r}}$ & $\begin{array}{l}\text { f } \\
\text { in }\end{array}$ & $\begin{array}{l}\infty \\
\stackrel{\infty}{0} \\
0\end{array}$ & $\begin{array}{l}\vec{\infty} \\
\dot{0}\end{array}$ & $\stackrel{2}{n}$ & $\stackrel{\text { f̊ }}{\circ}$ & $\underset{\text { in }}{\mathbb{1}}$ & $\hat{\grave{o}}$ & $\stackrel{\text { f }}{\rightarrow}$ & $\stackrel{8}{8}$ & $\stackrel{n}{0}$ \\
\hline 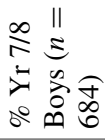 & $\stackrel{7}{\circ}$ & ْ̊ & $\begin{array}{l}\partial \\
\hat{n}\end{array}$ & $\begin{array}{l}J \\
0\end{array}$ & $\mid \begin{array}{l}\infty \\
\infty \\
0\end{array}$ & $\Xi$ & $\stackrel{\infty}{\dddot{n}}$ & $\underset{\infty}{\hat{\infty}}$ & $\underset{\text { O̦ }}{-}$ & $\stackrel{\sigma}{-}$ & $\frac{n}{2}$ & $\underset{\sigma}{\sigma}$ \\
\hline 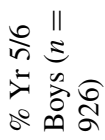 & $\stackrel{\text { f̊ }}{\circ}$ & बे & $\hat{\sigma}$ & $\begin{array}{l}0 \\
0 \\
0\end{array}$ & $\begin{array}{l}0 \\
\vdots \\
0\end{array}$ & 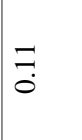 & $\stackrel{+}{\tilde{\sigma}}$ & $\begin{array}{l}\stackrel{+}{+} \\
\text { rे }\end{array}$ & $\begin{array}{l}\infty \\
0 \\
0\end{array}$ & $\stackrel{+}{-}$ & กै & $=$ \\
\hline 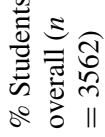 & 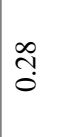 & $\frac{\pi}{2}$ & $\stackrel{?}{\text { f̧ }}$ & $\stackrel{?}{\stackrel{g}{-}}$ & $\frac{2}{\hat{0}}$ & ?ִ & $\tilde{n}$ & $\begin{array}{c}m \\
\infty\end{array}$ & $\stackrel{\underset{\sim}{i}}{i}$ & $\hat{i}$ & $\stackrel{n}{\longrightarrow}$ & $\underset{0}{0}$ \\
\hline 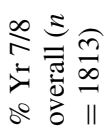 & $\stackrel{m}{0}$ & స̃. & $\frac{\pi}{\pi}$ & $\stackrel{n}{0}$ & $\mid \begin{array}{l}0 \\
0 \\
0\end{array}$ & $\begin{array}{l}0 \\
\infty \\
0 \\
0\end{array}$ & $\tilde{n}$ & $\begin{array}{l}\tilde{ \pm} \\
\stackrel{\Xi}{\oplus}\end{array}$ & 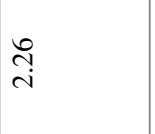 & $\hat{i}$ & 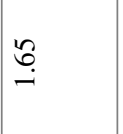 & $\stackrel{0}{=}$ \\
\hline 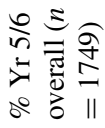 & $\stackrel{\overbrace{}}{0}$ & กั & $\begin{array}{l}\stackrel{0}{0} \\
i\end{array}$ & $\begin{array}{l}\text { Oొ } \\
-\end{array}$ & $\bar{a}$ & సิ & $\tilde{n}$ & $\frac{5}{6}$ & $\hat{n}$ & $\stackrel{\infty}{-\infty}$ & ?ִ & $\stackrel{1}{0}$ \\
\hline 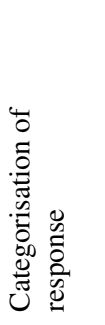 & 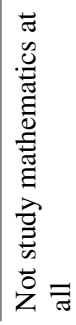 & 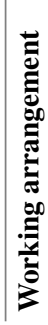 & 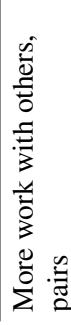 & 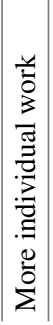 & 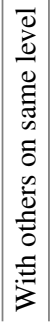 & 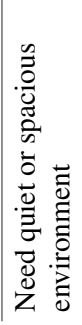 & 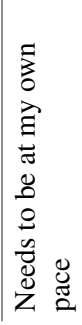 & 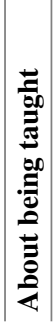 & 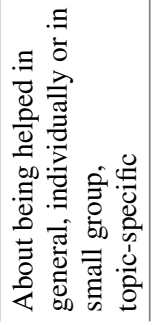 & 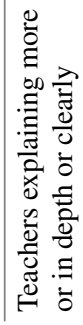 & 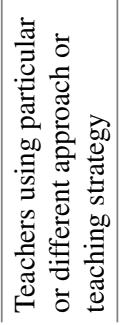 & 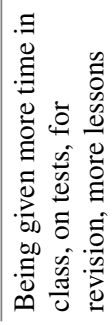 \\
\hline
\end{tabular}




\begin{tabular}{|c|c|c|c|c|c|c|c|c|}
\hline 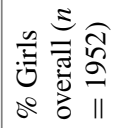 & $\hat{\sigma}$ & חొ & $\frac{n}{0}$ & $\stackrel{2}{0}$ & $\begin{array}{l}\tilde{\sigma} \\
0\end{array}$ & $\stackrel{\infty}{\longrightarrow}$ & J. & $\begin{array}{l}\hat{\infty} \\
0 \\
0\end{array}$ \\
\hline 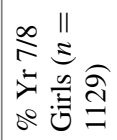 & $\hat{a}$ & $\stackrel{f}{\stackrel{0}{0}}$ & 0 & $\stackrel{\partial}{0}$ & $\begin{array}{l}0 \\
0 \\
0\end{array}$ & กี & 导 & $\begin{array}{l}0 \\
\infty \\
0\end{array}$ \\
\hline 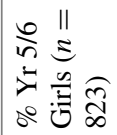 & $\stackrel{\sharp}{0}$ & 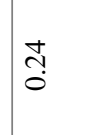 & ?ִ & 0 & $\begin{array}{l}0 \\
\dddot{0} \\
0\end{array}$ & $\hat{a}$ & 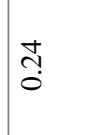 & $\mid \begin{array}{l}n \\
0 \\
0 \\
0\end{array}$ \\
\hline 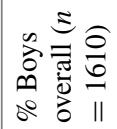 & $\overline{0}$ & ๓ై & ָे & $\stackrel{a}{a}$ & $\begin{array}{l}\tilde{S} \\
0 \\
0\end{array}$ & $\underset{-\sigma}{-}$ & $\frac{2}{0}$ & $\stackrel{+}{\mathrm{d}}$ \\
\hline 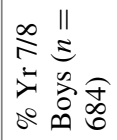 & $\stackrel{m}{0}$ & $\stackrel{\infty}{\infty}$ & $\frac{n}{0}$ & J & $\Xi$ & $\underset{i}{\stackrel{a}{i}}$ & $\frac{n}{0}$ & 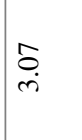 \\
\hline 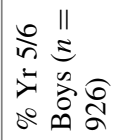 & 0 & $\overline{0}$ & กै? & $=$ & กิ & $\hat{\alpha}$ & 0 & $\stackrel{\sigma}{\sigma}$ \\
\hline 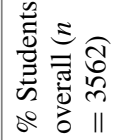 & $\bar{n}$ & mे & $\stackrel{\text { ra }}{0}$ & $\stackrel{ \pm}{0}$ & ְִ & $\stackrel{\infty}{?}$ & $\overrightarrow{\tilde{o}}$ & $\stackrel{g}{g}$ \\
\hline 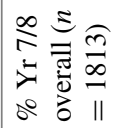 & $\begin{array}{l}\infty \\
\infty \\
0 \\
0\end{array}$ & ? & : & ָ̃ & $\hat{\sigma}$ & $\stackrel{શ}{i}$ & $\stackrel{m}{m}$ & 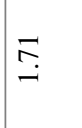 \\
\hline 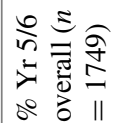 & $=$ & $\frac{1}{0}$ & ले & ○. & ते & $\hat{a}$ & 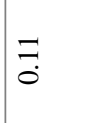 & I̊ \\
\hline 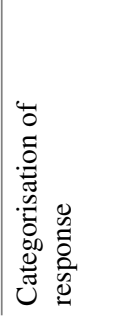 & 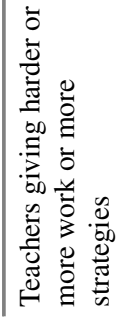 & 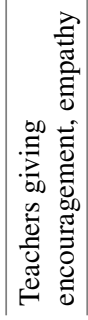 & 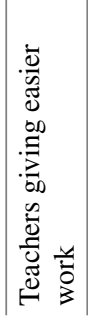 & 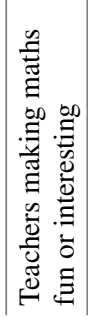 & 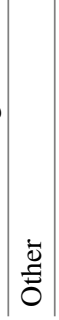 & 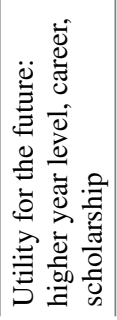 & 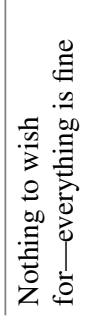 & 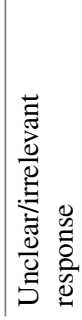 \\
\hline
\end{tabular}


Only $1 \%$ of the students' responses overall explicitly contained some sort of reference to comparison with others (suggestive of a performance goal orientation). The percentage of Year 5/6 boys' responses in this code $(3.35 \%)$ was much higher than that for the older boys' $(0.73 \%)$ or the girls' responses $(0.49 \%$ and $0.18 \%$ respectively). For example, a Year 5/6 boy wrote his wish to be: "the smartest in the school because I want people to ask me questions" (\#256). Of course, this does not imply that other students don't hold this type of goal, only that they chose not to express it in this survey.

The next most frequent category overall was 'Type of task' (43\%) but in this group a much higher percentage of Year 5/6 students (57\% compared to 30\% for Year 7/8) chose to make reference to type of task, and more particularly about a specific topic or concept. Fractions/decimals/percentage was the most frequent topic referred to by students, with times tables (multiplication tables) the next most frequent, for example:

To learn all of my x's tables and be the best I can at all of the maths work we do here in year 5 and at school. I want to learn this because I usually love maths so much when I was in year 4 but now I don't seem to like it anymore. I WANT TO LEARN THESE THINGS :) :) :);) :) :);) :) :) :) (Yr 5/6 girl \#711)

To get better at maths because even though I try hard doesn't mean I'm any good at it. I would especially like to get better at fractions and times Tables $(6,7,8)$ (Yr 7/8 girl \#740)

The percentage of girls' responses referring to these two topics at both the primary and secondary levels was slightly higher than the boys', but both genders at Year 5/6 and Year 7/8 highlighted these two topics in their responses. In all of the specifically mentioned topics or concepts, except algebra or equations, a higher percentage of Year 5/6 students made responses. It was intriguing that fluency with times tables seems to be a pervasive aim across year levels and genders. Does times tables proficiency hold a particular meaning of success in mathematics for this cohort?

Similar proportions of students at upper primary and lower secondary levels made explicit references to the affective dimension. Yet one code, wanting to make more effort-working/studying harder, not giving up, contained a higher percentage of responses from Year 7/8 students (6\% rather than $2 \%$ for Year 5/6). This suggests that the issue of effort or motivation is perhaps more salient to the older students in this cohort. There was a higher percentage of references related to the emotional dimension in the girls' data set (nearly $6 \%$ compared to $2 \%$ ), but perhaps still quite a low percentage overall, which was surprising given similarly aged students' apparent negative attitudes to mathematics in the literature. It was expected that more students would respond in this survey with affective language. A slightly higher percentage of Year 5/6 boys expressed an explicit wish for more enjoyment or fun in their mathematics learning.

Nearly $10 \%$ of the students overall made reference to their working arrangement, with a similar spread across year levels and genders; the most frequent code was a wish for more work with others in pairs or groups. A slightly higher percentage of Year 7/8 students than Year 5/6 referred to this wish in their responses, but both boys and girls at upper primary and lower secondary levels made a response about wanting 
more opportunities to work together. Some students explained the reasons for their desire to work more in groups, such as finding out how others solved problems (suggestive of learning multiple strategies):

\footnotetext{
I would want to work in groups more often because you get other people's methods of working problems out as well as solving the problems together. (Yr 7/8 boy \#154)

To be able to work in partners or small groups so I have many different ways to learn things (e.g. I can see how other students work out their problems) and it would also make maths a little more fun which for me makes it easier to concentrate, compared to if I'm bored in class. I tend to lose concentration and doze off, not helping with my learning. (Yr 7/8 girl \#550)
}

A higher percentage of Year 7/8 students explicitly referred to the role of the teacher in meeting their expressed wish $(10 \%$ rather than $6 \%$ for Year $5 / 6)$. This resonates with the review of studies finding more direct teacher effects for older middle school students (Rolland, 2012). There was a wide range of codes that related to the teacher, but with a relatively small frequency of responses in each. The most frequent code was about being helped, with nearly four times as many girls than boys expressing this wish, but interestingly with more Year 5/6 girls than the older girls and the boys. The Year 7/8 boys made slightly more frequent references to wanting teachers to use a particular or different approach or teaching strategy, but these still represent a small percentage overall (2\%). A higher percentage of Year 7/8 students than Year 5/6 students expressed a wish for being given more time in class, on tests, for revision, or more lessons. This also might relate to a perceived increase of pace and content at secondary school.

A higher percentage of Year 7/8 boys (2.5\%) than younger boys (1\%) or the girls ( 1 and $1 \%$ respectively) expressed a wish for their learning that related to their future aspirations, such as their achievement at a higher year level or their career. Yet the percentages were all low, suggesting that this cohort of middle school students were more focussed on their experience of mathematics in the present than their perceived utility of mathematics for the future. The next sub-section discusses the five most frequent codes overall for each gender.

\subsubsection{Girls' and Boys' Five Most Frequent Codes}

The students' responses demonstrate a wide range of aspirations, and there were responses from boys and girls in every code. Most were about learning or achievement (60\% overall $-56 \%$ of the boys and $64 \%$ of the girls). The next most frequent type of aspiration was about types of tasks, with most referring to a specific mathematics topic or concept. Fractions/decimals/percentage, and times tables were key areas of mathematics highlighted by both genders. The next three most frequent types of aspirations were about affect or motivation, working arrangements in lessons, and being taught (explicit reference). A slightly higher proportion of girls made responses in most of these codes, suggesting that they were more likely to have made survey responses that required coding in more than one code. 


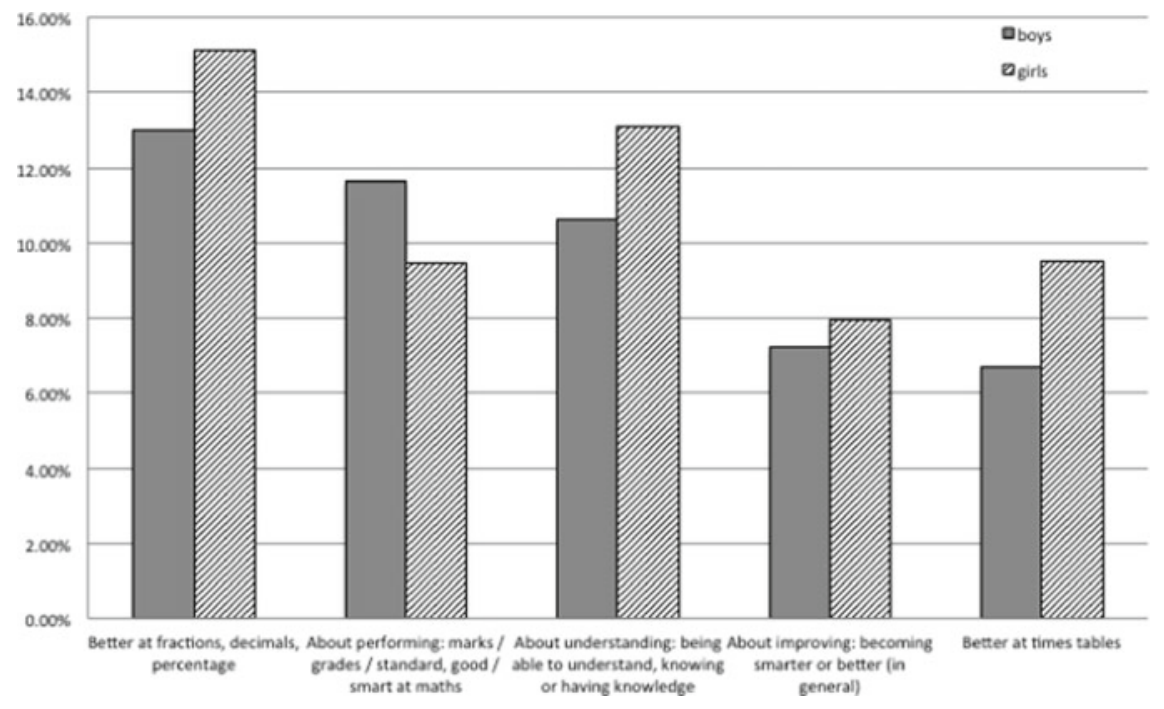

Fig. 8.2 The five most frequent codes for boys (shaded in grey)

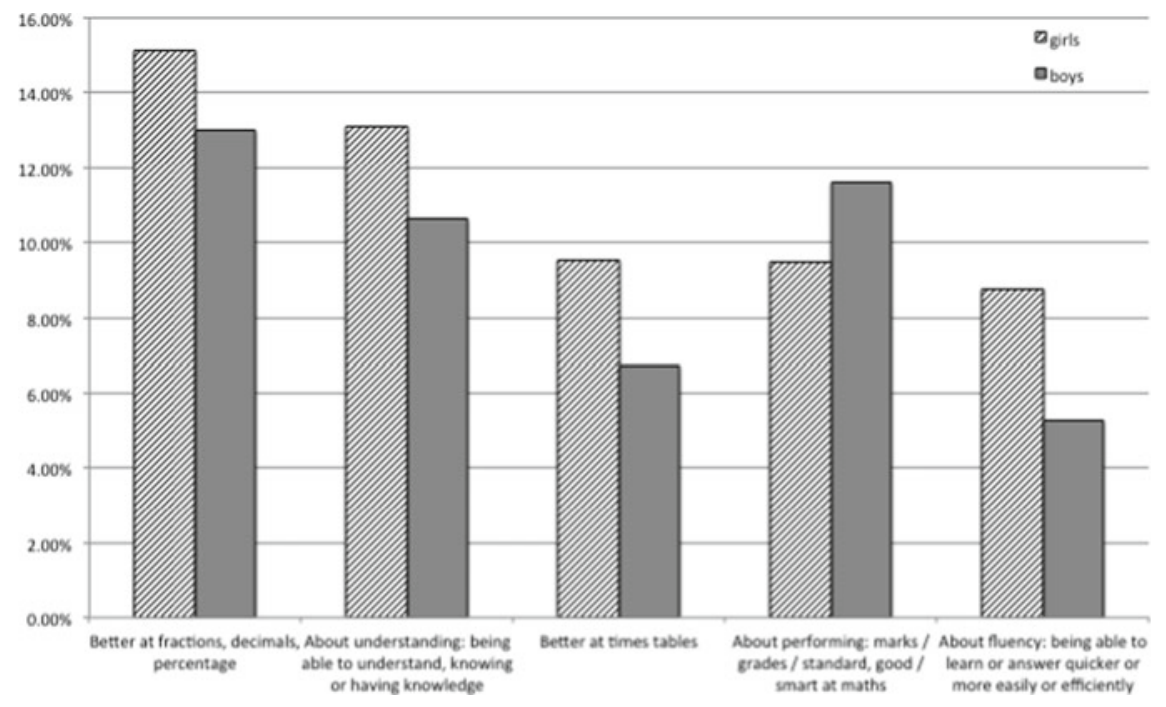

Fig. 8.3 The five most frequent codes for girls (shaded with diagonal lines)

Figures 8.2 and 8.3 present the five most frequent codes for boys and girls alongside comparative percentages for the other gender. It can be seen that two codes relate to specific topics and the other three to learning or achievement.

Four out of the five codes are common to both genders yet are in a different order. The girls' fifth code—about fluency—does not appear in the boys' list. The 
boys' fourth code_-about improving (in general)—does not appear in the girls' list, even though relatively more girls' responses were coded here. The two previously mentioned topic-specific codes appear in both lists, highlighting these areas of mathematics as of concern to both the boys and girls in this cohort. The next section examines the codes that seem to indicate a particular goal orientation, based on the language used by students in their responses.

\subsubsection{Evidence of Goal Orientations in Boys' and Girls' Spontaneously Generated Responses}

The framework of four different types of goal orientations (Table 8.1) was initially used in looking for evidence among the five most frequent codes for each gender. Wanting to improve in a particular topic or concept was the focus of two codes for both genders and is suggestive of mastery-approach goals because the intent is on acquiring new knowledge or skills. For the girls, the most frequent non-topicspecific code was about understanding: being able to understand, knowing, or having knowledge. This is also suggestive of a mastery-approach goal because of the focus on "understanding the content as thoroughly as possible."

The second most frequent (non-topic-specific) code for the girls was about performing: marks or grades or standard, good or smart at maths. As previously discussed, this could relate either to mastery or performance goals, depending on whether or not an individual seeks validation through performing well that they have mastered a task and acquired new skills (mastery) or that they have demonstrated competence and appear to have ability compared to others (performance). Hulleman et al. (2010) emphasised the need to distinguish between these reasons for wanting to perform well; even though on the surface such language about grades and results might look like performance goals, it is important to look explicitly for the desire to be compared favourably against other people. Some students used language that was suggestive of a link between good grades and a mastery goal, for example, "to get better and better at it and get really good marks; to be a fantastic learner and to understand hard maths in other years" (Yr 5/6 girl \#124), or "I would wish to become better at it and have a better understanding so I get above 80\%" (Yr 7/8 boy \#160). Some explicitly linked good grades to a performance goal because they described comparison to others e.g., "to get a higher score than Caitlyn on a math test" (Yr 7/8 girl \#723). This type of response was additionally coded under in comparison with others: being better than, the best, which is suggestive of performance-approach goals.

The girls' third most frequent (non-topic-specific) code was about fluency: being able to learn or answer quicker or more easily or efficiently. The language used by the students for responses in this code did not clearly differentiate between a wish for fluency for improved learning (suggestive of mastery-approach), or for not wanting 
Table 8.3 Codes evidencing particular goal orientations with percentages of boys' and of girls' responses

\begin{tabular}{|c|c|}
\hline Mastery-approach goal ( $\%$ boys, $\%$ girls) & Performance-approach goal \\
\hline $\begin{array}{l}\text { Interest and curiosity: } \\
\text { - About appropriate learning: at my level, more } \\
\text { or new or useful things, choice }(3.91,4.92) \\
\text { - More creative/visual/hands-on tasks, games } \\
(2.61,2.31) \\
\text { - More enjoyment, fun }(2.73,2.31) \\
\text { - Teachers making maths fun or interesting } \\
(0.25,0.05) \\
\text { Task/Challenge: } \\
\text { - About wanting to learn multiple strategies, } \\
\text { ways to solve, how others solve }(2.61,5.58) \\
\text { - About more challenge: being challenged, } \\
\text { doing harder work, being in higher class (6.58, } \\
\text { 5.48) } \\
\text { - Teachers giving harder or more work or more } \\
\text { strategies (0.31, 0.67) } \\
\text { Improvement or attainment: } \\
\text { - About understanding: being able to } \\
\text { understand, knowing or having knowledge } \\
\text { (10.62, } 13.11) \\
\text { - About thinking: using mental faculty well, } \\
\text { improving ability to think ( } 2.30,2.25) \\
\text { Better at a specific topic or concept (33.29, } \\
\text { 40.01) }\end{array}$ & $\begin{array}{l}\text { - Normative: In comparison with others: } \\
\text { being better than, the best }(2.24,0.31) \\
\text { - Appearance: About explaining my } \\
\text { understanding, showing what I know } \\
(0.56,0.77)\end{array}$ \\
\hline Mastery-avoidance goal & Performance-avoidance goal \\
\hline $\begin{array}{l}\text { - Improvement or attainment: About retaining: } \\
\text { not forgetting, remembering, memorising, off } \\
\text { by heart, revising }(2.61,5.48)\end{array}$ & $\begin{array}{l}\text { - Appearance or evaluative: Emotional } \\
\text { response-explicit reference to feeling } \\
\text { embarrassed, left out, left behind, less } \\
\text { smart than others }(0.19,0.72)\end{array}$ \\
\hline
\end{tabular}

to appear incompetent or dumb to others by being slow to understand or answer (suggestive of performance-avoidance).

In the boys' list of five most frequent codes, about performing was more frequent than about understanding - the reverse of the girls' list. Their third most frequent learning code was about improving: becoming smarter or better (in general). It does not appear on the girls' list. It was unclear from the students' responses whether or not the reason for wanting to improve related to a comparison with other people and therefore could not be used as evidence for one particular goal orientation.

The framework of different types of goal orientations (Table 8.1) was then used to look for evidence of particular goal orientations among the other codes. Those codes where students' spontaneously generated language evidenced a link to a particular orientation are presented in Table 8.3 along with the percentage frequencies of boys and girls. 
It can be seen that many more codes evidenced mastery-approach goals than any other type. Within the mastery goal types, it appears that interest, curiosity, and challenge were key foci for many of the boys' descriptions of their wishes, whereas learning different strategies and retaining knowledge were key foci for the girls. Yet both genders spontaneously generated responses that were coded in all of these codes.

\subsubsection{Evidence of a Mastery-Avoidance Goal Orientation}

The code that provided evidence of a mastery-avoidance orientation was about retaining: not forgetting, remembering, memorising, off by heart, revising. Just over $4 \%$ of students overall made such a response, but the girls' responses were more than twice as frequent as the boys' and also more frequent in the Year 7/8 data set. Examples include:

Being able to remember methods of working out things. I seem to forget methods after an amount of time. (Yr 7/8 boy \#44)

I want to be able to remember things that we learn and never forget them. (Yr 7/8 girl \#227)

Although this type of orientation has only recently been empirically validated (e.g., Elliot \& Murayama, 2008) this study provides some evidence that in a cohort similar to those in this study, more girls than boys may experience this type of goal orientation. Is this concern about forgetting what they have learnt related to the higher levels of maths anxiety found among girls in several studies?

\subsubsection{Evidence of a Performance-Avoidance Goal Orientation}

There was not one particular code that as a whole seemed to evidence a performanceavoidance goal orientation, but within the emotional response code, a number of responses related explicitly to the emotion of embarrassment or a negative affective response to being perceived unfavourably by others. When counted separately, the boys' responses represented $0.19 \%$ and the girls' $0.72 \%$ frequency. Although these were relatively small percentages, the nature of the students' use of language was examined more closely to seek further insight into this particular goal orientation and its relationship to negative affect and motivational issues.

The following responses highlight students' experiencing embarrassment in class through having to ask for help, not knowing the answer to a question, or being teased by peers:

My wish for learning my maths would be to not have as much students that will distract me and my learning and to not have people that think they're better than everyone and when we need help from other students they always say "oh that's easy" and when I ask for help from other students I feel embarrassed. (Yr 5/6 girl \#275)

For my teachers to help me clarify my work without feeling less smart than other people. (Yr 7/8 girl \#93) 
To be able to work with a group of people I am comfortable with and that I am able to ask questions without feeling embarrassed. (Yr 7/8 girl \#562)

To know everything in maths since I had such a hatred for maths in my previous years and now I am growing to like it. I feel embarrassed when the teacher asks me something and I don't know and I need Mrs *'s assistance. (Yr 5/6 boy 306)

To be the best in maths but not so smart that people start teasing me. (Yr 5/6 boy \#176)

These examples highlight that, for some students, their aspirations for mathematics learning relate to the avoidance of experiencing embarrassment in class. In terms of goal orientation they could be viewed as about any of the three aspects of performance-avoidance: avoiding looking incompetent or dumb (appearance), avoiding performing poorly in class (normative), or avoiding demonstration of a lack of ability relative to others and as judged by an authority figure (evaluative) (Elliot, 1999; Hulleman et al., 2010). Yet the last quote in the selection above highlighted that, for some students, being perceived by others as smart raised the fear of being teased about that, suggesting an influential role for peer expectations and social needs in students' mathematics learning.

Other emotional responses appeared to relate a mastery goal orientation to a motivational aspect of their learning. These are discussed in the next sub-section.

\subsubsection{Students Relating Mastery Goals to Affect and Motivation}

The desire for understanding, expressed by many of the students, can be related to a mastery-approach goal orientation, of wanting to learn as much as possible to improve their knowledge, to understand the content as thoroughly as possible, and acquiring new skills (Elliot, 1999; Hulleman et al., 2010). Some responses in the emotional response code further linked this desire, to understand mathematics, to various motivational variables. The desire for being able to understand the mathematics and the experience of confusion leading to a subsequent lack of motivation are illustrated by the following responses:

My one wish is to understand math much more and to get it a lot more. My only weakness in learning is math. My wish is to stop getting frustrated when I do it all the time. If I understand math more then I would enjoy math a lot more. It would be my dream to get math and to understand it more. I have difficulty a lot in math and like I said I would really really REALLY LIKE MATH A LOT MORE if I UNDERSTAND! (Yr 5/6 boy \#892)

To try a lot harder and focus more. I seem to doze off a bit when I get really confused. (Yr 7/8 boy \#606)

Is to try and understand what I'm trying to learn and to always keep my head up and not to give up when I'm stuck on a question. (Yr 7/8 boy \#167)

It would be that I could understand more that the teachers tell me and that I could understand fractions a bit better, I would also like to concentrate more in maths because sometimes I don't get what the teachers are saying. I think I learn differently to other people because sometimes I need to be told it in many different ways to understand. I think that I know how to do it but I just need the teachers to tell us in different ways. (Yr 5/6 girl \#183) 
These quotes illustrate that some students struggle to maintain their motivation when experiencing a negative emotion, such as confusion, in response to a task. As with the last quote above, some students also suggested a teaching approach for helping them to understand mathematics, such as being given multiple ways to solve a problem, suggesting their perception that a greater understanding will lead to increased motivation.

Some of the students' responses highlighted their desire for interesting and challenging tasks to engage them and to motivate them to learn:

To always be able to always do maths all day and for it to stay really fun and to get harder and harder so I can learn a lot about maths. (Yr 5/6 girl \#23)

To be able to have more interactive, interesting and fun math activities for both me and the school. (Yr 5/6 boy \#36)

My wish would be to make things more interesting in maths. It can get very boring sometimes and you don't really feel motivated to work. So maybe try and mix it up and try using the computers more or having breaks and letting us talk a bit more. (Yr 7/8 girl \#312)

To be able to choose what I want to learn in class. I think this would help my learning a lot because I would have the motivation and energy (not that I don't) to do more work especially when I'm learning something I' $m$ interested in. I would also like it if we could work in groups and partners more so we could work together in hard (or easy) problems. (Yr 7/8 girl \#442)

These types of responses also evidence a mastery-approach goal orientation in terms of interest and curiosity-learning something interesting - as well as mastering a challenge (Elliot, 1999; Hulleman et al., 2010). In the third and fourth quotes above, the students explicitly referred to their self-motivation as being influenced by their level of interest. The first and fourth quotes also referred to hard or harder work, suggesting that some students do value challenge in learning mathematics. They can be related to Middleton's (2013) central motivational variable of interest, specifically situational interest from tackling a novel task that is interesting and challenging.

Overall, it can be seen that analysis of the large data set generated by an openresponse question provided a variety of insights into the expressed wishes of middle school students. A wide range of codes was created interpretively to capture the more subtle differences between the students' use of language in their responses. Qualitative analysis of the codes provided insight into how some middle school students related their experience in the mathematics classroom to their goals, affective responses, effort, and motivation for learning.

\subsection{Conclusion}

This study provided the opportunity to learn more about middle school students' motivation and engagement in mathematics from their perspectives, by inviting them to write their aspirations in their own words as a complementary methodology to predefined surveys. The high response rate and the low incidence of irrelevant responses suggest that when consulted, students similar to this cohort are likely to be willing to 
share their views sincerely. Some students referred to intrinsic aspects of their aspirations for learning such as their own interest, attitude, effort, and self-motivation. Some students described extrinsic aspects of their environments that are perceived by them to influence their engagement in learning, such as challenging or interesting work, learning multiple strategies, collaboration with peers, help from their teacher, or not being embarrassed by others in class. As previously discussed, the overall percentage of references to emotions was lower than expected. It is possible that an additional survey question requesting the reasons for their wish might have elicited more references to affective factors including emotions. Those students who did provide unsolicited explanations often included emotional references, which linked their goals explicitly to particular emotions. This resonated with Hannula's (2006) conceptualisation of motivation as "a potential to direct behaviour through the mechanisms that control emotion" and which is "structured through needs and goals" (p. 175).

Although there are conceivably many ways to analyse such a data set from over 3500 free-format responses, this study used a framework of wishes related to: learning or achievement, being taught, affect or motivation, specific task types, and working arrangement. It examined the students' responses using theoretical perspectives on intrinsic motivational variables and goal orientations, and extrinsic learning environments. Comparisons between year levels and genders at upper primary and lower secondary levels provided evidence that particular aspirations were more salient for particular groups of students. For example, more students from Year 7/8 expressed their wish to make more effort, compared to younger students. The Year 7/8 girls made more frequent references to the desire for fluency and for learning multiple strategies. Previous research found a mismatch between secondary teachers' negative predictions and students' positive attitudes about learning multiple strategies (Leikin et al., 2006). In Japanese secondary classrooms, a problem-solving oriented lesson involves students demonstrating and discussing a variety of solutions to one problem (Ohtani, 2014). There is more to learn about secondary students' views about learning this way (Lynch \& Star, 2014), but it appears from this study that they may be more open to it than teachers predict.

The Year 5/6 students expressed more frequently their wish for more challenge in their learning. The Year 5/6 cohort also made more frequent reference to improving their knowledge or skills in a particular area of mathematics, such as fractions/decimals/percentage and times tables, yet both genders at Year 5/6 and at Year $7 / 8$ referred to these areas. These topics also appeared in the list of five most frequent categories for girls and for boys. This suggests that for many students, targeted support to improve their understanding in a particular area of mathematics would be motivating. It would be worth investigating further why times tables is of particular importance to students, a finding Grootenboer and Marshman (2016) also highlighted with New Zealand middle school students.

The Year 7/8 cohort made more references to wanting to work in small groups, perhaps because they had experienced fewer opportunities in secondary school (Banilower et al., 2013). A recent study found that secondary teachers were able to broaden students' learning opportunities by using collaborative learning (DeJarnette \& González, 2015); this study suggests that it might also be motivating for some 
students. More Year 7/8 students referred explicitly to teacher support (both socioemotional and instructional aspects) than those in Year 5/6, resonating with studies that found teacher support more strongly related to affective outcomes for older middle school students (Rolland, 2012). Overall both girls and boys and upper primary and lower secondary students made responses that were categorised across the full range of codes, suggesting that within one class of students similar to this cohort, a teacher is likely to find a diverse range of individual aspirations.

Evidence for all four goal orientations was found in the students' responses across several different categories, but with evidence that mastery goals are expressed more frequently than performance goals. This resonates with other studies on student goals (Brophy, 2005; Chouinard et al., 2007) but extends that work by suggesting that students do spontaneously generate evidence of performance goal orientations - that it is not survey items on this particular goal that suggest to students goals they don't actually hold. A mastery-avoidance goal orientation was evidenced in the small percentage of responses about retaining: not forgetting, remembering, memorising, off by heart, revising. More girls than boys evidenced this orientation, and this concern may relate to one possible reason why girls also have demonstrated higher maths anxiety in other studies (Grootenboer \& Marshman, 2016; Plenty \& Heubeck, 2013). A performance-avoidance goal orientation was evidenced in the small percentage of emotional responses that related to students' wishes not to be embarrassed.

It appears that a methodological approach giving students the opportunity to share their voice using a free-response format can provide worthwhile insights into the affective and motivational dimensions of a particular cohort of students' engagement and goals in learning mathematics. Individual and often detailed responses from the students provided further insight into the foundational desire for understanding mathematics, the influence of external features in their learning environments on their effort, and the key motivational factor of interest (Middleton, 2013), in particular tasks that are interesting and challenging.

There is more to understand and other conceptual lenses with which to view the students' aspirations for their learning. Because the data represent a snapshot in time, it was not possible to investigate the stability of students' expressions of wishes longitudinally. Perhaps a conclusion that can be drawn from the work to date is that seeking students' own voice on affective and motivational issues is valuable and may challenge some deficit theorising about middle school students' attitudes. Both the boys and girls expressed a wide range of hopes, which are overwhelmingly positive and often focussed on mastery-approach goals. Their language was often quite specific, suggesting that similar students to these are likely, when asked, to explain willingly and in detail what they desire in their learning and how teachers might support them. An implication for teachers is that rather than generalising these findings to other cohorts of middle school students, they might view their classes as comprised of many and varied individuals, to seek information about their specific wishes, and to find ways to incorporate students' own suggestions for promoting their engagement, learning, and achievement. 
Acknowledgements The student participants who contributed to the study on which this paper is based are acknowledged with appreciation. Special thanks to Peter Sullivan for his oversight of the research and Daya Weerasinghe for his contribution to the data analysis. Gilah Leder is acknowledged with appreciation for feedback on earlier versions of this chapter.

\section{References}

Ables, B. (1972). The three wishes of latency age children. Developmental Psychology, 6(1), 186. Allen, B. (2003). Pupils' perspectives on learning. In B. Allen \& J.-W. S (Eds.), Mathematics education: Exploring the culture of learning (pp. 233-241). London: Routledge Falmer.

Ames, C. (1992). Classrooms: Goals, structures, and student motivation. Journal of Educational Psychology, 84, 261-271.

Attard, C. (2013). "If I had to pick any subject, it wouldn't be maths": Foundations for engagement with mathematics during the middle years. Mathematics Education Research Journal, 25(4), 569-587.

Australian Curriculum Assessment and Reporting Authority. (2015). The Shape of the Australian Curriculum: Mathematics. https://acaraweb.blob.core.windows.net/resources/The_Shape_of_ the_Australian_Curriculum_v4.pdf. Accessed April 27, 2017.

Banilower, E. R., Smith, P. S., Weiss, I. R., Malzahn, K. M., Campbell, K. M., \& Weis, A. M. (2013, February). Report of the 2012 National Survey of Science and Mathematics Education. Chapel Hill, NC: Horizon Research, Inc. https://eric.ed.gov/?id=ED548238. Accessed April 27, 2017.

Bazeley, P. (2007). Qualitative data analysis with NVivo. London: Sage.

Brophy, J. (2005). Goal theorists should move on from performance goals. Educational Psychologist, 40(3), 167-176.

Chouinard, R., Karsenti, T., \& Roy, N. (2007). Relations among competence beliefs, utility value, achievement goals, and effort in mathematics. British Journal of Educational Psychology, 77(3), 501-517.

DeJarnette, A. F., \& González, G. (2015). Positioning during group work on a novel task in algebra II. Journal for Research in Mathematics Education, 46(4), 378-422.

di Martino, P., \& Zan, R. (2010). 'Me and maths': Towards a definition of attitude grounded on students' narratives. Journal of Mathematics Teacher Education, 13(1), 27-48.

Dweck, C. S. (2007). Boosting achievement with messages that motivate. Education Canada, 47(2), 6-10.

Eccles, J. S., \& Wigfield, A. (2002). Motivational beliefs, values, and goals. Annual Review of Psychology, 53(1), 109-132.

Elliot, A. J. (1999). Approach and avoidance motivation and achievement goals. Educational Psychologist, 34(3), 169-189.

Elliot, A. J., \& Murayama, K. (2008). On the measurement of achievement goals: Critique, illustration, and application. Journal of Educational Psychology, 100(3), 613-628.

Flutter, J., \& Rudduck, J. (2004). Consulting pupils: What's in it for schools? London: Routledge Falmer.

Gottfried, A. E., Marcoulides, G. A., Gottfried, A. W., Oliver, P. H., \& Guerin, D. W. (2007). Multivariate latent change modeling of developmental decline in academic intrinsic math motivation and achievement: Childhood through adolescence. International Journal of Behavioral Development, 31(4), 317-327.

Green, J., Martin, A. J., \& Marsh, H. W. (2005). Academic Motivation and Engagement: A Domain Specific Approach. Paper presented at the Australian Association for Research in Education Annual Conference, Paramatta. http://www.aare.edu.au/data/publications/2005/gre05384. pdf. Accessed April 27, 2017. 
Grootenboer,P., \& Marshman, M. (2016). Mathematics, affect and learning: Middle school students' beliefs and attitudes about mathematics education. Singapore: Springer.

Hannula, M. (2006). Motivation in mathematics: Goals reflected in emotions. Educational Studies in Mathematics, 63(2), 165-178.

Hollingsworth, H., Lokan, J., \& McCrae, B. (2003). Teaching mathematics in Australia: Results from the TIMSS video study (TIMSS Australia Monograph No. 5). Camberwell, Victoria: Australian Council for Educational Research.

Hulleman, C. S., Schrager, S. M., Bodmann, S. M., \& Harackiewicz, J. M. (2010). A meta-analytic review of achievement goal measures: Different labels for the same constructs or different constructs with similar labels? Psychological Bulletin, 136(3), 422-449.

Jang, L. Y., \& Liu, W. C. (2012). $2 \times 2$ Achievement goals and achievement emotions: A cluster analysis of students' motivation. European Journal of Psychology of Education, 27(1), 59-76.

Kaiser, G., Hoffstall, M., \& Orschulik, A. B. (2012). Gender role stereotypes in the perception of mathematics: An empirical study with secondary students in Germany. In H. J. Forgasz \& F. Rivera (Eds.), Towards equity in mathematics education (pp. 115-140). Berlin: Springer.

Kilpatrick, J., Swafford, J., \& Findell, B. (Eds.). (2001). Adding it up: Helping children learn mathematics. Washington, D.C.: National Academy Press.

King, L. A. (1995). Wishes, motives, goals, and personal memories: Relations of measures of human motivation. Journal of Personality, 63(4), 985-1007.

Leder, G. C. (1992). Mathematics and gender: Changing perspectives. In D. Grouws (Ed.), Handbook of research on mathematics teaching and learning (pp. 597-622). New York: Macmillan.

Leder, G. C., \& Forgasz, H. J. (2002). Two new instruments to probe attitudes about gender and mathematics. Resource document. ERIC, Resources in Education (RIE). https://eric.ed.gov/?id= ED463312. Accessed April 27, 2017.

Leikin, R., Levav-Waynberg, A., \& Mednikov, L. (2006). Implementation of multiple solution connecting tasks: Do students' attitudes support teachers' reluctance? Focus on Learning Problems in Mathematics, 28(1), 1-22.

Lieblich, A., Tuval-Mashiach, R., \& Zilber, T. (1998). Narrative research: Reading, analysis, and interpretation. London: Sage Publications.

Lynch, K., \& Star, J. R. (2014). Teachers' views about multiple strategies in middle and high school mathematics. Mathematical Thinking and Learning, 16(2), 85-108.

Martin, A. J. (2013). Goal orientation. In J. Hattie \& E. M. Anderman (Eds.), International guide to student achievement (pp. 353-355). New York, NY: Routledge.

Mayring, P. (2015). Qualitative content analysis: Theoretical background and procedures. In A. Bikner-Ahsbahs, C. Knipping, \& N. Presmeg (Eds.), Approaches to qualitative research in mathematics education: Examples of methodology and methods (pp. 365-380). Dordrecht: Springer.

Meece, J. L., Glienke, B. B., \& Burg, S. (2006). Gender and motivation. Journal of School Psychology, 44(5), 351-373.

Megowan-Romanowicz, M. C., Middleton, J. A., Ganesh, T., \& Joanou, J. (2013). Norms for participation in a middle school mathematics classroom and its effect on student motivation. Middle Grades Research Journal, 8(1), 51-76.

Middleton, J. A. (2013). More than motivation: The combined effects of critical motivational variables on middle school mathematics achievement. Middle Grades Research Journal, 8(1), 77-95.

Middleton, J. A., \& Jansen, A. (2011). Motivation matters and interest counts: Fostering engagement in mathematics. Reston, VA: National Council of Teachers of Mathematics.

Middleton, J. A., \& Spanias, P. A. (1999). Motivation for achievement in mathematics: Findings, generalizations, and criticisms of the research. Journal for Research in Mathematics Education, $30(1), 65$

Middleton, J. A., \& Toluk, Z. (1999). First steps in the development of an adaptive theory of motivation. Educational Psychologist, 34(2), 99-112.

Middleton, J. A., Lesh, R., \& Heger, M. (2002). Interest, identity, and social functioning: Central features of modeling activity. In H. Doerr \& R. Lesh (Eds.), Beyond constructivism: A models 
and modeling perspective on mathematics problem solving, learning and teaching (pp. 405-431). Mahwah, NJ: Erlbaum.

Ohtani, M. (2014). Construction zone for the understanding of simultaneous equations: An analysis of one Japanese teachers' strategy of reflecting on a task in a lesson sequence. In F. K. S. Leung, K. Park, D. Holton, \& D. Clarke (Eds.), Algebra teaching around the world (pp. 113-128). Rotterdam: Sense Publishers.

Pintrich, C. H., \& Schunk, D. (2002). Motivations in education: Theory, research, and applications (2nd ed.). Upper Saddle River, NJ: Prentice Hall.

Plenty, S., \& Heubeck, B. G. (2013). A multidimensional analysis of changes in mathematics motivation and engagement during high school. Educational Psychology, 33(1), 14-30.

Robinson, C., \& Taylor, C. (2007). Theorizing student voice. Improving Schools, 10(1), 5-17.

Rolland, R. G. (2012). Synthesizing the evidence on classroom goal structures in middle and secondary schools: A meta-analysis and narrative review. Review of Educational Research, 82(4), 396-435.

Schweinle, A., Meyer, D. K., \& Turner, J. C. (2006). Striking the right balance: Students' motivation and affect in elementary mathematics. The Journal of Educational Research, 99(5), 271-293.

Sullivan, P., Askew, M., Cheeseman, J., Clarke, D., Mornane, A., Roche, A., et al. (2014). Supporting teachers in structuring mathematics lessons involving challenging tasks. Journal of Mathematics Teacher Education, 18(2), 123-140.

Tafarodi, R. W., Nishikawa, Y., Bonn, G., Morio, H., Fukuzawa, A., \& Lee, J. (2012). Wishing for change in Japan and Canada. Journal of Happiness Studies, 13, 969-983.

Turner, J. C., \& Meyer, D. K. (2009). Understanding motivation in mathematics: What is happening in classrooms? In K. Wentzel \& D. Miele (Eds.), Handbook of motivation at school (pp. 527-552). New York: Routledge.

Urdan, T. (2001). Contextual influences on motivation and performance: An examination of achievement goal structures. In F. Salili, C. Chiu, \& Y. Hong (Eds.), Student motivation: The culture and context of learning (pp. 171-201). New York: Kluwer/Plenum.

Watt, H. M. (2004). Development of adolescents' self-perceptions, values, and task perceptions according to gender and domain in 7th- through 11th-grade Australian students. Child Development, 75(5), 1556-1574.

Watt, H. M., Shapka, J. D., Morris, Z. A., Durik, A. M., Keating, D. P., \& Eccles, J. S. (2012). Gendered motivational processes affecting high school mathematics participation, educational aspirations, and career plans: A comparison of samples from Australia, Canada, and the United States. Developmental Psychology, 48(6), 1594-1611.

Wilkie, K. J. (2016). Exploring middle school girls' and boys' aspirations for their mathematics learning. In C. Csíkos, A. Rausch, \& J. Szitányi (Eds.), Proceedings of the 40th Annual Conference of the International Group for the Psychology of Mathematics Education (Vol. 4, pp. 387-394). Praha Czech Republic: The International Group for the Psychology of Mathematics Education.

Wish. (2016). In Oxford living dictionaries. Retrieved from https://en.oxforddictionaries.com/ definition/wish.

Wolcott, H. F. (2009). Writing up qualitative research (3rd ed.). Thousand Oaks, CA: Sage. 
Open Access This chapter is licensed under the terms of the Creative Commons Attribution 4.0 International License (http://creativecommons.org/licenses/by/4.0/), which permits use, sharing, adaptation, distribution and reproduction in any medium or format, as long as you give appropriate credit to the original author(s) and the source, provide a link to the Creative Commons license and indicate if changes were made.

The images or other third party material in this chapter are included in the chapter's Creative Commons license, unless indicated otherwise in a credit line to the material. If material is not included in the chapter's Creative Commons license and your intended use is not permitted by statutory regulation or exceeds the permitted use, you will need to obtain permission directly from the copyright holder.

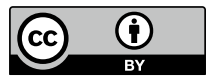




\title{
Chapter 9 \\ Implications of Training in Incremental \\ Theories of Intelligence \\ for Undergraduate Statistics Students
}

\author{
Valorie Zonnefeld
}

\begin{abstract}
This chapter documents the effects of training in incremental theories of intelligence on students in introductory statistics courses at a liberal arts university in the US. Incremental theories of intelligence examine the beliefs individuals hold of knowledge and how it is attained. An individual with an incremental theory of intelligence believes that intelligence can be developed. The research examined differences by gender in mastery of statistics and attitudes toward statistics for students who received growth mind-set training. A pre-test, post-test design utilised the Students’ Attitudes Toward Statistics ${ }^{\circledR}$ instrument and the Comprehensive Assessment of Outcomes in a first Statistics course. An ANCOVA revealed that females gained more than males on their value of statistics $(\mathrm{F}(1,63)=9.40, \mathrm{MSE}=3.79, p=.003$, $\left.\eta_{\mathrm{P}}^{2}=0.134\right)$ and decreased less for effort expended to learn statistics $(\mathrm{F}(1,63)=$ $\left.4.41, \mathrm{MSE}=4.07, p=.040, \eta_{\mathrm{P}}^{2}=0.067\right)$. Females also gained mastery of statistical concepts at a greater rate $\left(\mathrm{F}(1,63)=5.30, \mathrm{MSE}=0.06, p=.025, \eta_{\mathrm{P}}^{2}=0.080\right)$ indicating a possible path to alleviate the under-representation of females in STEM.
\end{abstract}

Keywords Statistics $\cdot$ Mind-set $\cdot$ Beliefs $\cdot$ Affect $\cdot$ Gender

\subsection{Introduction}

At the heart of research in mathematics education is a desire that all students become competent and confident in mathematics. Unfortunately, this does not describe a multitude of students in educational settings around the world (Mullis, Martin, Foy, \& Arora, 2012; Topper, 2011). In particular, females' success in mathematics is often hampered by negative gender stereotypes (Good, Rattan, \& Dweck, 2012). This research focuses on differences by gender in a common undergraduate mathematics course, introductory statistics.

Students' beliefs about themselves as learners of mathematics play a key role in their mastery of mathematics (Nurmi, Hannula, Maijala, \& Pehkonen, 2003; Schoen-

V. Zonnefeld $(\varangle)$

Dordt University, 498 4th Ave. NE, Sioux Center, IA, USA

e-mail: valorie.zonnefeld@dordt.edu 
feld, 1992). Dweck's (1999) seminal research on the role of students' implicit theories of intelligence, also referred to as mind-sets, examines students' beliefs about knowledge acquisition. Dweck (2006) identified two implicit theories of knowledge: incremental and entity. Incremental theorists, also referred to as individuals with growth mind-sets, believe that intelligence is malleable and can be increased with effort (Bruning, Schraw, \& Norby, 2011). Entity theorists view intelligence as unchangeable and are referred to as having fixed mind-sets (Dweck \& Leggett, 1988). Effort cannot influence intelligence in an entity mind-set since intelligence is fixed. These mind-sets play an important role in academic persistence and achievement, both of which are important for college success (Good et al., 2012). Research has shown that mind-sets can be altered and that targets of stereotype threat decrease achievement gaps with mind-set training (Aronson, Fried, \& Good, 2002).

This research is a continuation of a previous study on the role of mind-set training in introductory statistics college courses which noted that students who received mind-set training decreased in effort expended to learn statistics at a statistically significant greater rate while demonstrating less mastery of statistical content (Zonnefeld, 2015). One limitation of the previous research was a change in instructors and number of course credits and requirements between the control group and treatment group.

This follow-up research expands Dweck's important body of research by focusing on the differences within each treatment group by gender. All students completed both a pre-test and post-test which examined attitudes towards statistics and mastery of statistics. Students in the treatment group received training in incremental theories of intelligence throughout the semester during which they were enrolled in introductory statistics. Effects of incremental mind-set training were examined regarding student attitudes toward statistics and student mastery of statistical content by gender in both the control and treatment groups. Two research questions guide this research:

1. What differences exist by gender in the change in students' attitudes toward statistics for students who received training in an incremental mind-set and those who did not when controlling for initial attitudes?

2. What differences exist by gender in mastery of statistics for students who received training in an incremental mind-set and for those who did not when controlling for initial mastery?

Research on implicit theories of knowledge has grown rapidly in recent decades. Unfortunately, only a handful of studies have examined creating a growth mind-set in the mathematics classroom (Kim \& Kellert, 2010). This research answers the call from Dweck (2008) to "study ways in which the education environment can teach and support a growth mind-set over time" (p. 2). Shores and Smith (2010) have also called for future research, specifically in mathematics education, to focus on developing strategies to improve students' implicit theories of knowledge with the goal of helping students develop methods to cope with failure. This research heeds the call by examining the role of mind-set training by gender in introductory statistics courses. 
According to the Organisation for Economic Co-operation and Development, college graduation rates vary from 22 to $60 \%$ worldwide (Weston, 2014). Pang (2010) suggested that improving students' experiences in mathematics courses will increase the perseverance of many aspiring college graduates. Statistics is a unique mathematics course that is required for many undergraduate students and the number of students who take statistics continues to grow (Onwuegbuzie \& Wilson, 2003). Unfortunately, many of the students enrolled in statistics would not choose to take the course if it were not a program requirement (Cook, 2010). Subsequently, statistics becomes a 'problem subject' for many students (Onwuegbuzie \& Wilson, 2003). An examination of possible methods to support students is valuable and timely.

Recent decades "have seen an extraordinary level of activity focused on how students learn statistics" (Aliaga et al., 2005, p. 8). Unfortunately, given the growth of research in both implicit theories of intelligence and statistics education, a paucity of research exists connecting mind-sets, attitudes, and achievement in statistics courses. Results of this study add to the knowledge base of implicit theories of knowledge and support continuous improvement in undergraduate statistics pedagogy.

One limitation to the generalisability of this study is the statistics curriculum implemented by the college. All course sections used a reform-based statistics curriculum which was under development. The curriculum utilised simulation-based methods which introduced inference earlier in the semester (Tintle et al., 2016). This curriculum was in its final stages of development and was not expected to be a factor in the study.

The quasi-experimental design of this study was a limitation since it only allowed for conclusions of association, not causation. A delimitation of the sample was that it was comprised of students from one college who enrolled in a specific statistics course. This also limits the generalisability of the findings.

An additional limitation of this research was the role of the environment. There is evidence that the educator affects the learning, attitude, and even mind-set of students in their class (Cutts, 2008; Dweck, 2008). The professors for the treatment classes were debriefed on the study, theories of intelligence, and the role of the teacher in fostering incremental mind-sets in an effort to create a supportive classroom environment. Unfortunately, different instructors were used for the control and treatment groups. Additionally, the number of credits increased from 3-credits to 4-credits from the control to the treatment semester.

The remainder of this paper is organised as follows. Section two reviews relevant research followed by section three which outlines the methodology utilised. Section four shares the results of the study and statistical analysis followed by conclusions in section five. 


\subsection{Relevant Literature}

A review of relevant literature begins with current research on undergraduate statistics. This is followed by theoretical foundations, cognitive learning theory, and closes with gender stereotypes.

\subsubsection{Undergraduate Statistics Courses}

A common roadblock on many students' path to graduation is successfully completing a college-level mathematics course (Topper, 2011); this is a momentum point that is "very strongly correlated with postsecondary achievement" (Leinbach \& Jenkins, 2008, p. 20). Introductory mathematics courses have earned the title 'gatekeeper to achieving a college degree' with Bryk and Treisman (2010) arguing that "math should be a gateway, not a gatekeeper, to a successful college education" (p. 1).

A commonly required mathematics course in many undergraduate programs is introductory statistics (Ruggeri, 2011). Statistics is a unique mathematics course that combines quantitative skills with analysis. As a result of the need for analytical skills in a diverse set of professions, the number of students required to take statistics has rapidly increased in the past half century making statistics the most common subject across disciplines (Ruggeri, 2011). Statistics has morphed from a course taught to "a narrow group of future scientists in agriculture and biology, to a family of courses, taught to students at many levels, from pre-high school to post-baccalaureate, with very diverse interests and goals" (Aliaga et al., 2005, p. 7).

As a mathematics course, statistics creates an obstacle for undergraduates, as many students experience anxiety and negative attitudes toward the subject (Evans, 2007; Ruggeri, 2011; Ruggeri, Dempster, Hanna, 2008a; Ruggeri et al., 2008b). As student diversity has increased in introductory statistics courses, so have the demands. "Today's teachers face challenges of motivation and exposition that are substantially greater than those of half a century ago" (Aliaga et al., 2005, p. 7). With the increase in diversity of undergraduate majors, students may not see the relevance of statistics in their lives, contributing to a struggle for motivation (Kim \& Kellert, 2010).

One response to poor performance in introductory mathematics courses and low undergraduate retention rates is increasing the academic entrance requirements for students; however, ability is not the sole predictor of success (Lucio, Rapp-Paglicci, \& Rowe, 2011). Educators recognise that students of similar abilities often achieve at vastly different levels (Boese, Stewart, Perry, \& Hamm, 2013).

Cognitive learning theory may give insight into the disparity seen between students' achievements and their ability levels. While promising research has been conducted on mathematical mind-sets concerning students' belief in their ability to learn mathematics, no research is available on the impact of training in incremental theories of intelligence on their achievement and attitudes in introductory statistics courses. The next section will outline theoretical foundations for the research. 


\subsubsection{Theoretical Foundations}

While there is not a clear consensus regarding the theoretical frameworks to conceptualise affect in mathematics education (Hannula, 2004), I chose to use DeBellis and Goldin's (1997) framework of four concepts in affect research: emotions, attitudes, beliefs, and values as it encompassed the aspects that best fit my research questions and the instruments chosen.

Beliefs are an important concept in affect. An examination of a student's epistemological beliefs regarding mathematical knowledge and its acquisition can reveal important keys to student affect and achievement since beliefs "act as a filter" influencing all thoughts and actions (Nurmi et al., 2003, p. 454). Schommer (1990) suggested that student's beliefs regarding knowledge are complex and vary on four dimensions: simple knowledge, certain knowledge, fixed ability, and quick learning. See Fig. 9.1 for descriptions of each.

Implicit theories of knowledge focuses on the third and fourth dimensions of fixed ability and quick learning. The next section discusses cognitive learning theory in detail.

\subsubsection{Cognitive Learning Theory}

Cognitive learning theory focuses on metacognition, the effects of underlying thought processes on the learner. Students do more than gain knowledge and master skills while learning; they simultaneously build beliefs about their ability to be successful learners (Boekaerts, Otten, \& Voeten, 2003). This section starts with an examination of the role of attitudes in statistics education, followed by attribution theory and closes with mind-set theory.

\begin{tabular}{ll} 
Dimension & Description \\
\hline Simple Knowledge & Knowledge is accumulating data and facts. \\
Certain Knowledge & $\begin{array}{l}\text { Knowledge does not change. Once you know something, it stays the } \\
\text { same forever. }\end{array}$ \\
Fixed Ability & $\begin{array}{l}\text { Intelligence is fixed and cannot change. } \\
\text { Quick Learning }\end{array}$ \\
Learning either occurs quickly, or will not occur.
\end{tabular}

Fig. 9.1 Schommer's (1990) framework of beliefs regarding knowledge 


\subsubsection{Attitudes}

Student attitudes play an important factor in academic achievement creating a challenge for professors as anxiety and negative attitudes towards statistics are common (Chiesi \& Primi, 2010; Evans, 2007; Kesici, Baloğlu, \& Deniz, 2011; McGrath, 2014; Onwuegbuzie \& Wilson, 2003; Ruggeri et al., 2008a, 2008b). Chiesi and Primi (2010) examined undergraduate students enrolled in introductory statistics both before and after the semester using the Student Attitudes Towards Statistics- $36^{\odot}$ (SATS) instrument finding that attitudes at the beginning of the semester were related to achievement at the end of the course. An additional relationship indicated that students' attitudes at the beginning of the semester were directly related to their mathematical knowledge. This creates a challenge for many instructors since students enter introductory statistics with a wide variety of mathematical backgrounds. Evans (2007) found similar correlations between attitudes and achievement in statistics classes while Bandalos, Yates, and Thorndike-Christ (1995) observed a negative relationship between students' efficacy and their anxiety about statistics.

It is clear that attitudes impact students' achievement in statistics. Unfortunately, Evans (2007) found no methods in his research for instructors to help improve student attitudes. More research is necessary to understand and address the issues of statistics anxiety and negative attitudes toward statistics (Ruggeri et al., 2008a, b).

\subsubsection{Attribution Theory}

Bernard Weiner contributed a key advance in metacognition through attribution theory. Attributions are an important aspect of cognitive learning theory that can have both positive and negative influences on students. Attribution theory was proposed by Weiner (1985) in the mid-eighties and since then, has been promoted by educators and educational psychologists as an effective method to improve achievement and motivation for students with academic difficulties (Banks \& Woolfson, 2008; Robertson, 2000). Attributions are classified along three dimensions: locus, stability, and controllability (Banks \& Woolfson, 2008; Boekaerts et al., 2003). Locus refers to the location of the cause as internal or external to the student (Shores \& Smith, 2010). Stability is a belief about the possibility of change for the cause and controllability refers to the ability to affect future outcomes (Syed, 2013).

When students fall behind academically, it is important for teachers to understand what is causing their struggle (Shores \& Smith, 2010). Of particular concern are failure attributions that are stable and beyond a student's control (Hall, Hladkyj, Perry, \& Ruthig, 2004; Shores \& Smith, 2010). Attributions occur frequently in mathematics. Boekaerts et al. (2003) found evidence in their work with 113 middle school students in the Netherlands that attribution patterns are different in mathematics than the subjects of native language and history. Students attribute success in mathematics to effort, but failure to ability (Boekaerts et al., 2003). Effort is an important causal attribution since it is closely tied to a growth mind-set. Students will use effort attributions only if they believe that their intelligence can be improved. This concurs 
with research from Harari and Covington (1981) who found that students who used effort attributions persisted longer in tasks following a failure.

Connections between attributions and self-efficacy have also been observed. Students who believed they were lower achievers, regardless of their teacher's perception of ability, displayed more maladaptive attributions (Banks \& Woolfson, 2008). This finding points to the importance of attributions not only to low-achievers, but also for students who perceive themselves as low-achievers. Attribution theory is a foundation for mind-set theory and continues to play an important role in students' behaviours.

\subsubsection{Mind-Set Theory}

Mind-set theory expands upon the foundation built by Weiner (1985) in attribution theory to a more comprehensive approach as it not only looks back explaining reasons for success or failure, but also looks forward to include goals (Dweck, 1999). An impetus for the introduction of mind-set theory is new research in cognitive neuroscience. Research in recent decades has revealed how the brain functions and that its ability to grow and increase in intelligence is much greater than was previously assumed (Cutts, 2008; Dweck, 2010; Good, Aronson, \& Inzlicht, 2003). Knowledge about the increased neuroplasticity of the brain has powerful effects for individuals.

Mind-sets are metacognitive processes that an individual holds concerning beliefs about their cognitive abilities (Burns \& Isbell, 2007; Mangels, Butterfield, Lamb, $\&$ Dweck, 2006). Anderson (1995) referred to mind-sets as knowledge structures that influence affective reactions and behaviours. It should be noted that mind-sets are domain specific (Dweck \& Leggett, 1988) and affect motivation, goal setting, and persistence. In a typical population, approximately forty percent of individuals identify with the entity mind-set and forty percent relate to the incremental mindset with the remaining twenty percent of individuals not consistent enough in their responses to be classified as holding either theory (Dweck, 2008).

Entity theorists hold fixed mind-sets and see their environments and abilities as set with little that can be done to alter them (Dweck \& Leggett, 1988). They believe that an examination of their current abilities predicts their future capacity (Dweck, 1999). Students with a fixed mind-set feel smart with easy, low-effort successes, outperforming other students (Dweck, 1999). The self-imposed rule to look smart prohibits entity theorists from seeking remediation when necessary. Students' theory of intelligence affects their behaviours with students holding entity mind-sets responding differently to failure (Burns \& Isbell, 2007). Entity mind-sets are in contrast to the incremental mind-sets held by other students.

Incremental theorists hold a growth mind-set and believe that intelligence can be developed. They do not fear challenges or failure, but feel smart when they are fully engaged, stretching themselves, and putting their skills to use (Dweck, 1999). Incremental theorists thrive when they are growing and learning.

Evidence is mounting regarding the role that students' mind-sets play in learning mathematics. Research has shown that students with fixed mind-sets towards math- 
ematics and science ability "are at a significant disadvantage compared to students who believe that their abilities can be developed" (Dweck, 2008, p. 1). In a study of seventh-grade students, teachers, who were blind to treatment, chose three times as many students in the growth treatment group as showing marked improvement in their motivation compared to those in the control group (Blackwell, Trzesniewski, \& Dweck, 2007). One of the largest areas of difference between the entity and incremental mind-sets is in students' goal setting.

Theory of intelligence is a reliable predictor of student's goal orientation (Dweck \& Leggett, 1988; Heyman \& Dweck, 1998). Individuals that hold entity mind-sets tend toward performance goals, while individuals with incremental mind-sets favour mastery goals. Performance goals focus on demonstrating an individual's competence. Mastery goals focus on mastering a skill. An individual with this mastery goal will not see failing as a failure, but as a learning experience.

Goal orientation also affects individuals' views of effort. Dweck and Leggett (1988) found evidence that students with performance goals viewed effort and ability as inversely related. It is this irony that can be paralysing to students with performance goals. When they most need to exert extra effort, they draw back in a defensive response fearing that investing effort reveals their ability as deficient. In contrast to this, mastery goals provide an inoculation to failure in many students since failure is not alarming, but rather, an opportunity to learn (Dweck \& Leggett, 1988). Mastery goals are associated with students who seek out challenging tasks, increase motivation, and strive under failure (Grant \& Dweck, 2003).

Fortunately, there is evidence that mind-sets are dynamic and that individuals' tendencies change as they grow and develop with training in an incremental mindsets showing good potential in many studies (Anderson, 1995; Donohoe, Topping, \& Hannah, 2012; Kim \& Kellert, 2010). Training has also been linked to increased resiliency and academic performance in students (Donohoe et al., 2012).

While a majority of mind-set research discusses implicit theories of intelligence in a favourable light, there are also criticisms. Donohoe et al. (2012) questioned if it is possible to make a large difference in mind-set with only brief interventions. They, along with Blackwell et al. (2007), raised concerns about the longevity of the positive effects of implicit theory interventions. Some conflicting evidence has also arisen regarding the connection between mind-set and academic achievement (Blackwell et al., 2007). Furnham, Chamorro-Premuzic, and McDougall (2002) found evidence in a British study of college students that students' mind-sets were not related to achievement, but to their personality. The closing section of the literature review will examine research regarding gender stereotypes in mathematics.

\subsubsection{Gender Stereotypes}

The mathematics community has historically utilised a talent-driven approach to mathematics, emphasising that mathematics ability is innate (Clinkenbeard, 2015; Good et al., 2012; Leslie, Cimpian, Meyer, \& Freeland, 2015). Alongside this empha- 
sis is a persistent stereotype that males are more capable of mathematical thinking and quantitative reasoning than females (Dweck, 2008; Good et al., 2012; Steel \& Aronson, 1995). At their heart, stereotypes represent entity mind-set beliefs. They are erroneous knowledge structures that apply fixed abilities to certain groups of people (Anderson, 1995; Dweck, 2008). Aronson et al. (2002) found that stereotype targets behave similar to entity theorists when their gender is made salient by choosing easier, success-assuring tasks.

The combination in mathematics of a talent-driven approach and gender stereotypes creates ideal conditions for stereotype threat. Stereotype threat is a burden that an individual feels to confirm cultural stereotypes which limit his or her academic abilities and achievement (Aronson et al., 2002; Grant \& Dweck, 2003) and may provide important insight into why females have been historically under-represented in mathematics fields (Dweck, 2008). "A key factor driving students' intent to pursue math should be their personal sense that they belong in mathematics" (Good et al., 2012, p. 700). Women who identify with groups that have negative mathematical stereotypes may face obstacles. Aronson and colleagues (2002) claimed that a perceived stereotype could be strong enough to sway a student's implicit beliefs of intelligence. Students must first "be convinced that anyone can learn mathematics" or they have already crippled themselves by identifying with a 'have-not' group" (Clinkenbeard, 2015, p. 28).

Fortunately, there is evidence that training in incremental mind-sets can help females counter the negative effects of stereotypes. Good et al. (2003) conducted a study in which college students mentored seventh-grade students who were at-risk of stereotype threat. Students were divided into four groups. The first group received mentoring that encouraged a growth mind-set, the second group received mentoring concerning the transition to middle school, and the third group received both the growth mind-set and transition mentoring. The final group received an anti-drug message and served as a control for the experiment. At the end of the school year, females trained in the incremental mind-set received significantly higher scores on a standardised maths test (Good et al., 2003). Additionally, females showed greater gains than males and decreased the achievement gap. This finding supports Dweck's (2008) conclusion that females with growth mind-sets are less at risk of negative effects from stereotypes.

This review has examined literature regarding undergraduate statistics, theoretical foundations supporting the research, cognitive learning theory and the impact of gender stereotypes on female's mathematics achievement. The next section will examine the methods used to conduct the research. 


\subsection{Method}

\subsubsection{Population and Sample}

The population for this study was undergraduate students at a small, faith-based, liberal arts university located in the United States. This study made use of a pretest/post-test design. The research was quasi-experimental since a treatment was applied, but the sample was not randomly selected. The sample consisted of students who enrolled in introductory statistics in the semesters under examination and completed all aspects of the research.

The treatment group consisted of 121 students enrolled in introductory statistics courses during the experiment with a gender breakdown of $47.8 \%$ female and $52.2 \%$ male. The response rate was $52.9 \%$ resulting in 64 students who completed pre-test and post-test assessments in the four introductory statistics classes between August 2014 and May 2015.

The control group consisted of 234 students who enrolled in introductory statistics during August 2013 to May 2014. The response rate was $47.4 \%$ resulting in 111 students who completed pre-test and post-test assessments. The gender distribution in the control group was similar to the treatment group with $52.3 \%$ female and $47.7 \%$ male.

\subsubsection{Instrumentation}

Two instruments were used to assess each student's attitude toward statistics and mastery of statistical knowledge: The Student Attitudes Towards Statistics-36 ${ }^{\odot}$ (SATS) and the Comprehensive Assessment of Outcomes in a first Statistics course (CAOS). Both instruments were implemented at the beginning and the end of the course. Since both instruments were pre-existing with established reliability and validity, a pilot study was not conducted.

The SATS $^{\odot}$ (Schau, 2003) instrument was selected to assess each student's attitude since it has been widely used in statistics education research (Bond, Perkins, \& Ramirez, 2012; Chiesi \& Primi, 2010; Coetzee \& van der Merwe, 2010; Harpe, Phipps, \& Alowayesh, 2012; Swanson, Vander Stoep, \& Tintle, 2014). The 36-item online SATS ${ }^{\odot}$ tool provided a valid representation of students' attitudes regarding statistics. Each item required a response on a seven-point Likert scale. Responses were grouped into six components of attitude: affect, cognitive competence, value, difficulty, interest, and effort. Internal consistency for all components of the SATS ${ }^{\odot}$ (.66 < $\alpha<.85)$ was established (delMas, Garfield, Ooms, \& Chance, 2007). See Fig. 9.2 for sample questions.

The CAOS (delMas et al., 2007) measures mastery of statistical concepts and has been implemented widely in statistical education research (Hannigan, Gill, \& Leavy, 2013; Slauson, 2008; Tintle, Vander Stoep, Holmes, Quisenberry, \& Swanson, 2011; 


\begin{tabular}{ll} 
Component & Sample question \\
\hline Affect & I will like statistics. \\
Cognitive competence & *I will have trouble understanding statistics because of how I think. \\
Value & $*$ Statistics is worthless. \\
Difficulty & Statistics is a subject quickly learned by most people. \\
Interest & I am interested in understanding statistical information. \\
Effort & I plan to work hard in my statistics course. \\
\hline
\end{tabular}

Fig. 9.2 Examples of SATS ${ }^{\odot}$ component questions. The asterisk $(*)$ represents a reversed scored item

Tintle, Rogers, Chance, Cobb, Rossman, Roy, . . . \& Vander Stoep 2014; Zieffler, 2007). The 40-item instrument was administered online to assess students' mastery of statistics at both the beginning and at the end of each semester. Internal consistency for all components of the CAOS $(\alpha<.77)$ was established by Nolan, Beran, and Hecker (2012).

\subsubsection{Growth Mind-Set Treatments}

The incremental mind-set treatment was given to all students in the four introductory statistics classes between August 2014 and May 2015 which comprised the treatment group. The training was designed using materials and findings from successful interventions in the review of literature. The treatment consisted of four incremental mind-set-training sessions throughout each semester. The goal of the sessions was to help students understand how the brain functions biologically with a focus on the malleability of intelligence. In this study, each of the four 15-minute training sessions was implemented approximately three weeks apart. Each session occurred during class time and was led by the researcher to ensure consistency. Verbal permission to conduct the trainings was granted by the professors responsible for teaching each of the introductory statistics courses.

A number of approaches have successfully been employed to alter students' mental constructs. Both attribution training and mind-set training have employed the use of videos (Boese et al., 2013), reading activities (Kim \& Kellert, 2010), writing activities (Aronson et al., 2002; Hall et al., 2004), and computer-assisted instruction (Donohoe et al., 2012). In his study of attribution training, Robertson (2000, p. 118) found that no single medium was more effective than others. Given this finding, multiple approaches were implemented in an effort to differentiate the treatment delivery and connect with a variety of students in different methods.

The design of the sessions was adapted from the research of Berkeley, Mstropieri, and Scruggs (2011), Boese and colleagues (2013), Burk (2011), Cutts (2008), Hall 


\begin{tabular}{llll} 
Session & Topics & Activity Type & Consolidation \\
\hline 1 & $\begin{array}{l}\text { Fixed and growth mind -sets } \\
\text { brain physiology }\end{array}$ & $\begin{array}{l}\text { Presentation } \\
\text { reading } \\
\text { Card sort activity } \\
\text { presentation } \\
\text { thought questions } \\
\text { video }\end{array}$ & Discussion \\
& $\begin{array}{l}\text { Response to feedback } \\
\text { helplessness and mastery responses }\end{array}$ & Written reflection \\
3 & $\begin{array}{l}\text { Performance and learning goals } \\
\text { set course goals }\end{array}$ & $\begin{array}{l}\text { Video } \\
\text { presentation }\end{array}$ & Written reflection \\
& $\begin{array}{l}\text { Mind-sets in role models } \\
\text { The role of effort }\end{array}$ & $\begin{array}{l}\text { Presentation } \\
\text { Video }\end{array}$ & Written reflection \\
\hline & & & \\
\hline
\end{tabular}

Fig. 9.3 Treatment outline. An outline of each incremental mind-set training session

and colleagues (2004), and Sriram (2010) implementing combinations of a brief video, article, presentation, or activity which introduced concepts in incremental theory including mind-sets, the physiology of the brain, response to feedback, goals, and the role of effort. Following the success that Robertson (2000) found when combining strategy instruction with reattribution training, students were also given guidance in the sessions on successful techniques for mastering statistics. Dweck supported this approach with the rationale that telling a student to try harder is not enough without providing strategies to do so (Sparks, 2013). Pinxten et al. (2014) concur stating that "domain-specific interventions are more effective" than general interventions (p. 170). Students in the treatment were given guidance throughout each semester on how to respond to challenges and negative feedback in the course. They were also directed to resources to help improve their mastery of statistics including online material and tutoring that was available on campus, free of charge.

A consolidation activity closed each treatment to help students personalise the new information they received (Hall et al., 2004). The consolidation took the form of a small group discussion or an individual writing task. See Fig. 9.3 for the focus of each of the sessions.

\subsubsection{Data Collection}

The SATS ${ }^{\odot}$ and CAOS instruments were administered online, outside of class during the first week of class and again during the last week of class for the semester. The CAOS assessments had been regular requirements of introductory statistics classes for the institution since the fall of 2011 in conjunction with a grant for the National 
Science Foundation. Similarly, the SATS ${ }^{\odot}$ assessments had been regularly assessed since fall of 2013 in conjunction with the same grant.

Students who completed, at the minimum, the initial opt-out screen of all preassessments received credit for a daily assignment. Similarly, students who completed, at the minimum, the initial opt-out screen of all post-assessments received credit for a daily assignment.

The procedure for conducting the assessments ensured that students received the information and had adequate time to complete them. Students were introduced to the assessments during the first class period by the class instructor. After class on the first day, all students received an e-mail invitation with links to the assessments and a brief explanation of the purpose and procedures of the study. Each assessment was run through Survey Monkey ${ }^{\mathrm{TM}}$ and remained open for one week. A reminder e-mail was sent one day before the assessments closed. A similar process occurred with the post-test for each instrument.

To ensure that all individuals responsible for or affected by this research were informed and protected, appropriate permissions and reviews were completed prior to data collection including permission from the mathematics department and institutional research board of the institution. Additional permission was granted to use CAOS and SATS ${ }^{\odot}$ data for the control group from an ongoing National Science Foundation study from the principal investigator of the project. Students were assured of the confidentiality of their responses in the invitation. Informed consent was given through an initial opt-out screen for each assessment. This ensured students that they had the opportunity to not participate if they were uncomfortable with an assessment.

\subsubsection{Data Analysis}

Robust data analysis procedures were used throughout this research. Prior to any analysis, thorough data screening was employed to ensure that no outliers distorted the data. The threshold to determine and remove univariate outliers was observations beyond five standard deviations of the sample mean. Observations that violated three or more diagnostic measures were removed as bivariate outliers.

Appropriate statistical analyses were employed to address both research questions. An alpha level of .05 was used for all tests. A measure of effect size was calculated for all analyses as it provides an index of the magnitude of the differences between means which is independent of sample size (Warner, 2013). Using Cohen's (1988) index guidelines, large effect sizes represented measures of .4 and greater, medium effects between .25 and .4 and small effect sizes between .1 and .25 . The analysis for each research question follows. A post hoc power analysis indicated adequate power to detect large effects with ANCOVA for the treatment group $\left(N_{\text {Male }}=32, N_{\text {Female }}=\right.$ $32, d=.40,1-\beta=.88)$ and medium to large effects for the control group $(d=.3$, $1-\beta=.88, N_{\text {Female }}=58, N_{\text {Male }}=53$ ); (Faul, Erdfelder, Buchner, \& Lang, 2009). 
What differences exist by gender in the change in students' attitudes toward statistics for students who received training in an incremental mind-set and those who did not when controlling for initial attitudes?

The dependent variables for this research question were the post-test components of the SATS ${ }^{\odot}$ score with covariates of the pre-test components of the SATS ${ }^{\odot}$ score. The independent variable was the student's gender: male or female. ANCOVA was used to assess differences in post-test attitude scores while controlling for pre-test SATS $^{\odot}$ score by gender.

What differences exist by gender in mastery of statistics for students who received training in an incremental mind-set and for those who did not when controlling for initial mastery?

The dependent variable for this research question was the post-test CAOS score with the covariate pre-test CAOS score. The independent variable was the student's gender: male or female. An ANCOVA was used to assess differences in post-test mastery scores while controlling for pre-test mastery score by gender. The next section will share the results of this research.

\subsection{Results}

Section four examines the results of an intervention of incremental mind-set training in a college introductory statistics course. Areas examined included student attitudes toward statistics and student mastery of statistical content. The section opens with an examination of the response rate and sample demographics. The section then explores particular findings for each research question.

\subsubsection{Response Rate and Demographics}

The sample included all students who completed pre-test and post-test assessments in the introductory statistics classes between August 2013 and May 2015. The gender breakdown in the treatment group was evenly distributed with 32 females and 32 males. Adequate power was achieved to detect large effects $(d=.4,1-\beta=.88$, $N_{\text {Female }}=32, N_{\text {Male }}=32$ ) (Faul et al., 2009). The control group consisted of students enrolled in the introductory statistics course prior to the treatment between August 2013 and May 2014. The gender breakdown in this group was evenly distributed with 58 females and 53 males. Adequate power was achieved to detect medium to large effects $\left(d=.3,1-\beta=.88, N_{\text {Female }}=58, N_{\text {Male }}=53\right)($ Faul et al., 2009). 
Table 9.1 Post-test SATS ${ }^{\odot}$ scores by gender controlling for pre-test SATS ${ }^{\complement}$ in treatment group

\begin{tabular}{l|l|l|l|l|l|l}
\hline & Male $(n=32)$ & $\begin{array}{l}\text { Female } \\
(n=32)\end{array}$ & $M S E$ & $F$ value & $p$-value & $\eta_{P}^{2}$ \\
\hline Affect & $4.599(0.167)$ & $\begin{array}{l}4.177 \\
(0.536)\end{array}$ & 0.037 & 0.035 & .851 & 0.001 \\
\hline $\begin{array}{l}\text { Cognitive } \\
\text { competence }\end{array}$ & $4.890(-0.006)$ & $\begin{array}{l}4.776 \\
(0.286)\end{array}$ & 0.058 & 0.207 & .651 & 0.003 \\
\hline Difficulty & $3.900(0.213)$ & $\begin{array}{l}3.567 \\
(0.263)\end{array}$ & 0.140 & 0.408 & .525 & 0.007 \\
\hline Effort & $4.940(-1.227)$ & $\begin{array}{l}5.570 \\
(-0.766)\end{array}$ & 4.065 & 4.407 & $.040^{*}$ & $0.067^{\mathrm{a}}$ \\
\hline Interest & $4.289(-0.641)$ & $\begin{array}{l}4.141 \\
(-0.313)\end{array}$ & 1.298 & 1.678 & .200 & $0.027^{\mathrm{a}}$ \\
\hline Value & $4.812(-0.360)$ & $\begin{array}{l}5.059 \\
(0.184)\end{array}$ & 3.788 & 9.402 & $.003^{*}$ & $0.134^{\mathrm{a}}$ \\
\hline
\end{tabular}

Numbers in parenthesis represent the change from pre to post test

*Denotes significant difference at .05

${ }^{\text {a } D e n o t e s ~ s m a l l ~ o r ~ m e d i u m ~ e f f e c t ~ s i z e ~}$

\subsubsection{Attitude Toward Statistics}

Research question one states: What differences exist by gender in the change in students' attitudes toward statistics for students who received training in an incremental mind-set and those who did not when controlling for initial attitudes? Table 9.1 depicts the results for the treatment group on each component using a seven-point Likert scale with higher scores indicating more favourable attitudes. An encouraging finding for females demonstrated greater growth in comparison to males regarding their attitudes towards statistics. Statistically significant results were present for the effort and value components.

Table 9.2 depicts the results for the control group on the change in attitudes for the students who did not receive growth mind-set treatments. No statistically significant differences between attitudes of males and females were present with the exception of the effort component.

The effort component measured students' perceptions regarding the amount of work they expend to learn statistics (Schau, 2003). While motivation is difficult to measure and can include unconscious aspects, effort is a description of behaviour which is "a dependable manifestation of motivation" (Hannula, 2006, p. 167). It is typical on the SATS $^{\odot}$ to observe a decrease in the effort component from the pre-test to post-test as students refer to intended effort on the pre-test prior to the semester and the post-test is a closer measure of their actual effort. The effort component decreased for both males and females during the treatment semesters, but males decreased at a statistically significantly greater rate than females $(F(1,63)=4.41$, $M S E=4.07, p=.040)$. Students in the control group that did not receive growth mind-set treatments showed similar, although weaker, findings by gender as females 
Table 9.2 Post-test SATS $^{\odot}$ scores by gender controlling for pre-test $\mathrm{SATS}^{\odot}$ in control group

\begin{tabular}{l|l|l|l|l|l|l}
\hline & Male $(n=53)$ & $\begin{array}{l}\text { Female } \\
(n=58)\end{array}$ & $M S E$ & $F$ value & $p$-value & $\eta_{P}^{2}$ \\
\hline Affect & $4.280(-0.038)$ & $\begin{array}{l}3.747 \\
(0.052)\end{array}$ & 0.179 & 0.149 & .700 & 0.001 \\
\hline $\begin{array}{l}\text { Cognitive } \\
\text { competence }\end{array}$ & $5.053(0.150)$ & $\begin{array}{l}4.698 \\
(0.393)\end{array}$ & 0.121 & 0.170 & .681 & 0.002 \\
\hline Difficulty & $3.863(0.108)$ & $\begin{array}{l}3.665 \\
(0.116)\end{array}$ & 0.082 & 0.195 & .660 & 0.002 \\
\hline Effort & $5.638(-0.173)$ & $\begin{array}{l}5.879 \\
(-0.277)\end{array}$ & 2.637 & 3.979 & .049 & 0.036 \\
\hline Interest & $4.420(-0.594)$ & $\begin{array}{l}4.168 \\
(-0.371)\end{array}$ & 0.685 & 0.833 & .364 & 0.008 \\
\hline Value & $4.855(-0.403)$ & $\begin{array}{l}4.785 \\
(-0.083)\end{array}$ & 1.396 & 3.145 & .079 & 0.028 \\
\hline
\end{tabular}

Numbers in parenthesis represent the change from pre to post test

decreased in the effort component at a statistically significant lesser rate than males $(F(1,110)=3.98, M S E=2.64, p=.049)$.

Value increased for both genders in the treatment group with females gaining at a statistically greater rate than males $(F(1,63)=9.40, M S E=3.78, p=.003)$. The value component measured students' views regarding the usefulness, relevance, and worth of statistics in their personal and professional life (Schau, 2003). Students in the control group did not demonstrate statistically significant differences by gender for the value component $(F(1,110)=3.15, M S E=1.40, p=.079)$. The next section will examine students' mastery of statistics.

\subsubsection{Mastery of Statistics}

Research question two states: What differences exist by gender in mastery of statistics for students who received training in an incremental mind-set and for those who did not when controlling for initial mastery?

Table 9.3 depicts the results including an encouraging finding that females in the treatment group demonstrated statistically significant growth in their mastery of statistics compared to males. No significant difference by gender was present for mastery in the control group. This provides strong evidence of a difference by gender in response to incremental mind-set training. 
Table 9.3 Post-test CAOS scores by gender controlling for pretest CAOS scores

\begin{tabular}{l|l|l|l|l|l|l}
\hline & Male $(N=85)$ & Female $(N=90)$ & $M S E$ & $F$ value & $p$-value & $\eta_{P}^{2}$ \\
\hline Treatment & $0.562(0.060)$ & $0.583(0.110)$ & 0.063 & 5.296 & $.025^{*}$ & $0.080^{\mathrm{a}}$ \\
\hline Control & $0.604(.080)$ & $0.566(0.101)$ & 0.002 & 0.170 & .681 & 0.002 \\
\hline
\end{tabular}

Numbers in parenthesis represent the change from pre to post test

*Denotes significant difference at .05

a Denotes small or medium effect size

\subsection{Summary, Conclusions, Discussions, and Recommendations}

The final section of this paper will summarise, make conclusions, discuss findings, and provide recommendations for future practice and research.

\subsubsection{Summary}

This research examined the effects by gender of an intervention of incremental mindset training on students' attitudes toward statistics and mastery of statistical content in an introductory statistics course.

A quasi-experimental, pre-test/post-test design was used in this quantitative research and robust statistical analysis procedures were used throughout. The population was undergraduate students at a small, faith-based, liberal arts university in the Midwest. The students were predominantly Caucasian and of traditional college age. While the sample was not randomly selected, it was representative of students who typically enrol in this course.

The results of this study add to the research of implicit theories of knowledge in undergraduate statistics courses and support continuous improvement in undergraduate statistics pedagogy. A noteworthy contribution of this research is the positive results for females with mind-set training regarding attitudes toward statistics and mastery of statistics.

\subsubsection{Conclusions}

Based on this sample the following conclusions emerged regarding the benefit to females of incremental mind-set treatments in this introductory statistics course.

Females in the mind-set treatment condition increased their value of statistics at a significantly higher rate than males did on the $\mathrm{SATS}^{\odot}$ component of value. This is a significant finding given the historical underrepresentation of women in mathematics and STEM in general (Dweck, 2008; Good et al., 2003). The increase in female's 
value compared to males supports the notion that environments that communicate an incremental view of mathematics will improve the achievement of females in mathematics and science (Good et al., 2012).

Females in the mind-set treatment decreased in their effort towards statistics at a statistically significant lesser amount than males on the effort component of the SATS $^{\odot}$. The effort component gives insight into motivation as it implies that an individual is "moved to do something" (Ryan \& Deci, 2000, p. 54). This smaller decrease in effort for females is an indicator that females believed that they could "produce desired effects by their actions" allowing them to persevere when they faced challenges (Bandura, 1999, p. 28).

Females in the mind-set treatment demonstrated greater growth in their mastery of statistics compared to males as measured on the CAOS instrument. This concurs with Pinxten and colleagues' (2014) findings regarding the strong correlation between maths achievement and maths competence beliefs as growth mind-set training, at its core, addressed students' beliefs about their ability to learn mathematics.

\subsubsection{Discussion}

The purpose of the study was to determine the effects by gender of training of incremental mind-sets on students' attitudes towards statistics and their mastery of statistics. The first section examines effort, followed by value and mastery.

\subsubsection{Effort}

Effort is an important behaviour to examine as time spent studying is the secondbest predictor of college readiness, following only socioeconomic status (Strayhorn, 2014). The statistically significant lesser decrease in effort reported by females than males in the treatment group is an important finding as "academic effort expenditure has been frequently investigated in relation to students' goal orientations and causal attributions of success and failure" because of its internal, controllable nature (Pinxten, Marsh, De Fraine, Van Den Noortgate, \& Van Damme, 2013, p. 156). This provides evidence that training in a growth mind-set which includes goal setting and discussions of maladaptive attributions had a positive effect on females and the effort that they applied.

There is evidence that the valuation of effort and ability change with development as well. Harari and Covington (1981) found that early elementary students emphasised the role of effort in intelligence. This valuation gradually shifted throughout the educational experience to an emphasis on the role of ability in college students. As a result, many undergraduate students equate effort with lack of ability (Boekaerts, 1999). This is unfortunate since effort is required for students to work through struggle and is a normal part of learning mathematics ( $\mathrm{Su}, 2016)$. 


\subsubsection{Value}

Similar to effort, value of mathematics also declines as students enter middle school and high school (Turner \& Meyer, 2009). This research notes an encouraging finding, demonstrating a statistically significant improvement for females in the treatment group compared to males on the $\mathrm{SATS}^{\odot}$ value component. This is important to motivation in light of expectancy-value theory which states that motivation is a product of both the expectation that an action will produce an outcome and the value placed on that outcome (Bandura, 1999). Additionally, if incremental mind-set training helps females value mathematics, it may also improve their performance to help diminish a persistent stereotype in the mathematics community that males are more capable of mathematical thinking and quantitative reasoning than females (Dweck, 2008; Good et al., 2003, 2012).

\subsubsection{Mastery}

The statistically significant improvement in mastery of statistics, demonstrated by females in the treatment group when compared to males, is evidence of the importance of implicit theories of knowledge on student attitudes and behaviours. It provides evidence to support Urbina-Lilback's (2016) assertion that students should adopt a growth mind-set to gain an appreciation of effort and productive struggle in learning. The following section provides recommendations for future practice and research based on these encouraging findings.

\subsubsection{Recommendations}

Recommendations for practice include creating classroom environments that communicate an incremental view of mathematics. This is an important step toward increasing the representation and achievement of females in mathematics and science (Good et al., 2012). An understanding of the malleable role of intelligence should permeate all aspects of the classroom including discourse, assessment, and pedagogy (Urbina-Lilback, 2016). Good et al. (2012) conjectured that the disengagement of females with mathematics may result not from a disinclination, but from a decreased sense of belonging. In a large study of undergraduate students in calculus, they found that the perception of an entity-oriented environment and stereotyping were significant predictors of a sense of belonging for females. Fortunately, an incremental mind-set can help stereotyped individuals counteract the effects of stereotyping (Good et al., 2003).

Recommendations for future research include replication, as it is necessary to learn more about the effects of growth mind-set training on achievement and attitudes for both males and females. Research should replicate the current quantitative study to increase the sample size, but also add an aspect of qualitative research to understand 
why males and females respond in different ways. Additionally, more research on the role of mind-sets and incremental mind-set training should be conducted in various mathematics settings including elementary, secondary, and undergraduate classrooms to improve the generalisability of results.

\section{References}

Aliaga, M., Cobb, G., Cuff, C., Garfield, J., Gould, R., Lock, R., ...., Witmer, J. (2005). Guidelines for assessment and instruction in statistics education: College report. Alexandria, VA: American Statistical Association.

Anderson, C. A. (1995). Implicit theories in broad perspective. Psychological Inquiry, 6(4), 286. https://doi.org/10.1207/s15327965pli0604_2.

Aronson, J., Fried, C. B., \& Good, C. (2002). Reducing the effects of stereotype threat on African American college students by shaping theories of intelligence. Journal of Experimental Social Psychology, 38(2), 113-125. https://doi.org/10.1006/jesp.2001.1491.

Bandalos, D. L., Yates, K., \& Thorndike-Christ, T. (1995). Effects of math self-concept, perceived self-efficacy, and attributions for failure and success on test anxiety. Journal of Educational Psychology, 87(4), 611-623. https://doi.org/10.1037/0022-0663.87.4.611.

Bandura, A. (1999). Social cognitive theory: An agentic perspective. Asian Journal of Social Psychology, 2(1), 21-41. https://doi.org/10.1146/annurev.psych.52.1.1.

Banks, M., \& Woolfson, L. (2008). Why do students think they fail? The relationship between attributions and academic self-perceptions. British Journal of Special Education, 35(1), 49-56. https://doi.org/10.1111/j.1467-8578.2008.00369.x.

Berkeley, S., Mastropieri, M. A., \& Scruggs, T. E. (2011). Reading comprehension strategy instruction and retraining for secondary students with learning and other mild disabilities. Journal of Learning Disabilities, 44(1), 18-32. https://doi.org/10.1177/0022219410371677.

Blackwell, L. S., Trzesniewski, K. H., \& Dweck, C. S. (2007). Implicit theories of intelligence predict achievement across an adolescent transition: A longitudinal study and an intervention. Child Development, 78(1), 246-263. https://doi.org/10.1111/j.1467-8624.2007.00995.x.

Boekaerts, M. (1999). Self-regulated learning: Where we are today. International Journal of Educational Research, 31, 445-457.

Boekaerts, M., Otten, R., \& Voeten, R. (2003). Examination performance: Are student's causal attributions school-subject specific? Anxiety Stress and Coping, 16(3), 331-342. https://doi.org/ 10.1080/1061580031000095470.

Boese, G. D. B., Stewart, T. L., Perry, R. P., \& Hamm, J. M. (2013). Assisting failure-prone individuals to navigate achievement transitions using a cognitive motivation treatment (attributional retraining). Journal of Applied Social Psychology, 43(9), 1946-1955. https://doi.org/10.1111/ jasp.12139.

Bond, M. E., Perkins, S. N., \& Ramirez, C. (2012). Students' perceptions of statistics: An exploration of attitudes, conceptualizations, and content knowledge of statistics. Statistics Education Research Journal, 11(2), 6-25.

Bruning, R. H., Schraw, G. J., \& Norby, M. M. (2011). Cognitive psychology and instruction (5th Ed.). Boston, MA: Pearson.

Bryk, A. S., \& Treisman, U. (2010). Make math a gateway, not a gatekeeper. Chronicle of Higher Education, 56(32), B19.

Burk, J. (2011, September 10). Measuring mind-set in my classes. [Web log post]. Retrieved from http://quantumprogress.wordpress.com/2011/09/10/measuring-mindset-in-my-classes/.

Burns, K. C., \& Isbell, L. M. (2007). Promoting malleability is not one size fits all: Priming implicit theories of intelligence as a function of self-theories. Self \& Identity, 6(1), 51-63. https://doi.org/ $10.1080 / 15298860600823864$. 
Chiesi, F., \& Primi, C. (2010). Cognitive and non-cognitive factors related to students' statistics achievement. Statistics Education Research Journal, 9(1), 6-26.

Clinkenbeard, J. (2015). Attitudes and experiences in liberal arts mathematics. Journal of Humanistic Mathematics, 5(2), 26-50. https://doi.org/10.5642/jhummath.201502.04.

Coetzee, S., \& van der Merwe, P. (2010). Industrial psychology students' attitudes towards statistics. SAJIP: South African Journal of Industrial Psychology, 36(1), 1-8. https://doi.org/10.4102/sajip. v36i1.843.

Cohen, J. (1988). Statistical power analysis for the behavioral sciences (2nd Ed.). Hillsdale, NJ: Lawrence Erlbaum.

Cook, A. (2010). Improving the success rate in statistics. Paper presented at the discussion paper series, University of Queensland School of Economics. http://www.uq.edu.au/economics/415improving-the-success-rate-in-statistics.

Cutts, Q. (2008). Promoting a growth mind-set to learning. Report. Computer Science. Glasgow University. Glasgow, UK. Retrieved from https://www.google.com/search?q=Promoting+a+ growth+mindset+to+learning+Glasgow+University\&oq=Promoting+a+growth+mindset+to+ learning+Glasgow+University\&aqs $=$ chrome.. $69 \mathrm{i} 57.9176 \mathrm{j} 0 \mathrm{j} 7 \&$ sourceid=chrome \&espv $=210 \&$ es_sm $=122 \&$ ie $=$ UTF- 8 .

delMas, R. C., Garfield, J., Ooms, A., \& Chance, B. (2007). Assessing students' conceptual understanding after a first course in statistics. Statistics Education Research Journal, 6(2), 28-58.

DeBellis, V. A., \& Goldin, G. A. (1997). The affective domain in mathematical problem solving. In E. Pehkonen (Ed.), Proceedings of the 21st Conference of the International Group for the Psychology of Mathematics Education (Vol. 2, pp. 209-216). Finland: University of Helsinki.

Donohoe, C., Topping, K., \& Hannah, E. (2012). The impact of an online intervention (Brainology) on the mind-set and resiliency of secondary school pupils: A preliminary mixed methods study. Educational Psychology, 32(5), 641-655. https://doi.org/10.1080/01443410.2012.675646.

Dweck, C. S. (1999). Self-theories: Their role in motivation, personality, and development (Vol. 1). New York, NY: Taylor \& Francis.

Dweck, C. S. (2006). Mindset: The new psychology of success. New York: Ballantine Books.

Dweck, C. S. (2008). Mindsets and math science achievement. Retrieved from http:// opportunityequation.org/teaching-and-leadership/mindsets-math-science-achievement.

Dweck, C. S. (2010). Boosting achievement with messages that motivate. Canadian Education Association, 47(2), 6-10.

Dweck, C. S., \& Leggett, E. L. (1988). A social-cognitive approach to motivation and personality. Psychological Review, 95(2), 256-273.

Evans, B. (2007). Student attitudes, conceptions, and achievement in introductory undergraduate college statistics. The Mathematics Educator, 17(2), 24-30.

Faul, F., Erdfelder, E., Buchner, A., \& Lang, A. (2009). Statistical power analyses using G*Power 3.1: Tests for correlation and regression analyses. Behavior Research Methods, 41, 1149-1160. https://doi.org/10.3758/brm.41.4.1149.

Furnham, A., Chamorro-Premuzic, T., \& McDougall, F. (2002). Personality, cognitive ability, and beliefs about intelligence as predictors of academic performance. Learning and Individual Differences, 14(1), 47-64. https://doi.org/10.1016/j.lindif.2003.08.002.

Good, C., Aronson, J., \& Inzlicht, M. (2003). Improving adolescents' standardized test performance: An intervention to reduce the effects of stereotype threat. Journal of Applied Developmental Psychology, 24(6), 645-662. https://doi.org/10.1016/j.appdev.2003.09.002.

Good, C., Rattan, A., \& Dweck, C. S. (2012). Why do women opt out? Sense of belonging and women's representation in mathematics. Journal of Personality and Social Psychology, 102(4), 700-717. https://doi.org/10.1037/a0026659.

Grant, H., \& Dweck, C. S. (2003). Clarifying achievement goals and their impact. Journal of Personality and Social Psychology, 85(3), 541-553. https://doi.org/10.1037/0022-3514.85.3.541.

Hall, N. C., Hladkyj, S., Perry, R. P., \& Ruthig, J. C. (2004). The role of attributional retraining and elaborative learning in college students' academic development. Journal of Social Psychology, 144(6), 591-612. https://doi.org/10.3200/SOCP.144.6.591-612. 
Hannigan, A., Gill, O., \& Leavy, A. (2013). An investigation of prospective secondary mathematics teachers' conceptual knowledge of and attitudes towards statistics. Journal of Mathematics Teacher Education, 16(6), 427-449. https://doi.org/10.1007/s10857-013-9246-3.

Hannula, M. S. (2004). Affect in mathematics education-exploring theoretical frameworks: Introduction. In: Proceedings of the 28th Conference of the International Group for the Psychology of Mathematics Education, Bergen, Norway. Retrieved from https://www.emis.de/proceedings/ PME28/RF/RF001.pdf.

Hannula, M. S. (2006). Motivation in mathematics: Goals reflected in emotions. Educational Studies in Mathematics, 63, 165-178. https://doi.org/10.1007/s10649-005-9019-8.

Harari, O., \& Covington, M. V. (1981). Reactions to achievement behaviour from a teacher and student perspective: A developmental analysis. American Educational Research Journal, 18(1), $15-28$

Harpe, S. E., Phipps, L. B., \& Alowayesh, M. S. (2012). Effects of a learning-centered approach to assessment on students' attitudes towards and knowledge of statistics. Currents in Pharmacy Teaching \& Learning, 4(4), 247-255. https://doi.org/10.1016/j.cpt1.2012.05.002.

Heyman, G. D., \& Dweck, C. S. (1998). Children's thinking about traits: Implications for judgments of the self and others. Child Development, 69(2), 391-403. https://doi.org/10.1111/j.1467-8624. 1998.tb06197.x.

Kesici, Ş., Baloğlu, M., \& Deniz, M. E. (2011). Self-regulated learning strategies in relation with statistics anxiety. Learning and Individual Differences, 21(4), 472-477. https://doi.org/10.1016/ j.lindif.2011.02.006.

Kim, C., \& Kellert, J. M. (2010). Motivation, volition and belief change strategies to improve mathematics learning. Journal of Computer Assisted learning, 26(5), 407-420. https://doi.org/ 10.1111/j.1365-2729.2010.00356.x.

Leinbach, D. T., \& Jenkins, D. (2008). Using longitudinal data to increase community college student success: A guide to measuring milestone and momentum point attainment. CCRC Research Tools No. 2. From http://search.ebscohost.com/login.aspx?direct=true\&db=eric\&AN= ED499922\&site=ehost-live.

Leslie, S.-J., Cimpian, A., Meyer, M., \& Freeland, E. (2015). Expectations of brilliance underlie gender distributions across academic disciplines. Science, 347(6219), 262-265. https://doi.org/ 10.1126/science. 1261375 .

Lucio, R., Rapp-Paglicci, L., \& Rowe, W. (2011). Developing an additive risk model for predicting academic index: School factors and academic achievement. Child and Adolescent Social Work Journal, 28(2), 153-173. https://doi.org/10.1007/s10560-010-0222-9.

Mangels, J. A., Butterfield, B., Lamb, J., \& Dweck, C. S. (2006). Why do beliefs about intelligence influence learning success? A social cognitive neuroscience model. Social Cognitive and Affective Neuroscience, 1(2), 75-86. https://doi.org/10.1093/scan/ns1013.

McGrath, A. L. (2014). Content, affective, and behavioral challenges to learning: Students' experiences learning statistics. International Journal for the Scholarship of Teaching and Learning, $8(2), 1-21$.

Mullis, I. V. S., Martin, M. O., Foy, P., \& Arora, A. (2012). TIMSS 2011 international results in mathematics. ERIC Digest. Retrieved from ERIC database (ED544554).

Nolan, M. M., Beran, T., \& Hecker, K. G. (2012). Surveys assessing students' attitudes toward statistics: A systematic review of validity and reliability. Statistics Education Research Journal, 12(2), 103-123.

Nurmi, A., Hannula, M., Maijala, H., \& Pehkonen, E. (2003). On pupils' self-confidence in mathematics: Gender comparisons. International Group for the Psychology of Mathematics Education, $3,453-460$.

Onwuegbuzie, A. J., \& Wilson, V. A. (2003). Statistics anxiety: Nature, etiology, antecedents, effects, and treatments-A comprehensive review of the literature. Teaching in Higher Education, 8(2), 195-209. https://doi.org/10.1080/1356251032000052447.

Pang, T. (2010, January 17). Improve math education, improve student retention. [Web log]. Retrieved from https://chronicle.com/article/Strengthen-Math-Education/63536/. 
Pinxten, M., Marsh, H. W., De Fraine, B., Van Den Noortgate, W., \& Van Damme, J. (2013). Enjoying mathematics or feeling competent in mathematics? Reciprocal effects on mathematics achievement and perceived math effort expenditure. British Journal of Educational Psychology, 84, 152-174. https://doi.org/10.1111/bjep.12028.

Robertson, J. R. (2000). Is attribution training a worthwhile classroom intervention for K-12 students with learning difficulties? Educational Psychology Review, 12(1), 111-134. https://doi.org/10. 1023/A:1009089118008.

Ruggeri, K. (2011). The impact of misunderstanding the nature of statistics. Psychology Teaching Review, 17(1), 35-40.

Ruggeri, K., Dempster, M., Hanna, D., \& Cleary, C. (2008a). Experiences and expectations: The real reason nobody likes stats. Psychology Teaching Review, 14(2), 75-83.

Ruggeri, K., Diaz, C., Kelley, K., Papousek, I., Dempster, M., \& Hanna, D. (2008b). International issues in education. Psychology Teaching Review, 14(2), 65-74.

Ryan, R. M., \& Deci, E. L. (2000). Intrinsic and extrinsic motivations: Classic definitions and new directions. Contemporary Educational Psychology, 25, 54-67. https://doi.org/10.1006/ceps. 1999.1020.

Schau, C. (2003). Survey of attitudes toward statistics. Retrieved from http://www. evaluationandstatistics.com/bizwaterSATS36monkey.pdf.

Schoenfeld, A. (1992). Learning to think mathematically: Problem solving, metacognition and sense making in mathematics. In A. D. Grouws (Ed.), Handbook of research on mathematics learning and teaching (pp. 334-370).

Schommer, M. (1990). Effects of beliefs about the nature of knowledge on comprehension. Journal of Educational Psychology, 82(3), 498. Retrieved from http://search.proquest.com.ezproxy.usd. edu/docview/210953579? accountid=14750.

Shores, M. L., \& Smith, T. (2010). Attribution in mathematics: A review of literature. School Science \& Mathematics, 110(1), 24-30. https://doi.org/10.1111/j.1949-8594.2009.00004.x.

Slauson, L. V. (2008). Students' conceptual understanding of variability. (68), ProQuest Information \& Learning, US. Retrieved from http://search.ebscohost.com/login.aspx?direct=true\&db=psyh\& $\mathrm{AN}=2008-99110-187 \&$ site=ehost-live. Available from EBSCOhost psych database.

Sparks, S. D. (2013). 'Growth mind-set' gaining traction as school improvement strategy. Web log. Retrieved from http://www.edweek.org/ew/articles/2013/09/11/03mindset_ep.h33.html.

Sriram, R. (2010). Rethinking intelligence: The role of mind-set in promoting success for academically high-risk college students (Doctoral dissertation). Azusa Pacific University. Retrieved from http://search.proquest.com.ezproxy.usd.edu/pqdtft/docview/756252798/abstract/ 1409398B9003D278E59/17?accountid=14750.

Steel, C. M., \& Aronson, J. (1995). Stereotype threat and intellectual test performance of African Americans. Journal of Personality and Social Psychology, 69, 797-811.

Strayhorn, T. L. (2014). Modeling the determinants of college readiness for historically underrepresented students at 4-year colleges and universities: A national investigation. American Behavioral Scientist, 58(8), 972-993.

Su, F. (2016). The value of struggle. MAA Focus, 36(3), 20-21.

Swanson, T., Vander Stoep, J., \& Tintle, N. (2014). Student attitudes toward statistics from a randomization-based curriculum. Paper presented at the International Conference on Teaching Statistics, Flagstaff, AZ. http://icots.info/icots/9/proceedings/pdfs/ICOTS9_1F1_SWANSON. pdf.

Syed, D. (2013). Motivation: Beliefs and cognition. Notes. University of South Dakota.

Tintle, N. L., Vander Stoep, J., Holmes, V.-L., Quisenberry, B., \& Swanson, T. (2011). Development and assessment of a preliminary randomization-based introductory statistics curriculum. Journal of Statistics Education, 19(1), 1-24.

Tintle, N. L., Rogers, A., Chance, B., Cobb, G., Rossman, A., Roy, S., . . \& Vander Stoep, J. (2014). Quantitative evidence for the use of simulation and randomization in the introductory statistics course. Paper Presented at the International Conference on Teaching Statistics, Flagstaff, AZ. 
Tintle, N. L., Chance, B. L., Cobb, G. W., Rossman, A. J., Roy, S., Swanson, T. M., et al. (2016). Introduction to statistical investigations. Hoboken, $\mathrm{NJ}$ : Wiley.

Topper, A. (2011). Developmental education: Time to completion. Silver Springs, Maryland: Achieving the Dream Inc.

Turner, J. C., \& Meyer, D. K. (2009). Understanding motivation in mathematics: What is happening in classrooms? In K. R. Wentzel \& A. Wigfield (Eds.), Handbook of motivation at school (pp. 123-140). New York, NY: Routledge.

Urbina-Lilback, R. N. (2016). Snapshots of equitable teaching in a highly diverse classroom. Mathematics Teacher, 110(2), 126-132.

Warner, R. M. (2013). Applied statistics: From bivariate through multivariate techniques (2nd Ed.). Los Angeles, CA: Sage Publications, Inc.

Weiner, B. (1985). An attributional theory of achievement motivation and emotion. Psychological Review, 92(4), 548-573.

Weston, L. (2014, September 9). OECD: The US has fallen behind other countries in college completion. Reuters. Retrieved from http://www.businessinsider.com/r-us-falls-behind-in-collegecompetition-oecd-2014-9.

Zieffler, A. S. (2007). A longitudinal investigation of the development of college students' reasoning about bivariate data during an introductory statistics course. (67), ProQuest Information \& Learning, US. Retrieved from http://search.ebscohost.com/login.aspx?direct=true\&db=psyh\& AN=2007-99001-075\&site=ehost-live. Available from EBSCOhost psyh database.

Zonnefeld, V. L. (2015). Mindsets, attitudes, and achievement in undergraduate statistics courses. ProQuest Information and Learning, US. Retrieved from https://pqdtopen.proquest.com/doc/ 1734104481.html?FMT=ABS.

Open Access This chapter is licensed under the terms of the Creative Commons Attribution 4.0 International License (http://creativecommons.org/licenses/by/4.0/), which permits use, sharing, adaptation, distribution and reproduction in any medium or format, as long as you give appropriate credit to the original author(s) and the source, provide a link to the Creative Commons license and indicate if changes were made.

The images or other third party material in this chapter are included in the chapter's Creative Commons license, unless indicated otherwise in a credit line to the material. If material is not included in the chapter's Creative Commons license and your intended use is not permitted by statutory regulation or exceeds the permitted use, you will need to obtain permission directly from the copyright holder.

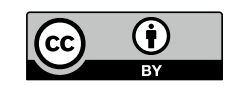




\title{
Chapter 10 \\ A Commentary: Extending the Research Discourse from Interests and Beliefs to Values
}

\author{
Wee Tiong Seah
}

\begin{abstract}
This commentary unpacks and interprets the various attributes that were examined in the chapters included in this section, that is, interest, motivation, personal meanings, and values. It looks at how they extend and deepen our understanding of the roles played by values and valuing in mathematics education research. It emphasises the opportunity for a re-focus on the purpose of learning mathematics to one of cultivating values and practising valuing, beyond acquisition of mathematical content knowledge and skills.
\end{abstract}

\subsection{Introduction}

This section features a collection of writings which investigate and deepen our understanding of mathematics learning and teaching from the perspectives of interest (Achmetli \& Schukajlow), motivation (Bofah \& Hannula; Middleton, Mangu, \& Lee; Wilkie), personal meanings (Vollstedt \& Duchhardt), values (Dobie), and multiple affective aspects including interest, motivation and value (Zonnefeld). Amongst these variables, values are often perceived to be the most fundamental, most internalised, and most stable (e.g. Bishop, 1988; Roccas, Sagiv, \& Navon, 2017; Stern, 2000), thus guiding the nature, form and activities of one's motivation and attitudes. In this context, this commentary will adopt the values perspective to interpret and summarise the content, with the aim of exploring how the values approach to mathematics education (research) might be enriched further.

W. T. Seah $(\bowtie)$

Melbourne Graduate School of Education, The University of Melbourne, Melbourne, Australia e-mail: wt.seah@unimelb.edu.au 


\subsubsection{Not Just Values, But Also, Values in Mathematics Education}

The 'values' construct is not new in the academic world (e.g. Kluckhohn, 1962), and this commentary will begin with a brief outline of its development. One line of research attention highlights the values that are inherent within the discipline, such as by UNESCO (1979) when it made reference to "the principal criteria which constitute the efficiency of this tool of investigation and communication [that is, mathematics]: intelligibility, brevity, accuracy, relevance, normality" (p. 10). Another direction of research tradition has been concerned with the purposeful and planned teaching of moral and civics values to students (see, for example, Thornberg \& Oğuz, 2013). Yet another research direction has been focussing on the emergence and/or portrayal of some of these values in the process of teaching and learning school subjects such as history, languages, and science (e.g. Allchin, 1999; Hill, 1991).

The construct of values/valuing as it applies to mathematics teaching and learning explicitly has been a relatively recent one, however. It was only in 1996 when Alan Bishop made public his conceptualisation of the categories of values that are espoused in the Western school mathematics classroom, that is, the classroom as a site of intersection amongst mathematical values, mathematics educational values, and general educational values. That took place in a regional mathematics education research conference in Vietnam, however, and thus most members of the Western research communities were introduced to these categories even more recently. In Bishop (2008), he wrote that his "research approach to values and Mathematical thinking has to date been to focus on mathematical values, and on the actions and choices concerning them" (p. 84).

This development in mathematics education above was a follow up to Bishop's (1988) earlier assertion that Western mathematics as a scientific discipline is an expression of a set of three complementary pairs of mathematical values, namely, rationalism and objectism, control and progress, and mystery and openness. These mathematical values would later make up one of the three categories of values in the (Western) mathematics classroom mentioned above. While mathematical values express the nature of (Western) mathematics as a scientific discipline, the category of mathematics educational values would reflect the attributes of mathematics teaching and learning that are deemed important, and are thus expected to be contextualised differently in different cultures. The third category is made up of what Bishop (1996) called general educational values, which refers to the societal and cultural values that are represented and taught through the school education process.

Bishop (1999) sees "values in mathematics education ... [as] the deep affective qualities which education fosters through the school subject of mathematics" (p. 2). DeBellis and Goldin (2006) extended this definition, when they wrote that "values, including ethics and morals, refer to the deep, 'personal truths' or commitments cherished by individuals" (p. 135). This reflects Halstead and Taylor's (2000) definition of values in the wider education scene, in which they regarded values as being the "principles and fundamental convictions which act as general guides to behaviour, 
enduring beliefs about what is worthwhile, ideals for which one strives, standards by which particular beliefs and actions are judged to be good or desirable" (p. 3), thereby differentiating values (that which is important) from beliefs (that which is true). Hill (1991) had proposed this similarly in the field of education in general, when he defined values as being "held by individuals to which they attach special priority or worth, and by which they tend to order their lives" (p. 4).

A consortium of some 21 research teams located in 18 different economies around the world has been collaborating on values-related mathematics education research since 2009. Called 'The Third Wave Project', it has been finetuning its operating definition of values. In the current view,

valuing refers to an individual's embrace of convictions which are considered to be of importance and worth. It provides the individual with the will and grit to maintain any 'I want to' mindset in the learning and teaching of mathematics. In the process, this conative variable shapes the manner in which the individual's reasoning, emotions and actions relating to mathematics pedagogy develop and establish. (Seah, 2018, p. 616)

These perspectives to values in mathematics education share a similar concern and objective, that is, examining what and how particular values would facilitate more effective mathematics learning and/or teaching. This is significant, given the many students around the world who are disengaged with school mathematics when they are as young as 12 years old, and many also do not choose to study the subject at the senior high school levels and beyond. The argument has been that when students, teachers, and other stakeholders value some particular enabling attributes of mathematics pedagogy, such as open-endedness and application, the subscription to these conative variables would provide the individual with the motivation, drive, and perseverance to see a purpose of studying mathematics, and to engage with the subject in school.

In this context, all the seven chapters in this section can be considered to be researching values/valuing to different degrees. In particular, both Dobie and Wilkie's respective studies made use of the values variable in a more direct manner. Dobie's research question was: "What is the relationship between students' personal values and their ideas about the usefulness of mathematics?". The statements in her survey instrument begin with 'It is important to me that ...', which is in line with the definition of values as being the attributes that are regarded as important. On the other hand, although Wilkie asked her participants to write down what wishes they had for mathematics learning, she had also explained that these were the things that mattered-and thus, were of importance and valued - to the students. Participantgenerated phrases such as 'being better at fractions' and 'wanting to make more effort' (see Table 8.1 in Chap. 8) could thus be interpreted as expressing convictions such as fractions and effort respectively.

The chapter written by Vollstedt and Duchhardt is in the same vein. They had used a questionnaire to survey 193 representative 15- to 16-year old students in Germany for their personal meanings towards mathematics. Although personal meanings may not necessarily represent personal valuing, some of the items in the questionnaire were asking the participants to indicate the extent to which they found particular attributes important—and thus, of value—as shown in Table 7.1 in Chap. 7. These 
would include stimulus statements such as "It is important to me that my family can be proud of my mathematics performance" and "It is important to me that at the beginning of mathematics class, the teacher summarizes the previous lesson".

Although Vollstedt and Duchhardt's chapter does not define values, it acknowledges values as a separate construct, while proposing that "a considerable amount of overlap can be assumed between the concepts and no sharp line of division can be drawn". The concepts referred to include personal meanings, and its conceptual overlap with the notion of values is understandable, given that personal meaning has been taken to denote relevance and personal significance, which thus relate to values' association with worth and importance. Vollstedt and Duchhardt also cited other researchers who regarded "meaning as a generating force for the development of values".

The research work of Bishop (1988), DeBellis and Goldin (1997), and Seah (2005) in the areas of values and valuing in mathematics education has been on identifying attributes of mathematics and its pedagogy which are regarded as being important by students or teachers, examining how these attributes promote a sense of engagement, will, and grit amongst learners, and investigating how teachers might subsequently promote the valuing of these enabling attributes to build engagement, will, and grit amongst the students. Yet, it is interesting that none of these researchers had been referred to in all the chapters here. Even Zonnefeld's reference to DeBellis and Goldin (1997) was related to their framework of affective concepts in general, rather than just on the characteristics of values themselves. In fact, the reference against which she had conceptualised values appears to reflect a view of values being a form of interest: "the value component measured students' views regarding the usefulness, relevance, and worth of statistics in their personal and professional life". Also, Dobie's research with personal values drew on Hill's (1991) definition of values in the general sense.

Instead, the expectancy-value theory which had been introduced by Eccles (1993) into educational research was used by Bofah and Hannula, by Achmetli and Schukajlow, as well as by Dobie. While this theory applies to education generally, its power here has been in facilitating a connection between the constructs of values and motivation, as can be seen in these chapters.

\subsubsection{Valuing Mathematics and Valuing Attributes of Mathematics}

There are two aspects to values and valuing in mathematics education. One is concerned with valuing mathematics, that is, an individual regarding the discipline as important. The other aspect operates independently of the first one, and is concerned with an individual having convictions with particular attributes of the discipline and/or its pedagogy.

Two studies in this section exemplify the first aspect. In one, Zonnefeld's teaching of growth mindset to undergraduates over a period of 12 months resulted in the female 
students valuing statistics much more than their male peers and also performing better than their male peers. This suggests a very significant relationship amongst the variables of values, gender, and performance. That this is in favour of female students further validates the importance of working with the notion of values, in terms of how this approach to mathematics education may empower female students' self-efficacy or confidence in being successful in understanding and performing in mathematics at school. In the other study, Bofah and Hannula's analysis of the 2011 Trends in International Mathematics and Science Study [TIMSS] data (Thomson, Hillman, \& Wernert, 2012) for five African countries included an assessment of students' valuing of mathematics. Importantly, the study found that amongst the various factors analysed, "the association between perceived social support and achievement is accounted for entirely or partly by how the students value and like mathematics". It needs to be mentioned, though, that Bofah and Hannula's notion of mathematics valuing was as a motivational belief in the tradition of the expectancy-value theory, and thus it has some utility flavour.

Individuals' valuing of attributes of mathematics and/or its pedagogy is also evident in this section. In Middleton, Mangu, and Lee's analysis of the responses of some 24,000 United States students when they were in the 9th grade and then when they were in the 11th grade two years later, one of the motivation scales was 'effort'. Here, the extent to which a student emphasises the role of effort in studying mathematics may be regarded as an expression of his/her mathematics educational value, that is, a value that is concerned with an aspect of the process of learning mathematics (Bishop, 1996). In this study, "effort, interestingly decreased across all [four] categories of students, and was especially low for" the group of students who did not intend to pursue a STEM career, and for the group of students who had the intention in the 9 th grade but no longer so two year later.

\subsubsection{The Relevance of Values to Contemporary Mathematics Curriculum Reforms}

An emerging trend of mathematics reforms in recent years has actually brought to the spotlight the significance of researching values. The publication of the 'Principles and Standards for School Mathematics' in 2000 by the National Council of Teachers of Mathematics [NCTM] in the United States had seen the introduction of five process standards alongside the usual content topics. These process standards represent the different ways through which content knowledge might be acquired and applied, and teachers are expected to foster these skills amongst their students. The five NCTM process standards are, namely, problem solving, connections, communication, representations, and reasoning and proof. This curriculum approach of a dual focus on content knowledge and process skills has since been a feature of many an education reforms across the world, such as in Australia, mainland China, Denmark, and Germany. In Australia, the national mathematics curriculum (Aus- 
tralian Curriculum, Assessment and Reporting Authority, 2016) requires schools to teach four identified 'proficiencies strands', namely understanding, fluency, problem solving, and reasoning. The point here is that whether they are called process standards, proficiency strands, or something else, these mathematics learning skills which are being emphasised in contemporary mathematics curricula are considered to be important in relation to learning mathematics well and effectively. That is to say, the Australian mathematics curriculum is requiring teachers to teach students to value understanding, fluency, problem solving, and reasoning at the same time that they are teaching the number line, decimals, symmetry, quadratic equations or probability.

This focus on teaching values at the intended curriculum and beyond is only too timely as we approach a time in human history when artificial intelligence and automation are redefining fundamental job skills in national economies around the world. Acknowledging that we will never be as skilful and efficient as robots and computers at computations and mathematical processing at the workplace an in daily life, (mathematics) education has the responsibility to prepare our next generations to stay relevant and to contribute to the emerging workforce and daily living needs. If soft skills such as teamwork and inclusivity are needed to complement the hard skills which machines and robots excel at, this is where mathematics education can be useful for 'robot-proofing' the human workforce. As should be evident now, these soft skills are also the values which can be nurtured through mathematics. To the extent that such attributes are already being introduced to students through mathematics lessons, we need to understand better how their teaching might be planned deliberately, and/or how it might be executed during class lessons.

\subsection{Comparing Results}

How do the findings represented in this section compare with those derived from related research conducted elsewhere? Wilkie's findings with regards to what upper primary and junior secondary school students in Australia wish for in mathematics learning resonates with the 'What I Find Important (in my mathematics learning)' [WIFI] study which was conducted in economies such as Australia, Hong Kong, Japan, Korea, Macau, Shanghai, and Taiwan in the first half of the 2010s (see Seah \& Wong, 2012). For example, in both Wilkie's study and Kinone, Shinno, and Baba (2013), the valuing of students in the middle years of schooling was found to be different from what students in the senior secondary school years valued, suggesting that different values are associated with different mathematics topics and different cognitive demands while some other values stay the same. Of course, there is also the possibility that during these teenage years, the child's values system is still being consolidated in what Morris Massey (1979) calls the socialisation stage of human values formation.

In another WIFI report, Zhang, Barkatsas, Law, Leu, Seah, and Wong (2016) analysed data collected from 1386 Grades 5/6 students studying in Wuhan (a Chinese 
city), Hong Kong, and Taiwan. The analysed data suggested that these students were valuing achievement, relevance, practice, communication, ICT, and feedback in their respective mathematics learning experiences. Similar between this study and Wilkie's is the positive tone of the values expressed. What is different, however, is that while the Australian students' values were mainly reflective of mastery approaches to goals (as interpreted by Wilkie), there was a balanced mix of mastery and of performance approaches to goal orientations from the students in the three East Asian economies which top such international comparative tests as TIMSS and PISA. Admittedly, neither of these studies were designed to identify if the nature of a student's value is reflective of mastery or performance goal orientations. As such, the research methods used were not designed to determine if East Asian students' valuing of achievement reflect either mastery or performance goal orientation. Yet, the possibility of such a difference in student values between East Asia and Australia may provide another perspective to an understanding of the difference in mathematics performance between East Asia and elsewhere in the world.

Wilkie's data also echoes Grootenboer and Marshman's (2016) findings with New Zealand middle school students, in that fluency with multiplication facts-emphasising the valuing of basic facts — was highly valued amongst the Australian student participants.

One of the findings of Achmetli and Schukajlow's study has been that students' experience with constructing multiple solutions to mathematical problems did not bring about any increase in students' interest in mathematics. This is somewhat surprising, especially given that many researchers (e.g. McLeod, 1992) have conceptualised interest as being easier to manipulate when compared to other affective variables such as beliefs and attitudes.

\subsubsection{Values Alignment}

While both Dobie and Wilkie's studies are more directly related to values in mathematics education, it is also interesting to note that each of them advocates for teacher alignment of student values in their practice. Wilkie ended her chapter by calling for teachers 'to find ways to incorporate students' own suggestions for promoting their engagement, learning, and achievement", which may not be easy to accomplish if what the students value individually represent a wide spectrum of attributes when considered as a class. Some of these values may be in conflict with one another too. On the other hand, Dobie's view was that "teachers can also work to increase alignment with students' values in the classroom". Indeed, values alignment by the classroom teacher is currently being investigated in a follow-up to the WIFI study, called WIFItoo, in Australia. The assumption has been that

values alignment should be regarded as already being part of day-to-day interactions. When individuals come together with their own value systems, they will always need to negotiate about different preferences and intentions to ensure that the interaction is successful. This calls for values alignment to take place, and it does not mean that one party needs necessarily 
to impose his/her/their values to the rest. There can always be middle-path compromises, for example. (Seah, 2018, p. 575)

After all, "all relationships ... are claimed to be strengthened by aligned values" (Branson, 2008, p. 381). How this alignment might be achieved, however, is not yet known, and the WIFItoo study aims to document the various ways in which teachers and their students co-construct values alignment such that productive teaching and learning can take place.

\subsubsection{Values Intervention Programs for Mathematics Classes}

Perhaps reflecting the newness of this research area, the studies in this section-and indeed, in several instances elsewhere as well—are not directly associated with the implementation of values-related intervention programs or education initiatives. Zonnefeld's study, however, is worthy of mention here. In fostering undergraduate classroom environments that support the development of the incremental view of mathematics, a range of affective variables were assessed for changes. At the end of the experimental period, an increase of students' valuing was only one of two statistically significant changes that took place. That female students' valuing increased more than that of their male peers "is a significant finding given the historical underrepresentation of women in mathematics and STEM in general".

Values were also not intentionally examined in the longitudinal study conducted by Middleton, Mangu, and Lee, although student's valuing of effort was evaluated in the study. Over a two-year period, changes in motivation indicators such as identity, interest, and self-efficacy had contributed to volatile changes in students' intention to pursue STEM programs beyond Year 11: "Relatively short-term motivations appear to greatly impact career aspirations. An effort should be made to make STEM curricula continuously attractive in new ways throughout a student's high school education, given the volatility of STEM career intentions". The stability (over two years in this study) of the students' valuing of effort when compared to the other scales surveyed, reinforces the conception that values are very internalised within an individual (see, for examples, Bishop, 1996; Stern, 2000). There are certainly implications here for the mathematics education (research) communities to explore more deeply how the variable of values might be used as a more reliable indicator or predictor of individuals' intentions, decisions, and/or actions in the process of teaching or learning mathematics. 


\subsubsection{Research Methodological Concerns}

As mentioned earlier, amongst the seven studies represented in this section, three might be considered to be researching values, while two other studies dealt with the valuing of mathematics and statistics. The remaining two focused on affective variables such as interest. All seven studies sourced their data from participants who were either in secondary schools or universities. There was no suggestion in the chapters why there was no primary school participant, though it may be argued that for variables such as values which are normally inferred from participant opinions rather than being presented explicitly through actions, a certain level of participant maturity and confidence is needed.

Indeed, the questionnaire method was evident in all the seven chapters, with five of these utilising the questionnaire as the only data source. Accordingly, five of the studies are purely quantitative, although this does not correspond to the five studies which had made use of the questionnaire method only. Wilkie's open-ended questionnaires were analysed qualitatively, for example. At the same time, Dobie had employed mixed methods to analyse her data which were collected through questionnaires, lesson observations, and interviews.

Amongst the studies represented in this section, conclusions about teacher and student valuing appear to be made through analyses of questionnaire responses, except in the case of Dobie's work in which lesson observations provided an additional source of information about the extent to which the students valued the usefulness of mathematics. The valuing of particular attributes, however, needs not necessarily be followed by actions which reflect this valuing. Competing values (see Seah, 2005) may lead to some values being suppressed by other values that are also subscribed to but are more dominant in an individual. Both Halstead and Taylor's (2000) view of values as being general guides to behaviour, and Hill's (1991) tentativeness when writing about values ordering our lives, allow for the competing values narrative.

Perhaps not surprisingly, amongst the chapters in this section, there is a dominance of research that were conducted in Western economies. Of the seven chapters, three were written by researchers based in the USA reporting on American research, two were from Germany, and one from Australia. Even though the remaining non-Western study, conducted by Bofah and Hannula, might be focussed on African nations, the researching was a secondary analysis of TIMSS data and conducted outside Africa. This form of documentation hides the fact that at the international congress whose presentations stimulated the production of this monograph, there were several other research presentations conducted by non-Western researchers and/or conducted in non-Western sites, such as Elizar (Indonesia); Atinuke and Juwe (Nigeria); Felix (South Africa); and Gun \& Bulut and Haser, (Turkey) (Hannula, Morselli, Erktin, Vollstedt, \& Zhang, 2017). Unfortunately, for various practical reasons, these studies are not represented here. This phenomenon is not unique to this event, of course. If we also consider the amount of related research which have been published in nonEnglish language publications, it is easy to imagine that what we get to access from English-language books, reports, journals and magazines constitute only a small 
part of what we collectively know and understand. This is unfortunate, given that the constructs of values and beliefs are highly contextualised in the diverse cultures globally within which they are internalised, activated, and espoused. There are certainly implications as we grapple with the optimisation of the school mathematics learning experiences for refugees, migrants and expatriate children around the world. There is thus a rather urgent need for the international mathematics education community to come together, to collaborate on possible solutions to this issue. In this regard, the kind of cooperation we see in Bofah and Hannula's research and writing is worthy of further exploration by colleagues worldwide. Another potential solution strategy might be for Western researchers to base their academic activities in targeted non-Western cultures, so that there are opportunities for sustained understanding, discussion and reflections by all parties involved.

Thus, from the values perspective, this section has pushed the boundaries of academic knowledge in the field a great deal. The various chapters have reinforced the notion of values as something that is perceived to be of importance and worth (in facilitating mathematics pedagogy). In addition to Bishop's (1996) categorisation of values in the mathematics classroom into mathematical, mathematics educational, and general educational, two of the studies represented in this section suggest that these valuing might manifest as a general valuing of the subject. Values' role in regulating the stability of affective variables such as interest is also suggested by a study here. More practically, what need to be valued by a mathematics student does not have to be the same across grade levels, education systems, and cultures. It might be a case of different values being associated with different mathematics topics and different cognitive demands, while some other values stay the same across the grade levels. It may also be reflecting the experience of a teenager going through values formation. It is also probably unique that students in Australia and New Zealand value basic facts highly. The significant role of values alignment has also been reinforced through the studies represented in this section.

The deeper understanding that is gained through the findings of the studies represented in this section could not have come at a more appropriate time, as the world is witnessing a fast transformation to hybrid intelligence and automation at work and in daily life, which seems to threaten the relevance of learning mathematics at school. A re-focus of the purpose of learning mathematics to one of cultivating values and practising valuing to complement what robots do might just be what is needed to bring about engagement and interest in mathematics amongst students.

\section{References}

Allchin, D. (1999). Values in science: An educational perspective. Science \& Education, 8, 1-12.

Australian Curriculum Assessment and Reporting Authority (ACARA). (2016). The Australian Curriculum: F-10 Mathematics. Sydney, Australia: ACARA.

Bishop, A. J. (1988). Mathematical enculturation: A cultural perspective on mathematics education. Dordrecht, The Netherlands: Kluwer. 
Bishop, A. J. (1996, June 3-7). How should mathematics teaching in modern societies relate to cultural values-Some preliminary questions. Paper presented at the Seventh Southeast Asian Conference on Mathematics Education, Hanoi, Vietnam.

Bishop, A. J. (1999). Mathematics teaching and values education: An intersection in need of research. Zentralblatt fuer Didaktik der Mathematik, 31(1), 1-4.

Bishop, A. (2008). Teachers' mathematical values for developing mathematical thinking in classrooms: Theory, research and policy. The Mathematics Educator, 11(1/2), 79-88.

Branson, C. M. (2008). Achieving organisational change through values alignment. Journal of Educational Administration, 46(3), 376-395.

DeBellis, V. A., \& Goldin, G. A. (1997). The affective domain in mathematical problem solving. In E. Pehkonen (Ed.), Proceedings of the 21st conference of the International Group for the Psychology of Mathematics Education (Vol. 2, pp. 209-216). Lahti, Finland: PME.

DeBellis, V. A., \& Goldin, G. A. (2006). Affect and meta-affect in mathematical problem solving: A representational perspective. Educational Studies in Mathematics, 63(2), 131-147.

Eccles, J. S. (1993). School and family effects on the ontogeny of children's interests, selfperceptions, and activity choices. In J. Jacobs (Ed.), Nebraska symposium on motivation: Developmental perspectives on motivation (pp. 145-208). Lincoln, NE: University of Nebraska Press.

Grootenboer, P., \& Marshman, M. (2016). Mathematics, affect and learning: Middle school students' beliefs and attitudes about mathematics education. Singapore: Springer.

Hannula, M., Morselli, F., Erktin, E., Vollstedt, M., \& Zhang, Q. P. (2017). Topic Study Group No. 28: Affect, beliefs and identity in mathematics education. In Proceedings of the 13th International Congress on Mathematical Education (pp. 507-510). Cham, Switzerland: Springer.

Halstead, J. M., \& Taylor, M. J. (2000). The development of values, attitudes and personal qualities: A review of recent research. Slough, UK: National Foundation for Educational Research.

Hill, B. V. (1991). Values education in Australian schools. Melbourne, Australia: The Australian Council for Educational Research.

Kinone, C., Shinno, Y., \& Baba, T. (2013). International comparative study 'The Third Wave' regarding values in mathematics education (2): Factor analysis on Japanese students' values in learning mathematics. Research Journal of Mathematical Education, 95, 105-112.

Kluckhohn, C. (1962). Values and value-orientations in the theory of action: An exploration in definition and classification. In T. Parsons \& E. A. Shils (Eds.), Toward a general theory of action (pp. 388-433). New York, NY: Harper \& Row.

Massey, M. E. (1979). The people puzzle: Understanding yourself and others. Englewood Cliffs, NJ: Brady.

McLeod, D. B. (1992). Research on affect in mathematics education: A reconceptualisation. In D. A. Grouws (Ed.), Handbook of research on mathematics teaching and learning (pp. 575-596). Reston, VA: National Council of Teachers of Mathematics.

Roccas, S., Sagiv, L., \& Navon, M. (2017). Methodological issues in studying personal values. In S. Roccas \& L. Sagiv (Eds.), Values and behavior: Taking a cross cultural perspective (pp. 15-50). Cham, Switzerland: Springer.

Seah, W. T. (2005). The negotiation of perceived value differences by immigrant teachers of mathematics in Australia. (Ph.D. dissertation). Monash University, Victoria, Australia.

Seah, W. T. (2018). Improving mathematics pedagogy through student/teacher valuing: Lessons from five continents. In G. Kaiser, H. Forgasz, M. Graven, A. Kuzniak, E. Simmt, \& B. Xu (Eds.), Invited Lectures from the 13th International Congress on Mathematical Education (pp. 561-580). Cham, Switzerland: Springer.

Seah, W. T., \& Wong, N. Y. (2012). What students value in effective mathematics learning: A 'Third Wave Project' research study. ZDM: The International Journal on Mathematics Education, 44, 33-43. https://doi.org/10.1007/s11858-012-0391-4.

Stern, P. C. (2000). Toward a coherent theory of environmentally significant behaviour. Journal of Social Issues, 56(3), 407-424. 
Thomson, S., Hillman, K., \& Wernert, N. (2012). Monitoring Australian Year 8 student achievement internationally: TIMSS 2011. Victoria, Australia: Australian Council for Educational Research. Retrieved from http://research.acer.edu.au/timss_pirls_2011/1/.

Thornberg, R., \& Oğuz, E. (2013). Teachers' views on values education: A qualitative study in Sweden and Turkey. International Journal of Educational Research, 59(1), 49-56.

UNESCO. (1979). New trends in mathematics teaching (Vol. IV). Paris, France: UNESCO.

Zhang, Q., Barkatsas, T., Law, H. Y., Leu, Y.-C., Seah, W. T., \& Wong, N.-Y. (2016). What primary students in the Chinese Mainland, Hong Kong and Taiwan value in mathematics learning: A comparative analysis. International Journal of Science and Mathematics Education, 14(5), 907-924.

Open Access This chapter is licensed under the terms of the Creative Commons Attribution 4.0 International License (http://creativecommons.org/licenses/by/4.0/), which permits use, sharing, adaptation, distribution and reproduction in any medium or format, as long as you give appropriate credit to the original author(s) and the source, provide a link to the Creative Commons license and indicate if changes were made.

The images or other third party material in this chapter are included in the chapter's Creative Commons license, unless indicated otherwise in a credit line to the material. If material is not included in the chapter's Creative Commons license and your intended use is not permitted by statutory regulation or exceeds the permitted use, you will need to obtain permission directly from the copyright holder. 
Part III

Engagement and Flow 


\title{
Chapter 11 \\ Intertwinement of Rationality and Emotions in Mathematics Teaching: A Case Study
}

\author{
Marina De Simone
}

\begin{abstract}
In this paper, I will analyse a mathematics teacher's classroom actions using a theoretical framework that tries to bring together the cognitive and affective dimensions, often considered separately. In particular, I will concentrate on the relation between the actions of a teacher, Carla, in her grade nine classroom and her reasons for those actions, through a combined analysis of the language and the emotional elements that accompany her speech. To carry out this analysis, I will combine Habermas' theory of rationality and the concept of emotional orientation developed by Brown and Reid within the research in mathematics related affect. From a methodological point of view, I interviewed the teacher to detect some of her expectations for her teaching decision. To confirm that these expectations I identified a priori are those that actually guide Carla during her teaching practice, I also analysed her classroom activity focusing mainly on her "emotional indicators", namely gestures, facial expressions, emphasis of the words, repetition, and so on. Finally, I examined the lessons more carefully in order to identify intertwinement between the teacher's rationality and emotions.
\end{abstract}

Keywords Mathematics teacher $\cdot$ Decision-making $\cdot$ Rationality $\cdot$ Emotional orientation $\cdot$ Linear equations

\subsection{Introduction}

This paper draws on my earlier research, on how cognition and affect are intertwined in a mathematics teacher's decision-making processes (De Simone, 2015). Decisionmaking is a characteristic feature of teaching since teachers are constantly making decisions within the classroom. Indeed, many authors have recognized that decisionmaking has a crucial role in the work of mathematics teachers. For example, Bishop

\footnotetext{
M. De Simone (凶)

Faculté de Psychologie et des Sciences de l'Education, Université de Genève,

Bd du Pont d'Arve, 40, 1211 Geneva, Switzerland

e-mail: marina.desimone@unige.ch 
(1976) considers decision-making as the activity that is " ... at the heart of the teaching process" (p. 42).

The rationality and emotions of the mathematics teacher are considered in the research described in this chapter as two sides of the same coin. Thus I attempt to go beyond the Cartesian dualism between the res extensa and the res cogitans towards a holistic view of both body and mind. Indeed, the neuroscientist Damasio (1994) speaks in terms of "Descartes' error" in relation to "the abyssal separation between body and mind [...]; the suggestion that reasoning, and moral judgment, and the suffering that comes from physical pain or emotional upheaval might exist separately from the body." (pp. 249-250) Damasio's work supports the view that accounting only for the rationality of the teacher would not allow one to make a complete-or even a valid - analysis of the process involved in teachers' decision-making.

In the first section of the paper, I will explain why and how the original research problem evolved. In particular, I will introduce the theoretical lens I chose for analysing the rationality of the teacher, which started with the work of Habermas. I will then continue to discuss some critical debates around Habermas' approach. This critique enabled me to formulate a kind of rationality in which the affective dimension of decision-making is emphasized, drawing on recent research in mathematics related affect. After describing the methodological choices I made in my research, I will move on to a case study analysis of one grade nine mathematics teacher, Carla whose decision-making will be shown to intertwine both rationality and emotions. In the light of this case study I will then discuss how and why the adopted theoretical framework allows an analysis of teacher behaviour in detail.

\subsection{Theoretical Framework}

Originally, my research aim was to study rationality in the teacher decision-making processes, in the context of discursive activity of explaining linear equations. I set my research in the framework of Habermas' (1998) philosophical theory of rationality, re-elaborated and adjusted to mathematics education (Boero, Douek, Morselli, \& Pedemonte, 2010; Boero \& Planas, 2014). In particular, Habermas speaks of discursive rationality of a rational being involved in a discursive activity. First of all, he defines a rational being as a human being who "can give account for his orientation toward validity claims" (Habermas, 1998, p. 310). Then, he explains that the discursive rationality has three different roots: the knowledge, the action, and the speech or, in a different manner, the knowing, the acting, and the speaking.

At this point, it already became evident that the discursive rationality of the teacher is deeply connected to her decision-making space, because a rational being involved in a discursive activity is a decisional agent. Each root of the discursive rationality is connected to a particular type of rationality: the knowledge is connected to the epistemic rationality, the action is connected to the teleological rationality, and the speech is connected to the communicative rationality. The structure of discourse determines an intertwinement of the knowledge, the action, and the speech "by 
bringing together" the three types of rationality (Habermas, 1998, p. 309). These three types of rationality are inseparable, since a rational being acts in a specific manner to achieve a goal, on the basis of a specific knowledge, and communicating in a precise way. Hence, the three types of rationality are always present in the discursive activity; the only thing an external observer can see is the prevalence of one of the three types over the others. For example, it could be that, in a specific moment of the discursive activity of the teacher, only the epistemic rationality is "visible" and there is no sign of the teleological one.

As Habermas affirms, the epistemic rationality is connected with a specific idea of knowledge that is not in a trivial sense a collection of facts. Habermas explains that, "in order to know something in an explicit sense, it is not, of course, sufficient merely to be familiar with facts that could be represented in true judgements. We know facts and have a knowledge of them at our disposal only when we simultaneously know why the corresponding judgments are true. Otherwise we speak of intuitive or implicit knowledge — of a "practical' knowledge of how one does something" (Habermas, 1998, pp. 311-312). Epistemic rationality requires that we can also give an account of the justification for the knowledge at play. Conversely, someone is irrational when she puts forward her beliefs in a dogmatic way, "clinging to them although she sees that she cannot justify them" (Habermas, 1998, p. 312). By its very nature, the epistemic rationality is deeply entwined with the action and the use of language. For this reason, epistemic rationality is not a self-supporting structure, but it is always combined with action and discourse.

Furthermore, Habermas (1998) speaks of teleological rationality when "the actor has achieved this result on the basis of the deliberately selected and implemented means" (p. 313). Developing this perspective, Habermas affirms that a successful actor has acted rationally when, first, he knows and he is conscious of why he was successful, and then "this knowledge motivates the actor (at least in part) in such a way that he carries out his action for reasons that can at the same time explain its possible success" (p. 314).

Finally, he states that the communicative rationality "is expressed in the unifying force of speech oriented toward reaching understanding" (Habermas, 1998, p. 315). The communicative use of linguistic expressions not only gives a "life" to the intentions of the subject, but also represents the actually occurring communicative state and, furthermore, establishes interpersonal relations with a second person. Once again, the communicative rationality is strictly connected to the epistemic and the teleological ones: "what the speaker wants to say with an expression is connected both with what is literally said in it and with the action as which it should be understood" (p. 315). Hence, this philosophical lens seems to be suitable for analysing the decision-making processes of the teacher through the interplay among the different types of rationality.

However, several philosophers and social theorists have highlighted that, in the development of his theory, Habermas did not take into account the emotional side of human beings. For example, Rienstra and Hook (2006), quoting the philosopher Heller, asserted that "Habermas leaves no room for 'sensuous experiences of hope and despair, of venture and humiliation', accusing him of completely avoiding the 
'creature-like' aspects of human beings" (p. 13). Moreover, Steinhoff stressed that not only will argumentation be used to obtain consensus from the interlocutor about the statements, but all sorts of non-verbal means also play a significant role in the discursive activity. In particular, Steinhoff (2009) affirms that when people conduct discourses "they do try to convince the listener (and for this purpose not all listeners have to be participants in the discourse), but not just with arguments; they also use emotion, rhetoric and all means of achieving strategic influence, and the conflict resolution that discourse might be aimed at does not have to be consensual either (why not, for example, through majority decision?)" (p. 147). Summarizing, emotions are connected to reasoning at every moment, in discerning what is true and what is not and providing justifications of what we are stating.

Putting together Habermas' ideas and the critical debates of them, I posited that affective factors are entwined with those of rationality in the decision-making processes of the mathematics teacher. Hence, the original research aim was enlarged, becoming a study of the intertwinement between the emotional and rational aspects in the decision-making processes of a mathematics teacher. There is a need for theoretical frameworks for articulating how these affective factors might be involved in decision-making.

Research in mathematics education has progressively extended to perceive the existence of a mutual interaction between the affective sphere and cognition in mathematics learning (Zan, Brown, Evans, \& Hannula, 2006). But it was in the field of human neuropsychology that I found the most helpful ideas on the relationship between the affective and the rational sphere, starting with the work of Damasio (1994, 1999). Moreover, while educational research often treated decision-making, reasoning, and processes related to reading, language, and mathematics as detached from emotion and body, Immordino-Yang and Damasio (2007) have shown that "learning, in the complex sense in which it happens in schools or the real world, is not a rational or disembodied process; neither is it a lonely one" (p. 4). For them, emotion is "a basic form of decision making, a repertoire of know-how and actions that allows people to respond appropriately in different situations" (p. 7). This neurological research is also becoming applicable in the field of mathematics education. For example, Brown and Reid (2006) have developed and adapted the hypothesis of somatic markers (Damasio, 1994) for studying the decision-making processes.

Brown and Reid (2006) proposed a theoretical framework grounded on the notion of emotional orientation in order to study the decision-making processes of both the teacher and the students. Their study is significant for my research because of its interest in that particular emotional aspect of human behaviour, which Brown and Reid felt to be neglected, and which they saw as "related to the decision-making that happens before conscious awareness of the decision to be made occurs" (p. 179). Hence, the concept "emotional orientation" allows me to speak of the interconnection between rationality and emotion. In fact, as the words themselves suggest, the "orientation" in a teacher's decision-making processes is "emotional", that is, affected by emotions in a certain way. In fact, the authors refer to the notion of emotional orientation as "the criteria for acceptance of an explanation by members of a community" (p. 181) and they consider emotions to be the foundation of such criteria. 
So the criteria, namely the decisions that for example a teacher takes within the classroom are affected by emotions. To better explain this point, they also recall the somatic markers hypothesis of Damasio (1994), proposing to consider somatic markers proper as a basis for mathematical emotional orientations. Somatic markers are structures that inform our actions and decision-making, pushing us to decide something because "It feels right" in terms of its acceptance in a community. So, emotions related to being right are attached to somatic markers, sets of which constitute emotional orientations. In decision-making, "many possibilities are rejected because they are associated with negative somatic markers" (p. 180), while positive somatic markers imply possible behaviours, being revealed by the decisions of the teacher in the activity. If emotional orientation refers to criteria (decisions) to accept an explanation and if at the basis of the choice of such a criterion there are emotions, then we can see emotional orientation as an aspect linked to emotions when choosing certain criteria (decisions) and not others.

For operationalizing the notion of emotional orientation of a teacher, we need an adaptation in terms of her "set of expectations": the term "expectation" is connected to her "emotions of being right" when she uses specific criteria for accepting an explanation by the class rather than other ones (Ferrara \& De Simone, 2014).

Summarizing, I will investigate the intertwinement of rationality and emotions in the teacher's decision-making processes, drawing on this adaptation of the notion of emotional orientation, analysing the decisions a teacher makes in the classroom through the interplay among the different types of rationality à la Habermas.

My research questions are twofold: how does the use of emotional orientation help us understand the decisions of teachers, and thus complement the Habermasian rationality framework and how might it help us understand why teachers make certain choices in their teaching and not others?

\subsection{Methodology}

This study utilizes data from my doctoral thesis (De Simone, 2015), which involved three teachers and their grade nine classrooms. The students were 14 years old and they studied in a scientifically oriented secondary school in Italy. In particular, I chose to focus on lessons on linear equations because this topic is a crucial component of the Italian national curriculum for high school. It is one of the first mathematical content areas in which the delicate "shift" is made from the arithmetical world to the algebraic one. In this chapter, I will concentrate on one of the teachers, Carla, who has completed a master degree for training other teachers.

Carla was first a priori interviewed about the topic of linear equations. The interview was twenty minutes long and was videotaped with the camera facing the interviewer and the subject. The interviews were transcribed for the analysis. Thereafter, five of her lessons were also videotaped. The teacher utterances and bodily actions were transcribed for data analysis. 


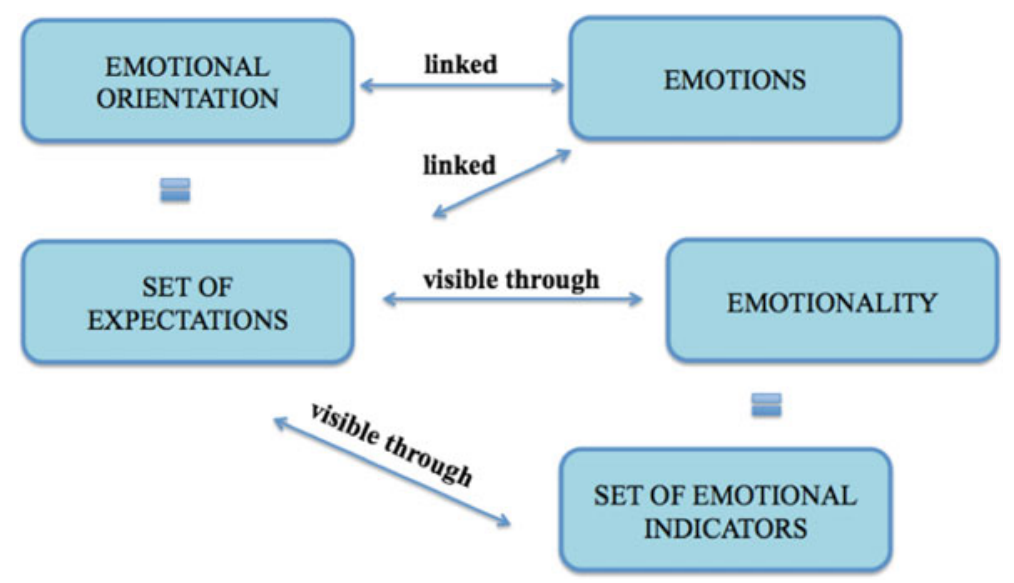

Fig. 11.1 The analytical framework

Concerning the structure of the analysis, I first considered the a priori interview. From what Carla explicitly described to me, I was able to identify some of her expectations with respect to her students. At this stage these expectations were just potential, because it could be that they would not actually drive the actions of the teacher in class. Hence, I also looked at what actually happened in the classroom in order to see if there was a correspondence between what the teacher stated $a$ priori and how she actually behaved in the classroom. For determining whether the expectations were actually reflected in the classroom activity, I looked at the "emotional indicators". In other words, for determining the expectations which the teacher actually reflected in the classroom activities, I observed the gestures, the facial expressions, the emphasis of the words, the repetition, the rhetorical questions, the pauses, the tone of voice, and so on. For example, if a teacher had a very insistent rhythm of words in asking examples, then she actually had the expectation that students would be able to make examples. The emotional indicators informed me about the emotionality of the teachers, where the term emotionality comes from the Penguin Dictionary of Psychology in which it is defined "in terms of behaviours that are observable and theoretically linked to the (hypothetical) underlying emotion..." (Reber et al., 1995). Hence, the expectations of Carla were visible through her emotionality (see Fig. 11.1).

Then, I examined the lessons more carefully in order to identify the intertwinement between the rationality and the emotionality. In particular, I looked at Carla's decisions through the three components of rationality (epistemic, teleological, and communicative) and, looking simultaneously at the emotional indicators and expressions of their expectations, I was able to say something about why she made those decisions and not others.

The emotionality of Carla was revealed by her prosody, her gestures, her facial expressions, her postures, and so on. As her emotionality was found to be always intertwined with her rationality, the teacher emotionality can be interpreted in terms of the Habermasian rationality; as epistemic emotionality, teleological emotionality, and communicative emotionality. 
For example, the epistemic emotionality surfaced when Carla decided to draw on the concept of identity she had already introduced previously and, remaining in a waiting posture, she nodded after confirming that students actually remembered it. Thus, it was not just the kind of knowledge she chose to consider (epistemic rationality), but why she decided to draw on that particular knowledge. The reason is connected to her expectation that the previous knowledge was valid for students and this expectation was made visible through the posture of waiting for something and her nodding after the confirming response by the students.

The teleological emotionality could be highlighted when Carla justified the meaning of solving a linear equation and, at the same time, her voice had the highest pitch corresponding to the word "sense". It was not just the action the teacher made to accomplish a goal, namely justifying the resolution of a linear equation for finding the solution, but also the fact that she had the expectation that the justifications serve to give meaning to what the students are doing. This expectation was made visible through the high pitch of her voice.

The communicative emotionality surfaced when Carla had an insistent rhythm of voice when asking examples. Then, it was not just a matter of the words oriented toward reaching understanding, but also why she decided to communicate with an insistent rhythm. The reason was connected to her expectation that students would be able to make examples and the expectation became clear through the insistent rhythm. Overall, I considered the epistemic emotionality as related to why the teacher used that specific justification of the knowledge at play, the teleological emotionality as related to why the teacher made that action to achieve a goal, and the communicative emotionality as related to why the teacher used that speech oriented towards reaching understanding within the classroom. For pragmatic necessities of analysis, these three types of emotionality could appear to be separated. Nevertheless, it is important to stress that they were always intertwined and present in the discursive activity of the teacher.

\subsection{Data Analysis}

For the topic of equations, Carla started with the definition of an open statement as a logic proposition in which the truth value is determined by the value of one or more independent variables. The open statement contains at least one variable, the value of which is selected within a referring universe set (e.g. $\boldsymbol{U}$ ). The open statement is indicated by a capital letter of the alphabet (e.g. $\boldsymbol{P}$ ) and the variable is indicated in brackets by a lower case letter of the alphabet (e.g. $\boldsymbol{x})$. The open statement $\boldsymbol{P}(\boldsymbol{x})$ can be true or false with respect to the value assumed by the variable $\boldsymbol{x}$, chosen within the universe set $\boldsymbol{U}$. For example, given the universe set $\boldsymbol{U}=\{\boldsymbol{x} \in \boldsymbol{N}: \boldsymbol{x} \leq 20\}$ the open statement $(\boldsymbol{x}): \boldsymbol{x}$ is even, is true for $\{2,4,6,8,10,12,14,16,18,20\}$ and false for the others.

Carla explained what an open statement is in order to show linear equations as open statements in which the verb is "being equal to". This open statement can be 
true for one value ascribed to the variable (determined equation), it can be false for each value of the variable (impossible equation), or it can be true for all the values substituted to the variable (indeterminate equation).

The following passage comes from the a priori interview of Carla in which she spoke about her conception of the role of the previous knowledge of students:

The greatest problem I'm trying to solve - I realised and it's becoming dramatic in the last years - is the problem of the stability of knowledge, in that I feel that in many classrooms, except the good ones, students don't remember what we did and, for me, this is serious. That is, for example, in grade ten, I would like to refer to something that I did before, on which I have even insisted, without having to repeat it entirely (...) the big problem to solve, in that I persist a lot, is being able to find a way for constructing a core (miming a base with her hand), a base of knowledge (miming a list with her open hand), of abilities that stay. For me, aside from time economy -'cause, maybe, it's a bit annoying having always to recall it's really a matter that has to do with cognitive science, I don't know, I wouldn't know how to face it, but it's becoming a general problem, then we should look for (...) the problem is looking for meaningful activities that allow (...) fixing things.

As showed in this brief piece above, for Carla, classroom culture was very important for having knowledge stability. Hence, from what she declared, I identified her expectation of constructing new knowledge from what has been already done in the classroom.

The expectation determined choices, for example, as the next excerpt of Carla's lessons will show (Table 11.1). She recalled the definition of "open statement", for constructing that of equation, as a particular open statement with the verb "to be equal to":

Table 11.1 First excerpt of Carla's classroom activity

1. $\mathrm{T}$ : then, we considered open statements. In general, what is an open statement? [pause, gesture as in Fig. 11.2]

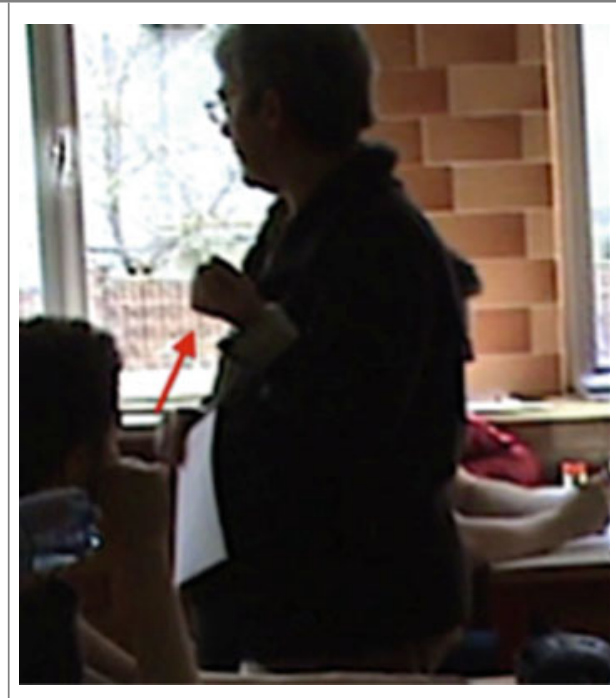

Fig. 11.2 Carla's gesture

2. S10: a proposition that

(continued) 
Table 11.1 (continued)

3. $\mathrm{T}$ : it is a phrase where a variable appears for which, first of all, we have to define [pause and waiting,

Fig. 11.3] what is the universe set, right? Try to answer to the questions I make in order to [Fig. 11.4] summarize. For an open statement, can we say if it is true or false?

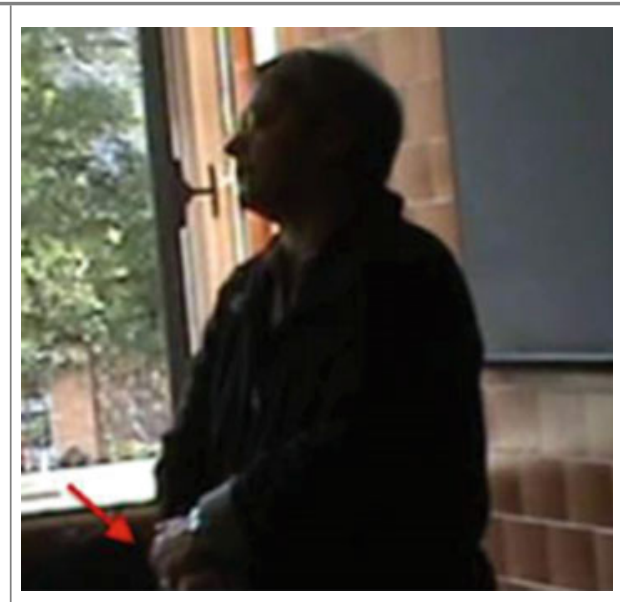

Fig. 11.3 Carla pauses with her hands gathered together

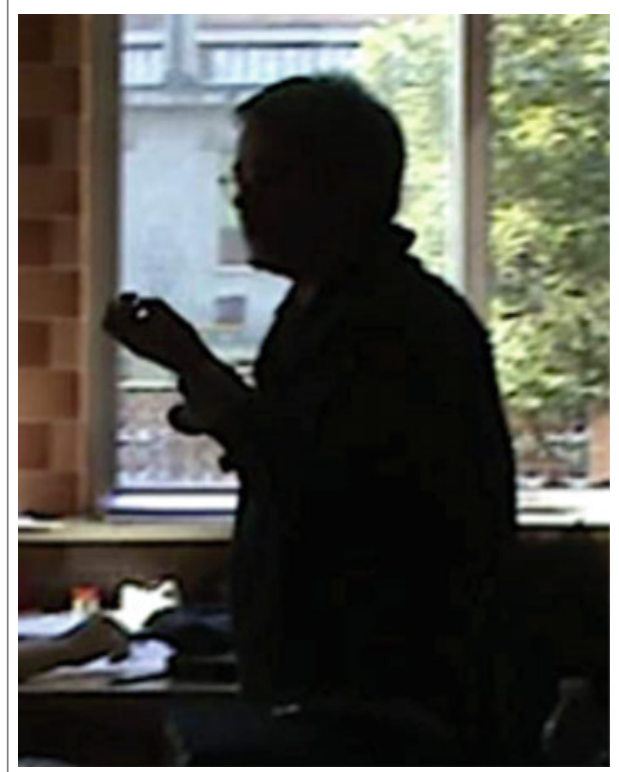

Fig. 11.4 Carla's gesture that conveys the meaning of summarizing

4. Ss: no, we can't say

5. S19: what is the truth set

6. T: [nodding] in general, what do we call the truth set? 
Table 11.1 (continued)

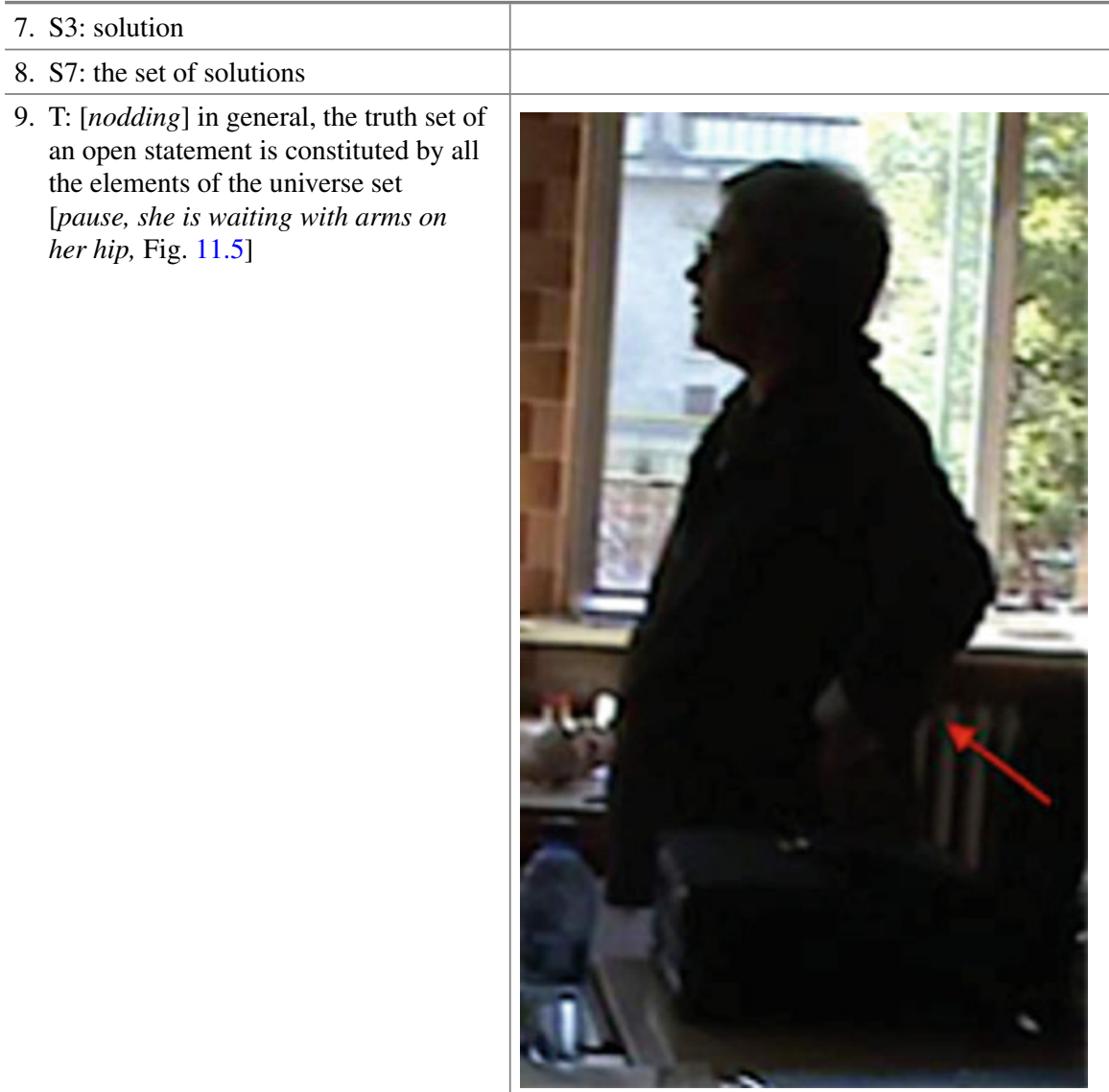

Fig. 11.5 Carla's posture of waiting for an answer from her class

10. S5: that makes true the statement

11. T: that makes it true, then the equations-and this fact had to emerge here-are particular open statements in which the predicate is "to be equal to". Then, as for all the open statements, of an equation [raising her eyebrows], obviously given the universe set, we ask ourselves what is the truth set, that for tradition it is called the set of solutions, and an element of it, it is called a solution. 
Carla focused students' attention on how they have already defined an "open statement". Indeed, she wanted to introduce the concept of equation as an open statement with the predicate "to be equal to". For this reason, she explicitly asked her students what an open statement is. She accompanied this request with the gesture in Fig. 11.2, through which she seemed to hope to have the classroom in her control. Then, she wanted to remind the students of the importance of saying what the referring universe set is. She was waiting for an answer from students as shown in Fig. 11.3 (\#3). She expected someone to say something, because, in the previous part of the lesson, she stressed that for an open statement it is important to specify the universe set. In fact, the statement's truth value depends on the set in which it is defined. At the end, she answered herself with a rhetorical question ("what is the universe set, right?" \#3). Then, she continued, because, probably, she felt confident that the students were aware of this fact. Indeed, the discussion continued and Carla with her students considered what the truth set of an open statement was. Later she was expecting, probably a little irritated (Fig. 11.5: \#9), that students would remember its definition.

Carla's epistemic emotionality was constituted by the knowledge of the concept of an open statement, by the important role of the universe set (rational key), and by her hope that students had already learned the definition of an open statement (emotional key). In particular, she was waiting for a relevant feedback from her students because she had already explained open statements and, probably, she felt that she had been effective in doing that. This emotional key was disclosed, for example, by the gesture in Fig. 11.4; by the posture of waiting for students' response as shown in Fig. 11.5; by the rhetorical question ("what is the universe set, right?") through which it is clear that this knowledge had been already introduced. In fact, it was not necessary to explain it again, but just recalling it with a rhetorical intonation. Carla's teleological emotionality concerned both the recalling what they have already discussed about open statements in order to speak of equations (rational key) and her expectation that it would be sufficient to just review open statements, because she was expecting that students remember them (emotional key). This emotional key was disclosed by the verb "summarize" that comes along with the gesture in Fig. 11.4. This could be seen as a hint of her expectation about the validity of the previous knowledge: it was already known by the students, hence now it was important to answer her questions just to summarize the previous knowledge. As a human being, she could not detach her body from her speech, hence her discourse was full of emotional elements. In particular her speech was accompanied by postures, gestures, and rhetorical intonation which together contributed to her communicative emotionality.

Moreover, in the passage below (Table 11.2), Carla constructs the "properties of linear equations" by referring back to the "law of monotonies ${ }^{1}$ " for equalities that were explained at the start of the year. As will be shown in the next section, students were able to construct this mathematical content themselves, by drawing on their previous knowledge.

\footnotetext{
${ }^{1}$ They are laws related to the substitution property, according to which adding/subtracting the same number to, or multiplying/dividing by it, both sides of an equality does not change the equality.
} 
Table 11.2 Second excerpt of Carla's classroom activity

1. T: Instead [highest pitch] for the
second "law of monotony" [nodding,
she stops in speaking, she bites her
lips and she closes her fist: Fig. 11.6]?

In this brief passage, the teacher was speaking of the second monotony law (\#1). When students constructed that knowledge, she remained - for the whole time-in the same attitude that was constituted by her closed fist, her nodding and tightening her lips (\#1, \#2, \#3, \#4, \#5: Fig. 11.6). Hence, there was an epistemic emotionality from Carla that was not only the knowledge of the "laws of monotony" for equalities (rational key), but also the fact that Carla hoped for her students to remember what they had already done with equalities. This way they could see the analogy to equations, given that she was expecting students to consider equations as open statements of equalities (emotional key). This emotional key was shown, for example, by her emblematic attitude indicated, for example, by her pauses and her nodding 
(Fig. 11.6) when the students, one after the other, jointly constructed the principles of equivalence in \#2, \#3, \#4, \#5. The teacher was engaged in the discursive activity with the class not only from a rational point of view, but also from an emotional point of view: she has hopes, expectations, and also needs. Both these sides were reflected in her speech because a teacher cannot be purely rational only in her discourse. Hence, I speak of the communicative emotionality of Carla. It was disclosed by her posture, her gestures, her stopping in speaking, and the tightening of her lips. This information allows me to say something about why she decided to act in a certain way.

In the a priori interview, Carla spoke of the role of justification in her teaching activity, as can be seen in the following excerpts:

(gesture with joined fingers and she beats on the table) I insist very much on why the letters instead of numbers [...] It is always a discourse to give sense, a meaning to what we are doing.

I always justify the use of letters, I anticipated it a lot, for example when we speak of problems I say that, through letters, we can solve a class of problems, instead of solving a single numerical problem [...] When I treat the resolution of equations, I am very careful of the conscious use of the properties of equations. I'm worried that it is not a mechanical thing.

As shown above, justification was very significant for Carla and, for this reason, I infer that she had an expectation that the justifications are necessary to give sense to what she and her students do.

Moreover, Carla was not just concerned with giving justifications during her classroom activity, but, as can be seen below, she expected that justifying would become an ordinary practice also for the students, in order to give a sense to what they are doing:

(self-confident tone of voice) ah yes, sure, I ask always "let's justify your reasoning" (she begins to gesture), "let's justify your answer", yes, sure, both during the work within the classroom and in the exams in class" [...] (Carla spoke about the national assessment for the middle school). For me, something is evolving in middle school. Many people say that this assessment "falls on the head", but it serves to give meaning to what is being done. Many tasks in this assessment have the question "Explain why", and then students have to expose and justify their reasoning [...]. I make many tests of the type "know" and "know-how"; the "know" is the set of justifications that students give in relation to what they do. Concerning equations, for example, I gave a problem of the type "given an equation, write an equivalent one to it applying just the first principle of equivalence and explain why".

As anticipated above, the teacher not only gave reasons to what she does herself, but, at the same time, she also had the expectation that also her students would feel the need to justify to give sense to what they do.

I found these two expectations on the role of justification contributing to the shaping of Carla's emotional orientation, which was reflected many times during her classroom activity. For example, in the specific passage of her lessons that I'm going to show, Carla gave many equations to her students to solve and she explicitly declared that in order to solve them, they "have to give a meaning to what you read". In different moments, Carla posed her students questions like "How do you justify your answer?", or "Let's justify your answer" (Table 11.3). 
Table 11.3 Third excerpt of Carla's classroom activity

1. $\mathrm{T}$ : There were equations in which you had to find the truth set, treating them as they are, that is as open statements, without making particular calculation, but trying to see which elements make the statement true. Then, in $(x+1)^{2}=81$ and $U=Z$, what did you find?

2. S5: 8; S9:-10; Ss: -9

3. T: the unique way for seeing who is right is trying to substitute. Try to substitute, then pay attention, I have told you that this has to be always kept in mind, that you have to give a [she makes a punctual gesture for stressing the next word "sense" [Fig. 11.7 and pronounces it in the highest pitch] sense of what you read. Then, solving the equation $(x+1)^{2}=81$ means asking if there exists a value $x$ such that doing $x+1$ and squaring it, we obtain 81 , working in [highest pitch and raising eyebrows] $Z$, this should make sense to you that [Fig. 11.8, indicating $x+1$ with fingers $] x+1$, [she inclines her body towards the class] how it has to be?

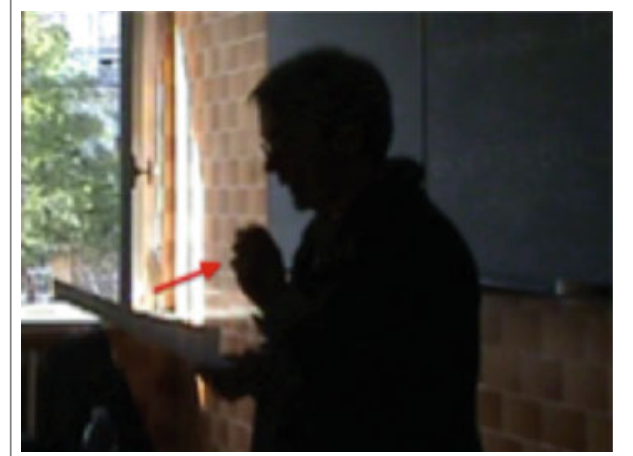

Fig. 11.7 Carla's gesture for stressing the word "sense"

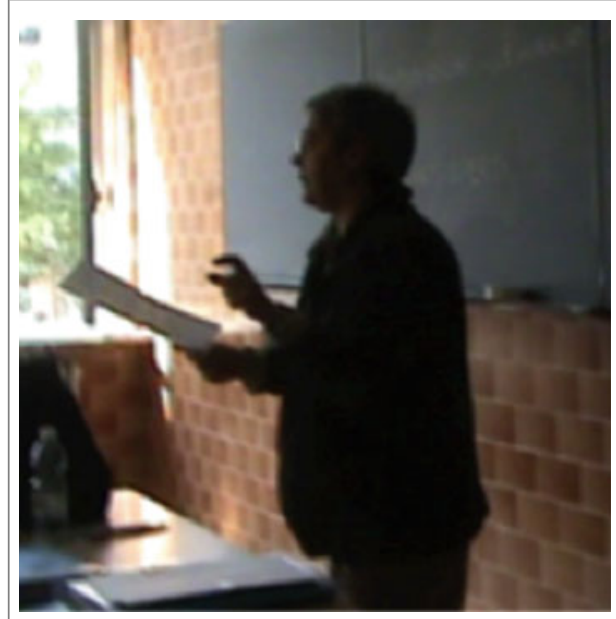

Fig. 11.8 Carla's gesture for referring to a part of the considered equation 
Table 11.3 (continued)

4. Ss: 9 or -9

5. T: How $x+1$ has to be? If it's squared must be [she inclines her body towards the class, Fig. 11.9] 81? $x+1$ must be equal to 9 or -9 because of [pronouncing and raising eyebrows, Fig. 11.10] integers whose square is 81 there is not only 9 but also -9 and then what are the elements?

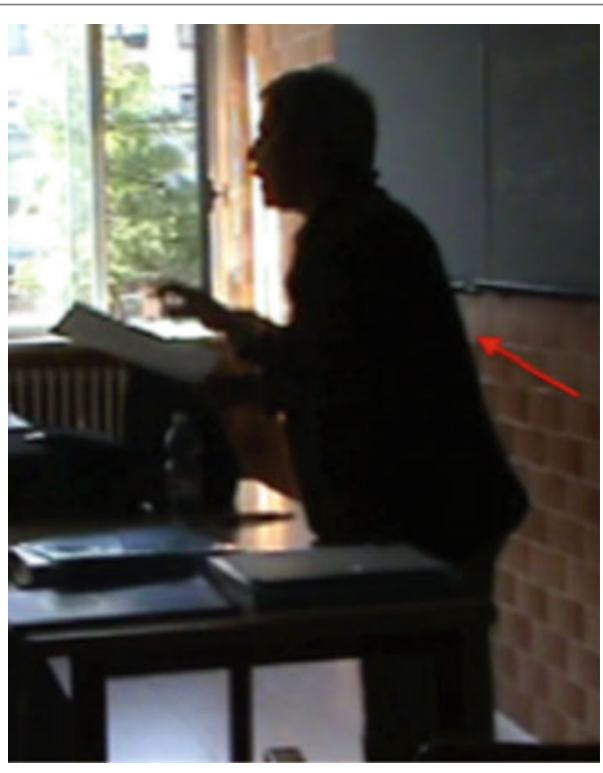

Fig. 11.9 Carla's posture for involving the whole class in the discussion

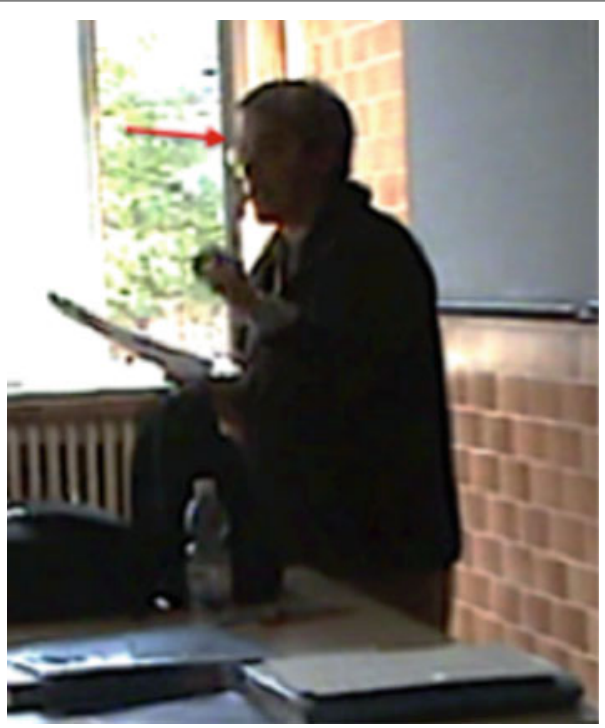

Fig. 11.10 Carla's facial expression

6. Ss: 8 and -10

7. $\mathrm{T}: 8$ and -10 [nodding], and in $(x+5)(x-2)=0, U=Z$, what have you found? 
Table 11.3 (continued)

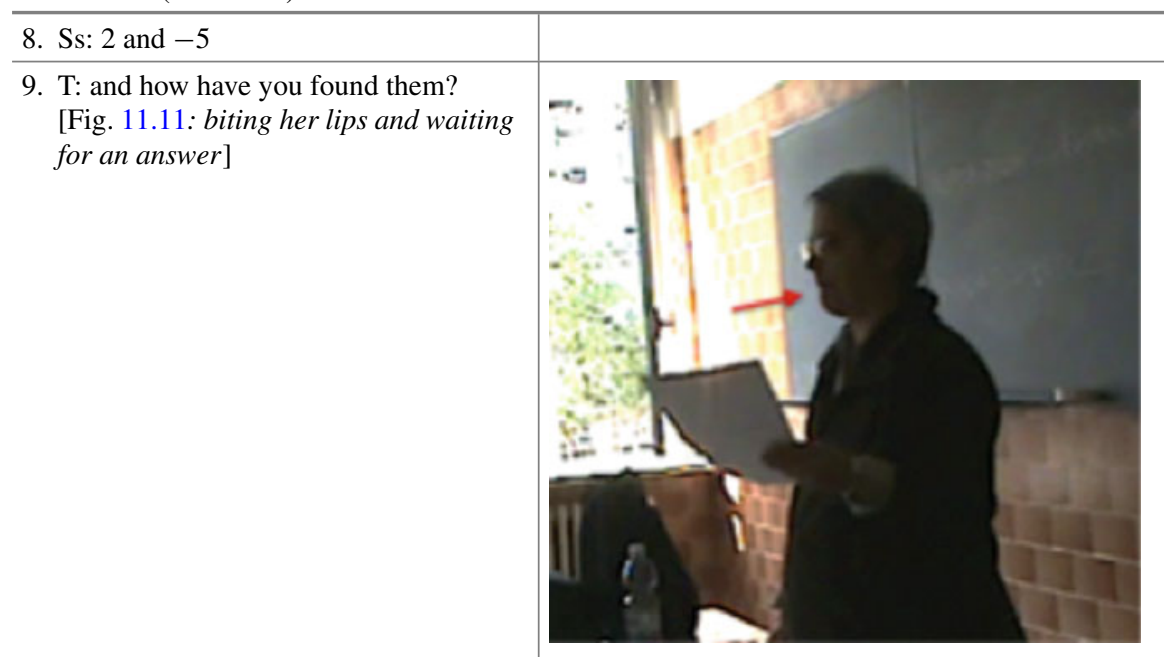

Fig. 11.11 Carla's facial expression when she is waiting for an answer

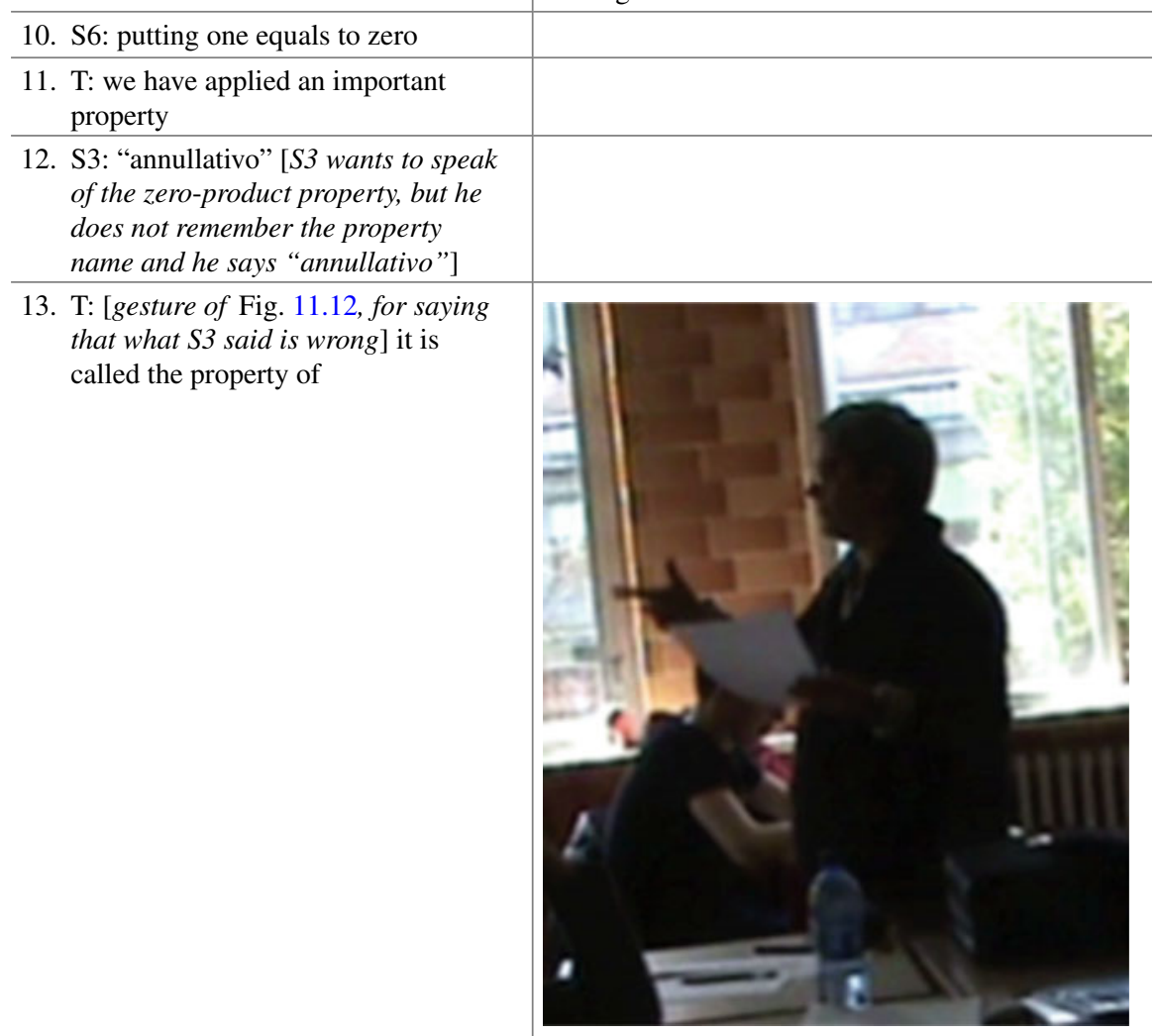

Fig. 11.12 Carla's gesture pointing a student (continued) 
Table 11.3 (continued)

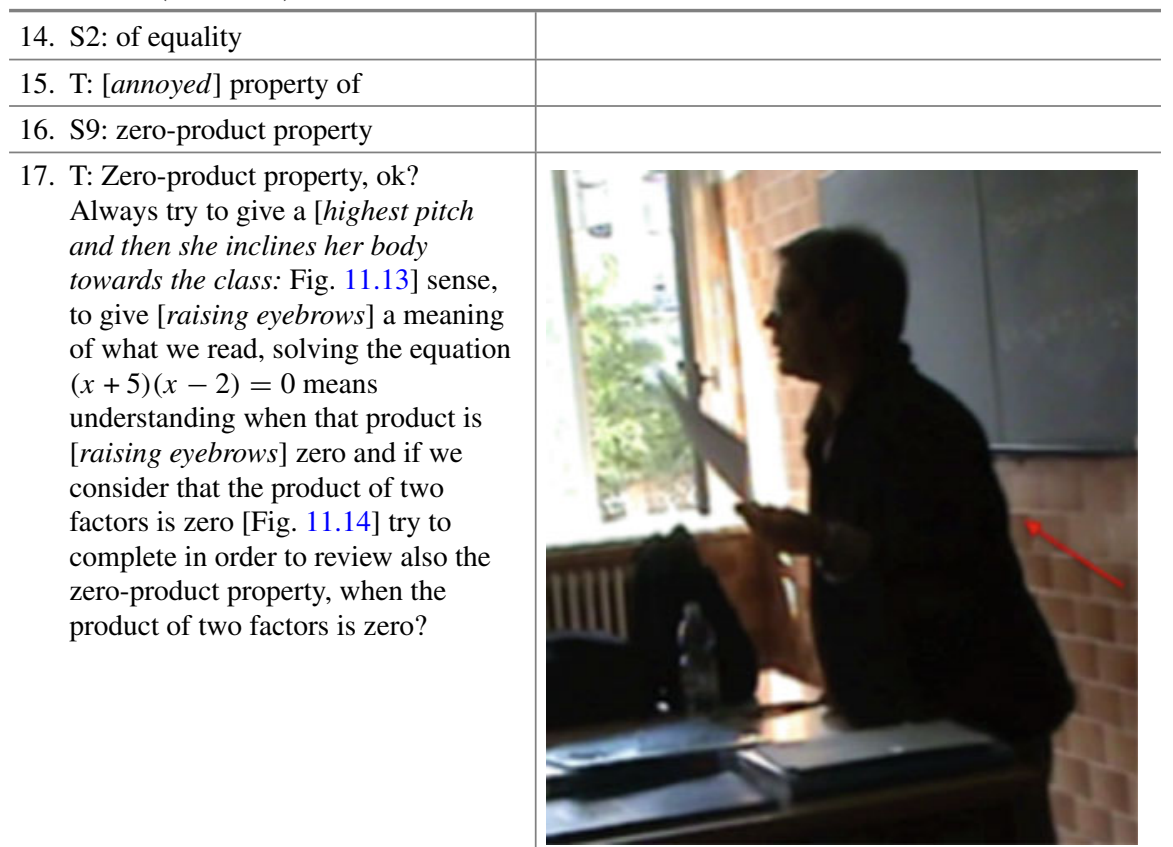

Fig. 11.13 Carla's posture for involving the whole class in the discussion

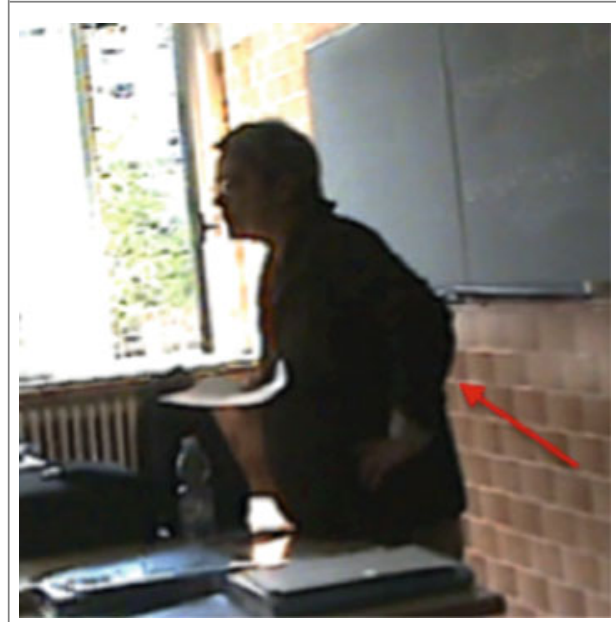

Fig. 11.14 Carla's posture

18. Ss: when one of them is zero

19. $\mathrm{T}$ : [nodding and raising eyebrows] when at least one of them is zero and [pause] vice versa 
Carla discussed with her class an activity in which students had to find the solution set with respect to the assigned universe set. She was very careful in justifying what she did and she required the same attitude from the students. For example, in the case of the equation $(\boldsymbol{x}+1)^{2}=81$, in $\boldsymbol{U}=\boldsymbol{Z}$, there were different opinions among students (\#2). Hence, Carla invited them to substitute the number for the unknown in order to verify who was right (\#3). She explicitly explained what is the meaning of solving the equation $(x+1)^{2}=81$ and she stressed that students had to always keep in mind the sense of what they read or did (\#3). This statement was accompanied by a particular facial expression and a gesture (Fig. 11.7) for emphasizing what she was saying, by her inclining her body towards the class and pronouncing the word "sense" in a higher pitch and with eyebrows raised (\#3). Returning to the example, she repeated what students already said, that is, the solutions of the equation in $\mathrm{Z}$ are 9 or -9 . She stressed why these are the solutions: because 9 and -9 are the only integers whose square is 81 (\#5). This justification came along with her inclining her body towards the class as in Fig. 11.9 and stressing of the word "integers", raising eyebrows again (Fig. 11.10). In the justification of another equation, $(x+5)(x-2)=0$ in $\boldsymbol{Z}$, she explicitly asked students how they had found that solution, expecting an answer, biting her lips as in Fig. 11.11 (\#9). Moreover, when she wanted to justify the resolution of one equation with the zero-product property and the students did not remember it, she seemed annoyed (\#13, \#15). Furthermore, she required the students to recall the zero-product property in order to understand the justification of the resolution of that equation (\#17: In Figs. 11.13 and 11.14 she inclined her body towards the class to encourage a response from the students).

Hence, it is possible to outline the three different natures of the intertwined rationality and emotionality of the teacher. The epistemic emotionality was constituted both by the resolution of a quadratic equation (rational key) and by the fact that she was expecting that students feel the need for justification (emotional key). This emotional key was shown, for example, by her raising her eyebrows and inclining her body towards the class corresponding to a request of justification from the students, and by her biting the lips for waiting for the justification from the students. She was expecting the same behaviour from students also when they did not justify correctly what they had done with an equation. In fact, she seemed very annoyed after the wrong answer (\#15) and she was waiting for them to recall the zero-product property in Fig. 11.14 (\#17). Her teleological component was prompted by the fact that Carla wanted to justify all the solutions of the equation (rational key), but she went further, because she was hoping for the justifications to be giving a sense for what they were doing (emotional key, revealed by her facial expression in Fig. 11.13, and by the pronouncing the term "sense" in a high pitch \#17). Moreover, the teacher's teleological emotionality was seen in a meta-level teleological component that went beyond just clarifying what students were doing. In general, her speech, being emotionally involved, couldn't be neutral and for this reason there were two different aspects in her discourse: from one side there is what she was saying, but, from the other one, there were all the different aspects (gestures, prosody...) that showed her emotional engagement in the discussion. Hence, the teacher had also communicative emotionality. 


\subsection{Discussion and Conclusion}

As shown in the data analysis, I have been able to better understand Carla's decisions through the concept of emotional orientation, operationalized as the set of her expectations. In particular, by identifying the epistemic, the teleological, and the communicative emotionalities, I was able to explain why she decided to put into play that specific knowledge related to equations; why she acted in a specific way for achieving a particular goal; why she spoke in a particular manner within the classroom when she was trying to help her students understand. With the pure rationality à la Habermas, I could have only described the decisions of the teacher, without accounting for their underlying reasons. In this sense, complementing the Habermasian rationality with the affective dimension has given an added value, allowing me to explain the reasons for the teacher's moment-to-moment decisions.

In my doctoral thesis (De Simone, 2015), I analysed many others parts of Carla's lectures, in which her expectations about the stability of the knowledge of the students and about the role of the justification were present. The interesting thing is that these expectations were always visible through the same the emotional indicators (e.g., prosody, facial expressions, and gestures). Hence, it is reasonable to outline a "model" for Carla. For example, Carla recalled previous knowledge when she introduced the definition of a new mathematical concept, for example that of linear equation. Hence, concerning her expectation about the stability of the previous knowledge, she employed the same emotional indicators. In particular, she increased the tone of voice, she pronounced, and she specified with gestures what she wanted her students to recall. Hence, it seems quite clear that she expected her students to have understood the importance of what they have already learned. In addition, she invited students to recall it shortly before the introduction of a new topic, raising eyebrows and gesturing to encourage them to draw on previous knowledge. In particular, she appeared quite irritated when students did not react to her suggestions. Then, her hope that students would remember previous knowledge in order to construct new knowledge by drawing on previously learnt material became visible. In short, she seemed "to pass on" the need of justifying and, simultaneously, she hoped that she was effective in doing it.

Moving on to the role that Carla gave to justification, she showed almost the same emotional indicators. For example, she articulated with emphasis and she increased the tone of voice for what she wanted to justify, she raised her eyebrows and she inclined her body towards the class. Probably, she hoped that her students would understand that she was highlighting the need to justify in order to give sense to what they do. In addition, it appeared quite clear that she expected the same approach from students; in fact, she always inclined towards them as if "to transfer" this need for justification. In particular, she expressed her insistence that students should give a meaning to what they do, waiting for justifications, and being quite irritated when they avoided them.

Summarizing, the activity of the teacher, Carla, was the combined result of both the rational component constituted by her decisions and the emotional component 
constituted by what she was feeling in that precise moment. The latter cannot be prepared a priori. The emotions were triggered by the expectations that Carla had for her teaching. I will use the metaphor of the actor in order to better capture this situation. The actor knows how the story he plays will finish. Hence, the actor is prepared a priori and, when he is playing the story, he has to communicate this to the audience. In the case of the teacher, she also knows where she wants to go, but, unlike the actor, she does not know a priori if she will obtain it, because it depends on how the students react. This fact produces expectations in the teacher and, then, she employs all of her means to reach her aim. The teacher establishes a communicative channel with students in order to have answers of a certain type from them.

Hence, the rationality and the emotionality of the teacher are not separable but coexist in the complex activity of the subject. I do not mean that emotion rules rationality. The teacher does not base her teaching just on her sensibility, nor just on her passion. It is the combination of the rational and emotional sides that will allow her to obtain efficient results.

\section{References}

Bishop, A. J. (1976). Decision-making, the intervening variable. Educational Studies in Mathematics, 7(1-2), 41-47.

Boero, P., Douek, N., Morselli, F., \& Pedemonte, B. (2010). Argumentation and proof: A contribution to theoretical perspectives and their classroom implementation. In Proceedings of the 34th PME Conference (Vol. 1, pp. 179-204). Belo Horizonte, Brazil: PME.

Boero, P., \& Planas, N. (2014). Habermas' construct of rational behavior in mathematics education: New advances and research questions. In P. Liljedahl, C. Nicol, S. Oesterle, D. Allan (Eds.), Proceedings of the 38th PME and PME-NA Conference (Vol.1, pp. 205-235). Vancouver, Canada: PME.

Brown, L., \& Reid, D. A. (2006). Embodied cognition: Somatic markers, purposes and emotional orientations. Educational Studies in Mathematics, 63(2), 179-192.

Damasio, A. (1994). Descartes' error. New York, NY: Avon Books.

Damasio, A. (1999). The feeling of what happens: Body and emotion in the making of consciousness. San Diego, CA: Harcourt.

De Simone, M. (2015). Rationality in mathematics teaching: The emergence of emotions in decisionmaking (Doctoral dissertation). Dipartimento di Matematica "Giuseppe Peano", Torino, Italy. https://iris.unito.it/handle/2318/1509078?mode=full.300\#.W5YvHlcYHUo.

Ferrara, F., \& De Simone, M. (2014). Using Habermas in the study of mathematics teaching: The need for a wider perspective. In P. Liljedahl, C. Nicol, S. Oesterle, D. Allan (Eds.), Proceedings of the 38th PME and PME-NA Conference (Vol. 1, pp. 223-228). Vancouver, Canada: PME.

Habermas, J. (1998). On the pragmatics of communication. Cambridge, MA: MIT Press.

Immordino-Yang, M. H., \& Damasio, A. (2007). We feel, therefore we learn: The relevance of affective and social neuroscience to education. Mind, Brain, and Education, 1(1), 3-10.

Reber, A. S., Allen, R., \& Reber, E. S. (1995). The Penguin dictionary of psychology. New York, NY: Penguin Press.

Rienstra, B., \& Hook, D. (2006). Weakening habermas: The undoing of communicative rationality. Politikon, 33(3), 313-339.

Steinhoff, U. (2009). The philosophy of Jürgen Habermas: A critical introduction. Oxford, UK: Oxford University Press. 
Zan, R., Brown, L., Evans, J., \& Hannula, M. (2006). Affect in mathematics education: An introduction. Educational Studies in Mathematics, 63(2), 113-121.

Open Access This chapter is licensed under the terms of the Creative Commons Attribution 4.0 International License (http://creativecommons.org/licenses/by/4.0/), which permits use, sharing, adaptation, distribution and reproduction in any medium or format, as long as you give appropriate credit to the original author(s) and the source, provide a link to the Creative Commons license and indicate if changes were made.

The images or other third party material in this chapter are included in the chapter's Creative Commons license, unless indicated otherwise in a credit line to the material. If material is not included in the chapter's Creative Commons license and your intended use is not permitted by statutory regulation or exceeds the permitted use, you will need to obtain permission directly from the copyright holder.

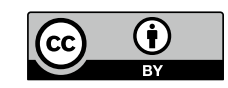




\title{
Chapter 12 \\ Teachers' Classroom Engagement Structures: A Comparative Study of a Novice US and an Experienced UK Mathematics Teacher
}

\author{
Deena Khalil, Elizabeth Lake and Ayanna Johnson
}

\begin{abstract}
This chapter describes the 'in-the-moment' affect of one novice and one experienced teacher by building on the contributions of Goldin, Epstein, Schorr, and Warner's (2011) 'engagement structure' archetypes. The two case studies depict the powerful mathematical affect exhibited whilst teaching by describing a constellation of interacting strands within each structure. Findings reveal that engagement structures, first theorised for students, may be inferred from observations across different demographic and professional teaching contexts. We believe the value of engagement structures is in helping teachers notice how their 'in-the-moment' behaviour as mathematics teachers may mirror the 'in-the-moment' behaviour of their mathematics learners. We suggest engagement structures offer a lens for examining teachers' affective states, and the role the affective domain can play in teacher education and professional development.
\end{abstract}

Keywords Emotions • Engagement structures • "In-the-moment" affect • Mathematics teaching $\cdot$ Teacher professional development

\subsection{Introduction}

Policymakers, politicians, and practitioners agree that one of the most important inschool relationships students have access to are teachers, and research supports this notion (Hill \& Ball, 2009; Planke \& Condliffe, 2013). The issue of teacher recruitment and retention, and the myriad of factors affecting teachers', $\mathrm{p}$ job dissatisfaction then, is important (Au, 2007; Collie, Shapka, \& Perry, 2012; Haberman, 2005).

D. Khalil $(\bowtie) \cdot$ A. Johnson

Howard University, 2400 Sixth St. NW, Washington, DC 20059, USA

e-mail: deena.khalil@howard.edu

E. Lake

Institute of Education, University College London, 20 Bedford Way, Bloomsbury, London,

WC1H 0AL, UK

e-mail: elizabeth.lake@ucl.ac.uk

University of East Anglia, Norwich Research Park, Norwich, NR4 7TJ, UK

(C) The Author(s) 2019

M. S. Hannula et al. (eds.), Affect and Mathematics Education,

ICME-13 Monographs, https://doi.org/10.1007/978-3-030-13761-8_12 
Mathematics teachers are no exception, with many leaving teaching within their first few years (Ingersoll \& Perda, 2010; Liu, Rosenstein, Swan, \& Khalil, 2008). One reason for teacher attrition is teacher burnout and stress (e.g. Kyriacou, 2001), where such conditions are linked to negative teacher affect (e.g. stress, low self-efficacy) and engagement with their environment. Scholars have argued that an individual's affective well-being in organisations can lessen burnout and job dissatisfaction whilst improving engagement and retention (Carmack, 2014), particularly among teachers (Parker, Martin, Colmar, \& Liem, 2012).

Therefore, an area worth considering is teachers' affect (Gee, 2002; Goldin, 2014; Moore, 2008); particularly among mathematics teachers. Some scholars have described how mathematics teachers may experience more and comparatively stronger emotions (e.g. mathematics anxiety, low self-efficacy) compared to other teachers (Bursal \& Paznokas, 2006; Goldin, 2014). Others, like Liljedahl (2005), suggest that teachers who are more attentive to their affective domains also experience change in their attitude and beliefs towards mathematics topics, possibly resulting in higher confidence in their mathematical ability. This mimics a similar finding reported by DeBellis and Goldin (2006) when they examined, by observing students, behaviours and emotional expressions during various mathematical tasks. They suggest that participants who could recognize their affect, and who could develop metaaffect within themselves, were able to unlock confidence in their mathematical ability. If within mathematics education our agenda is to describe the essential components of powerful affect within learning environments, where powerful implies a productive and potentially more adaptive outcome (Goldin, 2014), then examining teacher inthe-moment emotions in relation to mathematics classroom experiences is essential; such examination may identify where affect has the potential to be used to develop meta-affective traits in teachers, which in turn may have an indirect positive influence on students' in-the-moment emotions and confidence as well.

One possible way to infer teachers' 'in-the-moment' affect is through observations of teachers practicing in both controlled clinical experiences in teacher preparation programmes (Dieker, Hynes, Hughes, \& Smith, 2008) and within the chaotic dynamics of everyday classrooms (Meyer \& Turner, 2006; Schorr \& Goldin, 2008). Though the observation of mathematics as an emotionally challenging endeavour is well established, Bibby (2002) noted that the exploration into the connection between emotion and learning is much more recent. Some of the most recent research comes from other disciplines. For example, there is growing recognition within neuroscience of the importance of emotion within corporal responses to cognitive processing. Emotions acts as a trigger for and driver of cognitive development (Brown \& Reid, 2006; Dalgleish \& Power, 1999; Damasio, 2006; Drodge \& Reid, 2000). Other recent research recognises that difficulties in learning mathematics in context have more complex roots than simply addressing teaching as activating cognitive procedures or learning concepts (Calvo \& D'Mello, 2011). For example, Titsworth, McKenna, Mazer, and Quinlan (2013) talk about exposure to positive emotions as better for supporting recall, whilst Mottet and Beebe (2002) suggest that affect directly determines time spent on a task. 
While we know that teachers can inspire and motivate students to engage with mathematics (Zeldin \& Pajares, 2000), what is not yet sufficiently researched is how such emotions as experienced by teachers may influece their behaviours when engaging with students during daily interaction. Whilst there are numerous quantitative studies that document factors that influence teachers' affective traits (e.g. self-efficacy studies), few studies examine them qualitatively (Goldin, 2014). Fewer still examine "in-the-moment" affective states, and possible links between affective states and their relationship with the praxes of teaching (Hagenauer, Hascher, \& Volet, 2015; Khalil, Hughes, Gosselin, \& Edwards, 2016). One of the reasons why emotion as a state is rarely examined is the complexity of inferring them during a teaching context. More specifically, the issue of the hidden nature of emotions makes research highly interpretive. Fenton-O'Creevy, Soane, Nicholson, and Willman (2011) posited that "applied empirical work in field settings [on emotion] has been limited" (p. 1045), because researchers attempting to tackle the issue found it difficult logistically, as the fluidity of communication between teacher and student has multiple agendas and levels.

In this paper, we propose using engagement structures (ES) to explore teachers' emotions whilst in action (Goldin et al., 2011). First inferred from observing students solve algebraic and calculus mathematical problems using SimCalc software, the construct of ES is intended to provide a comprehensive tool by which to examine the affective dimension of learning (Schorr \& Goldin, 2008; Schorr, Epstein, Warner $\&$ Arias, 2010). In this paper, we use this model of ES to describe the affective dimension of teaching. In the following paragraphs, we describe the ES that were inferred from the teaching practices of two mathematics teachers: Mykia, a novice teacher, who 'rehearses' an upper elementary school mathematics lesson twice as part of her lesson study, and Adam, an experienced high school teacher in the UK. These are the first and second cases respectively.

We sought to use the differing cases of Mykia and Adam because we wanted to propose that, despite the dissimilarity in contextual factors and temporal levels of teacher education experience (elementary vs. secondary, United States vs. United Kingdom, urban vs. rural, novice vs. experienced, Black female vs. white male), engagement structure archetypes may indeed be inferred from the act of teaching as well as learning mathematics regardless of such differences. As critical instance case studies, the examples of Mykia and Adam allow for thorough investigation of specific instances of a phenomenon and can provide answers to questions raised about possible assertions through detailed study (Gerring, 2017). Thus, we chose these critical instances that investigated the teaching differences between Mykia and Adam to "[in]form an essential part of a teacher's identity in terms of ... personal development" (Goldin, Rösken, \& Törner, 2009), informing us of the possible ways teachers' affective positioning can influence sociomathematical norms and practices. Mykia exemplifies a teacher candidate whose affect alters her practices noticeably over time, whilst Adam represents how such changes in affect may become less noticable once elements of classroom practice are experienced. We precede these cases with a literature review to further juxtapose the similarities and differences of 
the two cases, in an attempt to provoke discussion about the in-the-moment affect of the two teachers as they teach mathematics lessons.

\subsection{Perspective and Conceptual Framework}

This enquiry is grounded in two bodies of literature, the first on the theory of ES that relates the role mathematical affect has on one's 'doing' mathematics as a learner (Goldin, 2014; McLeod, 1994). The second is on the professional dimensions of teacher's learning trajectory and practice (Borko, 2004).

First, we build on Goldin and colleagues' work (Goldin, 1998, 2000; Goldin, Epstein, and Schorr, 2007; Schorr \& Goldin, 2008; Schorr et al., 2010) that led to their theory of ES. An ES is characterised as a "behavioural/affective/social constellation," that situates and describes "in-the-moment" states that individuals experience when interacting with mathematics as problem solving (Goldin et al., 2011, p. 549). The original nine ES are archetypes, identified as Get the Job Done, Look How Smart I Am, Check This Out, I'm Really Into This, Don't Disrespect Me, Stay Out Of Trouble, It's Not Fair, and Let Me Teach You. Each ES is composed of 'in-the-moment' and stable affective components called strands (e.g. goal or motivating desire, affective pathways, expression of affect, meanings encoded by emotions, meta-affect, self-talk or inner-speech; p. 549). These structures begin with a learners' emotional pathways, and archetype the corresponding behavioural dynamics. Goldin and colleagues' earlier work on systems of affective representation evolved from mapping emotional sequences (affective pathways) whilst solving mathematics problems, to considering a problem solver's emotions about emotions (meta-affect; Schlöglmann, 2006).

Most scholars researching affect focus on individual affective traits, such as selfefficacy, values and beliefs (DeBellis \& Goldin, 1997, 2006; Schlöglmann, 2006; Weber, 2008). For example, Weber's (2008) research collected data by occasional interview over several months, and therefore reveals more about longer-term affect. These researchers build on prior substantial psychological research that indicates that expression of positive emotions whilst communicating is supportive of engagement within a broader understanding of behaviours, as 'ways of being' (Schutz, Hong, Cross, \& Osbon, 2006). Such research positions emotions as ways for learners to gain satisfaction, and are associated with identified primary emotions. One notable associated shift in this research is from Liljedahl (2005). He found that restoring a productive pathway needed only one event (e.g. the 'Ah-ha!' moment) rather than repeated events as Goldin had suggested earlier. If such 'Ah-ha!' moments are indeed pivotal, then one may hypothesize that exploring one's rapidly changing "in-themoment" affective states (demonstrated via external expressions of emotions, such as facial expressions, body language, exclamations, etc.) may hold the potential to be an important point of reflexivity and overall satisfaction for teachers engaged with mathematics. However, the literature has been relatively silent on any examination of the temporal emotive dimension in learning environments, and particularly for 
teachers with different experience levels and across a myriad of teacher education contexts and venues.

Secondly, we drew on literature that situates teachers' practice and behaviours as part of their learning trajectories and continuous professional development as a means of improving teaching practice (Desimone, 2009). Teacher professional development is a process that addresses both teachers' developmental progression and their instructional practice, as they both intersect (Flores, Park, \& Bernhardt, 2016). Teacher instructional behaviours have three dimensions: affective, cognitive, and motivational. Internal framings of teacher practices, and behaviours, are rarely guided by what they know (cognitive domain), but more by what they feel (affective domain) or need (motivational domain; Korthagen, 2016). In this kind of research, teacher behaviours relate to fixed affective traits like (conscious and unconscious) beliefs, attitudes, and values (Goldin, 2014; Lazarus, 1991), or how such emotional traits relate to teachers' needs or motivational desires (Goldin, 2015; Mansfield \& Volet, 2010). However, external framings of teacher behavioural practices are mediated by their own history and disposition as learners (Hollingsworth, 1989; Zeichner \& Gore, 1990) and teachers (Borko, 2004), as well as their sociocultural and sociopolitical contexts, be it at classroom, school, or district level (Darling-Hammond \& McLaughlin, 1999) or because of accountability conditions at these multiple levels (Desimone, 2009; Spillane, Halverson, \& Diamond, 2004).

Scholars utilizing a situated view of learning environments often seek to gain a deeper understanding of affect (Borko, 2004; Greeno, Collins, \& Resnick, 1996; Lave \& Wenger, 1991) from a sociocultural (Cobb, 1994; Kelly, 2006), socio-political (Borko \& Putnam, 1996; Cohen \& Ball, 1990), and socio-mathematical standpoint (Patrick, Ryan, \& Kaplan, 2007). For example, Verner, Massarwe, and Bshouty (2013), in applying ES to their teacher candidates' affect while problem solving in a mathematics methods course, added a new structure based on their candidates' values and beliefs, and called it 'Respect My Culture.' Indeed, numerous scholars have opined on the importance of socio-cultural dynamics behind classroom transactions; respect, for instance, has been a posited as a key tenet for establishing equitable and engaging environments (Delpit, 1995; Freire, 2005; Milner et al., 2003; Nieto, 2003). In fact, "warm demand," is a teaching practice often associated with nondominant teachers' dispositions of both offering respect, and demanding it (Cooper, 2003; Gregory \& Weinstein, 2008; Howard, 2001; Kleinfeld, 1975; Monroe, 2005; Ware, 2006).

The versatility and potential of ES as a tool for modelling teacher professional development is important. Indeed, our future intention is to develop such a model in response to Goldin's (2014) call for "research-based professional development of mathematics teachers that addresses the affective domain." (p. 410). In an effort to pursue this, in this paper we aim to examine the original ES model as proposed for students in 2011 by Goldin and colleagues in two ways. First, we considered the model's potential as applicable to different internal and external framings of mathematics teaching environments. For example, Lewis (2013) and Verner et al. (2013) have already demonstrated ES's degree of portability out of the US city context and within K-12 and post-secondary mathematics classrooms. Secondly, 
Table 12.1 An example of one of Goldin et al.'s (2011) engagement structures in tabular form

\begin{tabular}{|c|c|c|c|}
\hline ES & Key strands & Description & Additional information \\
\hline \multirow[t]{5}{*}{$\begin{array}{l}\text { Get The Job } \\
\text { Done (GJD) }\end{array}$} & Desire & $\begin{array}{l}\text { To complete an assigned } \\
\text { mathematical task } \\
\text { correctly, following given } \\
\text { instructions, thus fulfilling } \\
\text { an implied obligation. } \\
\text { "The motivating desire } \\
\text { for task completion in Get } \\
\text { the Job Done may evoke } \\
\text { more procedural, } \\
\text { time-efficient strategies or } \\
\text { algorithms." (p. 552) }\end{array}$ & $\begin{array}{l}\text { Belief that mathematics } \\
\text { is mainly procedural, } \\
\text { answer orientated and } \\
\text { rule governed, requiring } \\
\text { thoroughness, with given } \\
\text { directions from an } \\
\text { authority. Meeting } \\
\text { expectations and } \\
\text { compliance are valued }\end{array}$ \\
\hline & Need & $\begin{array}{l}\text { What Murray calls } \\
\text { deference: "to yield to the } \\
\text { influence of an allied } \\
\text { other." (p. 154) }\end{array}$ & \multirow{4}{*}{$\begin{array}{l}\text { Get The Job Done allows } \\
\text { a person "with such } \\
\text { beliefs to use his } \\
\text { knowledge to complete } \\
\text { the task procedurally, if } \\
\text { possible; to ask for } \\
\text { step-by-step help..., and } \\
\text { to detach from further } \\
\text { cognitive engagement, all } \\
\text { without calling his } \\
\text { beliefs into question." } \\
\text { (p. } 557 \text { ) } \\
\text { One may set out to Get } \\
\text { The Job Done, but notice } \\
\text { along the way that he } \\
\text { understands something } \\
\text { another person does not. } \\
\text { Initially, Let Me Teach } \\
\text { You becomes active in } \\
\text { task completion. The } \\
\text { imparting of } \\
\text { understanding becomes } \\
\text { the major motivating } \\
\text { desire, with the goal of } \\
\text { simply completing the } \\
\text { assigned task no longer } \\
\text { salient: Get The Job } \\
\text { Done has branched into } \\
\text { Let Me Teach You }\end{array}$} \\
\hline & Evoked by & Being given directions. & \\
\hline & Behaviour & $\begin{array}{l}\text { "Oriented toward } \\
\text { straightforwardly carrying } \\
\text { out the work. In group } \\
\text { work, others may be } \\
\text { enlisted in this goal." } \\
\text { (p. 553) }\end{array}$ & \\
\hline & Emotional satisfaction & $\begin{array}{l}\text { From fulfilling the } \\
\text { obligation through task } \\
\text { completion, not } \\
\text { necessarily from } \\
\text { mathematical learning. } \\
\text { Different ES may evoke } \\
\text { different meta- affective } \\
\text { responses. For example, } \\
\text { when Get The Job Done is } \\
\text { active, frustration is likely } \\
\text { to be experienced and } \\
\text { related to fulfilling the } \\
\text { motivating desire }\end{array}$ & \\
\hline
\end{tabular}


a wider aim is to explore any mapping of emotions between teacher and student, as patterns emerging for any individual might act to facilitate or block the experience of emotions (for teachers and for students) as engagement is a bi-directional transaction between them (Boykin et al., 2011). In other words, studying teachers in action may offer a means of exploring how teacher affect relates to classroom 'transactions' between teachers and learners (Boykin et al., 2011). Exploring the compatibility of the ES model for this purpose is a crucial first step. In the first study, we drew our cases from how the inferred ES were activated and how they interacted. In Table 12.1 we summarize examples of how the ES of Get the Job Done can be activated, as this ES is central to the descriptive cases of both Mykia and Adam (for more details on other ES see Goldin et al., 2011 and Schorr et al., 2010).

It is important to note that unlike affective traits, affective states are by no means static, thus ES are similarly not static although at any one moment there is a dominant emotionally directive one (Goldin et al., 2011). Thus though the existing ES model applies to teachers (see Lake \& Nardi, 2014), as we will demonstrate through the cases of Mykia and Adam, there may also later prove to be significant differences in what positions are available, and hence which ES are accessible within mathematics teacher identities.

\subsection{Methodology}

\subsubsection{Research Question}

The primary question driving this paper is: in what ways can the description of teachers' activated ES be used as a tool to examine the powerful mathematical affect teachers demonstrate when teaching across different mathematics classroom environments?

\subsubsection{Study Design}

In this paper we draw on two studies that sought to explore mathematics teachers' praxes and affect. The first study sought to explore novice teachers' affect as part of their clinical practice (Dieker, Rodriguez, Lignugaris-Kraft, Hynes, \& Hughes, 2014). Twenty-one novice teachers (NTs) were observed (18 females; 3 males; all African-American). These novice teachers were enrolled in the third year of an elementary mathematics education practicum methods course which included 32 hours of clinical practice, at a Historically Black University in the United States. As part of a modified "lesson study" (Puchner \& Taylor, 2006), the teacher educators collaborated with novice teachers to design a 90-minute lesson based on fractions that aligned with the Common Core State Standards of Mathematics. Fractions have been 
proven to be a conceptually challenging topic for elementary teachers (Lee \& Boyadzhiev, 2013), and researchers have shown that assigning the topic for rehearsals allows novice teachers to focus on how to teach as opposed to what to teach (Dieker et al., 2014). The NTs were asked to design their lesson using the 5-E Learning Cycle (Bybee, 2015), and based on feedback from the teacher educator on the lesson plan, NTs revised and then selected 15 min of what they considered to be engaging instruction to rehearse in TeachLivE ${ }^{\mathrm{TM}}$ whilst being video-taped. Rehearsing in a simulated classroom environment like TeachLivE ${ }^{\mathrm{TM}}$ (Dieker et al., 2008), a mixed-reality classroom setting where a teacher can practice instruction strategies by engaging with students presented as avatars. TeachLivE ${ }^{\mathrm{TM}}$ allows teachers to rehearse instruction in a 'safe' environment, where circumstances are more controlled by the simulator to elicit emotional responses and behaviours from the teacher (Dieker et al., 2014). For example, the 'urban' level exhibited in the TeachLivE' evoke teachers' responses to student avatars who offer a degree of scepticism and dissent, engaging in questioning and exhibiting more expressive behaviours in the classroom setting. Learning to teach in 'safer' and 'easier' conditions may then positively affect teachers' overall job satisfaction and retention, which is why clinical work is considered by many to be the most influential component of teacher education programmes (Ronfeldt, 2012). However, "teacher education programmes [have yet to] move from changing beliefs per se to making teachers aware of beliefs and other factors affecting practice" (Goldin et al., 2016, p. 24).

The second study sought to explore eight experienced teachers' affect whilst teaching a mathematics lesson as part of their role as secondary school teachers in the UK. The sample was drawn from a relatively rural area in England, and was collected early in the school year when norms were being set for classroom engagement. This predominantly qualitative research explored the interaction of teachers based on episodes indicating a productive affective interaction. These were identified as incidents of smiling or laughter, or body language. The primary question addressed the wider research question of how teachers productively use positive emotions within their teaching to support student learning and to encourage engagement in mathematics. In addition to interviews to document their professional life history and to ascertain wider views and beliefs about the teaching and learning of mathematics, teachers were observed during normal mathematics lessons and were later provoked into revealing their experienced emotions by watching video clips from the observations during stimulated recall interviews.

\subsubsection{Participant Context}

In the first study, Mykia, a novice teacher, prepared a lesson plan based on several iterations of feedback from the teacher educator. She then selected $15 \mathrm{~min}$ of instruction from her lesson plan to rehearse in TeachLivE ${ }^{\mathrm{TM}}$. After rehearsing, Mykia received feedback and coaching from two teacher educators and reflected on her experience in a journal. She then revised and re-taught her 15-minute lesson plan to get feedback, 
and again reflected on the experience (30 min of teaching; two times of feedback from teacher educators; two post-rehearsal journals).

In the second study, Adam, an experienced teacher with a management role, has taught the same lessons many times over in more than 8 years of teaching and hence is ideal to compare and contract with Mykia. Adam was observed on several occasions, teaching the same class (aged 14-15), but for different curriculum topics. These included a discussion of upper and lower bounds, sequences, or how to construct a stem and leaf diagram. In the data collected for Adam, for this paper, we draw on interview reflections on his teaching as a whole prior to observation, and from his reflections specifically focussed on four lesson episodes in a series of videostimulated post-observation discussions.

\subsubsection{Data Sources and Analyses}

Despite differences in purpose in gathering the data and some differences in the analysis methods, the two research designs combined in this paper have striking similarities in the inferred ES. These similarities indicate an applicability of the model that has useful implications for further research, as can be seen from the discussion below despite the fact that the UK study of experienced teachers was smaller and studied each of the teachers through initially identifying affect. This agenda contrasts with the US study, which had an additional agenda of novice teachers' self-efficacy development. Data analysis involved first contextual analysis of each teacher's mathematical autobiography/life history, video transcripts of rehearsals/teaching and post-teaching reflections through journals or interviews.

In both predominantly qualitative studies, the researchers cycled through the data set and created tables and analytic matrices (Creswell, 2009) to compare teacher candidates' motivating desires, behaviours, and beliefs during teaching. The focus on these strands, as described above, is specifically to understand the patterns and themes of each teacher's affective experience whilst teaching.

Document analysis of video transcripts and post-teaching journals or audiorecorded reflections were conducted, where coding served to search for further evidence of teachers' ES. In the first study, to establish inter-rater reliability, videos were coded by two research assistants and then by two researchers (Miles \& Huberman, 1994). The researchers first coded videos by searching for instances of the nine ES from the Goldin et al. (2011) study, then further coded each ES to find evidence of the seven "in-the-moment" interacting strands (i.e. the goal or motivating desire, affective pathways, expression of affect, meanings encoded by emotions, meta-affect, self-talk or inner-speech) for each structure as emerging ES patterns and themes were identified. In the second study, the preliminary search sought instances of emotional expression by the teacher; the second stage was to seek evidence of the interacting strands to associate with ES.

The outcome is two levels of analysis, both of which identify dominant ES. In the first study, we have ES associated with shifts within the minutiae of lesson inter- 
action, whilst in the second study, we see how ES apply to a short affect focused episodes of around two to three minutes. Self-reported autobiographical data and post-observation data from Mykia's journal reflections after rehearsing in TeachLivE $^{\mathrm{TM}}$, and Adam's post-observation commentary, along with coded video transcripts and the researcher's' participant observation, all served to triangulate data points to describe Mykia and Adam's in-the-moment ES as they taught a mathematics lesson. In the following paragraphs, Mykia's and Adam's mathematical affect are described; followed by a snapshot of the activated ES whilst teaching a mathematics lesson. Then, given the purpose of comparing and contrasting the teachers' experiences, we will next describe each teachers' ES (Mykia, then Adam) before discussing the implications.

\subsection{Mykia's Powerful Mathematical Affect}

Mykia showed consistent evidence of Goldin et al.'s (2011) ES. Mykia's evolution from demonstrating ES affiliated with more in-the-moment negative emotions, such as Stay out of Trouble, Don't Disrespect Me, It's not Fair, and Get the Job Done whilst in the first rehearsal, to ES with a more positive affect in her second TeachLivE ${ }^{\mathrm{TM}}$ rehearsal, such as Let Me Teach You, Check This Out, and I'm Really Into This, Look How Smart I Am is evidence of how affective states may be linked to affective traits such as self-efficacy. Mykia's personal experience spoke to how she wanted to "never deter students from learning," as she "hope[d] to be the most influential and inspiring teacher they've ever had." Her passion for becoming an educator was revealed by her enthusiastic reflection, "Every experience I've had inside the classroom is so fulfilling and exciting for me and I can't wait until I can do this every day of my life."

Mykia exemplifies the potential Goldin et al.'s (2011) ES pose for teacher development because rehearse teaching was a turning point for her (see Khalil \& Hughes, 2016 for details on NT self-efficacy increases). Mykia's affective experience in her first TeachLivE ${ }^{\mathrm{TM}}$ rehearsal boosted her belief in herself and her ability to teach mathematics: "TeachLivETM rehearsals boost my readiness and confidence in what I am teaching." Prior to her first rehearsal, Mykia's engagement with mathematics problem solving, ideation, or identification was rife with deeply embedded anxiety that overshadowed how she engaged with any part of the mathematics methods course. As she reveals in her mathematics autobiography, "When I think about math, long, drawn out equations and formulas that seem impossible pop into my head and I can't help but to become a little anxious."

In fact, one week prior to her first 'real' teaching experience, (i.e. her TeachLivE $^{\mathrm{TM}}$ rehearsal), she approached one of her instructors and said she was considering withdrawing from the class. This was a surprise for the instructor, who, despite recognizing Mykia's anxiety and prior negative affective experiences in mathematics as a learner, thought those emotions were an asset, as it seemed to motivate Mykia's strong performance in class. Furthermore, the instructor hoped that by helping teacher candidates reflect on conceptual and productive struggles in mathematics, 
teacher candidates' beliefs equating mathematics fluency with speed would change. Furthermore, the evaluation of Mykia's conceptual and productive struggles in mathematics support further research into these effects in an assimilated 'real' classroom.

In her mathematical autobiography, Mykia's self-efficacy and self-identity as a mathematics learner were very much about her perception of time on task, and her speed in relation to others. She noted that she, "loved mathematics [in her primary years] because [quick computations] was something that [she] was good at, whereas when assigned work that would take hours to complete, [she thought that she] never wanted to take another math class, especially with Mr. Wang."

However, she alluded to moving beyond such beliefs when she noted that she "can't always run from challenges," noticing the rewards of perseverance:

I completely grasped every concept Mr Wang taught us and even excelled on the AP Exam as most students at my school did not pass. I am so glad I stuck it out and stayed in the course. It's an amazing feeling to do well in something you're so used to doing poorly in.

Being able to understand and learn how to push through challenging mathematics tasks became a motivational desire for Mykia to complete Mr Wang's class. Many of the ES Mykia demonstrated during her TeachLivE ${ }^{\mathrm{TM}}$ rehearsals were similarly characterized by her belief systems (e.g. perception about time as it relates to her teaching performance), whilst others were more related to her "in-the-moment" emotion. However, it was Mykia's meta-affect and the sequence of her emotional states interacting with the heuristics of lesson planning and rehearsing mathematics, which ultimately led to her 'Ah-ha!' moment that she can teach mathematics (Goldin, 2000; Liljedahl, 2005).

\subsubsection{Evidence of Mykia's Engagement Structures}

Consistent with Mykia's overall affect as it related to mathematics, our characterization of Mykia's first rehearsal illustrates a dominance of the Get the Job Done engagement structure. Evidence of Mykia's Get the Job Done was inferred when she exhibited a focus to persevere through an explanation of her "butterfly method"(a mathematics procedure used to find the common denominator of fractions) during her rehearsals, despite a student's incredulous question, "Is this part of the class?" Mykia's expressed her motivating desire was to get through the entire lesson first, as her performance goal to teach was construed by us as a behaviour about her interaction with the mathematics lesson and less about students' learning. Mykia's pattern of behaviour during this activated ES involved her speaking quickly and rushing through the lesson, without acknowledging any further questions from her students, and solving all parts of the lesson's problem without attending to a bidirectional engagement with students. This hyper-focus may have been in deference to the instructions to complete a 15-minute rehearsal (instructions she felt obliged to comply with). Mykia reflects, 
I was able to get through the lesson, but if I paced better, I could have finished and done more examples for knowledge checks of the tools I had just taught.

Indeed, we suggest the "motivating desire for task completion evoked more procedural, time-efficient strategies" (Goldin et al., 2011, p. 552) such as Mykia's fast-paced instruction and dogmatic perseverance to comply with her image of a what a teacher is to accomplish, i.e. to 'deliver' a lesson, are evidence of the interaction strands of the Get the Job Done ES. However, her lack of attention to students' questions may indicate the engagement structure, Don't Disrespect Me, may also have become active as ES do not occur in isolation.

The engagement structure Don't Disrespect Me seemed equally dominant in Mykia's first rehearsal, and was illustrated through Mykia attempting to establish control of the classroom discourse. Early in her first rehearsal, when a student asked Mykia the question "Why do I even have to learn this?" She hesitantly replies, "Excuse me Kevin? No, I will address questions at the end." Mykia's motivating desire was to establish a level of respect for herself by stating policies in a no-nonsense, assertive tone. However, her assertiveness had a quiet, proud quality to it, and in this engagement structure, her respect for students' sense of worth was evident as well. This value is reflected in her reflection, "I think it is very important to build students' confidence in every subject at a very young age. If the foundation is strong, then learning new concepts will always be fun and easy."

We infer that Don't Disrespect Me was markedly evident even within the very short duration of rehearsals, and was characterized by Mykia showing respect for everyone's dignity, requiring it back, and providing a 'safe' mathematical space free of belittlement. Goldin et al. (2011) have suggested Don't Disrespect Me and Check This Out ES are central to students who may be attempting to assert their agency and identity when faced with possible scepticism or dissent around their mathematical decisions. In a similar vein, the avatars were designed to evoke a similar behaviour from the teacher candidates when their instruction was questioned. We suggest evidence of this was when Mykia felt the need to "save face" when challenged by her students. Whilst Mykia exhibited an external expression of frustration at being challenged by a student's combative question, Mykia's motivating desire was to meet the perceived challenge this particular student posed by "shut[ting him] down." We inferred Mykia's external expression of affect from her elevated tone and punctuated body language which seemed "socioculturally dependent as well as idiosyncratic" (Goldin et al., 2011, p. 553). However, in her post-teaching reflection, Mykia noted;

\footnotetext{
Although I was able to shut all these [student distractions] down within the first few minutes, I heard that they were worse with some of my classmates. I see how important it is to incorporate tasks that really engage the students so you can have their undivided attention for the time that you have.
}

This comment exemplifies some of the encoded meaning behind her expression, as it was at once a way to protect herself from perceived loss of worth, whilst protecting students' sense of worth. Thus, when challenged further, Mykia's self-concept had her assertively and competently replying: 
Student: What does the body of the fraction supposed to mean?

Mykia: You will learn that in a second!

Whilst assertive, Mykia's tone was not expressed in a way that may insult students for asking. By virtue of being in a rehearsal, Mykia also seemed to exhibit the engagement structure Let me teach you, where she wanted to demonstrate her mathematics ability to herself, the avatar students, and her instructors. For example, through a series of questions, Mykia's exhibited that her motivating desire, a mastery goal, was to be able to help a confused student understand how to transform an improper fraction into a mixed fraction. Mykia scaffolded questions in a patient, warm tone, and demonstrated the steps to explain the solution to the problem. This activated engagement structure, exhibited midway through Mykia's first rehearsal, seemed to be a pivotal moment for Mykia, as she began to believe she can teach.

Pressing forward in an attempt to teach fractions procedurally through the "butterfly method," where the "butterfly" outline is a notation of cross multiplication to find a common denominator, Mykia prepared a poster with a butterfly to illustrate this technique of adding fractions. Although Mykia's use of this practice may not be a conceptually demanding mathematical practice, it would seem the Check This Out engagement structure was activated by the opportunity to express herself artistically through a familiar mathematics strategy. Perhaps Mykia's return to familiar strategy to find a common denominator is what she needed for her affective development, as it motivated her to engage in the Check This Out ES, which may in turn have been the incident that helped improve her self-efficacy (see Khalil \& Hughes, 2016 for details). Furthermore, this engagement structure may be linked to Mykia's intrinsic motivation of meeting the challenge to provide clarity to difficult mathematics problems.

Thus, Mykia's motivating desire, the intrinsic reward, associated with the "informing function" (Zimmerman \& Schunk, 2008, as cited in Goldin et al., 2011, p. 553), was seen when Mykia assisted CJ, since CJ struggled the most during the lesson. Mykia found it enjoyable to know that $\mathrm{CJ}$ was gaining the information and learning from her butterfly fraction method. The external emotions she seemed to exude included excitement and enthusiasm, and it was evident in her tone of voice that she was enthusiastic about having the opportunity to help teach a struggling student master the content (a mastery goal). Mykia's dialogue with CJ suggested her possible payoff for offering a new perspective to $\mathrm{CJ}$ are more consistent with the Check This Out engagement structure.

Mykia: What is a benefit of what you learned from the lesson today, CJ?

CJ: You drew a butterfly...I don't know, what she said (pointing to the student that answered before him).

Mykia: Ok, what was the purpose of the butterfly?

CJ: To learn how to add and subtract fractions.

Mykia: Good Job!

The ES Check This Out and Let Me Teach You both suggest that Mykia's "beliefs have reciprocal influence on [her] in-the-moment mathematical engagement" 
(Goldin et al., 2011, p. 556), and thus may prove to be very powerful affective structures for understanding teachers' adaptivity. However, by far the most often inferred engagement structure in Mykia's first rehearsal was Stay out of Trouble, where Mykia avoided interactions that may lead to distress. For example, we hypothesize Mykia avoided feeling vulnerable in her inability to answer a question (performanceavoidance goal), perhaps due to her initial self-concept that she has low capability. However, this engagement structure quickly turned into Don't Disrespect Me, as students took Mykia's initial sign of vulnerability as an open sign to challenge the premise of the teacher's mastery of the topic.

The final engagement structure that was activated in Mykia's first TeachLivETM rehearsal was It's Not Fair. Here, Mykia showed signs of unhappiness with rehearsing with avatars, as opposed to K-12 students in the field, as she described their disengagement and her lack of ability to use proximity as frustrating. For example, Mykia found it unfair that a particular student continued to disengage in classroom instruction, whilst the rest of the class participated in the discussion and were "alert and ready to learn." Therefore, Mykia's motivating desire was to involve this student in participation of the lesson. The unresponsiveness of the student (head on the table and not moving) evoked frustration, evident in Mykia's behavioural patterns, as she perceived the student's noncompliance as unfair to her demand of other students' attention. Mykia addressed this inequity by insisting the student, Maria, participate in the class activity, exclaiming: "Maria, I need you to wake up?!" During this time period, it is possible that Its Not Fair and Get the Job Done were operating simultaneously, as there was little that could be done to restore her sense of fairness in addressing disengagement from an avatar student. Therefore, this may have influenced Mykia's motivating desire to fulfil a performance goal of finishing the lesson (Goldin, 2014).

In the second rehearsal, the change in Mykia's beliefs about her mathematical ability to teach had changed to one where she did believe she can teach. This change led to more activation of the ES Let Me Teach You, I'm Really into This, and Look How Smart I Am. Noticeably, fewer incidents of ES that may have been associated with her former lower self-efficacy, such as Get The Job Done, Stay Out of Trouble, or Pseudo-Engagement were evidenced in the second rehearsal. Evidence of the activated ES Mykia displayed in her second TeachLivE ${ }^{\mathrm{TM}}$ rehearsal included Let Me Teach You, where she used re-voicing as a way to explain concepts to Kevin and CJ, and I'm Really Into This, as she focused more on teaching mathematics than on student participation. She also showed more instances of Look How Smart I Am. All three of these ES are about "communicating mathematical ideas, and explicitly incorporat[ing] affective, cognitive, and behavioural components" (Goldin et al., 2011, p. 556). As Mykia stated:

I felt more comfortable in my knowledge of the information and was able to teach without the visual aid I prepared. I think I was effective in meeting my objectives. The students were able to answer all of verbal summative and formative assessments during and after my lesson. The students were able to recall information, including definitions and steps of the butterfly method. 
Thus, when the students, Kevin and CJ, struggled to understand the questions to arrive to an answer, Mykia's motivating goal was first to transform a mathematically challenging learning environment into a productive challenge for the student (Let Me Teach You), and second to attend to the "imparting of understanding" (Goldin et al., 2011, p.555). Thus, when a student was reluctant to provide an answer, Mykia used her meta-affect of what she experienced in the first rehearsal to transform the experience from a difficult learning situation into a productive experience for the student. Therefore, Mykia's behaviour patterns changed by explaining and demonstrating problem-solving techniques for the student, with her satisfaction derived from governing student engagement more effectively with the mathematics, and ensuring students understand the mathematical problem.

Mykia: First I would like to go over the numerator of a fraction. Kevin, what is the numerator?

Kevin: I don't know

Mykia: Can you give me a guess?

Kevin: It's like part of a fraction or something

Mykia: Right, it is a part of the fraction, it's the top number of a fraction

According to Goldin et al. (2011), individuals that evoke the Let Me Teach You ES may gradually branch into a Look How Smart I Am, as we believe achieving emotional satisfaction and affirmation from her students helped Mykia to focus on the procedural fluency of the butterfly method.

It is noteworthy that Mykia's feelings of comfort whilst rehearsing improved her overall affect and led to the appearance of ES that were more intrinsically motivating for her. Mykia displayed several moments of I'm Really Into This, where she exhibited interest or "flow" (Csikszentmihalyi, 1990) in explaining operations with fractions to the point she seemed almost oblivious to the presence of the avatar students and the passing of time as she focused more on her teaching than on time completion or classroom participation. Once the students mastered the process and began to appreciate how the method resembled a butterfly, Mykia expressed pleasure in the students' engagement. Mykia's external emotions were evident in her facial expressions and body language. Here is an excerpt of the pride she viscerally exemplified for the I'm Really Into This ES:

Mykia: First step is to add the body to your fraction. To add the body you will draw a wing around the denominator of the first fraction and the numerator of the second fraction.

Student: It's a butterfly!

Mykia: Right, it is a butterfly! So as you did here, you add the antennas next. Now we will get to the math.

Ultimately, Mykia describes her happiness with the flow of her second rehearsal teaching session, stating:

The delivery was more genuine and I believe the students took well to my lesson, because I didn't have to focus too much on classroom management as I did the first time and the students responded better overall. 
She went on to explain,

This is one lesson that after taking the critique I received the first time and using that to improve, I felt extremely comfortable in my delivery and I believe the students learned what I expected them to at the end of it all.

Thus, Mykia's increased attention to areas she could improve on from her initial feedback allowed her to become more enthusiastic about her delivery of her lesson plan. The constructive feedback she obtained from TeachLivE ${ }^{\mathrm{TM}}$ rehearsals provided Mykia a higher positive self-regard for her abilities to perform teaching fractions (Liljedahl, 2005) and coincided with the ES Let Me Teach You, I'm Really into This, Look How Smart I Am. and Check This Out. Whilst there was an instance of Don't Disrespect Me in the second TeachLivETM, the majority of the ES were about "service [to the] group's task completion" (Goldin et al., 2011, p. 555) rather than other ES that were motivated by the teacher's performance-avoidance goals and less productive "in-the-moment" affect.

\subsection{Adam's Mathematical Affect}

Turning to Adam, who, as discussed above, provides a contrast to the less experienced Mykia, we first outline how ES appear in the data collected for Adam.

The overall impression given by Adam was of confidence. The dominant activated ES for Adam were Let Me Teach You supported by Look How Smart I Am, Check This Out and I'm Really Into This, with indications of Get the Job Done. Examples of these are drawn from four illustrative episodes selected as showing emotions deemed powerful through tone, body language, and observed laughter and banter. Adam predominantly used language, tone, emphasis, and tempo to convey this, as a faster pace tended to indicate, or at least give an impression of increased engagement and interest.

Within each of three observed lessons, Adam's teaching style was composed of different phases, each with a specific tempo and agenda that are combined to develop a mathematical storyline for his students. He engages in 'in-the-moment' behaviours, acknowledging by eye contact, use of 'we' to include the students as audience, and facial expression as reactions to student contributions, thus maintaining his approachable style. He seems comfortable with breaking the mathematical storyline, not trivially, but with substantial deviations, a characteristic with an observable affective impact if student aligning responses and laughter are indicative. For example, in one lesson Adam deviates extensively into a scenario about counting sheep to reinforce the meaning of $n$ within sequences. This deviation occurs within a lesson where the main storyline centres on generating the rule for a given sequence of numbers. Adam, in interview, tells a story about when his school was short of mathematics specialists as they struggle to both recruit and retain qualified teachers (Fisher \& Royster, 2016). The story illustrates his unease with just Getting The Job Done, as that ES gives him little pleasure in his teaching, saying, "Um...so you kind 
of lose some of the nice bits of the job, all the perks, all the nice feeling, if you are just trying to get the job done." This sentiment speaks to the stress many teachers feel due to the high-stakes mathematics they teach, where even experienced teachers are vulnerable to the continuous onslaught of new requirements and standards (Borko, 2004).

As well as using expressive vocal tone and emphasis to stress mathematical points, Adam's speaking pattern contained more observable emotions, compared to other parts of the lesson. The pace in these parts of the recordings became slower and more repetitive. His voice had contrasting volume, and became louder for significant junctures in mathematical explanation. It is likely that students, exposed to this pattern regularly, would soon 'tune in' to what he intended to highlight as important. To illustrate this, in a lesson about upper and lower bounds, he broke his speech into a rhythmic beat to provide emphasis, not once, but in a repetitive pattern, as he said "as big as possible." This could be heard as as-big-as-poss-i-ble, divided into six equal rhythmic beats. The effect is to highlight the importance of this part of the communication. In the video, Adam appeared able to focus single-mindedly on a task, a behaviour exhibiting a desire to experience flow, defined as complete absorption in what one does and tuning out of the rest of the world (Csikszentmihalyi, 1990).

In post-observation discussion, Adam described his perceived expected behaviours for a mathematics teacher: to satisfy student need for achievement through task completion via engaging pathways, perhaps with less regard to whether, or what type of learning, is achieved. One of the conventional 'expected' behaviours and social interaction rules for mathematical success is quickness (Black, Mendick, \& Solomon, 2009). Adam felt the need for completion of activities, even if it meant de-prioritising other aspects of learning, thus perhaps valuing utility. The issue of pace troubled him, as he returned to this theme often in the interview, saying "I was talking quite a lot and we weren't getting through the content as quick as we should have done." Similarly, Adam may have experienced some discomfort or frustration in that the students did not have enough consolidation time and there would not be enough time to round off the lesson properly, “...in the normal way...I think that I was also aware that again I hadn't [...] kind of switch off and just sit and let them do something for a longer period of time...."

The lesson observation data suggests Adam inhibited student deviation by body language and gesture, or by comments or questions, in order to complete tasks quickly. He placed emphasis on pace, and identified examples of competitiveness both in mathematics and in administrative tasks. He talked of losing some of his own faith in mathematics, exactly when he was challenged at university and could not perform highly enough to meet the demands of this competitiveness, an indicator that reveals a deep perception of equating mathematical fluency with speed.

Adam also appeared to find personal satisfaction in his own successes, both intrinsic and extrinsic. The satisfaction of mastery in teaching skills was illustrated through his use of idiosyncratic, observable yet often subtle, use of gesture and interjections. This use was frequently used to modify unwanted student behaviour. His external expressions of emotion included laughter and smiles, raised eyebrows used to encour- 
age questions, and rapid and emphatic use of body movement. The gestures were quickly executed and indicative of strategic 'norms' for the group. For example, he used a rapid and directed 'Shh' for seeking the attention of the class, and he used the word 'travellate' (Subsequently, this was identified as an abbreviation recognisable to students as "traffic light your objectives"), which had meaning for this class (they were expected to assess their learning), and all students promptly responded as expected. This well-established belief is evidenced when he talks about his own achievements, in particular the frequent use of a contented ' $\mathrm{hmm}$ ' when he is proud of a remembered experience. Other examples include his statement that students liking mathematics because they also like him, which he found personally rewarding, "I think um [contented]...students I teach get that enthusiasm from me."

\subsubsection{Evidence of Adam's Engagement Structures}

Goldin et al. (2011) define Get the Job Done through characteristics such as deference to establishment and following of rules, often procedural. The evidence supporting this ES is led by a motivating desire to appease an obligation; to cover the prescribed curriculum. Some indication of this can be seen in the following:

Adam: Right guys. Pause on what you are doing. I'll show you something quickly to help tie this together.

And at another time,

Adam: $\quad$...well... have you done this before?

Students: Yeah

Adam: So, yeah, right, a quick recap on how they work.

Adam's expression of affect is supported by his pace and tone of voice. In an interview, Adam expressed unease with high-stakes mathematics, saying teachers lose the 'nice[r] bits' of teaching, but then also immediately justified it, saying "So for them to improve, it's often knowing exactly where they get the exam marks from." High-stakes mathematics, as an extrinsic motivation, may have lead Adam to disengage in longer discussions with his students, as evidenced by his non-verbal inhibitions of student questions as he attempts to cover the curriculum. However, Get the Job Done is not entirely satisfying for Adam, and there are more significant intrinsic motivators that drive his other ES.

A second activated ES Adam experienced is Look How Smart I Am. A teacher adopting such a structure, as in the case of a student, would try to impress with ability or knowledge, both highly valued, and would give value to increased selfregard. They would respond to an admiring audience and may have a performance goal orientation that includes competitiveness. In interview, Adam said, "I have just always excelled at maths, I could always do everything in maths lessons and I found other lessons quite hard." Competitiveness may be rooted in his stories about his early mathematical experiences. At about age 5, he says, in comparison to other 
children, Adam said, "I was just able to do it...I just got any kind of numbers or anything."

Yet Adam also exhibited elements of another ES, Check This Out, where value is given to utility, yet also to mathematics solely as an enjoyable experience motivated by intrinsic or sometimes extrinsic reward. This engagement structure includes both conscientiousness and consideration for what benefits there are in the activity. Adam shifted to a faster pace and a slightly louder voice for these points in the lesson, giving an impression of interest as he said, "Right! Think about this!"

To a lesser degree, there is some evidence of a further ES, I'm Really Into This in Adam's data. Goldin et al. (2011) suggest that the underlying need within this ES is for understanding, part of a mastery and goal orientation. Adam appeared to find satisfaction in the experience of teaching and in finding solutions to challenges within his role. For example, he appeared absorbed in what Amy, one of his students, was saying. This appeared as single-minded behaviour centred on the mathematics as displayed, with Adam saying, "Amy, the expert, is going to tell us about stem and leaf diagrams." In another observation, Adam showed complete absorption in the task at one point in the lesson, when he faced the board, muttered briefly to himself and was then silently absorbed, almost as if he was doing the mathematics on the board alone in the room, modelling I'm Really Into This. Later in the same lesson, his manner indicated excitement that the students had an opportunity to engage in challenging mathematics, saying, "This guys is where it's going to stretch..." These data suggest I'm Really Into This in a social sharing context.

Both ES, Check This Out and I'm Really Into This, are strongly associated with Adam's teaching. Yet the strongest match for Adam is with Let Me Teach You, with evidence widely occurring within the data, of a desire to help others understand and of adopting a position of nurturance. Adam especially showed satisfaction in fulfilling this desire, and that the belief that he will find gratification in a positive response or appreciation is well established. He commented after one lesson, "there's a little group and they're like, yeah, I really like maths [laughs] ... they like the subject... they like me as well."

\subsection{Comparison Points from the Two Case Studies}

Drawing together the data from the two studies provides insight into how ES might appear at different stages in a teachers' professional learning trajectory. It is notable that both teachers aspired to be motivational, that Adam retained enthusiasm and the desire to be a good teacher, and that the desire to be inspiring remained after so many years. Both teachers experienced turning points that influenced their approach to teaching, and the use of ES may support further exploration of the potential impact of such turning points, or Ah-ha! moments. The changes Mykia experienced in her affective states through participation in the TeachLivE ${ }^{\mathrm{TM}}$ rehearsals was also complemented by a significant improvement in her mathematics self-efficacy (see Khalil \& Hughes, 2016) and reform-based teaching (see Khalil et al., 2016). Evidence 
of Adam's pivot and improved affective traits, on the other hand, were grounded in his return and re-commitment to teaching after a short stint as an IT consultant. Having "kind of like lost the love a bit for maths...", Adam returned to the classroom when, as he says, he realised that other careers lacked the affective, cognitive, and motivational stimulation he thrived on. A further similarity between Mykia and Adam is the role of a past teacher in building their mathematical identity. For Mykia, this was Mr. Wang; for Adam, it was a school teacher he recalled, "just really clicked with him ... and [whose] style suited" him.

The activated ES of Get The Job Done draws attention to the role of time and the accountability of the role of a teacher as one of the constraints for all teachers, regardless of experience. For Mykia, Get The Job Done was centred on completion of the lesson in the given time; this time pressure had not lessened for the more experienced teacher Adam, who commented frequently on time both in his interview and in the lessons. They both spoke quickly and, most significantly, there were points where they both either deferred students' questions for later or inhibited questions. However, it is important to note that Get The Job Done was not dominant during all teaching episodes, but appeared when the pressures of accountability motivated them.

As an experienced teacher, Adam had some of the time-efficient strategies that Mykia had not yet developed, which was evidenced by the shorter time Adam had Get The Job Done as his dominant ES. He also saw how the expectations of curriculum and exam preparation might be met, and where he could allow time for discussion without longer-term implications. To point, in Mykia's second rehearsal, Get The Job Done was less dominant and she was more dialogic as she figured out how to manage her time more effectively and engage with the mathematics and the students in a more productive way.

Don't Disrespect Me was not a dominant ES for Adam, and this was similarly the case for the majority of the experienced teacher sample. However, he was observed several weeks into the academic year when perhaps the behaviour management strategies commensurate with Don't Disrespect Me would likely be already established. It could also be a result of his familiarity with the mathematics taught, or the sociocultural context in which he taught. Mykia did not have the advantage of mathematics teaching experience and; indeed, the behaviour "chosen" in TeachLivE "TM was a level 3 (out of 5), which meant avatar students behaved in ways to simulate an 'urban' environment (Enicks, Whitten, Morgan, \& Dieker, 2013). Despite the problematic nature that such a stereotype may mean, Mykia and several fellow novice teachers recognized the socio-cultural dimension of this affective domain (Goldin, 2014) that undergirded the behaviours that students in TeachLivE exhibited. Through an empathetic tone, Mykia and other novice teachers were able to address unwanted behaviour quickly, apparently effortlessly, and with an aplomb that belied their novice status. Perhaps the novice teachers' shared socio-cultural background as part of a non-dominant group aided their sensitivity to demonstrating and demanding respect (Freire, 2005), and enabled their recognition of students' behaviours as possible assets, as opposed to a deficit that needed to be 'managed'(Frey \& Doyle, 2001). Indeed, Verner et al. (2013), in applying ES to novice teachers' affect whilst prob- 
lem solving in a multi-cultural mathematics methods course, added a new structure, Respect My Culture, thus suggesting the social and cultural dynamics behind behaviours should be another integral part of examining classroom transactions.

It is also worth mentioning that Adam and his fellow colleagues may consider it unprofessional to show emotions that are evident in Don't Disrespect Me or other ES associated with negative emotional states as associated with the It's Not Fair and Stay Outof Trouble ES, as some of the characteristics could be perceived as an indicator of difficulty or inexperience with mathematical problem-solving. Alternatively, more experienced teachers may have more practice self-regulating as the daily teaching challenges become less and less daunting 'in-the-moment.' Indeed, Verner et al. (2013) discovered that a manifestation of ES evolved within the learning process, and was motivational for novice teachers in an ethno-mathematical teacher education course. Perhaps a third explanation is differences in familiarity with content and pedagogical content knowledge.

Both Adam and Mykia exhibited characteristics associated with the more productively orientated ES of Check This Out, I'm Really Into This, and Let Me Teach You, which may speak to their adaptive engagement with their mathematical practice. We would like to suggest that the dominance of such ES may have students, in the future, identifying Mykia or Adam as their significant role model. What may warrant further investigation is how these ES are connected to one another during a teacher's "in-themoment" practice, and how they may resonate with students' similar ES modelling. Thus what seems important is not only the ES but the dominance and combination of ES used within a teaching session, informed by the beliefs of the teacher.

\subsection{Discussion and Implications: Engagement Structures as Overarching in Mathematics Teaching and Learning}

In this paper, we explore the emerging usefulness of ES as a framework to understand Mykia's sociocultural (Cobb, 1994; Kelly, 2006), socio-political (Borko \& Putnam, 1996; Cohen \& Ball, 1990), and socio-mathematical (Patrick, Ryan, \& Kaplan, 2007) engagement with teaching over two rehearsals, and compare Mykia's emerging practice to Adam's more established teaching practice. The importance of teachers attending to their affective domain whilst teaching has been shown to illuminate change in attitudes and beliefs of 'resistant' teachers (Liljedahl, 2005). Teachers that transform their attitudes and beliefs towards the learning of mathematics create instances of what Liljedahl calls Ah-ha! experiences of insight. These can serve as a valuable resource in fostering mathematical performance. It seems reasonable to suggest new teachers experience more such moments. These Ah-ha! experiences were evident through Mykia's first rehearsal, and the benefits of her positive beliefs about mathematics and her ability to do mathematics was evident in her second rehearsal. We might then assume that for the contrast of Adam, that he had prior 
experience of many Ah-ha! moments, and what we see in the data are the longerterm adjustments following such experiences.

If we consider the above discussion in terms of how ES are underpinned by teachers' motivational needs, which then activates the ES, then there is also a recognition of a driving need to reconcile the disparity between each teacher's existing perceptions of their teaching and their motivation to become what they perceive to be the ideal teacher. Both give importance to modelling enthusiasm, and this must inevitably inform the ES. Krzywacki and Hannula (2010) explored the existing and ideal self and the gap between these two selves that evokes needs. Horn, Nolen, Ward, and Campbell (2008) specifically discussed this in terms of teacher development, where they explored what new teachers see as the ideal teacher. They concluded that the most effective development resulted from experiencing tensions caused by gaps. This seemed to spur teacher's developing pedagogical reasoning, as well as their adaptability and coordination.

There are many implications from approaching classroom analysis using ES and examining the emergence of teaching from a temporal lens. We propose that ES can be used as a lens into teacher development that connects affective and motivational domains to their mathematical behaviours across the teacher professional learning trajectory. We believe that ES can be used in teachers' affective development as an 'active learning' tool, where teachers develop their practice by reflecting on their behaviour and viewing teaching as 'learning' (Peressini, Borko, Romagnano, Knuth, $\&$ Willis, 2004). Since teachers' behaviours include their instructional practice, we suggest ES can serve as both a theory of teacher professional learning and a theory of instruction (Wayne, Yoon, Zhu, Cronen, \& Garet, 2008). In other words, we suggest that ES can serve as a theory to connect teacher emotional development to their behaviours, including their teaching and learning practices across the teacher learning trajectory.

Moreover, Goldin et al.'s (2011) theory of ES has overarching value, in that it can connect teachers' prior 'in-the-moment' behaviour as mathematics learners with their 'in-the-moment' behaviour as mathematics teachers. We suggest ES can serve as a key area for teacher knowledge development where teachers may link how their "in-the-moment" mathematical affect connects to students' affective domains and mathematical practices. That is, ES can be bidirectional and can serve both students and teachers. Further, raising teacher awareness of their ES and student ES may support development of affective classroom practices, such as managing change. When teachers recognize the mirroring of their affective ES by their students and then respond accordingly, the idea of transcendental ES can aid with teachers' concern for pupils (Fuller, 1969), and may prove a viable framing for culturally responsive teaching (Delpit, 1993; Gay, 2010). This recognition situates ES as an especially powerful intervention measure for students and teachers to co-construct and engage in meaningful learning transactions in a community of practice (Boykin et al., 2011; Darling-Hammond \& Richardson, 2009; Lave \& Wenger, 1991).

Establishing discussions with teachers on identifying and addressing in-themoment' ES of both students and teachers, as part of professional development, may promote affective teacher behaviours with a powerful effect for learning. A 
longer term aim must be to counter the detrimental attributes of negative emotions in school, those that detract from teaching and learning, both now and in the future. This is important for teachers' overall well-being at the personal level, and for what Liu et al. (2008) described as teacher quality at the school organisational level, as affect (such as satisfaction) renews and recommits teachers to schools. This stands in sharp contrast to the new professional "technicist" skills that are frequently promoted in teacher education (Zeichner, 2010). It is now more imperative than ever to examine teachers' affective as well as cognitive abilities to teach mathematics in order to serve all students with a socially just and equitable education.

\section{References}

$\mathrm{Au}, \mathrm{W}$. (2007). High-stakes testing and curricular control: A qualitative meta-synthesis. Educational Researcher, 36(5), 258-267.

Bibby, T. J. (2002). Shame: An emotional response to doing mathematics as an adult and a teacher. British Educational Research Journal, 28(5), 705-721.

Black, L., Mendick, H., \& Solomon, Y. (Eds.). (2009). Mathematical relationships in education. Identities and participation. London, England: Routledge.

Borko, H. (2004). Professional development and teacher learning: Mapping the terrain. Educational Researcher, 33(8), 3-15.

Borko, H., \& Putnam, R. T. (1996). Learning to teach. In D. C. Berliner \& R. C. Calfee (Eds.), Handbook of educational psychology (pp. 673-708). London, England: Prentice Hall.

Boykin, A. W., Noguera, P., \& Ebrary, I. (2011). Creating the opportunity to learn: Moving from research to practice to close the achievement gap. Alexandria, VA: ASCD.

Brown, L., \& Reid, D. (2006). Embodied cognition: Somatic markers, purposes and emotional orientations. Educational Studies in Mathematics, 63(2), 179-192.

Bursal, M., \& Paznokas, L. (2006). Mathematics anxiety and preservice elementary teachers' confidence to teach mathematics and science. School Science and Mathematics, 106(4), 173-180.

Bybee, R. W. (2015). The BSCS 5E instructional model: Creating teachable moments. In: National Science Teachers Association (pp. 1-35). Arlington, VA: NSTA.

Calvo, R. A., \& D'Mello, S. K. (Eds.). (2011). New perspectives on affect and learning technologies (Vol. 3). New York, NY: Springer.

Carmack, S. (2014). Making Sense of Well-being: A Mixed-methods study applying sense-making theory to explore the role of communication competence and social support in physical, emotional, mental and comprehensive well-being (Doctoral dissertation, George Mason University).

Cobb, P. (1994). Where is the mind? Constructivist and sociocultural perspectives on mathematical development. Educational Researcher, 23(7), 13-20.

Cohen, D. K., \& Ball, D. L. (1990). Relations between policy and practice: A commentary. Educational Evaluation and Policy Analysis, 12(3), 331-338.

Collie, R. J., Shapka, J. D., \& Perry, N. E. (2012). School climate and social-emotional learning: Predicting teacher stress, job satisfaction, and teaching efficacy. Journal of Educational Psychology, 104(4), 1189.

Cooper, P. M. (2003). Effective white teachers of black children: Teaching within a community. Journal of Teacher Education, 54(5), 413-427.

Creswell, J. W. (2009). Editorial: Mapping the field of mixed methods research. Journal of Mixed Method Research., 3(2), 95-108.

Csikszentmihalyi, M. (1990). Flow: The psychology of optimal experience. New York, NY: Harper and Row. 
Dalgleish, T., \& Power, M. J. (1999). Handbook of cognition and emotion. Chichester, New York: Wiley.

Damasio, A. R. (2006). Descartes' error: Emotion, reason and the human brain. London, England: Vintage.

Darling-Hammond, L., \& McLaughlin, M. W. (1999). Investing in teaching as a learning profession: policy problems and prospects. In L. Darling-Hammond \& G. Skyes (Eds.), Teaching as the learning profession (pp. 376-412). San Francisco, CA: Jossey-Bass.

Darling-Hammond, L., \& Richardson, N. (2009). Research review/teacher learning: What matters. Educational Leadership, 66(5), 46-53.

DeBellis, V. A., \& Goldin, G. A. (1997). The affective domain in mathematical problem solving. In E. Pehkonen (Ed.), Proceedings of the 21st Conference of the International Group for the Psychology of Mathematics Education (Vol. 2, pp. 209-216). Lahti, Finland: PME.

DeBellis, V. A., \& Goldin, G. A. (2006). Affect and meta-affect in mathematical problem solving: A representational perspective. Educational Studies in Mathematics, 63(2), 131-147.

Delpit, L. (1993). The politics of teaching literate discourse. In Freedom's plough: Teaching in the multicultural classroom (pp. 285-295).

Delpit, L. (1995). Other people's children: Cultural conflict in the curriculum. New York, NY: New York Press.

Desimone, L. M. (2009). Improving impact studies of teachers' professional development: Toward better conceptualizations and measures. Educational Researcher, 38(3), 181-199. https://doi.org/ 10.3102/0013189x08331140.

Dieker, L., Hynes, M., Hughes, C., \& Smith, E. (2008). Implications of mixed reality and simulation technologies on special education and teacher preparation. Focus on Exceptional Children, 40(6), $1-20$.

Dieker, L., Rodriguez, J., Lignugaris-Kraft, B., Hynes, M., \& Hughes, C. (2014). The future of simulated environments in teacher education. Teacher Education and Special Education, 37(1), $21-33$.

Drodge, E. N., \& Reid, D. A. (2000). Embodied cognition and the mathematical emotional orientation. Mathematical Thinking and Learning, 2(4), 249-267.

Enicks, A., Whitten, E., Morgan, D., \& Dieker, L. (2013). Findings on the use of TeachLIVE®, a mixed-reality teaching environment, to prepare special educators. In Association of Teacher Educators Annual Meeting. Atlanta, GA: ATE.

Fenton-O'Creevy, M., Soane, E., Nicholson, N., \& Willman, P. (2011). Thinking, feeling and deciding: The influence of emotions on the decision making and performance of traders. Journal of Organizational Behavior, 32(8), 1044-1061.

Fisher, M. H., \& Royster, D. (2016). Mathematics teachers' support and retention: Using Maslow's hierarchy to understand teachers' needs. International Journal of Mathematical Education in Science and Technology, 1-16.

Flores, A., Park, J., \& Bernhardt, S. A. (2016). Learning mathematics and technology through inquiry, cooperation, and communication: A learning trajectory for future. In M. Niess, S. Driskill, $\&$ K. Hollebrands (Eds.), Handbook of research on transforming mathematics teacher education in the digital age (p. 324). IGI Global: Hershey, PA.

Frey, A., \& Doyle, H. D. (2001). Classroom meetings: A program model. Children and Schools, 23(4), 212-222.

Freire, P. (2005). Teachers as cultural workers: Letters to those who dare teach with new commentary by Peter McLaren, Joe L. Kincheloe, and Shirley Steinberg Expanded Edition. Boulder, CO: Westview.

Fuller, F. F. (1969). Concerns of teachers: A developmental conceptualization. American Educational Research Journal, 6(2), 207-226.

Gay, G. (2010). Culturally responsive teaching: Theory, research, and practice. New York, NY: Teachers College.

Gee, J. P. (2002). Identity as an analytic lens for research in education. Review of Research in Education, 25, 99-125. 
Gerring, J. (2017). Case study research: Principles and practices. New York: Cambridge University Press.

Goldin, G. A. (1998). Representational systems, learning, and problem solving in mathematics. The Journal of Mathematical Behavior, 17(2), 137-165.

Goldin, G. A. (2000). Affective pathways and representation in mathematical problem solving. Mathematical Thinking and Learning, 2(3), 209-219.

Goldin, G. A. (2014). Perspectives on emotion in mathematical engagement, learning, and problem solving. In R. Pekrun \& L. Linnenbrink-Garcia (Eds.), International handbook of emotions in education (pp. 391-414). New York, NY: Routledge.

Goldin, G. A. (2015). Motivating desires for classroom engagement in the learning of mathematics. In Proceedings of the 21 st International Conference on Mathematical Views (MAVI). Milan, Italy: Polytechnic University of Milan.

Goldin, G. A., Epstein, Y. M., \& Schorr, R. Y. (2007). Affective pathways and structures in urban students' mathematics learning. In D. K. Pugalee, A. Rogerson, \& A. Schinck (Eds.), Mathematics Education in a Global Community: Proceedings of the 9th International Conference of the Mathematics Education into the 21st Century Project (pp. 260-265). Beijieng, China: ICME.

Goldin, G. A., Rösken, B., \& Törner, G. (2009). Beliefs - No longer a hidden variable in mathematics teaching and learning processes. In J. Maass, \& W. Schlöglmann (Eds.), Beliefs and attitudes in mathematics education: New research results (pp. 1-18). Rotterdam: Sense Publishers.

Goldin, G. A., Epstein, Y. M., Schorr, R. Y., \& Warner, L. B. (2011). Beliefs and engagement structures: Behind the affective dimension of mathematical learning. ZDM Mathematics Education, 43, 547-556.

Goldin, G. A., Hannula, M. S., Heyd-Metzuyanim, E., Jansen, A., Kaasila, R., Lutovac, S., et al. (2016). Attitudes, beliefs, motivation, and identity in mathematics education. An overview of the field and future directions. In Springer open (pp. 1-35). New York, NY: Springer.

Greeno, J. G., Collins, A. M., \& Resnick, L. B. (1996). Cognition and learning. In D. Berliner \& R. Calfee (Eds.), Handbook of educational psychology (Vol. 77, pp. 15-46).

Gregory, A., \& Weinstein, R. S. (2008). The discipline gap and African Americans: Defiance or cooperation in the high school classroom. Journal of School Psychology, 46(4), 455-475.

Haberman, M. (2005). Teacher burnout in black and white. New Educator, 1, 153-175.

Hagenauer, G., Hascher, T., \& Volet, S. E. (2015). Teacher emotions in the classroom: Associations with students' engagement, classroom discipline and the interpersonal teacher-student relationship. European Journal of Psychology of Education, 30(4), 385-403.

Hill, H., \& Ball, D. L. (2009). The curious and crucial case of mathematical knowledge and teaching. Phi Delta Kappan, 91(2), 68-71.

Hollingsworth, S. (1989). Prior beliefs and cognitive change in learning to teach. American Educational Research Journal, 26, 160-189.

Horn, I. S., Nolen, S. B., Ward, C., \& Campbell, S. S. (2008). Developing practices in multiple worlds: The role of identity in learning to teach. Teacher Education Quarterly, 35(3), 61-72.

Howard, T. C. (2001). Telling their side of the story: African-American students' perceptions of culturally relevant teaching. The Urban Review, 33(2), 131-149.

Ingersoll, R. M., \& Perda, D. (2010). Is the supply of mathematics and science teachers sufficient? American Educational Research Journal, 47(3), 563-594.

Kelly, P. (2006). What is teacher learning? A socio-cultural perspective. Oxford Review of Education, 32(4), 505-519.

Khalil, D., \& Hughes, G., (2016). Paradox or process? A description of novice teachers' powerful mathematical affect and their instructional performance in Teachlive ${ }^{\mathrm{TM}}$ Rehearsals. In C. Csikos, A. Rausch, \& J. Szitanyi (Eds). Proceedings of the 40th Conference of the International Group for the Psychology of Mathematics Education (Vol. 3, pp. 83-90). Szged, Hungary: PME.

Khalil, D., Hughes, G., Gosselin, C., \& Edwards, L. (2016). TeachLive ${ }^{\mathrm{TM}}$ rehearsals: One HBCU's study on prospective teachers' reformed instructional practices and their mathematical affect. In M. Wood, E. Turner, \& M. Civil (Eds.), Proceedings of the 38th Annual Meeting of the North 
American Chapter of the International Group for the Psychology of Mathematics Education. Tucson, AZ: University of Arizona.

Kleinfeld, J. (1975). Effective teachers of Eskimo and Indian students. The School Review, 83(2), 301-344.

Kyriacou, C. (2001). Teacher stress: Directions for future research. Educational Review, 53(1), $27-35$.

Korthagen, F. (2016). Inconvenient truths about teacher learning: Towards professional development 3.0. Teachers and Teaching, 1-19.

Krzywacki, H., \& Hannula, M. S. (2010). Tension between present and ideal state of teacher identity in the core of professional development. In M. M. F. Pinto \& T. F. Kawasaki (Eds.), Proceedings of the 34th Conference for the International Group for the Psychology of Mathematics Education(Vol. 1, pp. 267-271). Belo Horizonte, Brazil: PME.

Lake, E., \& Nardi, E. (2014). Looking for Goldin: Can adopting student engagement structures reveal engagement structures for teachers? The case of Adam. In C. Nicol, S. Oesterle, P. Liljedahl, \& D. Allan (Eds.), Proceedings of the 38th Conference of the International Group for the Psychology of Mathematics Education. Vancouver, BC: PME.

Lave, J., \& Wenger, E. (1991). Situated learning: Legitimate peripheral participation. Cambridge, UK: Cambridge University Press.

Lazarus, R. S. (1991). Emotion and adaptation. New York, NY: Oxford University Press.

Lee, H. J., \& Boyadzhiev, I. (2013). Challenging common misconceptions of fractions through GeoGebra. In R. McBride \& M. Searson (Eds.), Proceedings of Society for Information Technology and Teacher Education International Conference. Chesapeake, VA: AACE.

Lewis, G. (2013). Emotion and disaffection with school mathematics. Research in Mathematics Education, 15(1), 70-86.

Liljedahl, P. G. (2005). Mathematical discovery and affect: The effect of AHA! experiences on undergraduate mathematics students. International Journal of Mathematical Education in Science and Technology, 36(2-3), 219-234.

Liu, E., Rosenstein, J. G., Swan, A. E., \& Khalil, D. (2008). When districts encounter teacher shortages: The challenges of recruiting and retaining mathematics teachers in urban districts. Leadership and Policy in Schools, 7(3), 296-323.

Mansfield, C. F., \& Volet, S. E. (2010). Developing beliefs about classroom motivation: Journeys of preservice teachers. Teaching and Teacher Education, 26(7), 1404-1415. https://doi.org/10. 1016/j.tate.2010.04.005.

McLeod, D. B. (1994). Research on affect and mathematics learning in the JRME: 1970 to the Present. Journal for Research in Mathematics Education, 25(6), 637-647.

Meyer, D. K., \& Turner, J. C. (2006). Re-conceptualizing emotion and motivation to learn in classroom contexts. Educational Psychology Review, 18(4), 377-390. https://doi.org/10.1007/ s10648-006-9032-1.

Miles, M. B., \& Huberman, A. M. (1994). Qualitative data analysis: A sourcebook. Beverly Hills, CA: Sage.

Milner, H. R., Flowers, L. A., Moore, E., Moore, J. L., \& Flowers, T. A. (2003). Preservice teachers' awareness of multiculturalism and diversity. The High School Journal, 87(1), 63-70.

Monroe, C. R. (2005). Understanding the discipline gap through a cultural lens: Implications for the education of African American students. Intercultural Education, 16(4), 317-330.

Moore, F. (2008). Agency, identity, and social justice education: Preservice teachers' thoughts on becoming agents of change in urban elementary science classrooms. Research in Science Education, 38, 589-610.

Mottet, T. P., \& Beebe, S. A. (2002). Relationships between teacher nonverbal immediacy, student emotional response, and perceived student learning. Communication Research Reports, 19(1), $77-88$.

Nieto, S. (2003). What keeps teachers going? New York: Teachers College Press. 
Parker, P. D., Martin, A. J., Colmar, S., \& Liem, G. A. (2012). Teachers' workplace well-being: Exploring a process model of goal orientation, coping behavior, engagement, and burnout. Teaching and Teacher Education, 28(4), 503-513.

Patrick, H., Ryan, A. M., \& Kaplan, A. (2007). Early adolescents' perceptions of the classroom social environment, motivational beliefs, and engagement. Journal of Educational Psychology, 99(1), 83.

Peressini, D., Borko, H., Romagnano, L., Knuth, E., \& Willis, C. (2004). A conceptual framework for learning to teach secondary mathematics: A situative perspective. Educational Studies in Mathematics, 56(1), 67-96.

Planke, S. B., \& Condliffe, B. F. (2013). Pressures of the season: An examination of classroom quality and high-stakes accountability. American Educational Research Journal, 50, 1152-1182.

Puchner, L. D., \& Taylor, A. R. (2006). Lesson study, collaboration and teacher efficacy: Stories from two school-based math lesson study groups. Teaching and teacher education, 22(7), 922-934.

Ronfeldt, M. (2012). Where should student teachers learn to teach? Effects of field placement school characteristics on teacher retention. Educational Evaluation and Policy Analysis, 34(1), 3-26.

Schlöglmann, W. (2006). Meta-affect and strategies in mathematics learning. In M. Bosch (Ed.), Proceedings of the Fourth Congress of the European Society for Research in Mathematics Education (pp. 275-285). Barcelona: Universitat Ramon Llul, IQS.

Schorr, R. Y., \& Goldin, G. A. (2008). Students' expression of affect in an inner-city simcalc classroom. Educational Studies in Mathematics, 68(2), 131-148.

Schorr, R. Y., Epstein, Y. M., Warner, L. B., \& Arias, C. C. (2010). Mathematical truth and social consequences: The intersection of affect and cognition in a middle school classroom. Mediterranean Journal for Research in Mathematics Education, 9(1),107-134.

Schutz, P., Hong, J., Cross, D., \& Osbon, J. (2006). Reflections on investigating emotion in educational activity settings. Educational Psychology Review, 18(4), 343-360.

Spillane, J. P., Halverson, R., \& Diamond, J. B. (2004). Towards a theory of leadership practice: A distributed perspective. Journal of Curriculum Studies, 36(1), 3-34. https://doi.org/10.1080/ 0022027032000106726.

Titsworth, S., McKenna, T. P., Mazer, J. P., \& Quinlan, M. M. (2013). The bright side of emotion in the classroom: Do teachers' behaviors predict students' enjoyment, hope, and pride? Соттиnication Education, 62(2), 191-209.

Verner, I., Massarwe, K., \& Bshouty, D. (2013). Constructs of engagement emerging in an ethnomathematically-based teacher education course. The Journal of Mathematical Behavior, 32(3), 494-507.

Ware, F. (2006). Warm demander pedagogy: Culturally responsive teaching that supports a culture of achievement for African American students. Urban Education, 41(4), 427-456.

Wayne, A. J., Yoon, K. S., Zhu, P., Cronen, S., \& Garet, M. S. (2008). Experimenting with teacher professional development: Motives and methods. Educational Researcher, 37(8), 469-479.

Weber, K. (2008). The role of affect in learning real analysis: A case study. Research in Mathematics Education, 10(1), 71-85.

Zeichner, K. (2010). Competition, economic rationalization, increased surveillance, and attacks on diversity: Neo-liberalism and the transformation of teacher education in the US. Teaching and Teacher Education, 26(8), 1544-1552.

Zeichner, K. M., \& Gore, J. M. (1990). Teacher socialization. In W. R. Houston (Ed.), Handbook of research on teacher education (pp. 329-348). New York, NY: Macmillan.

Zeldin, A. L., \& Pajares, F. (2000). Against the odds: Self-efficacy beliefs of women in mathematical, scientific, and technological careers. American Educational Research Journal, 37(1), 215-246. 
Open Access This chapter is licensed under the terms of the Creative Commons Attribution 4.0 International License (http://creativecommons.org/licenses/by/4.0/), which permits use, sharing, adaptation, distribution and reproduction in any medium or format, as long as you give appropriate credit to the original author(s) and the source, provide a link to the Creative Commons license and indicate if changes were made.

The images or other third party material in this chapter are included in the chapter's Creative Commons license, unless indicated otherwise in a credit line to the material. If material is not included in the chapter's Creative Commons license and your intended use is not permitted by statutory regulation or exceeds the permitted use, you will need to obtain permission directly from the copyright holder.

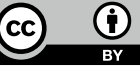




\title{
Chapter 13 \\ Exploring Flow in Pre-service Primary \\ Teachers Doing Measurement Tasks
}

\author{
Ana Belén Montoro and Francisco Gil
}

\begin{abstract}
When students experience flow (states of deep concentration and enjoyment) while carrying out academic tasks, they become more motivated to study the subject and they attain higher achievement. Flow experienced by 230 pre-service primary education teachers attending a course about teaching and learning measurement at primary school was explored in this study. A questionnaire was distributed at the end of each of the five practical sessions in which students solved measurement tasks. The lowest percentage of students in flow was found while they were engaged in problem-solving tasks. A video analysis of group work provided some possible explanations.
\end{abstract}

Keywords Flow experiences $\cdot$ Pre-service teachers $\cdot$ Problem solving $\cdot$ Tasks

\subsection{Introduction}

Over recent decades the importance of motivation, beliefs, and emotions in learning has been highlighted (DeBellis \& Goldin, 2006; Middleton, 2013; Schunk \& Mullen, 2012). Motivation, according to Kanfer (1994), is the force or impulse that drives individuals to perform an activity, regulating its direction and intensity.

When the reasons, or motivation, for an action are external to it, such as obtaining a reward or avoiding punishment, this type of behaviour ceases when the stimulus or the deterrent is removed. In contrast, if someone chooses to do an activity because they find it interesting, enjoyable and satisfying, their attention is focused on it and their motivation is permanent. In fact, this kind of motivation, intrinsic motivation, is the most intense and sustained action (Deci \& Ryan, 1985).

Sadly, Professor Francisco Gil died in April 2018.

\footnotetext{
A. B. Montoro (凶)

University of Granada, Calle Prof. Vicente Callao, 40, 18011 Granada, Spain

e-mail: amontoro@ugr.es

F. Gil

University of Almeria, Almeria, Spain

(C) The Author(s) 2019
}

M. S. Hannula et al. (eds.), Affect and Mathematics Education,

ICME-13 Monographs, https://doi.org/10.1007/978-3-030-13761-8_13 


\subsection{Flow Theory}

The term flow was introduced by Csikszentmihalyi (1975) after observing and interviewing a large number of individuals who dedicated a great deal of time and effort to activities which afforded them little money or recognition. He wanted to know how they felt when they were doing these activities and why they found them so rewarding.

Surgeons, athletes, dancers, and chess players, among many others, described their experiences (flow) in a similar way. They faced challenging situations that required the total use of their skills, aimed at a well-defined goal, receiving frequent information about their progress towards achieving it. They were so focused on their activity that they isolated themselves from what was happening around them, forgetting everything about themselves and their problems, and sometimes losing track of time. They felt in control of their performance and of the activity, and experienced a feeling of effortlessness. All these factors resulted in an intrinsically rewarding experience that individuals would subsequently repeat in order to feel these same sensations over and over again (Csikszentmihalyi \& Csikszentmihalyi, 1988). All of the flow dimensions are summarized in Fig. 13.1.

Nakamura and Csikszentmihalyi (2002) argued that providing clear goals, immediate feedback, and a balance between personal skills and the challenges posed by the activity are necessary conditions for flow to occur, rather than the characteristics of the experience itself. Among these three aspects, the level of challenges and skills perceived by the subject has acquired special relevance. After exploring the quality of everyday life experiences, it became apparent that flow occurred when individuals perceived a high level of challenges and skills. Apathy and boredom

Fig. 13.1 Flow dimensions

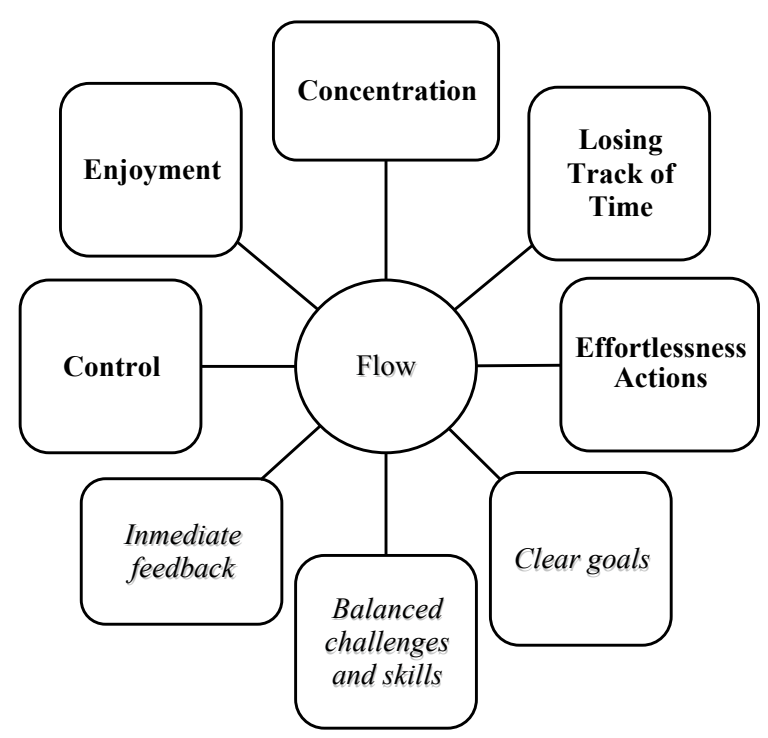


were linked to the perception of low challenges, and anxiety occurred when individuals perceived that the challenge of the activity was above and beyond their abilities. Much research has been carried out using this model, the Quadrant Model of Flow, to measure flow experiences (Hektner \& Csikszentmihalyi, 1996; Rathunde \& Csikszentmihalyi, 1993).

The Quadrant Model of flow evolved from data gathered using the Experience Sample Method (ESM), which relies on a device which emits random signals and prompts participants to fill in a brief questionnaire. Using open-ended and scale-type questions (Hektner et al., 2007) information is gathered at the time of the prompt about the activity they were doing, and their cognitive, affective and motivational state. Quadrant Model of Flow evolved to another one with eight channels (Strati, Shernoff, \& Dornbusch, 1996).

\subsubsection{Flow Experiences in Education}

Although the Flow theory was first tested in the art world in which artists spend many hours in deep concentration working on their paintings and sculptures, it has been applied to many other settings, including education (Shernoff, Abdi, Anderson, \& Csikszentmihalyi, 2014).

Research work showed that when students experience flow in academic tasks they attain higher levels of achievement (Larson, 1998) and motivation in the subjects studied, choosing courses that include these activities in future stages of their education or in extracurricular activities (Whalen, 1998). This is one of the most important reasons for doing further research and applying the flow theory to education. In the words of Csikszentmihalyi:

The flow experience acts as a magnet for learning, that is, for developing new levels of challenges and skills. In an ideal situation, a person would be constantly growing while enjoying whatever he or she did. (Csikszentmihalyi, 1997, p. 33)

Using the Quadrant model of flow, Csikszentmihalyi, Rathunde, and Whalen (1993) found that the school environment and home study were surroundings in which gifted students most frequently experienced flow. On the other hand, the activities in which children aged from 9 to 15 most often undergo the flow experience were sports, play and study. Specifically, $20 \%$ of the students who took part in the survey claimed they experienced flow when studying (Mesurado, 2010).

\subsubsection{Flow and Mathematics Education}

Heine (1997) carried out a study with seven groups of students who attended a course focused on improving mathematical skills in gifted learners. He found that intrinsically motivated students achieved higher outcomes than those who were extrinsically 
motivated. Furthermore, he compared the flow levels of the seven groups and noticed a decrease in the initial level in five of the groups participating in the course. These groups spent more time listening to their teachers' explanations and memorizing concepts, whereas the other two groups focused on their work, either individually or in groups, discussing or explaining their ideas. Moreover, they spent time working on problems that required the application of known concepts to new situations. Thus, applying algorithms or doing common or routine problems was considered boring and novel problems were perceived as too difficult.

Schweinle, Turner, and Meyer (2002) found that typical 5th and 6th grade students enrolling in compulsory mathematical courses had the best experiences when they perceived challenges slightly above those they usually encountered. However, their skills perception far outweighed the challenges of the tasks. As seen above, this situation lies outside the Flow Channel and so the Quadrant model of flow predicts boredom. In fact, they found that positive emotions only increase with challenges if the perception of mathematical skills is high. When ability is perceived as low, increasing the level of challenges produces a decrease in students' perception of selfefficacy (Schweinle, Turner, \& Meyer, 2008). In 2006 the same authors compared the learning strategies and environment created by four teachers whose classrooms were classified as provoking flow, apathy, anxiety, and boredom using the Quadrant model of flow. The main differences were the kind of feedback and evaluation provided, the importance given to the tasks, and the way in which they introduced challenges and supported autonomy, cooperation, and persistence (Schweinle, Turner, \& Meyer, 2006).

Along the same lines, Liljedahl (2016) proposed the flow theory as a tool for analyzing teachers' professional practices. Specifically, he compared the extent to which teachers clarify goals, give feedback, and establish challenges in their classrooms, and also the way in which they did it. Observing these practices, he was able to predict in which classroom flow is more likely to occur.

Sedig (2007) designed educational software to enable university students to experience flow while learning geometric plane figure translations, rotations and symmetry. To this end, mathematical tasks were perfectly integrated into a game (interest), SuperTangrams, which sets simple and well-defined rules (clear goals), gives players freedom to choose what they want to do, and allows learners to go through tasks at their own pace (autonomy and control). The game also has several levels of difficulty and a learning module of mathematical concepts that is fully integrated and aimed at the goal of the game. Likewise, it provokes epistemic conflicts and promotes reflection (challenges-skills balance). It also contains background music, special effects, and colourful graphics to engage full attention.

\subsubsection{Flow in Pre-service Teachers and In-Service Teachers}

Our first approach to flow theory in mathematics (Montoro, Gil, \& Moreno, 2013) addressed two questions. As noted above, Schweinle et al. (2008) found that Quadrant 
Model of Flow did not fit well to data from primary school students in mathematical classes. This result, and the fact that the majority of flow theory research had been carried out with talented students (Nakamura, 1998) or using freely chosen activities, had raised questions about the necessity of having great mathematical skills to flow when doing mathematics.

Furthermore, after reviewing the methodology used to identify flow experiences, in addition to ESM and the Quadrant Model of Flow, many closed questionnaires were found. Most of them used the flow dimensions proposed by Csikszentmihalyi (1990) and summarized in Fig. 13.1 (González-Cutre, Sicilia, Moreno, \& FernándezBalboa, 2009; Heine, 1997; Jackson \& Csikszentmihalyi, 1999). However, some authors eliminated some of these dimensions because they considered them to be prerequisites or consequences of the flow experience (Rodríguez-Sánchez et al., 2009; Whalen, 1998).

Moreover, Jackson and Csikszentmihalyi (1999) highlighted that not all dimensions are present in all activities. For example, a long-distance runner does not experience losing track of time because, by the nature of the activity, he or she must monitor time to regulate the speed required to reach the goal. Taking this into account, it was necessary to know which dimensions of flow are linked with mathematical flow situations.

In Montoro et al. (2013) an adaptation of an open questionnaire, used by Whalen (1998) to identify flow activities with talented student, was distributed to 35 mathematics students, 32 engineering students, and 54 pre-service primary school teachers. The questionnaire asks students to name mathematical activities and everyday activities that make them feel each of the flow dimensions, and also the activities where most of these dimensions are present. The data obtained supported RodríguezSánchez, Cifre, Salanova, and Åborg (2008) and Ghani and Deshpande's (1994) approach to identify flow through high levels of concentration and enjoyment. That is, an activity provokes flow in someone if they are deeply concentrated, lose all track of the time, isolated from what is happening around them, and enjoy doing it. Moreover, the percentage of pre-service teachers who claimed to flow with mathematical activities in some moment of their lives was more than $80 \%$ of the survey respondents. That suggests that it is not necessary to have great mathematical skills to flow when doing mathematics, specially, taking into account the gaps in the mathematical knowledge of pre-service teachers found in different research (MECD, 2013). Problem solving was the main flow activity.

Zhu (2001), Gray (2003) and Bakker (2005) pointed out that it is more likely for students to experience flow doing a task when their teachers are also in flow. We could assume, then, that teachers would need the skill to match the challenge of teaching their subjects. Mathematics is considered one of the most demanding and anxiety-provoking subjects (Shernoff, Knauth, \& Makris, 2000). In fact, a high percentage of Spanish pre-service teachers claimed they felt anxious about mathematics, experienced low self-confidence and, therefore, had given up mathematics as soon as it was possible for them to do so (Pérez-Tyteca, 2012). Helping to instill flow in mathematics teachers' training could have an indirect influence on their students' flow experience in mathematics classes. 
Although flow depends on individuals, tasks, and environments in which the tasks are performed, the research described in this chapter starts by analyzing the tasks as they represent the most controllable variable. Teachers are responsible for selecting, designing and implementing the tasks used in their classrooms.

Until now, most of the research into flow in education had assessed its frequency in courses using questionnaires completed at the end of the course. This methodology has a limitation: the problem of knowing which tasks made them experience this feeling. In fact, in our previous study (Montoro et al., 2013), this limitation was also present since the concept of problem can range from a routine exercise to an unknown situation without an immediately available answer.

\subsection{The Present Study}

The primary purpose of the present study is to explore the characteristics of mathematical tasks that enable the occurrence of flow in pre-service primary teachers. To achieve these goal, quantitative and qualitative data were combined to analyze flow as experienced by pre-service teachers facing mathematical tasks set in their training courses. In the first phase, a closed questionnaire was used to compare the percentage of pre-service teachers who experienced flow in different mathematical tasks. Likewise, we sought to obtain information about how interesting, useful, complex and demanding the task had proved to be, how clear the goal of the task had been and if feedback had been forthcoming. Using the data from this phase, one task was selected to be analyzed in depth. Specifically, the behaviour of a group of students solving a problem and their emotions were examined and video-taped. Problems referring to these tasks need to be explored further because an effective way of obtaining solutions is not yet known.

\subsection{Phase 1}

The main aims of this phase of the study were to find out which mathematical tasks provoked flow in a higher percentage of pre-service teachers and to analyze how these tasks were perceived by them.

\subsubsection{Participants}

For reasons of availability, it was decided to explore the flow experienced by 230 pre-service primary school teachers who attended the compulsory "Teaching and Learning Measurement in Primary Education" course at the University of Almeria. 
They were divided into four different groups of roughly 60 students who were taught by the two authors of this paper.

The sample was heterogeneous: $45 \%$ of the students had started the teacher training degree after completing the social sciences baccalaureate at secondary school, $20 \%$ from secondary school science baccalaureate, $20 \%$ from professional/vocational training courses, $8 \%$ from humanities baccalaureate at secondary school and $7 \%$ after passing the university entry exam for mature students (over 25 years of age). Thus, we found a wide range of mathematical training among our sample. In fact, most participants began the course without a good command of school mathematical contents such us operations with decimal numbers, area-perimeter relationship and solving elementary problems.

While we did not find a great difference in students' percentage by gender $(58 \%$ female and $42 \%$ male), there was a great variety of ages: $36 \%$ of students were 21 years old when they attended this course (so they had started this degree as soon as they finished high school), 53\% were between 22 and 27, and $11 \%$ ranged from 28 to 51 years old.

\subsubsection{Tasks}

The course "Teaching and Learning Measurement in Primary Education" was structured in theoretical and practical sessions. In the theoretical sessions, comparison, measurement, and estimation situations were proposed by the teacher and discussed jointly with the group. Likewise, the main mistakes made and difficulties encountered by primary school pupils in similar tasks were explained by the teacher. In the practical sessions, students worked in groups of four or five to solve mathematical tasks. The tasks were designed bearing in mind that participants were expected to find them easy enough to do without becoming mentally blocked, but they were not trivial exercises. Thus, difficulties arose when they faced these tasks. However the pre-service teachers managed to overcome obstacles and re-direct their strategies working as a group. They also expanded their mental structures to include these new situations and saw examples of tasks easily adaptable to primary school ages. Table 13.1 contains a brief description of the tasks.

These five tasks were chosen to be analyzed for several reasons. Firstly, several researchers found that in student-focused classrooms performing tasks individually or with peers can attain a higher level of flow (Heine, 1997; Shernoff, Knauth, \& Makris, 2000). Choosing these activities gave us more opportunities to analyze flow experiences in our course. The second reason is methodological: it was easier to observe feelings in our students while working in groups since they had to talk to one another to find a solution.

The results obtained by Heine (1997) led us to expect that these tasks would provoke flow in a high percentage of students because, objectively, there were only two novel problems. One was the section of task 2 which consisted of measuring the 
Table 13.1 Description of the five tasks

\begin{tabular}{l|l|l}
\hline Task & Description & Material \\
\hline 1 & $\begin{array}{l}\text { Visually ranking objects according to } \\
\text { length, weight, capacity, area, and } \\
\text { volume. } \\
\text { Selecting a way to test the task and find } \\
\text { the right answer. }\end{array}$ & $\begin{array}{l}\text { Shelves, string, different material } \\
\text { spheres, weighing scales, bottles, water, } \\
\text { cards with different shapes, sheets, } \\
\text { scissors, two stones, an empty shaving } \\
\text { foam bottle, and buckets. }\end{array}$ \\
\hline 2 & $\begin{array}{l}\text { Measuring the length of several parts of } \\
\text { the body and finding patterns or } \\
\text { relationships among them. Calculating } \\
\text { the capacity of a mouthful of drink, a } \\
\text { handful, and the lungs. Obtaining the } \\
\text { area of body skin. }\end{array}$ & $\begin{array}{l}\text { Ruler, test tubes, balloons, buckets, } \\
\text { water weighing scales, and toilet paper. }\end{array}$ \\
\hline 3 & $\begin{array}{l}\text { Estimating and measuring the } \\
\text { dimensions of a building }\end{array}$ & $\begin{array}{l}\text { Cyclometer, ruler, and a video } \\
\text { explaining Thales' Theorem }\end{array}$ \\
\hline 4 & $\begin{array}{l}\text { Creating formulas to calculate the area } \\
\text { of different geometric shapes, using an } \\
\text { equilateral triangle as a unit }\end{array}$ & Geoplane, isometric sheets \\
\hline 5 & $\begin{array}{l}\text { Using different instruments to measure } \\
\text { objects in the classroom }\end{array}$ & $\begin{array}{l}\text { Calliper, laser ruler, micrometre, } \\
\text { inclinometer, and dynamometer }\end{array}$ \\
\hline
\end{tabular}

capacity of the lungs and the other was task 4, which sought to discover formulas to calculate the area of plane figures using triangular (instead of a square) units.

\subsubsection{The Flow Questionnaire}

As our purpose was to measure the level of flow experienced by each student at the end of each of the five tasks described above, a brief questionnaire written in Spanish was required. Moreover, the tasks selected here promoted autonomous work, so the experience might vary greatly from one student to another and their perception of the tasks could be very different.

For this reason, the questionnaire had two parts. The first part was composed of those items used to identify flow experiences: two items about concentration and four about enjoyment. In the second part, there were items referring to aspects considered in previous research work as necessary conditions for flow to occur, namely: clear goals, feedback, complexity, interest, and relevance.

For each one of these variables, a positive and a negative item were developed. For example, for deep concentration, the following items were used: "My attention was completely focused on the activity" and "My concentration was easily interrupted by any distraction". In their answers, participants indicated the extent to which they agreed with each sentence on a five-point scale ranging from 1 (strongly disagree) to 5 (strongly agree). 


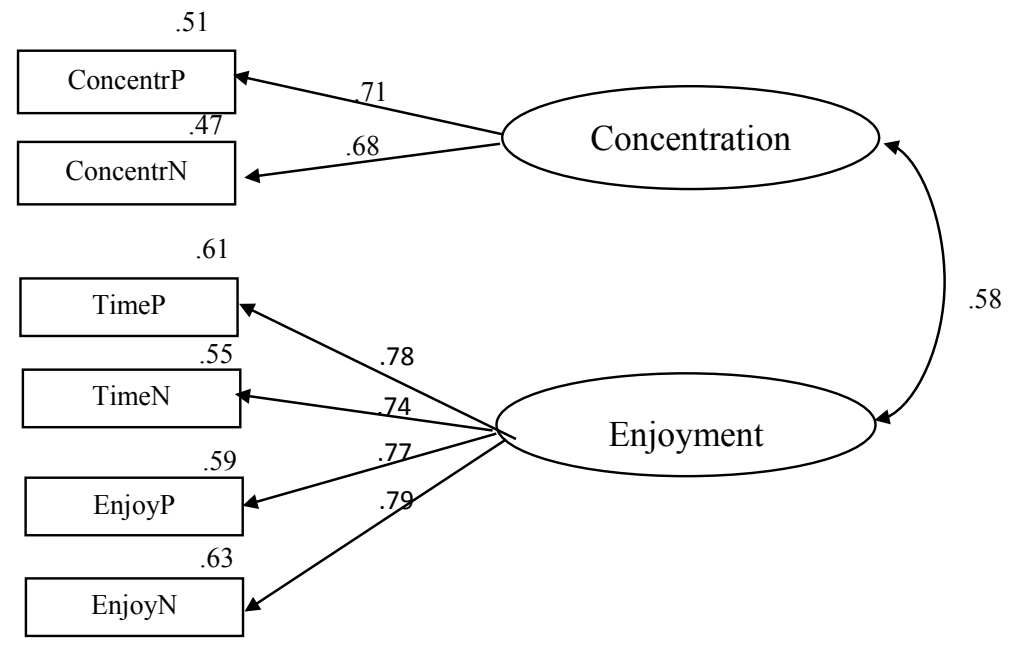

Fig. 13.2 Two factor model of flow. Reliability indicators and loadings

For each student's response to the questionnaire, negative items were inverted and average scores on each scale were calculated. Considering that flow is characterized by a high level of both concentration and enjoyment as discussed above, in instances where students averaged 4 or above (equivalent to agree on all questions) in both concentration and enjoyment, they were considered to be in flow.

An exploratory factor analysis of the data collected in the two first tasks suggested using concentration and enjoyment to identify flow experiences. Interest and loss track of the time are used as enjoyment indicators with the activity (Montoro \& Gil, 2011).

A Confirmatory Factor Analysis was carried out using the data from the five tasks described above, and the two-factor model including concentration and enjoyment showed a good fit. Specifically, as can be seen in Fig. 13.2, the model presented loadings above 0.6 which is established as appropriate (Ruiz, Pardo, \& San Martín, 2010), and the indicators' reliability exceed 0.5 which is considered appropriated (Andrade \& Coba, 2006), excepting the case of the negative item of concentration (ConcentrN).

The goodness of fit of the model was evaluated using absolute and relative goodness of fit indices. Although the Chi-square test is the best known, it was not used here because it assumes multivariate normality and it is sensitive to sample size, rejecting models when large samples are used, and accepting models with very small samples (Byrne, 2010). Researchers have developed different goodness-of fit indices to address these limitations, and suggest to combine them rather than using only one of them. As can be seen in Table 13.2, the Goodness of Fit Index (GFI) and Comparative Fit Index (CFI) values were higher than 0.9, and Root Mean square Residual (RMR) value was less than 0.05, which indicated good fit. Moreover, the Root Mean Square Error of Approximation (RMSEA) values lower than 0.08 represent rea- 
Table 13.2 Relative goodness of fit indices

\begin{tabular}{l|l|l|l|l}
\hline & GFI & RMR & CFI & RMSEA \\
\hline Value & 0.96 & 0.039 & 0.903 & 0.069 \\
\hline Acceptance criterion & More than 0.9 & Less than 0.05 & More than 0.9 & Less than 0.08 \\
\hline
\end{tabular}

sonable errors of approximation in the population. To know more about the items design, the validation process and the fit of other possible models, see Montoro and Gil (2013) and Montoro (2015).

\subsubsection{Results}

Differences in flow experienced in the various tasks are shown below. Table 13.3 shows the number of students who performed each task and how many of them claimed to have attained a high level of concentration and enjoyment doing the task. The percentage of students who experienced flow with each task is shown within a frame.

As expected, $67.2 \%$ of the responses corresponded to flow states. Although these tasks were associated with pleasant situations for most students (at least 50\% experienced flow), there were differences among the percentages of students who experienced flow in all tasks (Table 13.3). For example, while tasks about using measurement instruments, comparing magnitudes, and measuring parts of the body provoked flow in more than $70 \%$ of students, the percentage of students in flow during task 4 , which consisted of obtaining formulas to calculate areas, was roughly $50 \%$. In this task, although the percentage of students concentrating on it was similar to that obtained in the other tasks, the percentage of students who enjoyed doing it was considerably lower.

Once differences on percentage of students in flow among tasks were found, mean and standard deviation of enjoyment and concentration in each task were calculated. As can be seen in Table 13.4, the lower the mean on each variable, the higher the standard deviation. Thus, there was greater agreement in concentration and enjoyment scores given by students when the task had a higher capacity to provoke high concentration and enjoyment. Furthermore, there was generally more agreement in the level of concentration achieved in the task than in the degree of enjoyment students felt in its execution.

In order to find out if the differences on the mean among tasks were significant Bonferroni adjustment for repeated t tests were applied. We determined statistically significant differences when $P$-value was less than 0.01 . Moreover, when statistical significance differences on mean were found, effect sizes were calculate with Cohen's $d$ formula (Table 13.5). We determined a "small" effect size when $d$ was less than 0.25 ; a "medium" effect size if $d$ was from 0.25 to 0.50 , and a "large" effect size if $d$ was greater than 0.5 (Morales, 2012). 
13 Exploring Flow in Pre-service Primary ...

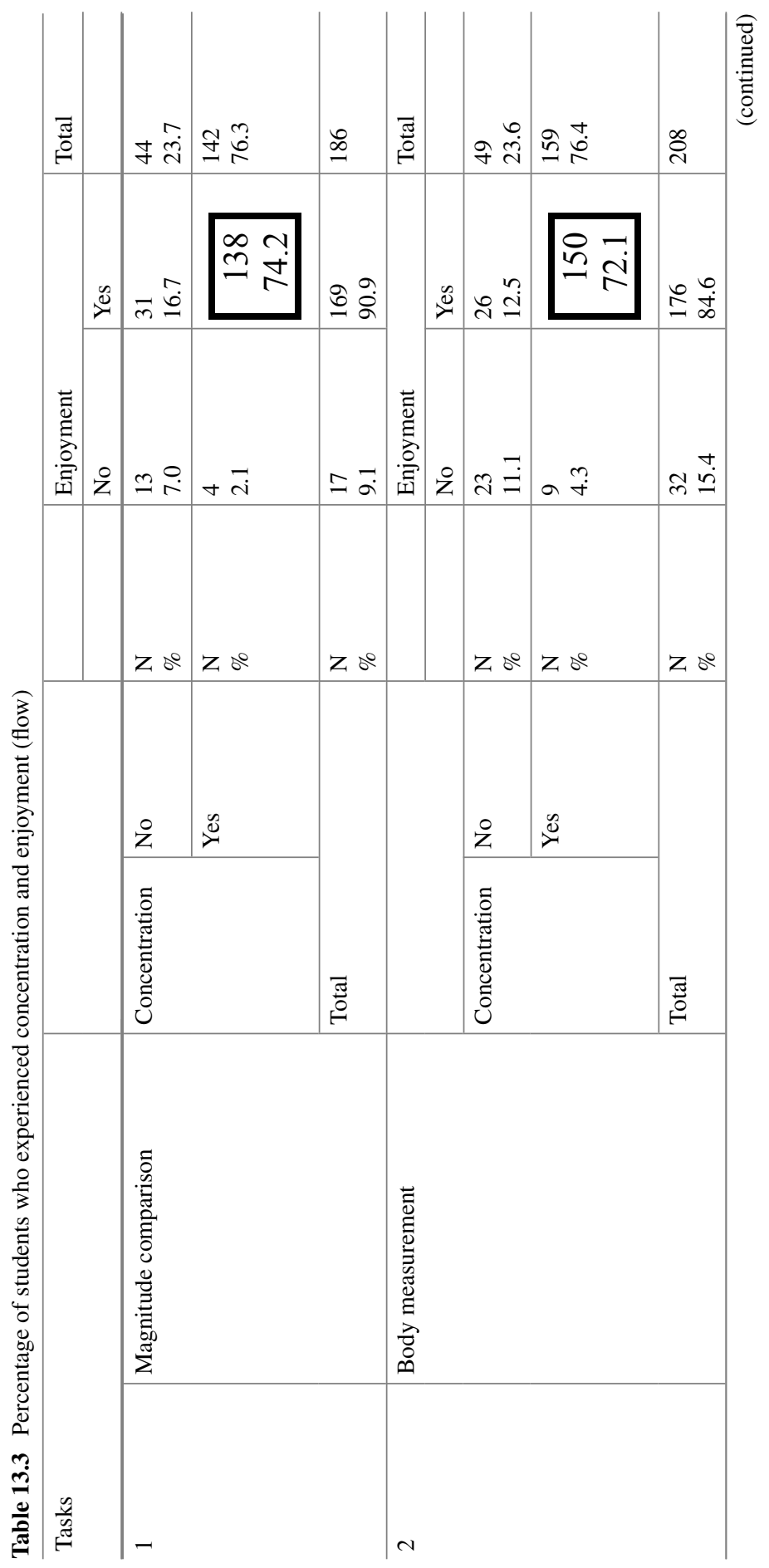




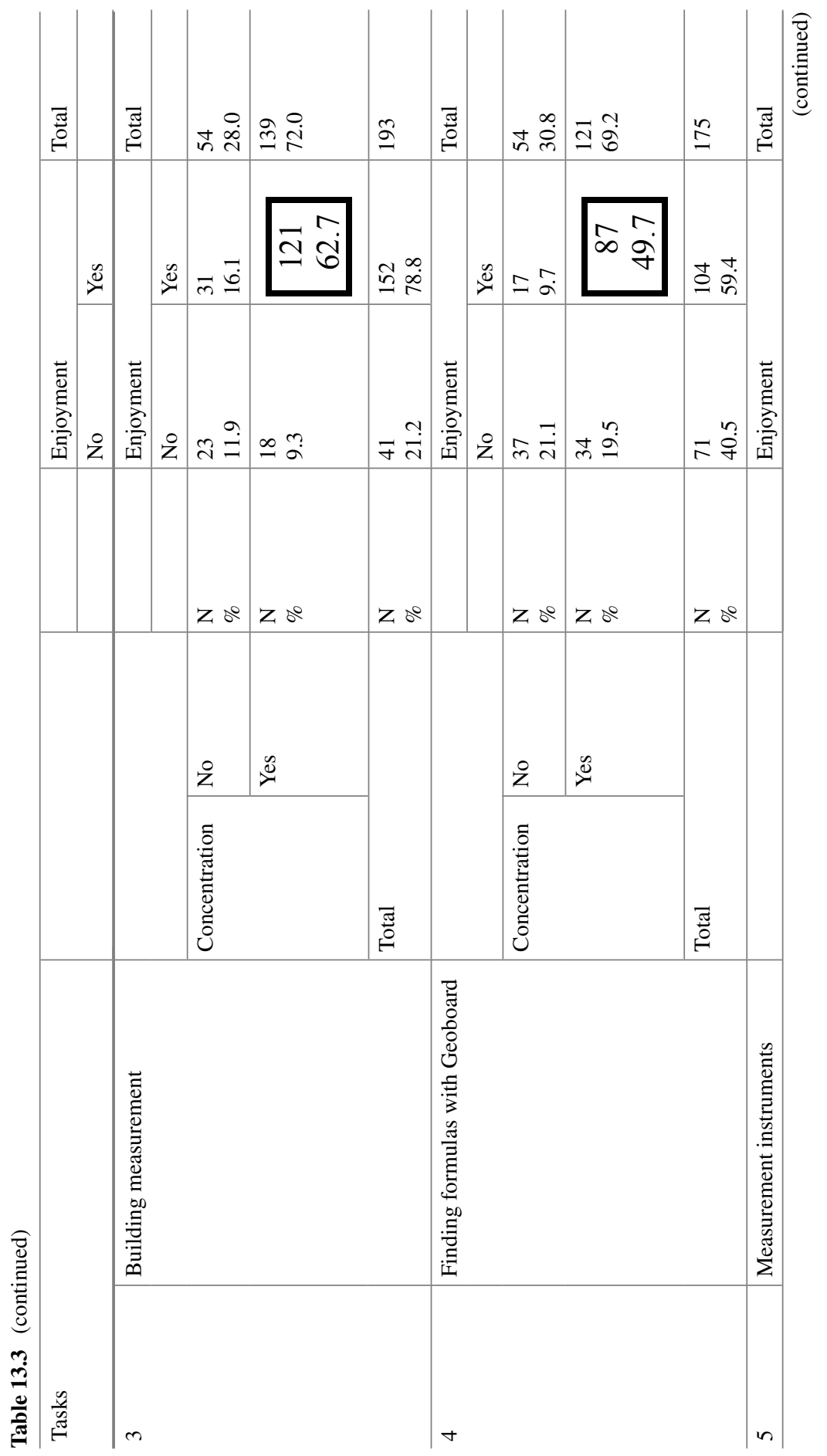


13 Exploring Flow in Pre-service Primary ...

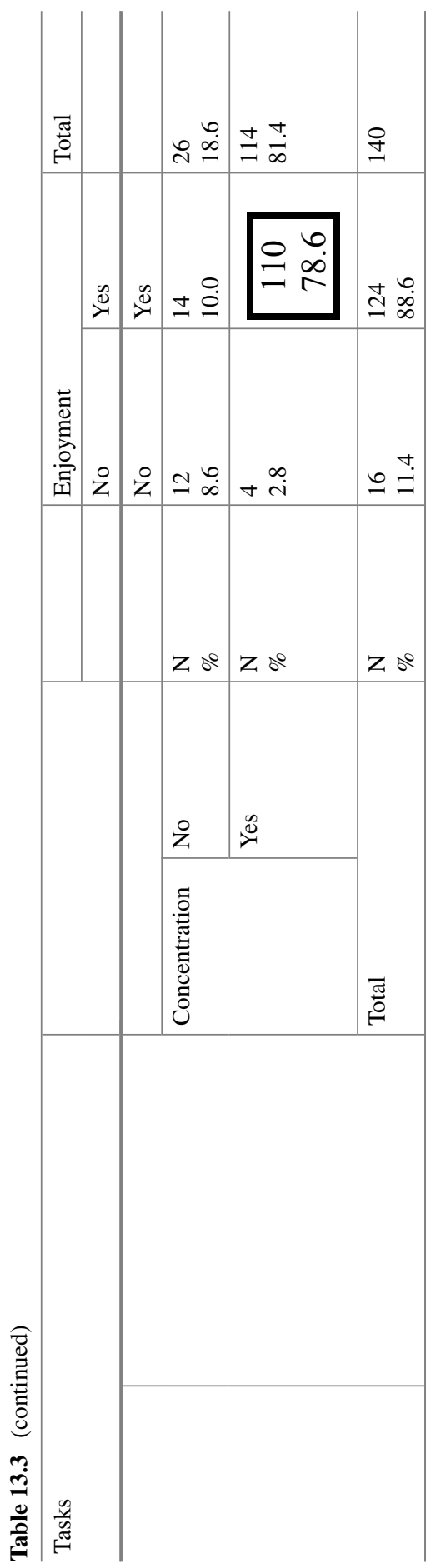


Table 13.4 Descriptive statistics. Concentration and enjoyment of each task

\begin{tabular}{l|l|l|l|l}
\hline & Tasks & $\mathrm{N}$ & $\bar{x}$ & $\sigma$ \\
\hline \multirow{5}{*}{ Enjoyment } & 1 & 185 & 4.478 & 0.415 \\
\cline { 2 - 5 } & 5 & 140 & 4.451 & 0.480 \\
\cline { 2 - 5 } & 2 & 208 & 4.440 & 0.543 \\
\cline { 2 - 5 } & 3 & 194 & 4.295 & 0.587 \\
\cline { 2 - 5 } Concentration & 4 & 175 & 3.924 & 0.867 \\
\cline { 2 - 5 } & 5 & 140 & 4.254 & 0.650 \\
\cline { 2 - 5 } & 2 & 185 & 4.176 & 0.627 \\
\cline { 2 - 5 } & 3 & 208 & 4.135 & 0.744 \\
\cline { 2 - 5 } & 4 & 194 & 4.060 & 0.669 \\
\hline
\end{tabular}

Table 13.5 Statistical significance and effect size on concentration and enjoyment

\begin{tabular}{|c|c|c|c|c|c|c|c|c|c|}
\hline & \multicolumn{2}{|l|}{2} & \multicolumn{2}{|l|}{3} & \multicolumn{2}{|l|}{4} & \multicolumn{2}{|l|}{5} \\
\hline & & $P$ & $D$ & $P$ & $d$ & $P$ & $d$ & $P$ & $d$ \\
\hline \multirow[t]{2}{*}{1} & Concentration & 1 & - & 1 & - & 0.081 & - & 1 & - \\
\hline & Enjoyment & 1 & - & 0.002 & 0.257 & 0.000 & 0.693 & 0.639 & - \\
\hline \multirow[t]{2}{*}{2} & Concentration & & & 1 & - & 0.053 & - & 1 & - \\
\hline & Enjoyment & & & 0.002 & 0.192 & 0.000 & 0.619 & 0.634 & - \\
\hline \multirow[t]{2}{*}{3} & Concentration & & & & & 1 & - & 0.455 & - \\
\hline & Enjoyment & & & & & 0.000 & 0.440 & 1 & - \\
\hline \multirow[t]{2}{*}{4} & Concentration & & & & & & & 0.006 & 0.330 \\
\hline & Enjoyment & & & & & & & 0.000 & 0.630 \\
\hline
\end{tabular}

As can be seen, the only statistical significance difference on the mean on concentration was found between task 4 and task 1, with medium effect size. However, differences statistically significant were found between task 4 and the rest of the tasks, and between task 1 and 3. The differences between 3 and task 1 and 4 has a moderate effect, since the rest was large. In sum, the main differences were found in the level of enjoyment of task 4.

If task 4 is analysed objectively it could be said that it is more complex because it requires using high-order thinking skills (analysis, evaluation, and creation of new ideas). The other tasks required applying and adapting known concepts and procedures to new situations. Moreover, the task was designed to make students feel like a child learning formulas for calculating the area of plane shapes with a similar task. Although the task is easily adaptable to primary school levels, the task is not contextualised in real life and there are not surprising results.

But, how did the student evaluate the tasks? To make the results easier to understand and describe, similar tables to 13.4 and 13.5 with the rest of the variables from 
Table 13.6 Descriptive statistics, significance and size effect of facilitators in tasks (part 1)

\begin{tabular}{|c|c|c|c|c|c|c|}
\hline & Tasks & $\mathrm{N}$ & $\bar{x}$ & $\sigma$ & ES & Sig. \\
\hline \multirow[t]{8}{*}{ Complexity } & 5 & 166 & 2.123 & 0.819 & & \\
\hline & & & & & 0.316 & 0.003 \\
\hline & 2 & 219 & 2.520 & 0.768 & & \\
\hline & & & & & 0.350 & 0.001 \\
\hline & 1 & 211 & 2.824 & 0.715 & & \\
\hline & 3 & 214 & 2.932 & 0.881 & & \\
\hline & & & & & 0.784 & 0.000 \\
\hline & 4 & 209 & 3.665 & 0.858 & & \\
\hline \multirow[t]{6}{*}{ Clear goals } & 5 & 165 & 4.230 & 0.748 & & \\
\hline & 1 & 211 & 4.042 & 0.756 & & \\
\hline & 2 & 220 & 3.911 & 0.745 & & \\
\hline & 3 & 215 & 3.786 & 0.921 & & \\
\hline & & & & & 0.320 & 0.001 \\
\hline & 4 & 206 & 3.476 & 0.945 & & \\
\hline \multirow[t]{6}{*}{ Interest } & 1 & 213 & 4.645 & 0.468 & & \\
\hline & 2 & 219 & 4.550 & 0.539 & & \\
\hline & 5 & 166 & 4.410 & 0.656 & & \\
\hline & 3 & 217 & 4.380 & 0.654 & & \\
\hline & & & & & 0.387 & 0.000 \\
\hline & 4 & 209 & 4.048 & 0.813 & & \\
\hline
\end{tabular}

the questionnaire (complexity, clear goal, feedback, utility and interest) were combined. Table 13.6 shows descriptive statistics of each variable, ranked by mean, and $d$ and $p$ values, when differences were statistically significant and relevant. In this way, the effect size of the differences between the mean of two tasks is always equal or higher than the $d$-value shown in the sixth column of Table 13.6 and any row between them. For example, the $d$-value corresponding with the difference of means in complexity between task 5 and 2 is 0.316 , between task 5 and task 2 is 0.801 , and between task 5 and 4 is 1.677 (the highest $d$-value obtained in all the variables).

As can be seen in Table 13.6, statistically significant differences in the level of complexity were found between all the tasks, except between task 1 and 3 . Task 4 was perceived as the most complex task, with a 3.6 average score on a 5-point scale. Compared with the other tasks the difference in average scores of complexity was statistically significant and the size effect was high.

Moreover, statistically significant differences and a medium size effect were found in average scores on clear goals between task 4 and tasks 3 and 5, and large size effect between task 4 and tasks 1 and 2. The goal of task 4 was less clear for students than the other. 
Table 13.7 Descriptive statistics, significance and size effect of facilitators in tasks (part 2)

\begin{tabular}{l|l|l|l|l|l|l}
\hline & Tasks & $\mathrm{N}$ & $\bar{x}$ & $\sigma$ & $d$ & $P$ \\
\hline \multirow{5}{*}{ Feedback } & 5 & 165 & 3.970 & 0.770 & & \\
\cline { 2 - 7 } & 1 & 211 & 3.965 & 0.815 & & \\
\cline { 2 - 7 } & 2 & 219 & 3.737 & 0.797 & & \\
\cline { 2 - 7 } & 3 & 215 & 3.695 & 0.885 & & \\
\cline { 2 - 7 } & 4 & 209 & 3.555 & 0.875 & & \\
\hline Usefulness & 1 & 211 & 4.491 & 0.571 & & \\
\cline { 2 - 7 } & 2 & 220 & 4.400 & 0.613 & & \\
\cline { 2 - 8 } & 5 & 165 & 4.367 & 0.615 & & \\
\cline { 2 - 7 } & 3 & 215 & 4.309 & 0.658 & & \\
\cline { 2 - 7 } & 4 & 209 & 4.201 & 0.729 & & \\
\hline
\end{tabular}

Moreover, task 4 was considered the least interesting task. Similar to the clear goals, relevant and statistically significant differences was found between task 4 and the rest, with a large effect on differences between task 4 and task 1.

In the case of the usefulness of the tasks significant and relevant differences were only found between task 1 and tasks 4 and 3. These differences were also found on the feedback provided, and between task 4 and task 5 . All of these differences have medium size effect. Furthermore, students may have considered these tasks useful for their training (Table 13.7).

\subsection{Phase 2: Factors Influencing Flow}

The results from the last phase led us to analyze task 4 in detail in order to identify aspects of it that hinder flow experiences, and thus, if possible, to modify them in order to raise the percentage of students in flow in future courses.

To this end, groups of students were asked to volunteer to be videotaped while solving each task. Finally, it was decided to analyze the responses to the questionnaire of one group in which the members had all concentrated hard on the tasks and found them all enjoyable, except that of obtaining formulas to calculate the area of plane shapes which was the only task that did not provoke flow in them.

The group was composed of the following members:

- One student who passed but did not obtain a high mark. She is confident of her abilities and strategies when facing easy tasks. However, she has doubts when the task is complex or when she is with classmates who have a good command of mathematics and do not think in the same way as she does (P1). 
- Two students who passed the subject without a high mark, who like mathematics, have high self-confidence, and persevere to overcome obstacles and correct mistakes (P2 and P3).

- One student who obtained a distinction in the course, loves mathematics, and has wanted to be a teacher since she was a child. She has high self-confidence and does not give up when faced with difficulties (P4).

- Videos were analyzed using Atlas.ti 7 software, which allowed us to select extracts, codify them, and create comments that facilitated idea-links without losing the richness of the audiovisual data.

To codify the videos we used 16 categories. Some of these were codes to identify flow experiences: concentration/lack of concentration, enjoyment/lack of enjoyment, and positive emotions/negative emotions. Other categories represented the presence or absence of aspects linked to flow in previous research work that were included in the questionnaire described above: perceived complexity, clear goals, feedback, relevance, and interest. The third column in Tables 13.8, 13.9 and 13.10 shows examples of the coding system.

Subsequently, we focused our attention on changes that occurred in the reported level of concentration, enjoyment or emotions, in order to find the causes of these changes. We specifically looked for an increase in the complexity of the task, interaction between students, interaction with the teacher, and other possible aspects of the task and surroundings. In this case, it was essential to pay attention to what the students were doing at that moment in time, what they were saying, how they said it, their body language, their facial expressions, and their gestures.

Firstly, "key elements" were identified in the video. These were segments that were especially rich in positive or negative emotion or that depicted changes in students' behaviour or emotion. For reasons of consistency, in addition to the authors, independent researchers familiar with flow theory watched the video and noted segments that were particularly emotionally charged. Subsequently, the key elements of the video were transcribed in two columns, one transcribing the student's speech and another describing how it was delivered or expressed and what the student was doing at each moment (see examples in Tables 13.8, 13.9 and 13.10). It was necessary to watch the videos numerous times to ensure that no important fact or detail had been overlooked.

Other categories emerged from this analysis. In addition to lack of feedback, of clear goals, increased complexity of the task, and how interesting the task was, changes in students' behaviour could be largely explained by their level of selfconfidence and the interest shown by their colleagues in the group when expressing their ideas. 


\subsubsection{Results}

The session began with the teacher's description of the aim of the tasks: to acquire a significant teaching and learning method in order to obtain formulas to calculate the area of plane figures and to confront the difficulties of this learning process. The teacher then explained what the task consisted of: obtaining formulas to calculate the area of different plane figures, and taking as a unit an equilateral triangle with sides measuring one centimetre. To ensure that they understood the goal, it was necessary to solve the first example together. Even though the participants solved rapidly the first shape proposed (equilateral triangle), they found the task complex (Table 13.8).

Finding the formula for equilateral triangles, regular hexagons, rhombi and rhomboids is a task of intermediate complexity. It can be solved using decomposition geometric or numeric (searching patterns) methods. Each member of the group discovered the formula for one of these plane figures (P1, P3, P4, and P2, respectively) and was able to understand and evaluate the ideas of their peers. Therefore, their colleagues, and the Geoboards, provided them with immediate feedback.

At the beginning of the task, $\mathrm{P} 4$ (nominated by the group) was responsible for completing the working document for this task. In some situations this activity deprived her of time to reflect on the pattern of the task, which was, in the students' opinions, the most interesting aspect. Something similar happened to P1 who needed more time than P2 and P3 to discover formulas. They were sometimes so absorbed in their discussions or in the search for formulas that they did not listen to P1's ideas or even try to involve her in the activity (Table 13.9).

In this situation P4 asked her partners for help to complete the document. P2 usually organised the ideas proposed using geometric terminology and saying what to put into the document, although in general everybody contributed. However, although in this situation P4 asked her partners for help to complete the document. P2 usually organized the ideas proposed using geometric terminology and saying what to write in the document, although in general everybody contributed. However, although P1 was still working and suggesting ideas, her interventions become fewer as the task advanced. She only tried to understand the ideas proposed by her peers and drew the plane figures on the Geoboard. She seemed unwilling to continue doing the task. In contrast, the rest of the group showed signs of enjoying it, especially P2 and P3.

Table 13.8 Perceived complexity of the task

\begin{tabular}{l|l|l}
\hline Speech & Actions and comments & Codes \\
\hline $\begin{array}{l}\text { P3: Shall we do this with all the } \\
\text { shapes? }\end{array}$ & $\begin{array}{l}\text { The expressions on their faces show } \\
\text { that they find the task complicated. }\end{array}$ & Complexity \\
\cline { 1 - 2 } $\begin{array}{l}\text { Teacher: yes. But... you have done } \\
\text { one in just a minute! Perfect! }\end{array}$ & $\begin{array}{l}\text { P2 moves her hands as if to say: "My } \\
\text { goodness!" }\end{array}$ & Goals \\
\cline { 1 - 1 } P1: I know, but it was the easiest one & & \\
$\begin{array}{lll}\text { Teacher: Well... don't worry, just do } \\
\text { your best }\end{array}$ & & \\
\hline
\end{tabular}


Table 13.9 Working on hexagon formula

\begin{tabular}{|c|c|c|}
\hline Speech & Actions and comments & Codes \\
\hline P2: Ok, the one with 2 has 24. & \multirow[t]{2}{*}{$\mathrm{P} 3$ points to the sides of the hexagon } & \multirow[t]{4}{*}{ Concentration } \\
\hline P3: 2 times $1,2 \ldots$ & & \\
\hline P2: $6 \times 2=12$. No, it doesn't work & $\mathrm{P} 2$ counts fast & \\
\hline $\begin{array}{l}\text { P1: there are three triangles in each } \\
\text { side... ah, no. }\end{array}$ & $\begin{array}{l}\text { P1 is focused on her Geoboard but } \\
\text { she gets it wrong when counting. }\end{array}$ & \\
\hline $\begin{array}{l}\text { P3: Look! } 12 \times 2 ! 1,2,3,4,5,6,7 \\
8,9,10,11,12 . \text { Times } 2,24\end{array}$ & \multirow{4}{*}{$\begin{array}{l}\text { P3 shouts and slaps P2's hand. She } \\
\text { counts the triangles that fit in the } \\
\text { perimeter. She seems to have found } \\
\text { the pattern. }\end{array}$} & \multirow[t]{2}{*}{ Enjoyment } \\
\hline P1: what? & & \\
\hline $\begin{array}{l}\text { P2 and P4: Let's try with another } \\
\text { size }\end{array}$ & & \multirow[t]{2}{*}{ Interest } \\
\hline P3: Me, me, me, please & & \\
\hline $\begin{array}{l}\text { P3: } 96.24 \times 4 \text {. What did I tell you? } \\
\text { It's the sides that multiply by } 4 . \text { No! }\end{array}$ & $\begin{array}{l}\mathrm{P} 3 \text { speaks excitedly. } \mathrm{P} 2 \text { high-fived } \\
\text { P3 who continues explaining the } \\
\text { rule. }\end{array}$ & \multirow[t]{2}{*}{ Enjoyment } \\
\hline P1: 4* 1, 2, 3, 4, 5, 6, 24. Times 4. & P1 counts the sides of the hexagon. & \\
\hline $\begin{array}{l}\text { P3: Multiply by the gaps. Yes, P1 is } \\
\text { right. We count the side, } 4 \text {. Multiply } \\
\text { by the number of sides, } 6 \text {. It's } 24 \text {. } \\
\text { And then, we multiply by the } \\
\text { number of gaps. } 24 \times 4 \ldots \text { and it } \\
\text { works. }\end{array}$ & $\begin{array}{l}\text { P3 finishes P1's sentence, speaks } \\
\text { very excitedly. She has just } \\
\text { remembered her idea. }\end{array}$ & Feedback \\
\hline
\end{tabular}

The rest of the figures required composition and decomposition strategies and the creation of new ideas such as measuring height with $60^{\circ}$ instead of $90^{\circ}$. However, to continue measuring the height in the usual way $\left(90^{\circ}\right)$, it would have been necessary to calculate the height of the equilateral triangle used as unit and to adjust the formulas.

This increased complexity was reflected in the mental block caused by the need to change strategy. The lack of suitable and useful alternatives among those proposed provoked mixed feelings in the group. Except P1, who seemed to have resigned herself to trying to understand the ideas of her peers, the other students seemed a little confused and cross (Table 13.10). Nevertheless, they persevered despite the difficulties and suggested new ideas. For example, P3 observed that they needed to know the height of the equilateral triangle in order to continue. They decided to assume it measured $1 \mathrm{~cm}$. (the same as the side), and obtained the same formula as for the rhomboid figure (Fig. 13.3). Although P3 thought it was strange that the two shapes had the same formula, they were convinced that it was the correct answer because it worked for all the rectangles drawn on the Geoboard. In the right-angle triangle they considered that putting two right-angle triangles together they could get one rectangle with the same base and height. Thus, their formula also worked for all the right-angle triangles drawn on the Geoboard. 
Table 13.10 Working on scalene triangle

\begin{tabular}{|c|c|c|}
\hline Speech & Actions and comments & Codes \\
\hline P2: but... it does not look good. & \multirow[t]{3}{*}{ P2 seems to be a little angry } & \multirow[t]{3}{*}{ Lack of enjoyment } \\
\hline P4: You are right... & & \\
\hline $\begin{array}{l}\text { P3: Move to the next one, which } \\
\text { has all the sides equals and when } \\
\text { she [teacher] comes, we do it. }\end{array}$ & & \\
\hline $\begin{array}{l}\text { P2: it is like this, but how can we } \\
\text { count now? }\end{array}$ & $\begin{array}{l}\text { P2 shows the Geoboard to her } \\
\text { colleagues }\end{array}$ & \multirow[t]{4}{*}{ Interest } \\
\hline $\begin{array}{l}\text { P4: We could count just the ones } \\
\text { we know. Ow, but those we } \\
\text { have... }\end{array}$ & \multirow[t]{2}{*}{ P4 starts to count. } & \\
\hline P2: That's why! & & \\
\hline P3: and what about those? & $\begin{array}{l}\text { P3 was almost always looking at } \\
\text { her Geoboard. }\end{array}$ & \\
\hline $\begin{array}{l}\text { P2: I have a plan. If we join this } \\
\text { little piece with this other, it's one } \\
\text { triangle. }\end{array}$ & \multirow[t]{6}{*}{$\begin{array}{l}\mathrm{P} 2 \text { is joking. All laugh, but } \mathrm{P} 3 \\
\text { notices that it is not such a bad } \\
\text { idea. }\end{array}$} & \multirow[t]{3}{*}{ Enjoyment } \\
\hline $\begin{array}{l}\text { P3: With this one... Seriously, } \\
\text { these two together form one. And } \\
\text { this one with this also. }\end{array}$ & & \\
\hline P4: It is true & & \\
\hline $\begin{array}{l}\text { P2: and, can you explain me that } \\
\text { one? }\end{array}$ & & \multirow[t]{3}{*}{ Concentration } \\
\hline P4: and that one? & & \\
\hline P2 and P3: ok, move to the next. & & \\
\hline
\end{tabular}

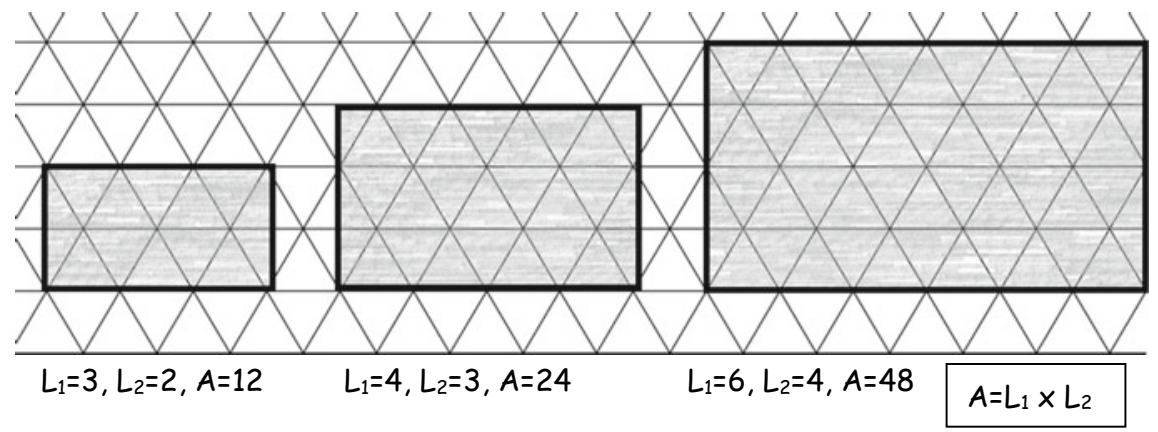

Fig. 13.3 Resolution of rectangle 
Fig. 13.4 Resolution of the scalene triangle

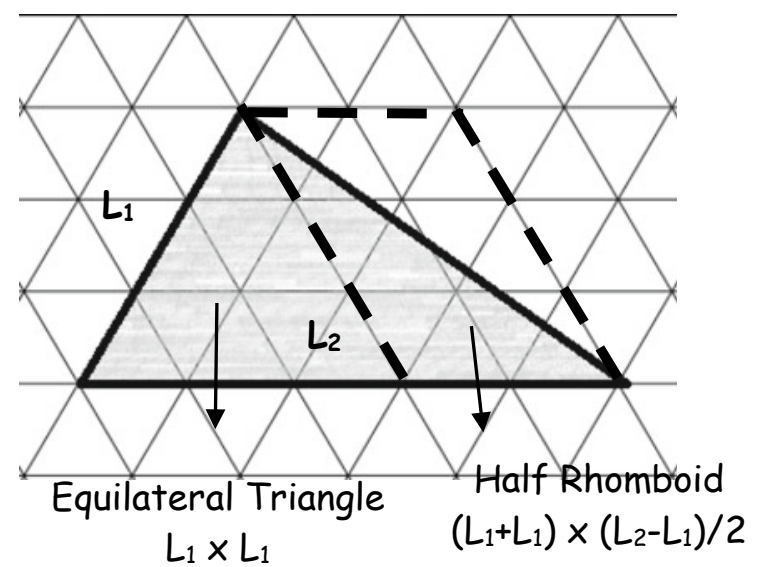

However, the scalene triangle produced in them a mental block because they did not know how to count the triangles inside. It seemed that they wanted all the triangles inside the scalene triangle to fit completely or be divided exactly in half in order to keep using the same strategy.

As soon as the teacher arrived she suggested thinking about different strategies and asked them how they had solved the rectangle formula. At that moment she made them aware of the fact that they had made a mistake supposing that the height of the equilateral triangle was the same as its sides (Fig. 13.3). Their formulas would not work if they used a ruler to measure. The Geoboard had given them misleading feedback in this situation. P1 and P3 did not understand why it was not valid but they did not say anything until the end of the session. They might have failed to understand the problem or they might not have been aware of the need to use a common unit to measure the base and the height of the rectangle in order to find a useful formula for any shape drawn on white paper. This might have been caused by a conflict between the students' goal, which could have been to discover a pattern or rule for calculating the area of plane figures using the Geoboard, and the teacher's goal, which was to find a valid formula to do this calculation in general.

With the exception of P1, all students continued working on a solution to the problem. P3 and P4 showed flexible thinking. P3 found a decomposition of the scalene triangle in figures with formulas already known to them (Fig. 13.4). She felt proud of her achievement but realized that getting an algebraic formula was a really complex task. As soon as she tried, and encountered difficulties, she began to doubt the validity of her decomposition. Since the teacher had told them that the rectangle formula was incorrect, her self-confidence decreased. The group finally completed the problem with the teacher's help.

Having succeeded with other figures, and solved this one, encouraged students to continue working. However their affective mood was different: none of them were enthusiastic. In short, P2 and P3 showed signs of enjoyment and of being focused on finding patterns. However, explaining their ideas and expressing them in algebraic 
language was perceived as tedious. Thus, it can be stated that they were in and out of flow states during the first part of the session. Nevertheless, the inconsistency that emerged between the feedback provided by the Geoboard and teacher's feedback, the fast increase in complexity of the task, and a potential conflict between the teacher's and the students' goals that became apparent in the second part of the task, hindered the occurrence of flow experiences.

In the case of P1, it was observed that the speed with which her peers made further progress in the task stopped her from developing new skills to solve rhomboids and from being be able to solve the next shape, thus, she regarded her skills as unequal to the challenges of the task. Something similar happened with P4 who started to participate finding patterns after the second figure. However, she showed signs of willingness to do this task when she tried to get another colleague to complete the working document so that she could look for the rule.

\subsection{Conclusion and Discussion}

As stated in the introduction, our main goal, as a researcher and a teacher-trainer, is to create educational environments in which pre-service primary education teachers can have more opportunities to experience flow. Specifically, we decided to focus on analyzing the mathematical tasks that provoked flow in pre-service primary school teachers working in groups.

Data from 230 pre-service primary students show tasks which provoked flow for over $70 \%$ of the students when working in groups. These data suggest that under certain conditions almost every student can experience flow when learning mathematics. In our case, the tasks were considered useful for their training and future working life. The students found the tasks neither too easy nor too difficult but realized that their previous ideas were wrong and led them to make mistakes when tackling this activity. However, in group discussions they were able to adapt their procedures and overcome difficulties. Subsequently, they felt they had learned from their work and that their future students would also learn if they, as teachers, adapted the tasks to their pupils' ages. Thus, they acquired useful learning as both mathematics students and future teachers.

Although the environment in which these five tasks were carried out was the same (teacher, classroom, members of each group, time to finish it, topic of study...), the percentage of students who experienced flow changed from one task to another. It was discovered that the easier the task was perceived to be, the higher percentage of students experienced flow. However, none of the tasks analyzed was considered either too easy or too difficult. Therefore, it is necessary to analyze what happened in this situation.

The highest percentage of students in flow was found in a task that consisted of using measurement instruments and reproducing what the teacher had done with another object. The next percentage of students in flow was found in magnitude comparison and body measurement tasks that required modification of a known 
procedure or concept to be applied to new situations, thus presenting a medium level of complexity (Anderson \& Krathwohl, 2001). In contrast, the only task considered to be problem-solving showed the lowest percentage of students in flow. Conversely, in Montoro et al. (2013), university students named problem solving as the main flow activity in mathematics. This fact could be explained by the ambiguity of the term problem-solving. Text books usually use this term referring to contextualized exercises.

Students found Task 4 complex, their results were unsurprising, and the task was not contextualized in the real life.

After analyzing the development of problem-solving tasks with a group of students, clear goals and feedback were found to be crucial to flow experiences. We believe that when task complexity levels increase rapidly, using heterogeneous groups hinders the flow experience in students with lower mathematical skills, as they lack time to reflect on the tasks or to draw their own conclusions. This might also influence their self-confidence in a negative way. In these situations we suggest using homogeneous groups and/or collaborative work techniques to ensure that all members have the opportunity to think about task solutions.

In conclusion, to facilitate the emergence of flow when working in groups, in addition to the fact that the tasks must be interesting and useful for their real life or their training, our data suggest the necessity for all the three factors proposed in previous research to be present: pre-service primary school teachers must be clear about task requirements, receive immediate feedback on their performance, and feel able to face challenges and overcome difficulties. Moreover, they must notice that they significantly contribute to the group.

Further research currently being conducted indicates that the closed questionnaire, described in part four, is a useful tool for identifying flow in primary and secondary school students learning mathematics (Berenguel et al., 2016; Gil, Torres, \& Montoro, 2017).

In Gil et al. (2017), the flow produced in students when listening to their teacher's explanations and carrying out similar exercises to those the teacher had just done, was greater than that which occurred when performing open tasks, external to the textbook.

This suggests that some teachers are able to produce flow in students with their explanations. One reason for this result is that students with average skills find clear goals in repetition and know how to start working on a procedure. Furthermore, this helps them to avoid becoming mentally blocked and boosts their self-confidence.

It would be interesting to analyze the differences between average students attending compulsory mathematics classes and those studying mathematics as an extracurricular activity. Specifically, it would be enlightening to examine the influence on flow of problem solving exercises for which students learn metacognition techniques and heuristics, and then to analyze in depth the role of challenges and self-confidence in average students attending compulsory curricular mathematics classes. 


\section{References}

Anderson, L. W., \& Krathwohl, D. R. (2001). A taxonomy for learning, teaching, and assessing: A revision of Bloom's taxonomy of educational objectives. New York, NY: Longman.

Andrade, J., \& Coba, M. (2006). Modelización de ecuaciones estructurales. Retrieved from http:// bibdigital.epn.edu.ec/handle/15000/227.

Bakker, A. B. (2005). Flow among music teachers and their students: The crossover of peak experiences. Journal of Vocational Behaviour, 66, 26-44.

Berenguel, E., Gil, F., Moreno, M. F., \& Montoro, A. B. (2016). Concentración y disfrute de estudiantes de secundaria realizando tareas abiertas. UNO, 71, 67-71.

Byrne, B. M. (2010). Structural equation modeling with Amos: Basic concepts, applications, and programming (2nd ed.). New York, NY: Taylor and Francis Group.

Csikszentmihalyi, M. (1975). Beyond boredom and anxiety. San Francisco, CA: Jossey-Bass.

Csikszentmihalyi, M. (1990). Flow: The psychology of optimal experiences. New York, NY: Harper Collins.

Csikszentmihalyi, M. (1997). Finding flow. The psychology of engagement with everyday life. New York, NY: Basic Books.

Csikszentmihalyi, M., \& Csikszentmihalyi, I. S. (1988). Optimal experience: Psychological studies of flow in consciousness. Cambridge, England: Cambridge University Press.

Csikszentmihalyi, M., Rathunde, K., \& Whalen, S. (1993). Talented teenagers: The roots of success and failure. New York, NY: Cambridge University Press.

DeBellis, V. A., \& Goldin, G. A. (2006). Affect and meta-affect in mathematical problem solving: A representational perspective. Educational Studies in Mathematics, 63, 131-147.

Deci, E. L., \& Ryan, R. M. (1985). Intrinsic motivation and self-determination in human behavior. New York, NY: Plenum.

Ghani, J. A., \& Deshpande, S. P. (1994). Task characteristics and the experience of optimal flow in human-computer interaction. The Journal of Psychology, 128, 381-391.

Gil, F., Torres, T., \& Montoro, A. B. (2017). Motivación en matemáticas en estudiantes de primaria. International Journal of Developmental and Educational Psychology, 1(1), 85-94.

Gray, P. (2003). Analysis of teachers' flow experiences as they relate to principal classroom walkthroughs. Unpublished data from the report to Shawnee Mission School Board, Shawnee Mission, Kansas.

González-Cutre, D., Sicilia, A., Moreno, J. A., \& Fernández-Balboa, J. M. (2009). Dispositional flow in physical education: Relationships with motivational climate, social goals, and perceived competence. Journal of Teaching in Physical Education, 28, 422-440.

Heine, C.A. (1997). Task enjoyment and mathematical achievement. Unpublished doctoral thesis. University of Chicago, United Stated of America.

Hektner, J.M., \& Csikszentmihalyi, M. (1996). A longitudinal exploration of flow and intrinsic motivation in adolescents. Paper presented at Annual Meeting of the American Educational Research Association. New York, NY. Retrieved from http://files.eric.ed.gov/fulltext/ED395261. pdf.

Hektner, J.M., Schmidt, J.A., \& Csikszentmihalyi, M. (2007). Experience sampling method: Measuring the quality of everyday life. Thousand Oaks, CA: Sage.

Jackson, S. A., \& Csikszentmihalyi, M. (1999). Flow in sports: The keys to optimal experiences and performances. Champaign, IL: Human Kinetics Publishers.

Kanfer, R. (1994). Motivation. In N. Nicholson (Ed.), The Blackwell dictionary of organizational behavior (pp. 1-53). Oxford: Blackwell Publishers.

Larson, R. (1998). Flow and writing. In M. Csikszentmihalyi \& I. S. Csikszentmihalyi (Eds.), Optimal experience: Psychological studies of flow in consciousness (pp. 71-90). Cambridge, England: Cambridge University Press.

Liljedahl, P. (2016). Flow: A framework for discussing teaching. In C. Csíkos, A. Rausch, \& J. Szitányi (Eds.), Proceedings of the 40th Conference of the International Group for the Psychology of Mathematics Education. Szeged, Hungary. 
MECD. (2013). TEDS-M. Estudio internacional sobre la formación inicial en matemáticas de los maestros. IEA. Informe Español. http://www.mecd.gob.es/dctm/inee/internacional/teds-mvol2linea.pdf?documentId=0901e72b8171f9cf. Accessed 12 January, 2014.

Mesurado, B. (2010). La experiencia de flow o experiencia óptima en el ámbito educativo. Revista Latinoamericana de Psicología, 42(2), 183-192.

Middleton, J. A. (2013). More than motivation: The combined effects of critical motivational variables on middle school mathematics achievement. Middle Grades Research Journal, 8(1), 77-95.

Montoro, A. B. (2015). Motivación y matemáticas: Experiencias de flujo en estudiantes de Maestro de Educación Primaria. Almeria, Spain: Editorial Universidad de Almería.

Montoro, A. B., \& Gil, F. (2013). Measuring flow in mathematical tasks. In A. M. Lindmeier \& A. Heinze (Eds.), Proceedings of the 37th Conference of the International Group for the Psychology of Mathematics Education (Vol. 5, p. 130). Kiel, Germany: PME.

Montoro, A. B., \& Gil, F. (2011). Elaboración y aplicación de un instrumento para medir experiencias de flujo. In A. Estepa, A. Contreras, J. Deulofeu, M. C. Penalva, F. J. García, \& L. Ordoñez (Eds.), Investigación en Educación Matemática XVI (pp. 397-406). Jaen: SEIEM.

Montoro, A. B., Gil, F., \& Moreno, M. F. (2013). Experiencias de flujo en el aprendizaje de las matemáticas. European Scientific Journal, 9, 243-262.

Morales, P. (2012). El tamaño del efecto (effectsize): análisis complementarios al contraste de medias. Retrieved from http://www.upcomillas.es/personal/peter/investigacion/Tama\% F1oDelEfecto.pdf.

Nakamura, J. (1998). Optimal experiences and the uses of talent. In M. Csikszentmihalyi \& I. S. Csikszentmihalyi (Eds.), Optimal experience: Psychological studies of flow in consciousness (pp. 71-90). Cambridge: Cambridge University Press.

Nakamura, J., \& Csikszentmihalyi, M. (2002). The concept of flow. In C. R. Snyder \& S. J. Lopez (Eds.), Handbook of positive psychology (pp. 89-105). Oxford: Oxford University.

Pérez-Tyteca, P. (2012). La ansiedad matemática como centro de un modelo causal predictivo de la elección de carreras (Unpublished doctoral thesis), University of Granada, Spain.

Rathunde, K., \& Csikszentmihalyi, M. (1993). Undivided interest and the growth of talent: A longitudinal study of adolescents. Journal of Youth and Adolescence, 22, 1-21.

Rodríguez-Sánchez, A. M., Cifre, E., Salanova, M., \& Åborg, C. (2008). Technoflow among Spanish and Swedish students: A confirmatory factor multigroup analysis. Anales de Psicología, 24, $42-48$.

Ruiz, M., Pardo, A., \& San Martín, R. (2010). Modelos de ecuaciones estructurales. Papeles del Psicólogo, 31(1), 34-45.

Schunk, D. H., \& Mullen, C. A. (2012). Self-efficacy as an engaged learner. In S. L. Christenson, A. L. Reschly, \& C. Wylie (Eds.), Handbook of research on student engagement (pp. 219-235). New York, NY: Springer.

Schweinle, A., Turner, J. C., \& Meyer, D. K. (2002). Motivational and affective quality of students' experiences in mathematics classrooms. Paper presented at the Annual Meeting of the American Psychological Association. Chicago. Retreived from http://files.eric.ed.gov/fulltext/ED470006. pdf.

Schweinle, A., Turner, J. C., \& Meyer, D. K. (2006). Striking the right balance: Students' motivation and affect in elementary mathematics. The Journal of Educational Research, 99(5), 271-293.

Schweinle, A., Turner, J. C., \& Meyer, D. K. (2008). Understanding young adolescents' optimal experiences in academic settings. The Journal of Experimental Education, 77(2), 125-143.

Sedig, K. (2007). Toward operationalization of "flow" in mathematics learnware. Computers in Human Behaviour, 23, 2064-2092.

Shernoff, D. J., Abdi, B., Anderson, B., \& Csikszentmihalyi, M. (2014). Flow in school revisited. Cultivating engaged learners and optimal learning environments. In M. J. Furlong, R. Gilman, \& E. S. Huebner (Eds.), Handbook of positive psychology in schools (pp. 211-226). New York, NY: Routledge. 
Shernoff, D. J., Knauth, S., \& Makris, E. (2000). The quality of classroom experiences. In M. Csikszentmihalyi \& B. Schneider (Eds.), Becoming adult: How teenagers prepare for the world of work (pp. 141-164). New York, NY: Basic Books.

Strati, A. D., Shernoff, D. J., \& Dornbusch, S. M. (1996). Beyond the classroom: Why school reform has failed and what parents need to do. New York, NY: Springer.

Whalen, S. P. (1998). Flow and the engagement of talent: Implications for secondary schooling. NASSP Bulletin, 82, 22-37.

Zhu, N. (2001). The effects of teachers' flow experiences on the cognitive engagement of students (Unpublished doctoral thesis), University of San Diego and San Diego State University.

Open Access This chapter is licensed under the terms of the Creative Commons Attribution 4.0 International License (http://creativecommons.org/licenses/by/4.0/), which permits use, sharing, adaptation, distribution and reproduction in any medium or format, as long as you give appropriate credit to the original author(s) and the source, provide a link to the Creative Commons license and indicate if changes were made.

The images or other third party material in this chapter are included in the chapter's Creative Commons license, unless indicated otherwise in a credit line to the material. If material is not included in the chapter's Creative Commons license and your intended use is not permitted by statutory regulation or exceeds the permitted use, you will need to obtain permission directly from the copyright holder.

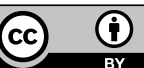




\title{
Chapter 14 \\ A Commentary: Accounting- of and Accounting-for the Engagement of Teachers and Teaching
}

\author{
Peter Liljedahl
}

\subsection{Introduction}

In this commentary, I reflect on the chapters by De Simone; Khalil, Lake, and Johnson; and Montoro and Gil (this volume) and how they contribute to our understanding of engagement within mathematics education. However, to build a foundation for this reflection, I will first elaborate on the concept of engagement.

Within the context of mathematics education, the terms engaged and engagement are used both colloquially and theoretically. Colloquially, engagement is used either to refer to a person's participation in something (verb)—she was engaged in a problem solving exercise-or to refer to how a person participates in something (adjective)-they were so engaged that I could not get their attention. Although these two meanings stem from the same understanding of engagement as involvement the first use refers to the act of being occupied with something, while the second often refers to how that occupation is experienced-with affect and motivation. This is not to say that the first is devoid of experience, but rather that the focus is on the doing rather than the experience of the doing.

This distinction between the verb and adjective form of engagement also exists within mathematics education research wherein the empirical and theoretical pursuit is further bifurcated into a distinction between, what Mason (2002) refers to as, an accounting-of and accounting-for. That is, research on engagement has been split into a cataloguing of ways in which participants engage-an accounting-of - and explanations for why they engage in this way-an accounting-for. In what follows I first explore this bifurcation through the four theoretical lenses of engagement structures (Goldin, Epstein, \& Schorr, 2007; Goldin, Epstein, Schorr, \& Warner, 2011; Schorr \& Goldin, 2008), studenting (Allan, 2017; Fenstermacher, 1986, 1994; Liljedahl \& Allan, 2013a, b), flow (Csíkszentmihályi, 1990, 1996, 1998), and forms

P. Liljedahl ( $₫)$

Simon Fraser University, Vancouver, Canada

e-mail: liljedahl@sfu.ca 
of engagement (Alvarez, 2016; Remillard, 2012). Following this I introduce the three chapters that comprise this section of the book, again applying Mason's (2002) duality of accounting-of and accounting-for.

\subsubsection{Engagement Structures}

Engagement structures (Goldin et al., 2007, 2011; Schorr \& Goldin, 2008) began as an accounting-of the differing ways in which students in a classroom setting engage (verb) with problem solving. Through close observation and careful coding nine behaviours emerged: Get the Job Done, Look How Smart I Am, Check This Out, I'm Really into This, Don't Disrespect Me, Stay Out Of Trouble, It's Not Fair, and Let Me Teach You.

These behaviours were accounted-for a collection of ten "simultaneously present and dynamically interacting" components (Goldin et al., 2007) that come together to form an engagement structure (Goldin et al., 2011). This structure sits at the intersection of the behavioural, affective, and social. The ten individual components that make up this "behavioral/affective/social constellation" (Goldin et al., 2011, p. 549). These ten components are:

1. Goal or motivating desire

2. Patterns of behaviour

3. Affective pathway

4. External expressions of affect

5. Meanings encoded by emotional feelings

6. Meta-affect pertaining to emotional states

7. Self-talk

8. Interactions with systems of beliefs or values

9. Interactions with longer-term traits, characteristics, and orientations

10. Interactions with strategies and heuristics (Goldin et al., 2011, p. 549).

The first seven of these components are based on the in-the-moment state of the student whereas the last three components are based on the more enduring traits of the students. Using these ten components to account-for the nine behaviours resulted in an in-depth understanding of what motivates each of the accounted-of behaviours.

- Get the Job Done-In this behaviour, the student's goal is to complete a mathematical task or activity assigned by the teacher and to fulfil the explicit or implicit obligation. The behaviour is a clear focus on carrying out the work.

- Look How Smart I Am-Here the student's goal is to impress their peers, teacher, or themselves with their mathematical ability, knowledge, or genius. This key marker of this behaviour is "showing off" by trying to produce a solution faster, or to produce a solution that is more correct, more efficient, or more elegant than others. 
- Check This Out-The underlying desire behind this behaviour is a potential payoff-intrinsic or extrinsic. The potentiality of this payoff is heavily predicated on the perceived value of what it is that the student is working on. The behaviour is punctuated by an increased attention to the task in pursuit of the payoff.

- I'm Really into This - This behaviour is expressed in situations where the student has entered into a state of deep engagement (Csíkszentmihályi, 1990). The goal that drives this behaviour is the desire to remain in this state, tuning out distractions, and seeking evolving complexities in the task as their ability increases. The physicality of this behaviour is one of focus, rapt interest, and enjoyment.

- Don't Disrespect Me-The motivating desire behind this behaviour is the preservation of the student's dignity, status, or sense of self-respect and well-being. The behaviour is observable as resistance to the challenge, defensiveness, face saving, and excessively charged discussions or arguments.

- Stay Out Of Trouble-In this case the student desires to avoid conflict or distress with peers or the teacher. They achieve this through avoidance and striving to not be noticed by others often prioritizing these goals addressing the mathematical task.

- It's Not Fair - The motivating desire behind this behaviour is to redress a perceived inequity and often occurs when the student perceives inequitable workload recognition from the teacher. The behaviour is focused on correcting this inequity rather than addressing the mathematical work itself.

- Let Me Teach You-In this behavior the student's behaviour is guided by the altruistic desire to help another student understand or solve the problem. The behaviour of helping other is punctuated by the satisfaction derived by being able to successfully help another student.

\subsubsection{Studenting}

Like with engagement structures, the work on studenting began with an accounting-of student behaviours in various learning situations. Fenstermacher (1986) first introduced the term studenting as the set of behaviours that help students learn.

The concept of studenting or pupiling is far and away the more parallel concept to that of teaching. Without students, we would not have the concept of teacher; without teachers, we would not have the concept of student. Here is a balanced ontologically dependent pair, coherently parallel to looking and finding, racing and winning. There are a range of activities connected with studenting that complement the activities of teaching. For example, teachers explain, describe, define, refer, correct, and encourage. Students recite, practice, seek assistance, review, check, locate sources, and access material. The teacher's task is to support R's desire to student and improve his capacity to do so. Whether and how much $\mathrm{R}$ learns from being a student is largely a function of how he students. (p. 39)

He later expanded this definition to also include the student behaviours that do not help them to learn. 
[T]hings that students do such as 'psyching out' teachers, figuring out how to get certain grades, 'beating the system', dealing with boredom so that it is not obvious to teachers, negotiating the best deals on reading and writing assignments, threading the right line between curricular and extra-curricular activities, and determining what is likely to be on the test and what is not. (Fenstermacher, 1994, p. 1)

This notion of studenting was used by Liljedahl and Allan (2013a, b) to look closely at student engagement (verb) across a variety of more traditional mathematics classrooms and classroom activity settings—doing tasks in class, taking notes, homework, group work, review, and lecture. Results from this accounting-of student behaviours showed a disturbing trend towards the later of Fenstermacher's definition. For example, while doing tasks in class Liljedahl and Allan (2013a) found that in some classes upwards of $80 \%$ of the students' behaviours did not contribute to learning. These non-learning behaviours included slacking (not doing anything), stalling (avoiding doing anything), faking (pretending to work), and mimicking (mindlessly following routines). In the context of homework (2013b) they found that 70-80\% of the studenting behaviour did not contribute to learning with the dominant nonlearning studenting behaviours being cheating, not doing it, or getting help. This last behaviour was interesting because in each case it was shown that, for the most part, the help aided in getting the homework done, but not in furthering the learning. If the homework was marked there were more of these types of behaviours with all three behaviours being almost equally distributed. If the homework was not marked then cheating sharply decreased, getting help stayed about the same, and not doing the homework increased drastically with an overall slight decline in the non-learning studenting behaviour. In the context of note taking, Liljedahl and Allan found that over half of the students were not attending to what they were writing and, instead, just mindlessly copied what was on the boards. More troubling was the fact that over $90 \%$ of the students never looked back at their notes. These passive studenting behaviours around notes were, like the other examples, not at all conducive to learning.

Allan (2017) did a detailed accounting-for these studenting behaviours using the theoretical framework of Leont'ev's (1978) activity theory. Her results were varied and detailed but can be summarized nicely in her analysis of two students who, from the outside, seemed to exhibited the same behaviours, but for very different reasons. While the first student had a primary motive of learning and a secondary motive of getting a good grade, the second student had the reverse - a primary motive of getting a good grade and a secondary motive of learning. Although subtle, this difference in motives made a world of difference in how they engaged in various classroom activities. Although invisible to an outside observer the main difference was that the motive of learning manifest itself as continuous engagement, while a primary motive of getting a good grade resulted in discrete engagement. Only a close accounting-for was able to reveal these nuanced differences in the accounted-of behaviours. 


\subsubsection{Flow}

In the early 1970s Mihály Csíkszentmihályi (1990, 1996, 1998) became interested in studying the optimal experience-that moment where we are so focused and so absorbed in an activity that we lose all track of time, we are un-distractible, and we are consumed by the enjoyment of the activity.

... a state in which people are so involved in an activity that nothing else seems to matter;

the experience is so enjoyable that people will continue to do it even at great cost, for the

sheer sake of doing it. (Csíkszentmihályi, 1990, p. 4)

In his pursuit to understand the optimal experience, Csíkszentmihályi (1990, 1996, 1998) studied a population of people he thought most likely to experience this phenomenon-musicians, artists, mathematicians, scientists, and athletes. Out of this research emerged an accounting-of the elements common to every such optimal experience (Csíkszentmihályi, 1990):

1. There are clear goals every step of the way.

2. There is immediate feedback to one's actions.

3. There is a balance between challenges and skills.

4. Action and awareness are merged.

5. Distractions are excluded from consciousness.

6. There is no worry of failure.

7. Self-consciousness disappears.

8. The sense of time becomes distorted.

9. The activity becomes an end in itself.

While the last six elements on this list are characteristics of the internal experience of the doer, the first three elements can be seen as characteristics existing in the environment of the activity and crucial to occasioning of the optimal experience - the third of which became the central focus of Csíkszentmihályi's (1990, 1996, 1998) work.

Csíkszentmihályi’s (1990, 1996, 1998) analysis of the optimal experience comes into sharp focus when accounting-for the consequences of having an imbalance in this system. For example, if the challenge of the activity far exceeds a person's ability they are likely to experience a feeling of anxiety or frustration. Conversely, if their ability far exceeds the challenge offered by the activity they are apt to become bored. When there is a balance in this system a state of, what Csíkszentmihályi refers to as, flow is created (see Fig. 14.1). Flow is, in brief, the term Csíkszentmihályi (1990, 1996, 1998) used to encapsulate the essence of optimal experience and the nine aforementioned elements into a single emotional-cognitive construct.

Thinking about flow as existing in that balance between skill and challenge (see Fig. 14.1), however, obfuscates the fact that this is not a static relationship. Flow is not a collection of fixed ability-challenge pairings wherein the difference between skill and challenge are within some acceptable range. Flow is, in fact, a dynamic process (see Fig. 14.2). As students engage in an activity their skills improve. In 


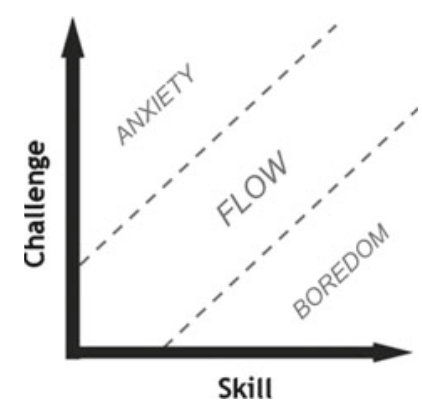

Fig. 14.1 Graphical representation of the balance between challenge and skill (Csíkszentmihályi, 1990, 1996, 1998)

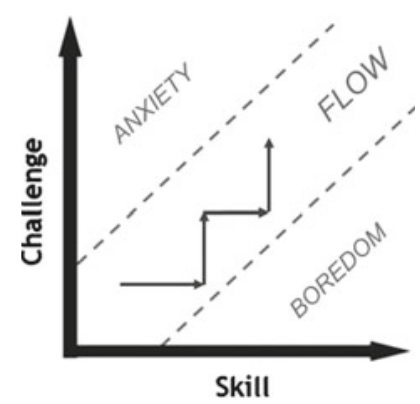

Fig. 14.2 Graphical representation of the balance between challenge and skill as a dynamic process (Liljedahl, 2018)

order for these students to stay in flow the challenge of the task must similarly increase (Liljedahl, 2016, 2018).

However, this theory of flow did not always match up with the data Csíkszentmihályi (1998) was analyzing. In particular, he found that a balance of challenge and skill did not always produce flow and became "a frustrating puzzle in an otherwise fruitful research program" (Csíkszentmihályi \& Csíkszentmihályi, 1988, p. 260). Massimini and Carli (1988) eventually found that flow only occurred if there was a balance between challenge and skill and when both of these were in an elevated state. Otherwise it would produce apathy (see Fig. 14.3). This realization eventually led to an even more nuanced model (see Fig. 14.4) involving eight distinct states resulting from different challenge-skill ratios (Massimini, Csikszentmihalyi, \& Carli, 1987).

Csíkszentmihályi's $(1990,1996,1998)$ notion of the optimal experience and the resulting framework of flow is one of the only ways in which we can account-for the adjective form of engagement. 


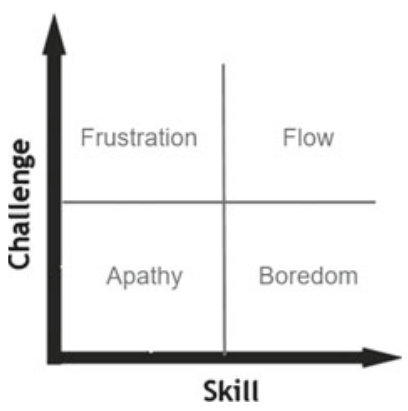

Fig. 14.3 The four-channel model of flow (Massimini \& Carli, 1988)

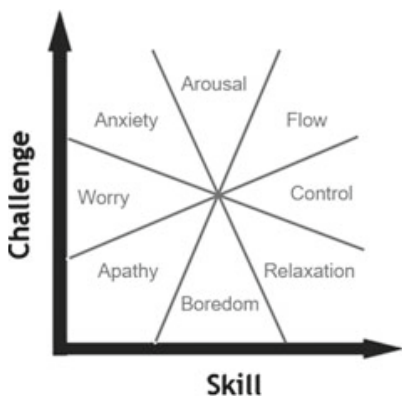

Fig. 14.4 Visual representation of the eight states of the challenge-skills ratio (Massimini et al., 1987)

\subsubsection{Modes of Engagement}

Drawing on Ellsworth's (1997) work on film study and Rosenblatt's (1982, 1980) theory of transactions, Remillard (2012) developed a model of how textual resource developers position their audience and their resource, and how teachers, in turn, interact with that resource. This theory begins with the mode of address, which is about positioning the reader in a particular way so as to know how to initiate the interaction between the reader and the resource. This is followed by the forms of address, which are the particular looks and formats embedded in the resource that manifest the mode of address. A reader will interact with this resource through a particular stance called a mode of engagement. This stance, in turn, guides the forms of engagement, which are the various ways in which the reader engages with the resource and what they look for.

Looking at Remillard's (2012) theory through the lens of Mason's (2002) accounting-of and accounting-for, the idea that the authors of textual resources position the reader and that the reader brings a stance to their interaction with the resource is an accounting-of the fact that both the production of a resource and how that resource is utilized is guided by goals and volitions and that in order for the inter- 
action between author and reader to begin some assumptions about these goals and volitions needs to be made. The modes and forms of the address of the resource and the modes and forms of the engagement of the reader are an accounting-for the ways in which these assumptions manifest themselves.

Alvarez (2016) extended and re-purposed Remillard's (2012) theory to both account-of and account-for the interaction between a professional developer and a group of teachers. In this regard, the modes of address referred to the ways in which the professional developer positioned the teachers and the forms of address referred to the different pedagogical approaches the professional developer used with the teachers. From the other side, the modes of engagement were the stances that the teachers brought to the experience and the forms of engagement were the different ways in which the teachers engaged in the professional development sessions. In this sense, the notion of engagement (verb) in both Remillard's (2012) theory and Alvarez's (2016) re-purposing is different in nature than in the aforementioned three theories in that engagement is not the primary goal of this framework, but rather a by-product of the efforts to account-for the interaction between a textual resource and its reader.

\subsection{Engagement of Teachers and Teaching}

Although situated within a broad set of contexts, the aforementioned theories of engagement, can be appropriated for use within the specific context of the teaching and learning of mathematics. In what follows, I summarize the ways in which the authors of the three chapters that comprise this section of the book have done so and draw attention to how their work is both an accounting-of and -for engagement. Although each of these chapters are, ostensibly, about understanding engagement, each of the results also makes a contribution to our understanding of how to create engagement. Further, although each chapter is explicitly about teachers, two of the chapters also offer us subtly insights into the engagement of the learner. In my summary I try to pull out these more elusive aspects of the contributions.

\subsubsection{Teachers' Classroom Engagement Structures: A Comparative Study of a Novice US and an Experienced UK Mathematics Teacher}

To begin with Khalil, Lake, and Johnson co-opt the framework of engagement structures (Goldin et al., 2007, 2011; Schorr \& Goldin, 2008), developed and used to account-of and -for student engagement (verb), to do both an accounting-of and an accounting-for teachers' engagement (verb). This novel application of the framework, coupled with the notion of learning trajectories (Desimone, 2009), enables 
the authors to account-for the in-the-moment affect of two teachers and eventually reveals that the teacher' in-the-moment behaviours may mirror their students' inthe-moment behaviours and underpins the teachers' emotional needs.

There are three implications emerging from this research. First, and foremost, the framework of engagement structures (Goldin et al., 2007, 2011; Schorr \& Goldin, 2008) can be used to "connect teachers' prior 'in-the-moment' behaviour as mathematics learners with their 'in-the-moment' behaviour as mathematics teachers" (Khalil, Lake, \& Johnson, this volume). Further, this framework can be used as a lens to connect their affective and motivational domains to these same behaviours-both past and present. Finally, and moving beyond the framework as a tool for the accounting-for teachers behaviour, the framework of engagement structures can be used to actively help in teachers' affective development and to connect their emotional development to their behaviours in-the-moment and across their overarching learning trajectory as teachers.

The novel appropriation of the engagement structures framework (Goldin et al., 2007, 2011; Schorr \& Goldin, 2008) coupled with an explicit desire to not only understand teacher behaviour, but also to change their behaviour brings to the fore the importance of explicitly linking teachers' practice to their past experiences as a learner and teacher with the in-the-moment emotions. Khalil, Lake, and Johnson have done an exceptional job of theorizing this complex confluence and actualizing it as both research and intervention.

\subsubsection{Exploring Flow in Pre-service Primary Teachers Doing Measurement Tasks}

Montoro and Gil chapter sits at this same intersection between research and intervention with their dual intention of trying to provide pre-service primary teachers flow experiences (Csíkszentmihályi, 1990, 1996, 1998) while at the same time looking closely at the elements present when these experiences occur. Mobilizing the theory of flow (Csíkszentmihályi, 1990, 1996, 1998) within a mixed-method approach, the authors were able to account-for the difference in the flow experiences of 230 participants and to hypothesize a way towards creating engaging (adjective) experiences for this population of learners. The methodological approach used in this paper is both rigorous and illuminating, giving us a much needed glimpse into the occasioning of flow.

The authors begin their work by looking closely at the participants' enjoyment and concentration on each of five measurement tasks. Exploratory and confirmatory factor analysis reveals that $70 \%$ of the participants experienced elements of flow in tasks $1,2,3$, and 5, with only $50 \%$ having the same experience with task 4 . A cursory analysis of the five tasks reveals that, while all the tasks are situated in the context of measurement, only task 4 has a problem solving focus. The authors conjecture that this results in an imbalance between the challenge of the task and the ability of 
the doer (see Fig. 14.1) and results in a decrease in the occasioning of flow. This is confirmed through video analysis of one group of pre-service teachers working on these tasks.

This video analysis further illuminates, not only why task 4 does not promote flow to the same extent as the other four tasks, but also why the other four tasks do. Drawing heavily on flow's dimension of balancing challenges and skills (Csíkszentmihályi, 1990, 1996, 1998), Medina and Caudra's analysis reveals the importance of tasks being easy to begin and that an early entry proves to be vital to ensuring that flow is initiated. Even if the initial entry proves to be incorrect it is more fruitful for occasioning flow than to begin correctly with something difficult. This result contradicts Massimini et al. (1987) who predicted that low challenge would produce apathy (see Fig. 14.4). However, the result is in line with Csíkszentmihályi's earlier work and offers us a more nuance understanding of how to engage (adjective) not only pre-service elementary teachers in particular, but also learners in general.

\subsubsection{The Intertwinement of Rationality and Emotions in the Mathematics Teaching: A Case Study}

Finally, De Simone looks at one teacher, Carla, and her engagement (verb) while teaching. Although not drawing on the aforementioned theories of engagement, she does account-for Carla's decision-making process through the joint and intertwined theories of rationality (Habermas, 1982, 1998) and affect (Brown \& Reid, 2006). De Simone argues that with only "the pure rationality à la Habermas, [she] could only have described the decisions of the teacher, without accounting-for [my emphasis] their underlying reasons". To get at the reasons she needed emotions-more specifically, emotional orientation (Brown \& Reid, 2006) and its resultant and visible emotionality - to see the expectations in Carla's decision-making. In so doing, De Simone makes a powerful contribution to our understanding of the interplay between teacher knowledge and teacher practice-something that is often overlooked in our rush to improve teaching.

Although her work is descriptive in nature, De Simone offers us a means to think about how her results can be used to improve teacher decision-making. Whereas emotions and emotionality are situated and fleeting, the rationality is grounded and can be "prepared a priori". Although not the topic of this chapter, De Simone's methodological use of emotionality gives us insight into the reciprocal relationship between teacher and student in the decision-making process. Whereas Carla's emotionality signaled her intentions to the researcher, it also signaled these same intentions to the students-helping to inform their own decision-making process within the classroom. 


\section{References}

Allan, D. (2017). Student actions as a window into goals and motives in the secondary mathematics classroom (Unpublished Ph.D. thesis). Simon Fraser University.

Alvarez, M. (2016). Teaching teachers: A look inside professional development (Unpublished Ph.D. thesis). Simon Fraser University.

Brown, L., \& Reid, D. A. (2006). Embodied cognition: Somatic markers, purposes and emotional orientations. Educational Studies in Mathematics, 63(2), 179-192.

Csíkszentmihályi, M. (1990). Flow: The psychology of optimal experience. New York, NY: Harper and Row.

Csíkszentmihályi, M. (1996). Creativity: Flow and the psychology of discovery and invention. New York, NY: Harper Perennial.

Csíkszentmihályi, M. (1998). Finding flow: The psychology of engagement with everyday life. New York, NY: Basic Books.

Csíkszentmihályi, M., \& Csíkszentmihályi, I. (1988). Optimal experience: Psychological studies of flow in consciousness. Cambridge, New York: Cambridge University Press.

Desimone, L. M. (2009). Improving impact studies of teachers' professional development: Toward better conceptualizations and measures. Educational Researcher, 38(3), 181-199. https://doi.org/ 10.3102/0013189x08331140.

Ellsworth, E. (1997). Teaching positions: Difference, pedagogy, and the power of address. New York: Teachers College.

Fenstermacher, G. (1986). Philosophy of research on teaching: Three aspects. In M. C. Whittrock (Ed.), Handbook of research on teaching (3rd ed., pp. 37-49). New York, NY: Macmillan.

Fenstermacher, G. (1994, revised 1997). On the distinction between being a student and being a learner. Paper presented at the annual meeting of the American Educational Research Association, New Orleans, LA.

Goldin, G. A., Epstein, Y. M., \& Schorr, R. Y. (2007). Affective pathways and structures in urban students' mathematics learning. In D. K. Pugalee, A. Rogerson, \& A. Schinck (Eds.), Mathematics Education in a Global Community: Proceedings of the 9th International Conference of the Mathematics Education into the 21st Century Project (pp. 260-265). Charlotte, NC: Center for Mathematics, Science and Technology Education.

Goldin, G. A., Epstein, Y. M., Schorr, R. Y., \& Warner, L. B. (2011). Beliefs and engagement structures: Behind the affective dimension of mathematical learning. ZDM Mathematics Education, $43,547-556$.

Habermas, J. (1998). On the pragmatics of communication. Cambridge, MA: MIT Press.

Habermas, J. (1982). Habermas: Critical debates. Cambridge, MA: MIT Press.

Leont'ev, A. (1978). Activity, consciousness, and personality. Englewood Cliffs, NJ: Prentice Hall. (Original work published 1975).

Liljedahl, P. (2016). Building thinking classrooms: Conditions for problem solving. In P. Felmer, J. Kilpatrick, \& E. Pehkonen (Eds.), Posing and solving mathematical problems: Advances and new perspectives (pp. 361-386). New York, NY: Springer.

Liljedahl, P. (2018). On the edges of flow: Student problem solving behavior. In S. Carreira, N. Amado, \& K. Jones (Eds.), Broadening the scope of research on mathematical problem solving: A focus on technology, creativity and affect (pp. 505-524). New York, NY: Springer.

Liljedahl, P., \& Allan, D. (2013a). Studenting: The case of "now you try one". In A. M. Lindmeier $\&$ A. Heinze (Eds.). Proceedings of the 37th Conference of the International Group for the Psychology of Mathematics Education (Vol. 3, pp. 257-264). Kiel, Germany: PME.

Liljedahl, P., \& Allan, D. (2013b). Studenting: The case of homework. In M. Martinez \& A. Castro Superfine (Eds.), Proceedings of the 35th Conference for Psychology of Mathematics Education-North American Chapter (pp. 489-492). Chicago, IL: USA.

Mason, J. (2002). Researching your own practice: The discipline of noticing. New York, NY: Routledge. 
Massimini, F., \& Carli, M. (1988). The systematic assessment of flow in daily experience. In M. Csikszentmihalyi \& I. Csikszentmihalyi (Eds.), Optimal experience: Psychological studies of flow in consciousness (pp. 266-287). New York, NY: Cambridge University Press.

Massimini, F., Csikszentmihalyi, M., \& Carli, M. (1987). The monitoring of optimal experience. A tool for psychiatric rehabilitation. The Journal of Nervous and Mental Disease, 175(9), 545-549. https://doi.org/10.1097/00005053-198709000-00006.

Remillard, J. (2012). Modes of engagement: Understanding teachers' transactions with mathematics curriculum resources. In G. Gueudet, et al. (Eds.), From text to 'Lived' resources: Mathematics curriculum materials and teacher documentation (pp. 105-122). New York, NY: Springer.

Rosenblatt, L. M. (1980). What facts does this poem teach you? Language Arts, 57(4), 386-394.

Rosenblatt, L. M. (1982). The literary transaction: Evocation and response. Theory Into Practice, 21(4), 268-277.

Schorr, R. Y., \& Goldin, G. A. (2008). Students' expression of affect in an inner-city simcalc classroom. Educational Studies in Mathematics, 68(2), 131-148.

Open Access This chapter is licensed under the terms of the Creative Commons Attribution 4.0 International License (http://creativecommons.org/licenses/by/4.0/), which permits use, sharing, adaptation, distribution and reproduction in any medium or format, as long as you give appropriate credit to the original author(s) and the source, provide a link to the Creative Commons license and indicate if changes were made.

The images or other third party material in this chapter are included in the chapter's Creative Commons license, unless indicated otherwise in a credit line to the material. If material is not included in the chapter's Creative Commons license and your intended use is not permitted by statutory regulation or exceeds the permitted use, you will need to obtain permission directly from the copyright holder.

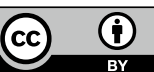




\section{Part IV}

Identity 


\title{
Chapter 15 \\ The Interplay of Rationality and Identity in a Mathematical Group Work
}

\author{
Laura Branchetti and Francesca Morselli
}

\begin{abstract}
This contribution originates from a joint work aimed at networking theoretical tools and employ them to better understand teaching and learning episodes, with a special focus on mathematical group work. In a socio-cultural perspective, two theoretical lenses are combined: the construct of rational behavior, initially developed by Habermas and adapted in mathematics education, and that of identity. In this paper we propose a general description of our approach and present the main findings emerged after investigations in grade 6 (group work on negative numbers) and grade 4 (arithmetics problem solving). The networked analysis sheds light into mathematical group works: the students' mathematical identities turn into prevailing dimensions of rational behavior and the interplay of dimensions of rationality affects the participation into the group activity. Moreover, the teacher is shown to have a role in students' identifying process, affecting indirectly the students' participation.
\end{abstract}

Keywords Identity $\cdot$ Rationality $\cdot$ Group work

\subsection{Introduction}

Adopting a sociocultural perspective, we argue that the learning of mathematics takes place in a social context through interactions. Students' interaction in a small group is a complex process in which students are involved at many levels, not only at the cognitive one, mediated by culture and characterized by processes of objectification (alignment with culture) and subjectification (thinking and becoming process of being-with-others mediated by alterity) (Radford, 2011).

In this contribution, we discuss the issue of group work, combining two theoretical lenses: the construct of rational behavior, originally developed to better understand

\author{
L. Branchetti ( $\varangle)$ \\ University of Parma, Parma, Italy \\ e-mail: laura.branchetti@unipr.it \\ F. Morselli \\ Faculty of Mathematics, University of Genoa, Via Dodecaneso 35, 16146 Genoa, Italy \\ e-mail: morselli@dima.unige.it


individual argumentation and proving processes, and the construct of identity, aimed at figuring out the effects of verbal and non-verbal acts concerning the participants on a teaching and learning activity. In the first part of the contribution we present a literature review on group work, we frame our research interest in a sociocultural perspective and we introduce the theoretical lenses we choose for our research. Afterwards, we briefly refer to the networking methodology and set up the research question in terms of the combined theoretical tools. Finally, we present the main findings of our networked analysis, illustrating them by means of relevant examples coming from our experiments.

\subsection{Literature Background: Group Work}

To be able to work in group in order to solve problems is considered nowadays one of the most important skills to develop at school in order to become able to work in team and contribute fruitfully to face challenges within a social context (OECD, 2013).

In the field of education, group work is not only aimed at developing social skills - in the traditional sense of becoming able to interact and work with other managing emotions and conflicts - but is also used as a resource for teaching, that is to say a method to make the students learn better and in a more significant and lasting way. The educational use of group works has been widely studied, in particular after the milestones of Johnson and Johnson (1980), Sharan (1980) and Slavin (1990). Those studies report a good effect of group work on students' learning and discuss some indicators of efficacy in group work. Group work, with different strategies such as cooperative learning, collaborative and peer tutoring, is valued for its fostering significant learning processes; however, group work is not always fruitful, as pointed out by the aforementioned researchers (and known by many teachers). Relevant required features are: positive interdependence (every student's contribution is necessary), promotive face-to-face interaction (ongoing interaction is necessary for success), individual accountability (the performance of every member should be taken in account seriously by the others), group processing (to manage conflicts, to give and receive assistance, to exchange information, to use critical thinking). We may note that the aforementioned features deal with social skills that are independent from the subject and the topic of the discussion, even if at a closer view the accountability of every single student may depend on the topic of discussion.

Group work at school has additional requirements, since in that case the social interaction happens within an institutional context that has its specific goals: it may happen that the desired (in the teacher's mind) goal of the group work may be different from the direction the natural evolution of the activity leads to. What happens in group work at school is not a mere question of negotiation of meaning but is a continuous interplay between the individual dimension, the group, the classroom, the teacher and, finally, the culture (Radford, 2011). Recently, some authors identified indicators 
for the analysis and evaluation of the quality of group work. In particular, drawing from the work of Pons Parra et al. (2012), Spagnuolo (2017, p. 86) elaborated the following list of Likert indicators:

1. Being responsible of one's own role, respecting the assigned tasks.

2. Expressing the understanding of the activity, of the assignment and of the task during the approach, process and productions steps.

3. Asking (spontaneously or not) for explanations on the content (concepts, interpretations) and on the objectives of the assigned activity.

4. Providing (spontaneously or not) explanations on content (concepts, interpretations) and on the objective of the assigned activity.

5. Asking (spontaneously or not) for explanations on the different sides of the resolution process of the activity.

6. Providing (spontaneously or not) explanations on the different sides of the resolution process of the activity.

7. Asking (spontaneously or not) for explanations on the different sides of the obtained final result and of its possible implications.

8. Providing (spontaneously or not) explanations on the different sides of the obtained final result and of its possible implications.

9. Accepting and respecting the decision taken by the group on the obtained result.

10. Taking into consideration others' opinion.

11. Speaking critically, but constructively, on one's own and others' argumentation and considerations.

12. When speaking, attempt to reach an agreement point with the others, of reaching a point of shared knowledge.

Our interest is framed in this trend of research, with a specific focus on what may happen during mathematical classes.

\subsection{Theoretical Framework}

\subsubsection{Group Work in a Sociocultural Perspective}

The pioneering analysis carried out by Vygotskij (1978) concerning the crucial role of social activities mediated by signs and language in the development of mathematical thinking traced a path in which a whole thread of researchers placed their roots. The effects of students' interactions in classroom activities have been studied, described and interpreted in mathematics education since its origins, see Radford (2011) for an overview. We rely on a sociocultural perspective, according to which the learning of mathematics takes place in a social context through interactions and is deeply affected by culture (Radford, 2006, 2011). Radford (2006, p. 58) affirms:

Certainly, the students were actively engaged in what has been termed a "negotiation of meaning". But this term can be terribly misleading in that it may lead us to believe that the 
attainment of the concept is a mere consensual question of classroom interaction. [...] meaning also has a cultural-historical dimension [...]. It is in fact this cultural object that shapes and explains the teacher's intervention [...] classroom interaction and the students' subjective meaning are pushed towards specific directions of conceptual development. Cultural conceptual objects are like lighthouses that orient navigators' sailing boats. They impress classroom interaction with a specific teleology.

Students are involved in a double-faced problem: they meet at the same time the culture and the others and have to find a place in both the cultural and the classroom discourses, that are related but not necessarily equal. Particularly, we will focus on the classroom discourse side. Even if the attainment of a concept is not a mere consensual question, the agreement between students is very important in mathematics group activities, as we will show. We refer to Radford's interpretation of cultural-historical activity theory (Roth, Radford, \& Lacroix, 2012). This theory is rooted in Leont'ev and Vygotskij's dialectical psychological theories. The keyword activity is defined as a common place in which cognition and consciousness arise; through activity individuals relate not only to the world of objects but also to other individuals. Learning is the result of a shared common practice that involves students' subjectivities and in which subjectivities moves towards others and culture to find and transform themselves. In Radford (2008) it is pointed out that students' interaction in a small group is a complex process in which students are involved at many levels, not only at the cognitive one. The processes of objectification (students align their thoughts with culture) and subjectification (a thinking and becoming process of beingwith-others mediated by alterity) that take place in the teamwork are mediated by culture.

\subsubsection{Identity}

We refer to the definition of identity by Sfard and Prusak (2005, p. 1): "Identity is a set of reifying, significant, endorsable stories about a person". Identity stories can talk about the way a person relates to the mathematics and so can influence the participation in the teamwork, the engagement, and definitively, success or failure in mathematics activities. Heyd-Metzuyanim (2009) adds non-verbal acts to the verbal stories in order to better explore the interaction dynamics. Then she classifies the acts, clarifying whether they are identifying processes or not. Identifying utterances (verbal or non-verbal) are "those that signal that the identifier considers a given feature of the identified person as permanent and significant" (Heyd-Metzuyanim, 2009, p. 2). The prototypical cases are exemplified in the quoted paper by HeydMetzuyanim (2009). In a further work, Heyd-Metzuyanim (2013) analyzes teacherstudent interactions and argues that in some cases interaction is non-productive and turns into a co-construction of the student's identity of failure. Thus teachers play a role not only in the mathematizing process, but also in the identifying one. 


\title{
15.3.3 Rationality
}

The construct of rationality was developed by Habermas (1998) in reference to discursive practice and later adapted to mathematical activity (see Morselli \& Boero, 2009 for the special case of mathematical proving). According to Habermas, rational behavior may be seen as made up of three interrelated dimensions: epistemic dimension (related to the control of the propositions and their chaining), teleological dimension (related to the conscious choice of tools to achieve the goal of the activity) and communicative one (related to the conscious choice of suitable means of communication within a given community). In the case of mathematics, fostering students' approach to argumentation and proof as a rational behavior means promoting the integration between the epistemic aspect (conscious validation of statements according to shared premises and legitimate ways of reasoning), the communicative aspect (conscious adhering to rules that ensure both the possibility of communicating steps of reasoning, and the conformity of the products (proofs) to standards in a given mathematical culture), the teleological aspect (conscious choices to be made in order to obtain the aimed product). When dealing with peer interaction, the communicative dimension plays a crucial role, as well as the epistemic one, which is linked to the possibility of changing opinion:

\begin{abstract}
Someone is irrational if she puts forward her beliefs dogmatically, clinging to them although she sees that she cannot justify them. In order to qualify a belief as rational, it is sufficient that it can be held to be true on the basis of good reasons in the relevant context of justification - that is, that it can be accepted rationally. The rationality of a judgment does not imply its truth but merely its justified acceptability in a given context. (Habermas, 1998, p. 310)
\end{abstract}

\subsubsection{Networking Identity and Rationality}

Mathematics education is a wide research field characterized by many different approaches, methodologies, problems and theoretical tools. In order to allow the researchers to collaborate using different research tools belonging to different theories, expert researchers carried out a meta-analysis about theories in mathematics education. This process of study is characterized by the search for possible connecting strategies and the theorization of the networking of theories (Prediger, BiknerAhsbahs, \& Arzarello, 2008). The choice among the possible connecting strategies, like comparing, contrasting, coordinating, combining, depends on the specific kind of analysis and on the compatibility of theories at different levels (principles, methodologies, research problems, research questions), as theorized by Radford (2008). In our case, we chose the combining strategy, which consists in "looking at the same phenomenon from different theoretical perspectives as a method for deepening insights on the phenomenon" (Prediger et al., 2008, p. 172). We decided to combine the lenses of rationality and identity in order to analyze in depth episodes of group interaction. The choice of combining the two lenses is linked to our aim of understanding how the individual participation and the students' interactions affect the group work in 
the special case of a mathematical activity aimed at producing and presenting argued solutions; moreover, we are interested in understanding what dynamics may lead a student to renounce to participate or to go on contributing significantly to the mathematical activity conserving a personal point of view. Thus, we need analytical tools to take into account both the individual and the social processes.

In our view, the two lenses are functional to our focus on group work in mathematical activities. The lens of identity is used to study situations in which each student interacts with peers presenting himself as good or not in mathematics and is recognized by the peers as accountable or not in mathematics lessons. The lens of rationality supports the analysis of the search for a group agreement on a mathematical question, that is not only a social process, but also a relevant mathematical activity: students must provide answers and explanations that are correct from a mathematical point of view, but also useful according to the goal of the activity (the question posed by the teacher) and accepted by their peers, thus combining the different dimensions of rationality.

\subsection{Purpose of the Research}

Our research focuses on the degree at which the members accept the solution of the group (Branchetti \& Morselli, 2016, 2017). In particular, we are interested in a specific case of mathematical activity: problem solving in which a solution has to be motivated and argumentation tasks. In those cases, reaching an agreement may be particularly complex since the students have to manage simultaneously their own processes and the others' processes and to deal with mathematical objects and culturally accepted ways of reasoning. Hence, we aim at studying the dynamics that lead a group of students to reach an agreement on the solution to present to the classroom within an institutional context. To this aim, we perform a double, simultaneous, analysis of what is happening to every student and what is happening in the interaction, taking in account both the problem-solving level and discussion level.

In order to describe the final state of the group in respect of the solution and to define precisely what we consider a group solution and an agreed solution we introduce some terms.

First, we define 'solution' a couple composed by an answer and an explanation. It is possible - and yet frequent, as we will show - that the solution is not completely understood and accepted by all the members as couple composed by an answer and an explanation. For instance, a student could accept and agree with the answer but not with the explanation, or could have an intuition of the answer but may not be able to motivate it and thus could "borrow" the explanation of another group mate. It may then happen that the group converges towards a solution that is accepted as a group solution by the group, even if there is not a real individual convergence and understanding. We consider those situations relevant, since we are interested not only in the social skills but also in the disciplinary relevance of the activity for 
every student and we assume that it is not good for the student to interrupt his/her own thinking process and to move towards a group solution that is not understood completely. Thus, we aim at understanding what kind of dynamics make the members of the group decide to present a solution as a group solution and what happens to the students who did not agree with or did not understand it. More specifically, we refer to specific situations when students, working in group, are asked to carry out a task and provide a group solution, made up of the answer and the explanation for the answer. After the end of the group work, each group is expected to present the group solution to the whole class. The group presentation is the starting point for a class discussion. We point out that such a setting, where students are asked to reach a group solution (that contains an explanation) and to present it to the whole class, makes working in group really central and related to the mathematical activity at issue. During the first part of the activity (group work), the students are expected to solve the task collaboratively. Two levels are necessarily intertwined: solving the problem and converge towards a unique, agreed solution, both in terms of answer and in terms of explanation. We call agreement the situation in which all the group members, at the end of the group work, accepts to present a given solution (answer A, explanation E) as a group solution, and non-agreement the situations in which the group does not come to a convergence and does not present a group solution. Of course, not all situations of agreement represent a real convergence. We call solid agreement the situation in which the group members not only accept, but also comprehend both the answer A and the explanation E. On the contrary, we call forced agreement all those situations in which the group presents a group solution, but there is not a real convergence and comprehension. Cases of forced agreement may take place when the group presents the solution (answer + explanation) as something accepted by all the members, but actually the group members converge to the answer but do not converge on the explanation, not all the members understand the explanation.

In Branchetti and Morselli (2017) we observed a group presenting the solution to the whole class and the teacher. By means of the combined framework we showed that a group solution may not be reached when the interaction is only at the communicative level and not at the epistemic one. A possible cause of the bad balance between dimensions was indeed the presence of different mathematical identities in the group that discouraged the groupmates to propose different explanations, contradicting the one who was more accounted by the teacher as good in mathematics. The dynamic emerged exactly during the group solution presentation: when the teacher proposed to the leader to change the answer - that had been accepted just because of the student's accountability - one of the classmates reacted saying that he had not understood the explanation but he had agreed anyway because he had a similar intuition about the answer. He could not accept to change the answer, while he had accepted not to understand the explanation and to propose the solution as a shared one. This example shows the existence of situations of forced agreement, and suggests the crucial role of the teacher in co-constructing mathematical identities.

In this contribution, we pursue our reflection on the cases of non-agreement and forced agreement. We wonder whether conflicting identities and/or the intertwining 
of dimensions of rationality may act as obstacles for convergence. More specifically, we address the following research questions:

RQ1: Whether and how dynamics within the group (read in terms of identity and rationality) may lead to a forced agreement rather than on a real agreement? Whether and how such dynamics may lead to a non-agreement?

RQ2: What is the role of the teacher in leading to a non-agreement, forced or solid agreement?

In order to investigate these issues, we performed a networked analysis on a series of episodes issued from different teaching experiments. The episodes refer to the crucial phases of the group work (with or without the intervention of the teacher). In the following we report excerpts from two episodes and we exemplify the data analysis based on the research questions. Then we resume the main findings of our research, confirmed by the observations of different episodes.

\subsection{Method}

In order to tackle our research questions, we performed cycles of analysis and interpretation: we questioned the episodes with the aim of better understanding the dynamics of group work, and we drew from the analysis the first idea of non-agreement as a result of conflicting identities, acting on different dimensions of rationality (preliminary results, here further developed, may be found in Branchetti \& Morselli, 2016, 2017).

We present here the analysis of two examples. The first excerpt comes from an experiment carried out in grade 6 concerning the concept of negative numbers. The work of a group of 5 students (age 12) is analyzed in detail. The second excerpt comes from an experiment concerning the evolution of interactions in a particular setting for teamwork in primary school (grade 4). We study the work of a group of 4 students who interact with the teachers. The example comes from a Master thesis in Psychology with particular attention to the role of the spontaneous representations (Monaco, 2015).

The experiments we refer to, although referring to different grades (grade 5, grade 8), share some crucial features: the students were used to work in group and provide group solutions (in terms of answer and explanation); the teacher was used to set up class discussions after the group work; argumentative activities were widespread and valued as fruitful occasions for meaning making.

We point out here that we used data coming from different experiments; the coherence of results is promising in terms of possible generalization. Data at disposal are the video recordings of the class sessions, the pictures of the whiteboards, the written notes of the students. For our analysis we mainly relied on the transcripts of the discussions (group discussions and/or class discussions). Hereunder we describe the method we used for the analysis of each episode. 
Table 15.1 Prototypical cases and labels (Heyd-Metzuyanim, 2009)

\begin{tabular}{|c|c|c|c|c|c|}
\hline & \multicolumn{3}{|l|}{ Type } & Example & Identifying? \\
\hline Mathematizing & \multicolumn{3}{|l|}{ Mth } & & No \\
\hline \multirow[t]{6}{*}{ Subjectifying } & \multirow[t]{2}{*}{$\begin{array}{l}\text { Pe: partici- } \\
\text { pation } \\
\text { evaluating }\end{array}$} & \multicolumn{2}{|c|}{$\begin{array}{l}\text { Sp: related to a specific } \\
\text { performance }\end{array}$} & $\begin{array}{l}\text { Saying "I } \\
\text { do not } \\
\text { under- } \\
\text { stand" }\end{array}$ & No \\
\hline & & \multicolumn{2}{|c|}{ Ge: generalizing } & $\begin{array}{l}\text { Saying "I } \\
\text { hate doing } \\
\text { this" }\end{array}$ & $\begin{array}{l}\text { If } \\
\text { consistent } \\
\text { with other } \\
\text { data }\end{array}$ \\
\hline & \multirow[t]{4}{*}{$\begin{array}{l}\text { Me: mem- } \\
\text { bership } \\
\text { evaluating }\end{array}$} & \multirow[t]{2}{*}{ Vb: verbal } & Di: direct & $\begin{array}{l}\text { Saying "I } \\
\text { am a math } \\
\text { person" }\end{array}$ & Yes \\
\hline & & & Id: indirect & $\begin{array}{l}\text { Changing } \\
\text { the subject } \\
\text { of } \\
\text { discourse, } \\
\text { which can } \\
\text { be } \\
\text { interpreted } \\
\text { as "I do not } \\
\text { want to talk } \\
\text { about this" }\end{array}$ & $\begin{array}{l}\text { Depends on } \\
\text { the nature } \\
\text { and } \\
\text { frequency } \\
\text { of the } \\
\text { utterance }\end{array}$ \\
\hline & & \multirow[t]{2}{*}{$\begin{array}{l}\text { Nv: } \\
\text { non-verbal }\end{array}$} & Di: direct & $\begin{array}{l}\text { Raising } \\
\text { one's hand, } \\
\text { which may } \\
\text { interpreted } \\
\text { as "I wish } \\
\text { to speak } \\
\text { about this" }\end{array}$ & $\begin{array}{l}\text { Only if } \\
\text { recurrent }\end{array}$ \\
\hline & & & Id: indirect & $\begin{array}{l}\text { Groaning at } \\
\text { a given } \\
\text { task, which } \\
\text { may be } \\
\text { interpreted } \\
\text { as "I do not } \\
\text { like this" }\end{array}$ & $\begin{array}{l}\text { Only if } \\
\text { recurrent }\end{array}$ \\
\hline
\end{tabular}

As already outlined, we combined the lenses of rationality and identity. At first, we analyzed the episode in terms of identity and subjectification, as derived from HeydMetzuyanim's paper (2009). Some sentences from the transcript were interpreted following the criteria proposed by the author in Table 15.1 and labeled with the codes identity (I) and subjectification (S). Also, the specific codes for subjectification used by Heyd-Metzuyanim were used.

Afterwards, we added the analytical tool of rational behavior. We referred to the epistemic dimension when one sentence was linked to a mathematical fact, and we 
spoke of lack at epistemic level if some assumption was taken per se, without the need for a justification. For instance, accompanying an answer by an explanation such as "Because the teacher told us", without paying any effort towards a real understanding, was interpreted in terms of lacks in epistemic rationality. We referred to the teleological dimension when the action was clearly linked to a goal (and we reported a lack in teleological rationality when the reference to the final goal was missing). We referred to communicative rationality when a special care was paid to the organization of the discourse, so as to make the listener to understand. For instance, one student's wide use of drawings and diagrams was linked to her effort in making her positions understandable to others, thus to a communicative dimension.

\subsection{Data Analysis}

\subsubsection{Example 1}

The episode comes from the experiment carried out in grade 6 concerning the concept of negative numbers. At first, students were asked to answer individually these questions: (1) What is a number? (2) What is it possible to do with numbers? Afterwards, they worked in group on a task to be solved on the Cartesian axes. The negative part of the axes was used by the students and such a solution was after institutionalized by the teacher. Finally, the students were asked to answer in group to the following questions: (3) You said that numbers are [reference to their former individual answers][...] and with numbers you can do [reference to their former individual answers]... Do you confirm your opinions now? (4) Negative numbers are numbers in the sense you intended before?

Here we confine the analysis to one episode referring to the group work on questions 3 and 4; we focus on the group made up by five students: Giu, Ari, Luc, Mar, Ale.

The transcript is analyzed in terms of identity and rationality. Concerning the analysis in terms of identity (performed according to the labels that were introduced in Table 15.1), we point out that some labels are assigned even if in the selected excerpt the utterances are not recurrent, because they are repeated many times in the whole transcript.

11 Giu: it must be for all the operations, and then -3 times -2 is equal to?

12 Ari: just a minute, I wrote: This means that it is negative number, but anyway you can do $-2+-3$ [in column] you get -5 .

13 Teacher: and how do you get it?

14 Ari: the sign means that it is a negative number, then I can do... that sign does not mean anything! It just means that it is a negative number, so...

15 Giu: no, Ari, what you are saying is meaningless.

16 Ari: yes. 
17 Giu: $\quad-16:-4$ ? [laughing].

18 Ari: $\quad-16$ ? You must do $16-4$ [after, she adds the minus before the numbers, in column].

19 Giu: $\quad$ try and do the division.

The division.

20 Ari: ok.

21 Luc: $\quad$ wait a minute! [she takes the pen].

22 Giu: let me speak!

23 Luc [she does -4 divided by -2 , and she writes -2 ]. Here you are! -4

24 Ari [does again 16:4].

In sentence 11 , Giu is mathematizing but also identifying as good in math. (Mth) (I) [Me Nv Di]. Giu provokes a change in the discourse generality: If it is true, it has to be always true, for every kind of operation (Mth). Giu wants to bring the discussion to an epistemic level: she suggests that, in order to have negative numbers as numbers, it must be possible to perform operations, and she asks for justification and meaning for this (epistemic dimension of rationality).

In sentence 12, Ari proposes to write down how to perform an addition of negative numbers. She is satisfied with the result and she is not looking for a justification or a deeper understanding of the meaning of negative numbers. Her intervention is less on the epistemic level and more on the teleological one, according to the final aim reaching a solution to write down (teleological dimension).

In sentence 13, Ari is mathematizing and suggesting a path from numbers as natural to numbers as positive and negative (Mth).

In sentence 15, Giu introduces the question of the sense of the operations with negative numbers. She also talks about Ari [Pe Sp], identifying Ari as a person not good in math. She did it for the whole discussion saying that as usually she does not understand [Me V Di]. This intervention, as the previous one, may be interpreted in terms of rationality. Giu has a clear position (negative numbers are not like positive numbers) and she wants to hold this position. To this aim (teleological dimension) she challenges the proposals of her mates. Her way of challenging is mainly at the epistemic level: she asks for further justification.

This changes the status of the following statements (epistemic dimension).

In sentence 17, Giu laughs when she does not agree with Ari's proposals, showing self-confidence in math (I) [Me Nv Di]. In order to challenge Ari's position (teleological dimension), Giu challenges her in terms of result and meaning of the operations with negative numbers (epistemic dimension).

In sentence 19, Giu is mathematizing but also identifying as good in math and saying to Ari what she has to do (I). [Me Nv Di].

In sentence 20, Ari interrupts her activity accepting Giu's request [Pe Nv Sp].

Also Luc (sentence 21) tries to find a place in the discussion [Me Nv Di].

Giu (sentence 22) intervenes claiming her right to participate [Me Nv Di].

Luc (sentence 23) tries to answer to Giu's provoking question but she does it in a very hasty way that does not satisfy Giu's request. She acts aiming at intervening 
and proposing a solution for the group, but we may note that her solution is not accompanied by a justification (lack on the epistemic dimension). She is rather more interested in providing a solution and foster an agreement among the mates. She has a clear goal and acts accordingly (teleological dimension). To reach this aim, she puts an effort in communication (communicative dimension).

The analysis oft he transcript shows that individuals' identities affect the students' participations to the group work; moreover, students have different aims (reaching a shared conclusion, see Luc and Ari, versus imposing his/her solution, see Giu, versus reaching understanding) and act accordingly (teleological rationality); this has effect in terms of prevailing epistemic (in the case of Giu) or communicative (in the case of Luc) dimensions and, consequently, on a fruitful participation to the group work. As a consequence, there is a final situation of non-agreement.

\subsubsection{Example 2}

The example comes from an experiment performed in grade 4. The group was composed by four primary school students. The students were asked to solve a problem together using a big paper and marker pens while the teacher and the other classmates were looking at them; then they were asked to present the solution to the classroom and to explain how they reached a common solution. This setting, conceived by the teacher-researcher as a means to foster the elicitation of explanation and problem solving strategies gives us information both on the group work and on the subsequent presentation of the group solution. The last request (to explain how they reached a common solution) is particularly important for our analysis since we observed in previous analyses that being asked to reach a common solution could lead the group to a forced agreement that is not based on statements proposed the epistemic level but rather on social dynamics influenced by the students' identities.

The teacher posed the following problem:

A snail wants to climb a wall 7 meters high. It starts from the bottom in the morning and goes 2 meters up until the sunset; then during the night it glides a meter down. It restarts again the day after and so on: during the day it goes 2 meters up, during the night it glides a meter down. How many days does it take to it to glide the wall?

Here we present the transcript and analysis of the group work, including the interaction with the teacher.

1. Sara: Each centimeter is a meter: 1, 2, 3, 4, 5, 6, and 7. Now I trace all the lines. Let's say that the pink is the first day. Here I draw the snail and it does two meters and climbs down one meter. Then, starting from here, it does two more and goes down one. From here again it does two and goes down one. Then two more and one down. From here it does two more and goes down one. I did some mistake... wait... I got 6 , but I noticed that there is this little piece, since it goes down one meter [she points to the trait between B and A, see Fig. 15.1]. 
Fig. 15.1 The sketch provided by the group

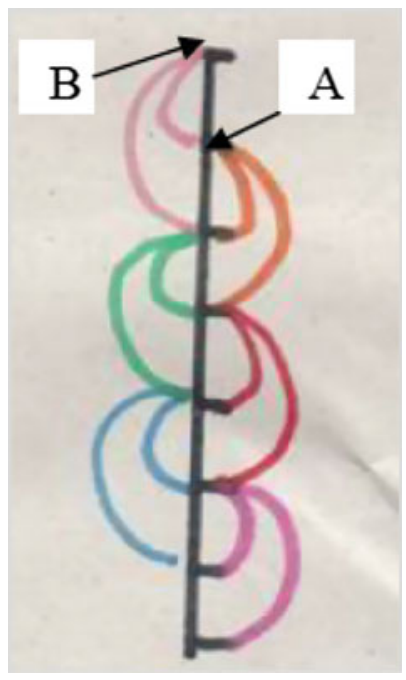

2. Marco: After it goes up, another day... it does in this way: one it goes up, and after it jumps on the wall.

3. Sara: But it cannot arrive on the air, eh...

4. Raul: If it already finished, why does it have to go down?

5. Sara: Anyway, I noticed this: six days, but I was not sure; because it does in this way: the first day, the second, the third, the fourth, but at the sixth it comes here [she points to point A] it does not come upper.

6. Marco: Then, it will take seven [days].

7. Raul: When it arrives, it has finished, has not it? What does it do, go down?

8. Sara: Anyway it is written that by night it slides down.

9. Raul: It slides when it is in the wall and not when it is arrived.

10.Sara: Then it results to me: it does 6 days, but after it does also this little piece to get up.

In sentence 1 we see an instance of Mathematizing (Mth): Sara explains to the group mates her reasoning showing a good self-confidence (I) [Me Vb Id]. She is efficient in representing the problem on the paper and describing her reasoning; she is also able to revise and correct herself during the explanation (communicative and epistemic dimension). In the last part of her intervention she imagines the snail reaching the top of the wall $(7 \mathrm{~m})$ at the end of the 6th day, but she claims that, during the subsequent night, the snail must climb one meter down, according to what is written in the text of problem. Hence, the problem is not yet solved, because there is still one "little piece" (one meter) to be climbed. Sara is working at epistemic level, accompanying all the steps of the solving process with a clear reference to the information provided by the text of the problem. She is led by a pure "mathematical" rationality, where the problem and the situation must conform to the "rules" given by the text. 
In sentence 2, Marco tries to complete Sara's discourse providing an interpretation of what might happen in the little piece. Here again we see an instance of Mathematizing (Mth). Marco is led by the final goal of reaching a solution (teleological rationality).

In sentence 3, Sara expresses some doubts on Marco's conclusion: if the snail climbs up from $6 \mathrm{~m}$, it must climb up 2 more meters, because the text says that each day the snail climbs $2 \mathrm{~m}$ up. Hence the snail should reach the level of $8 \mathrm{~m}$. But the wall is only $7 \mathrm{~m}$ high, then the snail should, when climbing $2 \mathrm{~m}$ up, reach "the air". From one side, Sara wants to find a solution that respects the mathematical "rule" given by the text; from the other side, she does not feel comfortable with a hypothetical solution where the snail arrives "on the air". Sara is trying to respect the text rule and to match it with the sense of the problem. Her intervention is still at the epistemic level.

In sentence 4, Raul poses a question, intervening in the discussion with a personal mathematical point of view (Mth) (I) [Me Vb Id] and trying to interpret the solution modelling the concrete situation. Raul's intervention is at epistemic level, since he supports his intervention with his own understanding of the problem: the text gives a mathematical rule for the movement of the snail, but once the top of the wall is reached, the snail stays on the wall and does not need anymore to climb down. Differently from Sara, he relies on a "modeling" and contextualized rationality, that supports his going back and forth between mathematics and real life. Despite Raul's intervention, in sentence 5 Sara goes on affirming her point of view, confirming herself as good in mathematics (I) [Me Vb Id].

In sentence 6, Marco intervenes once again in order to complete Sara's reasoning. We note that Marco is efficient in providing quick solutions to Sara's doubts, according to his final aim of providing a final solution, possibly shared by all the mates (teleological and communicative dimension).

In sentence 7, Raul goes on keeping his personal point of view and confirming himself as good in mathematics (Mth)(I) [Me Vb Id] and posing again the same question. His intervention is still at epistemic level, but in reference to his modeling and contextualized rationality.

In sentence 8, Sara goes on affirming her point of view, confirming herself as good in mathematics (Mth) (I) [Me Vb Id]. Also Sara's intervention is at epistemic level, since she grounds her position on the text of the problem. She relies on a mathematical and non-contextualized rationality.

11. Martina: I would do the same as Sara. The snail climbs up of two in the morning and one down by night, because it slides down. The day after it restarts, but by night it slides down again. I did like Sara [she draws another sketch, see Fig. 15.2].

12. Sara: But Martina, in my mind your solution has something wrong. Sorry but if it slides until here [pointing D], now it restarts from here [pointing $\mathrm{C}]$ ?

13. Marco: It must restart from here [pointing to point $A$ on the previous sketch]. 
Fig. 15.2 Martina's sketch

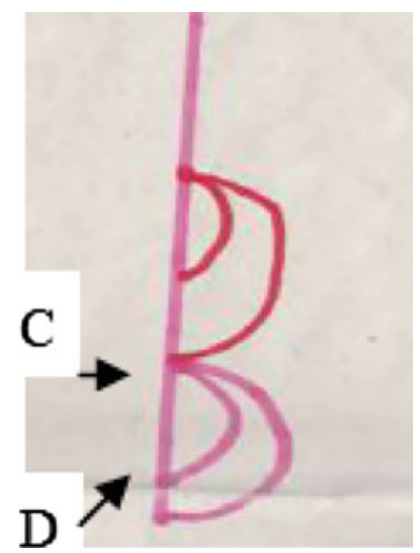

14. Sara: But for me there is something wrong ... the snail employs 6 days and a little piece because this remains empty, it arrives there [pointing to A].

15. Marco: 6 days and a sunset.

Martina (sentence 11) tries to participate in the discussion reproducing Sara's reasoning and identifying herself as not good in math (she repeats twice "I did like Sara, I would do as Sara"). [Pe Vb Id]. We may note that Martina is not able to reconstruct Sara's reasoning, possibly because she did not completely understand it. Trying to reproduce rather than really understanding, and not realizing that the reproduced reasoning contains some mistakes are evidences of lack in epistemic rationality. She does not mathematize.

In sentence 12, Sara replies to Martina acting on the epistemic level and confirming herself as good in mathematics (Ep) (I) [Mb Vb Id].

In sentence 13, Marco rephrases Martina another time without adding something or proposing a point of view (communicative dimension).

Once again, in sentence 15 Marco proposes a quick solution to solve Sara's doubt (teleological dimension).

16. Teacher: So what is your solution?

17. Sara: For me it is 6 days and a bit.

18. Marco: 6 days and a half.

19. Raul: 6 days and a half?

20. Sara: Because it arrives here, and not here in 6 days.

21. Marco: Because when it slides it goes down.

22. Sara: And then, now, from here I cannot go 2 steps upper, because otherwise it goes in the air. It cannot fluctuate.

23. Marco: But here is the end of the wall and after it starts sliding down.

24. Raul: I do not agree with this. [...] I counted 1, 2, 3, 4, 5, 6 and then it stays there, if we come back it never arrives to the top. 
25. Sara: But I wanted to say that when it arrives it must slide down. The text says that by day it climbs two and by night it slides down one.

26. Teacher: So what is your answer?

27. Raul: $\quad$ It is 6 .

28. Teacher: Do you all consider the answer convincing?

29. Marco: For me yes, because if we do what Sara suggested it does not work. Raul is right because if we make it slide down it remains here and never reaches the end.

30. Sara: Now I'm convinced too, because in the text we are asked "How many days does it take?". This is the question. For me they are right, because in the end the snail is on a line and cannot go down. Then for me it is 6 days and stop.

\section{Martina: I think like Sara.}

In sentence 16, the teacher intervenes in order to lead to the group to the end of the activity.

In sentence 17, Sara presents her answer.

In sentence 18, Marco rephrases Sara's solution.

Raul expresses his doubts about the proposed solution. Hence, in sentence 20 Sara adds an explanation for her solution.

In sentence 21 Marco adds something to Sara's explanation (in order to foster Raul's understanding of Sara's proposal). In sentence 22, Sara expresses again her doubt about the final part. We may note that Sara is acting at epistemic level (grounding her explanation on her understanding of the text) and communicative level (using the sketch to make Raul understand her explanation).

In sentence 23, Marco reinforces Sara's explanation. Anyway, Raul disagrees and proposes his own explanation to support a different answer. Raul is acting at epistemic level, since he accompanies his solution with an explanation, which is grounded on his understanding of the text.

In sentence 25, Sara replies going on her own path: since the text says it slides down by night it MUST slide down. She identifies again herself as good in mathematics (I) [Me $\mathrm{Vb} \mathrm{Id]} \mathrm{and} \mathrm{tries} \mathrm{to} \mathrm{found} \mathrm{her} \mathrm{explanation} \mathrm{on} \mathrm{solid} \mathrm{bases} \mathrm{(epistemic} \mathrm{dimension).}$

In sentence 26 , the teacher intervenes again to make the group converge to a unique solution.

After Raul's answer (sentence 27), the teacher accounts him as the one who gave the good answer even if it is evident that not all the members share his position.

After the teacher's intervention, Marco changes suddenly his answer (he no more supports Sara) and also the explanation (sentence 29). We may note that Marco's explanation, anyway, is different from Raul's one: it is based on the fact that adopting Sara's perspective it is not possible to reach the end. The teleological dimensions of rationality (it is necessary to reach a solution) is prevailing.

Due to the teacher's intervention, also Sara goes back to her solution and modifies it (sentence 30). Sara accepts Raul's answer but tries to explain it relying again on her personal epistemic approach: once reached the top pf the wall, the snail should slide down, but the processes is interrupted by a line. This explanation is very different 
from Raul's one, because Raul bases his considerations on real life (almost thinking as a snail in the situation), while Sara de-personalizes the snail, that could also be a point on a line, and thus a further element is necessary to agree with the others: there must be an external constraint that impede to it to go on with the process "imposed" by the text. In other words, Sara adds a constraint to her interpretation of the text.

Finally, in sentence 31 agrees with Sara. Martina, as we observed before, renounces to her personal point of view, only acts at the teleological level (the final goal is to provide a solution to the teacher) and also confirms her lack of self-confidence in mathematics.

The analysis shows one case where the group solution is far from being shared at the same level by all the group members. Indirectly, Sara and Raul identify themselves as good in mathematics (see sentences 5, 7, 8, and 25). Martina does not really participate into the solving process, identifying as not good in mathematics and aligning herself to the position of Sara (see sentences 11 and 31). Her identity of not good in mathematics goes along with a lack in epistemic rationality. Marco puts a great effort in finding a mutual understanding: his final aim is to produce a group solution, and the prevailing teleological dimension leads him to act as mediator between Raul and Sara, rather than a facilitator that really helps mutual understanding (see sentences 6, 13, and 15).

Concerning Martina and Marco, we may say that the combined analysis helps us to better characterize their participation into the group work.

The interactions between Raul, Sara and the teacher, read in terms of the combined framework, give us new insights into the concept of forced agreement. First, we may observe that the initial lack of agreement between Sara and Raul is due to the presence of two strong "mathematical identities" and on the fact that each of them is relying on the epistemic dimension of rationality, but with a great difference: Raul employs a modeling and contextualized rationality (see sentences 4, 7, 24), while Sara relies on a mathematical and non-contextualized rationality (see sentences 1, 5, 8). The different rationalities cause a different approach to the problem and, finally, a different solution (see sentences 17 and 27). Only the teacher's intervention leads Sara to change their position. Sara's way to manage the "obliged change" (see sentence 30), without giving up on the epistemic level and trying to conserve her identity, is very interesting since it leads us to enlarge the set of possible behaviors due to the interactions between different identities and rationalities in group works. The effect of the interaction between different identities with the mediation of the teacher leads to a particular case of forced agreement that we never observed before: one of the students, Sara, aligned her position without renouncing to her identity, but rather forcing the suggested solution to be included in her previous strategy as a particular case. We may note that the presence of different forms of rationality (modeling and contextualized vs. non contextualized) could have become even more fruitful if it had been identified and stressed by the teacher. 


\subsection{Findings}

In this section, we summarize the main findings of our analysis in reference to the research questions.

\section{Finding 1: Identities and prevailing dimensions of rational behavior are inter- wined and their mismatch may cause a lack of agreement}

A crucial issue, when dealing with group works, is the students' participation into the activity. Identity may affect such a participation, at two levels: at the level of degree of involvement and at the level of nature of the interventions during the activity.

Concerning the first level, we may say that students that do not identify themselves as good in mathematics tend to avoid participation (see Martina in Example 2), while students who identify themselves as good in mathematics tend to involve into the activity (see Giu in Example 1, Sara and Raul in Example 2). The second level adds insight into the nature of such participation, which can be described by means of the dimensions of rationality. Concerning teleological rationality, individual students may act according to different (and sometimes conflicting) aims: imposing his/her own solution over all the group (see Giu in Example 1); refuting somebody else's proposal, independently of its correctness (see again Giu in Example 1); reaching a shared conclusion, providing a solution (any solution) to the teacher (see Luc, Example 1; Marco, Example 2). Accordingly, some students focus mainly on epistemic aspects (finding a correct answer and a sound explanation) (see Giu, Example 1; Sara and Raul, Example 2), while for other students the communicative dimension is prevailing (not only reaching a solution, but making it comprehensible for all the groupmates) (see Luc, Example 1; Marco, Example 2). Networking the two analyses, we may say that the mathematical identity turns into prevailing dimensions of rational behavior-epistemic in the case of good mathematical identity and communicative in the other cases - and that the interplay of dimensions of rationality affects the participation into the group activity and the quality of the interaction. The effectiveness of the group work, both in terms of solution production and of meaning making depends strongly on such factors.

\section{Finding 2: Teachers' interventions may affect significantly interactions in group works}

That teachers may have relevant effects on the ways students participate in group works and interact with the groupmates. More specifically, teachers' interventions during the group work may change the balance between students' identities, causing one student, identified by the teacher as good in mathematics, to impose his/her solution on the group-mates, and, conversely, other students, identified as less good in mathematics, to give up and accept passively a solution proposed by one mate. In Example 2 we showed a situation of initial non-agreement, caused by two strong mathematical identities that rely on different kinds of epistemic rationality, that progressively turns into a forced agreement, due to the intervention of the teacher that implicitly accepts one of the proposed solutions and forces the other students to accept it. We also observed that the students, according to their mathematical identities and their epistemic dimensions, react to this situation in different ways, and for 
the student Sara the forced agreement is turned into a deeper understanding of the situation.

\subsection{Conclusions}

Our analysis shows that both social skills and disciplinary issues influence the students' ability to participate in a group work in a quite complex way. Particularly, we focused on the interplay between identity and the prevailing dimension of rationality of the students' discourses that we consider important and not independent factors influencing group works in mathematics. We argue that only a good "mathematical identity" (the student feels he/she is good in mathematics) may lead the students to participate in the group work moving to an epistemic level and thus to develop relevant social skills related to mathematics, like being able to pursue the convergence of a group work towards a common solution respecting an own personal point of view and checking by him/herself the validity of the explanation, in despite of the 'popularity' of the solution or of the accountability of the group mate who is proposing a solution.

In the analysis of Example 2, we also showed that the teacher's intervention caused a significant reaction in the group, changing the authentic interaction between the students and provoking a forced agreement. This confirms that it is a plurality of factors to affect, time after time, the students' "mathematical identities" (and identities in general) and the teachers may play a significant role. This also reinforces the general statement that the relation teacher-students involves not only the mathematizing but also the identifying process, leading in some cases to a co-construction of the student's identity of failure, as pointed out by Heyd-Metzuyanim (2013).

\subsection{Further Developments and Implications for Practice}

From our findings, the necessity of a deep reflection on the role of the teacher emerges: the teacher seems to play not only as a mediator between students' different positions, but also as - maybe indirect and unaware-identifier of his/her students as people who can have accountability in a mathematical group work or not. Hence, possible directions for further research are: analyzing teachers' awareness of their role during group work and solution presentation, and of the impact of their interventions on the evolution of social dynamics and on the students' prevailing dimensions of rationality; studying whether and how teachers may help students to manage the relation with the group and make the students more and more aware of the social dynamics underlying group work. Particularly, we are interested in understanding how far the teachers are able to distinguish between productive interventions, that make the students keep their own identities and encourage them to move to the epistemic level 
of rationality, and interventions that lead the members to give up their own proposal and accept another one.

Moreover, we plan to organize professional development activities based on the findings of our research, in order to promote the evolution of the teachers' awareness on the issue of identity and rationality during group work. To this aim, we will provide them theoretical tools to analyze transcripts of their own interventions or of interventions of other teachers and we will organize sessions of joint analysis with them. In this way, our theoretical reflection on the interplay between identity and rationality will provide the ground for teacher professional development interventions (Tsamir, 2008).

\section{References}

Branchetti L., \& Morselli F. (2016). Identity and rationality in group discussion: An exploratory study. In K. Krainer \& N. Vondrová (Eds), Proceedings of the Ninth Congress of the European Society for Research in Mathematics Education, CERME9, 4-8 February 2015 (pp. 1146-1152). Prague, Czech Republic: Charles University in Prague, Faculty of Education and ERME.

Branchetti, L., \& Morselli, F. (2017). Identity and rationality in classroom discussion: Developing and testing an analytical toolkit. In C. Andrà, D. Brunetto, E. Levenson, \& P. Liljedahl, P. (Eds.), Teaching and learning in math classrooms (pp. 197-206). New York, NY: Springer.

Habermas, J. (1998). On the pragmatics of communication. Cambridge, MA: MIT Press.

Heyd-Metzuyanim, E. (2009). Mathematizing, subjectifying and identifying in mathematical discourse-Preliminary ideas on a method of analysis. In Tzekaki, Kaldrimidou \& Sakonidis (Eds), Proceedings of PME 33 (Vol. 1, pp. 389-396). Thessaloniki, Greece: Aristotle University of Thessaloniki.

Heyd-Metzuyanim, E. (2013). The co-construction of 'learning difficulties' in mathematics-Teacher-student interactions and their role in the development of a 'disabled' mathematical identity. Educational Studies in Mathematics, 83(3), 341-368.

Johnson, D. W., \& Johnson, R. T. (1980). Promoting constructive student-student relationships through cooperative learning. Minneapolis, MN: Minnesota University.

Monaco, A. (2015). La risoluzione dei problemi matematici: strategie e rappresentazioni spontanee in evoluzione. Unpublished Tesi di Laurea (Dissertation), Roma, Italy: Università la Sapienza.

Morselli, F., \& Boero, P. (2009). Habermas' construct of rational behavior as a comprehensive frame for research on the teaching and learning of proof. In F. L. Lin, F. Hsieh, G. Hanna, \& M. de Villiers (Eds.), Proceedings of the ICMI Study 19 Conference: Proof and Proving in Mathematics Education (Vol. 2, pp. 100-105). Taipei, Taiwan: The Department of Mathematics, National Taiwan Normal University.

Organization for Economic Co-operation and Development (OECD). (2013). Competency framework. Paris, France: OECD.

Pons Parra, R. M., Serrano González-Tejero, J. M., Luna Serrano, E., Cordero Arroyo, G., Lomeli Agruel, C., \& Moreno Olivos, T. (2012). Validación de un instrumento para analizar el parámetro de mutualidad en el proceso de interacción entre iguales. Revista Mexicana de Psicología, 29(1), 86-96.

Prediger, S., Bikner-Ahsbahs, A., \& Arzarello, F. (2008). Networking strategies and methods for connecting theoretical approaches-First steps towards a conceptual framework. ZDM-The International Journal on Mathematics Education, 40(2), 165-178.

Radford, L. (2006). The anthropology of meaning. Educational Studies in Mathematics, 61(1-2), 39-65. 
Radford, L. (2008). The ethics of being and knowing: Towards a cultural theory of learning. In L. Radford, G. Schubring, \& F. Seeger (Eds.), Semiotics in mathematics education: Epistemology, history, classroom, and culture (pp. 215-234). Rotterdam: Sense.

Radford, L. (2011). Classroom interaction: Why is it good, really? Educational Studies in Mathematics, 76, 101-115.

Roth, W. M., Radford, L., \& LaCroix, L. (2012). Working with cultural-historical activity theory. Qualitative Social Research, 13(2), 1-15.

Sfard, A., \& Prusak, A. (2005). Telling identities: In search of an analytic tool for investigating learning as a culturally shaped activity. Educational Researcher, 34(4), 14-22.

Sharan, S. (1980). Cooperative learning in small groups: Recent methods and effects on achievement, attitudes, and ethnic relations. Review of Educational Research, 50, 241-271.

Slavin, R. E. (1990). Cooperative learning: Theory, research, and practice. Englewood Cliffs, NJ: Prentice-Hall.

Spagnuolo, A. (2017). The effects of the equality parameter on mathematics students' performance. A comparative analysis of peer education interventions in teaching/learning of linear and quadratic functions. Unpublished Ph.D. dissertation, University of Ferrara, Italy.

Tsamir, P. (2008). Using theories as tools in mathematics education. In D. Tirosh \& T. Wood (Eds.), International handbook of mathematics teacher education: Tools and processes in mathematics teacher education (Vol. 3, pp. 211-233). Rotterdam, The Netherlands: Sense.

Vygotskij, L. S. (1978). Mind in society: The development of higher psychological processes. Cambridge, MA: Harvard University Press. 
Open Access This chapter is licensed under the terms of the Creative Commons Attribution 4.0 International License (http://creativecommons.org/licenses/by/4.0/), which permits use, sharing, adaptation, distribution and reproduction in any medium or format, as long as you give appropriate credit to the original author(s) and the source, provide a link to the Creative Commons license and indicate if changes were made.

The images or other third party material in this chapter are included in the chapter's Creative Commons license, unless indicated otherwise in a credit line to the material. If material is not included in the chapter's Creative Commons license and your intended use is not permitted by statutory regulation or exceeds the permitted use, you will need to obtain permission directly from the copyright holder.

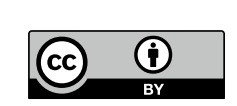




\title{
Chapter 16 \\ Belief Changes in the Transition \\ from University Studies to School \\ Practice
}

\author{
Ralf Erens and Andreas Eichler
}

\begin{abstract}
Teachers' intended instructional design of lessons are represented by their belief systems as a part of mathematics-related affect. This chapter focuses on 20 prospective secondary teachers' beliefs towards their teaching of calculus at uppersecondary level. The theoretical framework in relation to the international discussion on beliefs and affect and methodological considerations referring to a qualitative design will be outlined. Afterwards the focus lies on studying these teachers' beliefs with a particular concern for how these beliefs might change depending on the stage of their professional development. Results from a qualitative study of preservice teachers and teacher trainees will be discussed centred on whether and how changes in their belief systems occur. Our results show that the teachers' central beliefs remain stable whereas subordinated and peripheral beliefs slightly change.
\end{abstract}

Keywords Teacher beliefs $\cdot$ Calculus $\cdot$ Professional development $\cdot$ Belief change

\subsection{Introduction}

Teachers are challenged to consistently change or to modify their beliefs beyond a status quo achieved after university studies (Clarke \& Hollingsworth, 2002). This individual and life-long learning aims to achieve the overarching goal for mathematics instruction, i.e. to seek a teaching style that facilitates the best possible students' learning.

Teachers' beliefs and goals as a target of the mentioned life-long learning are understood to impact on both the teachers' actual teaching of mathematics (e.g. Eichler \& Erens, 2015) and also the teachers' professional development (e.g. Philipp, 2007). For this reason, it is an important challenge for research in mathematics edu-

R. Erens $(\varangle)$

University of Education Freiburg, Kunzenweg 21, 79117 Freiburg, Germany

e-mail: ralf.erens@ph-freiburg.de

A. Eichler

University of Kassel, Heinrich-Plett-Straße 40, 34132 Kassel, Germany

e-mail: eichler@mathematik.uni-kassel.de 
cation to investigate the status quo and the development of mathematics teachers' beliefs. Speer (2005, p. 365) expressed the importance of teachers' beliefs as follows: "Beliefs appear to be, in essence, factors shaping teachers' decisions about what knowledge is relevant, what teaching routines are appropriate, what goals should be accomplished, and what the important features are of the social context of the classroom." However, Schraw and Sinatra (2004, p. 100) stated to the research concerning teachers' beliefs development that "[t]here has been little research on teachers' personal epistemologies, how these beliefs develop and are affected by teacher education". A similar statement is given by Levin (2015) ten years later. For this reason, one main aim of this chapter is to make a contribution to the research concerning the development of prospective mathematics teachers' beliefs.

Existing research indicates several phases in which a development and also a change of teachers' beliefs took place (e.g. Oliveira \& Hannula, 2008). First of all, a highly relevant phase of the belief development is located before teachers become teachers, i.e. in the teachers' own school-time (e.g. Kaasila, Hannula, Laine, \& Pehkonen, 2006; Richardson, 2003). A further main phase of the professional socialisation of teachers is-after the crucial transition from school to university (e.g. Gueudet, Bosch, Disessa, Kwon, \& Verschaffel, 2016)_ given by these teachers' university studies (e.g. Fives \& Buehl, 2012). In this phase, teacher educators try to ensure that prospective teachers' beliefs are developed according to educational goals. For example, Bernack-Schüler, Leuders, and Holzäpfel (2015) reported a case that shows the failed attempt of teacher educators to change the beliefs of students. Research has identified a further crucial phase of belief development when teachers acquire their first experiences in the classroom (Huberman, 1989; Oliveira \& Hannula, 2008). This phase could consist of a so-called "shock due to practice" (Dann, Müller-Fohrbrodt, $\&$ Cloetta, 1981) that describes a phase when teachers' beliefs are challenged by the teachers' first practical experiences. Again, there are few findings concerning this phase in either education research (Levin, 2015) or in mathematics education research (e.g. Oliveira \& Hannula, 2008). The research of Dann et al. (1981) made the prediction that teachers tend to neglect reform-oriented or student-centred teaching styles, when they teach on their own the first time, but, however, return to teaching orientations that they learned in university studies (cf. also Oliveira \& Hannula, 2008). Of course, mathematics teachers might change their beliefs also in their phase as qualified teachers and teacher trainers in professional development courses aiming to develop teachers' beliefs (e.g. Liljedahl, 2010). However, in this paper, we focus on the phase of mathematics teachers' development between the end of their university studies and their start as qualified teachers, i.e. a phase that lasts 18 months in Germany (cf. Eichler \& Erens, 2014).

This report addresses one main topic of our research programme, i.e. to investigate the development of mathematics teachers' beliefs. In this research programme, we restrict our focus to calculus. The rationale for this focus is given by some evidence that teachers' beliefs differ concerning different mathematical topics (Eichler \& Erens, 2015; Franke, Kazemi, \& Battey, 2007). For example, a teacher's belief towards modelling as a central part of mathematics teaching may considerably vary if the teacher is thinking about geometry, statistics or calculus (Eichler \& Erens, 
2015). Accordingly it is reasonable to also restrict the focus on a specific mathematical discipline when regarding the development of teachers' beliefs. For example, if a teacher mentions different beliefs about mathematics in general at different times, it is not possible to reconstruct if the teacher changed his beliefs or if the teacher has different mathematical disciplines in mind. To avoid a bias based on teachers' different beliefs towards different mathematical disciplines is the main reason to focus on a specific mathematical discipline for this paper, i.e. calculus. Since there is a lack of research referring to teachers' beliefs towards calculus (cf. Bressoud, Ghedamsi, Martinez-Luaces, \& Törner, 2016; Gutiérrez, Leder, \& Boero, 2016), we focus in depth on the specificity of calculus teachers' beliefs in our research program. However, due to the focus for this paper, i.e. the development of teachers' beliefs, we discuss the specificity of beliefs towards calculus only secondarily.

To conclude, the present chapter aims to focus on the development of secondary mathematics teacher beliefs towards calculus as the central part of the mathematics syllabus of upper secondary education in Germany. For this, we outline our theoretical framework consisting of a brief summary of the construct of beliefs and specific trends in teaching calculus. We further refer to the method of our research. A main part of this chapter is to explicate our findings concerning the following two research questions:

- To what extent do distinguishable features in the structure of prospective secondary teachers' beliefs towards teaching calculus change in the transition between the end of their university studies and their start as qualified teachers?

- What are the reasons for potential beliefs changes in the course of professional education as a teacher?

We conclude this chapter with a discussion of our research findings and brief comments concerning possible issues for future research.

\subsection{Theoretical Framework}

\subsubsection{Teacher Beliefs}

Beliefs could be understood as part of mathematics-related affect (Hannula, 2012). In this framework beliefs consist of cognitive, motivational and affective aspects (Hannula, Op 't Eynde, Schlöglmann, \& Wedege, 2007; Fig. 16.1). According to this model, we regard teachers' beliefs and teachers' goals, and, thus, we investigate the intersection of cognitive and motivational aspects of teachers' mathematics-related affect.

Using the definition of Philipp (2007) and Pajares (1992) a teacher's beliefs could be understood as his or her propositions about a certain topic that are individually thought to be true. For example, a teacher could hold the following belief (propo- 


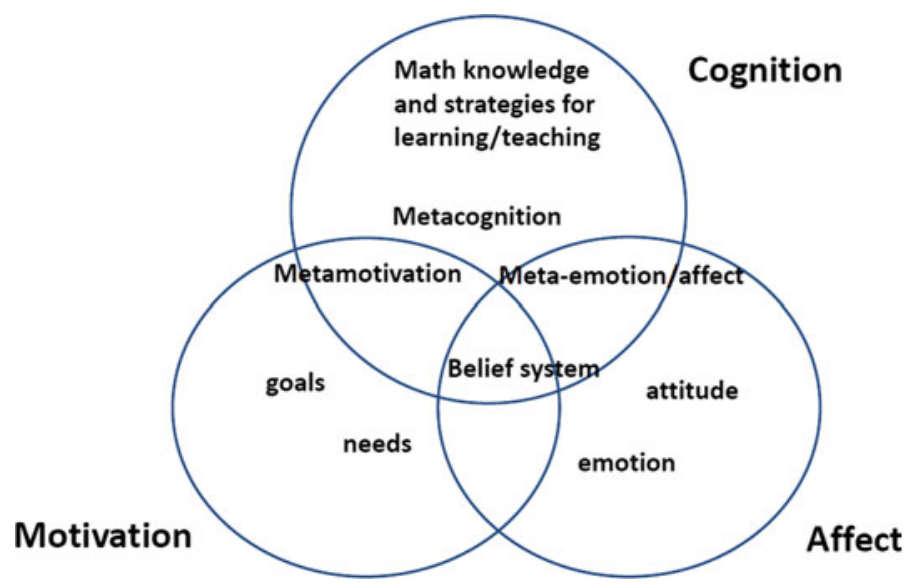

Fig. 16.1 Aspects of teachers' mathematics related affect Hannula et al. (2007)

sition): “Applications are useful to promote networked thinking". This proposition has an individual logical value for the teacher.

Goals could be understood as representing a teacher's conviction of an appropriate way of teaching (Eichler \& Erens, 2014). In contrast to beliefs, teaching goals like "I want to teach applications" or "I want my students to promote networked thinking" have no logical value. In educational psychology, goals are seen as a "representation of what it is an individual is trying to achieve in a given situation" (Wentzel, 2000). In our research we use the construct of goals as a trait, i.e. the decision making, when planning future teaching (cf. Heckhausen \& Gollwitzer, 1987). Following the definitions of beliefs and goals, beliefs connect goals on different hierarchical levels. Thus a primary goal is connected by a proposition (belief) with a subordinated goal.

There is a wide consensus that teachers' beliefs are organized in systems of beliefs (Fives \& Buehl, 2012; Green, 1971; Philipp, 2007). Three aspects that are also important for our research are described as constituting a belief system: First, beliefs are understood to have an individual grade of centrality. Thus, a teacher could hold some beliefs more strongly (central beliefs) than other beliefs (peripheral beliefs). For our purpose of describing the development of teachers' beliefs, this aspect is crucial since central beliefs seem to be more stable than peripheral beliefs (cf. Liljedahl, Oesterle, \& Bernèche, 2012). A second aspect concerns the distinction between primary and derivative beliefs (cf. Green, 1971). Finally, the third characteristic of the belief system is the existence of different clusters of beliefs that are not necessarily logically connected. Thus, beliefs could be contradictory. In our research approach, we focus particularly on a coherent mathematical topic like calculus to potentially yield a coherent system of logically connected beliefs.

In the same way like beliefs, goals could be understood to exist in different grades of centrality and could be potentially contradictory. Referring to the aspect of primary and derivative beliefs, teachers' goals could be distinguished as primary goals and 
subordinated goals emphasising the hierarchical structure of different goals (see above). Subordinated goals (e.g. teaching of applications) could be also central, but represent a technology to achieve primary goals (e.g. achieving a networked thinking).

For investigating the structure of teachers' beliefs (the first research question), we use overarching concepts of beliefs and goals represented by "world views" (Grigutsch, Raatz, \& Törner, 1998) or epistemological beliefs (Hofer \& Pintrich, 1997) about mathematics (or calculus), with reference to school mathematics or about teaching and learning mathematics. According to Grigutsch et al. (1998) we refer to four world views:

- A process-oriented view represents beliefs that mathematics is a creative activity consisting of problem solving using different and individual ways.

- An application-oriented view represents beliefs that the utility of mathematics for real world problems is the main aspect of the nature of mathematics.

- A formalist view represents beliefs that mathematics is characterised by a strongly logical and formal approach.

- A schema view represents beliefs that mathematics is a set of calculation rules and procedures to apply for routine tasks.

Although Grigutsch et al. (1998) formulated their world views referring to mathematics in general, each of the four views can be related to a certain topic like calculus. We further use a distinction of teachers' overarching goals about a learning orientation. Following Staub and Stern (2002), we refer to two different learning orientations:

- A transmission view represents beliefs that the teacher has to control students' learning and has to organise the learning process step by step.

- A constructivist view represents beliefs that the teacher must organise a learning environment in which the students create their learning process for themselves.

Finally, the research of Skott $(2009,2015)$ implies one should also take into account the "social entities" (Skott, 2009, p. 45) of different classrooms or different schools. This is especially important when considering prospective teachers after their university studies, as this constitutes the novice stage of their teacher career (Huberman, 1989). In this phase prospective teachers are confronted with the realities of mathematics teaching in the classroom that may challenge or confirm their existing beliefs. Moreover prospective teachers also become a member of school as an organisation and are influenced by the context in their socialisation (Kelchtermans \& Ballet, 2002). The socialisation process is seen as a "meaningful interaction between the beginning teacher and the school as an organisation with its different actors" (ibid., p. 106), which may influence prospective teachers' beliefs. In this paper we use the term socialisation more broadly comprising the period from own schooldays up to qualified teaching. The induction period in the transition from university to teacher training to becoming a qualified teacher needs to capture and encompass the settings of both, the specific social context of a school (Skott, 2009) and social prac- 
tices or teaching approaches promoted by teacher educators or experienced teachers (Skott, 2015).

\subsubsection{Teaching Calculus}

Teachers' beliefs and goals concerning the teaching and learning of mathematics are necessarily focused on specific mathematical objects (cf. Philipp, 2007). As outlined above, we restrict the space for these belief objects to the teaching and learning of calculus as a main topic of mathematics teaching in upper secondary schools. Regarding the teaching and learning of calculus we defined trends elsewhere (Eichler \& Erens, 2014, pp. 654-656) that consist of patterns of teachers' beliefs and goals and, thus, represent types of calculus teachers that are-except for the last type-also theoretically existent in further studies (e.g. Artigue, 1996; Oates, 2012; Robert \& Speer, 2001). We briefly explain these four trends.

- For teachers following an empirical generic trend, process-oriented goals are central whereas these teachers refuse a formalist view. Goals that potentially refer to the application-oriented view or emphasise the use of technology are subordinated to goals representing the process orientation.

- For teachers following an empirical modelling trend, application-oriented goals are central. If other goals are also central for these teachers the related goals are subordinated to goals representing the application orientation.

- For teachers following an empirical moderate New Math trend, formalist oriented goals are central. Goals that potentially refer to the application-oriented view or that emphasise the use of technology are subordinated to goals representing the process orientation.

- For teachers following an empirical schema trend, schema-oriented goals are central whereas other goals are mostly neglected.

A development of teachers' beliefs and goals in their professional socialisation could be regarded as a change between empirical trends or a change between world views. In this paper, we primarily refer to a change of the four world views that predominantly constitute the empirical trends.

In contrast to teaching goals, the topics of calculus teaching are well defined and include the concepts of function, of derivatives, of integrals or of the connection between derivatives and integrals (e.g. Tall, 2009). For this reason, the main questions for teachers in our study and even for different countries all over the world (Bressoud et al., 2016) refer to teaching goals instead of selecting specific topics. These questions that represent also parts of different trends indicated above, concern

- the extent of real applications as a main topic for calculus teaching (e.g. Blum, 2000).

- the extent of exactness when introducing concepts of calculus (e.g. Tall, 2009).

- the selection of competing approaches for concepts, e.g. the derivative. 
- the extent of using technology (e.g. Tall, 2008).

Prior research on mathematics teachers' beliefs referring to geometry, calculus and stochastics has provided evidence that teachers hold distinguishable beliefs about different mathematical objects or topics. As teachers at secondary level naturally teach all mathematical disciplines, their domain-specific beliefs vary significantly (Eichler \& Erens, 2015). Investigating (prospective) teachers' domain-specific beliefs on calculus, we refer to the trends outlined above, the mathematical world views and, finally, the aforementioned main specific questions for teaching and learning calculus when regarding the teachers in our study.

\subsection{Method}

As calculus is the core discipline of the curriculum at upper secondary level, we refer to a sample of prospective teachers qualifying for mathematics teaching in secondary schools ("Gymnasium"). To become a mathematics teacher, prospective teachers study two subjects at university followed by a second phase of a teacher education programme based at school and state institutions. In this second phase the teacher trainees attend courses taught by teacher educators (who are also teachers) consisting of subject-specific pedagogy, practical teaching content, curriculum-based lesson planning and teaching methods. These courses are complemented by part-time teaching in schools. This phase after graduating from university and before beginning their career as a qualified teacher is compulsory for prospective teachers, lasts about 18 months and includes the first intense practical experience of the prospective teachers in school. The second phase is completed with the award of a State Examination. For this graduation observed and assessed lessons and teacher training examinations are criteria. These examinations are a decisive aspect for a future career in teaching. Thus there exists a dependent relationship between educators and trainees that might affect instructional planning processes during traineeship. Therefore the perception of teacher training might be seen by prospective teachers in terms of achieving a set of given demands and views of appropriate classroom practice. These views might be ambivalent with prospective teachers' existing beliefs before or during the intervention of the teacher training programme. In this chapter we refer to a sample of ten preservice teachers (PT), who have just completed their mathematics undergraduate courses at university, and ten further teacher trainees (TT) that have participated in the subsequent teacher education programme between university and the career as a qualified teacher in school. The ten preservice teachers had just finished their final exam at university. The ten teacher trainees were in the middle of the practical phase as teacher trainee. The rationale for conducting the study with these two subgroups lies in the hypothesis, that concerning the status quo of their development as a teacher we could differ between the existence of a more retrospective consideration of appropriate teaching approaches (preservice teachers: own schooldays, university; see Richardson, 2003) and a perception of (future) teaching that is formed by 
reflection of one's own teaching practice (teacher trainees: see Oliveira \& Hannula, 2008).

In a theoretical sampling, we varied the characteristics of the 20 teachers as much as possible. Thus, the teachers were recruited from different universities and teacher training colleges from the south-western part of Germany. Since one's beliefs could be assumed to be inextricably connected to the community of (teaching) practice in a certain teacher training college or, respectively, in a certain university, this design of the data collection was crucial. In order to avoid specific correlations with teachers' further teaching subjects (e.g. physics \& mathematics), we also varied the second subject of the teachers.

In order to investigate possible belief changes, the teachers were interviewed twice with a time span of at least one year between the first and second interview. In the first interview data were collected by semi-structured in-depth interviews focusing on calculus and including different topics related to calculus, e.g. instructional content, teaching goals, reflections on the nature of calculus as a mathematical discipline and as an issue of school mathematics, the students' beliefs, and calculus textbook(s) used by the teachers. Further, we used prompts to provoke teachers' beliefs, e.g. tasks of textbooks, fictional or real statements of teachers or students concerning instructional objectives relevant to calculus. In the second interview validation of analysis of the first interview was accomplished by confronting interviewees with key statements from their first interview and eliciting either agreement or further adjusting and explanation. Further questions about self-perception concerning their development and about the influence of their teacher educators plus a set of new task-prompts were used.

For analysing the verbatim transcribed interviews, we used a qualitative coding method (Mayring, 2015) that is close to grounded theory (Glaser \& Strauss, 1967). Based on the research questions, the aim of the analysis was to determine distinguishable features of teachers' beliefs relating to the above described theoretically and empirically defined trends of calculus teaching. Coding was done by assigning text passages and statements by teachers to the four deductive categories which were described in a coding manual. In this analysing process the characteristic patterns representing the four main trends were developed and modified step by step. Additionally new categories emerged from the data material in an inductive manner such as notions of observed or experienced teaching practices or the integration of technology into classrooms specifically relating to calculus. For example, we developed codes such as 'paper-and-pencil skills' or 'technology as an instrument' to analyse teachers' beliefs regarding the advantages or disadvantages of the use of technology in mathematics classrooms. The combination of deductive and inductive categories and codes were used to analyse the whole data set of first and second interviews using a qualitative data analysis software (MaxQDA) for systematic evaluation. Data coding was conducted by at least two persons and slight differences in coding were solved by discussion and consensus. The allocation of central beliefs that we described in detail in Eichler and Erens (2015) could be attained if teachers showed this belief coherently in several episodes through the whole first interview concerning different contexts, described concrete examples, and showed reactions to interview prompts 
and tasks according to their central beliefs. By confronting participants with characteristic excerpts from their first interview and individual case summaries about central beliefs, the accuracy of interpretation of the first round of data could be validated. The hierarchy of goals, i.e. the distinction of primary and subordinated goals is similarly based on an interpretation that is validated by a coherent interpretation of different episodes of the transcripts. For illustrating a related interpretation we use the example given above in terms of a real teacher quotation: "With these applications I want to promote networked thinking." Our interpretation of this quote is that application is a means to an end and, thus, is not a primary goal, but subordinated to the goal of letting students achieve a networked thinking.

\subsection{Results}

We have organised the discussion of our results as follows: We primarily discuss the main changes in the structural elements of the teachers' belief systems that we found from the first interviews of the preservice teachers (PT) and the teacher trainees (TT) to the second interview one year later. We refer to both interviews for the aspects of application orientation, problem orientation, formalism, schema orientation and technology orientation. Finally, we discuss the main reasons for changes and also for the stability of beliefs, i.e. an orientation towards the times as a student in school, authorities of teacher trainers and final exams.

In order to understand teachers' beliefs and belief changes ingrained in personal experiences and learning trajectories it is important to reveal how (prospective) teachers approach their professional world. As "beliefs are expected to significantly influence the ways in which teachers interpret and engage with the problems of practice" (Skott, 2015, p. 19), these cannot be exhaustively described by one cluster of central beliefs or goals. As a matter of fact, many teachers in our sample show a coexistence of more than one cluster of central goals.

\subsubsection{The Application View}

The centrality of an application-oriented view is apparent in more than half of our sample. In this paper, we illustrate central beliefs by a few examples and focus on belief changes. Mrs. M, a preservice teacher (PT), explains her preference for an application-oriented introduction to the concept of the difference quotient. Her primary rationale to be application-oriented is given in this quotation, i.e.

Mrs M. (PT, 1st interview): For an introduction, I would definitely use an example with body growth or population growth. Mainly because these are questions that arouse students' interest and seem to be useful for them. 
This teacher stresses that the concept of the rate of change using realistic examples is considered to be essential together with different representations of real data to be visualized in tables, graphs and subsequently functions. Reacting positively to given prompts Mrs M. also mentions standard examples from one or two textbooks at the beginning of her teacher training. Also other teachers refer to various realityoriented examples which in their view further the illustration of function and the derivative concept. Typically one of the arguments for their rationale for application tasks constitutes the motivation and attraction of interest of their students.

In her development in the second interview Mrs M. reveals that applications have no value per se, but serve as a starting point for examining more abstract contents of calculus. However, the tasks Mrs M. used for her teaching are combined with a confirmation of an application-oriented view. Regarding her reasons for this central belief the systematic use of mathematical methods enables her to demonstrate the potential of calculus beyond pure mathematical questions.

Mrs M. (PT, 2nd interview): ...these applications should be combined with an insight into relations with the more abstract concepts - understanding the scope of such concepts and mathematical processes behind these. With exponential functions we used applications with medication degradation processes and other examples.

There are further teachers that express, in the second interview, the same structure of beliefs or rather goals as Mrs M. who considers application-oriented goals to be central but subordinated to process-oriented goals,. These teachers linked, especially in the second interviews, application orientation to comprehension of concepts going beyond the knowledge of a definition and applications are not solely used for the motivation of students. It is interesting that the aim of teaching application for further teaching goals was more clearly emphasised by these (mainly preservice) teachers.

The example of Mrs M. represents the difference between primary and subordinated goals. Since application orientation is a central goal of Mrs. M, this goal is subordinated to a primary (and central) goal, i.e. the insight into profound understanding of terminology and concepts. Realistic applications as a starting point for developing and illustrating more abstract calculus concepts constitutes a trend in mathematics education in recent years that we subsumed under the empirical generic trend (cf. Eichler \& Erens, 2015). If teachers in our sample coherently provide evidence for a central application-oriented view, this often correlates with a strong tendency to re-invent calculus concepts according to the generic principle or generic trend. For these teachers, application seems to be a means to an end to achieve process-oriented goals. In order to distinguish between the two subgroups the preservice teachers with such application-oriented beliefs show a development that application tasks are not merely a motivational tool, whereas the correlation described above remained stable for the teacher trainees.

However, we also found teachers (preservice and trainee) for whom application orientation is both a central and a primary goal.

Mr A. (TT, 1st): In my future calculus courses modelling will be very, very important. Therefore using realistic applications is a fundamental goal, e.g. modelling periodic processes; describing the problem with mathematical tools. 
This teacher trainee follows an empirical modelling trend that has been promoted in mathematics education in recent years. Realistic applications are used to learn calculus in a way that is full of relations to real-world applications. In the second interview, it was apparent that central beliefs did not change with regard to application orientation. However, the teachers' central beliefs gained partly a broader foundation and sometimes a modified rationale. For example, for $\mathrm{Mr} \mathrm{A}$. the norms in his trainee education courses become a rationale for his central belief:

Mr A. (TT, 2nd): Well, trying to establish connections between real-life problems and essential concepts of calculus has been reaffirmed in my teacher training - the larger concepts of teaching were discussed there (...) fortunately things like concept formation and application tasks have been a good match and fell on fertile ground.

Being urged to make a decision between the last two aspects mentioned in the quotation, Mr A. decided clearly in favour of a priority for applications. Thus the modelling trend from the first interview could be confirmed and a process-oriented view is subordinated.

If teachers explicitly want to integrate modelling tasks including real-data problems into their calculus teaching, their system of goals either has no further central goals or these are subordinated (e.g. Mr A.). This is the case for both the first and the second interview. Again another group of teachers can be classified for the structure of goals and even the development of these goals: those teachers who were identified to have application and process goals as a central belief cluster were asked to make a prioritising decision in the subsequent interview together with trying to elicit reasons for their choice. In all five cases teachers made their decisions for process orientation which means that application goals are still central, but subordinated. Thus in both interviews, teachers of this type understood applications as a means to achieve process orientation. The data provide insights into the development and reasoning for this belief although assumedly qualitative differences in the development of the two groups (from PT to TT vs. from TT to qualified teacher) are not visible in teachers' reasonings. To conclude, concerning the development of application-oriented goals it can be ascertained for both subgroups that in second interviews the centrality of such goals was confirmed. It is worth noting that relevant teacher trainees either show a confirmation for this central application belief with a modified rationale or see applications as a means to achieve process orientation. The latter can also be found with preservice teachers, whose rationale for this point develops beyond the motivation and attraction of student interest into calculus.

\subsubsection{Process Orientation}

For several teachers from our sample the data yields a centrality of a process-oriented view that seems also to be stable referring to the teachers' professional socialisation. We illustrate this stability based on the example of Mrs. U. (TT). She was confronted 
with four different statements. One of these statements representing a process orientation is indicated below.

Statement 1: In teaching calculus it is most important that students have studied and understood the central concepts and they can solve problems mainly by themselves.

Mrs. U. (TT) valued this statement higher than statements representing further world views and articulated her own opinion concerning her selection as follows:

Mrs U. (TT, 1st): As it is stated here, that's a bit of a danger concerning calculus, that some things are carried out just because it is done like that. The overall picture is missing then, but I have the ambition to teach calculus in encouraging students to try to connect different concepts such as differentiation and integration.

In the second interview Mrs U. confirmed her overarching central goal of a process orientation. However, in comparison to the first interview, Mrs U. considered processoriented goals in relation to goals representing other world views being subordinated to the process orientation:

Mrs U. (TT, 2nd): For me it is essential that students do not learn rules mindlessly in calculus but most importantly they should comprehend the logic and framework behind it as well as being able to solve problems by means of this framework for specific applications.

For this trainee teacher, logical thinking, connections and problem-solving issues need to be combined in order to further students' comprehension of abstract mathematical concepts such as in calculus.

In general, there are some strong indications that preservice teachers and teacher trainees expressing a process orientation as a central goal, did not change this belief neither in transition from university to teacher training nor by the influence of teacher training.

Mrs U. and other teachers show a broader reflection of their classroom practice by including different world views when they express their preference for a process orientation. Other teacher trainees showed a broader reflection of their classroom practice by taking into account possible obstacles for a process orientation. However, also these teachers maintain their process orientation as a central goal. We illustrate this finding based on the case of Mrs K. (TT). In her first interview Mrs K. mentioned that using applications in her calculus courses is equally important to a generic approach:

Mrs K. (TT, 1st): ...using these application tasks I would like to make them see the connections and the relevant thought processes.

With an increased teaching experience, however, she mentioned in the second interview that achieving a process-oriented approach in actual teaching is indeed a difficult endeavour:

Mrs K. (TT, 2nd): Well, these problem-solving strategies and investigative tasks are more strenuous for the students because they really have to think. It is not just memorizing a rule and applying formulas. Of course it is easier for 
them to do these packages of routine tasks rather than trying to discover regularities by way of examples. That's challenging - for me and for my students, but nonetheless it's more interesting.

The reflection and acknowledgement of difficulties in achieving this goal might lead to an emotional state that can be described as disillusionment. Although a teacher challenges himself to transform central teaching goals into actual classroom practice this might result in a rearrangement taking into account many contextual and social factors that overlap the central goals.

Teachers who mentioned a process orientation like Mrs K. partly indicated that heuristic and creative activities to solve problems in different ways cannot be administered to classrooms with a growing heterogeneity of students. $\mathrm{Mr} \mathrm{N}$. expressed this belief in his second interview:

Mr N. (TT, 2nd): ...whether it is really possible for them [students] to grasp the connections and problem-solving strategies very much depends on the ability of the class. If you notice that $90 \%$ percent of the group just don't get it, then one has to adjust one's teaching.

Summarizing our findings about process orientation it can be ascertained that the overall majority of teachers in our sample showed a stability in their process-oriented goals that are the core of an empirical generic trend. A further main characteristic of these teachers is that they reflect their central goal in the second interview broader than in the first interview. Due to an increased teaching experience this reflection can be found more often in second interviews of teacher trainees.

\subsubsection{Formalist View}

Only a minority of teachers can be categorized as emphasising a formalist view as a central and primary belief, although examples exist: Mr G., a teacher trainee, is one of these teachers. In the first interview Mr G. stressed the centrality of the formal deduction in calculus and emphasized e.g. sequences, convergence issues, or formal proofs.

Mr G. (TT, 1st): Well, I daresay I could do calculus at school with a more theoretical and formal approach - similar to introducing concepts in algebra and topology. Maybe for some it would make things easier, but it will probably not be possible to implement this in most courses.

In the second interview Mr G. confirmed the centrality of his formalist conceptions working as a professional teacher. However, taking into account the perspective of high school students, Mr G. acknowledges the need to simplify proofs with a certain degree of transparency as well as the need to include plausibility arguments instead of "hard" and formal mathematical proofs.

Mr G. (TT, 2nd): Looking at the proofs in calculus: I do these formally, correctly, but I have to skip the odd step, simplify or use illustrative examples for case distinctions. But without calculus, I can't do any real mathematics. 
In the second statement the emergence of a sensible compromise between his central formalist view on calculus and calculus teaching and the high challenge for his students becomes apparent. Whereas his original beliefs could be based on his mathematical socialization at the university (Ph.D. in pure mathematics), his beliefs in the second interview could be the result of the influence of colleagues, the teacher educators, and, particularly, his experiences with the students in daily classroom practice. However, there are considerable similarities with the teachers that we discussed in the former sections: The teachers' central beliefs seem to be stable. Further the teachers took into account further ways to achieve their central goals. These ways, methods or rather technologies could be understood as subordinated goals that serve as a means to an end.

The majority of teachers in our sample more or less rejected formalist goals in the first interview, as the following two quotes demonstrate:

Mrs M. (PT, 1st): These formal mathematical constructs, for example integral with lower and upper sums, is not important. [...] That's too difficult for most of them [students], very time-consuming and needs too much brain capacity which can be used more reasonably.

Mrs W. (TT, 1st): There is just no time in calculus courses for these formal developments of concepts and personally I would rather emphasize other things.

This view is confirmed in the second interview. In many cases the level of acceptance of formalism even decreased comparing first and second interviews. The reason for this decrease was explained by the high difficulty in formal abstraction especially for the weaker students. For this group of teachers, the rejection of formalist goals is predominantly restricted to issues like formal proofs. However, these teachers tend to value another notion of formalism concerning the documentation of task solutions by students. The formal correctness of task processing and its solution documentation is increasingly mentioned in the second interview.

Assumedly this could be interpreted as a quasi-logical belief in teachers' individual belief systems. The clear distinction between formal (algebraic) rigour and outcomes of student work rather hints at an alternative explanation: a necessary basic agreement in documentation needs to be accomplished in order to guarantee a common standard agreement with colleagues (comparability of results) as well as meeting the requirements set by school management authorities regarding the marking of central exams:

Mrs M. (PT, 2nd): The written solutions for tasks need to be formally correct, e.g. in class tests, just as we practiced it in lessons, and I expect students to pay attention to these, $[\ldots]$ this is especially important for them in their final exams.

These goals could be explained by reasoning that a discourse about mathematical issues is only possible if a basic framework of terminology and notation is attained. The need to acquire a common understanding about definitions and concepts in calculus focuses on a strategy of using key terms of mathematical language from a set of formal and conceptual terms. 
Mrs W. (TT, 2nd): There are certain terms and definitions that students need to know. They must know them and they need to associate the basic concept that lies behind it. If they don't know the technical term they may describe it, but I often have to remind them that these are important to know. My interest is that they can communicate about concepts and to make them know what exactly they are doing without coding things into foreign words.

Summarizing the development referring to formalist views, the comparison of data of the first and second interviews shows either a confirmation of rejecting or subordinating formalist beliefs. An increasing expression of the importance of a formal language and solution documentation can be found in the development of formalist views especially with teacher trainees working as qualified teachers at the time of second interviews.

\subsubsection{Schema View}

In their mathematical socialisation in retrospection of their own schooling in calculus many teachers in our sample make reference to a schema view in their secondary education experience in the first interview. Changing perspectives from student to teacher, the overall majority of teachers in our sample have a critical stance on a strong schema view at the first data collection and such teaching goals are at most peripheral. However there is an example of one preservice teacher who shows a schematic approach to calculus as a central goal and who sustained a calculus course in high school with characteristic elements of schematic routines and extensive emphasis on calculating derivatives:

Mr F. (PT,1st): In my high school course we practised differentiation rules without end. Perhaps this was exaggerated but in today's classes these skills are often missing (...) if you try to address application-oriented tasks the main hurdle for many students are basic differentiation rules. Therefore these skills have to be internalized.

Although excessive training of rules is seen critically, there is an implicit approval of calculation procedures required for solving more complex tasks. The identification of a schema view could coherently be established in the first interview and was confirmed in the second interview. The quotation above, however, implies that mastering calculation skills have always been and still are an essential part in his belief system and have been embedded in the changed perspective from student to teacher. Being confronted with reconsidering the importance of either process or application views in comparison with his earlier statements referring to a schema view, this teacher confirmed the priority of calculation procedures that students need to master the basics levels for all kinds of calculus tasks; especially for exam-style application-oriented tasks basic skills are indispensable in his view. For all three teachers (two trainee, one preservice) with a schema view as a central belief, such application-oriented 
(and other) goals stay clearly subordinated and peripheral in their belief system and are at most part of their system of goals.

Arguments that emerge from the data of both interviews reveal interesting developments with regard to their teacher socialisation. The majority of teachers of both subgroups judge excessive training of schematic tasks as negative although some mention experiences from their own schooling positively in first interviews. The explanation of this prior experience is simply a high success rate. A pattern can be identified with those teachers who explicitly refused emphasising a schema view in first interviews. The disaffirmation of a schema view however does not automatically imply the absence of such goals. In second interviews, due to the identification of a large heterogeneity in learner groups, these teachers propose to integrate accurately dosed schematic exercises. Preservice teachers mainly argue with particular needs of low-achieving students whereas teacher trainees additionally mention expectations of permanent colleagues who might diagnose missing skills in follow-up levels.

Mrs B. (PT, 2nd): The schematic aspect is helpful for the weaker students who don't manage to solve the complex problems anyway. Sensible exercise tasks enable these students to bring about a certain routine: they just don't get to grips with the transfer of mathematics and application.

Mr C. (PT, 2nd): ...such curve sketching tasks are always the same. Students might like that because they practise it thoroughly and have a feeling of success instead of constantly having to think about new problem-solving strategies. But basically that is boring and not reasonable.

Mr A. (TT, 2nd): Of course students need these routine tasks - the weaker students especially, (...) and of course I don't want colleagues to complain that they haven't learned enough when they take over one of my classes.

These exemplary remarks show a development in teachers' socialization process. Preservice teachers are concerned about students' mathematical success and related positive emotions in mathematics. Repeated procedural tasks are seen as a means to an end to facilitate moments of mathematical success and positively influence students' mathematical affect. Teacher trainees additionally feel the peer pressure of mathematics colleagues of their school, where they work permanently at the time of the second interview.

Not rejecting a schema approach per se, there is another development in the discussion about the pros and cons of a schema view that appeared exclusively in the data of teacher trainees. Deviating from the teachers who explicitly reject automated procedures some teacher trainees show yet another rationale when working as a qualified teacher.

Mr H. (TT, 1st): Curve sketching, yes, needs some time. But they [students] need to practice that necessarily, (...) and need to know which criteria must be checked.

Mr H. (TT, 2nd): Well, I see a certain connection between mastering the routines and problem-solving skills: if you always have to think about how the basics work you do not have the capacity to solve more complex tasks. 
These quotations from first and second interview show a development that a certain amount of procedural training is seen as necessary to be increasingly integrated for two main reasons: first basic procedures such as finding extreme points of a function are considered to be a necessary fundamental concept in a sequential hierarchy of applying mathematical knowledge to given tasks and problems in calculus. Secondly these basics are subsequently needed to achieve further superordinated goals of process and application orientation.

Apart from the developments described above, another reason for an increasing importance of schematic features in second interviews is only given by some teachers who are in transition from trainee to qualified teacher.

Mrs U. (TT, 2nd): Personally I am convinced that these [routine calculations] are less important, if not unnecessary. In the school context, however, preparing students for their exam, the significance of these tasks changes.

Even though there is a negative response to a task prompt representing a schema view, there are nuances in these teacher trainee's beliefs due to a pedagogical responsibility towards those students who are not able or less able to solve tasks going beyond memorized procedures but need at least a high success rate in standard test tasks. As both class and final examinations consist of a calculator-free part (standard tasks) and a second part where students are allowed to use graphic or symbolic calculators, the role of technology and its impact on teaching calculus will be discussed next.

\subsubsection{Role of Technology}

Regarding our sample of teachers, we found two antithetical belief systems referring to the integration of technology in upper secondary calculus courses, i.e. belief systems that we call "the old school" and "technology supporter". Teachers describing themselves as belonging to "the old school" consistently express severe doubts about technology use in helping students' mathematical learning. In contrast to "oldschool" teachers there are "technology supporters", who expressly utilise graphic and symbolic technology in order to realise a problem-oriented approach to teaching calculus. In between, our data suggest that teachers' beliefs about technology range in a continuum that extends from scepticism to reluctance up to those teachers who use the given technology in the curriculum as a means to an end.

In the same way as reported for the world views, the technology supporters and also the teachers representing the old school show a considerable stability concerning their central goals. In their development the teachers representing the old school are an example for which also negatively formulated goals show a stability or even increase. For example Mr G. expressed negatively connotated beliefs referring to the use of technology:

Mr G. (TT, 1st): One may use these calculators but it also needs time to make students understand how to use it, (...), and often things get even more com- 
plicated because they often don't know what they are actually doing mathematically. [...] I think I will do without the device as much as possible.

Mr G. (TT, 2nd): Neither in my teacher training nor in textbooks or other resources have I come across reasonable tasks where the use of a graphing calculator really makes sense. It is just translating the text task in order to operate the pocket calculator - for me that's not mathematical thinking.

In both interviews Mr G. described himself as belonging to the "old school" and does not see any benefit in using technology. The refusal of using a calculator in the first interview might still be due to challenges that novice teachers meet on a basic instrumental level. In the second interview, however, Mr G. showed an increasing rejection of such tools and stressed the view that students may be tempted to use the technological device as a universal "remedy" for problem-solving and sees more harm done than any benefit.

Teachers that tend to value technology for mathematics teaching mostly describe in the first interviews the key advantage of using technology as the possibility of visualisation of mathematical objects, e.g. functions.

Mr S. (TT, 1st): Above all, I use the calculator to visualize things, particularly when it comes to introducing new concepts. First we calculate a lot of specific values instead of abstracting the given task immediately.

Very few teachers emphasise the possibility of further benefits of using technology (Tall, 2008), e.g. checking results and relieving students from procedural investment:

Mrs E. (PT, 1st): Often my students use the calculator in order to check their results. First they think about their strategy of solving the given task and then they can reassure themselves about solutions.

As mentioned before for the development of central beliefs, the teachers for which the use of technology is a central (but subordinated) goal tend to broaden their understanding of the benefit of technology supported teaching. For example Mr S. emphasised in the second interview that he sees the benefit of technology even beyond visualisations and other reasons mentioned above.

Mr S. (TT, 2nd): ...now we use the calculator even more in terms of generating examples and then try to find conjectures. The students actually come up with hypotheses which, of course then have to be formally validated.

After completing his teacher training he wants to achieve a generic development of calculus concepts in facilitating students' conceptual learning by experimenting with mathematical objects in an inductive way.

By using technology as a means to an end, the analysis of second interviews suggests that technology increasingly paves the structural way to further support central teaching goals such as an emphasis on modelling realistic data. Actually, especially those teachers who valued high application-oriented goals or process-oriented goals also tend to value the benefit of technology highly. With respect to different stages in their professional development, there are hardly any differences between preservice 
teachers and teacher trainees. At the individual level, these teachers show similar paths of development.

Pedagogical considerations concerning technology use at secondary school are among many aspects of teachers' developmental trajectory. Methodological and instructional teaching decisions and prospective teachers' beliefs on teaching orientations will now be addressed.

\subsubsection{Teaching Orientation and Teaching Scripts}

Beliefs about learning mathematics at school may be related to the notion of personal experience and evidence-based teaching practices. Regarding the reconstruction of the teaching orientations at the point of data collection when they were in teacher training (PT, 2nd \& TT, 1st) many teachers tend to a traditional teaching script: teacher instruction followed by a method of development by questions, exercises and a joint discussion of results. In their first own teaching many teachers want to move on "safe ground" before starting experiments.

Mr H. (TT, 1st): In my lessons I would like to exercise less guidance than my own maths teacher but I am still struggling to relinquish my teacher control. But I think my students have less experience with these methods and don't feel enough responsibility that they need to produce results. I definitely have to grow into my role with more experience.

Although $\mathrm{Mr} \mathrm{H}$. and other teachers in our sample do not favour a transmission view there are numerous examples of self-reported teaching scripts which resemble a predetermined sequence of actions characterized by small steps, a method of conceptualising content by detailed teacher questions followed by single exercises. The analysis of second interviews shows a notable change. The majority of teachers report that they aim at integrating more student-centered methods of instruction with a higher degree of cognitive activation of their students. The use of exploratory tasks with a bottom-up approach either using or generating examples is often mentioned as well as the aim of a high degree of social interaction between teacher and students.

$\mathrm{Mr} \mathrm{H}$. (TT, 2nd): The more teaching experience I have the more I achieve a sound balance towards teacher-student interaction. At the beginning I wasn't able to get good [mathematical] results with these student-centered tasks, now I increasingly use these rather open teaching methods.

A changed stance about teaching calculus in contrast to a "traditional" teaching orientation seems to demonstrate that cognitive, emotional and motivational traits in his belief system moved towards a more constructivist orientation.

Specific changes that can be noticed comparing statements from both interviews regarding teaching orientation mainly concern a much higher variation of teaching concepts in implementing various formats of modern teaching methods (e.g. different formats of group work, internal differentiation or classroom management), which might result from theoretical and practical inspirations drawn from mentor teachers 
or teacher educators. However, the exact sources for these changes cannot be deduced from the data as particular trainee colleges and teacher educators may have different curricula.

Interestingly those teachers in our sample (5 out of 20) who did not see their traineeship as a benefit for their professional education and development, emphasise in their statements about their teaching orientation that quality features of good instruction in their calculus courses are a clear teacher-centered lesson structure, numerous elements of traditional teaching (e.g. teacher speaks in front of the class) and the non-suitability of calculus content for inquiry-based learning concepts. Although causal relationships between different clusters of beliefs need to be made carefully, it is worthwhile mentioning that three teachers with a rather strong transmissive teaching orientation also belong to the group of teachers who put forward a negative view towards the use of technology in calculus courses. Summarising our findings on teaching orientation it can be ascertained for one group of teachers that teaching orientation and associated lesson scripts remain very stable and are characterised by a more transmissive orientation. With a comprehensibly stronger development being noticeable in the group of teacher trainees due to their more advanced stage of professionalization, three quarters of our sample show a progression towards a higher variation of more student-centered and constructivist teaching scripts coinciding with a high adaptability of teaching methods.

\subsection{Why Do Beliefs Change or Do Not Change?}

\subsubsection{Impact and Influence of Teacher Educators or Education Program}

Since we focus in this paper on the development of beliefs, a crucial question is why these beliefs changed or did not change. Although some of the teachers refer to their own time at school or their university studies, we first focus on a potential impact on the teachers' beliefs in our study, i.e. the teacher educators in the phase of teacher traineeship. Actually, one of the aims of teacher education courses is to further develop the professional competence of prospective teachers, including teaching skills in methodical issues and the ability to process subject knowledge with regard to learning processes. This might entail to challenge existing beliefs that contradict the view of appropriate classroom practice of teacher educators. Assessed lessons and teacher training examinations are decisive criteria for the trainees' future career. Thus there exists a dependent relationship between educators and trainees that might affect instructional planning processes during traineeship.

In their training education teacher trainees work at one school and first attend lessons of experienced teachers but also teach themselves accompanied by teacher mentors. In the second year they teach classes with full responsibility. Additionally 
trainees get theoretical and practical input at education colleges in courses taught by their teacher educators.

When teacher trainees are faced with pedagogical decisions, the question is to what degree the intervention of a teacher educator effects change in trainee's beliefs. The awareness of the authority of teacher trainers can be validated in all the interviews of our sample, as the following example confirms:

Mr C. (PT, 2nd): Quite important to me is that my lessons are well-structured; and that this structure is visible especially to my teacher trainers.

We illustrate the relationship between the intervention of teacher educators and the development of teachers' beliefs with the case of Mr G. who showed a preference for formalist oriented goals (see above). Mr G. showed a reflection of teaching approaches suggested by teacher educators that seems to reshape his teaching goals:

Mr G. (TT, 1st): In conceptualizing new content I always use a task-oriented approach, which is a guideline given by our teacher trainers. In my opinion it's not bad, but I think it's too stringently guided like our trainers want it to be implemented. [...] From time to time I vary a little bit, but at the moment I must keep in mind my assessed exam lessons with my students. [...] however in doing so the teacher guidance is quite high so I sometimes think I could just demonstrate the tasks myself.

Reflecting on his first teaching experience Mr G.'s view on appropriate classroom practice is being challenged and a process of nuanced replacement takes place which is (partly) initiated by theoretical input of his teacher training course. Thus, partly the authority of a teacher trainer and partly the trainees' own reflection seem to impact on this teacher's beliefs. The implementation of a specific teaching concept is an instrument of nuanced change: On the one hand $\mathrm{Mr}$ G. expressed a strategic alignment with the teacher educator's idea on conceptualization of new content; on the other hand his reflection showed that a cognitive process of individual adaption concerning his teaching orientation is under way. The suggested "task-oriented approach" is regarded as a meaningful and appropriate inspiration on a content-related and methodological level for instructional practice. Reflecting on his instructional planning, the canonicalized nature of this approach is critisised by him as being too prescriptive. Particularly the degree of teacher guidance is associated with a rather transmissive learning orientation. His beliefs, however, are not in accordance with the teacher trainers' views, and thus his future teaching will presumably differ from the task-oriented approach, as the following quote from the second interview shows:

Mr G. (TT, 2nd): I tried out the suggestions and concepts I got there. If it works, it's ok. But drumming in particular ideas and concepts; no, that was a bit overdone. I question whether this has brought any change in my teaching.

The intervention of a teacher trainer will presumably not inaugurate any long-term change in trainee's beliefs, if there is no accordance with their reflection of their own classroom experience and also their central goals that seemed to exist before starting as teacher trainees. In second interviews teachers were explicitly asked about the influence of their teacher educators. Nearly all teachers of our sample claimed that 
their teacher educators had no or very little influence on their beliefs towards calculus teaching. The range of influence of teacher educators rather comprises pedagogical ideas and methodological suggestions in order to further teachers' instructional repertoire. About one third explicitly negate any influence of their teacher educators, such as Mrs R.:

Mrs R. (TT, 2nd): Well, some concepts and methods, which were introduced, stimulated my considerations about calculus teaching but as a result I strongly disagreed with my teacher educator, e.g. the suggestion of a formal deduction of the derivative of the sine function...that's absurd in my opinion.

These teachers disagree with their educators' conceptions for the learning and teaching of calculus and see them as supervisors and inspectors who definitely have no influence on their beliefs towards teaching calculus. Contrary to the examples described above, about two thirds of our sample acknowledged that teacher educators managed to make them develop a sense for an adaptability of teaching methods, selecting appropriate tools and resources for teaching and identifying barriers to student learning:

Mrs D. (PT, 2nd): Our instructor in my mathematics course provided us with a lot of useful material and inspirations. I used his material and suggestions not because it was expected but rather because I considered it appropriate.

Further Mrs D. reports about a planned and enacted teaching unit where she tried out inquiry-based learning methods which were analyzed with a reflective stance and suggestions for improvement. The development of an orientation to being adaptable as a teacher, to consider variations to different methods of teacher-student interaction as well as searching for alternatives to ineffective pedagogical approaches is one of the main areas of reported change or rather development mentioned by our teachers:

$\mathrm{Mr}$ T. (TT, 2nd): Influence of teacher training? Well, my lessons have hopefully become a lot more professional compared to when I started. In my courses I learned a lot about different teaching methods as well as being able to experiment with alternative methods of instruction. These I still use in my lessons now.

In determining the impact of the teacher education program, it is interesting from a cognitive and emotional perspective that young teachers' pedagogical beliefs and intended methods of instruction which have been developed or confirmed during their teacher training remain stable between the first and the second interview.

Independent of the level of acceptance towards the teaching conceptions of teacher trainers, our data suggests that neither teacher educators nor education courses are agents of belief change concerning mathematical world views or trends of an intended calculus teaching. As one teacher put it metaphorically: "you can't teach against your personal convictions-that's like wearing a wrong coat and it doesn't fit". This metaphor, of course, refers to central beliefs. In contrast, nearly every teacher shows slight changes in indicating new or modified subordinated or rather peripheral beliefs referring to the teaching of calculus. To conclude, preservice and trainee teachers' deep-seated beliefs about calculus are not affected by teacher educators 
whereas changes are noticeable in their teaching orientation. To what extent these changes occur does not only depend on the acceptance of teacher educators as a benefit for teachers' professional development but additionally on whether teachers follow a transmissive or more constructivist learning orientation (see 16.4.6. teaching orientations). Further positive and negative experiences in teacher training courses might affect possible changes. Concerning the point of possible changes (rather in the first or second year of teacher training, i.e. 2nd interview of PT or TT) our data does not show any discernible contrasts.

\subsubsection{Influence of Final Exams}

Apart from the intervention of teacher training, another important factor that interferes with teachers' beliefs during teacher training is students' final examinations as an external authority. Assumptions that mathematics teaching is too much focused on task requirements of central examinations have been confirmed and are logically named teaching-to-the-test-effects (Maag Merki, 2011). The degree of concern might still be less prevalent as preservice and trainee teachers usually have little need to deal with central exams in their first practice experiences. It is an expected and established result that preservice teachers are mainly preoccupied with substantial issues of their lesson planning (cf. Oliveira \& Hannula, 2008). Therefore this external authority and its possible effect on intended calculus teaching with a focus on schematic and exam-style training is touched—if at all—only superficially in first interviews and slightly rises in second interviews. The degree of examination concerns increases more significantly when comparing both interviews of teacher trainees. In particular teacher trainees show an expanding orientation towards selecting exam-style tasks, as requirements of examination tasks are analyzed and serve as a benchmark. As mentioned in the section about a schema view, schematic routines are assigned a greater role in some teachers' belief system but remain subordinated to other central goals. To the same end and with similar reasons, some teachers' views on formalist and application goals play a more crucial role with regard to trends of application tasks and formal documentation in examinations.

\subsubsection{Influence of Prior Beliefs and Social Context}

Taking into account what is known about the development of preservice teachers, research on preservice teacher beliefs has produced evidence that prior beliefs serve as a filter for their professional learning in teacher education (Kagan, 1992; Richardson, 2003). Prior beliefs that originate from own experiences learning mathematics at school include pedagogical beliefs about goals and instructional preferences referring to specific contents of mathematics teaching. As teachers were asked explicitly in the first interview about their own high-school background concerning calculus it 
is possible to elicit characteristic lines of argumentation, e.g. memorized procedures such as intensely practiced derivation rules as well as curve sketching were partly attributed positively, either because of a personal high success rate or as they were seen as a necessary prerequisite for mathematics courses at university. However, beliefs that calculus is a collection of rules and procedures are firmly rejected by most teachers. As shown above assessment requirements, on the other hand, do have an influence on teachers' beliefs as the significance of memorized procedures, which have to be applied to corresponding examination tasks, is reaffirmed but remains subordinated.

Possible origins of central beliefs could be identified with regard to milestones of teachers' mathematical socialisation. In the case of Mr G., his mathematical career included a Ph.D. in pure mathematics which might explain his central formalist views. In his first interview evidence can be found that there exists a discontinuity between working on mathematical research and teaching calculus to high school students. His beliefs in the second interview change as a result of the indirect influence of teacher educators and, particularly, his experiences with the students in classroom practice. Referring to the discontinuity of university level of formality to the school level, some teachers' beliefs change. There is a decrease of formalist goals related to the moderate New Math trend and associated therewith, especially noticeable with teacher trainees, a rising intention of a correct and meaningful usage of mathematical terminology and language in classroom discourse.

Starting into their teaching career, novice preservice teachers and teacher trainees quickly notice a potential and actual gap between their own beliefs, theoretical aspects on teaching issues from their university or education courses and actual classroom experiences. According to recent research literature there exist different kinds of these gaps, one of these being the transition point from university into teaching (Gueudet et al., 2016). Reflecting on possible mismatches our teachers show that a cognitive process of individual adaption concerning these issues is under way. Reflection as a crucial variable of teachers' development of beliefs is also reported by Decker, Kunter, and Voss (2015) or Skott (2015).

Further belief changes can be found in second interviews of preservice teachers when they reflect on their collaboration with experienced mathematics teachers at their school. Meeting expectations of a school-based curriculum for secondary calculus classes constitutes a reason for increasing views of application orientation according to the modelling trend, as exam-style tasks also include problems with application contexts. Both groups of teachers in our sample thus show a growing sense of the institutional setting and social norms, in particular teacher trainees in second interviews are aware of both, peer support and pressure. Their beliefs and goals relate dynamically to the given social context.

However, there are considerable similarities with the teachers that we discussed in the former sections: The teachers' central beliefs seem to be stable whereas subordinate beliefs are modified or change depending on teachers' perceptions of their social and professional context and, correspondingly, the opportunities and limits of potential change. 


\subsection{Discussion and Conclusion}

As illustrated by examples of teachers in our sample the professional socialisation between the end of university studies and their start as qualified teachers yields both, a stability of central and primary beliefs and goals and a change and rearrangement of subordinated goals and peripheral beliefs.

Mrs K. (TT, 2nd): I think that these core beliefs are something one sticks to - that is just a teaching conviction that hardly changes - at least with me. Nevertheless - especially for me as a young teacher at the beginning of my career, I will hopefully develop my lessons further and further. But the really big concepts for my teaching will not change dramatically.

Indeed our sample of preservice and trainee teachers confirms this statement. Those beliefs which were identified to be central in the first interview were confirmed by the teachers in the second interview as concerns the above mentioned views of application, schema, formalist and process orientation. Slight but minor shifts in the hierarchical structure occurred for the whole sample but we found a remarkable stability concerning these beliefs.

On the one hand, our research does not agree with the findings of Dann et al. (1981) or Huberman (1989) whose research implied a considerable change of beliefs as a result of the first practical experiences. This is especially the case when central beliefs are regarded. However, our study could not yield a deeper insight whether slight changes of subordinated beliefs or the appearance of peripheral beliefs are a starting point for further changes. Further, our results agree with the statement of Liljedahl et al. (2012) concerning the stability of central beliefs. Referring also to Liljedahl the stability of central beliefs is not a tautology in our study since we defined central beliefs as coherently expressed beliefs in different situations in our interviews (see above). Concerning slight changes in the development of central beliefs, the results for both subgroups show that teachers give more profound reasons for their central beliefs and goals and reveal pragmatic yet sophisticated patterns of argumentation (e.g. central formalist and schema view). Due to teachers' ongoing professional development in their traineeship and increasing teaching experience, it is not surprising that the spectrum of arguments by trainee teachers is qualitatively broader than that of preservice teachers. Regarding peripheral beliefs changes, such as shifts in selecting suitable training tasks (schema), setting requirements for correct mathematical terminology (formalism) and variation of teaching methods, one could simply argue that these happen as a result of practical teaching experience.

However, when looking at possible points of rupture in the education of future teachers in more detail, it is possible to identify some mechanisms and reasons for belief changes. Regarding our sample of teachers, it seems possible to partly ascertain two overarching factors of potential belief changes which are intertwined with each other, namely authority and reflection.

The first factor involves different issues like the (anonymous) teacher of a prospective teacher's own schooldays. Interestingly, our research provides hardly any indication for a transfer of beliefs and concepts of teachers' own schooldays that was 
partly suggested in the literature (cf. Kaasila et al., 2006). By contrast, our teachers seem to hold contradictory beliefs to their schooldays in terms of rejecting a pure schema view. Other authorities for our teachers are their teacher trainer or mathematical experiences in university studies. Actually, our teachers seldom refer to university studies but mainly refer to teacher trainers. However, the teacher trainers seem to have at most a slight impact on the teachers' beliefs. If prospective teachers' teaching orientation is in accordance with conceptions conveyed by teacher trainers, these are adopted. Our results however show that teacher trainers are no agents of belief change concerning central beliefs about calculus teaching. Finally, a more impacting authority are centralized exams which is in line with the findings of Maag Merki (2011).

The factor of reflection is based on a (self-referred) reflection including the experience as student in school or university, but in particular the reflection of teaching and learning in the teachers' first practical experience. Reflection also includes considering the growing heterogeneity of students as well as an individual need to establish a coherence of content beliefs towards calculus and respectively a further adaptability of instructional teaching conceptions. With hardly any practical experience in teaching before starting teacher traineeship, this reflection seems to be a scaffolding process gaining importance particularly in the second half of traineeship, as the findings from our data suggest. The crucial influence of reflection for the teachers in our sample is in accordance with the findings of several researchers: For example, also Cooney, Shealy, and Arvold (1998) reported that reflection plays a crucial role in teacher development. Similar statements have been given more recently on the basis of research reviews or empirical studies by Fives and Hill (2015) or Decker et al. (2015).

With the insights gained from this investigation, one might aim at more longitudinal research for extended periods. Following teachers through their teacher education and their first year of teaching is a start to understand how teachers' beliefs develop throughout their career (cf. Levin, 2015). As mentioned before, an interesting question is if the slight changes in the belief systems of our teachers are a temporary phenomenon or the starting point for further development and, potentially, also a change of central beliefs. Since our research also yielded results of experienced teachers who sometimes prefer more intensely formalist goals (see Eichler \& Erens, 2014), one could hypothesize that the slight development of teachers' beliefs in the direction of formalist oriented goals could result in a stronger development in the first years as a qualified teacher. However, to gain insight in this development, a stronger focus on a long-term development is necessary (cf. Levin, 2015) to investigate whether and how beliefs develop considering cognitive and motivational aspects of teachers' mathematics-related affect. 


\section{References}

Artigue, M. (1996). Learning and teaching elementary analysis. In C. Alsina, J. M. Alvarez, M. Niss, A. Pérez, L. Rico, \& A. Sfard (Eds.), 8th International Congress on Mathematics Education-Selected Lectures (pp. 15-30). Sevilla: S.A.E.M. Thalès.

Bernack-Schüler, C., Leuders, T., \& Holzäpfel, L. (2015). Understanding pre-service teachers' belief change during a problem solving course. In C. Bernack-Schüler, R. Erens, T. Leuders, \& A. Eichler (Eds.), Views and beliefs in mathematics education (pp. 81-93). Wiesbaden, Germany: Springer.

Blum, W. (2000). Perspektiven für den Analysisunterricht. Der Mathematikunterricht, 46(4/5), $5-17$.

Bressoud, D., Ghedamsi, I., Martinez-Luaces, V., \& Törner, G. (2016). Teaching and learning of calculus. In G. Kaiser (Ed.), Teaching and learning of calculus. ICME-13 Topical Surveys. Cham, Switzerland: Springer.

Clarke, D., \& Hollingsworth, H. (2002). Elaborating a model of teacher professional growth. Teaching and Teacher Education, 18, 947-967.

Cooney, T. J., Shealy, B. E., \& Arvold, B. (1998). Conceptualizing belief structures of preservice secondary mathematics teachers. Journal for Research in Mathematics Education, 29(3), 306-333.

Dann, H. D., Müller-Fohrbrodt, G., \& Cloetta, B. (1981). Sozialisation junger Lehrer im Beruf: "Praxisschock" drei Jahre später. Zeitschrift für Entwicklungspsychologie und pädagogische Psychologie.

Decker, A. T., Kunter, M., \& Voss, T. (2015). The relationship between quality of discourse during teacher induction classes and beginning teachers' beliefs. European Journal of Psychology of Education, 30(1), 41-61.

Eichler, A., \& Erens, R. (2014). Teachers' beliefs towards teaching calculus. ZDM-The International Journal on Mathematics Education, 46(4), 647-659.

Eichler, A., \& Erens, R. (2015). Domain-specific belief systems of secondary mathematics teachers. In B. Pepin \& B. Roesken-Winter (Eds.), From beliefs to dynamic affect systems in mathematics education (pp. 179-200). Dordrecht, The Netherlands: Springer.

Fives, H., \& Buehl, M. M. (2012). Spring cleaning for the "messy" construct of teachers beliefs: What are they? Which have been examined? What can they tell us? In K. R. Harris, S. Graham, \& T. Urdan (Eds.), APA Educational Psychology Handbook (Vol. 2, pp. 471-499). Washington, DC: APA.

Fives, H., \& Hill, M. G. (Eds.). (2015). International handbook of research on teachers' beliefs. New York, NY: Taylor and Francis, Routledge.

Franke, M. L., Kazemi, E., \& Battey, D. (2007). Understanding teaching and classroom practice in mathematics. F. K. Lester (Ed.), Second handbook of research on mathematics teaching and learning (pp. 225-256). Charlotte, NC: Information Age.

Glaser, B., \& Strauss, A. (1967). The dicovery of grounded theory. Chicago, IL: Aldine.

Green, T. (1971). The activities of teaching. New York, NY: McGraw-Hill.

Grigutsch, S., Raatz, U., \& Törner, G. (1998). Einstellungen gegenüber Mathematik bei Mathematiklehrern. Journal für Mathematikdidaktik, 19(1), 3-45.

Gueudet, G., Bosch, M., Disessa, A., Kwon, O. N., \& Verschaffel, L. (2016). Transitions in mathematics education. In G. Kaiser (Ed.), Transitions in mathematics education. ICME-13 Topical Surveys. Cham, Switzerland: Springer.

Gutiérrez, A., Leder, G. C., \& Boero, P. (Eds.). (2016). The second handbook of research on the psychology of mathematics education: The journey continues. New York, NY: Springer.

Hannula, M. S. (2012). Exploring new dimensions of mathematics-related affect: Embodied and social theories. Research in Mathematics Education, 14(2), 137-161.

Hannula, M. S., Op 't Eynde, P., Schlöglmann, W., \& Wedege, T. (2007). Affect and mathematical thinking. In D. Pitta-Pantazi \& G. Philippou (Eds.), European Research in Mathematics Educa- 
tion V, Proceedings of the Fifth Congress of the European Society for Research in Mathematics Education (pp. 202-208). Cyprus: Department of Education, Larnaca, University of Cyprus.

Heckhausen, H., \& Gollwitzer, P. M. (1987). Thought contents and cognitive functioning in motivational versus volitional states of mind. Motivation and Emotion, 11(2), 101-120.

Hofer, B. K., \& Pintrich, P. R. (1997). The development of epistemological theories: Beliefs about knowledge and knowing in their relation to learning. Review of Educational Research, 67, 88-140.

Huberman, M. (1989). The professional life cycle of teachers. Teachers College Record, 91(1), $31-57$.

Kaasila, R., Hannula, M. S., Laine, A., \& Pehkonen, E. (2006). Facilitators for change of elementary teacher student's view of mathematics. In J. Novotná, H. Moraová, M. Krátká, \& N. Stehlíková (Eds.), Proceedings of the 30th Conference of the International Group for the Psychology of Mathematics Education (Vol. 3, pp. 385-392). Prague, Czech Republic: Charles University.

Kagan, D. M. (1992). Implication of research on teachers' belief. Educational Psychologist 27(1), 65-90.

Kelchtermans, G., \& Ballet, K. (2002). The micropolitics of teacher induction. A narrativebiographical study on teacher socialisation. Teaching and Teacher Education, 18(1), 105-120.

Levin, B. (2015). The development of teachers' beliefs. In H. Fives \& M. G. Hill (Eds.), International handbook of research on teachers' beliefs (pp. 48-65). New York, NY: Taylor and Francis, Routledge.

Liljedahl, P. (2010). Noticing rapid and profound teacher change. Journal of Mathematics Teacher Education, 13(5), 411-423.

Liljedahl, P., Oesterle, S., \& Bernèche, C. (2012). Stability of beliefs in mathematics education: A critical analysis. Nordic Studies in Mathematics Education, 17(3-4), 101-118.

Maag Merki, K. (2011). The introduction of state-wide exit examinations: Empirical effects on math and English teaching in German academically oriented secondary schools. In M. A. Pereyra, H.G. Kotthoff, \& R. Cowen (Eds.), PISA under examination: Changing knowledge, changing tests and changing schools (pp. 125-142). Rotterdam, The Netherlands: Sense.

Mayring, P. (2015). Qualitative content analysis: Theoretical background and procedures. In A. Bikner-Ahsbahs, C. Knipping, \& N. C. Presmeg (Eds.), Approaches to qualitative research in mathematics education (pp. 365-380). Dordrecht, The Netherlands: Springer.

Oates, G. (2012). Applications and implications of recent research for teaching calculus: A report from the 2011 delta conference on undergraduate mathematics teaching and learning. In Proceedings of the 12th International Congress on Mathematical Education, 8-15 July, 2012, COEX, Seoul, Korea. Seoul: International Congress on Mathematical Education ICME-12.

Oliveira, H., \& Hannula, M. S. (2008). Individual prospective mathematics teachers: Studies on their professional growth. In K. Krainer \& T. Wood (Eds.), Participants in mathematics teacher education (pp. 13-24). Rotterdam, The Netherlands: Sense.

Pajares, F. M. (1992). Teachers' beliefs and educational research: Cleaning up a messy construct. Review of Educational Research, 62(3), 307-332.

Philipp, R. A. (2007). Mathematics teachers' beliefs and affect. In F. K. Lester (Ed.), Second handbook of research on mathematics teaching and learning (pp. 257-315). Charlotte, NC: Information Age.

Richardson, V. (2003). Preservice teachers' beliefs. In J. Raths \& A. McAninch (Eds.), Teacher beliefs and classroom performance: The impact of teacher education (Vol. 6, pp. 1-22). Greenwich, CT: Information Age.

Robert, A., \& Speer, A. (2001). Research on the teaching and learning of calculus/elementary analysis. In D. Holten (Ed.), The teaching and learning of mathematics at university level (pp. 283-299). Berlin, Germany: Springer.

Schraw, G., \& Sinatra, G. M. (2004). Epistemological development and its impact on cognition in academic domains. Contemporary Educational Psychology, 29, 95-102. https://doi.org/10.1016/ j.cedpsych.2004.01.005.

Skott, J. (2009). Contextualising the notion of 'belief enactment'. Journal of Mathematics Teacher Education, 12, 27-46. 
Skott, J. (2015). The promises, problems, and prospects of research on teachers' beliefs. In H. Fives \& M. G. Hill (Eds.), International handbook of research on teachers' beliefs (pp. 13-30). New York, NY: Taylor and Francis, Routledge.

Speer, N. M. (2005). Issues of methods and theory on the study of mathematics' teachers' professed and attributed beliefs. Educational Studies in Mathematics, 58, 361-391. https://doi.org/10.1007/ s10649-005-2745-0.

Staub, F., \& Stern, E. (2002). The nature of teacher's pedagogical content beliefs matters for students' achievement gains: Quasi-experimental evidence from elementary mathematics. Journal of Educational Psychology, 94(2), 344-355.

Tall, D. (2008). Technology and calculus. In M. K. Heid \& G. W. Blume (Eds.), Research on technology and the teaching and learning of mathematics: Synthesis, cases and perspectives. Vol. 1: Research synthesis (pp. 207-258). Charlotte, NC: Information Age.

Tall, D. (2009). Dynamic mathematics and the blending of knowledge structures in the calculus. ZDM - The International Journal on Mathematics Education, 41(4), 481-492.

Wentzel, K. R. (2000). What is it that I'm trying to achieve? Classroom goals from a content perspective. Contemporary Educational Psychology, 25(1), 105-115.

Open Access This chapter is licensed under the terms of the Creative Commons Attribution 4.0 International License (http://creativecommons.org/licenses/by/4.0/), which permits use, sharing, adaptation, distribution and reproduction in any medium or format, as long as you give appropriate credit to the original author(s) and the source, provide a link to the Creative Commons license and indicate if changes were made.

The images or other third party material in this chapter are included in the chapter's Creative Commons license, unless indicated otherwise in a credit line to the material. If material is not included in the chapter's Creative Commons license and your intended use is not permitted by statutory regulation or exceeds the permitted use, you will need to obtain permission directly from the copyright holder.

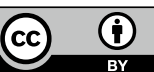




\title{
Chapter 17 \\ The Struggle for Recognition and the Professional Identities of Mathematics Teachers
}

\author{
Clyde B. A. Felix
}

\begin{abstract}
All teachers are perpetually engaged in a struggle for recognition of who they are, what they are, and what they are worth. We know that this affects their professional identities, but not enough about what the effects are. This narrative inquiry explores how a struggle for recognition in a rapidly changing post-apartheid school system affected the professional identities of three South African mathematics teachers. Examined through a set of theoretical lenses consisting of Honneth's levels of recognition; Kelchtermans' components of the retrospective dimension of a professional self; and, Huttunen and Heikkinen's circles of recognition, their stories reveal an ability to cope with a lack of recognition by counterbalancing its negative effects with the positive effects of recognition sourced from experiences elsewhere. Surprisingly, their stories have more in common than their sociocultural differences seem to suggest.
\end{abstract}

Keywords Recognition $\cdot$ Self-confidence $\cdot$ Self-respect $\cdot$ Self-esteem $\cdot$ Personal interpretive framework $\cdot$ Professional identity

\subsection{Background}

Recognition is not a new issue in philosophical debate; yet, it is relatively new in educational research (Fleming \& Finnegan, 2010) where it offers a fresh view of teachers' professional growth (Heikkinen, 2003). While social theorists remain divided in their assessment of the emancipatory potential of recognition (Schaap, 2004); there seems to be consensus amongst them on its usefulness as a theoretical tool in the on-going philosophical debates regarding issues of reconciliation and social justice. Thus, the relative novelty of recognition theory in education is rather conspicuous; especially, since education is all about social justice, and recognition is at the heart of it. After all, "[a] teacher's work is a process of receiving and giving recognition" (Huttunen \& Heikkinen, 2004a, p. 164). It would make sense, therefore, for recognition theory

C. B. A. Felix ( $ه)$

Nelson Mandela University, PO Box 77000, Port Elizabeth 6031, South Africa

e-mail: clyde.felix@mandela.ac.za 
to be applied in educational research; for instance, to explore the close interrelationship between recognition and identity or "personhood" (Ikäheimo, 2002, p. 448) in view of a better understanding of teacher professional identity. It is important to understand how the struggle for recognition affects the professional identities of teachers; especially, in continuously changing contexts such as the current postapartheid South African education system. We know that recognition shapes the sense that teachers have of their own professional identities and that this influences their reactions to change and their performance in the workplace (Scholes \& de González, 2011); moreover, that human life is a struggle to be recognised as somebody who is worth something (Heikkinen, 2003). We do not know enough, however, about the mechanisms of recognition to help people to carry on with their job, to enhance their wellbeing, and to understand how a lack of recognition can result in burnout at work, especially, in teaching and learning communities (Huttunen \& Heikkinen, 2004a). This chapter explores how the professional identities of three South African mathematics teachers are affected by their struggles for recognition in the context of a rapidly changing post-apartheid schooling system. All three of the participating teachers are from the Eastern Cape Province; one of the poorest provinces in the country. The struggle for recognition emerged spontaneously as a theme in their autobiographical narratives as they strove to make sense, not so much of who they are, but of what they are as mathematics teachers, and what they are worth professionally. This theme will be explored here through a novel set of theoretical lenses consisting of a combination of Honneth's (1995) hierarchical levels of recognition; Huttunen and Heikkinen's (2004a) circles of recognition; and, Kelchtermans' (1993) components of the retrospective dimension of a professional self or identity.

\subsection{Theoretical Framework}

It is important to note that key aspects of a teacher's professional identity, such as autonomy and self-realisation, can only be achieved intersubjectively through the recognition gained from significant others (Murphy, 2010; Honneth, 2012); recognition is important in social interaction, and "a crucial element in the formation of a person's identity" (Huttunen \& Heikkinen, 2004b, p. 1). The meaning of recognition is not clear and unequivocal, neither in its everyday or philosophical use, nor in the English or German language (Ikäheimo, 2002). Ikäheimo (2002) and Heikkinen (2003) point out three distinct interpretations of recognition that are common in everyday use: firstly, recognition in the sense of identification; secondly, recognition in the sense of admitting one's mistakes; and thirdly, recognition in the sense of acknowledging and honouring the status of the other. While Ikäheimo (2002) focuses on only the third interpretation, I follow Heikkinen (2003, p. 1) in focussing on the first and third interpretations. The first interpretation is of recognition as a reference to perception and identification, in other words, to "recognise something as something", for instance, to be recognised $a s$ a teacher. The third interpretation is of recognition as a reference to acknowledgement and honouring of the status of the other, in other 
words, to "recognise something as worth something", for instance, to be recognised as a worthy teacher. Noticing the close interrelatedness of these two interpretations, Heikkinen (2003) argued that, "to recognise something as something is half-way towards recognising something as worth something, and vice versa" (p. 2). For the individual, the most basic form of recognition is often to be noticed or seen; the worst kind of humiliation is not to be noticed or seen. The recognition in which we are interested, however, is of the genuine kind, not polite behaviour (etiquette) or fake compliments with the intention to manipulate in a behaviouristic manner (Huttunen \& Heikkinen, 2004a). Recognition has been described as a "vital human need" (Taylor, 1992, p. 26); however, like most other human needs, it does not come without a struggle. The struggle for it goes beyond being noticed or seen; it is a struggle to be recognised, not only as a professional, but also as a worthy professional. For individual autonomy - a type of individual relation-to-self that allows one to be self-confident in one's needs and beliefs, and to value one's capacities- to emerge and flourish, reciprocal, inter-subjective recognition is mandatory (Honneth, 2012). The struggle for professional recognition is also a struggle for gaining membership and for legitimate participation in the activities of professional communities of practice (Heikkinen, 2003; Huttunen \& Heikkinen, 2004a). A teacher's struggle for professional recognition is also a struggle for a professional identity; whether it is only a light struggle, such as in a friendly environment amongst family, friends and encouraging colleagues, or a heavy struggle resembling a "bloody battle" among adversaries (Huttunen \& Heikkinen, 2004b, p. 3).

\subsubsection{Honneth's Three Levels of Recognition}

At the heart of Honneth's (1995) theory is the premise that "practical identityformation presupposes inter-subjective recognition" (p. 92) at three hierarchical levels of social integration: emotional bonding (love); the granting of rights (legality); and a shared orientation to values (solidarity). The individual gradually progresses form the first level on to higher levels. The first and most basic of Honneth's (1995) three hierarchical levels of recognition is the establishment of self-confidence ( Selbsvertrauen); usually, during childhood and in primary relationships of love, friendship and care with significant others. At this level it is key for one's needs to be expressed without fear of rejection and abandonment; for one's existence as an individual in social interaction to be recognised; for one's right to exist to be reaffirmed; and for one's uniqueness as an individual (Who am I?) to be recognised. Through the experience of such special relationships with significant others, one becomes aware of one's own uniqueness and special characteristics and develops a positive image of one's abilities (Fleming \& Finnegan, 2010). This is a precondition for further development; without self-confidence the attainment of the more advanced levels of self-relations, namely self-respect and self-esteem, would be impeded (Honneth, 1995; Huttunen, 2001; Huttunen \& Heikkinen, 2004a; Murphy, 2010). Through the experience of unconditional love, one develops the ability to love one-self and others 
(Fleming \& Finnegan, 2010). Moreover, through such early relations with one's parents one develops a basic level of trust (Huttunen \& Heikkinen, 2004a) and the ability to trust others, which is an important aspect of interpersonal relations. Although it is fundamental for children's development, the first level of recognition is important for everyone, regardless of their age. The experience of love and care, according to Huttunen and Heikkinen (2004a), is "a precondition for the development of an individual's identity and morality (Sittlichkeit)" (p. 167).

The second of Honneth's (1995) levels of recognition is the establishment of selfrespect (Selbstachtung) which comes with the recognition of one's professional self by civil society as a legally mature person with legal rights (What am I?). This is linked to the attainment of a qualification which allows one to practice as a professional with legal and moral autonomy and "with equal rights, in the institutional order as a full-fletched member of a community" (Honneth, 1995, p. 133). This answers in the professional "need to be recognised as a free and autonomous citizen ... as a mature person with mind of her own and right to make legal contracts" (Heikkinen, 2003, p. 1) and is usually articulated in a teacher's diploma that gives the graduate the right to practice as a teacher in certain societies. At this level, the individual is trusted with the responsibility for his or her own actions; as opposed to a paternalising attitude which denies the individual freedom of will, autonomy and the ability to work independently (Huttunen, 2001; Huttunen \& Heikkinen, 2004a).

The third and highest of Honneth's (1995) levels of recognition, self-esteem (Selbstschätzung), refers to recognition and acknowledgement of our abilities and accomplishments at work (What am I worth?), for instance, when mentors and colleagues recognise one's successes at work (Heikkinen, 2003). According to Huttunen (2001), individual freedom of will can only be expressed through self-directed, autonomous work, and it is only when that freedom of will is directed towards common good that respect and recognition of the community is earned: "[T]he individual really becomes recognised as a person who has something to give to the community. The reciprocal recognition of each other's work creates a strong feeling of solidarity in the community. In such communities individuals are strongly motivated and enjoy their work" (p. 426). Such a shared orientation to values fosters solidarity.

Honneth's (1995) three levels of recognition are summarised in Table 17.1. This table would not be complete without showing the forms of disrespect associated with each of these levels of recognition and briefly explaining how these relate to the teachers' struggles for recognition and professional identity. Thus, the table has been adapted accordingly, followed by an explanation of the forms of disrespect associated with each of the levels of recognition.

At the first level, the disrespect is an assault on an individual's physical integrity. Extreme forms of this could be physical abuse and even rape. The denial of physical integrity is likely to result in permanent psychological damage, which could interfere with the development of practical self-relations (Huttunen, 2001; Huttunen \& Heikkinen, 2004a) and interpersonal relations.

At the second level, the disrespect is the denial of an individual's social integrity, usually through the denial of rights and social exclusion. The individual is denied freedom of will, not considered a subject of his or her own actions, but rather as an 
17 The Struggle for Recognition and the Professional Identities ...

Table 17.1 Honneth's (1995) levels of recognition and associated forms of disrespect

\begin{tabular}{l|l|l|l}
\hline Levels of recognition & First & Second & Third \\
\hline Mode of recognition & Emotional support & Cognitive respect & Social esteem \\
\hline Dimension of personality & Needs and emotions & $\begin{array}{l}\text { Moral } \\
\text { responsibility }\end{array}$ & Traits and abilities \\
\hline Forms of recognition & $\begin{array}{l}\text { Primary } \\
\text { relationships } \\
\text { (love, friendship) }\end{array}$ & $\begin{array}{l}\text { Legal relations } \\
\text { (rights) }\end{array}$ & $\begin{array}{l}\text { Community of } \\
\text { value (solidarity) }\end{array}$ \\
\hline Developmental potential & - & $\begin{array}{l}\text { Generalization, } \\
\text { de-formalization }\end{array}$ & $\begin{array}{l}\text { Individualization, } \\
\text { equalization }\end{array}$ \\
\hline Practical relation-to-self & $\begin{array}{l}\text { Basic } \\
\text { self-confidence }\end{array}$ & Self-respect & Self-esteem \\
\hline Forms of disrespect & Abuse and rape & $\begin{array}{l}\text { Denial of rights, } \\
\text { exclusion }\end{array}$ & Denigration, insult \\
\hline $\begin{array}{l}\text { Threatened component of } \\
\text { personality }\end{array}$ & Physical integrity & Social integrity & Honour, dignity \\
\hline
\end{tabular}

Note Adapted from Honneth (1995, p. 129)

object that causally reacts to stimuli, with the result that the development of moral responsibility is stunted (Huttunen, 2001; Huttunen \& Heikkinen, 2004a).

At the third level, the disrespect is the denigration and insult of an individual's honour and dignity, usually by withholding recognition for work worthy of recognition and giving feedback only when mistakes have been made. Such denial of recognition for good work and continuous negative feedback will inhibit the development of the individual's self-esteem. In worst case scenarios, for instance, when disrespect turns into "mudslinging", usually by people who suffer from weak self-esteem themselves, the struggle for recognition could turn into a vicious circle which may have severely detrimental effects on the development of interpersonal relations (Huttunen, 2001; Huttunen \& Heikkinen, 2004a).

\subsubsection{Huttunen and Heikkinen's Circles of Recognition}

Noting the importance of recognition in social interaction and identity formation, Huttunen and Heikkinen (2004b) distinguished between positive circles of recognition, which create feelings of solidarity and job satisfaction, and negative circles of recognition, which have erosive effects on working communities, like lack of solidarity and diminished motivation for teamwork. Heikkinen (2003, p. 2) explained that while positive circles of recognition refer to "reciprocal giving and getting of recognition [which] leads to a sense of solidarity"; negative circles of recognition, in contrast, refer to "lack of reciprocal recognition [which] may lead to an atmosphere of indifference and disregard". A summary of the main differences between the pos- 
Table 17.2 Differences between Huttunen and Heikkinen's positive and negative circles of recognition

\begin{tabular}{l|l}
\hline Positive circle of recognition & Negative circle of recognition \\
\hline $\begin{array}{l}\text { Developed through reciprocal recognition } \\
\text { through which persons respect each other as } \\
\text { persons and appreciate each other's skills and } \\
\text { abilities }\end{array}$ & Persons downplay each other \\
\hline $\begin{array}{l}\text { Creates a feeling of solidarity and satisfaction } \\
\text { with one's job. Individuals feel that they are } \\
\begin{array}{l}\text { important and respected members of the } \\
\text { community }\end{array}\end{array}$ & $\begin{array}{l}\text { Erodes the working community. The lack of } \\
\text { solidarity diminishes the individuals' } \\
\text { motivation for teamwork and thus affects the } \\
\text { results of work; often resulting in burnout }\end{array}$ \\
\hline
\end{tabular}

Note Adapted from Huttunen \& Heikkinen (2004a, 2004b)

itive and negative circles of recognition (Huttunen \& Heikkinen, 2004a) is offered in Table 17.2.

There are several reasons why it is important to know the mechanisms behind positive and negative cycles of recognition; for instance: to promote a supportive atmosphere in teacher education (Heikkinen, 2003); to enhance the well-being of teaching staff and assist them to cope with their job and avoid burnout; and to assist teachers and mentors to become better at what they do (Huttunen \& Heikkinen, 2004b). Both recognition and the professional identities of teachers depend on interpersonal subjectivity and therein lies the potential of recognition to affect professional identities. It makes theoretical sense, therefore, to construe the circles of recognition as a conceptual bridge between the teachers' struggle for recognition on the one hand and their quest for a professional identity on the other. Interestingly, both teacher professional development and the struggle for recognition are life-long learning processes (Kelchtermans, 2004).

\subsubsection{Kelchtermans' Components of a Personal Self}

The personal interpretive framework proposed by Kelchtermans (1993) is useful because it allows for a narrative understanding of teacher professional identity. This framework shares some characteristics with narratives; two of these are evident in Vanassche and Kelchtermans' (2016) description of it as: "always temporary", and as "a lens through which they [teachers] perceive their job situations, give meaning to, and act in them" (p. 2). An individual teacher's professional self, however, is more than an idiosyncratic construction; the self also is a product of that individual's interaction with the environment. Anspal et al. (2012) explained that the self is shaped by writing or talking about it, and that teacher professional identity development puts the self in a specific context, for instance, the school environment.

Kelchtermans (1993) acknowledged the interwoven nature of past, present, and future in biographical perspectives in his personal interpretive framework and split 


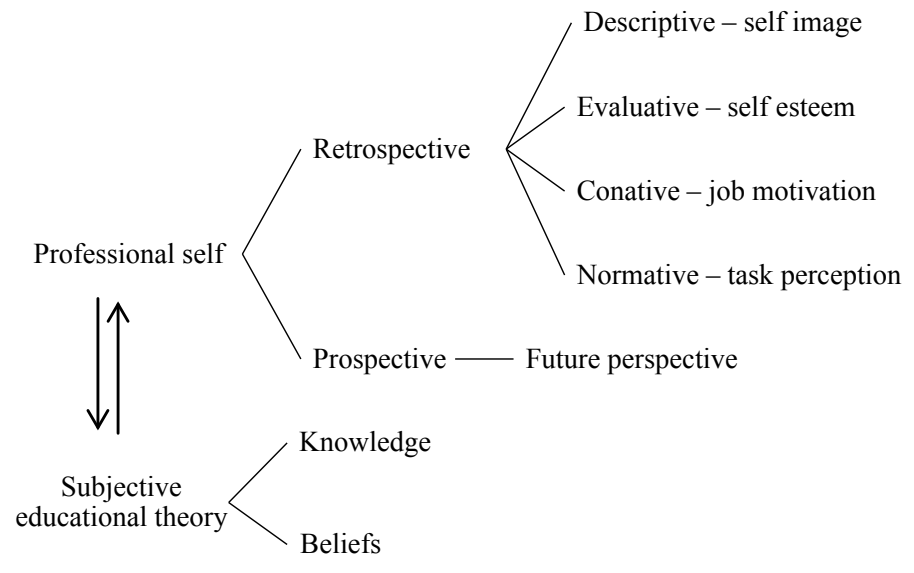

Fig. 17.1 Kelchtermans' components of the personal interpretive framework. Note Adapted from Kelchtermans (1993, p. 448)

the professional self (identity) into a retrospective and a prospective dimension. The teachers' notion of their professional self (identity) and their subjective educational theory, based on their knowledge and beliefs, are in reality intertwined and tightly woven into their personal interpretive framework: this is acknowledged in Fig. 17.1 with a double arrow between professional self and subjective educational theory.

The retrospective dimension deals with conceptions of the professional self as the individual looks back from the present into the past and consist of four components (Kelchtermans, 1993, p. 449):

- Descriptive (Self-image) component: the global characterisation of oneself as encapsulated in one's self descriptive statements. In other words, how a teacher describes him- or herself as a teacher. Often descriptions are formulated in terms of general principles that govern teachers' professional behaviour; but also by referring to the way teachers think they are perceived by others.

- Evaluative (Self-esteem) component: the evaluation of oneself as a teacher. Often the learners are seen as the most important determinants of a teacher's self-esteem. Indicators include the learners' school results, but also the quality of the personal relationship with the teacher. Other important indicators include, for example, comparison with other teachers.

- Conative (Job motivation) component: the motives for choosing the job, staying in it, or leaving it. In other words, the things about their job that motivates or demotivates teachers.

- Normative (Task perception) component: the way teachers conceptualise their job. This is crucial as a norm in evaluating their professional behaviour and may include narratives of the quality of their relationship with their learners, and/or their striving for professional (didactical) competence. 
The prospective dimension (future perspective) deals with teachers' expectations for future developments of their job situation and how they feel about this. The subjective educational theory is described as: "the personal system of knowledge and beliefs teachers use while performing their job" (Kelchtermans, 1993, p. 450). This might be the result of career experiences that a teacher has had and how these are, more or less reflectively, integrated into practice. As Kelchtermans (1993) explained: "In terms of the conceptual framework one could say that the subjective educational theory contains the knowledge and beliefs that are used by the teacher to implement the personal-professional programme implied in the task perception" (p. 450). The content of a subjective educational theory can only be reconstructed in a fragmented way:

One never gets the whole picture. Not only because it changes with new experiences, but also because the teacher per definition has no conscious access to his or her entire 'theory'. Further the reconstruction is bounded by the reflective capacity of the teacher and by the degree he or she is willing to share his or her ideals with someone else. (Kelchtermans, 1993, p. 451)

This study draws on the four components of the retrospective dimension of Kelchtermans' (1993) personal interpretive framework which comprehensively cover the aspects of a teacher professional identity which could be influenced by struggles for professional recognition in the workplace.

\subsection{Methodology}

The struggle for professional recognition in the workplace emerged as a salient theme in the autobiographical narratives of mathematics teachers who participated in a narrative inquiry (Clandinin \& Connelly, 2000; Connelly \& Clandinin, 1990; Daiute \& Lightfoot, 2004; Kramp, 2004) into the narrative shaping of their professional identities. Their narratives were collected over a period of eighteen to twenty four months. Seven experienced mathematics teachers participated in the original study; they were purposively selected from government funded schools in the Eastern Cape Province of South Africa; and their teaching experience and sociocultural backgrounds were taken into account during the selection process. The sample included only participants with first-hand experience of the continuously changing context of the post-apartheid South African education system over the past twenty years and who are representative of the demographic profile and cultural diversity of teachers in government funded schools the Eastern Cape Province of South Africa. The focus of this chapter is on the struggles for recognition distilled from the autobiographical narratives of three of the original seven participants (P1, P2 and P3) whose demographic profiles are summarised in Table 17.3.

During the semi-structured interviews participants were asked to reflect, in as much detail as possible, on the high points, low (nadir) points, and turning points in their professional teaching careers. These interviews were audio-recorded, transcribed in verbatim, and later reviewed by the teachers using member checking to 
Table 17.3 Demographic profile of the participants

\begin{tabular}{l|l|l|l|l|l|l}
\hline & $\begin{array}{l}\text { Age (in } \\
\text { years) }\end{array}$ & $\begin{array}{l}\text { Ethnicity } \\
\text { and } \\
\text { gender }\end{array}$ & Home language & $\begin{array}{l}\text { Teaching } \\
\text { experi- } \\
\text { ence (in } \\
\text { years) }\end{array}$ & $\begin{array}{l}\text { School } \\
\text { district }\end{array}$ & $\begin{array}{l}\text { School } \\
\text { type }\end{array}$ \\
\hline P1 & 50 & $\begin{array}{l}\text { Black } \\
\text { male }\end{array}$ & isiXhosa & 23 & $\begin{array}{l}\text { Port } \\
\text { Elizabeth }\end{array}$ & $\begin{array}{l}\text { Urban, } \\
\text { township }\end{array}$ \\
\hline P2 & 48 & $\begin{array}{l}\text { 'Coloured' } \\
\text { female }\end{array}$ & Afrikaans/English & 26 & $\begin{array}{l}\text { Port } \\
\text { Elizabeth }\end{array}$ & $\begin{array}{l}\text { Urban, } \\
\text { township }\end{array}$ \\
\hline P3 & 56 & $\begin{array}{l}\text { White } \\
\text { male }\end{array}$ & English & 32 & $\begin{array}{l}\text { Port } \\
\text { Elizabeth }\end{array}$ & $\begin{array}{l}\text { Urban, } \\
\text { ex-Model } \\
\text { C }\end{array}$ \\
\hline
\end{tabular}

confirm the validity and credibility of the transcripts (Creswell \& Miller, 2000). Because English is not the mother tongue of all of the participants, it was sometimes necessary to infer meaning from what they have said; for instance, inferring from Participant 1's (P1's) remark, "this teacher is not the one who is driving what you are driving" ( $\mathrm{P} 1 ; 1$ st interview), the meaning that the other teacher is not cooperating because they lack a shared orientation to values or solidarity. Where such inferences were necessary, the researcher's interpretation was verified using member checking (Guba, 1981; Creswell \& Miller, 2000). Consistency in responses across interviews of a participant was regarded as evidence of the occurrence of events as narrated (Caruso, 2013). During a narrative analysis, there is need for on-going conceptualisation while collecting data (Vandenberghe, 1996); hence, a blend of horizontal or cross-case analysis (Miles \& Huberman, 1994) and constant comparative analysis (Glaser \& Strauss, 1967) was used to uncover common themes or patterns. Participants were interviewed at least four times each over a period of roughly eighteen to twenty four months, making it possible to fill gaps in their storylines, clarify uncertainties and check inferences.

\subsection{Results and Discussion}

While the results of this study cannot be generalised, the negative effects of a lack of professional recognition, or disrespect, in the workplace on the three participants' self-respect (What am I?) and self-esteem (What am I worth?) are evident in their autobiographical narratives. The narrative data shows that the disrespect is either at Honneth's (1995) second level, self-respect, or at the third level, self-esteem, and that for all participants the first level, self-confidence, remains intact. There is also evidence in the narrative data that the negative effects of such disrespect give rise to negative circles of recognition, characterised by mutual downplaying of each other, lack of solidarity and diminished motivation for teamwork; all of these have negative implications for the professional identities of the participants. There is also 
strong evidence, however, that the participants have developed strategies to cope with the negative effects of such lack of recognition or disrespect; for instance, they would draw on narratives of positive circles of recognition, interspersed with feelings of reciprocal recognition, solidarity, and job satisfaction, to minimise the effects of negative circles of recognition on their professional identities. The narrative data also shows that the source of positive circles of recognition seems to be the participants' strong sense of self-confidence (Who am I?); most likely, because all of them had been privy to primary relationships of love, friendship, and care with significant others. Thus, the narrative data underlines the importance of Honneth's (1995) first level of recognition, self-confidence, as a precondition for the development of identity and morality (Huttunen \& Heikkinen, 2004a), and for enhancing the survival options of those on the receiving end of lack of recognition, or disrespect, on the other levels. The following discussion will focus on three of the selected participants' narratives of their experiences of lack of recognition, or disrespect, in the workplace: exploring the effects on their professional identities, and how they managed to cope.

\section{The Story of Participant 1}

In this story, Participant 1 (P1) recounts the struggle for recognition of his worth as a mathematics teacher in a context where his colleagues are denying his contributions to the learners' good results and turn down his genuine offers to share some of his expertise with them. This happened at a school in a historically 'Black' township of Port Elizabeth about a year after P1, a fully qualified mathematics teacher with a fair amount of experience, had accepted a teaching post there.

[Y]ou do your utmost best to assist a particular teacher now in ensuring that the learners are doing their best and what you are trying to put in is not appreciated. That, to me, becomes my low point. You will find that learners are keen to work, but this teacher is not the one who is driving what you are driving or you are not in the same level. That, to me, it's one of the key things that kills me! And it makes me to be demotivated, because at the end of the day you try to help, but this help is not appreciated even if those learners move to a higher level. That is [what] I will consider as a low point [...] We look at the results [matric pass rates] of the school, when I got into this particular school; I worked with learners though I came in September 2001. They got 89\%. The following year I worked with those learners in the midst of educators not trying to assist me because I came and the results were high. And they said: 'No, it's not your results!' But I said: 'All right, I'm going to prove a point!' The following year I worked with the learners. After school, we were staying; we were working, both with maths and physical science; because those were my specialities. Working with those learners then proved fruitful. We got $99 \%$ so only one learner failed; it's the one that was not attending the school! So that to me, is my, my experience, where you are not needed and then you pull yourself away. Where learners are going all out you tend to have much success. I do have some resistance, or there is some resistance from time to time from the educators as you are assisting the learners. It's like you are intimidating, but it should not be! We are assisting learners and helping the learners. So if a situation where you feel that you are uncomfortable. That to me, I feel, is not the way you should be because we are helping the learners here and learners must do their best. You must let go of your selfish egos because you are thinking that I am intimidating whereas I just want to assist the learners. So to me, it is one of the things. [...] It's as if, if you give assistance, the accolades will go to you. Which is not like that! Teachers sometimes they said: 'All right, I'm going to do $a$ and $b$ and $c$, and see what he will do!' So you have those ones that wants to pull down. We call it a 'pull-down-syndrome'. But at the end it's at the detrimental the child. So there were 
some incidents where teachers... they do not welcome the external assistance. Actually, it's a really, really sad case $(\mathrm{P} 1 ; 1$ st interview).

In this story, P1's struggle for recognition is against a form of disrespect linked to Honneth's (1995) third level of recognition, self-esteem, and described as a denigration and insult to an individual's honour and dignity. P1 regards it as a "low point" in his career. In South Africa, good pass rates or "results" are highly valued, especially in the final school-leaving or "matric" examination, and are frequently used as a measure of a teacher's worth; linking the individual's self-esteem with learner performance. When P1's colleagues denied his contributions to the school's good pass rates in mathematics and science, "No, it's not your results!", and attempted to undermine him, "All right, I'm going to do $a$ and $b$ and c, and see what he will $d o$ !", he experienced their actions as an insult and denigration of his worth as a teacher and self-esteem. He refers to this kind of deliberate disrespect as a "pulldown-syndrome". This story is about P1's struggle for recognition of his worth as a competent mathematics and science teacher: "maths and physical science... those were my specialities". It is not surprising that he describes this experience as a "low point" in his teaching career. The effects of negative circles of recognition (Heikkinen, 2003; Huttunen \& Heikkinen, 2004a, 2004b) are evident in their downplaying of each other, "All right, I'm going to do a and b and c, and see what he will do"; their lack of shared orientation to values or solidarity, "this teacher is not the one who is driving what you are driving"; and, diminished motivation for teamwork, "where you are not needed and then you pull yourself away". Negative circles of recognition often lead to a demoralising atmosphere, which can result in exhaustion and burnout (Heikkinen, 2003). This has affected P1's motivation for teamwork and the conative (job motivation) component of his professional identity. He described the experience as "one of the key things that kills me! And it makes me to be demotivated". Usually, the resulting atmosphere of indifference and disregard is enough to make most teachers consider leaving the profession and, in severe cases, can even cause burnout (Huttunen \& Heikkinen, 2004a). Apparently, P1 has managed to survive by counterbalancing the effects of negative circles of recognition with the effects of positive circles of recognition drawn from other experiences linked to levels lower down on Honneth's (1995) hierarchical scale of recognition. He has two such stories in his narrative repertoire. The first is a story of the role that his family had played in the development of his self-confidence.

Because my father divorced my mother at an early age, I was very, very young and that in itself made me to have certain vows that I have with me. My mother was able to take us... we were two from my mother... was able to take us from... I don't know whether you have seen a dog taking its puppy from one place to another? Though she was a domestic worker she made sure that at least there is something for us for our education as well and that to me... even in difficult times she will make sure that we have at least money to go and study. I studied at different universities and before I could do that, I had to go back and work myself before I can again go. So it was her influence that has made where I am or what I have become, meaning the support she has given me whilst growing up in her father's house. That's also one of the great things that I've learnt as a father-figure in the house. I've learnt it from grandfather-that is [name of grandfather]. They usually called him [nick-name of grandfather] and even now I have a shop that is called [name of shop] because of thinking 
about him and honouring him for what he has done in my life. My family, the ones, they have been there for me, meaning they did not trouble me or even having problems with me when I say I must go and study. Study was number one because they know that I was the leader in the study groups $(\mathrm{P} 1 ; 2$ nd interview).

This story of how the support, love and care of his significant others (his mother, grandfather, wife and two children) have laid the foundations for the establishment of self-confidence, is in line with Honneth's (1995) first level of recognition, that of emotional bonding (love). His mother made sure of that her children could express themselves without fear of abandonment. Despite being divorced with no fixed address and a low paying job, as a domestic servant, she nevertheless took care of her children's needs: "I don't know whether you have seen a dog taking its puppy from one place to another?" They knew that they could count on their mother to make provisions for his studies, "even in difficult times she will make sure that we have at least money to go and study". This enabled P1 to develop self-confidence, which he acknowledges as follows: "So it was her influence that has made where I am or what I have become, meaning the support she has given me". The rest of his family was also supportive. His grandfather, acting as a father figure, provided a stable home; and his wife and children understood and supported his studies. A positive circle of recognition (Heikkinen, 2003; Huttunen \& Heikkinen, 2004a, 2004b) is evident in the reciprocal recognition, for instance, "they have been there for me" and in return, "honouring him [grandfather] for what he has done in my life". Also in the feeling of solidarity and satisfaction of knowing that they supported him, "they have been there for me [...] because they've seen how involved I was in my studies". This made him aware of his own uniqueness and special characteristics and helped him to develop a positive image of his abilities (Fleming \& Finnegan, 2010). This also gave him the self-confidence to complete his studies and to become a qualified mathematics teacher; paving the way for recognition at Honneth's (1995) second level of recognition, granting of rights (legality), which usually culminates in self-respect for the recognised. The fact that $\mathrm{P} 1$ is a well-qualified mathematics teacher with ample selfconfidence, elevates his struggle for recognition beyond Honneth's (1995) second level, that of self-respect (What am I?), to the next level, that of self-esteem (What am I worth?). This is how the effects of the positive circle of recognition helps P1 to counterbalance the effects of the negative circle of recognition. The second story is of the early recognition of P1's mathematical and teaching proficiency by his high school teachers, and later by his college lecturers. This story, like the first one, is also in line with Honneth's (1995) first level of recognition. Although the experience can hardly be described as an act of emotional bonding or a caring relationship of love with significant others in the traditional sense, it still contributed to the development of P1's self-confidence.

We were not having enough educators, so I was taken to teach the lower classes. As it was moving up from standard six [Grade 8], standard seven, standard eight [...] So, that then became, what I call my passion for maths [...] I can start again from my high school. The way educators trusted me in ensuring that I'm helping those learners... And those learners actually were doing their best! And I found that it is exciting. But as I moved on, I found that as I moved maybe to a college, I found that, that college lecturer used me again within 
the class to help. As I moved the university, I found that I've been utilised again. So that to me, ugh... has really made me change the way I do things, and the excitement that is there is still there because I've been utilized in one way or the other. I don't know why they are not using others but they will use me all the time. So I love that. Ugh, I love to share. I love to make sure other people understand maths (P1; 1st interview).

Qualified mathematics teachers are scarce in the Eastern Cape Province. When no qualified teachers available, learners often, spontaneously, end up teaching each other. In P1's story this was not a spontaneous process, "I was taken to teach the lower classes". This process, sanctioned by the teachers at the school, is perhaps why he construes this experience as recognition of his mathematical and teaching proficiency: "The way educators trusted me in ensuring that I'm helping those learners... And those learners actually were doing their best!". This and other similar experiences are construed as recognition of his uniqueness as an individual with special characteristics, "I don't know why they are not using others but they will use me all the time", and contributes to a positive image of his abilities, "So I love that". The effects of positive circles of recognition are evident in the reciprocal recognition in the respect shown for P1's skills and abilities, "educators trusted me"; and, in feelings of solidarity and job satisfaction, "the excitement that is there is still there because I've been utilized in one way or the other"; and also, "I don't know why they are not using others but they will use me all the time". In P1's own view, this is evidence of these professionals recognising him as a member of their professional community of mathematics teachers. Such experiences of professional inclusion contributes to the formation of a professional identity (Castañeda, 2014). In P1's story, all four of Kelchtermans' (1993) components of a retrospective self are affected; for instance, the normative component, "that to me... has really made me change the way I do things"; the descriptive component, "I love to share. I love to make sure other people understand maths"; the evaluative component, "those learners actually were doing their best!" and "they will use me all the time"; and lastly, the conative component, "the excitement that is there is still there". All of these are positive outcomes for his professional identity brought about by the experience of a positive circle of recognition. It could be argued that asking P1 to take those classes was an act of necessity and desperation because there were no qualified mathematics teachers; and, that it is common practice to use senior students as student assistants in college and university; therefore, these were not necessarily instances of recognition. However, from a narrative perspective, the way in which $\mathrm{P} 1$ makes sense of these experiences is important; and, there is strong evidence that he sees these as instances of recognition: "I don't know why they are not using others but they will use me all the time" (P1, 1st interview). His argument makes sense, because they could have used others instead. The recognition that $\mathrm{P} 1$ received from his teachers and lecturers made him aware of his passion for teaching mathematics, gave him self-confidence, and shaped him into who he is as a mathematics teacher. As shown here, this would be a valuable source in later struggles for more advanced levels of recognition. Notably, in the struggle for self-esteem when the actions of his colleagues called into question his worth as a mathematics teacher. The ability to counterbalance the effects negative circles of recognition with the effects of positive circles of recognition, drawn from beyond 
the immediate contexts of his struggles, have enabled P1 to survive the disrespect of his colleagues in the constant struggle for recognition.

\section{The Story of Participant 2}

In this story, Participant $2(\mathrm{P} 2)$ recounted her struggles to maintain her self-respect in a context where colleagues downplayed her qualifications and refused to work with her. All of this happened at a school in a historically 'Coloured' township of Port Elizabeth where she had started her teaching career at least twenty-six years before the interview. In this township school, like in P1's school, there have been very little post-apartheid changes, except for the many curriculum changes. There has been no change in the demographic profile of the staff, so all of the teachers are from broadly similar sociocultural backgrounds.

[L]ow points are when you don't get the cooperation of, firstly, your students, and then another major thing is when [...] you don't get cooperation with your colleagues. When you work with somebody you're supposed to work in a group, and, you just find you are fighting a losing battle. This person is just going ahead and doing his or her thing... You know. And for me, at the end of the day, it's not about me [...] but when your colleagues work against you, that is very demotivating [...] You are three or four teaching Grade 8 Maths, and I'm working here, you're working there... and he's working over there... And each one is just doing his own thing. That is very, that's low... That's the low point for me. But I've had to learn to work around that. I've had to learn to make, make it work, because even though you try hard to get your colleagues to work together, you just don't get the necessary cooperation, but at the end of the day, I've had to learn to work around it [...] When colleagues are better qualified than you are, they have this attitude; you cannot come and tell them! I've had that experience [...] when I tried to tell the person 'You mustn't do it like this, you must do it like that' and gave the things that I had, the person said to me that they don't like the way I speak to them, and they can't understand, because they are academically better qualified than I am [...] I can take it, I can handle it, but I don't want to hear that all the time. For me, it's not about qualifications. I mean I'm a what? I am a [name of college] teacher and I went and did my, the ACE [Advanced Certificate in Education] Maths Literacy Course and, I'm happy! I don't need to go and get Masters and whatever... I'm content. I'm not searching [...] For me at the end of the day, if my children fare well, I'm good and if they don't, what can I do about it, it's not about me, it's about the child at the end of the day [...] It doesn't matter what qualifications I've got, we are here at the end of the day because of the children [...] a lot of people will tell you that they compete, but experience counts... but for me that's not important. Fine, I'm teaching 20 odd years and you learn as you go along and you find out, today it doesn't work, and you had to try something different the next day, but when you have colleagues that don't cooperate... and you've tried, you've tried to speak, you've tried to sort it out in the office, and the Principal has tried his part, but the person is just not giving his cooperation, what more can you do? You know what I'm saying? So, that's a major problem and I'm not the kind of person... who can speak to other people... I'm not... I'm a quiet, I see myself as quiet, as a shy person, but when I'm in my classroom, that's where I perform, where I enjoy myself in front of the children (P2; 1st interview).

The disrespect shown in this story is social exclusion, "even though you try hard to get your colleagues to work together, you just don't get the necessary cooperation"; and, the denial of legal rights, "When colleagues are better qualified than you are, they have this attitude; you cannot come and tell them!" Linked to Honneth's (1995) second level, self-respect, the downplaying of P2's qualifications is a form of denigration and insult; and, the questioning of her legal authority and moral autonomy to speak to them on equal terms as a fellow professional teacher is a form of 
denial of rights and exclusion. Both are assaults on her self-esteem and self-respect as a teacher. Her question "I mean I'm a what?" implies that her struggle is mainly about maintaining self-respect. She knows that she is suitably qualified and is quite content with her qualifications, "For me, it's not about qualifications [...] I'm happy! I don't need to go and get Masters and whatever". The effects of negative circles of recognition (Heikkinen, 2003; Huttunen \& Heikkinen, 2004a, 2004b) are evident in the downplaying of each other, "they have this attitude; you cannot come and tell them! [...] because they are academically better qualified"; the lack of solidarity, "your colleagues work against you"; and, diminished motivation for teamwork, "you're supposed to work in a group, and, you just find you are fighting a losing battle". It seems that P2 is quite resolute in maintaining her self-respect; not all of the components of her professional self or identity were affected, even though the experience has prompted her to reflect on them all. Her rhetorical question "I mean I'm a what?" can be interpreted either as a reflection on her self-image as a teacher, linked to the descriptive component, or, as a reflection on her task as a teacher, linked to the normative component. However, both the descriptive component, "I see myself as quiet, as a shy person, but when I'm in my classroom, that's where I perform", and the normative component, "It doesn't matter what qualifications I've got, we are here at the end of the day because of the children", seem intact. She links the normative component to her didactical competence and its value for the learners, "For me at the end of the day, if my children fare well, I'm good", rather than attainment of higher qualifications. The evaluative component, which depends on indicators such as comparison with other teachers and the learner performance also seem intact, " $a$ lot of people will tell you that they compete [...] but for me that's not important". It seems that only the conative component of P2's professional self or identity was affected, "when your colleagues work against you; that is very demotivating" and "people who think they know more than you, who are not prepared to learn from you, and then you just feel, sometimes you just feel it's not worth it" (P2; 3rd interview). Further analysis of P2's autobiographical narratives shows that, like P1 above, she has learnt to counterbalance the effects of negative circles of recognition with the effects of positive circles of recognition drawn from experiences elsewhere. She has two stories of experiences that involve intersubjective recognition and that show all of the characteristics of positive circles of recognition in her narrative repertoire. The first story relates to Honneth's (1995) first level of recognition, the establishment of self-confidence, and primary relations of love and care in her family.

The support system was there; you know what I'm saying? My parents were there, but I could never go to them, and ask them to help me with homework. I had to do it on my own. I've got a brother and a sister who are younger than me. We had to sit and figure out things for ourselves. Even at high school when homework... they wouldn't ask if you'd done your homework. You must just know that you must do your homework. So, I knew they were there, but they couldn't support as far as content [...] They were not educated; you know what I'm saying? My father, well, he must have done Standard 6, my mother didn't even finish primary school. So, that is the way they couldn't support us, but in every other way, we knew that we could depend upon them. They supplied... the things, it was there. My father was the only one who worked. My mother never worked. She was a housewife which was a plus point because in the afternoon you come home, she is at home. So that was a plus point. 
She may not have been able to help me academically, but the fact that she was there, made a big difference. We knew that we could depend upon them. If I asked for anything then we would be told: we cannot afford it at this time, but we will get it for you sometime. So, that was a good thing. What else? But like I say, academically, and when it came to anything school, you had to fight it through on your own (P2, 2nd interview).

The effects of positive circles of recognition are evident in the reciprocal recognition between parents and children, "they couldn't support us [with homework], but in every other way, we knew that we could depend upon them", and, "they wouldn't ask if you'd done your homework. You must just know that you must do your homework"; and, in the solidarity among them, "the fact that she [their mother] was there, made a big difference. We knew that we could depend upon them". The love and care necessary for the development of self-confidence was there, "The support system was there [...] My parents were there”. She knew that she could express her needs freely without fear of rejection or abandonment, "we knew that we could depend upon them. They supplied... the things, it was there". Her self-confidence was further strengthened, because their parents could not help with their schoolwork so the children had to help themselves, "when it came to anything school, you had to fight it through on your own". This was useful because in made her confident in her own abilities. The second story is about her experiences of participating in the regional cluster system. These are professional communities of practice, in discipline specific areas, that involve teachers from different schools in a geographic region.

Ever since we [teachers] have started the clusters where we work together in groups, just like the schools in the Northern Areas [of Port Elizabeth] it's... been very, what is the word? Motivating! Because we get together and discuss problems we may have, we get together and we work on question papers together... This week or next week again we're going to have our meeting [...] It works, uhm, like a bomb! [...] each school gets a turn to set papers. And then, not only get together for papers, we get together to discuss how we can help one another... What am I doing that's working, and how can we assist one another, and then, also friendships have been cemented even through this (P2; 1st interview)

The effects of positive circles of recognition are evident in the reciprocal recognition and solidarity amongst cluster members, "we get together and discuss problems we may have, we get together and we work on question papers together [...] we get together to discuss how we can help one another... What am I doing that's working, and how can we assist one another [...] friendships have been cemented"; and job satisfaction, "It works, uhm, like a bomb!" The obvious differences between her experiences of intersubjective recognition as a member and participant in the cluster system and the lack of respect and disrespect of her colleagues at school prompted this reflection: "People in the clusters don't know you as good as the people on your staff. You don't work every day with people in the cluster. So, I don't know if the problem is with me, or what. Many times I have asked myself the question. Am I the problem? What am I doing wrong?" (P2; 2nd interview). Nevertheless, the intersubjective recognition received within the cluster system compensates for denied intersubjective recognition of her colleagues at school, "[M]aybe the cluster makes up for it because we work extensively together. We're at the stage now where we email tasks and tests and exam papers to one another, so maybe that makes up for it. But 
it's still not the same as having somebody here at the school" (P2; 3rd interview). Her experiences in the cluster system, "Motivating! Because we get together and discuss problems we may have [...] It works, like a bomb! [...] we get together to discuss how we can help one another", help to counteract the demotivating experience with her colleagues at school, “you've tried, you've tried to speak, you've tried to sort it out [...] but the person is just not giving his cooperation, what more can you do?" To summarise, P2 has been able to remain resolute in maintaining of her self-respect amidst the continuous struggle against the disrespect shown by her colleagues, because she has learnt how to counterbalance the effects of negative circles of recognition with the effects of positive circles of recognition drawn from experiences beyond the immediate context of her struggles.

\section{The Story of Participant 3}

In this story, Participant $3(\mathrm{P} 3)$ recounts the struggle for recognition of his worth as a mathematics teacher in a context of affirmative action where his hard work and dedication over the years were not recognised and rewarded. This happened at a school in a historically White neighbourhood of Port Elizabeth where P3 had started his teaching career at least thirty-two years before the interview. In the context of the post-apartheid schooling system, the demographic profile of staff and learners has shifted from exclusively White to almost exclusively Non-white.

And then I started applying for deputy head posts, etcetera, because I felt I was ready for that $[\ldots]$ Unfortunately, for me there was a lot of turmoil in the education area and a lot of re-deployments, if you can remember. And, people were redeployed from certain other schools, and came to our school, and were brand new in our situation [...] and their promotion was given above mine. In other words, they were promoted to a deputy [...] my service and loyalty and dedication and passion counted for zippo at that particular stage [...] This used to be traditionally a White school and there were White teachers... that people of colour were given the opportunity [...] That was the hardest time, the disappointment of not being recognised despite all the work that I was putting in $[\ldots]$ and it knocked my passion a little bit in terms of the school. Not in terms of the maths, but in terms of the school itself... It was a bit of a setback [...] That was one incident, and, and the biggest one by far because since then I haven't actually wanted to apply. There have been situations where I could have applied again, but I haven't wanted to. I just feel that I don't, I don't want that anymore. It's sort of being ripped out of my heart, that part (P3, 1st interview).

The disrespect shown in this story is typical of Honneth's (1995) third level and is about and the struggle for self-esteem and for P3's worth as a teacher to be recognised. The story is about the denigration and insult of not getting the desired promotion post, regardless of all the hard work and the extra responsibilities that he had taken on: "my service and loyalty and dedication and passion counted for zippo at that particular stage". The school had to apply affirmative action and P3 was overlooked for the promotion post. The effects of negative circles of recognition are evident in a lack of solidarity and diminished motivation for teamwork, "it knocked my passion a little bit in terms of the school. Not in terms of the maths, but in terms of the school itself"; and, in the emotional reactions of P3 to the perceived disrespect, "since then I haven't actually wanted to apply. There have been situations where I could have applied again, but I haven't wanted to. I just feel that I don't, I don't 
want that anymore. It's sort of being ripped out of my heart". The denial of P3's promotion probably had less to do with disrespect and misrecognition of hard work and dedication and more to do with the politics of transformation and affirmative action; for instance, there is no evidence of persons downplaying each other typical of negative circles of recognition. From a narrative perspective, however, it is more important to know how P3 makes sense of this experience; and, he made the negative effects on his self-esteem as a teacher and as a father quite clear.

[W] hen that disappointment of that promotion thing happened, I actually felt, not only disappointed [...], but I felt almost like I'd let my family down in terms of I told them that hard work and dedication and being on time was so important and that you will be rewarded for that. And here I was, having done all of that, and not getting rewarded. So it was almost like I'd said the wrong thing to my children. I know I didn't, but it was... They looked at me and thought, 'Gosh, I wonder if this old man's been telling the truth all the time?' So it was more of a personal thing at home as well. It was like a disappointment. I felt that I'd let down my family (P3, 3rd interview).

A prerequisite for recognition on Honneth's (1995) third level is an intersubjectively shared orientation to common values and goals, "that indicate to each other the significance or contribution of their qualities for the life of the other" (p. 121), which usually culminates in enhanced self-esteem of the recognised. In P3's story, such intersubjective solidarity is missing. His struggle is the result of a mismatch between his personal goal of promotion, perceived as a form of recognition for "hard work dedication" which is linked to his personal values of "service and loyalty and dedication and passion" and the institutional goal of transformation by promoting people of colour through affirmative action "people of colour were given the opportunity". This experience has affected P3's self-esteem as a father and family man; calling into question the integrity of the values he had taught to his children and amplifying the effects of the negative circle of recognition; and the evaluative and conative components (Kelchtermans, 1993) of his professional self or identity. This is evident in the emotional comments, "[T] hat was the hardest time, the disappointment of not being recognised despite all the work that I was putting in", which indicates that he had used his application for promotion as a crude evaluation of his worth as a teacher; and 'I just feel that I don't, I don't want that anymore. It's sort of being ripped out of my heart", which indicates how demotivating the experience has been. Having one's ego-claims disregarded can be so emotionally overwhelming that one becomes incapable of continuing with an action (Honneth, 1995). This seems to be the case with P3 not wanting to apply for promotion anymore. While some of his previous colleagues left the school because of similar experiences, "People that were here didn't really count for much. Some of the newcomers got in... You know! [...] People did leave" (P3; 1st interview), P3 has learnt to survive by counterbalancing the effects of negative circles of recognition with the effects of positive circles of recognition drawn from other life experiences. Two positive stories in his narrative repertoire, both linked to Honneth's (1995) first level of recognition, emotional bonding (love), stand out. The first one is about self-confidence gained through the love and care in his family life. 
I want to start with my own family life [...] My family was a very normal... sort of united family [...] My Mum was always at home! That was very important. I remember when I, when I got home from school, my mother was at home [...] Those issues one doesn't realise as a child, when you're growing up, have a huge supporting role because the parent is showing such an interest in you, you then feel obliged to show an interest in your schoolwork! [...] My father was always there from a sporting point of view [...] He'd ask me about my Maths but worked late hours so he could not really help. So, none of them helped me physically with the actual doing of the Maths, but they helped me with the motivation of it [...] They'd sacrifice some of their own things so that we could get on in life [...] That inward motivation to succeed, that is something that I think one gets if you, I don't know if this is true or not, but I feel that if you come from a slightly deprived background or poorish background, there's definitely this will to get to improve your own life, so that your family's life can improve (P3; 2nd interview).

A "very normal... sort of united family" life has enabled P3 to establish selfconfidence, knowing that he could depend on the love and care of his parents and that his needs could be expressed without fear of rejection or abandonment because "[t]hey'd sacrifice some of their own things so that we could get on in life". His mother was "always at home" and ready to make sure that all of his needs were taken care of and his father also tried to do his part, but he was mostly at work, "he'd ask me about my Maths but worked late hours so he could not really help", so he focussed on the sport. Their actions can be linked to Honneth's (1995) first level of recognition where such emotional bonding (love) is necessary for the attainment of self-confidence. The effects of positive circles of recognition are evident in the reciprocal recognition between parent and child and feelings of solidarity and mutual satisfaction, "because the parent is showing such an interest in you, you then feel obliged to show an interest in your schoolwork, which in fact is what your parents are wanting you to do!" The attainment of self-confidence has laid the foundations for the attainment of his degree and self-respect knowing that he has earned the legal right to practice as a professional mathematics teacher. There is only evidence of Kelchtermans' (1993) conative component a professional self in this story. P3 refers to it his "inward motivation to succeed" in his job which stems from having witnessed how his parents (particularly his father) struggled: "You know, so I think the inward motivation comes from trying to live a better life than maybe my parents had lived"(P3; 2nd interview). This resilience, together with a firm and resolute self-confidence, all effects of the positive circles of recognitiMarkkuon evident in this story, are the counterbalances that help him to neutralise the effects of negative circles of recognition such as those evident in the story of the denied promotion post. Other stories of P3 that involve positive circles of recognition are mostly anecdotal and about previous learners, for instance, the following one of a chance encounter with a previous learner in a supermarket:

It's made me understand [...] what a big effect that you have on children's lives. As you teach children from grade eight to grade twelve, you teach them mathematics, and you forget that you are teaching them life skills and that you are a role model for them... serving as a role model. You forget about those things... those things however come back to you when you bump into a child, which I still do, uhm, in a supermarket and he says he'll never forget the time... that he got disciplined by me for not doing his homework. He then did his homework and he passed maths and today he's financially secure with a sound job, and he, he'll show 
genuine appreciation. So that has changed my... It hasn't changed me, but it has made me aware of the impact that you have on children's lives, other than just mathematics (P3; 1st interview).

This is another example of recognition linked to Honneth's (1995) third level, a shared orientation to values (solidarity), which strengthens of P3's self-esteem. The effects of positive circles of recognition (Huttunen \& Heikkinen, 2004a, 2004b) are evident in the reciprocal recognition between the previous learner and $\mathrm{P} 3$, with the learner showing "genuine appreciation" for the role that P3 has played in his life and with P3 recognising the learner for making him "aware of the impact that you [P3] have on children's lives, other than just mathematics", but also in the mutual feelings of solidarity and satisfaction with the outcome of the disciplinary action taken by P3 against the previous learner, with the learner turning out "financially secure with a sound job" and showing "genuine appreciation". This experience has prompted P3 to reflect on two components of Kelchtermans' (1993) professional self. The evaluative component because of the of "big effect that you have on children's lives", is construed as positive for his self-esteem; and, the normative component, "you teach them mathematics, and you forget that you are teaching them life skills and that you are [...] serving as a role model" extended the mathematics teacher's job to include life-skills and role modelling.

These are the narratives of the participants' struggles for professional recognition; the strategies that they have developed to cope with it; and, how these have affected their professional identities.

In conclusion, while the sample in this study is far too small to yield any generalizable results, it does highlight a few pertinent issues related to the struggle for recognition and the professional identities of mathematics teachers. For instance, the sample included participants representative of the socio-cultural spectrum of mathematics teachers across government-funded schools in the Eastern Cape Province of South Africa, yet there was very little variation in their nature of their stories. Perhaps, because the focus was on teachers who had managed to survive the on-going and sometimes radical changes in the post-apartheid education system, and therefore there would be similarities in their experiences and survival strategies. One similarity is that all of them have a strong sense of self-confidence grounded in narratives of loving and caring family relations; they know who they are and they are able to draw on this in the their struggles for recognition. Another is that all of the participants are qualified mathematics teachers, which gives them the self-respect to practice as professionals with the necessary legal and moral authority; they know what they are and are able to draw on this in their struggles for recognition. The only apparent anomaly is the second participant (P2) whose struggle appeared to be for self-respect, even though she is a qualified mathematics teacher. She struggles, not because she has no self-respect, but because her self-respect is threatened. Her struggle is for maintenance of her self-respect. Another striking similarity amongst the participants is that their struggles for recognition are at the level of self-esteem; that is, for recognition of their worth as mathematics teachers. Another pertinent similarity is that participants seem to have developed an ability to cope with their struggles for recognition by 
counterbalancing the effects of negative circles of recognition on their professional identities with the effects of positive circles of recognition drawn from other experiences beyond the immediate contexts of their struggles. To enhance the significance of this finding, it should be corroborated in different contexts. Perhaps, if more is known about this is a coping strategy, it could be used to assist other teachers so that less of them will be inclined to give up the struggle for recognition and leave the profession. This study introduced a novel set of theoretical lenses consisting of Honneth's (1995) three hierarchical levels of recognition; Kelchtermans' (1993) four components of a professional self; and, Huttunen and Heikkinen's (2004a) circles of recognition; and, demonstrated how these theoretical lenses could be used to make sense of narratives of recognition and professional identities. Finally, recognition lies at the heart of education and yet many worthy teachers do not receive the recognition that they deserve and many leave the profession. More research is necessary to get a better understanding of recognition in education. Perhaps the pertinent issues highlighted in this study should be studied in more detail, perhaps in different contexts, to render a more holistic picture and data that could be generalized across contexts.

\section{References}

Anspal, T., Eisenschmidt, E., \& Löfström, E. (2012). Finding myself as a teacher: Exploring the shaping of teacher identities through student teachers' narratives. Teachers and Teaching: Theory and Practice, 18(2), 197-216.

Caruso, L. F. (2013). The micropolitics of educational change experienced by novice public middle school principals. NASSP Bulletin, 97(3), 218-252.

Castañeda, J. A. (2014). Learning to teach and professional identity: Images of personal and professional recognition. Profile, 16(2), 49-65.

Clandinin, D. J., \& Connelly, F. M. (2000). Narrative inquiry: Experience and story in qualitative research. San Francisco, CA: Jossey-Bass.

Connelly, F. M., \& Clandinin, D. J. (1990). Stories of experience and narrative inquiry. Educational Researcher, 19(5), 2-14.

Creswell, J. W., \& Miller, D. L. (2000). Determining validity in qualitative inquiry. Theory into Practice, 39(3), 124-130.

Daiute, C., \& Lightfoot, C. (2004). Theory and craft in narrative inquiry: Editors' introduction. In C. Daiute \& C. Lightfoot (Eds.), Narrative analysis: Studying the development of individuals in society (pp. vii-xviii). Thousand Oaks, CA: Sage.

Fleming, T., \& Finnegan, F. (2010). Honneth and recognition as sensitizing concept for narrative analysis: An Irish suggestion. Retrieved from http://www.dsw.edu.pl/fileadmin/www-ranlhe/ files/Honneth_and_Recognition.pdf.

Glaser, B. G., \& Strauss, A. L. (1967). The discovery of grounded theory: Strategies for qualitative research. Chicago, IL: Aldine.

Guba, E. G. (1981). Annual review paper: Criteria for assessing the trustworthiness of naturalistic inquiries. Educational Communication and Technology, 29(2), 75-91.

Heikkinen, H. L. (2003). Becoming a teacher-Struggling for recognition. Paper presented at the European Conference on Educational Research, University of Hamburg, September 17-20, 2003. Retrieved from http://www.leeds.ac.uk/educol/documents/00003446.htm.

Honneth, A. (1995). The struggle for recognition: The moral grammar of social conflicts. (J. Anderson, Trans.). Cambridge, UK: Polity Press. 
Honneth, A. (2012). The I in we: Studies in the theory of recognition (English ed.). (J. Ganahl, Trans.) Cambridge, UK: Polity Press.

Huttunen, R. (2001). Critical adult education and the political-philosophical debate between Nancy Fraser and Axel Honneth. Educational Theory, 57(4), 423-433.

Huttunen, R., \& Heikkinen, H. L. (2004a). Teaching and the dialectic of recognition. Pedagogy, Culture \& Society, 12(2), 163-174.

Huttunen, R., \& Heikkinen, H. L. (2004b). Recognise me, respect me! Retrieved from http://www. oulu.fi/ktkold/life/Julkaisut/tekstit/ecer.htm.

Ikäheimo, H. (2002). On the genus and species of recognition. Inquiry, 45(4), 447-462.

Kelchtermans, G. (1993). Getting the story, understanding the lives: From career stories to teachers' professional development. Teaching and Teacher Education, 9(5/6), 443-456.

Kelchtermans, G. (2004). CPD for professional renewal: Moving beyond knowledge for practice. In C. Day \& J. Sachs (Eds.), International handbook on the continuing professional development of teachers (pp. 217-237). Buckingham: Open University Press.

Kramp, M. K. (2004). Exploring life and experience through narrative inquiry. In K. deMarrais \& S. D. Lapan (Eds.), Foundations for research: Methods of inquiry in education and the social sciences (pp. 103-121). Mahwah, NJ: Lawrence Erlbaum.

Miles, M. B., \& Huberman, A. M. (1994). Qualitative data analysis (2nd ed.). Thousand Oaks, CA: Sage.

Murphy, M. (2010). On recognition and respect: Honneth, intersubjectivity and education. Educational Futures, 2(2), 3-11.

Schaap, A. (2004). Political reconciliation through a struggle for recognition. Social \& Legal Studies, 13(4), 523-540.

Scholes, B., \& de González, G. (2011). The nature of recognition in TEFL teachers' lives. Profile, 13(1), 75-87.

Taylor, C. (1992). The politics of recognition. In C. Taylor \& A. Gutmann (Eds.), Multi-culturalism and "the politics of recognition" (pp. 25-73). Princeton, NJ: Princeton University Press.

Vanassche, E., \& Kelchtermans, G. (2016). A narrative analysis of a teacher educator's professional learning journey. European Journal of Teacher Education, 1-13.

Vandenberghe, R. (1996). The staff room: A key place to understand professional culture. Teaching and Teacher Education, 12(1), 115-117.

Open Access This chapter is licensed under the terms of the Creative Commons Attribution 4.0 International License (http://creativecommons.org/licenses/by/4.0/), which permits use, sharing, adaptation, distribution and reproduction in any medium or format, as long as you give appropriate credit to the original author(s) and the source, provide a link to the Creative Commons license and indicate if changes were made.

The images or other third party material in this chapter are included in the chapter's Creative Commons license, unless indicated otherwise in a credit line to the material. If material is not included in the chapter's Creative Commons license and your intended use is not permitted by statutory regulation or exceeds the permitted use, you will need to obtain permission directly from the copyright holder.

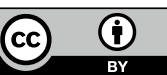




\title{
Chapter 18 \\ Teachers' Professional Identity
}

\author{
Andreas Karaolis and George N. Philippou
}

\begin{abstract}
The present study examines teachers' professional identity, focusing on the development of a measurement instrument. The final scale resulted in two consecutive steps. First, we analyzed the responses of 104 primary teachers on a pilot scale with 73 items. This analysis resulted in a scale with 58 items, which was administered to 315 primary teachers, leading to the final scale comprised of 48 items in seven dimensions. Through further analysis, we found that specific teacher characteristics appear to be related to teachers' professional identity. Hierarchical cluster analysis indicated that there exist three groups of teachers with different identity characteristics - characterized as teachers with positive professional identity, teachers with negative professional identity, and uncommitted teachers. Semi-structured interviews revealed significant differences between the teachers of the three groups regarding the majority of the seven dimensions. In conclusion, we propose confirmation of the scale in different cultures and further examination of the characteristics of the three groups of teachers, as a mean to enhance pre-and-in service education programs. We also propose the development of professional identity scales for mathematics teachers and teachers specialized in other school subjects.
\end{abstract}

Keywords Identity $\cdot$ Professional identity $\cdot$ Teachers $\cdot$ Scale

\subsection{Introduction}

During the past decades, the concept of teachers' professional identity (TPI) has attracted widespread attention and emerged as an important area of research (Akkerman \& Meijer, 2011; Beauchamp \& Thomas, 2009). Quite a few existing studies across countries have considered the TPI as a key factor in understanding teach-

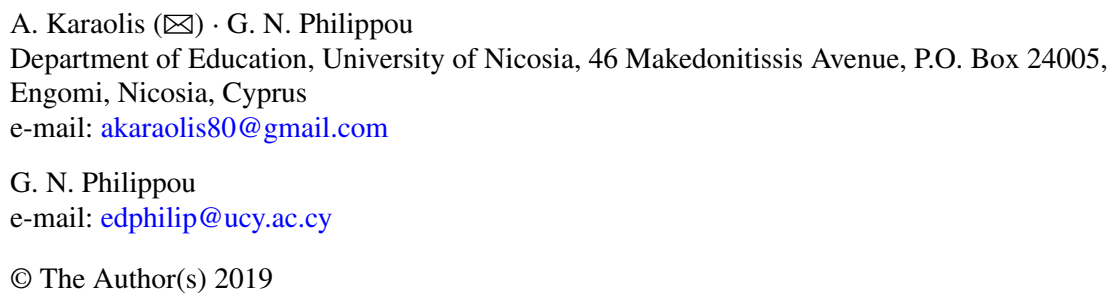


ers' professional lives, career decision making, motivation, effectiveness, retention, professional development and their attitude toward educational change (Beijaard, Meijer, \& Verloop, 2004; Day, Elliot, \& Kington, 2005; Lasky, 2005). However, despite the growing body of literature on TPI, Beijaard et al. (2004) in their review of research, maintain that the concept of TPI continues to appear with different meanings and definitions. In particular, in the domain of teaching and teacher education, researchers who study TPI differ in terms of how they define, view and study this concept. They usually agree though, on the fact that professional identity (PI) is at the same time a product and a process (Olsen, 2010). The term product draws upon psychological theory and can be understood as the meanings that people attach to themselves as a result of the interaction among elements of the teacher as a person and as a professional at a given moment. The term process refers to changes in that perception because of influences and meanings that is attributed by "others" through social practice.

Recently, the concept of TPI has come to the foreground in the field of mathematics education, examining how both specialized and non-specialist mathematics teachers (such as primary school teachers) understand themselves in the context of mathematics. The difference is that primary teachers who teach mathematics are generalists, meaning that they do not personally identify to the subject and hence they do not consider themselves as mathematics teachers. On the other hand, the challenge for the mathematics teachers is even more complex, since they have to develop both mathematics and teaching identities (Adler, Ball, Krainer, Lin, \& Jowotna, 2005).

Considering the difference between primary school teachers (generalist-teaching several subjects) and secondary school teachers (specialists in specific school subjects), in our study we have only covered the first group of teachers. It remains to develop specific scales appropriate for teachers specialised in different school subjects, e.g., mathematics, science, etc. The developed scale may provide the basis for this task.

\subsection{Theoretical Background and Aims of the Study}

The concept of identity has been conceptualized and used by scholars and researchers from three different perspectives: the psychological, the sociological, and the postmodern. However, recent conceptualizations of teacher identity seem to reflect rather the sociological and the postmodern views. The sociological approach emphasizes the sociological processes as primary influences on TPI, while the postmodern approach stresses the notion of multiple identities, which are continuously reconstructed and connected to people performances. In a more balanced approach, the theory of dialogical self (Hermans, 1996) conceives TPI "as both unitary and multiple, both continuous and discontinuous, and both individual and social" (Akkerman \& Meijer, 2011, p. 308). This dialogical position between individual and social dimensions is crucial for the formation of TPI since no professional identity exists without both dimensions (Krzywacki \& Hannula, 2010). 
Although TPI is influenced by social relationships and the context, as sociological approach emphasizes, we argue that the main contribution to the process of its construction and reconstruction comes from the part of the individual, through the processes of interpretation, self-reflection, and agency. If one claims that teachers' identity is socially determined, it is hard to understand how they can still act as 'unique' individuals and professionals, showing agency as they move from various contexts. Furthermore, even though teachers may have a number of sub-identities connected to specific situations, as the postmodern approach suggest, an entirely decentred characterization of TPI raises the question of how a teacher can maintain any sense of professional self through time or how he can be recognized as the same person as he was yesterday. Therefore, a completely decentralized idea of identity is not possible in order to understand how TPI evolves and how individuals are able to maintain a sense of self through time (Akkerman \& Meijer, 2011). Even though we acknowledge the dynamic nature of TPI in which both the individual and the social dimensions are key elements, we consider that TPI draws upon psychological theory, as the process centered on the individual and his/her self-reflections in the mirror of human nature.

Several scholars have found that TPI is related to images of self (Knowles, 1992; Nias, 1989). In teaching, one's conception of himself/herself as a person is interwoven with how he/she acts as a professional. The person cannot be separated from the profession; "it seems unlikely that the core of the personal will not impact the core of the professional" (Loughran, 2006, p. 112). In the same line, Nias (1989) has concluded that TPI is closely bound with personal and professional values and is only adjusted according to circumstances. She considers TPI as part of a deeply protected core of self-defining beliefs and values, which gradually become part of the individual's self; she further argues that most teachers have an over-riding concern that is the preservation of a stable sense of their PI. Furthermore, Ball (1972) separates the substantial (stable) from the occasional identity, which is the presentation of self that varies according to specific situations for assessment. The substantial identity is the basic presentation of a person's general perception of himself/herself. According to Gee (1990), postmodern notions are not to deny that each person has a "core identity" that holds more uniformly for ourselves and others across contexts. We argue that the core (or substantial) identity arises from the natural desire of the individual to maintain a consistent and coherent sense of self that separates and stigmatizes each person. Consequently, a general definition that may fit our view is that: "TPI is the perception that teachers have of themselves at a present time" or the answer to the question: "Who am I as a teacher at this moment?" (Beijaard et al., 2004). This present image consists of a conscious understanding of his/her own professional self. 


\subsubsection{Factors of the TPI}

The concept TPI includes strong affective factors such as beliefs, emotions, orientations, motivations, and attitudes (Frade \& Gómez-Chacón, 2009). Some major psychological concepts have emerged as factors or dimensions of TPI from past research. For example, Kelchtermans (2009) lists the following five interrelated factors of TPI: self-image, self-esteem, job motivation, task perception, and future perspective. For Day (2002), TPI includes job satisfaction, professional commitment, self-efficacy, and work motivation.

In conclusion, we have been able to identify the following concepts, some way or another, related to TPI: self-efficacy, self-esteem, professional commitment, job satisfaction, task orientation, work motivation, and future perspective. These concepts operate as a personal lens through which teachers reflect on their practice and generally consider themselves at work. Even though these concepts may constantly interact, separating them would provide a deeper comprehension of teachers' selfunderstanding and feelings about their work (van Veen \& Sleegers, 2009).

Several researchers have recently used these concepts as dimensions of professional identity (Canrinus, Helms-Lorenz, Beijaard, Buitink, \& Hofman, 2012; Lamote \& Engels, 2010). In this line, the present study attempts to identify these concepts in order to develop a valid and reliable instrument for measuring TPI. A brief description of these concepts follows.

Self-esteem concerns a general descriptive assessment of the teacher's performance in relation to his work; it also refers to the evaluation of a teacher on the basis of expectations compared with the expectations of others (Kelchtermans, 1993). It is an indication of the relationship between the actual self-image and the ideal self-image (Kelchtermans \& Vandenberghe, 1994). A highly important source for self-esteem is the feedback from significant "others" which is continuously filtered and interpreted by the individual. For most teachers, the students are the most important source of feedback, as it is the ultimate reason for their existence. Students have the ability to empower or destroy the self-esteem of teachers since the latter spend most of their working lives with students and the interactions with them define their professional reality (Nias, 1989). The positive self-esteem, however, is fragile to variations in time and must be constantly supported. Self-esteem is positively related with job satisfaction (Bullough, 2009).

Self-efficacy refers to one's ability to succeed in a certain task (Bandura, 1993) and comprises an important moving factor. In education, efficacy beliefs are defined as beliefs that one has in his ability to succeed in a particular teaching task (Charalambous, Philippou, \& Kyriakides, 2008). Self-efficacy is positively related to motivation (Bandura, 1993) and especially to the intrinsic motivation (Ryan \& Deci, 2000). A significant positive correlation has been also found between self-efficacy and professional commitment, and between self-efficacy and job satisfaction (Caprara, Barbaranelli, Steca, \& Malone, 2006; Chan, Lau, Nie, Lim, \& Hogan, 2008). Selfefficacy is a future-oriented assessment regarding perceptions of competence and is affected by previous successful experiences, indirect experiences, persuasion by 
others and emotional feedback (Hoy \& Spero, 2005). Teachers' self-efficacy plays an important role in students' learning outcomes since the quality of teaching and effective classroom management is directly linked with the confidence that teachers have in their abilities, which in turn affect their enthusiasm and professional commitment (Bandura, 1993).

Professional commitment refers to the psychological ties of a person with his job (Lee, Carswell, \& Allen, 2000). Tyree (1996) refers to four dimensions of professional commitment: commitment to care, commitment as a professional ability, commitment as identity, and commitment as a career. As Nias (1989) mentions, after 20 years of relevant research, the word "commitment" appeared in almost every interview. It was a term used to distinguish those teachers who feel care and take their profession seriously, from those who measure their own interests first. Furthermore, when teachers develop professional satisfaction from their commitment, they derive a sense of pride for their professionalism.

Professional commitment can be influenced by several factors such as student behavior, administrative support, parental demands and educational reforms (Day, 2002; Tsui \& Cheng, 1999). Professional commitment can be understood as an integral phenomenon, the center of which is a set of basic, relatively permanent values based on personal beliefs, images of self and a sense of the role which may be challenged by significant changes (Day et al., 2005). Furthermore, it was found that commitment has a considerable influence on students' achievement and attitudes (Day et al., 2005; Tsui \& Cheng, 1999). Finally, professional commitment is positively related with self-efficacy and job satisfaction (Bogler \& Somech, 2004).

Job satisfaction refers to the positive or negative judgments people make about the value of their work (Weiss, 2002). Job satisfaction of a teacher can be defined as the emotional response to his work and his teaching role (Skaalvik \& Skaalvik, 2010). Many studies have attempted to identify the sources of satisfaction of teachers in both primary and secondary education (e.g., Dinham \& Scott, 1998; Evans, 2001) and several factors were found to contribute to teachers' job satisfaction: relationships with children, the mental challenge of teaching, autonomy and independence, opportunities for testing new ideas, participation in decision making and reform efforts, social relations with colleagues and opportunities for professional development (Latham, 1998; Zigarelli, 1996). In contrast, sources of dissatisfaction for teachers include monotony of everyday life, lack of motivation, indiscipline on the part of students, lack of support and appreciation from colleagues and manager, excessive workout, low salary and the negative treatment from society (Nias, 1989; Zembylas \& Papanastasiou, 2006). These factors cause various negative feelings like frustration and vulnerability to teachers. Job satisfaction was found to be related to professional commitment and change of teachers motives (Canrinus et al., 2012).

Work motivation comprises of the forces that push a person to spent time, energy and resources to initiate behaviors related to his work (Latham \& Pinder, 2005). Motives determine the form, direction, intensity and duration of these behaviors. The reasons that teachers choose the teaching profession can be divided into altruistic, intrinsic, and extrinsic (Kyriacou \& Coulthard, 2000). Altruistic motivation includes teaching as a socially important job, intrinsic motivation includes personal 
satisfaction and enjoyment from work, while extrinsic motivation is related to factors such as social awareness, job security and high salaries.

Work motivation influence teachers' decisions to stay or to abandon their career and is considered one of the most important aspects of their PI (Kelchtermans \& Vandenberghe, 1994). Huberman, Grounauer, and Marti (1993) argue that the motives that push teachers to choose teaching profession as a career are often contradictory since usually there are numerous contextual factors that play an important role in their decision. They argue that in addition to considering the initial motives that lead young persons to become teachers, it is important to document the evolution of motivation during their educational career as well, in order to understand how their motives evolve over time. In this study, the reasons for teachers choosing the profession are examined in relation to the current motives.

Task orientation refers to the task that one is expected to pursue as a good teacher, regarding the aims of education, the teaching process, and the teacher-student relations (Billig et al., 1988). It is mainly related to the cognitive aspect of TPI, as it refers to the perceptions of teachers in relation to their work and the key tasks that need to perform (Kelchtermans, 2005).

Task orientation includes deeply ingrained beliefs about the purpose of education and teaching methods (Lamote \& Engels, 2010) that guide teachers' professional activities and behaviors (Akkerman \& Meijer, 2011). These beliefs can be viewed as a lens, through which teachers perceive and filter external information and play an important role in the development of their PI (Kagan, 1992). There are three dimensions of task orientation, (a) relationship between teacher and students, (b) purposes of education and (c) didactic approach (Denessen, 1999). For each of these dimensions, teachers may have either a student-centred approach focusing on the process or a teacher-centred approach focusing on the content. In the case of student-centred approach, teachers emphasize the active involvement of the students in the moral purposes of education and the construction of knowledge, while more teacher-centred approach gives more emphasis on classroom discipline, the students' qualified equipment and the development of knowledge and skills. However, teachers may have both student-centred and teacher-centred perceptions at the same time (Van Driel, Bulte, \& Verloop, 2005).

Future perspective concerns how a teacher foresees himself in the coming years and how he/she feels about it (Keltchermans, 2009). This dimension has been ignored in the literature since there are few studies that have linked this concept to other aspects of TPI. The dreams that people have about the kind of teachers they want to become and whether they can be fulfilled, influence their decisions, their feelings and their behavior. Therefore, apart from the significant experiences of the past, selfunderstanding of the individual is also affected by the future expectations as well (Keltchermans, 2009). 


\subsubsection{Aims of the Study}

The above concepts have been examined separately or in groups, but rarely altogether as dimensions of a unitary construct (e.g., Canrinus et al., 2012). Although research on TPI in recent years has been increased, the interest has mainly been focused on student-teachers and the effect on their identity development during the transition to school (e.g., Timostsuk \& Ugaste, 2010), or the impact of innovations when teachers facing educational reforms (e.g., Lasky, 2005). At the same time, most researchers rely on biographical and interpretative research, which have as a basic methodological tool the interviews (e.g., Van Veen \& Sleegers, 2009).

The most frequently mentioned TPI scale (Canrinus et al., 2012) includes only some of the above concepts. Hence, the need for a reliable instrument based on the maximum possible dimensions, a TPI scale that reflects the overall picture that teachers have about themselves as professionals. Another area in which research is so far missing from the literature is a possible connection between TPI and teachers' personal characteristics, namely: gender, teaching experience, professional post, and academic qualifications. It will also be interesting to look for teachers groups with a different PI profile, as teachers with similar PI may behave analogously in the class. Apart from the development of the scale and the analysis of quantitative data, semi-structured interviews were used to a deeper understanding of TPI.

Therefore, the aims of this study were:

1. To develop a valid and reliable instrument for measuring primary teachers PI,

2. To search for possible differences between TPI according to their, personal characteristics and,

3. To locate possible groups of teachers with different PI profile.

In order to fulfill its aims, this study employed a mixed-method design which used both the qualitative and quantitative approaches. We utilized both approaches in a way that has "complementary" strengths (Johnson \& Turner, 2003). According to Greene, Caracelli, and Graham (1989), different types of data can be used in order to seek elaboration, enhancement, and clarification. Furthermore, two different types of data can provide validity evidence by seeking corroboration and integrity of findings, establishing triangulation of the study. This study employed quantitative surveys to develop the scale, used the scale to examine how teachers differentiate on TPI according to their individual characteristics and to investigate whether different clusters of teachers exist on the basis of the scale factors. Then, qualitative semi-structured interviews followed to illustrate and elaborate on these differences in more depth, since the use of qualitative data "sheds light" to the quantitative findings, "putting flesh on the bones of dry quantitative findings" (Bryman, 2006, p. 106). Specifically, semi-structured interviews were conducted to interpret and to understand in more depth the differences between teachers. 


\subsection{The Development of the TPI Scale}

For the development and validation of the scale measuring TPI, two consecutive phases were completed, the pilot study and the final study.

\subsubsection{The Pilot Study}

For each of the above mentioned concepts of the TPI for which related measurement scales were identified, we have selected and formed items for the trial scale; for the remaining concepts we proposed items, on the basis of the existing literature. Specifically, the initial trial scale consisted of 73 items, covering all possible factors as follows.

Self-esteem: We have proposed 5 items. Sample item: "I feel that my students are proud to have me as their teacher". Self-efficacy: We have adjusted 11 items from the scale "Teachers' sense of efficacy scale" (Tschannen-Moran \& Woolfolk Hoy, 2001) which comprise three dimensions: student motivation, teaching strategies, and discipline in the class. Sample item: "I can explain even the most difficult concepts to my students in order to understand them". Professional commitment: We have adjusted 9 items from the scale "Commitment in Teaching" (Van Huizen, 2000). Sample item: "As a teacher, I believe I have a key role in society". Job satisfaction: We have proposed 10 items. Sample item: "I am thrilled by my profession". Work motivation: We have proposed 9 items. Sample item: "I chose to become a teacher because it is the profession I have always dreamed of". Task orientation: We have proposed 22 items. Sample item: "Students learn best when knowledge is transferred from teacher". Future perspective: We have proposed 7 items. Sample item: "I expect in the future that I will have the professional development that I deserve".

These 73 items comprise the initial trial Likert-type scale of six alternatives (1absolutely disagree, 6-fully agree), which was administered to 104 primary teachers in public schools across Cyprus. At the same time, the teachers were asked to state their demographic data: gender, years of service, qualifications, and educational post. Two open questions were added to the motivation factor, asking the teachers for their reason to become and their reason to remain a teacher. Out of the 104 participants, 85 were females and 19 were males. The average number of years of teaching was 21.2.

Exploratory factor analysis with varimax rotation and principle component were carried out of the responses to these 73 items. Initially, the 73 items were extracted into 9 factors that had eigenvalues greater than 1.25 and explaining the $56.75 \%$ of the total variation. Since only three items were found to load on the factors 7 and 8 , these items were omitted and the factor analysis was repeated with the other 70 items, using the same criteria. The second exploratory factor analysis was extracted into 7 factors. Job satisfaction did not appear as a factor by itself as the relevant items loaded mainly on professional commitment. This result can be justified because the 
emotional aspect of job satisfaction is also contained as an aspect of professional commitment. Furthermore, the items classified as self-esteem loaded mainly on selfefficacy. Again, this result can be attributed to the fact that these 2 concepts have high conceptual relevance. Consequently, these two factors were excluded from further analyses. At the same time, task orientation was found to be separated into constructivist and traditional perceptions, while motivation was split into intrinsic and extrinsic motivation. After removing the 12 items of self-esteem and job satisfaction, the scale remained with 58 items.

\subsubsection{The Development of the Final Scale}

The scale of 58 items found above was administered to a stratified sample of 315 primary teachers, 40 males $(12.69 \%)$ and 275 females $(87.31 \%), 240$ were ordinary teachers, 15 were school principals, 47 were assistant school principals, and 13 substitutes; 64 had 0-10 years of service, 149 had 10-20 years of service and 102 over 20 years of service; 17 had a Ph.D., 174 a Master degree, and 124 only a bachelor degree.

The responses of this sample were analyzed using descriptive and inductive statistics of the SPSS statistical package. As regards the factors of TPI, a number of exploratory factor analyses were conducted in order to check the pilot scale and to confirm the theoretical differentiation factors constituting TPI, as recorded in the literature. Since the constructed items had not yet been used together in any previous research, we conducted a principal component analysis (PCA) in order to reduce the confounding of constructs and purify the latent variables. In the main study, an exploratory factor analysis was followed by a confirmatory factor analysis in order to check the proposed measurement scale. The reliability of the factors was tested using the Cronbach's alpha index.

The first exploratory factor analysis led to 8 factors with eigenvalues $>1.25$, but the scree plot indicated that the grouping of the path appeared after the seventh factor. At the same time factor loading and variance led to disregarding 6 items with variance $<.40$ and 4 items which failed to load to the appropriate factor. A second exploratory factor analysis of the remaining 48 items with the same criteria led to 7 factors that explained $50.90 \%$ of the total variance. To further confirm the factor analysis of the 48 items, a confirmatory factor analysis using varimax rotation and maximum likelihood was applied, revealing the same factor analysis structure $\left(\chi^{2}=\right.$ 1360.61 , degrees of freedom $=813, p=0.001$ ). The remained factors, the number of items in each factor, the variance explained by each factor, and an indicative item per factor with its loading, respectively follow:

Self-efficacy (11 items, explained $13.82 \%$ of the total variance): "I can motivate students with a low interest in the class, as well" (load 0.76).

Constructivist perceptions (11 items, explained 7.73\%): "Students learn better when they control, program and direct the learning process by themselves" (load $0.65)$. 
Table 18.1 Mean, standard deviation, reliability and number of items for the 7 factors

\begin{tabular}{l|l|r|l|l}
\hline FACTORS & $\mathrm{M}$ & $\mathrm{SD}$ & $\alpha$ & $\mathrm{N}$ \\
\hline Self-efficacy & 4.33 & .72 & .92 & 11 \\
\hline Constructivist perceptions & 4.53 & .59 & .80 & 11 \\
\hline Intrinsic motivation & 3.89 & 1.11 & .79 & 4 \\
\hline Extrinsic motivation & 2.86 & 1.03 & .79 & 5 \\
\hline Traditional perceptions & 3.14 & .61 & .74 & 8 \\
\hline Future perspective & 2.05 & .81 & .71 & 4 \\
\hline Professional commitment & 3.83 & 1.04 & .73 & 5 \\
\hline
\end{tabular}

Intrinsic motivation (4 items, explained 6.52\%): "I chose to become a teacher because I love working with children" (load 0.77).

Extrinsic motivation (5 items, explained 6.23\%): "I chose to become a teacher because I would have good working conditions, such as the working hours and vacations" (load 0.80).

Traditional perceptions ( 8 items, explained 6.14\%). "Students learn better when the teaching emphasizes the content (what we learn)" (load 0.65).

Future perspective (4 items, explained 5.53\% of the variance): "I worry about my future as a teacher" (load 0.71). * reverse coding.

Professional commitment (5 items, 5.16\%): "If I could find an equally good job, I would give up the teaching profession" (load 0.70). ** reverse coding.

Table 18.1 shows the mean, the standard deviation and the reliability for each factor. The Cronbach's alpha obviously present from moderate to high internal reliability for all factors $(\alpha=.71-.92)$. The items of self-efficacy show the highest reliability $(\alpha=.92)$, while the items of future perspective show the lowest internal reliability $(\alpha=.71)$. The latest can partly be attributed to the fact that this factor comprises of only 4 items.

The participant teachers seem to have rather high self-efficacy $(\mathrm{M}=4.33)$, rather low motivation, higher intrinsic than extrinsic motivation $(\mathrm{M}=3.89$, against $\mathrm{M}=$ $2.86)$, very low job expectations $(\mathrm{M}=2.05)$, and quite high, constructivist compared to traditional perceptions $(\mathrm{M}=4.52$, against $\mathrm{M}=3.14)$.

The Pearson correlation coefficients for the seven factors were quite reasonable. Self-efficacy was positively correlated with all the other factors (higher with constructivist perceptions, $r=.54, p<.01$ ), except with the external motivation. Constructivist perceptions were positively correlated with all the other factors except with external motivation; internal motivation was positively correlated with all the other factors except with external motivation, which in turn was correlated with traditional perceptions $(r=.25, p<.01)$, future perspective and negatively with professional commitment $(r=-.11, p<.05)$. 


\subsection{Teacher Personal Characteristics and PI}

Regression analysis was used to examine whether the PI is associated with teachers' personal characteristics (the second aim of the study). The search concerned possible differences between teachers' gender, teaching experience (three groups, GA: 1-10 years of service, GB: 11-20, and GC: 21-33 years of service), administrative post, and academic qualifications, regarding their TPI. The ANOVA was used to examine whether statistically significant differences exist, followed by post hoc tests using the Bonferroni correction for significance. The findings are summarized as follows.

a. Male teachers were found to significantly exceed female in external motivation $\left(\mathrm{F}_{(1,310)}=4.60, p<.05\right)$; the average of male teachers in this PI factor was $\mathrm{M}=$ $3.17(\mathrm{SD}=1.01)$, against $\mathrm{M}=2.80(\mathrm{SD}=1.02)$ for female teachers.

b. Statistically significant difference was found in intrinsic motivation, among the three groups of teachers by the length of service $\left(\mathrm{F}_{(3,310)}=3.61, p<.05\right)$. The difference existed only between the $\mathrm{GA}$ teachers $(\mathrm{M}=4.24, \mathrm{SD}=1.08)$ and the $\mathrm{GC}$ teachers $(\mathrm{M}=3.64, \mathrm{SD}=1.07)$. In other words, as the teacher's service time increases, their internal motives tend to decline. This can be attributed to the possible gradual reduction of enthusiasm of teachers and to the burnout that may occur over time.

c. Statistically significant difference regarding future perspective was found according to administrative post $\left(\mathrm{F}_{(3,310)}=4.30, p<.05\right)$. The school principals' mean $(\mathrm{M}=2.60, \mathrm{SD}=.90)$ was significantly higher than that of the teachers' mean $(\mathrm{M}=2.01, \mathrm{SD}=.75)$. This can be attributed to the negative career prospects of the teachers due to the social and economic crisis (see also the interviews). There were no statistically significant differences between principals and assistant principals and neither among ordinary teachers and assistant principals $(p>$ $.05)$.

d. Statistically significant difference was found among teachers with, and teachers without graduate qualifications, regarding constructivist perceptions $\left(\mathrm{F}_{(2,310)}=\right.$ $5.58, p<.05)$ and traditional perceptions $\left(\mathrm{F}_{(2,310)}=6.89, p<.05\right)$. Specifically, the average of teachers with only a bachelor degree in constructivist perceptions was lower $(M=4.41, \mathrm{SD}=.57)$ than the average of teachers with a Master's $(\mathrm{M}$ $=4.59, \mathrm{SD}=.58)$ and the teachers with a Ph.D. $(\mathrm{M}=4.82, \mathrm{SD}=.54)$, while the average responses of teachers with only a bachelor's degree in traditional perceptions was higher $(\mathrm{M}=3.26, \mathrm{SD}=.55)$ than the average of teachers with a Master's $(\mathrm{M}=3.07, \mathrm{SD}=.62)$ and the teachers with a Ph.D. $(\mathrm{M}=2.73, \mathrm{SD}$ $=.61)$. There was no difference between teachers with a Master's and teachers with a Ph.D. regarding the constructivist or the traditional perceptions $(p>.05)$. Consequently, it seems that teachers with advanced graduate studies hold more constructivist perceptions and simultaneously less traditional perceptions. Such a conclusion is assessed as very important since it connects the level of study with the kind of pedagogical beliefs of teachers. 


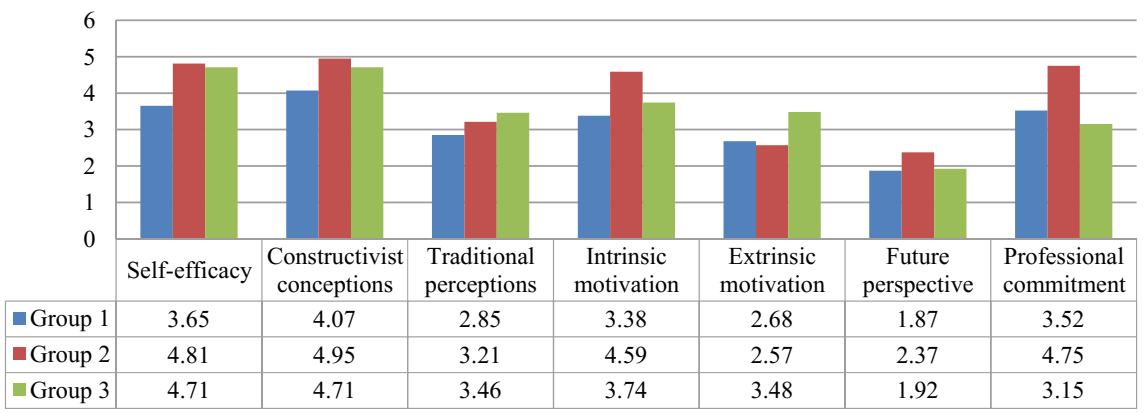

Fig. 18.1 Mean of each factor for each professional profile

\subsection{Groups of Teachers with Different PI Profile}

Hierarchical cluster analysis of the teachers' responses to the final scale was performed (Ward method) to search for possible groups of teachers with different PI. The dendrogram analysis resulted in three clusters of teachers and the non-hierarchical cluster analysis (K-means) examined these three groups in terms of the constructs that constitute TPI. Finally, we conducted ANOVA to detect any statistically significant differences between the three clusters.

In the first cluster there were classified 121 teachers (39\%), in the second 106 (34\%), and in the third 86 teachers $(27 \%)$. The first group with the lowest mean in all seven factors was characterized, as teachers with negative PI (group I). The second group with the higher mean in self-efficacy, constructivist perceptions, internal motives, future perspective and professional commitment, with major differences from the other two groups in the latter two factors, was characterized, as teachers with positive PI (group II). The mean of the third group exceeded the means of the other two groups in external motives and in traditional perceptions while having the lowest mean in professional commitment the same time. These teachers were called uncommitted teachers (group III). Figure 18.1 presents the mean of each factor for each professional profile.

According to Akkerman and Meijer (2011), characterization of teachers with a label may prove problematic, as it may imply stability of TPI. The present study shares the above concern and therefore, stresses that the given labels serve only descriptive purposes. There is no intention, by any means, to imply uniqueness or stagnation of TPI or that the teachers who currently belong to any group cannot be moved to another. The PI which the teachers appear to have through their responses to a questionnaire is the basic perception of themselves at a present time, through their effort to maintain a consistent and coherent sense of self.

The ANOVA revealed significant differences among the above three groups in terms of the seven factors. Specifically, in terms of self-efficacy $\left(F_{(2,310)}=195.22\right.$, $p<.05)$, constructivist perceptions $\left(F_{(2,310)}=106.87, p<.05\right)$, internal motivation $\left(F_{(2,310)}=43.63, p<.05\right)$, future perspective $\left(F_{(2,310)}=12.68, p<.05\right)$, external 
motivation $\left(F_{(2,310)}=24.84, p<.05\right)$, traditional perceptions $\left(F_{(2,310)}=31.54, p<\right.$ $.05)$ and in terms of professional commitment $\left(F_{(2,310)}=108.68, p<.05\right)$. Post Hoc analyses using the Bonferroni correction for significance, indicated that the only nonstatistical significant differences were: (a) among the teachers with positive PI and the uncommitted teachers in terms of self-efficacy $(p=.54)$, (b) among the teachers with negative PI and the uncommitted teachers in terms of future perspective ( $p=$ 1.0 ) and (c) among the teachers with negative PI and the teachers with positive PI in terms of external motivation $(p=1.0)$.

Then, a chi-square test of independence was performed to examine whether the three clusters of teachers differ regarding the personal teachers' characteristics; gender, teaching experience, administrative post, and academic qualifications. As resulted from the crosstabs analysis, there were no statistically significant differences between the teachers' professional profile and gender $\left(\chi^{2}(2)=3.960, p=\right.$ $.138)$, teachers' experience $\left(\chi^{2}(6)=6.874, p=.333\right)$, and administrative post $\left(\chi^{2}(6)\right.$ $=9.948, p=.127)$. However, there was a statistically significant difference between the observed and expected frequency regarding teachers' academic qualifications and the teachers' clusters, $\left(\chi^{2}(4)=22.42, p<.001\right)$. The teachers with graduate qualifications, (a Master's or a Ph.D. degree) were more likely to be classified to the second cluster as committed teachers. A possible reason for this finding can be attributed to the fact that teachers with graduate qualifications hold more constructivist perceptions and simultaneously less traditional perceptions and at the same time may have higher self-efficacy beliefs than their colleagues. This result is quite important, as it connects the level of the academic qualifications with TPI and must be evaluated accordingly by the educational authorities.

\subsection{A Deeper Examination of TPI}

For a deeper examination of TPI, we selected 20 primary teachers for semi-structured interviews; 7 from the group I, 7 from group II, and 6 from group III. The criterion for selecting these 20 teachers was the differences in their PI, which emerged from the quantitative analysis. Each interview lasted for about $1 \mathrm{~h}$ and was recorded using a digital recorder. The interview featured questions such as: "What do you think is your main task as a teacher?" and "How do you describe your future as a teacher?" The qualitative data were analyzed by inductive analysis and constant comparison methods, using the NVivo software package, to look for common patterns, differences, and substantive themes (Strauss \& Corbin, 1998). By comparing the patterns, we can enhance generality of the findings (Miles \& Huberman, 1994). In the next paragraphs, we present indicative comments with regard to each of the main TPI factor.

Self-efficacy: Regarding self-efficacy, no significant difference was identified between the 3 groups, as all teachers declared to feel highly efficacious. The main source of such feeling was their relations with students and the comments by parents and colleagues. However, a common theme that differentiated the teachers with neg- 
ative PI (group I) from the teachers of group II and III was the relationship between self-efficacy and motivation. For some of the group I teachers, self-efficacy and professional development was associated with external motives and the lack of internal motives.

For example, Charis (group I) said: "I feel that I am quite capable, but you know... (3 s pause) I am as capable as I need to be... I have not any motives to become even better... I am talking about promotion. If such motives existed I think I would be even better". Similarly, Myria (group I) connects her self-efficacy and commitment with the gradual loss of internal motives, which originated from her experience. She said: "The last few years I have lowered my expectations, both my own and for my students... I do not take it personal if some students do not follow... I do my best and that's it! I used to try to pull the student over with any mean... not anymore... There are no specific incidents that change my point of view; it was brick by brick from my everyday experiences and disappointments that just make me want to be formal or just good, but not great".

On the other hand teachers from groups II and III approach this issue from a different perspective, as they connect their self-efficacy with their internal motives. For instance, Nicholas (group II) said: "I constantly try to get better because I like the courses I teach... Mathematics and Natural Sciences... and because I owe it to the students I have in front of me... I know it's difficult times and that probably I will never get a promotion, but I will not punish the students for this".

The relationship between self-efficacy and motivation that emerged from the interviews analysis has been confirmed in several studies. As Bandura states (1993), the self-efficacy beliefs are positively related to the motivation and particularly with intrinsic motivation (Ryan \& Deci, 2000).

Task orientation: The majority of the teachers were found to hold both studentcentred and teacher-centred perceptions, emphasizing the ethical and social aims of education or drawing on the need to develop knowledge and skills, respectively. This finding is consistent with other researches which found that teachers may have both student/learning-centred and teacher/content-centred perceptions at the same time (Van Driel et al. 2005). However, their perceptions were somehow in line with their TPI group as there was a different pattern between the teachers of the three groups. The teachers from groups I and III tended to perceive more teacher-centred perceptions than those of group II. For instance, Chryso (group III) defined as her primary aim, "... the transfer of knowledge, followed by the character development". Chrysanthos (group I) was clear about his preference; He said that the process of knowledge construction is sometimes a waste of time; "If we insist on knowledge discovery, we shall cover half of the curriculum". Similarly, Kate (group III) said that "students enjoy knowledge discovery but the pressure to cover the subject matter is a trap leading to telling them how to find it".

On the other hand, the priority of Penelope (group II) was the social aim, “... to develop good citizens"; she said, "I am looking for students with emotional intelligence... not technocrat... the good and credible citizen, in the Greek sense of the terms". Another teacher, Stelios (group II) said, "I do not give readymade food, I 
always try to offer students the chance to construct knowledge by themselves, even though I know that some students can hardly make it".

Work motivation: Several researchers stretch the importance to monitor the development of motives during the career of teachers (Huberman et al., 1993). This perception guided the interview questions in relation to this factor in order to understand the evolution of the original motivation of teachers over time. The analysis of responses to the open question for the reasons that force teachers to remain in the profession revealed that the current motives are the same as the initial motives which led them to choose the profession.

The participants' comments about the reasons that led them to become teachers differed according to the PI group. The motives of the groups I and III were and remained mainly external. For instance, Olga (group I) mentioned, "Vacations, the working hours and the salary; those were the pros then and continue to be". Helen (group III) said, "I had no special love for the profession... no, my feelings did not change... to be honest, I do not even love my job".

On the contrary, most of the group II teachers were internally motivated. For instance, Stella (group II) mentioned her love for the children, as she said, “... my passion for helping children to learn what I love, arts. I feel the need to pass on this love to children". Joanna (group II) considered that "...the teaching profession offers the chance to change people and the society. That was my motive... it has now become even stronger".

Professional commitment: Professional commitment was also found to be related to TPI. When participants were asked about the meaning of "being committed" and to evaluate their commitment, teachers from groups I and III revealed different perceptions from teachers of group II.

For the teachers from groups I and III, the commitment was connected to the time needed for preparation and other factors, such as motivation. John (group I) said, "I don't think that I am $100 \%$ a committed teacher. I try my best in the class but I do not prepare myself properly... except when I expect my inspector to come... I think most teachers do the same". The civil servant mentality approach of John is obvious. Helen (group III) said, "During the 22 years of service I have never gone to my class without proper preparation... however, the odds to choose the same profession again is $60 \%$ no and $40 \%$ yes". Olga (group I) justified her low commitment due to working conditions, "If I had a music room, well equipped and smaller groups of students, I would have been better". She complained about underestimating her subject and stated: "If I could turn back the time, I would not have become a teacher". Some teachers of group I and III seemed to have regretted their choice since their commitment has been "wounded".

On the other hand, the commitment of the group II teachers was obvious and directed towards the students and to their profession in a broader sense. Anna (group II) expressed a high level of devotion, she stated: "I am as committed as I would like the teachers of my kids to be; as I demand from the doctor to be a professional and formal, I feel that I must also be professional". Stella (group II) expressed her commitment at a different level, as she defended her profession in a broader sense. 
She stated, "I get angry with those who behave casually because they tarnish the picture of our profession".

Future perspective: Despite some differences among the groups, it seems that all interviewees do not see any positive future, neither personal nor for the educational system. However, a different pattern among the groups was clear, with regard to reasons for a negative prospect. Teachers of groups I and III connect their future prospects as teachers, almost exclusively with the lack of external motives for professional and economic development. Stylianos (group I) and Vangelis (group III) complained about low promotion prospects and for the reduction of salaries. Stylianos said, "I try to forget all the problems when I am in the class, but I have no motives". In the same tune, Vangelis said, "Compared to prior conditions, I would have got a promotion in 3-4 years time, while now I have no hope for promotion, even in ten years' time". Aphrodite (group III) described the future negatively, though for somewhat different reasons. She was afraid that she won't be capable of fulfilling her obligations, as she wondered, "I am 46 and I feel already tired, imagine how difficult it would be for me in my remaining 17 years of service". She also brought up her worries about changes in student's behavior, as she said, "the conditions in schools are becoming more and more complicated and we have no reward to try our best".

On the other hand, teachers of group II expressed their worries about the negative future of the educational system in a broader and "unselfish" sense, as they referred to the dystocia for educational reform and prospects of the teaching profession to attract capable persons. Nina (group II) felt that the effort to reform the system was hopeless, as she said, "A hope... turned to be a conservative process. Moreover, there are no young people entering the profession, the Pedagogical Departments do not attract capable persons anymore". Anna (group II) also referred to the system and claimed: "My problem is with the system... we are in an unspecified process which changes according to the government, with drawbacks".

To a large extent the analysis of the interviews resulted in conclusions consistent with the quantitative data. Based on the two methodological approaches, it appears that the differences concerning the TPI factors are more pronounced among teachers with different professional profiles than with teachers belonging to the same professional group. However, the interviews have also revealed rather mild differences among teachers of the same group. A more general conclusion resulting from the semi-structured interviews is that all factors are interrelated and constantly interacting with each other. However, the concept that seems to be a key factor defining consciously or unconsciously teachers' thoughts, emotions, beliefs, and behavior, was work motivation as it was the most frequently mentioned factor. Based on the qualitative data, more attention should be paid to teachers' motivation during teacher education. 


\subsection{Conclusions, Discussion, and Limitations}

The aims of this study were to meet three needs which seemed to be missing from the research in teachers' PI, i.e., to develop a scale measuring TPI that takes into consideration as many factors/concepts as possible, to search for possible differences between TPI according to their personal characteristics, and to search for possible teacher groups with different PI. Apart from the quantitative data analyses, the latter aim was also examined using semi-structured interviews in order to deeper examine how teachers conceptualize themselves at work and locate possible differences among teachers with different PI.

The developed scale consists of five factors, two of them with two dimensions; motivation was split into intrinsic and extrinsic motivation, while task orientation was split into constructivist and traditional perceptions. The other three factors were self-efficacy, professional commitment, and future perspective. The structure of the developed scale remains to be tested for possible confirmation in different samples and in different cultures. Since the developed TPI scale refers to primary teachers who teach many different subjects (generalists), several special scales may be developed measuring the TPI in specific school subjects, e.g., mathematics, science etc. The present scale may provide the basis for such scales.

The differences between male and female teachers can somehow be explained, as well as the differences among teachers with and teachers without graduate qualifications. The relation, however, between teachers' personal characteristics and their PI needs further examination. Similarly, the three groups, characterized as teachers with negative PI (group I), teachers with positive PI (group II), and uncommitted teachers (group III), would also need to be confirmed. The characteristics of each group need further investigation, particularly with regard to possible influence that they may exercise in the educational process. The three groups evolved in this study would need to be confirmed for mathematics teachers and other secondary school subject teachers. Considerable differences were recorded mainly among group II and the other two groups. These differences were more intensive regarding work motivation, professional commitment, and future perspective. On the contrary, the differences that appeared among the group I and group III in the quantitative part were missing in the qualitative analysis. This can be attributed to the methodological weakness of Cluster analysis, which is one of the limitations of this study. Furthermore, when self-reporting instruments are used, there is always the risk that respondents provide "politically correct" answers. Although the respondents were guaranteed anonymity, this factor cannot be ruled out entirely. Even though such instruments make it practical to collect data for large-scale studies and offer the possibility of generalized findings, they necessarily sacrifice much of the complexity that can be inferred from qualitative methods. It must be acknowledged that although the developed scale outlines the professional image of teachers, it must be supplemented by qualitative data in order to fully record their PI.

Another direction for further research concerns the examination of possible ways to enhance these ideas through pre-and-in-service educational programs or through 
special interventions. Teacher education programs may concentrate on developing positive PI, while teacher mentors may consider ways to help teachers change their negative PI or their "uncommitted" approach, two groups which comprise $66 \%$ of the teachers in the current sample. In addition, self-recognition of one's own professional profile may work as a motive reconsideration of his self-beliefs (Alsup, 2006). Our interviews seem to indicate that this possibility is a realistic promise, particularly if we accept the view that PI is in a process of continual restructuring.

\section{References}

Adler, J., Ball, D. L., Krainer, K., Lin, F., \& Jowotna, J. (2005). Reflections on an emerging field: Researching mathematics teacher education. Educational Studies in Mathematics, 60(3), 359-381.

Akkerman, S. F., \& Meijer, P. C. (2011). A dialogical approach to conceptualize teacher identity. Teaching and Teacher Education, 27(2), 308-319.

Alsup, J. (2006). Teacher identity discourses: Negotiating personal and professional spaces. Mahwah, NJ: Lawrence Erlbaum.

Ball, S. J. (1972). Self and identity in the context of deviance: The case of criminal abortion. In R. Scott \& J. Douglas (Eds.), Theoretical perspectives on deviance (pp. 158-186). New York, NY: Basic Books.

Bandura, A. (1993). Perceived self-efficacy in cognitive development and functioning. Educational Psychologist, 28(2), 117-148.

Beauchamp, C., \& Thomas, L. (2009). Understanding teacher identity: An overview of issues in the literature and implications for teacher education. Cambridge Journal of Education, 39(2), 175-189.

Beijaard, D., Meijer, P. C., \& Verloop, N. (2004). Reconsidering research on teachers' professional identity. Teaching and Teacher Education, 20(2), 107-128.

Billig, M., Condor, S., Edwards, D., Gane, M., Middleton, D., \& Radley, A. (1988). Ideological dilemmas: A social psychology of everyday thinking. London: Sage.

Bogler, R., \& Somech, A. (2004). Influence of teacher empowerment on teachers' organizational commitment, professional commitment and organizational citizenship behavior in schools. Teaching and Teacher Education, 20(3), 277-289.

Bryman, A. (2006). Integrating quantitative and qualitative research: How is it done? Qualitative Research, 6(1), 97-113.

Bullough, R. V. (2009). Seeking eudaimonia: The emotions in learning to teach and to mentor. In P. A. Schutz \& M. Zembylas (Eds.), Advances in teacher emotion research: The impact on teachers', lives (pp. 33-53). New York, NY: Springer.

Canrinus, E. T., Helms-Lorenz, M., Beijaard, D., Buitink, J., \& Hofman, A. (2012). Self-efficacy, job satisfaction, motivation, and commitment: exploring the relationships between indicators of teachers' professional identity. European Journal of Psychology of Education, 27(1), 115-132.

Caprara, G. V., Barbaranelli, C., Steca, P., \& Malone, P. S. (2006). Teachers' self-efficacy beliefs as determinants of job satisfaction and students' academic achievement: A study at the school level. Journal of School Psychology, 44(6), 473-490.

Chan, W. Y., Lau, S., Nie, Y., Lim, S., \& Hogan, D. (2008). Organizational and personal predictors of teacher commitment: The mediating role of teacher efficacy and identification with school. American Educational Research Journal, 45(3), 597-630.

Charalambous, C. Y., Philippou, G. N., \& Kyriakides, L. (2008). Tracing the development of preservice teachers' efficacy beliefs in teaching mathematics during fieldwork. Educational Studies in Mathematics, 67(2), 125-142. 
Day, C. (2002). School reform and transitions in teacher professionalism and identity. International Journal of Educational Research, 37(8), 677-692.

Day, C., Elliot, B., \& Kington, A. (2005). Reform, standards and teacher identity: Challenges of sustaining commitment. Teaching and Teacher Education, 21(5), 563-577.

Denessen, E. (1999). Attitudes towards education: Content and student orientedness in the Netherlands (Unpublished doctoral dissertation). Radboud University Nijmegen, Nijmegen, The Netherlands.

Dinham, S., \& Scott, C. (1998). A three domain model of teacher and school executive career satisfaction. Journal of Educational Administration, 36(4), 362-378.

Evans, L. (2001). Delving deeper into morale, job satisfaction and motivation among education professionals: Re-examining the leadership dimension. Educational Management \& Administration, 29(3), 291-306.

Frade, C., \& Gómez-Chacón, I. M. (2009). Researching identity and affect in mathematics education. In M. Tzekaki, M. Kaldrimidou \& C. Sakonidis (Eds.), Proceedings of the 33rd Conference of the IGPME (Vol. 1, p. 376). Thessaloniki, Greece: PME.

Gee, J. P. (1990). Social linguistics and literacies: Ideology in discourses. London, England: Falmer Press.

Greene, J. C., Caracelli, V. J., \& Graham, W. F. (1989). Toward a conceptual framework for mixedmethod evaluation designs. Educational Evaluation and Policy Analysis, 11(3), 255-274.

Hermans, H. J. M. (1996). Voicing the self: From information processing to dialogical interchange. Psychological Bulletin, 119(1), 31-50.

Hoy, W., \& Spero, R. B. (2005). Changes in teacher efficacy during the early years of teaching: A comparison of four measures. Teaching and Teacher Education, 21(4), 343-356.

Huberman, A. M., Grounauer, M., \& Marti, J. (1993). The lives of teachers. New York, NY: Teachers College Press.

Johnson, B., \& Turner, L. A. (2003). Data collection strategies in mixed methods research. In A. Tashakkori \& C. Teddlie (Eds.), Handbook of mixed methods in social and behavioral research (pp. 297-319). Thousand Oaks, CA: Sage.

Kagan, D. M. (1992). Implication of research on teacher belief. Educational Psychologist, 27(10), 65-90.

Kelchtermans, G. (1993). Getting the story, understanding the lives. From career stories to teachers' professional development. Teaching and Teacher Education, 9(6), 443-456.

Kelchtermans, G. (2005). Teachers' emotions in educational reforms: Self-understanding, vulnerable commitment and micropolitical literacy. Teaching and Teacher Education, 21(8), 995-1006.

Kelchtermans, G. (2009). Who I am in how I teach is the message: Self-understanding, vulnerability and reflection. Teachers and Teaching: Theory and Practice, 15(2), 257-272.

Kelchtermans, G., \& Vandenberghe, R. (1994). Teachers' professional development: A biographical perspective. Journal of Curriculum Studies, 26(1), 45-62.

Knowles, J. G. (1992). Models for understanding pre-service and beginning teachers' biographies: Illustration from case studies. In I. F. Goodson (Ed.), Studying teachers' lives (pp. 99-152). London, England: Routledge.

Krzywacki, H. \& Hannula, M. S. (2010). Tension between present and ideal state of teacher identity in the core of professional development. In C. Frade \& L. Meira (Eds.), Proceedings of the 34 th Conference of the International Group for the Psychology of Mathematics Education. Belo Horizonte, Brazil: PME.

Kyriacou, C., \& Coulthard, M. (2000). Undergraduates' views of teaching as a career choice. Journal of Education for Teaching: International Research and Pedagogy, 26(2), 117-126.

Lamote, C., \& Engels, N. (2010). The development of student teachers' professional identity. European Journal of Teacher Education, 33(1), 3-18.

Lasky, S. (2005). A sociocultural approach to understanding teacher identity, agency and professional vulnerability in a context of secondary school reform. Teaching and Teacher Education, 21(8), 899-916.

Latham, A. (1998). Teachers' satisfaction. Educational Leadership, 55(5), 82-83. 
Latham, G. P., \& Pinder, C. C. (2005). Work motivation theory and research at the dawn of the twenty-first century. Annual Review of Psychology, 56, 485-516.

Lee, K., Carswell, J. J., \& Allen, N. A. (2000). A meta-analytic review of occupational commitment: Relations with person- and work-related variables. Journal of Applied Psychology, 85(5), 799-811.

Loughran, J. (2006). A response to 'reflecting on the self'. Reflective Practice, 7(1), 43-53.

Miles, M. B., \& Huberman, M. A. (1994). Qualitative data analysis: An expanded sourcebook. Thousand Oaks, CA: Sage.

Nias, J. (1989). Primary teachers talking: A study of teaching as work. London, England: Routledge.

Olsen, B. (2010). Teaching for success: Developing your teacher identity in today's classroom. Boulder, CO: Paradigm.

Ryan, R. M., \& Deci, E. L. (2000). Self-determination theory and the facilitation of intrinsic motivation, social development, and well-being. American Psychologist, 55(1), 68-78.

Skaalvik, E. M., \& Skaalvik, S. (2010). Teacher self-efficacy and teacher burnout: A study of relations. Teaching and Teacher Education, 26(4), 1059-1069.

Strauss, A., \& Corbin, J. (1998). Basics of qualitative research: Procedures and techniques for developing grounded theory. Thousand Oaks, CA: Sage.

Timostsuk, I., \& Ugaste, A. (2010). Student teachers' professional identity. Teaching and Teacher Education, 26(8), 1563-1570.

Tschannen-Moran, M., \& Hoy, A. W. (2001). Teacher efficacy: Capturing an elusive construct. Teaching and Teacher Education, 17(7), 783-805.

Tsui, K. T., \& Cheng, Y. C. (1999). School organizational health and teacher commitment: A contingency study with multi-level analysis. Educational Research and Evaluation, 5(3), 249-268.

Tyree, A. K. (1996). Conceptualising and measuring commitment to high school teaching. Journal of Educational Research, 89(5), 295-304.

Van Driel, J. H., Bulte, A. M., \& Verloop, N. (2005). The conceptions of chemistry teachers about teaching and learning in the context of a curriculum innovation. International Journal of Science Education, 27(3), 303-322.

Van Huizen, P. H. (2000). Becoming a teacher: Development of a professional identity by prospective teachers in the context of university - based teacher education.Doctoral dissertation. Utrecht, The Netherlands: University of Utrecht. Retrieved from http://hdl.handle.net/11245/1.180544.

Van Veen, K., \& Sleegers, P. (2009). Teachers' emotions in a context of reforms: To a deeper understanding of teachers and reform. In P. A. Schutz \& M. Zembylas (Eds.), Advances in teacher emotion research: The impact on teachers' lives (pp. 253-272). Dordrecht, The Netherlands: Springer.

Weiss, H. M. (2002). Deconstructing job satisfaction: Separating evaluations, beliefs and affective experiences. Human Resource Management Review, 12(2), 173-194.

Zembylas, M., \& Papanastasiou, E. (2006). Sources of teacher job satisfaction and dissatisfaction in Cyprus. Compare, 36(2), 229-247.

Zigarelli, M. (1996). An empirical test of conclusions from effective schools research. Journal of Educational Research, 90(2), 103-109. 
Open Access This chapter is licensed under the terms of the Creative Commons Attribution 4.0 International License (http://creativecommons.org/licenses/by/4.0/), which permits use, sharing, adaptation, distribution and reproduction in any medium or format, as long as you give appropriate credit to the original author(s) and the source, provide a link to the Creative Commons license and indicate if changes were made.

The images or other third party material in this chapter are included in the chapter's Creative Commons license, unless indicated otherwise in a credit line to the material. If material is not included in the chapter's Creative Commons license and your intended use is not permitted by statutory regulation or exceeds the permitted use, you will need to obtain permission directly from the copyright holder.

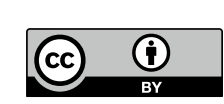




\title{
Chapter 19 \\ Identity at the Crossroads, Collision or Conciliation? A Commentary
}

\author{
Einat Heyd-Metzuyanim
}

\subsection{Synthesizing the Four Chapters on Identity and Teachers' Beliefs}

The four chapters in this book that have been collected under the term "identity" span a wide variety of empirical domains, theoretical frameworks and methodologies. In this commentary, I will first attempt to synthesize what can be learned from each of the chapters on its own, and what message can be taken from them as a whole. To do this, I will use my own discursive lens on identity (Heyd-Metzuyanim, 2015; Sfard \& Prusak, 2005), attempting to "translate" the different terminologies and findings into a single conceptual language. I will then examine what the discursive lens that I am proposing highlights about the different studies, including what it exposes that remains hidden or obscure in the chapter, as well as what this lens fails to expose. I will conclude by some meta-remarks about the state of (in)commensurabilities between different approaches to the study of identity in mathematics education.

The empirical domains covered in the four chapters span from teachers' beliefs about mathematics (Erens and Eichler), through their professional identity as teachers (Karaolis and Philippou), the struggle of South African teachers for recognition (Felix) to students identity construction as it interacts with rationality in mathematical group work (Branchetti and Morselli). Theoretical frameworks and underpinnings span from the psychological (Erens \& Eichler; Karaolis and Philippou) to the narrative and sociological (Felix) and the discursive (Branchetti and Morselli). Types of data range from questionnaires (Karaolis and Philippou), to interviews (Karaolis and Philippou, Erens and Eichler, Felix) to observations and transcriptions of classroom talk (Branchetti and Morselli). Analysis ranges from statistical analysis of large number of questionnaires, backed by qualitative analysis of interviews for validation purposes (Karaolis and Philippou), categories analysis of interviews (Erens and Eich-

\footnotetext{
E. Heyd-Metzuyanim ( $\square)$

Tehnion-Israel Institute of Technology, Haifa, Israel

e-mail: einat.metz@gmail.com
} 
ler), narrative analysis of interviews (Felix) and analysis of talk and communication (Brachetti and Morselli).

This wide variability of empirical domains, disciplines and methodologies, and especially the fact that these do not necessarily form into neat packages, signals that identity in mathematics education is a field at the crossroads of various disciplinary approaches. Recently (Heyd-Metzuyanim, 2017), I have claimed "identity" to be a nexus of studies of affect and discourse. The group of identity studies collected in this book shows that it is more than that-it may be thought of as a nexus of studies on the subject (human self) and the study of mathematical activity (including mathematical learning and teaching).

Yet in order for the field of identity to be thought of as a "nexus", and even more practically, for understanding how the four chapters can be synthesized, one has to find a common language to talk about them. On first sight, this seems to be a difficult task. Each of the papers uses the term "identity" differently, and relates with it to different topics. Karaolis and Philoppou define Teacher's Professional Identity (TPI) as "the meanings that people attach to themselves as a result of the interaction among elements of the teacher as a person and as a professional at a given moment". Felix, on the other hand, talks about teachers' professional identities as "continuously being shaped through the processes of becoming members of and participating in the activities of professional communities of practice" adding, in reliance on Sfard and Prusak (2005) that this professional identity is "storied". Branchetti and Morselli also refer to Sfard and Prusak's definition as "Identity as a set of reifying, significant, endorsable stories about a person", yet they talk about students' identities, not teachers', and do not refer to the community in which these students "become participants". Thus it is unclear to what extent their definition agrees with that of Felix. The problem becomes even more complex when one wishes to synthesize the findings of Erens and Eichler, who in fact do not use the term "identity" in their chapter at all. Rather, they use the term "teachers' beliefs" where they define beliefs as "propositions about a certain topic that are individually thought to be true".

On what basis, can we thus even claim that there is a common theme to the chapters, one which can be termed "identity"? This question has important implications to the young field of identity in mathematics education [see recent reviews of work in the field of learners' and teachers' identity by Darragh (2016), Lutovac and Kaasila (2017)]. If we do not know what belongs to the domain of "identity" and what does not, how can we proceed to even claim it is a "field"? How would we, researchers interested in "identity", know with whom we share our interests?

To gain some insight about the common themes and differences between the chapters, there is clearly a need for a common unit of analysis, a sort of conceptual "yardstick" that will enable translation of each of the chapters to one common language. Naturally, I will apply my own conceptual framework, which conceptualizes identity construction as a discursive or communicational activity (Heyd-Metzuyanim, 2015; Sfard \& Prusak, 2005). Yet I wish to stress that by doing this, I am not claiming that my own definition is the definition that should be adopted by all researchers. On the contrary, as I will show later on, this communicational lens has its own drawbacks. 
Yet it is also useful for translating different studies into one common language and for highlighting some interesting commonalities and differences between them.

A communicational lens on identity conceptualizes identity as a collection of narratives about a person. These narratives can be told in the first person (as in "I am a mathematics teacher") or in the third person ("she is a talented mathematics student"). The referee of the stories can be oneself (denoted as ${ }_{\mathrm{A}} \mathrm{A}_{\mathrm{A}}$ stories-stories told about oneself, by oneself, to oneself) or someone else (denoted by ${ }_{A} A_{C}$ : A tells a story about $A$ to $C$ ). They can also be told by a second party to a third party $\left({ }_{B} A_{C}\right)$, in which case the referent has not access to them (for example, when teachers talk about students in pedagogical meetings). Using this lens, one can see that all the chapters in this collection tell stories of this type. Mostly, these are ${ }_{\mathrm{A}} \mathrm{A}_{\mathrm{C}}$ stories, where the research participants tell stories about themselves to the researcher.

Thus, Karolis and Philippou report on their attempt to construct a survey for measuring Teachers Professional Identity (TPI). In communicational terms, this can be seen as developing an instrument that can efficiently collect 1 st $\mathrm{P}$ stories (of the ${ }_{\mathrm{A}} \mathrm{A}_{\mathrm{C}}$ type) of teachers about what Karolis and Philippou term "the answer to the question: 'Who am I as a teacher at this moment'". Of course, these 1st P stories are not as elaborated compared to naturally elicited talk of teachers about themselves. They can be thought of as short "modified versions" of these 1 st P stories, obtained by requesting participants to endorse (or not) certain pre-given narratives through Likertstyle items: narratives constructed by researchers and extracted from many previous narratives of people in similar roles. Given that Karolis and Philippou aim to obtain a general picture of teachers 1st $\mathrm{P}$ stories and commonalities within them, such an abbreviation and standardization of full-scale 1st $\mathrm{P}$ stories is a necessary procedure. They make up for it by obtaining richer and fuller stories through interviews with 20 teachers. Their study yields several interesting results. For example, they report that narratives about one's goals and aspirations as a teacher (motivational aspects), narratives about one's confidence in his/her effectiveness as a teacher (self-efficacy) and narratives about how students are best to be taught (constructivist vs. traditional perceptions) tend to "cluster together". These clustering are sufficiently strong (in statistical terms) to be termed as "types" of teachers' professional identity and to be examined in relation to other characteristics (such as teachers' experience, level of education, etc.).

Felix finds 1st $\mathrm{P}$ stories of teachers in relation to how other colleagues view them-and especially how they evaluate and respect them. His research highlights the relevance of the socio-political sphere in which teachers work and develop their 1st $\mathrm{P}$ stories about themselves. In other words, it brings to the fore the relevance of 3rd P stories about teachers (as told by others or even imagined by the teacher) to the construction of 1st P teachers' stories. Through the highly compelling stories of three teachers with long years of experience, and with widely different racial and social positions in the South African educational sphere, Felix not only exposes the struggles that such teachers encounter, but also the resources of strength and "survival" in such difficult settings.

Turning our gaze to the domain of students' 1st P stories, Branchetti and Morselli attempt to extract such stories of elementary school students about themselves as 
"good" or "bad" in mathematics. They do so by observing and analyzing their mathematical discourse in group activities. Branchetti and Morselli's findings point to interesting relationships between the rationality of students' statements, namely the ways in which students substantiate their mathematical claims (or do not substantiate them) and their communicated identity. They conclude that the existence of two "strong identities" in one group may lead to strong disagreements based on epistemic differences. These disagreements, if not carefully mediated by the teacher, may be prematurely dissolved due to communicational or social goals.

Finally, though Erens and Eichler use the term "teachers' beliefs", their research too deals with teachers' $1 \mathrm{st} \mathrm{P}$ stories, though these stories are interwoven with stories about mathematics, and more precisely, about the teaching and learning of calculus. The fact that their data deals with 1st P stories can be seen in the quotes they bring as example of teachers' beliefs. For example, they quote a teacher (Mrs. M) saying "For an introduction, I would definitely use an example with body growth or population growth. Mainly because these are questions that arouse students' interest and seem to be useful for them." (Erens and Eichler, emphasis added). As indicated by the phrase underlined, the quoted teacher is talking about herself, telling a story about how she would go about teaching a certain subject in calculus. Erens and Eichler's study reveals interesting insights about teachers' 1st $\mathrm{P}$ stories in relation to how they teach calculus (and how they claim it should be taught). For example, they find these narratives to be quite stable and not easily changed, not even by the pre-service program where these teachers have gotten their diploma from. Though they do find indications of teachers appropriating narratives from their educational surrounding, they mostly see teachers holding strongly to narratives that they had endorsed about the teaching and learning of calculus even before they started their training as teachers. Or at least, they find teachers reporting that they had not changed their beliefs during their teacher training process.

\subsection{What Is to Be Gained from a Unified Discursive View on Identity and Beliefs?}

Having translated the different studies of "identity" and "beliefs" according to one conceptual "yardstick", it is time to reflect on what this unified view enables us to see. Following are a few observations:

The gap between identity and mathematics. Though identity may be conceptualized as a nexus between research on affect and research on mathematical activity, the connection, as arising from these four chapters, is far from straightforward. Studies which concentrated mostly on 1st P stories (Felix; Karaolis and Phillipou), hardly dealt with mathematics. They both concentrated on teachers' professional identity, but rarely, if at all, related to these teachers' activity as teaching mathematics. In contrast, the two studies which did deal directly with the teaching of mathematics (Erens and Eichler, Branchetti and Morselli) reported on 1st P narratives only in 
indirect ways. While Erens and Eichler quoted subjects did include 1st P narratives, the authors mostly reported about these as propositions (beliefs) about the mathematics. Branchetti and Morselli, on the other hand, did talk about identities, yet their data rarely included any 1st P statement of the participants about themselves. This is understandable, given that learners rarely talk about themselves while doing mathematics. Thus Branchetti and Morselli attempted to extract the students' 1st P stories as communicated from their mathematical statements. For example, the girl reported in their study as "identifying as 'good in math"” never actually said an utterance similar to "I am good in math". Rather, the researchers assumed that her actions indicated she was telling such a story about herself to herself and to others.

The difference between stories-about-people (subjectifying) and stories about mathematics (mathematizing) is not a simple matter, and I believe that the focus on one side of the divide, at the expense of the other, is not a matter of chance. Studies of identity in particular, and of affect in general, have often found it difficult to connect between the "self" and the mathematics with which this "self" engages. There are several reasons why this gap is so difficult to overcome. One of them is an issue of time-scale. Whereas the time-scale in which identities (stable stories of oneself about oneself) get constructed and changed is often months and years, the timescale in which mathematical activity takes place is seconds and minutes. A result of this difference is a difference in researchers' methods of data collection and analysis. Whereas identity is often studied through interviews or other measures of self-report that can tell a story of a wide time-span (asking people to recount their history as learners, for example), mathematical learning is studied by observations, short interval pre and post-tests and similar measures.

Another, and probably related issue contributing to the gap, are the different theoretical frameworks used historically to examine self and identities versus those used to examine mathematical activity. There is of course wide variability in these theoretical frameworks, yet still, the great amount of research on mathematical learning and teaching is done from a cognitive-psychology perspective, while the research on identities is done either from a social-psychology or sociological and postmodern perspectives. The wide divergence of approaches to identity have made it difficult for the field to converge on findings about identity (Darragh, 2016), let alone to link itself to a field with widely different approaches such as cognitive psychology.

The collapse of 1st P and 3rd P stories in studies of identity. The "conceptual" yardstick of identity as 1st P stories exposes, on a close look, that the "identities", "beliefs" and "self" related constructs are often not exactly the participants' 1st P story but rather the 3rd $\mathrm{P}$ story of the researcher about the participant. In other words, stories of the type Researcher $\mathrm{A}^{\mathrm{A}} \mathrm{A}_{\text {Reader }}$ are collapsed or made indistinct with ${ }_{\mathrm{A}} \mathrm{A}_{\mathrm{A}}$ stories or even ${ }_{\mathrm{A}} \mathrm{A}_{\mathrm{C}}$ stories. The unpacking of the collapse can reveal alternative explanations of the data, which remain hidden behind the collapse and the voice of the researcher. 
Since ${ }_{A} A_{A}$ stories are, by definition, inaccessible to others (unlike ${ }_{A} A_{C}$ stories), one may claim that such a collapse is a necessary compromise that researchers have to make, if they want to say anything about the internal mental state of the person. Also, since bringing stories in their full ${ }_{\mathrm{A}} \mathrm{A}_{\mathrm{C}}$ form (as in quoting from interviews) is highly ineffective, especially if one wants to make a useful condensation of these stories over a large number of participants, one could claim that summarizing ${ }_{\mathrm{A}} \mathrm{A}_{\mathrm{C}}$ into researchers' narratives is inevitable. I do not argue with these claims. Rather, I wish to point to the ubiquity of the collapse between 1st P stories and 3rd P stories in the chapters, so as to exemplify my claims and to examine what is gained or lost from such a collapse.

Collapses between 1st $\mathrm{P}$ and 3rd P stories are so common in the writing on identity and more generally on human psychology that it is difficult to see how one could communicate about the subject without them. Take for example the following passage from Erens and Eichler, where they report on Mrs. U's quote and thereafter interpret it in their own words:

Mrs. U. (TT, 1st): As it is stated here, that's a bit of a danger concerning calculus, that some things are carried out just because it is done like that. The overall picture is missing then, but I have the ambition to teach calculus in encouraging students to try to connect different concepts such as differentiation and integration

This quote is followed by the following report: "In the second interview Mrs. U. confirmed her overarching central goal of a process orientation."

The "overarching central goal of a process orientation" is, of course, the story that Erens and Eichler tell about Mrs. U's goals, not the story she told. Mrs. U talked in terms of "encouraging students to try to connect different concepts". The term "process orientation" is not part of her lexicon (at least as seen in this quote), yet the message communicated by the text is that process orientation is her central goal (namely her 1st P story of her own goals). Thus, there is a collapse here between Mrs. U's 1st P stories and Erens and Eichler stories about her. Yet avoiding this collapse would mean that either Erens and Eichler interject each of their claim with a hedging of the sort "we interpret Mrs. U's beliefs to be of the sort that we term 'process orientation", which would be of course very cumbersome, or giving up analyzing her talk as indicating beliefs altogether. I will tend to the costs of such an abstention in a short while. Before I do that, however, I wish to exemplify the collapse of 1 st $\mathrm{P}$ and 3rd P stories with another short excerpt from the identity chapters, namely that of Felix, describing one of his teacher's feelings:

When P1's colleagues denied his contributions to the school's good pass rates in mathematics and science, "No, it's not your results!", and attempted to undermine him, "All right, I'm going to do a and b and c, and see what he will do!", he experienced their actions as an insult and denigration of his worth as a teacher and self-esteem. 
Here, we see the story of P1 about his colleagues collapsed with the author's story of how P1's colleagues treated him. This can be seen in statements like "When P1's colleagues denied his contributions" which describe P1's colleagues as indeed denying his contributions, not as the story of $P 1$ about his colleagues' denial of his contributions. Notably, this collapse hides alternative interpretations, such as that P1's colleagues said such things but did not intend to undermine him, or that their words and actions were interpreted wrongly (or differently than intended) by P1.

A second type of collapse can be seen in the story of P1's mental experiences collapsed with the author's story of these experiences. For example, when stating "he experienced their actions as an insult." Here, the collapse is between P1's stories of his mental experiences (which, in fact, do not include the word "insult" or any other direct description of an emotional state) and the author's 3rd P story of P1 as being insulted. To clarify how this is different than a discursive description, one just needs to examine the difference between "P1 felt insulted" and "P1 said he felt insulted". While in the first sentence, the researcher presents himself as a direct observer (and reporter) of P1's feelings, in the second, $\mathrm{P} 1$ is the sole observer of his own feelings while the researcher reports on $\mathrm{P} 1 \mathrm{~s}$ description of these feelings. Yet the ubiquity of this collapse in all writings on human feelings and emotions hints that such an unpacking is not such a simple matter. First, because people rarely talk about their mental states or emotions explictly. Thus, it would be rare to find someone like P1 saying "I felt insulted", and unless he used the specific word "insulted", a report of the type "P1 said he felt insulted" would be inaccurate at best. Since people rarely use "emotion words" unless explicitly called for, it is very easy for the researcher, perhaps even necessary, to "fill in" with his own story of these emotional states. A second reason such a collapse is difficult to avoid is that emotional states such as "being insulted" are not fully captured in any descriptive word that the interviewee may have said. To see this, one just needs to imagine P1 saying "I felt insulted because they said X Y Z about me" vs. the story he was quoted saying this. We, as readers can identify in ourselves feelings that we would pair with the word "insulted" better when we read a passage such as that quoted from P1 than from a static verbal description such as "I felt insulted".

Yet despite the ubiquity of the collapse between 1st $\mathrm{P}$ reports about feelings and researchers' reports (3rd P stories) about the subject's feelings, it is important to notice what we lose from this collapse. Most importantly, the collapse hides alternative possibilities to the 3rd P story offered by the researcher of the subject's feelings. For example, it may be that P1, if asked, would not have defined his feelings as exactly "insulted" but rather as "angry" or "resentful". The collapse desensitizes us to such alternative interpretations. It thus makes it easy, for us as readers, to unify our story of P1's feelings with the researchers' story and with P1's story without questioning the possible divergence between these different stories.

For reasons of brevity, I have brought only two examples of such collapses of 1st $\mathrm{P}$ and 3rd P stories, yet they are prevalent in all the chapters, as they are in other writings on identity and on human psychology in general. What should we take from this? One conclusion, which has been prominent in discursive psychology writings (Harré \& Gillett, 1994; Molder, 2015; Potter, 2010) is to avoid concepts referring 
to "inner" mental constructs altogether. The rationale is that such concepts are not only inaccessible to public investigation, they are also fraught with blurry definitions and susceptible, as shown above, to interpretations that do not accurately depict the discourse of the subject who is being studied. Yet what these advocates of abandoning mental constructs often fail to mention is that the usage of mental concepts such as "beliefs", "self" or even "identity" (in its more mentalistic definitions) serves in psychological theories to achieve ends that would be impossible to achieve without these concepts.

Take, for example, Felix's study of self-worth in relation to self-esteem and selfconfidence. Stripping Felix's findings to discursive terms, one may say that teachers' narratives about them being seen as worthy teachers, are found to go hand in hand with their narratives about feeling confident about themselves in more general domains ("self-confidence") and about having received loving and strengthening narratives from significant others when they were young. Such a communicational description is fine, yet it fails to achieve the causative explanation that Felix probably wishes to put forward-that self-worth is built upon self-esteem and that this, in turn, is built upon self-confidence. Without this causative claim, Felix's observations, which lead him to hypothesize about the importance of teachers' psychological stability to the successful endurance with counterproductive narratives around them, lose their explanatory force.

A similar claim can be made about Erens and Eichler's study, where beliefs are construed as objects that cause certain pedagogical actions. There would not be much sense in Erens and Eichler's study of teachers' beliefs, without the objectification of "beliefs" and "behavior" into objects relating to each other in a causal mechanism. After all, Erens and Eichler are probably interested in the teachers' beliefs not per se, but as indicators (or predictors) of teachers' actions in the classroom. So are Karolis and Phillipou, who are probably measuring Teachers' Professional Identity not for the sake of itself, but to be able to predict different profiles of teachers' identity in relation to their education as well as in relation to their conduct in the classroom. Even Branchetti and Morselli, who on the face of it seem to be dealing only with classroom discourse, are focused (though mostly implicitly) on causative explanations for students' actions. They state, for example, their goal to be able to relate between students' identities and the rationality of their arguments. This is not just to be able to describe the situation, but rather to be able to help the teacher to predict in which places "strong identities" and "weak identities" may interfere with successful learning in group situations. One may argue that the discursive lens can also point to causative explanations: those offered by the participants themselves. Yet it seems to me that all the authors of the reviewed chapters wish to do more than that - they wish to offer their own causative explanations for the phenomena they observe. 


\subsection{Conclusions}

The discursive lens that I have employed in this chapter to unify for myself (and the readers) the four chapters that use a variety of terminologies, proves to be useful for being a "conceptual yardstick" a well as illuminating some alternative interpretations of the data that the collapse of 1st P stories and 3rd P stories are bound to hide. Yet it also falls short of providing alternative explanations offered by the authors for their findings.

Why is this important? Since it exemplifies that any theoretical lens has some benefits, and some shortcomings. This revelation is of course as old as the study and theorizing of human activity. Yet being at the crossroads of psychological and discursive perspectives, the field of identity is at a constant danger of being divided by "paradigm wars" (Goldin, 2003). The question we should think about, as a young field, is how do we deal with this danger? Do we aim to conciliate the different paradigms? Do we choose to adhere to their divisions? The lens that I have used, that of discursive psychology, has not been famous for being a "conciliatory" lens. Rather, discursive psychologists have often criticized cognitive and social psychology without necessarily offering alternatives. On the other hand, "conciliatory" approaches have often come from dominant discourses, in which case one can claim that it is easy to call for conciliation from the point of view of the hegemonic discourse. It is a question to our field, how we can preserve the integrity of the approaches, avoiding "theoretical soups" and the usage of incommensurable theories or frameworks, while still benefiting from each of the approaches. The four chapters dealing with identity in this book prove that each of the approaches is valuable and therefore, none of them should be dismissed. How they should talk to each other, however, remains an open question.

\section{References}

Darragh, L. (2016). Identity research in mathematics education. Educational Studies in Mathematics, 93(1), 19-33. https://doi.org/10.1007/s10649-016-9696-5.

Goldin, G. A. (2003). Developing complex understandings: On the relation of mathematics education research to mathematics. Educational Studies in Mathematics, 54, 171-202.

Harré, R., \& Gillett, G. (1994). The discursive mind. Thousand Oaks, CA: Sage Publications.

Heyd-Metzuyanim, E. (2015). Vicious cycles of identifying and mathematizing-A case study of the development of mathematical failure. Journal of the Learning Sciences, 24(4), 504-549.

Heyd-Metzuyanim, E. (2017). Identity as a nexus of affect and discourse in mathematical learning. For the Learning of Mathematics, 37(3), 33-38.

Lutovac, S., \& Kaasila, R. (2017). Future directions in research on mathematics-related teacher identity. International Journal of Science and Mathematics Education, 1-18. https://doi.org/10. 1007/s10763-017-9796-4.

Potter, J. (2010). Contemporary discursive psychology: Issues, prospects, and Corcoran's awkward ontology. British Journal of Social Psychology, 49(4), 657-678. https://doi.org/10.1348/ $014466610 X 486158$. 
Sfard, A., \& Prusak, A. (2005). Telling identities: In search of an analytic tool for investigating learning as a culturally shaped activity. Educational Researcher, 34(4), 14-22.

Te Molder, H. (2015). Discursive psychology. The International Encyclopedia of Language and Social Interaction, 73-90. https://doi.org/10.1348/0261510042378209.

Open Access This chapter is licensed under the terms of the Creative Commons Attribution 4.0 International License (http://creativecommons.org/licenses/by/4.0/), which permits use, sharing, adaptation, distribution and reproduction in any medium or format, as long as you give appropriate credit to the original author(s) and the source, provide a link to the Creative Commons license and indicate if changes were made.

The images or other third party material in this chapter are included in the chapter's Creative Commons license, unless indicated otherwise in a credit line to the material. If material is not included in the chapter's Creative Commons license and your intended use is not permitted by statutory regulation or exceeds the permitted use, you will need to obtain permission directly from the copyright holder.

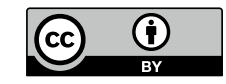




\section{Part V \\ Conclusion}




\title{
Chapter 20 \\ Fresh Perspectives on Motivation, Engagement, and Identity: A Conclusion
}

\author{
Markku S. Hannula, Gilah C. Leder, Francesca Morselli, Maike Vollstedt \\ and Qiaoping Zhang
}

\subsection{Summary}

In this book we have collected 15 chapters based on papers presented at the Topic Study Group on "Affect, beliefs and identity in mathematics education" during the ICME-13 conference in Hamburg, Germany, in 2016. We have also invited three experts to comment on subsections of the volume: Wee Tiong Seah on Interest, motivation, and values, Peter Liljedahl on Engagement and flow, and Einat HeydMetzuyanim on Identity.

All three commentators experienced some difficulties in finding clear coherence among the chapters. This underlines, as already mentioned in the introduction, the

\footnotetext{
M. S. Hannula $(\varangle)$

Faculty of Educational Sciences, University of Helsinki, P.O. Box 9, 00014 Helsinki, Finland e-mail: markku.hannula@helsinki.fi

Volda University College, Joplassvegen 11, 6103 Volda, Norway

G. C. Leder

La Trobe University, Melbourne, VIC, Australia

e-mail: g.leder@latrobe.edu.au

Monash University, Melbourne, VIC, Australia

F. Morselli

Faculty of Mathematics, University of Genoa, Via Dodecaneso 35, 16146 Genoa, Italy

e-mail: morselli@dima.unige.it

\section{Vollstedt}

Faculty of Mathematics and Computer Science, University of Bremen, Bibliothekstraße 5, 28359

Bremen, Germany

e-mail: vollstedt@math.uni-bremen.de

Q. Zhang

Department of Mathematics and Information Technology, The Education University of Hong

Kong, Lo Ping Road 10, Tai Po, Hong Kong SAR, China

e-mail: zqiaoping@eduhk.hk 
wide theoretical and conceptual variety in the field for theorizing affect. This multitude of theories makes it a daunting task to summarize the contents of this volume, but at the same time serves as a reminder of the rich, and ongoing journey leading from mathematics and education to mathematics education (Furinghetti, Matos, \& Menghini, 2012). As traced by these authors, research in fields as diverse as psychology, sociology, cultural, and political studies could be adopted or adapted to explore, in greater depth or through different lenses, issues of relevance and importance to those engaged in mathematics education. While interdisciplinary research undoubtedly has the potential to stretch the boundaries of current knowledge, for such work to be both cumulative and productive it should be accompanied, as much as possible, by a common language and terminological precision accepted across the different discipline boundaries.

Sometimes researchers used different terminologies for the same phenomenon due to the very different theoretical lenses they have chosen. For example, while Karaolis and Philippou as well as Felix recognized teacher professional identity to be simultaneously an individual and a social phenomenon, they approached it differently. While Felix focused on recognition by others as the key issue, Karaolis and Philippou focused on self-reflection. Hence, they drifted apart and ended up using partly very different conceptualizations and terminologies. Even when they both discussed self in relation to professional identity, Felix used the concepts selfrespect, self-confidence, and self-esteem, while Karaolis and Philippou used the concepts self-image, self-efficacy, and self-esteem.

With respect to methodology, there is great variation from in-depth qualitative case studies (e.g. Kahlil, Lake, \& Johnson) to very large longitudinal and comparative studies using quantitative methods (e.g. Bofah \& Hannula). Based on the contributions to this volume questionnaires and interviews are the dominating research methods for mathematics-related affect. These methods rely on self-report, meaning that the information we gain about affect is restricted by our research participants' ability to reflect their affect and their willingness to share their observations with us. Self-report is a viable research method, but it is very dependent on participant's ability of reflection and response style, and constrained by cultural difference (Paulhus \& Vazire, 2007). People do not have an infinite ability to recall all information relevant to a posed question. A self-reporter may have to resort to a "press release" version of his or her personality just to get on with the task (Paulhus \& Vazire, 2007, p. 232). However, the rich autobiographical narratives Felix collected for over a period of up to two years provides an opportunity to avoid many pitfalls of self-reporting.

Observation as an alternative method is illustrated in several chapters (Branchetti \& Morselli; De Simone; and to some extent also in Khalil, Lake, \& Johnson). The power of this approach is in recording minute details of the events that fleet by fast. For example, Branchetti and Morselli analyzed mathematical argumentation in a group sentence by sentence and De Simone addressed gestures and tone of voice as signals for teacher's emotional orientation.

Rather than choosing either self-reports or observation, one may choose both for the benefit of triangulation. Dobie used a mixed method approach, including ethnographic observations in classes one to three times per week for five months. 
These classroom observations provided her data on student willingness to collaborate that did not become apparent in the survey or the interviews. In a similar fashion, analyzing a video-recorded session of student collaboration allowed Montoro and Gil to explain some conditions for flow that were not apparent in the quantitative survey data.

Although it is possible to think about mathematical objects without leaving the mathematics-internal world, mathematics is a social construct and activity (Hersh, 1998). But still, when learning mathematics, it is usually also related to the world we live in. The special character of mathematics as well as of doing mathematics makes it loved by some students and hated by others (Henn \& Kaiser, 2001). This polarization may also have an effect on the affect that is related to (learning) mathematics. Thus, although some of the studies presented here might be easily replicated in other subjects, mathematics as a discipline still might have an impact on the results.

In most of the chapters, the role of mathematics was minimal, as discussed by Heyd-Metzuyanim in her commentary. Teaching or doing mathematics was often simply a context that was used to identify the participants or the activity in question, but mathematics had little explicit relevance. Could these studies be replicated in the areas of other school subjects? Probably, with little difficulty. In some cases the results might even be similar. Is this an unanticipated side-effect of interdisciplinary research? And, we need to ask, to what extent does such work move the field of mathematics education forward?

Nevertheless, the role of mathematics as the discipline that is dealt with in the situations studied, is not to be neglected. In comparison to other subjects, the nature of mathematics is special for instance due to its rigorous logic, cumulative structure, highly formalized special language, abstractness, and its role as a gatekeeper for many careers. Three chapters (Dobie; Middleton Mangu, \& Lee; Wilkie) discussed the role of mathematics in relation to careers, and two chapters address the specific nature of mathematics as a discipline, namely Erens and Eichler's study in the context of tertiary mathematics and Branchetti and Morselli's study in the context of argumentation on grade six.

The Topic Study Group 28 at ICME was aimed at addressing "all areas of affect, including attitude, anxiety, beliefs, meaning, self-concept, emotion, interest, motivation, needs, goals, identity, norms, values". How well does this book cover the different areas of research? To evaluate this, we used a method earlier employed for the analysis of trends in research on mathematics-related affect in affect working group of CERME conferences (Hannula, Pantziara, \& Di Martino, 2018). That analysis identified 51 different affect terms appearing in the titles of 134 CERME papers and their frequencies across the conferences. Then, total of 17,368 instances of affect term appearance were found with the following terms being most frequent: belief, emotion, affect(ive), motivation, goal, efficacy, and attitude.

We have searched for the same words in the chapters (except this chapter Fresh perspectives on motivation, engagement, and identity: A conclusion and not including the references) of this volume. The corpus has a total of 141,865 words and total of 4,739 affect term occurrences were found. As in the original study, we checked the context of words, when necessary, to include only those with the affective meaning. 


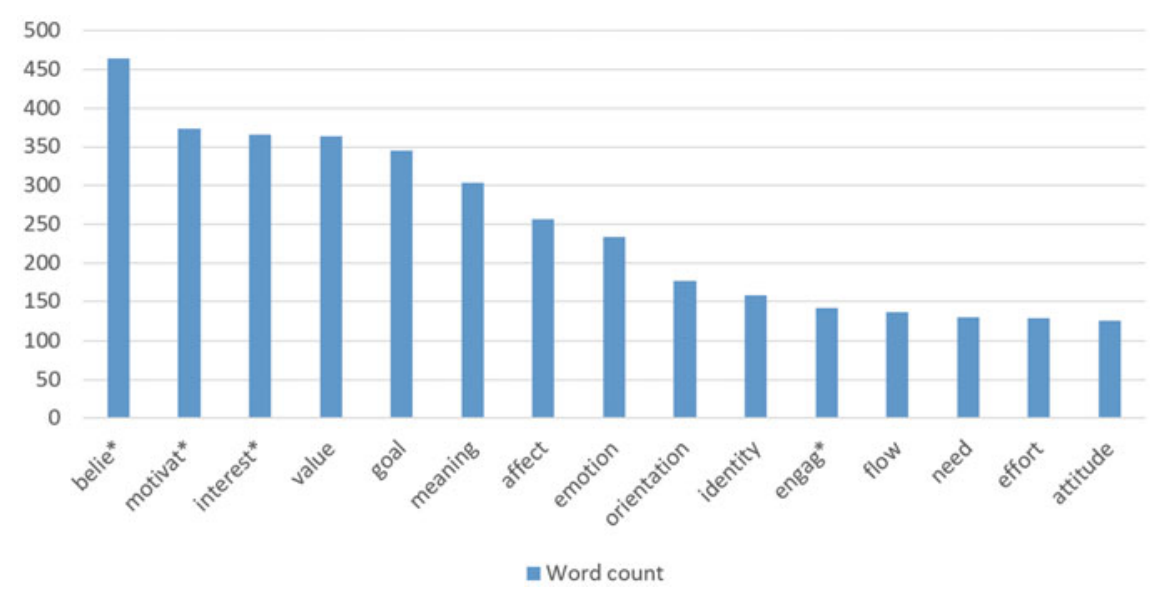

Fig. 20.1 Emotion words that appear more than 100 times in this book (not including the references or this chapter-Fresh perspectives on motivation, engagement, and identity: A conclusion)

The 15 most common words each occurred more than 100 times (Fig. 20.1). This list includes the most frequent words from CERME conferences, except for efficacy, which had 93 occurrences.

However, some words from our call of papers are missing from the list of most frequent words. Anxiety was mentioned 34 times and norms 27 times. The term self-concept appeared only eight times, but several related words compensate for it: self-confidence (38 times), self-efficacy (83 times), and self-esteem (36 times).

Based on this word count analysis, motivational concepts seem to have high prominence in the current volume, for example, the terms interest, value, goal, meaning, orientation, and need all appearing more than 100 times.

As in Fresh perspectives on motivation, engagement, and identity: An introduction, we use the three dimensions suggested by Hannula (2012) to categorize affectrelated theories to examine the terminology of this book. The first dimension identifies three different types of affect and we can see each type represented in this volume: cognitive (e.g. beliefs), motivational (e.g. values, motivation, and many others), and emotional (e.g., emotion, engagement, and flow).

The second dimension distinguishes between theories that focus on the relatively stable aspects of affect (i.e. traits) from the theories that focus on the dynamically changing aspects of affect (i.e. states). Most research in this volume focused on traits, as usual. However, there were four papers looking at the dynamics of affective states. De Simone examined teacher emotional orientations at the moments of decision making, Khalil, Lake, and Johnson investigated teacher's 'in-the-moment' affect, Montoro and Gil studied student flow during problem solving, and Branchetti and Morselli inquired the dynamics of interaction in a group. It is an indication of the relative novelty of this research that these three papers described new phenom- 
ena through case studies, which is typically the first stage of research. Clearly, the dynamic aspects of affect need more research.

The third dimension in Hannula's (2012) metatheory identifies three different traditions for theorizing affect: physiological theories, psychological theories, and social theories. Here, almost all chapters used psychological theories, conceptualizing affect as a characteristic of an individual. Two papers in identity were exceptions. Branchetti and Morselli examined identity in the dynamics of a group process and Felix examined teacher autobiographical narratives contextualized in the socio-historical context of their narrators. While only De Simone used an explicitly embodied theoretical construct (emotional orientations), many chapters use embodied methods, taking, for example, gestures, facial expressions, and tone of voice as indicators of emotions (De Simone; Khalil, Lake, \& Johnson; Montoro \& Gil). The high relevance of bodies for affective interaction was highlighted by Mykia's frustration (Khalil, Lake, \& Johnson) when she could not use physical proximity in the virtual classroom to engage a student.

The call for papers explicitly questioned the issue of the mutual relationship between affective constructs and their connection to cognition and other constructs studied in mathematics education, as well as the description of programs for promoting aspects of affect. Some of the chapters did discuss these issues.

The issue of the mutual relationship between affective constructs and cognition or, more in general, on mathematical activity, was developed in the papers by Achmetli and Schukajlow (who studied the interaction between the experience of competence and interest), Bofah and Hannula (who addressed the link between perceived social support and achievement), Zonnefeld (who focused on the effect of a course on mastery of statistics and attitude towards statistics), Morselli and Branchetti (who addressed the interplay between identity and rational behavior), and Vollstedt and Duchhardt (who found two meta-factors structuring the personal meanings into those showing an orientation to mathematics and to social inclusion). Only De Simone addressed the interplay between rationality and emotion with a focus on teachers, and not on students.

Interventions to promote affect were described only by Zonnefeld. The study of programs for promoting affect is therefore an issue that deserves further attention and is a promising avenue for further research.

Concerning the geographical representativeness of the authors in this volume, we note that Western Europe was predominant and Eastern countries were underrepresented. It is noteworthy that contributing authors with an African origin were conducting their research in Western universities. Moreover, we may note that the studies here presented were predominantly concerning a single country. Only Kahlil, Lake and Johnson presented a comparison between US and English teachers and Bofah and Hannula dealt with a set of countries. We argue that cross-cultural studies, and studies addressing affective issues explicitly in reference to cultural contexts could be of interest for the research field. An increased focus on socially and culturally contextualized studies would also strengthen the social turn in research on mathematics-related affect. 
For the purpose of identifying solid findings in our field, we need more experimental and longitudinal studies to confirm causal relationships between variables and cross-cultural comparative studies to confirm the universality of our findings. This is not an easy journey, as indicated by Bofah and Hannula's results, which showed that many of the relationships between gender, parental and teacher support, student affect, and mathematics achievement were not the same across the five African countries studied.

A potentially promising avenue for further research is examining the Mind-set theory as part of student beliefs. As shown in Zonnefeld's study, training students in incremental theories of intelligence was beneficial especially for female student's beliefs and achievement.

\subsection{A Final Comment}

The contents of this volume were spawned and loosely shaped by the material presented in Topic Study Group 28 at ICME-13. Underpinning both sets of endeavours is the importance of mathematics in and beyond the years of formal education. This reality was captured graphically by Australia's Chief Scientist: "What if we lived in a world without mathematics? ... Take away numbers, and you take away commerce, farming, medicine, music, architecture, cartography, cooking, sport... and every other activity we've invented since 3000 B.C." (Finkel, 2017, p. 3).

Widely accepted, too, is that both cognitive and affective factors influence students' learning of mathematics.

Individuals' attitudes, beliefs, and emotions play a significant role in their interests and responses to mathematics in general, and their employment of mathematics in their individual lives. Students who feel more confident with mathematics, for example, are more likely than others to use mathematics in the various contexts that they encounter. Students who have positive emotions towards mathematics are in a position to learn mathematics better than students who feel anxiety towards that subject (OECD, 2013, p. 42).

As testified by the different elements in this volume, identifying and capturing the various subsets of the affective domain continues to be a dynamic area of research. The snapshots and syntheses of work presented capture small but important links in the long chain of research on affect and mathematics and can serve as catalysts for further work. The challenge is to forge convergent rather than divergent pathways.

Acknowledgements Thanks to Enrique Garcia Moreno-Esteva for his help with counting the word occurrences. 


\section{References}

Finkel, A. (2017). Measuring up. Opening address. Presented at the 40th Anniversary Conference of the Mathematics Education Research Group of Australasia. Retrieved from http://www. chiefscientist.gov.au/wp-content/uploads/MERGA-speech.pdf.

Furinghetti, F., Matos, J. M., \& Menghini, M. (2012). From mathematics and education, to mathematics education. In M. A. (K.) Clements, A. J. Bishop, C. Keitel, J. Kilpatrick, \& F. K. S. Leung (Eds.), Third international handbook of mathematics education (Vol. 27, pp. 273-302). Springer International Handbooks of Education. New York, NY: Springer. https://doi.org/10.1007/978-14614-4684-2_9.

Hannula, M. S. (2012). Exploring new dimensions of mathematics-related affect: Embodied and social theories. Research in Mathematics Education, 14(2), 137-161. https://doi.org/10.1080/ 14794802.2012.694281.

Hannula, M. S., Pantziara, M., \& Di Martino, P. (2018). Affect and mathematical thinking: Exploring developments, trends, and future directions. In T. Dreyfus, M. Artigue, D. Potari, S. Prediger, \& K. Ruthven (Eds.), Developing research in mathematics education: Twenty years of communication, cooperation and collaboration in Europe (pp. 128-141). London, UK: Routledge.

Henn, H.-W., \& Kaiser, G. (2001). Mathematik - ein polarisierendes Schulfach [Mathematics-A polarizing subject]. Zeitschrift für Erziehungswissenschaft, 4(3), 359-380. https://doi.org/10. 1007/s11618-001-0042-y.

Hersh, R. (1998). What is mathematics, really? DMV-Mitteilungen, 2, 13-14. https://doi.org/10. 1515/dmvm-1998-0205.

OECD. (2013). PISA 2012 assessment and analytical framework: Mathematics, reading, science, problem solving and financial literacy. Paris, France: OECD. Retrieved from http://dx.doi.org/ 10.1787/9789264190511-en.

Paulhus, D. L., \& Vazire, S. (2007). The self-report method. In R. W. Robins, R. C. Fraley, \& R. F. Krueger (Eds.), Handbook of research methods in personality psychology (pp. 224-239). New York, NY: Guilford Press.

Open Access This chapter is licensed under the terms of the Creative Commons Attribution 4.0 International License (http://creativecommons.org/licenses/by/4.0/), which permits use, sharing, adaptation, distribution and reproduction in any medium or format, as long as you give appropriate credit to the original author(s) and the source, provide a link to the Creative Commons license and indicate if changes were made.

The images or other third party material in this chapter are included in the chapter's Creative Commons license, unless indicated otherwise in a credit line to the material. If material is not included in the chapter's Creative Commons license and your intended use is not permitted by statutory regulation or exceeds the permitted use, you will need to obtain permission directly from the copyright holder.

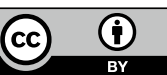

